J. Timo Weishaupt

From the Manpower Revolution to the Activation Paradigm

EXPLAINING INSTITUTIONAL CONTINUITY and Change in an Integrating Europe

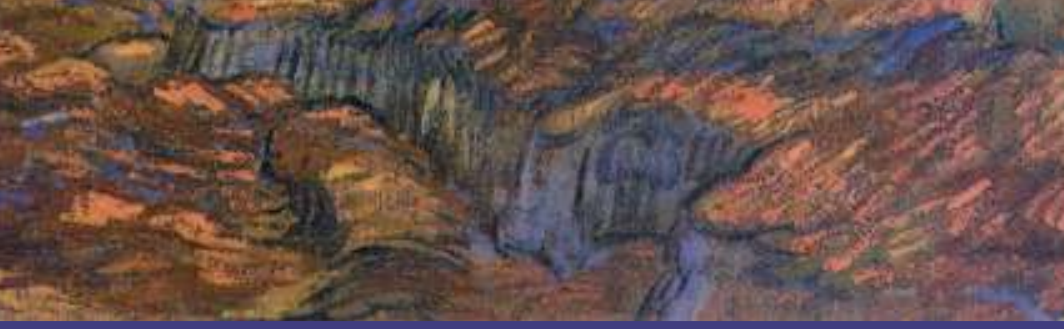

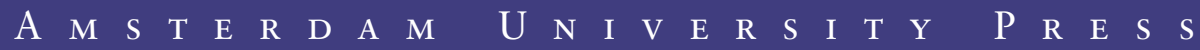


FROM THE MANPOWER REVOLUTION TO THE ACTIVATION PARADIGM 


\section{CHANGING WELFARE STATES}

Advanced welfare states seem remarkably stable at first glance. Although most member states of the European Union (EU) have undertaken comprehensive welfare reform, especially since the 1990s, much comparative welfare state analysis portrays a 'frozen welfare landscape.' Social spending is stable. However, if we interpret the welfare state as more than aggregate social spending and look at long-term trends, we can see profound transformations across several policy areas, ranging from labour market policy and regulation, industrial relations, social protection, social services like child care and education, pensions, and long-term care. This series is about trajectories of change. Have there been path-breaking welfare innovations or simply attempts at political reconsolidation? What new policies have been added, and with what consequences for competitiveness, employment, income equality and poverty, gender relations, human capital formation, and fiscal sustainability? What is the role of the European Union in shaping national welfare state reform? Are advanced welfare states moving in a similar or even convergent direction, or are they embarking on ever more divergent trajectories of change? These issues raise fundamental questions about the politics of reform. If policymakers $d o$ engage in major reforms (despite the numerous institutional, political and policy obstacles), what factors enable them to do so? While the overriding objective of the series is to trace trajectories of contemporary welfare state reform, the editors also invite the submission of manuscripts which focus on theorizing institutional change in the social policy arena.

\section{EDITORS OF THE SERIES}

Gøsta Esping-Andersen, University of Pompeu Fabra, Barcelona, Spain Anton Hemerijck, VU University Amsterdam, the Netherlands Kees van Kersbergen, VU University Amsterdam, the Netherlands Kimberly Morgan, George Washington University, Washington, USA Romke van der Veen, Erasmus University, Rotterdam, the Netherlands Jelle Visser, University of Amsterdam, the Netherlands 


\title{
From the Manpower Revolution to the Activation Paradigm
}

\author{
Explaining Institutional Continuity
} and Change in an Integrating Europe

J. Timo Weishaupt 


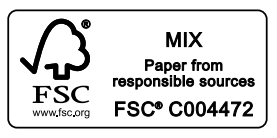

Cover illustration: Vincent van Gogh, Two farmers digging over (after Millet), Saint-Rémy, October 1889, Oil on canvas

Cover design: Crasborn Grafisch Ontwerpers BNo, Valkenburg a/d Geul Lay-out: V-3 Services, Baarn

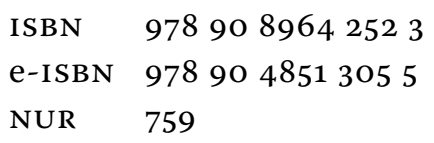

(C) J. Timo Weishaupt / Amsterdam University Press, Amsterdam 2011

All rights reserved. Without limiting the rights under copyright reserved above, no part of this book may be reproduced, stored in or introduced into a retrieval system, or transmitted, in any form or by any means (electronic, mechanical, photocopying, recording or otherwise) without the written permission of both the copyright owner and the author of the book. 


\section{Table of Contents}

\section{List of Boxes, Figures and Tables 9}

\section{Abbreviations 13}

\section{Acknowledgements 19}

I Introduction 21

I.1 The Research Questions 21

I.2 Competing Predictions about Labour Market Policy Regime Change: The Argument in Brief 23

I.3 Research Design, Case Selection, and the Evidence 27

I.4 Book Outline 30

II Theoretical Approach 35

II.1 Introduction 35

II.2 Defining Institutions 36

II.3 Historical Institutionalism: Explaining Continuity 38

II.4 Historical Institutionalism: Beyond Continuity 41

II.5 Causal Mechanisms to Explain Institutional Transformations: Ideas and Agency 43

II.6 Three Institutional Trajectories 56

II.7 Analytical Grid: Four Dimensions of Labour Market Policy Regimes 62

PART I ORIGIN AND CRISIS OF EUROPEAN LABOUR MARKET POLICY REGIMES

III Origin of European Labour Market Policy Regimes and the Manpower Revolution 73

III.1 Locating the Origins of Unemployment and Labour Market Policy 73

III.2 Locating the Origin of Active Manpower Policy 83 
III.3 The OECD and the Diffusion of Active Manpower Policy 85

III.4 Five Country Cases: Austria, Denmark, Germany, Ireland, and the UK 89

III.5 Conclusions 101

IV Labour Market Policy Regimes in Crisis: Divergence into

Three Distinct Clusters 105

IV.1 Labour Market Policy Regimes Under Stress: 1973-1979 105

IV.2 National Policies after the First Oil Crisis: Moderate Optimism and the Expansion of Active Manpower Policies 108

IV.3 Conclusions 118

IV.4 After the Second Oil Crisis: Shattered Illusions and Diverging Pathways 119

IV.5 National Policy Responses: Social-Investment, Labour-Shedding, and Marketisation Strategies 121

IV.6 Conclusions 139

PART II THE EMERGENCE OF THE ACTIVATION PARADIGM

V

The OECD's Repeated Reassessments and the EU as a Proliferator of New Ideas 151

V.1 The New Aspiration for an "Active Society" and the Road to the 1994 OECD Jobs Study 151

V.2 The European Union as a Proliferator of New Ideas: From Delors' 1993 White Paper to the European Employment Strategy 156

V.3 The Consolidation of Activation and the Emergence of the PES Service Model 165

V.4 Further Ideational Convergence: The Reassessed OCED Jobs Study and the Revised Lisbon Agenda 173

V.5 Conclusions 186

VI The Emergence of the Activation Paradigm: Analyzing Institutional Hybridisation 193

VI.1 Normative/Cognitive Dimension 194

VI.2 Organisational Dimension 201

VI.3 Financial Dimension 219

VI.4 Work Incentives Dimension 225

VI.5 Conclusions 245 
VII.1 Explaining the Process of Hybridisation in Continental Europe: Germany as a "Least Likely" Case 254

VII.2 Explaining Hybridisation in the Liberal World: Turning Vice into Virtue in Ireland 276

VII.3 Conclusions 291

VIII Conclusion 295

VIII.1 Do National Labour Market Policy Reform Efforts Exhibit Covariation across Western Europe, and if so, How and Why? 295

VIII.2 What Impact, if any, Have the Recommendations of International Organisations such as the OECD and the EU had on National Reform Agendas? 303

VIII.3 Have Recent Reform Activities, in the Context of the OECD Jobs Study and the EES, Fundamentally Transformed the Historic Composition of National Labour Market Policy Regimes, and if so, to What Effect? 305

VIII.4 Reactions to the Global Financial and Economic Crisis and the Future of the Activation Paradigm 308

\section{List of Interviews and Personal Conversations $\quad 315$}

Notes 321

Bibliography 341

Index $\quad 387$ 



\section{List of Boxes, Figures and Tables}

\section{List of Boxes}

$1 \quad$ Five Instruments of Active Labour Market Policy 67

2 Summary of 1964 OECD Recommendations 87

31994 OECD Jobs Study Recommendations

$4 \quad$ Five Guidelines Proposed at the 1994 Essen Council 158

5 Institutional Components of the EES (Luxembourg Process) 162

6 Four Pillars of the European Employment Strategy (1997-2002) 163

7 The New Deal Measures in the UK 165

8 The Danish "Active Line" 170

9 The "Ten Commandments" of the EES (2003) 175

10 Quantified Targets in the 2003 Guidelines 175

11 Common Principles of Flexicurity 178

12 Seven Policy Lessons in the OECD Reassessed Jobs Study (RJS) 180

13 Maximum Unemployment Benefits Durations in Months for Prime-Aged Workers, Indicating Changes in the Duration of UB Benefits Payments from mid-1990s to $2008 \quad 229$

\section{List of Graphs and Figures}

$1 \quad$ Points of Entry for New Ideas, Interpretations, and Reflections 55

2 Organisation of Employment Services 65

3 The Processes of Peer Review in the EU and the OECD 185

4 Employment Levels Among Older Male Workers Aged 6o-64 in Percent, 1996, 2002, and $2008 \quad 231$

5 The Core Elements of the Activation Paradigm 251 


\section{List of Tables}

Types of Institutional Evolution: Processes and Outcomes 43

Competing Causal Mechanisms and Necessary Conditions for Transformative Institutional Change 47

\section{Explaining Institutional Evolution: Summary Table 57}

Negative and Positive Incentive Structures of Labour Market Policy

Regimes 69

$$
\text { Increase in Unemployment as a Percentage of Civilian Labour Force, }
$$
1960-1979 106

Distribution of Government Spending on Labour Market Policy Measures in Denmark and Sweden, $1979 \quad 112$

Unemployment as Percentage of Civilian Labour Force, 1980-1990 119

Core Principles, Common Outcomes, and Tradeoffs in Three Welfare Clusters in the 1980 os 142

Real Gross Domestic Product (GDP); Percentage Change from Previous Period, 1974-1989 144

Inflation Rate (Consumer Price Index); Percentage Change from Previous Period, 1974-1984 144

General Government Gross Financial Liabilities; Percentage of Nominal GDP, 1985-1989 144

Overall Marginal Tax Wedge, 1978-1989 145

Labour Force Participation Rate, Total, 1973-1989 145

Labour Force Participation Rate, Female, 1973-1989 145

Annual Public Sector Growth Rates and Share in Total Employment, 1970-1989 146

Expenditures on Active Labour Market Measures as Percentage of GDP, 1980-1990 146

Expenditures on Specific Labour Market Measures as Percentage of GDP, $1987 \quad 147$

Timeline of Major Events (1989-2008) 183

Unemployment as Percentage of Civilian Labour Force, 1990-2007 188

Unemployment as Percentage of Youth (15-25 years of age), 1990-2008 189

Employment Rates, Total, 1990-2008 190

Employment Rates, Female, 1990-2008 191

Employment Rates, Older Workers Aged 55-64, 1990-2008 192

Workers and Employers' Social Security Contributions (SSC), 2000 and 2006220

Public Expenditures on ALMP as Percentage of GDP in West European Countries, 1997-2007 221 
Spending on ALMP as Percentage of GDP Divided by the Standardised Rate of Unemployment in West European Countries, 1997-2007 222

27 Total Public Expenditure on Employment/Work Subsidies as Percentage of GDP in West European Countries, 1997-2007 223

28 Total Public Expenditures on Direct Job Creation as Percentage of GDP in West European Countries, 1997-2007 224

29 Total Public Expenditures on Training as Percentage of GDP in West European Countries, 1997-2007 224

30 Average Net Replacement Rates for the Unemployed at the Initial Stage of Unemployment at Different Earning Levels, 2001 and $2006 \quad 227$

31 Average Net Replacement Rates for Long-term Unemployed Person at Different Earning Levels, 2001 and $2006 \quad 228$

32 Average Tax Rates for Full-time Workers at Different Wage Levels, 2000 and 2005238

33 Gross Statutory Minimum Wages (if applicable), 2000 and 2005239

34 Public Expenditures on Business Start-up Subsidies as Percentage of GDP in Western European Countries, 1997-2007 244

35 Overview of Labour Market Policy Regimes 248

36 FÁS Throughput, 1998-2006 285

$37 \quad$ Maternity and Parental Leave Entitlements $\quad 289$

38 Evolution of European Labour Market Policy - Thought and Practice 302

39 Harmonised Unemployment Rate as Percentage of Civilian Labour Force, 2008 through 2009, Quarters 309 



\section{Abbreviations}

ABM Public Works Projects (Germany)

ABP Area-Based Partnership (Ireland)

ACHI Actor-Centred Historical Institutionalism

AFG Work Promotion Act (Germany)

AK Chamber of Labour (Austria)

ALG-1 Unemployment Compensation I (UB, Germany)

ALG-2 Unemployment Compensation II (combined UA \& SA, Germany)

ALMP Active Labour Market Policy

ALU Working-Life Development Programme (Sweden)

AMFG Labour Market Promotion Act (Austria)

AMP Active Manpower Policy

AMS National Labour Market Board (Denmark and Sweden); Public

Employment Service (Austria)

AnCO Industrial Training Authority (Ireland)

APR Annual Progress Report

APW Average Person's Wage

ARGEn Joint Welfare and Employment Offices (Germany)

BA Federal Labour Office/Federal Employment Agency (Germany)

BDA Confederation of German Employers' Associations

BDI Federation of German Industries

BEPG Broad Economic Policy Guidelines

BMAS Ministry for Labour and Social Affairs (Germany)

BMfSFJ Ministry for Family Affairs, Senior Citizens, Women and Youth (Germany)

BMWA Federal Ministry for the Economy and Labour (Austria)

BWA Back to Work Allowance (Ireland)

CBI Confederation of British Industry

CCC Civilian Conservation Corps (US)

CDU Christian Democratic Union (Germany)

$\mathrm{CE} \quad$ Community Employment (Ireland)

CEP Community Enterprise Programme (UK)

CME Co-ordinated Market Economy

CSU Christian Social Union (Bavaria, Germany) 
DELSA Directorate for Employment, Labour, and Social Affairs (OECD)

DG Directorate General

DGB German Confederation of Trade Unions

DIHK German Chamber for Industry and Trade

DSFA Department of Social and Family Affairs (Ireland)

DSW Department of Social Welfare (Ireland)

DWP Department for Work and Pensions (UK)

ECB European Central Bank

EDRC Economic Development and Review Committee (OECD)

EEI European Employment Initiative

EES European Employment Strategy

ELSA Employment, Labour, and Social Affairs (OECD)

EMCO Employment Committee

EMU Economic and Monetary Union

EOCP Equal Opportunities Child Care Programme (Ireland)

EPL Employment Protection Legislation

ESA Employment Service Agency (UK)

ESF European Social Fund

ET Employment Training (UK)

EU European Union

EZ Employment Zone (UK)

FÁS Ireland's Employment and Training Authority

FDP Free Democratic Party (Germany)

FE Further Education

FF Fianna Fáil (Ireland)

FG Fine Gael (Ireland)

FIS Family Income Supplement (Ireland)

FPÖ Free Party of Austria

GDP Gross Domestic Product

HoPES Network of the Heads of Public Employment Services

HzA Help to Work (Germany)

IAP Individual Action Plan

IBK Industrial County Commission (Austria)

IFAU Institute for Labour Market Policy Evaluation (Sweden)

IG BCE Mining, Chemicals, and Energy Union (Germany)

IGC Intergovernmental Conference

ILO International Labour Organisation

INFAS Institute for Applied Social Science Research (Germany)

IPPR Institute for Public Policy Research (UK)

ITB Industrial Training Board (UK) 


\begin{tabular}{|c|c|}
\hline $\mathrm{JCP}$ & Job Creation Programme (UK) \\
\hline JCP & JobCenter Plus (UK) \\
\hline JER & Joint Employment Report \\
\hline JIP & Jobs Initiative Programme (Ireland) \\
\hline JRS & Job Release Scheme (UK) \\
\hline JS & Jobs Strategy \\
\hline JUMP & Youth with Perspectives (Germany) \\
\hline LES & Local Employment Service (Ireland) \\
\hline LME & Liberal Market Economy \\
\hline LMI & Labour Market Institution \\
\hline LMP & Labour Market Policy \\
\hline LO & Trade Union Confederation (Denmark and Sweden) \\
\hline LSC & Learning and Skills Council (UK) \\
\hline LTU & Long-term Unemployed \\
\hline $\mathrm{MBO}$ & Management-by-Objective \\
\hline MLP & Mutual Learning Programme \\
\hline MP & Member of Parliament \\
\hline MSC & Manpower Services Commission \\
\hline NAIRU & Non-Accelerating Inflation Rate of Unemployment \\
\hline NAP & National Action Plan \\
\hline NCIP & National Child Care Investment Programme (Ireland) \\
\hline $\mathrm{ND}_{25}+$ & New Deal for Long-Term Unemployed People (UK) \\
\hline NDYP & New Deal for Young People (UK) \\
\hline NEDC & National Economic Development Council (UK) \\
\hline NESC & National Economic and Social Council (Ireland) \\
\hline NESF & National Economic and Social Forum (Ireland) \\
\hline NFQ & National Framework for Qualifications (Ireland) \\
\hline NGO & Non-Governmental Organisation \\
\hline NI & National Insurance \\
\hline NIEC & National Industrial Economic Council (Ireland) \\
\hline NMS & National Manpower Service (Ireland) \\
\hline NPM & New Public Management \\
\hline NRP & National Reform Programme \\
\hline NSA & Next Step Agency (UK) \\
\hline OECD & Organisation for Economic Co-operation and Development \\
\hline OEEC & Organisation for European Economic Co-operation \\
\hline ÖGB & Austrian Trade Union Confederation \\
\hline $\mathrm{OMC}$ & Open Method of Co-ordination \\
\hline ÖVP & Austrian People’s Party \\
\hline PD & Progressive Democrats (Ireland) \\
\hline
\end{tabular}




\begin{tabular}{|c|c|}
\hline PES & Public Employment Service \\
\hline PLMP & Passive Labour Market Policy \\
\hline PNR & Programme for National Recovery \\
\hline PR & Proportional Representation \\
\hline PREA & Private Employment Agency \\
\hline PRETA & Pre-retirement Allowance (Ireland) \\
\hline PRSI & Pay-Related Social Insurance (Ireland) \\
\hline PSA & Personal Service Agency (Germany) \\
\hline PUMA & Public Management Service (OECD) \\
\hline RJS & Revised Jobs Strategy \\
\hline RTC & Regional Technical College (Ireland) \\
\hline SA & Social Assistance \\
\hline SAF & Swedish Employers' Confederation \\
\hline SBR & Stricter Benefits Regime \\
\hline SE & Social Economy (Austria) \\
\hline SES & Social Employment Scheme (Ireland) \\
\hline SGP & Stability and Growth Pact \\
\hline SMD & Single Member Plurality District \\
\hline SMW & Statutory Minimum Wage \\
\hline SOFI & Institute for Social Studies (Sweden) \\
\hline SPD & Social Democratic Party of Germany \\
\hline SPÖ & Social Democratic Party of Austria \\
\hline SST & Specific Skills Training (Ireland) \\
\hline TAG & Child Care Facilities Expansion Act (Germany) \\
\hline TEC & Training and Enterprise Council (UK) \\
\hline TEP & Territorial Employment Pact \\
\hline TOPS & Training Opportunities Scheme (UK) \\
\hline TSA & Training Service Agency (UK) \\
\hline TUC & Trade Union Congress (UK) \\
\hline UA & Unemployment Assistance \\
\hline UB & Unemployment Benefits \\
\hline $\mathrm{UBO}$ & Unemployment Benefits Office \\
\hline UI & Unemployment Insurance \\
\hline URO & Unemployment Review Officer \\
\hline VDA & German Association of Labour Exchanges \\
\hline VW & Volkswagen \\
\hline WASG & Electoral Alternative Work and Social Justice (Germany) \\
\hline WEP & Work Experience Programme (UK) \\
\hline WFTC & Working Families Tax Credit (UK) \\
\hline WIFO & Institute for the Study of the Economy (Austria) \\
\hline
\end{tabular}


WKÖ Austrian Chamber of Commerce/Employers' Confederation

WPA Works Progress Administration (US)

WZB Social Science Center Berlin

YEA Youth Employment Agency (Ireland)

YOP Youth Opportunity Programme (UK)

YPP Youth Progression Programme (Ireland)

YTS Youth Training Scheme (UK)

ZDH German Confederation of Skilled Crafts 



\section{Acknowledgements}

This book is the culmination of many years of work as a doctoral student at the University of Wisconsin, Madison and many months as a postdoctoral fellow at the Mannheim Centre for European Social Research (MZES). Perhaps more importantly, it is also a reflection of the many relationships I have had with many generous and inspiring people, whose support I greatly appreciate and without whom I could not have successfully completed this journey. The list is long, but I value each and everyone's contribution to the completion of this book.

First and foremost, I would like to express my deepest gratitude to my academic advisor Jonathan Zeitlin. Throughout my graduate career, Jonathan has defined what it means to be both an excellent scholar and mentor. His expertise, analytical sharpness, and theoretical rigor have motivated me to strive toward my full potential. His generosity with his time, and his prompt and constructive feedback have far exceeded my expectations, and his patience in reading countless dissertation chapters, seminar papers, and research proposals continues to amaze me. Jonathan's engagement with policymakers and experts beyond the classroom has also demonstrated to me that a concern for social issues can - and should - transcend academic scholarship and assist in imagining and creating a better world.

I would like to also thank Anton Hemerijck and Gerben Korthouwer, whose enthusiasm for this project has motivated me to turn my dissertation into a freestanding monograph, and whose careful readings of various drafts have helped me, I hope, to sharpen the argument of the book. Heartfelt thanks go to Orfeo Fioretos, Mark Pollack, and Graham Wilson for finding the time in their busy schedules to provide invaluable comments on my work. Many thanks also to Bernhard Ebbinghaus for providing financial support for the initial printing of this book. I am also indebted to my research assistants at the MZES, Daniel Hörer and Carlo Knotz, for their commitment and efforts.

This book would not have been possible without the financial support from the Center of German and European Studies (CGES), the European 
Union Center of Excellence (EUCE), the Center for World Affairs and the Global Economy (WAGE), and the Graduate School of the University of Wisconsin, Madison. I would like to also thank Professors Wolfgang Streeck and Jens Beckert for offering me the opportunity to reside as a guest scholar at the Max Planck Institute for the Study of Societies in Cologne, Germany, and the Board of Directors at the Mannheim Centre for European Social Research for providing numerous travel grants. I am also indebted to EQUALSOC, for financially supporting my 14-day research stay at the Swedish Institute for Social Research (SOFI), where I was able to benefit from many fruitful conversations with renowned scholars, such as Eskil Wadensjö, Tomas Korpi, Joakim Palme, Kenneth Nelson, and Renate Minas. I would also like to extend my gratitude to Henning Jørgensen, whose insights into the Danish case have been exceptional, and to Malin Junestav and Katarina Thorén for freely sharing their knowledge about the Swedish case.

Thank you very much also and especially to all the interviewees, who willingly shared their time with me and offered assistance and invaluable insights. I owe them an enormous debt for providing me with much of the information contained in this book, and for giving me a pleasant, guided tour through the maze of labour market policy. There are too many to identify by name or institution, but I thank them all because without them I would not have been able to complete this endeavour. Of course, I assume full responsibility for any errors in the case that interviewees do not agree with what I have written, and omissions, if they do not find all of the information they provided.

And, finally, I deeply thank my dear wife Sarah, to whom I dedicate this book. 


\section{Introduction}

\section{I.1 The Research Questions}

With the burst of the American housing bubble in late 2007 and the subsequent financial crisis that reached its climax with the collapse of Lehman Brothers in September 2008, skyrocketing unemployment and full-blown economic recessions became a global phenomenon in 2009. While the economic, political and social repercussions were felt worldwide, European policymakers were in particular reminded of both the vulnerability of their deeply institutionalised social welfare systems and - at the same time - the importance of adequate institutions, being able to cope with rising unemployment and growing inequality. This situation, however, is nothing new. Since the age of urbanisation and industrialisation, European nations have, from time to time, been exposed to deep and prolonged economic downturns, resulting in mass unemployment. The Great Depression of the 1930s, the years following the oil crises in 1973 and 1979, and more recently, the recessions after the collapse of the Soviet Union, the first Gulf War, and the European currency crisis in the early 1990s all resulted in significant increases in unemployment levels.

When faced with severe economic, political, and/or social challenges, policymakers begin to "look abroad" to see what other countries are doing (Casey 2009, 103). Already during the creation and expansion of initial welfare state structures in late $19^{\text {th }}$ century, policymakers sent delegates to neighbouring countries in search for institutional alternatives and solutions to pressing problems. Such efforts to learn from others were substantively improved after World War II (WWII) when the Organisation for Economic Co-operation and Development (OECD) was created in 1960, as an international, mainly European, body to promote policy convergence and to enhance transnational learning. During the 1990s, European policymakers placed even more emphasis on transnational lesson-drawing, not only by initiating the elaborate OECD Jobs Study (1992-1994), but also by launching the European Employment Strategy (EES) in 1997. 
Given that policymakers have frequently faced unemployment challenges throughout the $2 \mathrm{O}^{\text {th }}$ and the beginning of the $21^{\text {st }}$ century, and given that they have repeatedly and often systematically been exposed to, or actively solicited, new ideas from abroad, the following questions arise:

(1) Do national labour market policy reform efforts exhibit covariation across Western Europe, and if so, how and why?

(2) What impact, if any, have the recommendations of international organisations such as the OECD and the EU had on national reform agendas?

(3) Have recent reform activities, in the context of the OECD Jobs Study and the EES, fundamentally transformed the historic composition of national labour market policy regimes, and if so, to what effect? ${ }^{1}$

By systematically addressing these three interrelated questions, this book seeks to fulfil two purposes. At the empirical level, it aims to provide an account of labour market policy making and to delineate the institutional pathways taken by six European countries. While the "history" of labour market policy and its evolution is interesting and relevant in its own right, the main purpose of this book, however, is analytical and theoretical. Hence, it aims at objectively analysing the forms of institutional evolution - thus addressing questions pertaining to institutional convergence, persistence, and divergence - and explaining the direction of change taken by policymakers. The book's main contention is that the evolution of institutions is not simply determined by prevailing historical trajectories, economic conditions, or the strength of actor coalitions engaged in struggles over distributional outcomes, but also reflects policymakers' changing beliefs. In other words, I attribute a causal role to normative and cognitive ideas, thereby opening up the opportunity to take mutual learning and transnational policy diffusion seriously. This study therefore revisits the traditional core of historical institutionalist analysis (e.g., Hall 1986; 1989; 1993), while also offering an additional avenue to explain gradual, yet transformative institutional change, thus contributing to the promising research agenda launched by Kathleen Thelen and Wolfgang Streeck (Thelen 2003; 2004; Streeck and Thelen 2005). This book offers an actorcentred, historical-institutionalist approach (ACHI) to the explanation of labour market policy regime change that combines (reflexive) agency with historical trajectories. Accordingly, despite its focus on one particular policy nexus - labour market policy - the suggested approach may have a wider applicability in the study of the political sphere. 


\section{I.2 Competing Predictions about Labour Market Policy Regime Change: The Argument in Brief}

Most work on welfare state reform explicitly focuses on either domestic institutional settings or international economic structures to explain questions of institutional continuity and change. With respect to the former, many social scientists, in particular historical institutionalists, argue that institutions emerge out of political struggles, and once established, these institutions generate particular paths, which "lock in" actors' preferences and societal expectations, thus constraining policymakers' room to manoeuvre (e.g., Immergut 1990; Pierson 2001b). Moreover, not only do nationally specific institutional configurations condition policymakers' strategies, but countries also cluster into specific groupings with distinct systems of economic and welfare institutions (e.g., Iversen and Wren 1998; Esping-Andersen 2000a; Esping-Andersen 2002; Rothstein and Steinmo 2002a; Barbier and Ludwig-Mayerhofer 2004; Sapir 2006). Each grouping, in turn, faces a particular, rather than a common, set of public policy challenges and thus a "one-size-fits-all" institutional response is neither feasible nor probable. As such, most scholars writing in the historicalinstitutionalist tradition either predict institutional stability, which is induced by institutional "veto points" and causal mechanisms associated with path dependency, or argue that countries will adapt existing institutions in regime-specific ways, which are most adequate to the problems at hand. In either case, authors associated with this "path-dependency hypothesis" predict the reproduction of regime-typical sets of institutional configurations and sustained diversity.

In turn, authors who focus on economic globalisation - defined as increased international mobility of capital, goods, and services - typically argue that policymakers have no choice but to gradually accept the advances of neo-liberalism (e.g., Gilbert 2002; Goldberg and Rosenthal 2002). A common argument is that the "exit option" of internationally oriented businesses has disproportionately empowered capital to the detriment of organised labour. Consequently, governments find themselves in a "race to the bottom", cutting costs and regulations to prevent the off-shoring and outsourcing of domestic firms in an attempt to attract new investors with business-friendly environments. This scenario accentuates, inter alia, the perceived need to reduce expenditures for the welfare state, to further weaken organised labour, and to deregulate labour markets. These tendencies are further amplified in the European context by the tight financial corset arising from the Economic and Monetary Union's (EMU) 
national debt and inflation targets. A common conclusion is that policymakers have little choice but to restructure their welfare states along U.S. lines, i.e., they need to withdraw state responsibility (to reduce costs) and strengthen individual responsibilities (through sanctions), while increasing labour market flexibility (by removing employment protection legislation and other institutions that interfere with market forces). In short, in contrast to the first set of scholars who predicted continued institutional diversity, if not divergence, the authors associated with the "globalisation hypothesis" predict a convergence of labour market policy regimes, commonly associated with dismantling existing structures and a switch to an institutional path that will eventually lead toward one common neo-liberal destination.

While these sets of authors predict entirely different institutional outcomes, they both rely heavily on structural factors, including path dependency or global economic forces, to explain institutional stability or convergence. This book takes a different view, both with regard to the observed institutional outcomes and the primary explanatory sources. While there is no doubt that national, historical trajectories and global, structural forces strongly condition policymakers' behaviour, I argue that innovative actors can overcome both "path dependency" and the "golden straightjacket" associated with economic globalisation. ${ }^{2}$ As political actors (deliberately) "mix and match" institutions from various regimes, other institutional outcomes than persistence in institutional diversity and uni-modal convergence are analytically possible, including a process of institutional hybridisation.

In order to be able to theorise about this process of hybridisation, we need to first carefully trace the origins of national labour market policy regimes; second, establish a benchmark against which subsequent institutional changes can be assessed; third, define a set of objective criteria with which we can "measure" the degree and direction of change; and fourth, identify a set of causal mechanisms that allow for the emergence of such distinct trajectories. It is a rapidly growing body of historicalinstitutionalist literature about gradual, yet transformative institutional change that specifically provides the analytical tools to address the fourth of these steps (Thelen 2003; 2004; Streeck and Thelen 2005a). The underlying assumption in this literature is that institutions evolve over time and, even though processes are often slow and incremental, they can nevertheless result in path-breaking institutional changes. To capture such institutional developments analytically, Thelen and Streeck propose a set of five causal mechanisms that describe reoccurring pat- 
terns, namely displacement, layering, drift, conversion, and exhaustion (Streeck and Thelen 2005b, 19ff). In her subsequent work with Peter Hall, Thelen argues that the most promising way to locate the sources of these mechanisms lies with actor coalitions that are powerful enough to successfully pursue their (rational) interests (Hall and Thelen 2009). While this approach has generated valuable new insights, I concur, however, with Anton Hemerijck, who argues that the focus on the material interests of powerful coalitions unnecessarily limits actors' motivations. This analytical shortcut, in turn, may then produce an incomplete picture of institutional development as the "processes of welfare reform are multidimensional and highly reflexive and knowledge intensive endeavours" (Hemerijck 2007, 23).

In other words, this book builds on Thelen and Streeck's approach by focusing in a systematic and analytical manner on actor constellations (who holds power) and actor coalitions (who is aligned with whom). It does also, however, and perhaps more importantly, take the role of cognitive and normative ideas seriously. Hence, I follow Hugh Heclo's (1974) influential writings by analysing political processes as exercises of both "puzzling" and "powering", while adopting an ontology that perceives actors as being reflexive rather than instrumentally rational. I argue that it is precisely during phases of puzzling and reflexivity that international organisations such as the OECD and the EU play an important role, since they provide an avenue for the diffusion of new ideas and contexts for mutual learning. My main argument in this book is thus that actors have repeatedly reassessed their normative and cognitive beliefs about labour market policy and labour market governance, which in turn, triggered the patterns of transformative change that Streeck and Thelen have identified. Such reassessments occurred three times during the post-war period. The first reassessment occurred in the mid-1960s, when the OECD diffused new - Swedish - ideas about active manpower policy and a "modern" Public Employment Service (PES). Inspired by the OECD's proposals, political agendas were altered and new policy outputs initiated in many Western European countries. ${ }^{3}$ This "manpower revolution" effectively led to a partial convergence of institutions across regime types.

The oil crises of the 1970s, in turn, triggered a second phase of reassessment about labour market policy regimes, which, however, led to divergent responses and the emergence of three "worlds of welfare capitalism". This divergent policy response can best be explained by (a) the absence of a single, coherent set of "best practices" which had been present in the 1960s; (b) the emergence of monetarism as a new, competing economic 
paradigm to the previously dominant Keynesian views; and (c) the associated political struggles over new and old policy ideas.

In the mid-199os, the OECD - and this time also the EU - began articulating yet another set of new ideas about welfare and labour market reforms, reflecting, reinforcing and/or altering national actors' beliefs. The common ground of these two organisations was the concept of "activation", which originated - in the European context - in the UK during the late 1980 s, and was subsequently refined by Denmark in the early 1990s. This "new" concept of activation had successfully revived, but also repackaged and updated, the decade-old Swedish ideal of the "work line" (arbetslinjen), and entailed both positive and negative incentive structures - or rights and obligations - combined in such a way that jobseekers are incentivised to find their way (back) into gainful employment. Work is increasingly seen as the "best form of welfare", replacing traditional norms of "de-commodification" associated with Conservative and Scandinavian welfare regimes (cf., Esping-Andersen 1990).

Moreover, New Public Management (NPM) ideas, first endorsed in the UK during the 1980s (McLaughlin and Osborne 2002, 1), have refocused the roles and responsibilities of Public Employment Services. ${ }^{4}$ While NPM ideas varied both across time and space, the central message was always the same: public administration should emulate private business practices by focusing on customers and results (Christensen and Lægreid 2001, 109). Accordingly, both the EU and the OECD no longer saw PESs as state bureaucracies simply administering the unemployed, but envisioned them as "modern service providers", capable of effectively and efficiently delivering specialised services to an ever-growing clientele in an outwardlooking fashion. The most important elements of this new PES "service model" included: the use of management-by-objectives and advances toward decentralisation; rigorous, independent, and comprehensive labour market policy evaluations; merging of - or at least closer collaboration between - regimes for social assistance and unemployment benefits; active promotion of new local partnerships; competitive tendering for service provision; removal of restrictions of private employment service agencies; and finally, the expansion of self-help services and individual, in-depth case management (OECD 1997a; Commission of the European Communities 1998; 2000; Weishaupt 2010a).

Finally, both the EU and OECD gradually came to an agreement on the necessity for "constructive" state interventions to create more inclusive labour markets. This shift entailed a new political agenda and the endorsement of employment-promoting public policies. With respect to 
the former, policymakers shifted from a focus on reducing unemployment - and its theoretical foundation, the Non-Accelerating Inflation Rate of Unemployment (NAIRU) - to raising overall employment levels, which necessitated the activation of so-called "inactive" persons, or persons that are neither in employment nor in receipt of employment-related benefits. With respect to the latter, the EU and the OECD increasingly promoted the development of state-sponsored active-ageing policies, lifelong learning strategies, and the expansion of (public) provision of childcare to enable workers to postpone their exit from the labour market and to reconcile work and family life. In 2002, the EU's heads of state and government "quantified" these ambitions by setting targets for female and older worker employment rates, as well as for childcare places and the participation rate of adult workers in lifelong learning measures (Council of the European Union 2002). Likewise, by $2005 / 2006$, the OECD argued that state interventions were necessary to reach female employment rates above 60 percent, and that "appropriate help and encouragement" was needed to improve the employability of older workers (OECD 2005a; OECD 2006c).

In summary, the gradual diffusion of these three sets of congruent and mutually supportive ideas - originating mainly from the Anglo-Nordic worlds of welfare capitalism, and further developed by both the OECD and the EU - led to a process of institutional hybridisation and the emergence of an "activation paradigm", which increasingly blurred the differences between traditional welfare state clusters.

\section{I.3 Research Design, Case Selection, and the Evidence}

\section{Research Design}

This book relies on an epistemology that straddles interpretivism and positivism, a historical-institutionalist ontology with an actor focus, and a qualitative methodology. The epistemology is interpretivist as well as positivist because the main goal of this study is to detect, understand, and subsequently explain general patterns of institutional evolution in a carefully selected arrangement of cases. However, rather than (statistically) testing a set of mutually exclusive hypotheses as is typically done in positivist scholarship, my main aim is to reveal causal mechanisms, which offer explanations of how certain institutional outcomes are possible, or even probable, and why (cf., Lin 1998). This is to say, I show what the general patterns of institutional evolution look like in practice and offer insights such as " $\mathrm{X}$ leads to $\mathrm{Y}$ through steps A, B, C" (George and Bennett 
$2005,141)$. Likewise, my goal is not to discover a set of singular, invariant laws that hold in every instance. Instead, I propose a "middle-range" theoretical approach that systematically connects analytical propositions with empirical patterns in a context that has deliberately been delimited to Western Europe. As such, my epistemological view is not "dogmatic" in the sense of seeing interpretivist and positivist research as mutually exclusive worldviews. Rather, I concur with Lin $(1998,167)$ who argues that positivist research seeks to answer "what" questions, identifying causal relationships, while interpretivists answer "how" questions, identifying causal mechanisms. Accordingly, in my view, positivism and interpretivism are complementary rather than competitive, and both schools share the conviction that the pursuit of empirical knowledge is and should be driven by social science theory.

My ontology, or the underlying premises about the "character of the world", is historical institutionalist (cf., Hall 2003a). In this sense, this book explicitly assumes that any political process or institutional development is contingent on historical events, their trajectories, and prevailing institutions (cf., Rothstein and Steinmo 2002a, 16). In this way, both history and institutions matter, as the former provides a context in which actors make their decisions, while the latter condition and constrain actors' behaviour. Following the writings of Sven Steinmo (2009), I also share an evolutionary view of the political world based on the assumption that political processes and outcomes are fundamentally different from the physical world, where we can discover constant laws. Political processes and outcomes are more like living organisms studied in biology. In this sense, I perceive institutional continuity and change as being characterised by evolutionary processes in context-specific ways rather than by (linear) chains of independent events. In this evolutionary context, I assume that the world is occupied by purposive actors, whose preferences are not exogenously given or assumed (as it is typically the case in rational choice institutionalism), but are seen as endogenous. Allowing for endogenous preference formation means that I am sensitive to national contexts and particular actor constellations from which I develop propositions about what it is that actors "are trying to maximize and why they emphasize certain goals over others" (Steinmo and Thelen 1992, 9). Moreover, actors are also seen as "boundedly rational" and "reflexive". Actors are boundedly rational because they are seen as having a limited ability to (a) comprehensively solve complex problems, i.e., to find an unambiguous Pareto-optimal institutional solution, and (b) to fully predict the consequences of their actions and the policies they put in place. They 
are "reflexive" insofar as they constantly react to and learn from changing environments. In other words, actors' preferences are constantly in flux as they continuously adapt to the changing socio-economic environment and critically (re-)evaluate common practices and established institutions when exposed to new information or ideas (cf., Whitford 2002; Hemerijck 2007).

Because a historical-institutionalist ontology is at odds with assumptions generally required for standard regression analyses, this study applies the method of systematic process analysis to a small- $n$ of case studies against a larger comparative backdrop. More specifically, this study does not apply a large- $N$ technique for which I would need to assume unit homogeneity, "which is to say that, other things being equal, a change in the value of a causal variable $x$ will produce a corresponding change in the outcome variable $y$ of the same magnitude across all the cases" (Hall 2003a, 382). Rather, it relies on a small- $n$ comparison, which allows me to (a) thoroughly examine both the processes unfolding in each of my cases and the institutional outcomes in those cases, while (b) referring to, and building on, some prominent predictions of institutional change, and to (c) assess the validity of their rivals (cf., Hall 2003a, 393). In order to increase the validity of my findings, I not only offer a detailed account of the institutional processes, but also propose an analytical grid through which the main dimensions of institutional change and continuity can be systematically and objectively assessed.

\section{Case Selection and Evidence}

The small- $n$ of cases selected in this book includes three pairs of mature European welfare states: Sweden and Denmark, Austria and Germany, and the United Kingdom ${ }^{5}$ and the Republic of Ireland (henceforth Ireland). These six countries allow for three paired, cross-case comparisons and include representative cases from all of Esping-Andersen's (1990) worlds of welfare capitalism, including the Social Democratic (or Nordic), the Conservative (or Continental), and the Liberal (or Anglophone) cluster. Esping-Andersen's seminal work has become the cornerstone for most scholars interested in welfare state developments and will also be used here as a point of reference. Using pairs from various regime typologies increases the range of contexts and thus the variance on the main explanatory factors, including institutions, interests, and ideas. The six selected cases are characterised by both regime specificities and country differences, which will allow me to also assess the impact of institutional 
contexts and historical trajectories in a comparative "most similar" and "most different" framework (cf., Przeworski and Teune 1970).

Finally, the evidence for this book is based on a careful evaluation of the secondary literature as well as a wide range of primary sources, including media reports, policy papers, legislative documents, and a series of approximately 100 semi-structured interviews conducted with policymakers and stakeholders between 2006 and 2009 (for a detailed list, please refer to pages $315 \mathrm{ff}$ ). The first round of mainly exploratory interviews was conducted in spring 2006, where I gathered initial evidence, and conversed with experts, academics, and public officials to learn more about salient debates, crucial publications and other important sources of information that I could not have known without these on-site encounters. The second round of interviews was conducted over a longer period during the first half of 2007. The aim of this round of interviews with key individuals close to the policy-making process was to learn more about the fine-grained processes of policy formation, policy making, and policy implementation through detailed discussions. A third round of interviews was concluded in January 2008 and deliberately targeted officials in the national Public Employment Services and related ministries to learn more about the daily activities of policy delivery. The first three interview rounds were held in Austria, Belgium, Germany, Ireland and the UK, while a fourth and final round was conducted in August 2009 in Stockholm to corroborate my findings and interpretations of the two Nordic cases.

\section{I.4 Book Outline}

The book will proceed as follows. Following this introductory chapter, chapter II outlines my theoretical approach in greater detail, including a succinct definition of institutions, an outline of historical institutionalists' core assumptions and predictions about institutional stability and change, a discussion of the main critiques of historical institutionalist scholarship, and a presentation of the current literature on various patterns of gradual, but transformative institutional change. It then synthesises the existing literature and proposes incorporating three actor-centred mechanisms into the historical-institutionalist approach, including reshuffling, realignment, and reassessment. While the first two mechanisms are mainly concerned with actor constellations and actor coalitions respectively, i.e., power struggles over resources, the latter mechanism focuses on the causal role of normative and cognitive ideas, shaping pub- 
lic policy-making processes and outputs. Thereafter, I offer an analytical distinction between three possible institutional trajectories, ranging from sustained diversity, if not divergence, to uni-modal convergence at the extreme ends, and hybridisation, potentially leading to partial convergence, neo-divergence and neo-convergence in between. I close chapter II with the presentation of four analytical dimensions of convergence/divergence: ideational, organisational, financial, and work incentives. This last dimension includes an analytical grid that differentiates positive and negative, financial and non-financial incentives in labour market policy regimes.

Part I of the empirical analysis is divided into two chapters, capturing the origin and crisis of European labour market policy regimes. Chapter III comprises a historical reconstruction of the origins of labour market policy regimes in the late $19^{\text {th }}$ century and the emergence of the "manpower revolution" during the 196os. This chapter begins with briefly tracing the origins of unemployment insurance (UI) schemes, labour exchanges, and large-scale public works projects during the late 1800 s and early 1900 . The analytical focus is placed, however, on the 1950 s and 1960 s when a new labour market policy paradigm gradually emerged, resulting in pathsetting institutional change. More specifically, this new paradigm led to the establishment of a legal basis for active labour market policies in most Western countries, while also creating the organisational foundation to implement active labour market policies on a national scale through the establishment and/or modernisation of tripartite Public Employment Services. ${ }^{6}$ I further show that this "manpower revolution" was the immediate result of the active propagation and diffusion of Swedish "best practices" by the newly founded OECD, whose Manpower Commission was chaired by Swedish trade union economist Gösta Rehn, one of the two founding fathers of what became known as the Swedish Model (cf., Wadensjö 2001).

In chapter IV, I demonstrate how the initial oil shock in 1973 shifted national policy agendas away from supply-side-oriented to demand-sideorientated manpower measures. At that time, the underlying assumption of policymakers was that the crisis would be temporary, and therefore, the responses needed to be designed in a way that cushioned temporary hardships of jobless workers. The second oil shock in 1979, however, shattered the hopes of many governments to "wait out" the economic downturn, and many policymakers abandoned - some did so involuntarily - Keynesian strategies that were based on deficit spending. The parallel emergence and consolidation of monetarist theory, which was inspired by the scholarship of Nobel Price winners Milton Friedman and Edmund Phelps, triggered a "battle" over economic, labour and social policy ideas, and the 
pursuit of three different strategies to overcome the crisis: (a) a Nordic, mainly Swedish, "social investment state" response that prioritises the expansion of the welfare state and the public sector; (b) a Continental "labour shedding" response, which relied heavily on a reduction of excess labour; and (c) an Anglophone "invisible hand" response, based on marketisation, privatisation, and deregulation. Hence, I argue that the $1970 \mathrm{Os}$ and, even more so, the 1980 s were characterised by ideational and institutional divergence, which led to the crystallisation of three distinct reform patterns (cf., Esping-Andersen 1996, 15ff; Siebert 1997, 41; Palier 2004, 1). The core principals of each of the three clusters are briefly summarised at the end of chapter IV and serve as a "benchmark" against which contemporary reform processes and outcomes are measured.

Part II of the empirical analysis is divided into three chapters, covering roughly the past 20 years during which - so I argue - an "activation paradigm" emerged. Chapter V focuses on the international level and traces how the OECD and the EU interpreted the causes of, and remedies for, unemployment, underemployment and underachievement. In this chapter, I compare and contrast the normative and cognitive ideas that underlie the assumptions and prescriptions of both international organizations. I outline why the OECD launched the 1992-1994 Jobs Study, briefly sketch its mainly "neo-liberal" findings, and show how the OECD - after a series of evaluations - gradually reassessed many of its core assumptions and prescriptions. Over time, the OECD not only began to promote activation policy, the modernization of public employment services in line with New Public Management writings, and the newly emerging concept of flexicurity, but the OECD also acknowledged the economic validity of the "Nordic welfare model". Consistent with this new outlook, the OECD issued recommendations for state-led interventions with respect to lifelong learning and the reconciliation of work and family life. I also trace the origins of the EU's European Employment Strategy and explain why the EU launched its own benchmarking process, in addition to, but separate from, the OECD's. The EU's reassessments following critical reviews of the EES are also portrayed, which led to - after a reshuffle in the Commission - the launch of a revised EES that focuses more on "growth and jobs" and less on social equity goals. As a consequence, so I argue, an "activation paradigm" consolidated, and the EU gradually became more "liberal" and the OECD more "social democratic".

Chapter VI shifts the focus back to national institutions and assesses to what extent the cognitive and normative ideas articulated by both the $\mathrm{EU}$ and the OECD have been translated into new national policy agendas 
and public policies. For this purpose, an analytical overview of recent institutional developments is presented, which includes an assessment of the four dimensions of labour market policy regimes outlined in chapter II. The primary focus is on the same six cases analysed in chapters III and IV, but descriptive statistics are presented for - with occasional references made to - the other EU-15 countries, except Luxembourg. This chapter identifies an ideational and discursive shift in national politics across Western Europe, which has been translated into significant organisational and programmatic changes. It is argued that policymakers increasingly pursue similar goals based on shared problem definitions albeit with strategies filtered through national contexts - which has triggered a process of institutional hybridisation, characterised by both, partial convergence and persistence in national diversity. Partial convergence is demonstrated with the emergence of an "activation paradigm", which rests on three pillars: (a) activating labour market policies, including early interventions, case management, and conditional benefits; (b) a modern, customer and results-oriented PES, governed in a managerial style; and (c) a more inclusive, employment-promoting welfare state, that mobilises also women, older workers, and otherwise "inactive" persons. Persistence in differences, in turn, is visible in governments' expenditure efforts and their sources of funding.

Chapter VII asks how these transformative institutional changes have occurred in the context of national politics. For this purpose, the evolution of labour market policy from the mid-1990s until about 2008 is carefully traced in the two illustrative cases of Germany and Ireland. Both of these countries are important cases in analytical terms. Germany is the archetypical Bismarckian welfare state and co-ordinated market economy, characterised by a complex system of veto points. Hence, the German model has often been described as prone to incremental, institutional adaptations and path-dependent evolution (e.g., Manow and Seils 20oo; Wood 2001). As such, it is a "least-likely" case for radical change and institutional transformation (George and Bennett 2005, 121), and yet, we observe various reforms that could be interpreted as "path breaks" and "path departures" (Ebbinghaus 2005). Ireland, in turn, has pursued a deliberate course of institutional hybridisation (NESC 2005a), seeking to reconcile a liberal labour market with neo-corporatism and welfare expansion. Thus, both countries can serve as principal cases in the tracing of how institutional legacies affect such reform efforts and how "champions of institutional change" find the necessary "support, allies and relays to turn a fragile initiative into a new institutional path" (Djelic and Quack 2007, 165). 
In this chapter, I argue that both countries adopted similar institutional trajectories despite different welfare traditions, different partisan compositions, and different economic circumstances. More specifically, I trace the developments that have led to (1) the introduction of activating labour market policy; (2) the introduction of childcare strategies that challenge these countries' underlying norm of the male breadwinner model; and (3) the (partial) replacement of demand-reducing, "early exit" programmes with active ageing and lifelong learning strategies. While "power politics" certainly shaped the timing and content of the new public policies adopted by the respective parliaments, the similarity of these two countries' trajectories further emphasises the importance and reality of the EU/ OECD's influence and the cognitive/normative reassessments of policymakers.

Chapter VIII concludes by summarising the responses to the three central questions posed in the introduction and presents a brief reflection on the effects of the global financial and economic crisis on the future of the "activation paradigm". 


\section{Theoretical Approach}

\section{II.1 Introduction}

Can modern European welfare states withstand contemporary pressures associated with economic globalisation, capital mobility, persistent, often long-term un- and underemployment, the shift from manufacturing to service economies, ageing societies, and changing gender roles and family structures, or will they converge on a minimalist, individualistic, US-style model? This substantive, empirical and theoretical puzzle is at the very heart of most welfare state scholars' research. Facing the most severe financial and economic crisis in 60 years, many researchers have also begun asking how well European welfare states are prepared to cope with rising levels of unemployment, whether current institutional arrangements are sustainable, and how well they are equipped to generate job growth once the crisis comes to an end. In order to tackle such complex questions about the future of European welfare states, scholars need to have a good understanding of welfare states' past and present forms and functions, that is, they need to understand their origins and evolution.

Since the mid-1980s, a variety of new theoretical approaches have emerged offering explanations of social and political phenomena, commonly referred to as the New Institutionalism (Steinmo and Thelen 1992). Three varieties within this New Institutionalism are commonly identified: ${ }^{1}$ Sociological Institutionalism, Rational Choice Institutionalism, and Historical Institutionalism (Lichbach and Zuckerman 1997). With respect to welfare state development, it is scholars associated with the historical-institutionalist school who have produced a substantial amount of the most influential scholarship on welfare states (e.g., Esping-Andersen 1990; Pierson 1994; 1996; Visser and Hemerijck 1997; Hall and Soskice 2001; Pierson 2001b; Rothstein and Steinmo 2002b; Streeck and Thelen 2005a; Ebbinghaus 2006; Palier 2010). In light of these seminal works, historical institutionalism is often said to have emerged as the dominant approach to explaining welfare state trajectories and institutional evolu- 
tion more generally (Amenta 2003, 91f), while countless scholars use their findings as the starting point for their own research.

This book also falls in line with historical-institutionalist thought and aims to make three analytical contributions; two that are generally useful when analysing processes of institutional evolution, and one that is specific to the topic of this book. First, this book contributes to ongoing debates on regime type divergence and convergence by succinctly summarising and analytically fine-tuning the welfare state regime change trajectories theorised about in the literature. ${ }^{2}$ Second, it aims to develop a synthesis of leading historical institutionalists' work, while introducing three additional actor-, in contrast to, process-oriented causal mechanisms with which gradual and yet transformative patterns of institutional evolution can be explained. And third, this book offers an analytical tool kit for systematically analysing temporal and cross-national institutional changes in labour market policy regimes, which is considered an important area in the field of welfare state studies. In summary, my aim is to conceptualise political processes of institutional continuity and change and utilise existing and novel analytical tools that help us understand how certain kinds of institutional change become possible, or even probable, and why.

Considering these ambitions, the following chapter is divided into six sections. First, I offer a succinct definition of institutions; second, I outline historical institutionalists' core assumptions and predictions about institutional stability and change; third, I discuss the main critiques of historical institutionalist scholarship and present the current literature on various patterns of gradual but yet transformative institutional change; fourth, I synthesise the existing literature and propose three new actororiented modifications to the historical institutionalist literature; fifth, I analytically distinguish three possible institutional outcomes, which are derived from the existing literature; and sixth, I present an analytical grid to objectively assess institutional reform trajectories in the area of labour market policy regimes.

\section{II.2 Defining Institutions}

Welfare states comprise various sets of institutions, both formal and informal. Strikingly, and despite the rapid growth of institutionalist scholarship, historical or otherwise, there is no single, commonly accepted definition of an institution. While many researchers refer to Douglas North's 
$(1990,3)$ seminal definition of institutions as "the rules of the game in a society or, more generally ... the humanly devised constraints that shape human interaction", not everybody can agree on this definition, nor is it - due to its breadth - particularly helpful in every study. For instance, Streeck and Thelen (2005b, 10) argue that modern economies are political economies, i.e., they are governed by politics, in which key rules are formalised. Accordingly, informal rules such as the institution of a handshake in a German business meeting, while certainly important, need not be included. They consequently argue that the focus should be placed on "formalized rules that may be enforced by calling upon a third party" (Streeck and Thelen 2005b, 10, emphasis added).

Accordingly, in this book, I define institutions as formalised rules, which are enforceable by a third party. Such a definition has important analytical advantages. In contrast to definitions used by many sociological institutionalists, informal institutions are explicitly excluded, which sharpens the study's analytical precision. More specifically, when informal elements are included in the definition, it becomes difficult to objectively determine an institution's constitutive parts. Moreover, and perhaps more importantly, I argue that it is precisely the informal underpinnings of an institution that condition its stability. Therefore, informal elements become part of the explanans of formal institutional evolution, i.e., the explanandum (use of terms based on, Hempel and Oppenheim 1948). Similarly, the definition put forward by these two authors has an important advantage to those institutionalists - typically scholars that are identified as applying a particular interpretation of rational-choice institutionalism - that see institutions as providing order to a "chaotic world". In other words, while these "rational choice" scholars see institutions as equilibrium outcomes ${ }^{3}$ that are voluntarily created in order to induce stability into collective action (e.g., Krasner 1991; Shepsle and Bonchek 1997), Streeck and Thelen's definition highlights authority and obligation. Stressing the "obligatory" rather than the "voluntary" character of institutions, in turn, means that institutions no longer need to be based on functionalist assumptions as actors may be obliged to follow an institution even if it is against their will (Streeck and Thelen 2005b, 11). Adopting a non-equilibrium and non-functionalist based interpretation makes institutions subject to evolution, in contrast to stasis, a process that is driven "if by nothing else, by its necessarily imperfect enactment on the ground, in direction often unpredictable" (Streeck and Thelen $2005 \mathrm{~b}, 16)$. This is to say that institutions are continuously contested or reinterpreted and policymakers need to continuously adjust and revise 
institutional design decisions if institutions are to persist (Streeck and Thelen 2005b, 16).

To summarise, while the definition adopted in this book is not without its problems, it has certain advantages. On the one hand, it is narrow enough to avoid theoretical indeterminacy by explicitly focusing on formalised and consciously designed rules, while it also avoids theoretical over-determinacy that necessarily comes with scholars who adopt functionalist assumptions about institutions. On the other hand, this definition is broad enough to allow for the inclusion of formalised structures, which are typically based on codified rules, laws, or constitutions (e.g., vocational training systems or Public Employment Services), and public policies, i.e., programmes issued by governments with the intent to regulate the life of citizens and achieve particular societal goals (e.g., early retirement schemes or occupational training measures for the unemployed).

\section{II.3 Historical Institutionalism: Explaining Continuity}

Historical-institutionalist analyses offer important mid-range theoretical insights and typically share two focal points, namely history and institutions, which enable us to better understand government, politics and public policy (Pierson and Skocpol 2002, 696). The focus on history implies that historical-institutionalist researchers take the temporal dimension of their study seriously, i.e., they analyse politics as a "film" rather than as one or more "snapshots", as is often done in game-theoretic scholarship (Pierson 1996b). Historical institutionalists argue that politics is contingent on past events, and therefore historical legacies need to be part and parcel of any explanation of institutional development. Institutions, in turn, are often used as both independent variables, i.e., they are used as explanatory variables (the setting), and dependent variables, i.e., as the phenomenon to be explained (the outcome).

The strength of historical institutionalists' analyses is seen in explaining welfare state origins and, in particular, their trajectories. For this purpose, historical institutionalists build on three sets of explanatory variables, including (a) societal interests and their power vis-à-vis competing interests, (b) institutional arrangements that underpin politics and markets, and (c) ideational factors, constraining or enabling welfare state trajectories (cf., Hall 1997). Their main argument, in turn, is usually undertaken in two steps, including an interest-based expla- 
nation of institutional origins, and an institutions-based explanation of structural continuity. ${ }^{4}$ Accordingly, when explaining welfare state origins and initial trajectories, many historical-institutionalist scholars identify societal "power resources" or "class struggles" as the main variables (Esping-Andersen 1985; Esping-Andersen 1990; Rueschemeyer et al. 1992; for a more contemporary study, see Mares 2003). They postulate that "the struggle over welfare states is a struggle over distribution" (Huber and Stephens 2001,17), and thus coalitions between or across societal groups and the existence of large, cohesive political parties such as Social Democratic, Christian Democratic, or market-liberal parties that hold power over substantive periods of time determine the form and generosity of states' social policy regimes (in addition to Esping-Andersen, see also, Korpi 1983). A central theme in this literature is that large labour union movements, coupled with a hegemonic Social Democratic party, have led to the creation of generous, universal welfare states (e.g., Stephens 1980). Similarly, the dominance of Christian Democratic parties has also generated rather generous welfare states, but of a different character. Christian Democratic, or Continental, welfare states rely more heavily on the family to provide certain social services, favour a male bread-winner model, and make access to generous benefits conditional on employment (Esping-Andersen 1985; Esping-Andersen 1990; Kersbergen 1995). Lastly, the Liberal welfare states typically lacked strong Social Democratic or Christian Democratic parties at critical junctures in time, and are characterised by fragmented societal interests and universal, but minimalist welfare states (for an excellent review of how racial prejudices undermined the development of a more comprehensive welfare state in the US, see Katznelson 2005).

The second step in historical-institutionalist analyses is based on the argument that once welfare state structures and supplementary public policies are put into place, they leave policy legacies behind that condition subsequent governments' room for manoeuvre, i.e., they make politics path dependent. Path dependency refers to the idea that the longer an institution remains in place, the more actors adjust their behaviour and expectations according to this particular institutional setting, and thus, the more resilient it will become to radical changes. In other words, initial steps down a particular path will encourage further steps down that same path, and over time, paths not chosen "may become increasingly distant, increasingly unreachable alternatives" (Pierson 2004, 64). While the investment in existing institutions may therefore make alternative paths more costly, the existence and reliance on particular institutions also gen- 
erate "winners", who, in turn, will have a vested interest in preserving the institutional status quo. As a consequence, institutions become "sticky" and "locked-in", as politicians, who aggregate and channel societal group preferences into their party manifestos, refrain from pursuing policies that damage their chances for re-election. This means that the underlying mechanisms that trigger path dependency are positive feedback and increasing returns (Pierson 2000, 252). In light of these assumptions, Pierson argues that - in settings where path-dependent processes take place - political life is likely to be characterised by four features:

1. Multiple equilibria. Under a set of initial conditions conducive to positive feedback, a range of outcomes is generally possible.

2. Contingency. Relatively small events, if occurring at the right moment, can have large and enduring consequences.

3. A critical role for timing and sequencing. In these path-dependent processes, when an event occurs may be crucial. Because early parts of a sequence matter much more than later parts, an event that happens 'too late' may have no effect, although it might have been of great consequence if timing had been different.

4. Inertia. Once such a process has been established, positive feedback will generally lead to a single equilibrium. This equilibrium will in turn be resistant to change (Pierson 2004, 44, emphasis in original).

However, this positive feedback process is not the only causal mechanism identified by historical institutionalists. Most prominently, Hall and Soskice (2001) argue that specific institutional complementarities, or a set of institutions that strengthen and reinforce one another, also promote institutional continuity. Hall and Soskice herein distinguish two different types of equilibrium production regimes, including Liberal Market Economies (LMEs) and Co-ordinated Market Economies (CMEs), which can succinctly be summarised as follows:

In one, firms coordinate with other actors primarily through competitive markets, characterized by arms-length relations and formal contracting. Here, equilibrium outcomes are dictated by relative prices, market signals, and familiar marginalist considerations. In the other modality, firms coordinate with other actors through processes of strategic interaction of the kind typically modeled by game theory. Here, equilibrium outcomes depend on the institutional support available for the formation of credible commitments, including support for effective 
information-sharing, monitoring, sanctioning, and deliberation. ... At the one end of the spectrum stand liberal market economies (LMEs) where relations between firms and other actors are coordinated primarily by competitive markets. At the other end are coordinated market economies (CMEs) where firms typically engage in more strategic interaction with trade unions, suppliers of finance, and other actors (Hall and Gingrich 2004, 7f).

Therefore, rather than locating the source of stability in political parties that lack the political power or will to push through (unpopular) reforms, it is firms that are reluctant to dismantle well-established institutional configurations. Removing or substantially altering even parts of such institutionally complementary production regimes would disrupt its institutional equilibrium and consequently undermine a country's competitive advantages.

To summarise, based on the theoretical premises of institutional reproduction through complementarities or institutional inertia through positive feedback and increasing returns, most scholars in the historical-institutionalist tradition either assume that institutions develop only incrementally through adaptation, leaving the overall institutional structures intact, or they postulate that only a dramatic exogenous shock can cause institutional innovations due to radically altered external conditions. Accordingly, many historical-institutionalist scholars see an image of a "frozen welfare landscape" and perceive welfare states as "immovable objects" (Esping-Andersen 1996, 24; Pierson 1998, 539, respectively). ${ }^{5}$

\section{II.4 Historical Institutionalism: Beyond Continuity}

In recent years, historical institutionalists have become increasingly dissatisfied with their paradigm's lack of analytical flexibility. More and more scholars have begun to seek options other than stability, on the one hand, and radical change triggered by external shocks, on the other. The need for more analytical flexibility has further been emphasised by the work of numerous prominent scholars, including, for instance, Bleses and SeeleibKaiser (2004), Clasen (2005), Lessenich (2003), Palier (2004), Palier and Martin (2007), and Scharpf and Schmidt (200ob), which has shown significant institutional changes in European welfare state trajectories, way beyond what would be expected by Pierson's work, and in directions that 
do not necessarily fit the expectations outlined by Esping-Andersen (see section II.5 below). From this, a two-fold conclusion was drawn: first, "change is difficult, but it happens!" (Hemerijck 2007, 15); and, second, we need new tools to understand the conditions under which this change occurs (Streeck and Thelen 2005a).

In response to these conclusions, Streeck and Thelen (2005a) and their collaborators attempted to broaden historical-institutionalist scholars' analytical tool kit. Their recent work goes beyond the expected outcomes of institutional "lock in" and institutional breakdown as a result of external shocks by theorising about the possibility of incremental and yet transformative institutional change. How gradual and yet transformative institutional development becomes possible is captured by five causal mechanisms - where mechanisms are understood as "frequently recurring ways in which things happen" (Elster 1989; Scharpf 1997, cited in Thelen 2003, 233): displacement, layering, drift, conversion, and exhaustion (Streeck and Thelen 2005b, 19ff). Displacement describes a process in which dominant institutions are gradually replaced by dormant or foreign institutions. These new institutions, in turn, generate institutional incoherence, which creates space for deviant behaviour and increasingly cultivates a new institutional logic. Layering refers to a process where new institutions are added onto existing institutions. These new institutions gradually siphon off the support for the old institutions, and the initial compromise between old and new institutions slowly results in the defeat of the old ones. Differential growth is herein the main explanatory process. Drift has to do with deliberate neglect. Even though external conditions require institutional adaptation, actors purposely refrain from doing so, which gradually makes the existing institutional setting obsolete or minimises its value or functions. Conversion occurs when old institutions are redeployed to serve new functions or purposes, or new purposes are attached to old structures and, lastly, exhaustion describes a process where institutions gradually wither away, as the normal workings of the institution depletes its own functions or resources, due to decreasing returns or over-extension.

We can conclude that rather than expecting institutional change only in response to external shocks (and institutional reproduction otherwise), change can and does occur, albeit under a "veil of continuity" (expression borrowed from Schedler 200o). The following figure summarises the above described results of institutional change. 


\begin{tabular}{lcc} 
& Continuity & Discontinuity \\
\hline Incremental & Reproduction by Adaptation & Transformative Change \\
\hline Disruptive & Survival and Return & Breakdown and Replacement \\
\hline
\end{tabular}

Source: Streeck and Thelen 2005b, 9

\section{II.5 Causal Mechanisms to Explain Institutional Transformations: Ideas and Agency}

While Streeck and Thelen's new conceptualisation of processes of institutional change has vastly improved our understanding of institutional evolution, it remains somewhat underspecified with respect to the relevant actors and how these actors trigger the processes-oriented causal mechanisms of displacement, layering, drift, conversion, and exhaustion. The authors, however, provide two focal points. On a general level, they argue that fundamental change "ensues when a multitude of actors switch from one logic of action to another" (Streeck and Thelen 2005b, 18). This switch may happen as institutions, which are assumed to be political compromises, are continuously challenged by purposive political and societal actors. These challengers include both the "losers" of the status quo who are eagerly waiting for an opportunity to alter or eliminate existing institutions, and the "winners", if and when they become disappointed with particular institutional arrangements over time (cf., Thelen 2003). On a more specific level, Streeck and Thelen recommend shifting the attention to more subtle influences by emphasising the role of political actors working on the sidelines, whose "active sponsorship of amendments, additions or revisions" can make or break a government's reform agenda (Streeck and Thelen 2005b, 24). In either case, Streeck and Thelen's work suggests that paying particular attention to coalitions formed among powerful actors is the most promising way forward if we want to locate the sources for transformative institutional change (see also Hall and Thelen 2009, 25).

A focus on "coalitional politics" and shifts in the "balance of power" also means, however, that institutional change is more often than not reduced to struggles over "scarce resources" in which political competition is limited to ideological choices (within particular institutional constraints). 
While "power politics" is certainly a very important ingredient in explaining institutional evolution, it does not capture the whole story. Deciding what to fight for includes, and is often preceded by, "collective puzzlement" (Heclo 1974, 305), i.e., social processes in which actors' cognitive and normative ideas - old and new - can become the pinnacle nexus for institutional continuity or change. The omission of an ideational variable thus leads to incomplete explanations, or even worse, the detection of spurious relationships. Accordingly, in what follows, I will develop an analytical framework that builds on, but also redirects, Streeck and Thelen's research agenda in three steps. First, I will elaborate on this book's underlying ontology of agency, which is necessarily different from that of Streeck, Thelen and many other historical institutionalists; second, I will briefly review how historical-institutionalist scholarship has incorporated "ideational" explanatory factors in recent studies of the welfare state; and third, I will offer three actor-centred causal mechanisms with which we can analytically distinguish power politics "as usual" from collective puzzlement, and derive expectations on how the two processes interact.

\section{II.5a Ontology of Action and Agency}

As the previous sections in this chapter have shown, many historical institutionalists explicitly or implicitly borrow assumptions about political behaviour and institutional design from the rational choice literature. For instance, Pierson's understanding of path dependency is based on positive, economic/electoral interests-based feedback loops, while Hall and Soskice's assumptions about equilibrium outcomes and institutional complementarities presume rational actors, whose decisions are based on a cost/ benefit calculus. Even Streeck and Thelen prioritise rational action when they stress that institutions "are the object of ongoing skirmishes as actors try to achieve advantage by interpreting or redirecting institutions in pursuit of their goals, or by subverting or circumventing rules that clash with their interests" (Streeck and Thelen 2005b, 19). This implies that the actors are assumed to strategically pursue their "interests", which are based on a set of clearly specified and hierarchically ranked preferences. The ontology in this book takes a different perspective as it explicitly challenges the assumption that political actors are always rational utility-maximisers. Instead, actors are seen as reflexive agents in the sense that they continuously adapt to internal and external ideational stimuli, which can alter their beliefs about what is appropriate, effective, efficient, or modern. This kind of treatment, I believe, does justice to the historical-institutional premise 
that actors are embedded in their historical contexts, which inform their "mental maps", while also taking the role of normative and cognitive ideas seriously as Peter Hall did in his seminal works $(1986 ; 1989 ; 1993)$. The crux of the argument about actors' motivations is that in politics in general, and with respect to welfare politics in particular, policymakers face "problem situations" for which neither ends nor means are stable and preferences are not clearly delineable (cf., Whitford 2002, 342). Rather, the actors' creativity and their situation at that particular time in history becomes a crucial element in the definition of desirable outcomes and appropriate avenues. This implies that the conception of policymakers as rational individuals is problematic in at least three ways: (a) policymakers may not a priori know what their preference about a certain public policy or political structure is. More specifically, there may be great uncertainty about the most appropriate means to a desired end, while the end itself is also evolving over time and therefore never fixed (source of inspiration, Whitford 2002); this means (b) that actors cannot unambiguously identify the "winners" and "losers" of proposed institutional changes because the changes are complex, costs and benefits are widely diffused, and many effects are only visible in the long run; and (c) the assumption of a purely functional logic of institutions is not only problematic due to actors' inability to perfectly predict the future or an institution's implementation on the ground - as Streeck and Thelen argue - but also because it downplays the role of normative ideas, which underlie political action and set behavioural boundaries for policymakers and other stakeholders.

Ideas, in addition to benefit-maximising interests, are therefore the "medium by which people can imagine a state of affairs other than the status quo and such imaginations might plausibly spur them to act to try and make changes" (Lieberman 2002, 698). Ideas can thus offer institutional alternatives that were previously unavailable, or rule out others on the basis of normative or cognitive predispositions. But rather than using ideas in a deterministic way, I also concur with Sheri Berman who writes that social "scientists must be able to explain the backstory, why some of the innumerable ideas in circulation achieve prominence in the political realm at particular moments and others not. Since no intellectual vacuum ever exists, what is really at issue here is ideational change, how individuals, groups, or societies exchange old ideas for new ones" (Berman 2001, 233). Thus, what I suggest is that we analyse and pay close attention jointly to the effects of historical trajectories, actor constellations, and the role of normative and cognitive ideas, rather than treating each of them as competing variables. With respect to ontological considerations, this means 
that it is assumed that political actors constantly seek and actively solicit institutional design alternatives to existing formal structures and public policies, while new or re-emerging normative or cognitive ideas may offer new "scripts" about what is an efficient, modern, or legitimate institutional design (e.g., Fligstein 1991). Institutional entrepreneurs are therefore seen as being able to take a "reflective stance towards established practices", i.e., they can envision alternative processes and outcomes (Beckert 1999, 785). Accordingly, it is this focus on actors' ideas that allows us to understand how "human agency can defy the constraints of political and social structures and create new political possibilities" (Lieberman 2002, 698).

\section{II.5b The Role of Ideas in Historical-Institutionalist Writings}

While there are few social scientists who would argue that "ideas" do not matter in "unsticking" institutions and "unfixing" preferences and norms (Schmidt 2008), there remains great disagreement about when and how ideas matter, and why some ideas are influential, while others fade without having any impact. At the risk of oversimplification, one can identify essentially two groups of scholars who utilise ideas as explanatory variables. First, there are the "traditional" historical institutionalists who emphasise institutional continuity, which is occasionally ruptured by some external crisis. For them, ideas are essential during these "crisis moments" because actors are then, and only then, open up to new ideas (e.g., Blyth 2002; Hall 1989; McNamara 1998). In this scholarship, ideas are solely used as a "residual" variable, whose explanatory power is established by revealing that all other interest and institution-based explanations have failed (e.g., Berman 1998; Parsons 2003). Ideas are thus reduced to "road maps showing actors how to maximize their interests" (Goldstein and Keohane 1993, 11) or "strategic weapons" used in political battles (Blyth 2002). The consequence of this particular treatment entails that these scholars retain an ontology of rational - as opposed to reflexive - action and agency, while analytically prioritising ruptured rather than incremental institutional change.

However, there is also a second group of historical institutionalists who use ideas as causal variables in explaining incremental but transformative change (Heclo 1974; Hemerijck and Visser 2003; Béland and Hacker, 2004; Béland 2005; Hemerijck 2007; 2008). These scholars consider political actors not only as "vote maximisers" but also as "problem solvers", who constantly seek new information about institutional alternatives. When policymakers and institutional entrepreneurs "collectively wonder what to do", access to new cognitive and normative ideas can lead to a re-evaluation of 
existing policies, programmes or even paradigms, which can then trigger institutional changes (even in the absence of a crisis and ahead of policy failures). For these scholars, political actors and institutional entrepreneurs "not only 'power' (or whatever the verb form of that approach might be); they also puzzle" (Heclo 1974, 306). Accordingly, these scholars base their research in the literature on transnational policy diffusion and social learning with which they seek to "open the 'black box' of the cognitive and normative orientations of policy actors" (Hemerijck and Visser 2003, 2).

To summarise, we can identify four types of historical-institutionalist approaches that deal with the causes of institutional change (see table 2 below). First, "traditional" historical institutionalists argue that institutions are "sticky" and will - in the absence of a major external shock - adapt to challenges, thus reproducing themselves over time (EspingAndersen 1990; Pierson 2004). Second, we have those scholars who argue that institutions incrementally change as actors' interests adapt to changing environments. While external shocks are not a necessary condition for incremental but potentially transformative changes, these scholars rely primarily on the interplay of rational actors, the distribution of power among these actors, and the institutions in which they are embedded to explain change (Hall and Thelen 2009; Streeck and Thelen 2005b). The third group of scholars also utilises ideas as explanatory variables, but only if and when an external crisis forces political and social actors to reassess their normative and causal preconceptions (Blyth 2002; Hall 1989; McNamara 1998). Finally, there is a group of scholars that argues that much institutional change can be explained by the gradual changes in policymakers' normative and cognitive beliefs (Heclo 1974; Visser and Hemerijck 2003; Béland and Hacker, 2004; Béland 2005; Hemerijck 2007). The following table shows these competing schools of thought.

Table 2 Competing Causal Mechanisms and Necessary Conditions for Transformative Institutional Change

\begin{tabular}{ccc}
\hline & Interests (powering) & Ideas (puzzling) \\
\hline $\begin{array}{c}\text { External shock } \\
\text { (crisis, abrupt and }\end{array}$ & $\begin{array}{c}\text { Paul Pierson } \\
\text { revolutionary change) }\end{array}$ & $\begin{array}{c}\text { Peter Hall (1989) } \\
\text { Mark Blyth } \\
\text { Kate McNamara }\end{array}$ \\
\hline Endogenous evolution & Peter Hall (2001) & Hugh Heclo \\
(no crisis, incremental yet & Kathy Thelen & Anton Hemerijck \\
transformative change) & Wolfgang Streeck & Jelle Visser \\
\hline
\end{tabular}

Source of inspiration: Hemerijck 2007 
In what follows, I seek to synthesise the "powering" and "puzzling" explanations of endogenous, evolutionary change by analytically distinguishing three actor-based mechanisms.

\section{II.5C Three Actor-Centred Causal Mechanisms to Explain Transformative Institutional Change: Reshuffling, Realignment, and Reassessment}

Fritz Scharpf $(1997,29)$ reminds us that "in a world that is exceedingly complex and in which we will often be studying unique cases, we must have a good idea of what to look for if we wish to discover anything worthwhile". This section seeks to do precisely that. In an attempt to simplify a complex reality, I first establish the political contexts in which actors operate (i.e., the political structures) and subsequently propose three actor-oriented causal mechanisms, which identify under which conditions institutional entrepreneurs are able to identify and possibly agree on an institutional path that departs from the status quo and thus may lead to institutional transformation. These latter three causal mechanisms analytically differentiate between actor constellations, actor coalitions, and actors' ideas. Empirically, however, these processes are not mutually exclusive. Rather, the mechanisms are likely to occur simultaneously to the effect that, if they pull in the same direction, the mechanisms reinforce one another, or, if they pull in opposite directions, they may weaken one another.

\section{Political Structures and Institutional Change}

The development of economic institutions and welfare states is embedded in a political process, which is highly conditional on existing political structures. The most important political structures include electoral and legislative institutions. Electoral institutions are important because they condition the effective number of political parties and the way in which these parties compete. ${ }^{6}$ The two main electoral institutions typically identified in the literature include single-member plurality districts (henceforth SMD) and systems of proportional representation (PR). There are typically four characteristics associated with SMD electoral rules, including first, the dominance of two political parties, which alternate in heading the government. Second, the electoral competition between the two major contenders leads to clearly delineated partisan manifestos that allow "voters to identify and choose among competing government options available to them" (Shugart and Carey 1992, 7), which, third, leads 
to moderately ideological contests as the main political parties in these systems need to "compete for the swing voters in the centre of the political spectrum" (Downs 1965; Lijphart 1999, 63). And fourth, as SMD systems typically produce single-party cabinets, their governments "promote unified, decisive leadership and hence coherent policies and fast decisionmaking" (Lijphart 1999, 259).

PR systems, in turn, are typically more inclusive, as governments in these systems include "broad interests and multiple parties" (Shugart and Carey 1992, 11). Inclusiveness is the intended consequence of a system that promotes the viability of small parties and the inevitability of forming coalition governments in most cases (Powell 2000, 16). Electoral competition may therefore be characterised by many competing, often strongly ideological, visions and pre-election alliances between parties within the same ideological spectrum. The likelihood of swift policy changes may be reduced in such systems as compromises among two or more coalition partners are necessary. Thus, the weakness of PR systems is the presence of many veto players, who may create inertia and deadlocks (Pierson 2001b; Swank 2002; Tsebelis 2002).

Irrespective of a country's electoral rules that condition the number and strength of political parties, the level of "fragmentation" in a political system may be further amplified by its legislative institutions. Legislative institutions include those institutions that may present "veto points", such as bicameralism, federalism, or judicial review. Generally speaking, the expectation is that the more veto players and veto points there are in a political system, the less responsive it will be to institutional change. These political structures, however, only condition the situations in which actors find themselves. This is to say, political structures do not determine outcomes as politics is ultimately shaped by actors and agency. Let us now turn to the actual actor-based mechanisms, including two that are derived from political interests (powering) - including actor reshuffling and actor realignment - and one that is derived from normative and cognitive ideas (puzzling), i.e., the actors' reassessment of current institutional designs.

\section{Political Interests and Institutional Change}

Reshuffling. The first causal mechanism for actor-induced change is one that focuses on changes in the composition of the main political actors. Most importantly, it is national elections that may result in a reshuffling of actor constellations in the executive and/or legislative branches of government, which can subsequently trigger new public policies and changes 
to formal structures. The more actors in key positions are reshuffled, and the more these new actors' ideology differs from that of the old actors, the greater the potential for change. In other words, a complete change in government, say from a centre-left (coalition) government to a centreright coalition, increases the likelihood of institutional change (e.g., Boix 1998; Garrett 1998; Swank 2002). Smaller reshuffles, however, such as the replacement of an individual minister or changes in coalition partners, also offer an opportunity for new voices to be heard thus triggering further institutional contestation and deliberate alterations. What "kind" of change a (partially) reshuffled government introduces, however, is difficult to predict for any specific political party (in any country, at any point in time) because the preferences of the actors are highly conditional on the overall distribution of power, institutional contexts, as well as the interpretation of "problem situations" at that time. Nevertheless, one may be able to capture various political parties' Weltanschauungen during two post-war phases of welfare state development, namely the "golden years" (1950s to 1970s) and the "age of austerity" (since about 1980) (the latter term is borrowed from Pierson 2001b). More specifically, based on the seminal work of Esping-Andersen (1990), one can expect that marketliberal parties during the golden years sought to establish universal, but minimalist welfare states that limit market interference, strengthen the self-reliance of citizens, and provide means-tested support to those, and only those, in actual need. Social Democratic political parties, in turn, wanted (a) to "de-commodify" individuals by reducing their dependence for socio-economic well-being on market mechanisms, and (b) to counteract unequal social stratification through redistribution. Hence, Social Democrats believed in a strong state and sought to generate generous, universal welfare policies. Finally, Christian Democratic parties embraced a "subsidiarity" principle, which shifted responsibility for welfare administration and provision to non-state actors including the social partners (social insurance schemes), church groups and social NGOs (e.g., services for the elderly, disability care and poverty relief), and the family (child and elderly care). Christian Democrats preferred a degree of de-commodification somewhere between market-liberal and Social Democratic parties and accepted, if not perpetuated, social inequalities due to the fact that benefits are employment-related and status preserving, leading to a segmented welfare state.

Whether, however, partisanship remains a powerful explanatory variable in the age of permanent austerity is debatable (e.g., Huber and Stephens 2001; Korpi and Palme 2003; Allan and Sruggs 2004; Rueda 2006; 
2007). This controversy is due to competing factors that encourage not only welfare cut-backs, but also welfare recalibrations and the defence of the status quo. This is to say, even though market-liberal political parties have continued to be key advocates for cost "containment and [the] retrenchment of expenditures and institutional revisions", the extent to which they can act on their advocacy depends on the degree of popular support for existing welfare provisions and the credibility of the major opposition party as a defender of the welfare state (Kitschelt 2001, 274). Likewise, Social Democratic parties may maintain their ambition to "modify market outcomes and redistribute wealth to favour the least advantaged sectors and advance equality in general" (Boix 1998, 4). But these goals have become increasingly difficult to sustain as the international division of capital and labour forces Social Democrats to be cost conscientious, both with respect to public deficits and taxation (Pierson 2001a, 424). Finally, the portfolio of the Christian Democrats is also compromised in at least in two ways: first, fiscal austerity also limits Christian Democrats' room for manoeuvre, which, in turn, may affect their ability to pursue "consensual" politics (cf., Kersbergen 1995). Second, socioeconomic changes associated with secularisation, emancipation and deindustrialisation require Christian Democrats to adapt their ideological positioning as their "core" electorate shrinks (Korthouwer 2008, 9).

We can thus conclude that even though partisan actors still compete on various political platforms, politics in times of austerity is very different from politics during more expansionary times. Hence, the question is not only under what conditions political partisanship matters (for the evolution of welfare institutions), but also "how much" and "to what effect". This also means, however, that even though political choice remains "important though much more constrained by the new more internationalized economic environment" (Huber and Stephens 2001, 1), every description of welfare state evolution will remain incomplete without considering the effects of political reshuffles and partisan competition.

Realignment. The second dimension of actor-induced institutional change focuses on how (competing) interests are mediated, coalitions are formed, and pacts are negotiated. Hence, it not only matters who is "in power", but also what resources these actors have and what allegiances are possible. In other words, for an explanation of institutional continuity and change, it is important to be sensitive to how actors (re-)align themselves in the face of political struggles over power and ideas. Politics is, after all, a game in which actors, whose positions are less loudly heard or represented, are 
constantly waiting for an opportunity to shift the dominant discourses and agendas (cf., Schmidt 2008). These "marginal" or "marginalised" actors may become empowered through changes in the political environment, or empower themselves through a realignment of political forces, which allows for the articulation of institutional alternatives, which, in turn, shifts the power balances away from some actors in favour of others. Realignments of actors can therefore cause or prevent the formation of powerful cross-party coalitions, strengthen or weaken intra-party cohesion, and/or contribute to the construction of coalitions between political parties and societal actors, all of which constitute possible elements in explaining institutional continuity and change.

The most important actors outside of parliament are the "social partners", namely employers' representatives and associations, on the one hand, and organised labour, on the other. The social partners play a crucial role in both organising and reorganising welfare states and socio-economic outcomes. With respect to the former, traditional forms of social partnership are centred on wage negotiations, but also include the co- or self-administration of most welfare states' social insurance and labour market programmes. With respect to the latter, the social partners are consulted before major welfare state change is enacted in most countries and can thus influence committee opinions, parliamentary debates, and government decisions. The social partners can also play a facilitating role in co-ordinating policy initiatives and implementing welfare reforms, or obstruct changes to the status quo by defending their clienteles' interests (Ebbinghaus 2001, 103). Hence, (failure to build an) alignment with the social partners, or any one part(y) of the social partners, may be another critical element in the explanation of welfare state change. The traditional "power resources" literature, for instance, stresses that the alignment of Social Democrats with an encompassing labour movement was critical in establishing the Swedish welfare state (Esping-Andersen 1985; Korpi 1983). Likewise, more recent literatures explain welfare change in Ireland, Italy or Portugal with reference to the emergence of encompassing "new social pacts" that include, but are not limited to, negotiated agreements with the traditional social partners (Rhodes 2003).

Ultimately, actor-centred explanations of institutional evolution need to look "at" and "into" political parties, which remain the main vehicles for change, but also "beyond" them, because alignments with other societal actors may be critical for the occurrence, direction, and scope of change. In other words, whether or not old and new social partners are aligned with or "powering against" the government (or the opposition) can have 
important effects on institutional development. This is the case because co-operation, "concertation" or "pacting" not only creates political legitimacy for (unpopular) changes, but also creates more balanced results and reduces the likelihood of the subsequent defection of the involved actors (Culpepper 2002, 779).

\section{IdeAs And Institutional Change}

Reassessment. While the mechanisms of reshuffling and realignment answers Hall and Thelen's plea for the study of institutional change as a "process built on coalitional politics" (2009, 20), the third mechanism, reassessment, goes beyond interest-based accounts by focusing on the underlying ideas and collective puzzling that motivate politics. This type of broadened analytical framework is both an empirical necessity and an analytical advancement because it is "ideas [that] explain the form of change that is enacted" (Heffernan 2002, 749). Only by incorporating ideas into the analytical repertoire we can explain why and how partisan ideologies and positions change, why inter- and intra-party divisions emerge, and under what conditions actors (re-)align in old or new ways. Because ideas are a fuzzy concept, I analytically distinguish between two types of ideas that are frequently used in social science research: normative and cognitive ideas (e.g., Goldstein and Keohane 1993, 9). Normative ideas specify criteria for distinguishing just from unjust or appropriate from inappropriate public policy and political structures. This is to say, the analytical focus on normative ideas concerns itself with identifying the values that policymakers (and other stakeholders) uphold. Accordingly, normative ideas set "ideational boundaries" for institutional designers, thus ruling out some options a priori. Likewise, normative ideas can serve as an "ideational compass", directing policymakers in a specific direction of institutional change they perceive as an appropriate means to reaching a desirable goal. Cognitive ideas, in turn, include ideas about cause-and-effect relationships on which policymakers' strategies, policy evaluations, and their very goals may be based (e.g., Weir 1992). Changes in policymakers' cognitive ideas may thus directly affect actors' strategies, preferences, and understandings of "problem situations", and intellectually challenge taken-for-granted institutions or processes. Cognitive ideas can therefore either alter the direction of change (i.e., the forms and functions of public policies and structures), or affect the speed of change, serving either as "accelerators" in political processes of evidence-based policymaking, where actors' ambitions are corroborated by new information, or as "brakes", or even "stop signs", when political reform proposals are contradicted by empirical findings or theoretical models. 
Demonstrating the independent explanatory power of ideas thus necessitates two analytical steps. First, it needs to be shown that a reassessment of normative or cognitive ideas does "not simply reflect group interests or material conditions" and second, that these ideas have "made possible new courses of action that changed the material world itself" (Hall 1989, 369). While the first step requires a careful evaluation of the processes that lead to institutional changes and a "weighing" of the explanatory force of ideas against other idiosyncratic factors, the second step can only be substantiated if it can be shown that policymakers were aware of new ideas and that these ideas were reflected in the political discourse (Bennett 1997, 215). The main theoretical argument is that, through the introduction of new normative and/or cognitive ideas, the institutional status quo may become increasingly less attractive and policymakers will begin to seek institutional alternatives. Questions about the appropriateness and functionality of status-quo institutions may arise if they do not perform as expected, that is, when current institutions do not operate efficiently especially compared to other - perhaps foreign - institutions. This account of relative performance, however, does not necessarily presuppose a crisis moment. Instead, it may be based on the availability of new evidence or revised interpretations of problem situations by reflexive actors, which therefore triggers institutional changes "ahead of failure" (e.g., Hemerijck 2007, 37).

The introduction of new ideas and interpretations - normative and cognitive - can occur through domestic "trial-and-error" learning processes or cross-border policy diffusion. If we want to take the latter seriously, "we must overcome 'methodological nationalism' and combine comparative analysis of domestic policies and the study of international (European) social policy and its effects in national politics" (Visser and Hemerijck 2003, 3). International or transnational policy diffusion can thus be analytically seperated from domestic trial-and-error processes, and labeled "learning from others", i.e., the detection, observation and examination of politically attractive institutional alternatives in another country, or "learning with others", which entails a social, interactive and reiterative process of ideational exchange and deliberation among policymakers (cf., Visser and Hemerijck 2003).

In sum words, sources for cognitive and normative reassessments can come from "above" through international organisations, from the "left and right", i.e., foreign governments, ministries, agencies, or epistemic communities, and from "below" through (sub)national experts, the social partners, national pressure groups, or NGOs. The following graph visualises the "points of entry" for new ideas, interpretations, and reflections. 


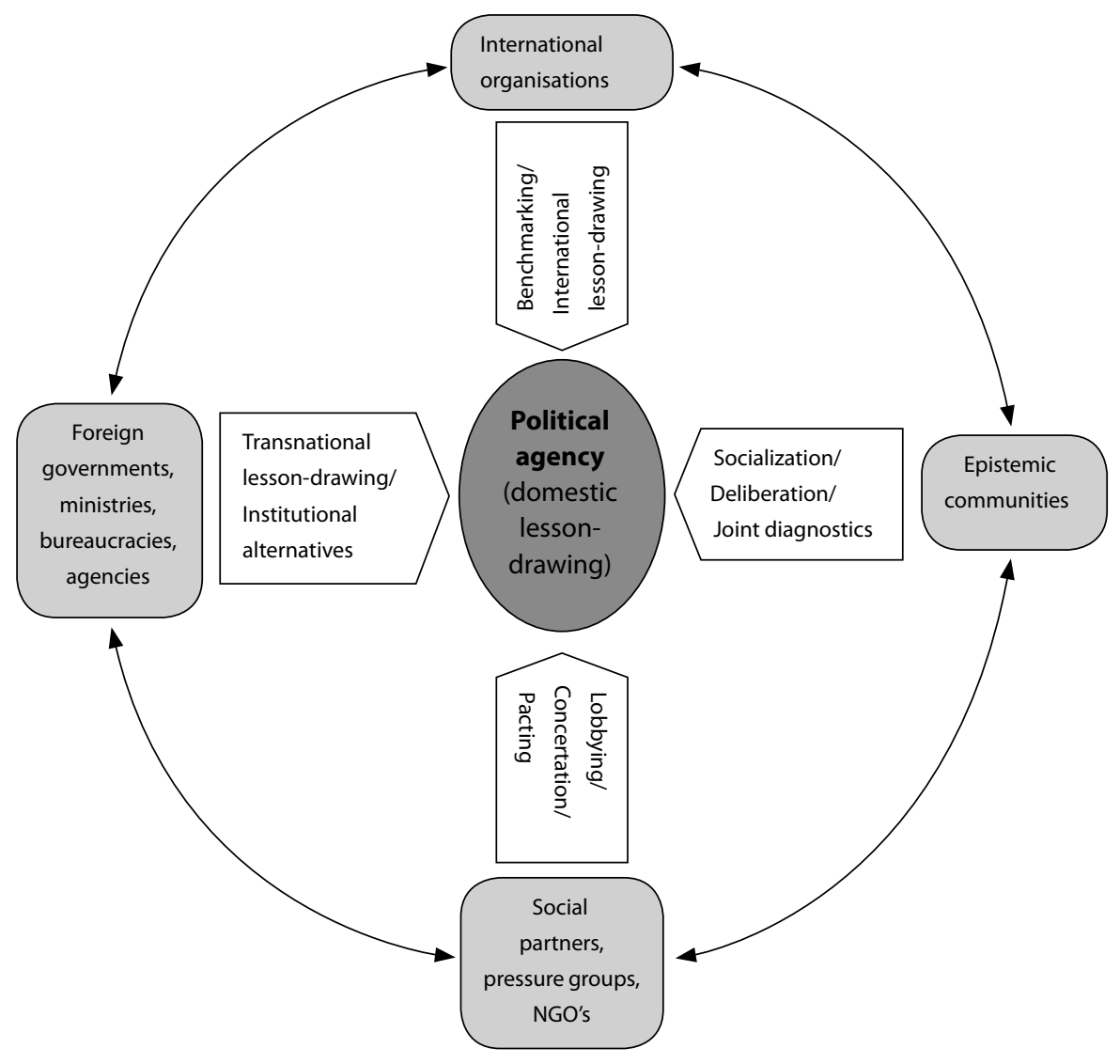

To summarise, the actor-centred, historical-institutionalist approach (ACHI) presented in this book is built around three focal points: situational contexts, power relations, and reflexive agency. In other words, ACHI includes carefully tracing the interactions between the various powerful political actors over time, who are interested in and capable of implementing (or resisting) institutional developments, while remaining sensitive to their institutional boundaries and the underlying ideas that shape their actions. Therefore, the main theoretical argument is that, in the absence of exogenous shocks, transformative institutional developments become possible when enough powerful actors endorse alternative ideas about institutional design. In other words, the presence of political actors in disagreement with prevailing institutions is a necessary condi- 
tion for institutional evolution. Political disagreement is not a sufficient condition, however, because disagreement needs to be coupled with the articulation of a feasible institutional alternative, and the existence of a political coalition powerful enough to endorse and translate this institutional alternative into action.

The ACHI research agenda thus attempts to answer the questions of who, when, where, how, and why institutional developments take place. To answer the who-question, it is necessary to identify the "core" actors, that is to say, the main actors involved in the policymaking process. The when- and where-questions are part and parcel of any historical-institutionalist study with a focus on critical junctures, political legacies, institutional complementarities, timing and sequencing. The how-question requires being sensitive to coalitional arrangements and prevailing ideas, conducive to inducing institutional development. And finally, when assessing the why-question, it is necessary to pay close attention to the core actors' preferences, their pay-offs, and their ideational underpinnings, which "filter" their realities and construct their preferences. It is of crucial importance, however, that ideas in this context are not merely reduced to "focal points" around which actors' preferences converge during times of crisis (e.g., Blyth 2002). Actors' ideas may instead actually change independently of external crises because actors may reassess the status quo due to processes of critical self reflection and/or the availability of new ideas, challenging the appropriateness or functionality of existing institutions. The following table presents a synthetic view of the causal mechanisms that explain the institutional evolution outlined by historical institutionalists.

\section{II.6 Three Institutional Trajectories}

Explaining welfare regime change is a complex and challenging task. While the academic literature outlined above has generated important insights about the impact of political legacies that make institutional changes contingent on past events and has proposed a set of mechanisms that obstruct or facilitate institutional changes, it is necessary to also delineate a set of potentially observable trajectories in order to understand institutional developments in relative and comparative terms. At the risk of oversimplification, and being well aware that welfare state development is a process and not a final destination, one can identify three potential, analytical scenarios that the academic literature alludes to: (1) continued institutional 
Table 3

Explaining Institutional Evolution: Summary Table

\begin{tabular}{|c|c|c|c|}
\hline $\begin{array}{l}\text { Mechanisms } \\
\text { Explaining } \\
\text { Radical Change }\end{array}$ & $\begin{array}{l}\text { Mechanisms } \\
\text { Explaining } \\
\text { Reproduction }\end{array}$ & $\begin{array}{l}\text { Mechanisms } \\
\text { Explaining } \\
\text { Transformative } \\
\text { Change } \\
\text { (process-oriented) }\end{array}$ & $\begin{array}{l}\text { Mechanisms } \\
\text { Explaining } \\
\text { Transformative } \\
\text { Change } \\
\text { (actor-oriented) }\end{array}$ \\
\hline \multirow{5}{*}{$\begin{array}{l}\text { External Shock } \\
\text { (existing logic no } \\
\text { longer applies; } \\
\text { radically alters cost/ } \\
\text { benefit calculations } \\
\text { of key actors and/ } \\
\text { or normative } \\
\text { \& cognitive } \\
\text { foundation) }\end{array}$} & $\begin{array}{l}\text { Increasing Returns } \\
\text { (sunk costs and } \\
\text { positive feedback } \\
\text { loops reinforce pre- } \\
\text { existing institutions; } \\
\text { alternatives } \\
\text { increasingly costly) }\end{array}$ & $\begin{array}{l}\text { Displacement } \\
\text { (defection leads } \\
\text { to rising salience } \\
\text { of subordinate } \\
\text { relative to dominant } \\
\text { institutions) }\end{array}$ & $\begin{array}{l}\text { Reshuffling } \\
\text { (introduction/ } \\
\text { replacement of } \\
\text { political actors) }\end{array}$ \\
\hline & $\begin{array}{l}\text { Institutional } \\
\text { Complementarities } \\
\text { (mutually } \\
\text { reinforcing sets of } \\
\text { institutions generate } \\
\text { comparative } \\
\text { advantages; } \\
\text { dismantling of one } \\
\text { element undermines } \\
\text { equilibrium of entire } \\
\text { regime) }\end{array}$ & $\begin{array}{l}\text { Layering } \\
\text { (differential growth } \\
\text { as new elements } \\
\text { attached to existing } \\
\text { institutions gradually } \\
\text { change their status } \\
\text { and structure) }\end{array}$ & $\begin{array}{l}\text { Realignment } \\
\text { (changes in actor } \\
\text { coalitions and } \\
\text { alliances) }\end{array}$ \\
\hline & & $\begin{array}{l}\text { Drift } \\
\text { (deliberate neglect } \\
\text { leads to slippage } \\
\text { in institutional } \\
\text { practices) }\end{array}$ & $\begin{array}{l}\text { Reassessment } \\
\text { (shift in political } \\
\text { actors' normative/ } \\
\text { cognitive ideas) }\end{array}$ \\
\hline & & $\begin{array}{l}\text { Conversion } \\
\text { (old institutions } \\
\text { are redeployed to } \\
\text { new purposes or } \\
\text { new purposes are } \\
\text { attached to old } \\
\text { structures) }\end{array}$ & \\
\hline & & $\begin{array}{l}\text { Exhaustion } \\
\text { (depletion leads to } \\
\text { gradual breakdown } \\
\text { of institutions over } \\
\text { time) }\end{array}$ & \\
\hline
\end{tabular}

Sources: Steinmo and Thelen 1992; Pierson 2004; Streeck and Thelen 2005b 
diversity across countries; (2) uni-modal or multi-modal convergence on commonly identifiable model(s) of pre-existing ideal-typical clusters; and (3) hybridisation, i.e., the process of "mixing and matching" of institutions across and within regime types, potentially leading to either partial convergence (convergence on some elements, while retaining others), neoconvergence (the establishment of an entirely new, but common combination of various institutions) or neo-divergence (the establishment of an entirely new, but different combination of institutions). ${ }^{7}$ The following section illustrates these potential trajectories by reference to the literature on labour market policy regimes.

Based on the logic of path dependency, the first possible institutional trajectory is - once a particular path has been taken - sustained institutional reproduction, leading to continued institutional diversity. The argument for this development comes in essentially two varieties (cf., Hemerijck 2007, 11). The first version - as outlined above - is based on the logic of increasing returns that "lock in" pre-existing sets of institutions and make path-altering changes unlikely (Pierson 1994; 1996a; 2001b; 2004). Once established, compromising or cutting existing rights and privileges becomes electorally unattractive and, as such, institutional inertia and minor adaptations are likely, which effectively perpetuates existing regime trajectories and typologies. Similarly, Esping-Andersen (2002) argues that welfare regimes share a particular historic trajectory and have developed in path-dependent ways. Accordingly, precisely because welfare states come in clusters, sharing similar problems and advantages, regime-specific rather than "one-size-fits-all" institutional changes can be expected (see also Iversen and Wren 1998; Iversen 2005). In the contemporary contexts, this means that the Nordic welfare states' generous and universal welfare policies and their heavy reliance on public sector jobs have been accompanied by high monetary costs. Consequently, sustaining popular support for the necessarily high levels of taxation and public expenditures constitute the Nordic welfare states' main challenge. The Liberal welfare states, in turn, rely on relatively low levels of taxation, low payroll costs, and a deregulated labour market, which has created a large number of private sector jobs. The flipside to this institutional choice, however, is widespread poverty, income inequality, and social exclusion. And finally, Continental welfare states face a vicious cycle of spiralling costs and shrinking income bases. Not only have Continental welfare states followed a strategy of deliberate "surplus labour shedding", but the subsequently necessitated rises in non-wage payroll costs encouraged firms to improve their productivity rather than to invest in new jobs, 
which has led to a further decline in overall employment rates, threatening the sustainability of the welfare state in general. Based on these different sets of institutional problems and advantages, Esping-Andersen predicts that welfare states will adapt in different ways and, accordingly, their institutional diversity will be retained.

Similar conclusions have also been drawn by the more recent scholarship on activation policy. Most prominently, Jean-Claude Barbier argues - as does Serrano Pascual (2007) - that while activation regimes have evolved in a similar direction, the relative distance between regime clusters has remained stable. In his interpretation, "hugely differing programmes and policies have been implemented. ... All of them appear as embedded in their societal coherence, in terms of the systems of social protection, the values and norms upon which these are based, as well as the industrial relations systems they are linked to" (Barbier 2001, 3). Within this context, Barbier identifies two diametrically opposed idealtype conceptions, one liberal and the other universalistic. In the liberal activation camp, he places both the UK and the US, where "ALMPs as well as social policies ... take a limited role, restricted to inciting individuals to seek work, providing quick information and matching services, as well as investing in short-term vocational training" (Barbier and LudwigMayerhofer 2004, 427). Conversely, in the universalistic world, which includes countries like Denmark or Norway, the state "not only cares for the provision of complex and extended services to all citizens, but simultaneously guarantees relatively high standards of living for the assisted, and, for the lower paid sections of the labour force, benefit levels close to actual minimum wages" (Barbier and Ludwig-Mayerhofer 2004, 427). While an unambiguous third pole has not (yet) emerged, the Continental European regimes - including France and Germany - represent intermediate cases, which "have emerged, dependent on their historical and societal traditions, [combining] elements from both ideal-types" (Barbier 2001, 11; see also Barbier 2007, 152; Barbier and Ludwig-Mayerhofer 2004, 428). He concludes that despite, or maybe because of the use of a "common language" and the "homogeneity of words" used to describe activation in various contexts, there are no signs of convergence with regard to values, the substance of the activation programmes, rights, or entitlements. It is therefore this plurality, in contrast to a commonality within activation policy, which remains "a challenge for further research" (Barbier and Ludwig-Mayerhofer 2004, 434). ${ }^{8}$

The second prediction is one of convergence on pre-existing regime types. In its extreme version, there are authors who predict uni-modal 
convergence. In this case, welfare state institutions in any developed industrial nation will, sooner or later, reach a common institutional, neoliberal destination. Most prominently, it is argued that the international forces of economic globalisation and capital mobility have severely constrained the room in which national governments can manoeuvre (Scharpf 200oa), which in turn forces governments to reduce welfare expenditures, deregulate labour markets, and embrace "work-oriented policies, privatization of social welfare, increased targeting of benefits, and the shift from an emphasis on social rights of citizenships to the civic duties of community members" (Gilbert 2002, 5; see also Goldberg and Rosenthal 2002). Accordingly, Gilbert concludes that even though the reform processes and speeds in various countries may vary, all of "these nations are sailing toward the same shores" (2002, 47). Similarly, Handler, who focuses on the most disadvantaged jobseekers, argues that European welfare states increasingly question, if not abandon, the "old" ideals of social citizenship and welfare entitlements and rely more on "new", ideologically driven ideals of workfare and conditional benefits. He argues that there is a common trend toward a "jobs first" strategy, that is to say, a new focus on work as the best way to assure social inclusion, which ironically leads to more rather than less social exclusion (Handler 2003, 230). While Handler acknowledges significant differences between Europe (not including the UK) and the US, he concludes that the overall character of European welfare states has changed, particularly with regard to the most marginalised jobseekers. In other words, he predicts trends toward a uni-model convergence with regard to the treatment of the long-term unemployed and socially excluded, who are increasingly being subjected to policies that resemble US-style workfare policies (Handler 2004, 209). ${ }^{9}$

Other authors, most prominently those associated with the Varieties of Capitalism (VoC) school of thought, argue that two ideal-typical economies currently exist upon which most countries will converge. The way in which production regimes relate to welfare regimes is through their labour market policies, meaning that liberal production regimes promote liberal welfare regimes, while co-ordinated production regimes promote more generous welfare regimes. As Peter Hall (2003b, 41) explains:

By forcing people into the workforce, the low benefit levels and strict eligibility criteria of a liberal welfare state, for instance, help sustain the highly fluid labour markets on which firms in liberal market economy [sic] tend to depend. They complement the low-wage, cost-conscious 
strategies characteristic of many firms in such economies by depressing the reservation wage. In contrast, by assuring workers of generous benefits should they become unemployed, the high benefit levels and prolonged benefit periods available to skilled workers in [coordinated] welfare states encourage individuals to develop the industry-specific skills central to the production strategies of many firms in coordinated market economies; and they encourage firms to make use of such skills by assuring them that skilled labour will remain available through a recession.

In other words, these authors predict a bi-modal institutional outcome, as LMEs and CMEs continue to reproduce their production regime types and their corresponding welfare regime types, while those countries located between the ideal types, i.e., "mixed" production and welfare regimes, are expected to converge on the LME model. This latter trend will be the case as it is substantially easier to "liberalise" a regime than to "coordinate" it.

The last group of scholars offers a third possible scenario. In addition to predicting the persistence of empirically and analytically distinct regime clusters or the convergence on one or more, pre-existing regime types, a third interpretation is put forward, namely that of institutional hybridisation. Institutional hybridisation depicts an institutional evolution in which political actors (deliberately or accidentally) "mix and match" policy features from within and across regime clusters, thus breaking certain pathways and diluting regime-specific characteristics. Hybridisation can lead to any one of three institutional outcomes: First, when policies are (re-)assembled in similar ways across regime types, institutional convergence on one new, hybrid model follows (neo-convergence). However, when institutions are mixed and matched differently in various cases, continued diversity will result, potentially leading to neo-divergence (source of inspiration, Zeitlin 2003). The possibility of partial convergence lies somewhere in the middle because countries will retain some of their original institutional characteristics, while adopting a mix of similar instruments in other areas. While this interpretation remains a minority view, there are a number of authors whose work could be described as observing trends of hybridisation..$^{10}$ For instance, Lindsay and Mailand $(2004,196)$ argue that there has been a "real and lasting shift" in the labour market policies of both the UK and Denmark. While there are still important differences between the two countries, both countries have taken a step toward the other and adopted a 
broadly similar approach in areas such as the re-balancing of rights and obligations, client-centrism, a real work focus, and the delivery through local partnerships (see also, Campbell and Pedersen 2007; Lindsay and Mailand 2004, 198). Similarly, Bruno Palier (2004, 2) isolates important common trends in Europe's social protection reforms, including a common focus on employment-oriented social protection policies, instituting supply-side social policy instruments, an overall tightening of benefits regimes, and privatisation of services (Palier 2004, 9). In other words, rather than seeing an overall trend of making welfare states "meaner" and "leaner", Lindsay, Mailand, Palier, Zeitlin and some other scholars argue that governments mix and match characteristics from various welfare traditions, and thus recalibrating their own systems, as opposed to retrenching, labour market policy regimes (see also Ferrera and Hemerijck 2003).

\section{II.7 Analytical Grid: Four Dimensions of Labour Market Policy Regimes}

As outlined in the introduction, this book is interested in welfare state reform in general but has a more modest ambition. The aim is to carefully compare and contrast labour market policy regimes, a key constituent in the welfare state make-up. For this purpose, I suggest distinguishing four analytical dimensions, which, when taken together, comprise the core elements located at the work-welfare nexus of any modern labour market: ideational, organisational, financial and work incentives.

\section{Ideational Dimension}

The first, ideational dimension of labour market policy regimes concerns policymakers' normative and cognitive underpinnings, hence their overarching principles guiding public policy, and the underlying cognitive assumptions about causes and remedies of labour market shortcomings. Therefore, the ideational dimension refers to the (declared) intentions about what economic results labour market policy is believed to be capable of delivering, and what social goals it aims to achieve. These goals typically involve a mix of labour market efficiency (i.e., the efficient supply of labour) and equality (i.e., the reduction and/or prevention of social exclusion and underachievement). The way in which these two (potentially rival) goals are weighed against each other is expected to vary over time, across regime types, and along partisan lines. Moreover, the actual 
choice of institutional solutions also includes an assessment of the most adequate form of delivery for these policies, which in turn is based on an interpretation of the problems at hand, and their root causes and remedies. As such, the cognitive element includes an assessment of whether the main causes of an unemployment crisis are mainly cyclical or structural in nature, and accordingly, also whether unemployment is the result of individual idleness or (systemic) market failures. While this cognitive judgment points to particular policy responses, policymakers' normative predispositions further affect the decisions about what kind of state intervention is appropriate, how much resources are necessary to implement the preferred institutional solutions, and which actors need to be organised.

\section{Organisational Dimension}

The second, organisational dimension includes all of the aspects that deal with the governance and delivery of labour market services. Governance in this context is defined as the institutional structures of authority transposing public law into action. The organisation of employment services can thus be analytically differentiated by looking at which actors, public or non-public, are responsible for the administration and delivery of public laws. Public employment services (PESs), governments' most important delivery arms of labour market policy, vary by the degree of their organisational centralisation and their loci of decision-making powers. At one extreme are those PESs with headquarters institutionally inseparable from a respective ministry for employment affairs, where the decisionmaking powers are entirely in the hands of public appointees and civil servants. In this state-operated model, the minister in charge has direct authority over, and responsibility for, the governance of the PES. The government thus steers, monitors, and funds the operations on the ground, including both regional and local offices. This version can be described as a "top-down" or vertical approach to labour market governance and is most clearly represented by the Japanese PES.

At the other extreme is the locally operated model, which is not directly steered by national PES headquarters and is not directly responsible to a governmental department on the national level. In a locally operated model, regional and/or local public authorities are in charge of "their" labour markets and have total control over their choice of policy measures and the partners they decide to work with. Local/regional authorities are, however, bound by public law and may receive government funding or 
subsidies. Contemporary empirical examples include Italy, Switzerland, and the United States.

In the third type, public officials share authority with the social partners, such as employer and employee representatives, or delegate responsibility to specifically appointed civil servants. In this semi-autonomous model, the PES is neither entirely incorporated into a governmental department nor entirely run by third parties, like the social partners or local authorities. Instead, a multi-partite body comprised of a variety of representatives from the responsible governmental department, local authorities, and/or the social partners share legal authority and political responsibility. Public law, however, binds the operations of a semi-public PES and the funding for its operations may include a multitude of sources, including general taxes, local taxes, and payroll contributions. Most contemporary European PESs fit this model, albeit with different "agents" and varying degrees of autonomy.

There are also "non-public" employment services that come in a variety of forms, including for-profit, not-for-profit and membership-based versions. For-profit employment services are typically operated by private employment agencies (PREAs). While PREAs in many countries work alongside PESs, there are a few countries in which public services have been fully outsourced to private, for-profit agencies. Australia and New Zealand are typically at the forefront of this development. There are also not-for-profit organisations that assist the unemployed in their job search and offer counselling services in just about every country. These services are offered alongside PES and PREA services and often include churchaffiliated groups and social NGOs. Finally, there are also employment services offered by the social partners that are either unilateral (solely employer or union run) or bilateral, i.e. jointly run by the social partners. Historically, labour unions or employer associations have operated many of Europe's employment services as part of the class struggle that occurred at the end of the 19th century. Even today, however, the political legacies of union-run employment services are still visible, most strikingly in the Nordic countries and Belgium, where unemployment insurance systems are still administered by labour unions (Zeitlin 2008a, 20).

To summarise, institutional structures of employment services vary greatly along the locus of authority (public vs. non-public) and the distribution of power (concentrated or shared). The following graph visualizes these dimensions. 


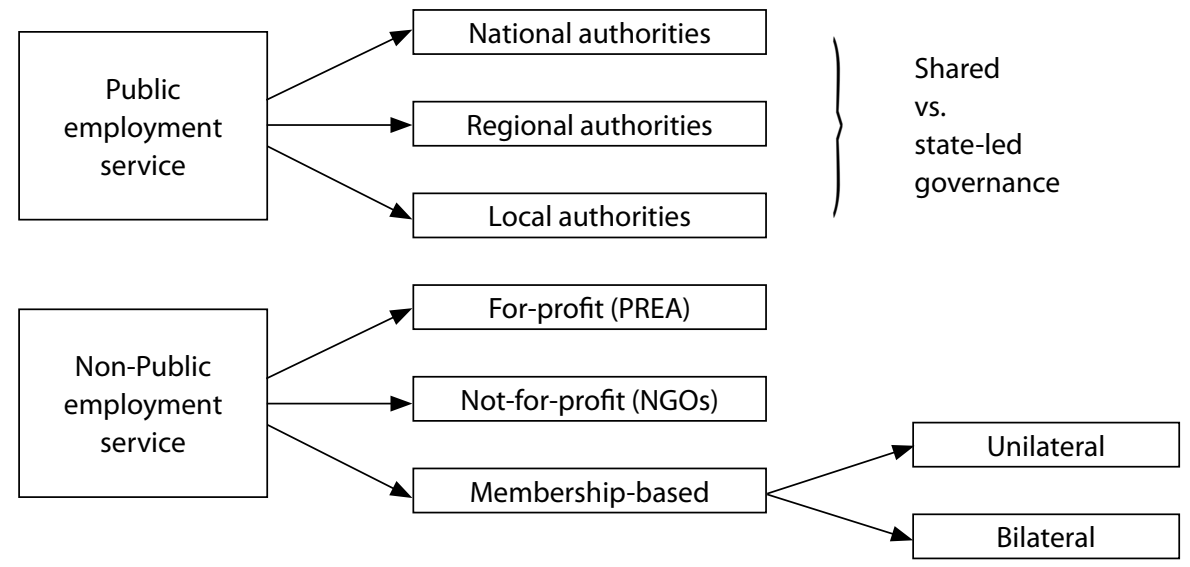

While the institutional structures of authority (i.e., their forms) vary greatly across employment services, variations within "public" models with respect to their operational principles and methods (i.e., their functions) are also very relevant. When we assess the operational principles and methods we arrive at an important insight into the logic that drives Public Employment Services' daily operations. Two dimensions with potential trade-offs have been identified as particularly relevant: one that focuses on economic vs. social concerns, and one that compares administrative vs. managerial concerns. Two questions arise in relation to this subject: (1) What are the employment services' guiding principles? This question addresses the importance of economic goals, which are typically associated with the efficiency and effectiveness of labour market measures, and the importance of social goals that are usually associated with equity concerns; (2) What is the relationship between the employment office and the individual jobseeker? Important insights can be gathered about the ways in which the organisations' principles are transposed into action by addressing the relationship between the employment office and jobseekers. PESs may see themselves as public bureaucracies, administrating unemployment. If so, they will consider their compliance with regulations as their core responsibility. In this scenario, the unemployed persons' legal status determines their "entitlement" to benefits and services, individual discretion is limited, the relationship is demarcated and hierarchical, and the administration of labour market measures remains largely separate from politics. In turn, employment services may also see themselves as "managers", delivering labour market services to their "cus- 
tomers" and thus maximising service quality and customer satisfaction are considered their core functions. In this scenario, the legal status of being unemployed may determine the range of services available to those who qualify, which, however, should not necessarily be considered an "entitlement" but a function of the employment officers' evaluation of the situation. As such, individual discretion is high, the relationship is quasi-contractual, and the administration reflects predominant political views.

\section{Financial Dimension}

The third, financial dimension is mainly concerned with two elements: the sources of revenue and the type and level of expenditure. The source of revenue is crucial as it (a) distributes costs and (b) legitimates the institutional structures of authority as the following section will demonstrate. The revenue for labour market programmes typically comes from one (or both) of two sources: payroll contributions from employees and/or employers, and contributions based on general taxation. If the main source of revenue is based on payroll contributions, the costs are narrowly distributed among the employed, which, in turn, is more likely to introduce a sense of "exclusiveness" and "entitlement" regarding the services by those who have contributed to them. It also legitimates the role of the social partners in labour market policy administration, as they represent the interests of those workers and employers who provide for the funding of these measures. But, if the main source of funding is based on general taxation, the costs are distributed more widely, which, in turn, is more likely to establish a sense of "inclusiveness" and "universalism". Moreover, since the former source is a direct tax on labour, it raises the price of labour, which may have a negative effect on job creation as well as net wages, which affects the motivation to seek (low-wage) gainful employment. The latter, conversely, is seen as a more indirect tax that affects society as a whole with less immediate effects on the price of labour, but may result in higher taxes in other areas.

The main expenditures for labour market policies include, on the one hand, transfer payments and, since the mid-197os, expenditures on "exit options" such as early retirement or disability pensions. These types of expenditures have been labelled "passive" labour market policies (PLMPs) since the late 1980 os. On the other hand, there are also "active" labour market policies (ALMPs), which include a variety of measures, all intended to promote some sort of "action" by benefit recipients such as support with job-search activities, occupational and social skills training, participation in employment projects and the like. While "passive" measures are intended to allevi- 
ate economic hardship during periods of unemployment, active measures aim to remove obstacles to employment, motivate jobseekers to actively seek and accept employment, and/or to retain or improve jobseekers' employability. The following five ALMP categories are typically identified by the OECD: public employment services, (re-)training courses, direct job creation, wage or employment subsidies, and business start-up subsidies. ${ }^{11}$

\section{Box 1 Five Instruments of Active Labour Market Policy}

\section{A. Organisation}

1. Public Employment Services - PESs refers to job-search assistance agencies that provide information and offer matching and placement services. The overarching aim is to increase labour market fluidity and efficiency. PESs monitor, organise, and implement most, if not all, active and passive labour market measures. PESs sometimes also provide additional social services such as counselling or aid with care responsibilities, or offer support with regional mobility.

\section{B. Policy Substance}

2. (Re-)Training Courses - These supply-side measures, offered with the aim of enhancing the ability of jobseekers to re-enter the workforce and to consequently retain employment. Training courses vary greatly regarding their quality, intensity, and duration. Some training courses include short (and inexpensive) "soft skill" courses that teach participants social skills such as teamwork or appropriate work behaviour, how to write an application or conduct a job interview. They often also include a motivational component. "Hard skill” training courses, in turn, include longer (and more expensive) technical skills training courses that equip and update participants' occupational skills. Both job-placement services and soft and hard-skills training courses are considered supply-side measures.

3. Direct Job Creation - The state (or its local agents) acts as an "employer of last resort" and creates public service employment programmes. The main clientele in such programmes are often socially excluded, long-term unemployed workers who face severe hurdles upon re-entering the workforce.

4. Wage or Employment Subsidies - Wage subsidies are intended to increase incentives for the unemployed to accept low-wage work, while employment subsidies are paid to employers in order to match the losses in productivity that firms incur when hiring "atypical" workers. Both direct job-creation schemes and wage or employment subsidies are considered demand-side measures.

5. Start-Up Subsidies are paid to the unemployed who want to start their own business. These measures are intended to create new jobs and improve the productive and innovative capacity of an economy. Start-up subsidies are mostly limited to qualified unemployment benefit recipients.

Source: Dar and Tzannatos 1999 
The fourth, work-incentives dimension analytically combines most of the aspects that comprise formal active and passive labour market policies. Herein, positive and negative incentive measures are identified and differentiated, which include the primary characteristics of any labour market policy regime, regardless of its respective welfare regime type. Each incentives category is further subdivided into financial incentives, or those incentives that are directly related to transfer payments, and non-financial incentives, i.e., incentives that condition the access to transfer payments or gainful employment. Consequently, negative financial incentives include unemployment benefits paid for short periods of time, low and means-tested social wages, ${ }^{12}$ and the unavailability (or phasing out) of "early exit" options. Negative nonfinancial incentives, in turn, describe the conditions jobseekers need to fulfil in order to access benefits and assistance payments. These conditions include active job-search requirements, broad definitions of "suitable" job offers, and strict, i.e., restrictive, eligibility criteria. Taken together, negative incentives reduce, or even eliminate, the financial reasons that encourage some people to remain inactive for extended periods of time or to voluntarily continue living a "life on benefits".

On the positive side, financial incentives to find, retain, or resume work can include wage or employment subsidies, tax credits for lowwage work, benefit "top-ups" for participation in public work schemes, or start-up assistance for self-employment. Taken together, these financial incentives are intended to make work pay, or, to significantly increase one's income through employment. In turn, the provision of non-financial services includes the provision of high-quality job-counselling services that improve job placement and matching, access to motivational, social, and technical skills training courses, child and elderly care support programmes, or the existence of social services, including transportation and/or assistance with mental health, debt, or substance abuse problems. These non-financial services can help remove obstacles to finding work and increase jobseekers' chances to retain gainful employment. The following box summarises these four sets of positive and negative work incentive structures. 
Table $4 \quad$ Negative and Positive Incentive Structures of Labour Market Policy Regimes

\begin{tabular}{|c|c|c|c|}
\hline $\begin{array}{l}\text { Negative Incentives } \\
\text { (financial) }\end{array}$ & $\begin{array}{l}\text { Negative Incentives } \\
\text { (non-financial) }\end{array}$ & $\begin{array}{l}\text { Positive Incentives } \\
\text { (financial) }\end{array}$ & $\begin{array}{l}\text { Positive Incentives } \\
\text { (non-financial) }\end{array}$ \\
\hline $\begin{array}{l}\text { - Short duration of } \\
\text { unemployment } \\
\text { benefit payments } \\
\text { - Low, means-tested } \\
\text { social wages } \\
\text { - Unavailability (or } \\
\text { phasing-out) of } \\
\text { "early exit" options } \\
\text { (early retirement or } \\
\text { disability pensions) }\end{array}$ & $\begin{array}{l}\text { Job-search } \\
\text { requirements } \\
\text { - Broad definition } \\
\text { of a "suitable" job } \\
\text { offer } \\
\text { - Strict eligibility } \\
\text { criteria } \\
\text { - Benefit sanctioning } \\
\text { when in breach } \\
\text { with benefit } \\
\text { conditions }\end{array}$ & $\begin{array}{l}\text { - In-work subsidies } \\
\text { - Tax credits } \\
\text { - Benefit top-up } \\
\text { for participation } \\
\text { in public work } \\
\text { schemes } \\
\text { - Self-employment } \\
\text { start-up subsidies }\end{array}$ & $\begin{array}{l}\text { - Job counselling } \\
\text { - Training courses } \\
\text { (soft and } \\
\text { occupational skills) } \\
\text { - Childcare } \\
\text { support }^{13} \\
\text { - Other services } \\
\text { (mobility, mental } \\
\text { health, debt, } \\
\text { substance abuse) }\end{array}$ \\
\hline
\end{tabular}



Part I

Origin and Crisis of European Labour Market Policy Regimes 



\section{Origin of European Labour Market Policy Regimes and the Manpower Revolution}

Even though most of the legal framework for active labour market policy was not formally introduced until the early 1950s, it is important to provide information about the path-creating efforts launched by European governments during the pre-WWII era. Accordingly, chapter III first offers a brief overview of emergence of the very concept of unemployment and the origins of labour market policy regimes. Subsequently, I elaborate on the genesis of the Swedish concept of ALMPs, initially known as active manpower policies, followed by a succinct introduction to the OECD, which successfully diffused this concept. This chapter then precedes with a synopsis of subsequent policy changes in five European countries: Denmark, Germany, Austria, the UK, and Ireland, in that order. Chapter IV discusses the international, i.e., OECD, and national responses to the two oil crises during the 1970s, which triggered significant economic challenges across Western Europe, including a significant increase in unemployment, spiralling inflation, and economic stagnation. The consequences and reactions to the two oil crises are covered sequentially, starting with the international dimension and followed by domestic policy responses. Both of these chapters are designed as - at times quite detailed and yet, necessarily incomplete - reconstructions that rely primarily, but not exclusively, on the existing secondary literature and officially published policy documents. The main purpose of these chapters is to provide both a historical backdrop and a benchmark for the assessment of contemporary institutional evolution.

\section{III.1 Locating the Origins of Unemployment and Labour Market Policy}

Throughout human history, there have always been people without stable sources of income, who would nowadays be considered unemployed. However, the very term "unemployment" as we know it today only arose as a meaningful concept with the rise of manufacturing and industrialisa- 
tion, i.e., during the birth of capitalism in the $19^{\text {th }}$ century (cf., e.g., Salais et al. 1986; Whiteside and Salais 1998). Prior to industrialisation, most people worked in agriculture, and for the majority of those who did not, work was often neither "stable" nor "institutionalised". Poor people without work were often employed on a temporary or seasonal basis as work became available (cf., Zimmermann 2006), and "unemployment" was neither a publicly acknowledged problem nor discussed in any systematic way by economists (Harris 1996, 52). Likewise, at the beginning of the $19^{\text {th }}$ century, less than five percent of the population lived in cities of more than 20,00o inhabitants, and, in about 1850 , urban dwellers only exceeded ten percent of total populations in Great Britain, the Netherlands, and Belgium (Alber 1982, 29).

While public authorities had adopted various poor laws since the end of the $16^{\text {th }}$ century - largely as a consequence of the Protestant Reformation and the "birth" of nation-states - these laws were characterised as "negative social policy" (Zöllner 1959). They were considered "negative" because assistance for the poor was mainly designed - up until the $19^{\text {th }}$ century - as a "repressive measure to discipline the poor" and typically included forced labour (Alber 1982, 25). Popular perceptions of, and official attitudes to, people without work were sceptical, and "private philanthropists no less than public officials dreaded the hazards of disincentives to mobility, interference with wages, ... and artificial creation of work" (Harris 1996, 53). Accordingly, local communities that delivered "poor relief" were mainly interested in keeping the poor in check and maintaining public order rather than providing any real assistance to those in need (Alber $1982,26)$. More comprehensive protection, in turn, was only available for members of guilds or crafts, or when provided by churches and charity organisations or other friendly societies (cf., Zeitlin 2008a, 19).

It was only in the second half of the $19^{\text {th }}$ century that a gradual reassessment took place and "modern poor relief" became less repressive and more needs-oriented (Alber 1982, 26). The reassessment of traditional poor laws coincided also with the emergence of modern "social security" systems. With industrialisation, urbanisation, and population growth during the mid- to late 1800 - and thus the rapid expansion of the proletariat and mass poverty - the bourgeoisie had increasingly been pressured to introduce public intervention to alleviate mass suffering. While these interventions where mostly aimed at preserving the ruling classes' privileges, they nevertheless constituted a "breakthrough" for the working class. Most important was German Chancellor Otto von Bismarck's introduction of three "path-creating" programmes, including health insurance 
in 1883 , accident insurance in 1884 , and old age and invalidity insurance in 1889 (Pilz 2004, 25). Governments across Europe subsequently followed his example, which constituted the beginning of the modern welfare state. Of great importance was also, however, the shift in official attitudes and public sentiment toward unemployment at the turn of the century. Unemployment had then become part of the "social question" and intellectuals and economists acknowledged it as a significant problem (cf., Harris 1996; Niess 1982; Price 2000, 8).

Following these reassessments and legislative changes, policymakers introduced two foundational pillars of modern labour market policy regimes, including the establishment of public employment services, matching available jobs with jobseekers, and the introduction of unemployment insurance (UI) schemes, that would protect workers and their families from the consequences of job loss. The first "meaningful" - as opposed to purely repressive - public works projects, organised by national governments, followed in the post-WWI era, establishing the idea of an "active" labour market policy.

Establishment of National Unemployment Insurance Systems:

From Bismarck to Ghent

While national unemployment insurance was not part of the original "social security" legislation in Bismarck's Germany - and did not become national law until 1927 - it was some of the small Swiss Cantons that organised the first public unemployment insurance programmes. These local programmes were, however, inspired by Bismarck's "experiments" with a public provision of welfare policy. Even though the Swiss programmes had some financial difficulties from the start, they nevertheless motivated other European policymakers - who increasingly acknowledged the existence of cyclical unemployment - to develop their own ideas of how publicly sponsored UI schemes could be designed. As a consequence, during the late 1890 os "municipal unemployment insurance schemes began sprouting throughout Western Europe" (Heclo 1974, 69), which represented an alternative to the union-run unemployment insurance programmes that had surfaced across Europe during the mid-180os. ${ }^{1}$

In Belgium, where the union movement was already well established, a new "mixed" form of these two programmes was first advanced in 1901. The public authorities in the Belgian city of Ghent decided to financially support - rather than run - the unions' voluntary UI schemes (Vandaele $2006,649)$. It was at this time that the "Ghent system" of workers' protec- 
tion - i.e., a voluntary insurance system, administered by labour unions and subsidised by the state - was established. Ghent's novel approach quickly spread across Europe, first to cities like Milan, Amsterdam and Strasbourg over a period of a few years (Heclo 1974, 70). France was the first country to establish a nationwide, Ghent-like system in 1905, while Norway (1906), Denmark (1907), the Netherlands (1916), Finland (1917), Belgium (1920), Luxembourg (1921), Switzerland (1924), and Sweden ${ }^{2}$ (1934) followed suit (Alber 1982, 28, table 1). A voluntary, union-administered fund was not only less expensive for local and national authorities, but it was also attractive because "workers themselves were to carry the main burden; if their own contributions were to fund the insurance it would be in their own best interest to closely scrutinise all applicants [and thus prevent welfare abuse]" (Edling 2006, 105). Yet, in order to institutionalise a Ghent system, two necessary conditions had to be fulfilled. First, because a Ghent system would also automatically encourage workers to apply for union membership, the government had to have the political will to empower unions. And second, the unions had to have the organisational capacity to deliver such systems. In particular the lack of political will is a crucial factor for any explanation of the variation in the timing of the introduction of Ghent systems across Europe.

During the time when the Ghent system rapidly spread throughout Europe, some policymakers pursued other, alternative strategies. Most prominently, British Prime Minister Winston Churchill and William Beveridge, a socially progressive Liberal, introduced the world's first mandatory, fully public unemployment insurance scheme in Great Britain in 1911 - and therefore also in Ireland, which did not gain independence until 1922 (Harris 1996, 53; Price 2000). While coverage was initially only about 17 percent - this was due to the relatively high minimum income requirement - by 1920 it had been extended to cover nearly all of Britain's workers (Phan-Thuy et al. 2001,3). The public option was designed to be the basic "safety net" for all workers, while unions were allowed to organise additional insurance schemes to supplement benefits during periods of unemployment. Austria and Germany - and Italy in 1919 - followed the British example and introduced mandatory, nationwide schemes in 1920 and 1927, respectively (cf., Alber 1982, 28; Wilk 1991; Pilz 2004). However, in contrast to the British system, where UI was organised by the central government and delivered by local labour exchanges established in 1909 (see next section), the Austrian and German systems were administered and implemented by public labour exchanges that were semi-independent and governed in equal parts by public authorities as well as labour union 
and employers' representatives. As such, three different ways to organise UI emerged in the early years of the $20^{\text {th }}$ century: a "Bismarckian", mandatory system financed by specific payroll contributions and governed by semi-public, tripartite labour exchanges; a mandatory, largely tax-based and centrally organised Anglophone system; and finally, a voluntary, publicly subsidised but union-run alternative, which was predominant in Scandinavia, but could also be found in large parts of Continental Europe.

The Birth of a National Public Employment Service:

Trend-Setter Germany

Just as labour unions and municipalities began developing UI schemes in the mid- to late 1800 os, they also began offering job-placement assistance. Among the first places where public "labour exchanges" (Arbeitsnachweise) emerged were the German cities of Dresden and Leipzig in 1840 and 1844 respectively (Schmid et al. 2005, 269). In the 1860 s, a small number of communist unions began to create their own labour exchanges as they began to recognise their importance in the class struggle (Schmuhl et al. 2003, 24). In the 1880s, a "wave" of union-run labour exchanges followed, with the sculptors, blacksmiths, and cigarette-sorter unions leading the way (Rottenecker and Schneider 1996, 44). In order to counter the unions' influence, employers' associations followed suit in the 1890 s, establishing their own, unilateral exchanges (Schmuhl et al. 2003, 26), which heightened mutual distrust and fed into the ongoing class struggles. Unions increasingly feared that employers would use their exchanges as a "strike-breaking" organisation, while employers were uneasy about having a union-based system that could lead to a "closed shop" (Phan-Thuy et al. 2001, 2).

Despite growing tensions in some parts of Germany, additional public labour exchanges were introduced in other parts, mainly in southern Germany, the Rhineland and in Berlin in the 1890 os. Remarkably, the boards of these new public labour exchanges were organised in a "corporatist" fashion, i.e., they included representatives from employer associations and labour unions (Schmuhl et al. 2003, 35). In 1898, the German Association of Labour Exchanges (Verband Deutscher Arbeitsnachweise, VDA) was founded and began receiving public subsidies in 1904. In 1908, the first legislative proposal followed with the aim of introducing similar tripartite labour exchanges across Germany (Schmuhl et al. 2003, 35). However, due to significant and prevailing disagreements between labour unions and employers in many parts of Germany, the government was unable to 
introduce this corporatist governance structure nation wide (cf., Trampusch 2000a). Nevertheless, municipal public labour exchanges continued to spread as both employers and unions increasingly realised the "advantages in separating employment services from the social struggle by planting them on neutral ground" (Phan-Thuy et al. 2001, 2).

The rapid expansion of Germany's public labour exchanges quickly served as a model for many other European countries. For instance, when William Beveridge visited Germany in 1907, he found 400 public labour exchanges, which had become "the most important" placement service, filling nearly half of all job vacancies (Phan-Thuy et al. 2001, 3). Beveridge's visit corroborated his ideas about the adequacy of public - thus "independent" - labour exchanges at which the unemployed were required to register and show a willingness to work. Based on his first-hand "evidence", which provided an institutional alternative to the dysfunctional poor laws associated with "workhouses" and the "disgrace of pauperism", Beveridge was able to convince fellow Liberals to issue concrete policy proposals for a similar scheme (Heclo 1974, 81f; Hennock 1982). Subsequently, Parliament passed the Labour Exchanges Act in 1909 and public labour exchanges were set up in Britain and Ireland, without, however, any institutionalised involvement from either the unions or the employers (cf., Price 2000, 19).

Other European countries also followed suit during the late turn of the century and began creating public and/or social partnership-based labour exchanges. In Austria, social partnership-based associations for job placement and apprenticeship accommodation (Vereine für Arbeitsvermittlung und Lehrlingsunterbringung) were first established in 1885 in Vienna. In 1898, the city government of Vienna organised the first Austrian public labour exchange, while various other cities followed suit in the period from 1902 until the outbreak of WWI in 1914 (Schmidt 1990, 170). In 1905, the public labour exchanges founded an association (the Reichverband der allgemeinen Arbeitsvermittlungsanstalten), that harmonised organisational practices and staff training (Schmidt 1990, 171). ${ }^{3}$

In Sweden, socially progressive Liberals established public labour exchanges run by municipalities in 1902 (Rothstein 1985, 156; Delander 1991, 8ff; King and Rothstein 1993, 153; Wadensjö 2009). From the beginning, many of the Swedish exchanges were governed by corporatist boards, and from 1907 onwards, only corporatist-governed exchanges received national funding (Blom-Hansen 2000, 160), which led to a rapid increase in public employment offices during the 1910s (interview, SOFI2). Denmark, in turn, introduced its first public employment service run by local authorities in 1913 (Madsen 2005, 283). The newly established municipal 
PESs were governed in a tripartite fashion, headed by a neutral chairman, and state funding subsidised up to a third of their operating costs. The director of the Copenhagen exchange, who was appointed by the government, became the quasi-supervisor of the Danish public exchanges, receiving advice from a social partnership-based Supervisory Council (Tilsynsråd) (Nørgaard1997, 204). ${ }^{4}$

While (various types of) public employment services began to emerge during the first years of the $2 \mathrm{O}^{\text {th }}$ century, which were still characterised by intense class struggles, the socio-political environment changed radically during WWI and the immediate post-war period. The war forced national governments to organise labour resources more effectively, whereas the aftermath of the war created massive numbers of returning soldiers looking for employment. At the same time, unemployment among unionised workers grew significantly, which further strengthened the union movement and increased pressures on public officials to accommodate the workers' demands. In Germany, the final days of WWI were characterised by a "truce" (Burgfriede) between employers and unions, which included a commitment not to expand their unilateral labour exchanges and to work towards the creation of more corporatist exchanges. Besides facing overwhelming post-war challenges, the social partners feared that the government would give local authorities a monopoly on labour exchanges - as the British government had done - and thus lobbied together for the creation of nation-wide, bipartite labour exchanges in the Stinnes-Legien Agreement of 15 November 1918 (Trampusch 2000a, 94). The German government was, however, not willing to concede full authority to the social partners and it was only after years of political struggle that Germany finally introduced the first national Public Employment Service the Reichsanstalt für Arbeitslosenvermittlung - in 1927. The Reichsanstalt was governed in a tripartite fashion, and included public officials as well as representatives from both workers and employers in equal parts. A national, tripartite structure thus represented a political compromise between unions and employers on the one side and the government on the other (Pilz 2004, 28). This also meant that local authorities lost their placement authority, and unemployment benefits were subsequently processed in local, tripartite employment offices. However, local authorities retained their responsibility for providing income support payments (Sozialfürsorge) for uninsured jobseekers and others in need. This division of responsibility between locally organised, needs-based, and tax-funded income support, on the one hand, and nationally organised, contributionsbased unemployment insurance, on the other hand, would emerge as the 
core structure of public assistance in Germany and became a core aspect of the conflicts surrounding the recent Hartz reforms (see chapter VII).

In Austria, the war and its aftermath also brought about the emergence of a centralised and social partnership-based PES. Already during the war, the newly founded Ministry for Social Support (Ministerium für soziale Fürsorge) was charged with the authority to oversee local employment offices, and some regions, or Länder, received their own regional headquarters (Landesstellen für Arbeitsvermittlung) (Schmidt 1990, 171). Once WWI had ended, the Social Democratic minister for social affairs appointed an "industrial county commission" (Industrielle Bezirkskommissionen, IBK) that would be in charge of both issuing financial support to the unemployed and assisting them in finding employment throughout Austria. These IBKs had equal numbers of representatives from both the labour unions and the business sector (Lechner et al. 1993, 210f). When Austria introduced its UI system in 1920, the ministry - upon the initiative of the Social Democratic Secretary of State (Sozial-Staatssekretär) Ferdinand Hanusch - transformed the labour exchanges (Arbeitsnachweise) into "unemployment offices" (Arbeitslosenämter) that handled job placement and unemployment benefit payments. Public offices rapidly expanded throughout the 1920 s until each district had its own office (Schmidt 1990, 171). The new unemployment offices were governed by a bipartite committee, which institutionalised social partner influence in labour market policy. However, the main "headquarters" remained with the ministry in Vienna. This upward trajectory of social partnership in labour market governance was abruptly disrupted when the US stock market crashed in February 1929. Austria experienced massive unemployment in the early 1930s, which resulted in an explosion of social expenditures, the collapse of Austria's democracy, and a brief civil war in 1934. In 1935, the new authoritarian, Christian-Social leadership replaced the IBK and unemployment office management across the board, ended the social partnership-based approach, and renamed the offices "regional employment offices" (Landesarbeitsämter) and "employment offices" (Arbeitsämter) respectively (Schmidt 1990, 170ff).

1935 was a critical year also for Sweden. The Social Democratic government pushed through its demands for a nationwide, heavily state-subsidised UI system, which, in turn, accelerated the growth in corporatist labour exchanges. The Social Democrats supported the spread of corporatist exchanges because it gave the government the ability "to check [benefit recipients'] willingness to accept work" (Wadensjö 2009). This was thus a first indication of the labour market approach that would later be known as 
the Swedish "work line", or the expectation that everyone capable of working should be in employment. Central PES headquarters - largely modelled on the German PES of 1927 - were then established during WWII.

The institutional changes in Denmark and Great Britain were less dramatic. Danish Social Democratic and socially liberal policymakers refrained from introducing a centralised PES or expanding local public offices. The Danes preferred a system of self-governance that was primarily organised by the labour unions. When unemployment quickly and significantly rose in the 1930 , policymakers massively expanded public "work camps" and large construction projects rather than reforming the unemployment system (Jørgensen 2002, 172). Meanwhile, the British government continued to consolidate its unilateral, centralilised system. As a result, the "exchanges ... ceased to be 'on trial' and were instead an accepted part of the state apparatus" (Price 2000, 85).

To summarise, while the late 18 oos were characterised by the establishment of UI systems and the creation of locally organised public and membership-based labour exchanges, the post WWI-era saw the emergence of nationally organised PESs and the consolidation of corporatist labour market governance systems in many European countries. Great variations in UI and PES design however emerged, reflecting both ideological preferences and labour union strength. Despite, or perhaps because of, these organisational differences, common developments are also observable. On the one hand, most national governments fully acknowledged unemployment as a national issue, occurring in cyclical patterns. This constituted a significant reassessment by policymakers, who until then had maintained the belief that markets were immaculate and unemployment solely the fault of "idle" jobseekers. On the other hand, governments were increasingly interested in influencing, if not controlling, both job-placement processes and the issuance of UI payments, either directly through political representation on national, regional or local governing boards, or indirectly, through financial support and legislative oversight. The ambitions of most governments to expand their responsibility in the handling of work and unemploymentrelated issues was further expressed in the International Labour Organisation's (ILO) second Convention conclusions of 1919, where Member States committed to establish "a system of free public employment agencies under the control of a central authority. Committees, which shall include representatives of employers and of workers, shall be appointed to advise on matters concerning the carrying on of these agencies" (ILO 1919, Article 2). The convention was ratified by Denmark, Sweden and the UK in 1921, Austria in 1924, and Germany and Ireland in 1925. 


\section{The Roots of "Active" Labour Market Policy}

Along with the emergence of UI schemes and public- and membershipbased labour exchanges, the first "active" labour market interventions were mainly initiated in the post-WWI period, which was a period of severe economic crisis. When unemployment skyrocketed in the 1920 and 1930s, European governments introduced a variety of public works projects, during which the unemployed would receive financial assistance in exchange for labour. "Public works" programmes had a long history but were mostly associated with the poor laws and "workhouses". However, these new programmes were qualitatively and quantitatively different for at least three reasons: First, these - often massive - programmes were organised by national governments rather than local authorities. Some of the most well-known examples of public work projects include the infamous Nazi programmes launched to build the Autobahn, or President Roosevelt's New Deal projects in the US, which included the creation of the Civilian Conservation Corps (CCC) and the Works Progress Administration (WPA), which employed millions of people. Second, the underlying logic of these public works project was fundamentally different. While the main aim of earlier work projects was to "discipline" the jobless and prevent welfare abuse, the goal of these new programmes was to provide "relief" to the unemployed during periods of massive unemployment. And third, workers who participated in most of these new public works projects actually received close to market wages, which was certainly not the case in the "workhouses" or other $19^{\text {th }}$-century public works projects.

It needs to be reiterated, however, that these public works programmes were only designed to provide work and wages for the unemployed. They were not designed to improve, or maintain, the "employability" of workers, which is the goal of contemporary ALMPs. The exception to this rule may have been Germany and Sweden, where active "measures for encouraging increased mobility in the labour force through vocational training, and travel and moving allowances" were already discussed during the 1920 s and 1930s respectively (King and Rothstein 1993, 162; for Germany, see Faust 1987, 276). However, the extent to which these measures were actually used prior to WWII was quite limited, and it would not be until the 1950s that this ALMP concept was actually enacted. 


\title{
III.2 Locating the Origin of Active Manpower Policy
}

\author{
[T]he worker should not be the slave of the manpower policy, \\ but rather the policy should be the tool of the workers. \\ Hermann BeERMANN, DGB $(1964,157)$
}

After the devastation of WWII, most of Europe experienced a period of rapid economic growth and technological innovation throughout the 1950s, an era, that is often dubbed the "golden age" of the welfare state (e.g., Huber and Stephens 2001). During this time, welfare state policies and unemployment insurance were expanded in both coverage and in levels of compensation. Moreover, full employment, as envisioned in ILO Convention 88 of 1948 - and reaffirmed in Convention 122 of 1964 - became not only a rhetorical goal but also an immediately attainable goal (except in Ireland and Italy, where unemployment remained over four percent). In most European countries the emerging challenge was one of labour shortages rather than unemployment. Accordingly, labour market interventions were typically limited to job-search assistance and voluntary participation in employment projects. "Active" labour market policies, as we understand them today, were used, if at all, only for a small group of people with specific and pressing needs in particular circumstances. In other words, during the 1950s, there was no "over-all, unified manpower programme ... concerned with the entire range of occupations and industries and with the long-range interests of workers, employers and the public" (Bakke 1964, 53).

A true "manpower revolution" - i.e., the comprehensive use of ALMPs - would only occur in the 1960s, when the OECD spread the idea of active "manpower policies" throughout Western Europe. The concept of manpower policy is credited to two Swedish trade union economists, Gösta Rehn and Rudolf Meidner ${ }^{5}$ (Martin 1975, 432, fn. 5), who outlined the expansion of active manpower policy as a supplementary instrument to macro-economic policy in various documents, but most importantly in the Trade Unions and Full Employment publication of 1951 (Landsorganisationen i Sverige 1953). Their discussion of manpower policy was placed in the context of economic growth and full employment, and was mostly seen as a means for sustaining non-inflationary growth, which could be achieved via two mutually supportive strategies: wage increases needed to be settled at the national level in a "solidaristic" way, i.e., equal pay for equal work, which, in turn, anticipated increased wage equity (Wadensjö 2009). These wages were to be set at the highest 
rate possible without compromising Swedish international competitiveness, while special increases for low-wage employees would lead to an equalization of incomes. This meant that firms that could only survive by paying low wages needed to rationalise, while inefficient firms would be forced to shut down. Both of these trends would then lead to an increase in overall productivity in the Swedish economy and, of course, unemployment. Therefore, the second, complementary strategy ensured that workers laid off by these firms would be "retrained and redeployed through specially designed labour market programmes into the competitive firms and industries where their services were needed" (Milner 1989, 107; see also, Esping-Andersen 1990, 168). This labour market intervention aimed to fulfil three interrelated desirable political goals: (a) enhancing the economy's productive capacity; (b) keeping inflation in check through the effective flow of labour, both across regions and occupations; and (c) improving social upward mobility and individual competences.

However, Rehn and Meidner's ideas would not become law until the early 1950 os as both the government - especially the Social Democrats' coalition partner from 1951 to 1957 , the Peasants League (later renamed the Centre Party) - and Swedish business remained sceptical about the need for such large-scale and costly economic interventions (personal conversation, SOFI2). This situation eventually changed due to three events: First, the 1957 elections gave the Social Democrats a clear mandate, thus effectively eliminating the need to align with the Peasants League in a coalition government. Second, the governmental reshuffle brought in a new Prime Minister and a new Finance Minister, both of which were proponents of the Rehn-Meidner model. And third, the Korean War and the Suez Canal Crisis induced high levels of inflation in mid-1950s, which led even leading employers to reassess their positions (Milner 1989, 110). In 1957, the government officially adopted the Rehn-Meidner model, which meant - inter alia - the development of new active manpower policies, the strengthening of existing programmes, and doubling expenditures on labour market measures (Milner 1989, 109). It was during this period that labour market training for adult employees and mobility grants became the foundation of Sweden's "active" labour market policy regime (Thoursie and Wadensjö 1997). ${ }^{6}$ 


\section{III.3 The OECD and the Diffusion of Active Manpower Policy}

The OECD, which grew out of the Organisation for European Economic Co-operation (OEEC) that was established to manage the Marshall Plan after WWII, was founded in Paris on 14. December 1960 (Barbezat 1997; Schäfer 2005, 58-61). The OECD's primary objective was to aid advanced industrial nations to reach their economic growth potentials, while keeping inflation in check. The best way to pursue this goal was through the construction, dissemination, and propagation of novel and convincing economic ideas. The OECD created the following two structures toward this end, which are still in place today: ${ }^{7}(1)$ the Council and the Committees, and (2) the Secretariat linked to the Secretary-General, who is also Chairman of the Council (cf., Marcussen 2004, 21ff). The Council is comprised of ambassadors from all of the Member States and is responsible for establishing the overall strategy of the OECD. The Council meets annually at the ministerial level to set jointly agreed-upon priorities to support common policymaking needs and to call attention to certain economic issues and ideas. Expert Committees comprised mainly of national civil servants are set up in specific policy fields, including, for instance education, the labour market, and investment. Representatives from all Member States participate in all of the Committees, supporting the Council's operations. The national representatives also solicit the input and advice from employers (through the Business and Industry Advisory Committee), worker representatives (through the Trade Union Advisory Committee), and other specialised NGOs. The Council and national governments seek and draw on the expertise and conclusions generated - usually by consensus - in these committees. Accordingly, this "first level" of internal OECD organisation is described as being "political, deliberative and consultative" (Marcussen 2004, 21).

The second level, the Secretariat, is divided into specialised policy Directorates and comprises professionals and administrative staff who support the workings of the respective Committees. Most of the involved professionals are economists, statisticians, or lawyers, and the modus operandi in the Secretariat is "administrative, analytical and data-processing" (Marcussen 2004, 21). The Secretary General oversees the workings of the Secretariat and chairs the Council, which makes him the key "link" between the experts and national governments. The "heart" of the OECD's Secretariat structure is the Economics Department, which "constitutes the very essence of the OECD staff's self-definition" (Marcussen 2004, 24). As we will see in greater detail in chapter V, the Economics Department produces 
the annual Economic Outlook as well as the country reviews, outlining key reform suggestions for individual members. To summarise, the OECD offers a forum in which policymakers and policy experts come together to exchange ideas, which are then systematically reviewed, analytically and theoretically tested, and supported with empirical and statistical data. In the field of employment and labour market policy, the OECD was - at that time - the "only player" in town, and for "new ideas to spread worldwide, they had to first pass the OECD filter" (Noaksson and Jacobsson 2003, 34).

In 1962, Gösta Rehn, a "very active and ambitious man" (personal conversation, SOFI2) was appointed Director of the OECD's Manpower and Social Affairs Directorate, a position he would hold until 1974. (Rehn and Svenska institutet för kulturellt utbyte med utlandet, 1984). One of the OECD Manpower and Social Affairs Directorate's "main tasks [was] the promotion of an active manpower policy" (OECD 1964a, 3), and it was through him that the "active manpower policy" ideas that the Swedish model was based on were quickly disseminated throughout the industrialised world (cf., Lenert 1964, 65; Rothstein 1985, 153). The main mechanism of policy diffusion was the application of the "country review procedure [which was applied] also to the study of manpower and allied social policies, which had proved so successful in other sectors of the Organisation" (OECD 1963, 7).$^{8}$ In 1963, the OECD produced its first country report on manpower policy, choosing Sweden as its first case study (OECD 1963). ${ }^{9}$ In addition to disseminating information about labour market structures and policies in OECD member countries, the OECD was also engaged in organising a series of expert conferences. For instance, the OECD organised a labour union seminar on active manpower policy in Vienna, in September 1963. Prior to the conference, the OECD members circulated various reports on active manpower policy, country case studies, and other supplementary material. The seminar's explicit goal was to provide an "ideational compass" that would guide governments in their reform efforts and promote an exchange of current experiences, as well as offering a forum for the presentation of management and trade union views (cf., OECD 1964b). An additional seminar was held in April 1964 for management and business representatives. The results of these seminars were communicated to the Manpower and Social Affairs Directorate. The Directorate then produced - and the Council endorsed - a set of key recommendations about active manpower policy in 1964 (OECD 1964c). These recommendations were subsequently circulated alongside a request to produce ministerial reports that would outline how governments enacted these measures into national law, which was due on 30 June 
1965. It was these 1964 OECD Recommendations that would subsequently serve as the frequently cited reference point for national reform efforts (see the following country studies). The OECD's recommendations can be summarised along three categories: goals, governance and instruments. ${ }^{10}$

\section{Box 2}

Summary of 1964 OECD Recommendations

\section{Goals of Active Manpower Policies (AMPs)}

1. AMPs shall promote economic growth by contributing to the increase of an economy's productive capacity and its utilisation

2. AMPs shall supplement macro-economic policy, alongside "fiscal and monetary policies designed to maintain high levels of employment and business activity"

3. AMPs shall have an expansionist effect on employment and production but an antiinflationary effect with regard to costs and prices, i.e., AMPs shall be used pro-actively and counter-cyclically

4. AMPs shall be used as (financial) means to assist firms' economic restructuring efforts

5. AMPs shall enhance individual occupational and geographic mobility

\section{Governance of National Labour Markets}

1. If necessary, create one central labour market authority (PES)

2. Establish local/regional PES offices that aid in the effective flow of labour

3. Endow PESs with "sufficient resources" so they can provide access to vocational guidance and occupational counselling to all "categories of workers, whether employed, under-employed, or unemployed"

4. Employers' and workers' organisations shall play a positive role in promoting economic growth and the improvement in the standards of all people

5. A public body shall gather and disseminate information/labour market data (i.e., forecast trends and needs)

\section{National Labour Market Measures}

1. AMPs shall be designed as supply-side measures, improving the skills of the workforce and jobseekers

2. While training opportunities should be provided by employers, "public authorities must see to it that total training capacity is adequate for the economy as a whole... Everybody needing and wishing to acquire new skills should be given the opportunity to qualify for the new and better jobs"

3 AMPs shall include the promotion of geographic mobility through the dissemination of information about job openings outside the home area and the collaboration of employment services with local housing authorities

4. Provide special measures for "marginal groups" to promote their participation in "useful employment," particularly when "shortages of labour exist or are impending"

5. Provide adequate unemployment benefits and compensation in cases of redundancy as well as allowances for those "undertaking resettlement, retraining, rehabilitation, and other readjustments" 
As Box 2 shows, the immediate focus of the OECD Recommendations was threefold: (1) establish a set of clear labour market policy goals; (2) outline key recommendations regarding the introduction or recalibration of public employment services to adequately organise and implement public labour market policy; and (3) provide key recommendations for the design and content of public labour market policy measures.

In March 1965, the OECD organised a seminar on the Public Employment Service to support the Recommendations. All of the OECD Member States' PESs were assessed during this seminar. The OECD pointed out that the old concept which considered a PES "a passive institution designed primarily to enrol the unemployed and to determine their eligibility for benefits" had become obsolete (OECD 1966, 11, emphasis added). The OECD pointed out that Sweden had an "outstanding" system that could serve as a benchmark for other members. At that time, Sweden was not only spearheading the manpower revolution, but had also established a modern PES. In 1947, the Swedish Social Democratic government nationalised all regional PESs and introduced a tripartite, national-level Labour Market Board (Arbetsmarknadsstyrelsen, AMS) instead. The AMS co-ordinated the activities of 25 tripartite County Labour Boards that, in turn, oversaw some 233 local employment offices (OECD 1963, 25). The new Swedish PES - effectively modelled on the German PES established in 1927 - remained a relatively independent organisation, but was bound by parliament's legislative framework and by the Ministry of Labour, which had authority over the AMS's budget.

In 1967, a Working Party that included representatives of all OECD members was convened. The Working Party was charged with evaluating materials that had been specifically commissioned by the OECD Manpower Division. This exercise led to the publication of a comprehensive review of public employment services in 1969. While the exchange of national viewpoints clearly revealed disagreement on many key issues, "[there] was agreement, without exception, that an active manpower policy was not only accepted, but was becoming an integral part of the economic life of each of the countries. [Moreover,] labour market and professional experts and practitioners [were] favourably disposed to the acceptance of a new and enlarged responsibility for the Employment Service" (Levine 1969, 49).

The 1960 s can thus be seen as a decade when ideas about active manpower polices, delivered by empowered and modernised public employment services, came to the forefront. As the OECD "exported" these ideas 
throughout Europe (Rothstein 1985, 153), the organisation effectively established itself as a major "ideational agent" in the realm of economic policy discourse in general and with respect to labour market policy in particular (Marcussen 2001). In other words, the OECD had become a key actor in preparing, disseminating, and popularising the use of active manpower policies and the modernisation and expansion of PESs. The following country overviews will provide some empirical evidence for this claim and outline key labour market policy developments.

\section{III.4 Five Country Cases: Austria, Denmark, Germany, Ireland, and the UK}

\section{Denmark}

The organisation of the Danish labour market remained largely in the hands of the social partners - mainly the labour unions - during the $1950 \mathrm{os}$ and most of the $1960 \mathrm{os}$. As a consequence, the Danish system was rather complex and fragmented. The central government, in turn, played only a minor role, which was most evident in three important areas: First, even though the government had formally placed the municipal PESs under the control of the Ministry of Social Affairs in 1942 - which led to an increase in the number of offices - the government continued to lack the ability to significantly influence their operations (Nørgaard 1997, 315). These offices also continued to play only a marginal role throughout the 1950 and 1960 s. This was in part due to the fact that only uninsured workers could access their services. Moreover, the offices were usually located on "dingy premises in back streets", and were seen as unattractive by jobseekers and employers (OECD 1974, 35). The majority of job placements still took place in the labour unions' labour exchanges, which were mostly organised along craft and occupational lines. The flipside of having union-run offices was that labour market mobility across occupations was limited and comprehensive information about the labour market remained scarce. In 1958, an attempt was made to improve the operations of the labour market through the introduction of a corporatist Labour Market Council (Arbejdsmarkedsråd) at the national level. However, the council was not a real decision-making body akin to the AMS in Sweden. It's main function was to serve as a forum for debate and "to make sure that nobody in the labour market establishment took any initiatives without the other parties knowing it" (Nørgaard 1997, 356, fn. 27). 
Second, a large number of about 60 union-run unemployment funds, which had emerged out of an extensive network of unionised self-help associations, established in the 1870 (Rothstein 1985), continued to administer unemployment insurance payments. Even though the central state tried to assume some oversight over the unemployment associations by establishing Local Occupational Committees, the effect these institutions had also remained limited (Nørgaard 1997, 317). The main disadvantage of a largely uncontrolled, union-run UI system was the lack of information and coverage. More specifically, access to UI funds was mainly limited to the "typical" male worker, while the central authorities also lacked insights into who the unemployed were and what skills were needed in the labour market, and thus they lacked the ability to effectively manage the supply and demand of labour and skills.

Third, while a nationwide system of technical schools had already been established in the 1870 (Kristensen and Petersen 1996, 9), there was, other than the standard company-based training, very little comprehensive adult training and retraining during the 1950s. The main innovation during the 1950 s was the Apprenticeship Law of 1958, which reorganised and somewhat streamlined the demands on apprentices and harmonised the content of training curricula. However, the systems remained mainly organised and financed by the social partners, which effectively limited the steering capacity of the Ministry of Education (OECD 1974, 37). The Ministry of Labour, in turn, financed and oversaw the training of both skilled and unskilled workers, while the social partners essentially controlled the curricula. In the 196os, two further improvements were made. First, unskilled labour, i.e., those who had never received any formal vocational training, were offered training opportunities (Specialarbejderuddannelser) in Specialized Workers Schools (later called AMU-Centres) in 1960. These courses were, however, relatively short - typically one to three weeks - and were primarily focused on the construction, metal, and road and rail sectors (OECD 1974, 4of). Second, in 1966, courses for skilled workers (Efteruddannelse) were offered. Skilled labour included all those who had already completed an apprenticeship training course and needed additional training (Kristensen and Petersen 1996, 11; Larsen 2005, 120; OECD 1974, 41). These courses were also mainly in the construction and metal sectors and normally lasted from two to four weeks, which was in stark contrast to the courses offered in Sweden, which averaged six months (Brehmer and Bradford 1974, 113). Workers already employed could ask their employers for permission to participate, and various courses could be taken throughout the year, so that employees could 
upgrade their skills continuously (interview, CARMA). Even though the government successively introduced and modernised its training and retraining courses in 1958, 1960, and 1966, there was still no overarching structure that co-ordinated the various efforts. The field remained split between the ministries of education and labour, while training and retraining efforts were mainly limited to the employed with lower skills sets in a few specific sectors, over whose curricula the government could exert little control.

In summary, job-placement services, unemployment insurance, vocational guidance and (re-)training for the employed were not systematically and centrally organised. Moreover, there was literally no training available for the unemployed who were seeking jobs. Not surprisingly then, by the mid-196os, "everyone in Denmark realise[d] that there [had to] be a transition to a uniform and more rational system of labour exchange services under public administration in the near future" (OECD 1967a, 19). Inspired by the Swedish experiences with active labour market policies (Kvist et al. 2008, 223; interview, CARMA), and after years of deliberating and negotiating within two commissions that had been specifically established to reform the labour market, the Danish government was finally able to enact some groundbreaking institutional changes in the period 1967-1970.

In 1967, the Social Democratic government passed a law, which shifted the marginal risk of unemployment insurance from the UI funds to the state. This meant that when unemployment levels and insurance expenditures exceeded a certain level, the state - i.e., the taxpayer - would reimburse the unemployment associations. While employers were not required to contribute to UI funds, workers continued to contribute their share (interview, CARMA). As such, the state took over the responsibility of the financial risks associated with unemployment, while the administrative role of the labour unions was consolidated. Only those who had exhausted their UI rights and the uninsured were required to seek means-tested social assistance payments, which were administered by municipalities. ${ }^{11}$ The Social Democrats also expanded the benefit system to cover part-time employees and the selfemployed, fixed UI contributions levels, and made unemployment benefit payments more generous by linking benefits to workers' previous salaries, thereby introducing an earnings-related benefit system similar to the one in Sweden. ${ }^{12}$ These reforms effectively increased the replacement rate from an average of about 40 percent of previous wages to an average of almost 75 percent (PLS Consult and Jensen 1997, 51). For low-income workers, the replacement rate was as high as 90 percent of 
previous wages. While these changes were mainly advocated by the labour unions, there were also concessions for employers. On the one hand, they were no longer financially liable for labour market policies, while, on the other hand, they were offered an expansion of "extensive freedom[s] over dismissals" (OECD 1996c, 18). Moreover, when a bipartite Review Board for Unemployment Insurance was created both labour and business jointly oversaw the unemployment insurance funds.

During the late 196os, the Danish government also issued a variety of laws that further revamped the labour exchanges system. These changes were introduced by the newly elected bourgeois coalition government, but were actually the product of "many years of preparations in commissions" (Jørgensen 2002, 172, see also Toft 2001). The changes were threefold: First, the unions lost their right to place workers into jobs, while state control over the PES offices became centralised through the creation of a central public employment service, the Arbejdsformidlingen (AF), which worked as a semi-autonomous agency under the auspices of the Ministry of Labour. Second, 29 regional PESs were created and charged with the authority to issue regional policies and to oversee the attached local offices. And third, the social partners were not only represented at the national level, where a newly established Labour Market Board (Landsarbejdsnæevnet) replaced the Labour Market Council, first established in 1958, but also in Regional Labour Market Boards (Regionale Arbejdsmarkedsncevn) that advised the regional PES offices.

In summary, the historic compromises leading to the labour market reforms in the period 1967-1970 institutionalised many of the 1964 OECD Recommendations, including the establishment of a national, corporatist PES and the introduction of more "adequate" benefit levels with a much broader coverage. Through these reforms, two pillars of the famous flexicurity model, namely flexible labour markets and comprehensive and generous benefits, were also established during this period. However, shying away from addressing the issue of (re)training for the unemployed, the Danish reformers remained much less ambitious than their Swedish (and German) neighbours. The Danish lack of interest in expanding training programmes to include the unemployed can be explained when we look at Denmark's economy, which was still dominated by the agriculture, textile, and clothing sectors during the "golden years" (Benner and Bundgaard Vad 2000, 408). The larger, industrial firms as found in Sweden and Germany, by contrast, were better able to make use of ALMPs. Not only did they have experienced human resource departments that were aware of governmental programmes available to workers, but also the skills of these industrial 
workers stood to benefit most from training courses. Perhaps more importantly, however, Danish "politicians thought that economic growth and full employment were permanent and that concepts like crisis and mass unemployment were ready for the museum" (Jørgensen 2002, 172). For these reasons, Danish policymakers prioritised improved job-placement and counselling services, flexible labour markets, and financial security through generous benefits during (short) spells of unemployment.

\section{Germany}

When the OECD published its recommendations in 1964, Germany already had many of the proposed labour market institutions in place. Germany had not only a well-funded, state-guided educational system and an elaborate system of vocational training, ${ }^{13}$ but also a national, corporatist PES. The German PES, first established in 1927 and reinstituted after the end of WWII, was organised as a semi-autonomous, tripartite federal office, bound by public law. The federal office directed the activities of 11 regional offices, which, in turn, were responsible for their local branches. All regional and local PES offices were governed in a tripartite fashion, ensuring the co-ordination of employers, workers, and local authorities' interests. The German PES - inter alia - administered unemployment benefits, provided vocational guidance (Berufsberatung), and organised preparatory vocational training and re-training courses (berufliche Vorbereitungs-, Fortbildungs- und Umschulungsmaßnahmen). These courses, in turn, were provided by external, mostly union- or employer-run providers (Träger) rather than the PES itself.

However, despite this advanced institutional framework, the actual scope of active manpower policies utilised by the PES remained marginal. This is to say, while some interventionist measures had already been instituted in the early 1950 o - especially for young jobseekers - the initially high levels of unemployment quickly became labour shortages in the later half of the 1950s. Accordingly, "active" manpower measures were largely phased out, while the new labour shortages were alleviated by the introduction of large numbers of guest workers from outside Germany. German labour market policy was thus reactive in the sense that compensation was paid to workers during spells of joblessness and "active" manpower policy was essentially limited to assistance with job searches.

In the mid-196os, however, German policymakers redirected and expanded Germany's labour market policy toward a more proactive orientation by prioritising the prevention of unemployment in the first place, 
reducing its duration in unavoidable situations, and generally improving occupational mobility in the working population. According to Günther Schmid, Germany's leading labour market expert, this "turnaround" in the orientation of Germany labour market policy was "primarily triggered by the OECD" (Schmid and Oschmiansky 2005b, 336, my translation), while the brief economic downturn in 1967 made the Swedish concept of active manpower policies an attractive reference point for German policymakers (interview, HBS). After policymakers reassessed the aim of Germany's labour market policy, the Work Promotion Act (Arbeitsförderungsgesetz, $A F G$ ) was issued in 1969 by the Grand Coalition, which was comprised of the Christian Democrats (CDU/CSU) and Social Democrats (SPD). The core elements of the AFG included the use of proactive measures to circumvent hurdles to finding work, improve occupational structures, secure high levels of employment, and promote economic growth (Schmuhl et al. 2003, 464). Much like the creation of the PES in Denmark in 1969, the $A F G$ represented a major legislative breakthrough - realised after years of tough negotiations - that would become the "formative pillar for Germany's entire labour market policy trajectory" (interviews, HBS, $\mathrm{BMAS}_{3}$ ). As such, supply-side measures such as occupational training for the unemployed became a centrepiece, which was based on the idea that everyone should be able to find and maintain suitable employment (Rottenecker and Schneider 1996, 163). While the AFG primarily targeted the unemployed, the government also adopted the Vocational Training Act (Berufsbildungsgesetz) on 16 August 1969 and the Vocational Training Promotion Act (Ausbildungsförderungsgesetz) on 19 September 1969, to improve the vocational training prospects of workers in employment. ${ }^{14}$ In order to be able to adequately deliver a significantly larger set of labour market measures, the PES was modernised, renamed the Federal Employment Office (Bundesanstalt für Arbeit, BA), and relocated to its new headquarters in Nuremberg. As planning and foresight became part and parcel of a proactive labour market policy regime, the BA also received support from the Institute for Labour Market and Occupational Studies (Institut für Arbeitsmarkt- und Berufsforschung), created in 1967.

\section{Austria}

Austria also underwent major institutional changes in 1969. As in Germany, active manpower policy had not been widely institutionalised during the immediate post-war era. In contrast to Germany, where unemployment remained an issue until the mid-1950s, Austria reached full 
employment almost immediately after the war. In 1947, with under three percent unemployment, Austria even faced its first shortages of skilled labour (Wilk 1991, 156). Thus, active manpower measures were not necessary, while labour shortages were quickly addressed by inviting guest workers, mainly from Turkey and Yugoslavia. When unemployment began to rise in the early 1950 s to 7.5 percent during a mild economic recession (Butschek 1981, 9), Austria offered some - albeit, very modest vocational training programmes for unemployed jobseekers (Wilk 1991, 161). By 1955, unemployment had declined again and the perceived need for reform subsided.

With the emergence of the Rehn-Meidner model in Sweden, the Austrian Trade Union Federation (ÖGB) began to demand the institution of active manpower policies along Swedish lines in as early as 1959. Their demands were quickly taken up by national experts (Aichholzer 1982, 70; Fischer and Potmesil 1984, 273; Wilk 1991, 162), and the first legislative proposal was presented in 1963 . This first proposal did not, however, find a broad enough coalition to actually introduce legislative changes. The next impetus for change - and external legitimisation of union demands came not only in the form of the 1964 OECD Recommendations, but also from an 1964/65 OECD inspection report that outlined recommendations for the adoption of active manpower policies (Tálos 1981, 339; Wilk 1991, 162). As in Denmark and Germany, political struggles prevented the swift passage of legislation, and it would not be until 12 December 1968 that the Labour Market Promotion Act (Arbeitsmarktförderungsgesetz, $A M F G$ ) was approved by Parliament to become law in 1969. As in Germany, the $A M F G$ redirected the overall aim of Austrian labour market policy "based on the logic of an active labour market policy to reach and sustain full employment and prevent unemployment" (Government of Austria 1968, my translation). Much like in Germany, the AMFG was accompanied by additional legislation that approved the institution of the Vocational Training Act (Berufsausbildungsgesetz) of 1969. As such, the $A M F G$, like the $A F G$ in Germany and the various aforementioned Danish labour laws, served as the foundation of contemporary Austrian ALMPs (interview, BMWA1).

With the $A M F G$, the Christian Democratic single-party government not only established a legal foundation for the use of active labour market policy, but also addressed the governance structures of Austria's PES, which became necessary for two reasons: First, the Austrian PES had been nationalised and placed under direct authority of the Ministry for Social Administration by the Nazis in 1938. In contrast to Germany, this sys- 
tem had been retained after the end of WWII in 1945, much to the dissatisfaction of the social partners (Wilk 1991, 158). ${ }^{15}$ The social partners and various policymakers had been waiting for an opportunity since the end of the war to challenge this "unresolved" institutional organisation question. The second factor concerned the actual role that the Austrian PES might play in the labour market. As in Germany, local employment offices not only offered job-placement services and paid benefits, but were also involved in vocational counselling and apprentice placements. In contrast to Germany, however, the Austrian local employment offices covered only "a very limited part of the Austrian labour market", which made an overhaul of the PES even more desirable, if not necessary (OECD 1967b, 42).

Accordingly, the $A M F G$ provided the context in which this "open" issue was to be settled with a compromise. On the one hand, the Christian Democrats, who had gained an absolute Parliamentary majority in 1966, codified in the $A M F G$ that the PES would be retained within the ministry (Wilk 1991, 163). One the other hand, however, the PES was completely overhauled, which was partially a concession to the social partners. First, the social partners were guaranteed an advisory function at all levels of PES governance. Furthermore, local employment offices were established nationwide, with additional branch offices in the larger districts. Finally, the organisation of services was revamped through the establishment of three service areas with separate functions, including a "counselling and placement" division that was responsible for providing information, advice, placement, occupational rehabilitation, and individual support services, a "benefits" division responsible for the financial and accounting aspects of unemployment insurance, and an "employment policy" division that dealt with the remaining tasks (Wilk 1991, 171).

In summary, the OECD Recommendations and the subsequent inspection report stimulated Austrian labour market reforms, which led to an overhaul of the Austrian PES and the introduction and codification of active manpower policies. However, in contrast to Denmark, Sweden, and Germany, which had established semi-autonomous PESs, the Austrian PES remained under direct ministerial jurisdiction. Despite its primarily state-led character, however, the Austrian government solicited and institutionalised the collaboration with the social partners at all levels of PES governance. 
With the end of WWII, the Labour government, inspired by the seminal Beveridge Report, introduced four legislative acts, constructing a "social security network, which protected everyone against destitution or want" (Fraser 2009, 275). This new, universal system covered the entire population against a variety of risks, including sickness, unemployment, retirement, and injuries through the National Insurance and Industrial Injuries Act of 1946. Thousands of qualified employees had to be recruited as some " 25 million people had to be classified, recorded and issued with national insurance numbers" during this period (Fraser 2009, 276). In line with these reforms, the local Labour Exchanges - which had been renamed Employment Exchanges during WWI (Lord Young 1990, 153) - were converted into Unemployment Benefit Offices (UBOs) where unemployed jobseekers had to regularly "sign in" in order to receive their benefits. ${ }^{16}$ Moreover, a separate Youth Employment Service was created to assist younger jobseekers. The system was funded by employer and employee contributions and was additionally subsidised by general taxation. The system was, in contrast to most Continental and Nordic European cases, fully administered by the government rather than the social partners (Finn et al. 2005, 4). The British system of adult education and vocational training was also organised differently. Britain's immediate post-war history was characterised by a "voluntarist" training system. This meant that the provision of training by the state was residual and limited to the problem of unemployed youth and special groups. Social partnership was uncoordinated and workers, individual employers, and various unions made their own arrangements. While this system "effectively excluded those workers - the vast majority - not directly placed in vocational schemes or coveted apprenticeships (King 1997, 385f), the underlying belief was that a laissez-faire approach could meet the demands of a modern economy (Wikeley 1990, 355; King 1997, 387).

During the 1960s, a major reassessment about the adequacy of the British system took place. On the one hand, Conservative and Labour policymakers alike realised that the system of voluntarism had significant shortcomings as British productivity had shown rapid declines. On the other hand, it was recognised that the UBOs had incurred a "dole image" in the public eye, while employers became increasingly dissatisfied with their placement services (OECD 1966, 75). Accordingly, politicians across party lines became increasingly interested in moving toward a more co-ordinated labour market system and major 
legislative proposals were initiated by Prime Ministers Harold Macmillan (Conservatives, 1957-1963), Harold Wilson (Labour, 1964-1970) and Edward Heath (Conservatives, 1970-1974). This era, which was characterised by a "corporatist temptation", ${ }^{17}$ culminated in major institutional changes: (1) the establishment of the tripartite National Economic Development Council (NEDC) in 1962, designed as a national "planning institution" with a remit to advise the government on economic policy (Hall 1986, 87); (2) the formation of Industrial Training Boards (ITBs) in 1965; and, most importantly, (3) the creation of a new PES, the tripartite Manpower Services Commission (MSC) in 1973 that was responsible for both job placement and adult vocational training (cf., Heyes 2000, 4).

The Industrial Training Act of 1964 was envisioned to revolutionise the British system of poor training (Finegold and Soskice 1988). However, the act was characterised not only by innovations but also by major shortcomings. Most importantly, while the act empowered the Minister of Labour to establish ITBs with the "prime function being to oversee the training provided by employers in each sector" (Wikeley 1990, 355), it left the "voluntary" aspects of the British vocational training system intact - largely due to the insistence of some employers (King 1997, 388). Accordingly, the ITBs were usually headed by a chairman from the industrial or commercial sectors, whereas employer, labour union, and education sector representatives served on the ITB boards. This meant that even though vocational training had found legislative recognition, the state was not able to directly affect the quality or content of training, and did not play an active role in encouraging employers to provide more training. Moreover, even though the act allowed the ITBs to raise a "training levy on firms within their industry" (Tamkin et al. 2006, 137), the state refrained from providing any new resources. As such, training remained fragmented, poorly funded and without an overarching framework. Last, because the unemployment rate remained low throughout the 1960 s, the main focus of the ITBs was to improve the skills of those with jobs. This, in turn, left low-skilled jobseekers with little state support (King 1997, 388).

Important changes in the British adult education system therefore predate the OECD Recommendations of 1964. The OECD, did however, have a major impact on the creation of a tripartite employment and training authority, and the introduction of a broad array of active manpower policies designed to address the needs of unemployed workers. When the UK's Department of Labour was "examined" by OECD representatives from Austria, Germany, the United States as well as by Gösta 
Rehn in 1968 (OECD 1970, 11), a "window of opportunity" opened for a radical reform of the PES and British labour market policies as the OECD's views coincided with those held by department officials (Price 2000, 136). Three responses are most noteworthy. First, new Job Centres were opened at attractive locations to provide improved job-placement services, in addition to, but separate from, UBOs, which oversaw benefit payments. At that time, the Conservative government believed that it was only the separation of employment from benefit services that could adequately address the negative image of the exchanges (Beale 2005, 68), a view that the OECD also advocated during their visit (OECD 1970, 24). Second, the multipartite MSC was established in 1973, not long after a team of British civil servants visited Sweden and West Germany to learn more about their corporatist models in 1971. The MSC was established to manage employment and training policies through the Employment Service Agency (ESA), which was in charge of the Job Centres and the Training Services Agency (TSA), which oversaw the ITBs. The MSC was headed by a chairman who was appointed by the Secretary of State, three CBI and three TUC representatives, two local authority representatives and one official representing the education sector (Wikeley 1990, 356). Thus the establishment of the MSC was a clear signal of the government's (renewed) commitment to "consensus management of the economy", while Labour and the TUC envisioned that the MSC could play a "strategic role" similar to that of the Labour Market Board in Sweden (Ainley and Corney 1990, 22). And third, the state took a more active role in the provision of training for the unemployed through the Training Opportunities Scheme (TOPS), which was launched in 1972. TOPS offered training (and a small allowance) to adults of at least 19 years of age who had not been in full-time education for at least two years and showed "a clear intention of taking up employment in the training occupation" (Beale 2005, 68).

In summary, the late 1960 os and early 1970 sere a time when Britain moved toward a more "co-ordinated" labour market regime by soliciting the support of the social partners, established a national authority that co-ordinated employment and training activities, and introduced and expanded active manpower policies. The OECD's recommendations, in turn, served as an important focal point and resource, "accelerating" and "legitimising" major labour market reforms (cf., also, Lewis 1978). 
Ireland

Ireland is similar to its British neighbour in that it had utilised a small set of Labour Exchanges established in 1909 as a means for jobseekers and employers to meet. The main functions of the Irish Labour Exchanges were similar to those in Britain, which included the issuance of benefit payments, while placement was only considered a "minor ancillary activity" and was limited to filling a small number of unskilled jobs, many of them in the public sector (NESC 1985, 206). The Irish UI system, like that of its British neighbour, was based on a flat-rate benefit at modest levels, and was very centralised, with the state being responsible for the administration and management of a separate "unemployment fund" (MacCashin 2004, 195). In 1952, a new legislative act fully integrated this unemployment fund into the national social security system and made it more generous. The benefit period was extended from six months - for those with a contribution history of six months - and the waiting period reduced from six to three days (MacCashin 2004, 199). Training, in turn, was also mainly "voluntarist" in nature, with little state involvement. During the late 1960 s and early 1970s, however, radical institutional changes were implemented, including the introduction and expansion of active manpower policies, the creation of the Industrial Training Authority (AnCO), which co-ordinated vocational training in 1967, and the establishment of the National Manpower Service (NMS) in 1971, which was responsible for the delivery of labour market services.

Generally speaking, Ireland was very receptive to the introduction of active manpower policies during the 1960s. Already in the late 1950s, the Fianna Fáil led government had decided to engage in a new economic course, which was subsequently initiated by Taoiseach, or Prime Minister, Sean Lemass (1959-1966) and pursued further by his successor Jack Lynch (1966-1973). More specifically, Ireland abandoned its strategy of "protectionism and import substitution industrialisation" in the early 1960s (Cousins 1995, 36), which, in turn, exposed older and more traditional industries to fierce international competition (cf., O'Donnell 2004, 50). Accordingly, the government was very interested in the OECD Recommendations (NESC 1985, 48) and requested its own report on the use of active manpower policies from the National Industrial Economic Council (NIEC) in $1964 .{ }^{18}$ Based on this report, the government issued a White Paper on Manpower Policy in 1965, which triggered a number of substantial institutional changes: First, the government created the Department of Labour (DfL) in 1966, which temporarily (until 1971) 
"took over the employment exchanges" that had previously been under the authority of the Department of Social Welfare (DSW) (OECD 1998, 25f). Second, the government issued the Industrial Training Act in 1967, which created AnCO, a semi-independent body with its own council. This legislation signalled the "beginning of a more comprehensive approach to training", which expanded significantly over time (NESC 1985, 50). These changes in industrial policy were coupled with educational reforms, including the introduction of free and open access to secondary education and access to free school transportation, the development of Regional Technical Colleges (RTCs), and the expansion of a scholarship scheme for tertiary education in the late 196os. Third, the responsibility for benefits payments was moved back to the DSW in 1971, while a PES, the "National Manpower Service (NMS) was set up as a separate functional entity within the Department of Labour" (OECD 1998, 26) to oversee the delivery of labour market policy, including job-placement and training services for the unemployed. Eight regional offices were introduced and a network of local offices was established and expanded in the years thereafter. Apprenticeship schemes were also expanded and active manpower policy was "primarily concerned with the supply side of the labour market" (NESC 1985, 51). Besides significantly revamping its active labour market policy framework, the Irish government also lengthened the duration of UB from six to 12 months in 1967 - and to 15 months in 1976 (McCashin 2004, 199).

To summarise, during the 1960 s and 1970s, Ireland's "welfare provisions [not only] converged on those in the United Kingdom" (O'Donnell 2004, 51), but its labour market provisions actually "outpaced" developments in Britain. While Ireland fell short of introducing a Continental or Nordic vocational training system, the "developments in Ireland in the 1960 s reflected the concept of active manpower policy as envisioned in the 1964 OECD Recommendations" (NESC 1985, 51) and policymakers took a significant step toward the co-ordination of its labour market through the creation of $\mathrm{AnCO}$ and a national placement agency.

\section{III.5 Conclusions}

Active labour market interventions were certainly not an entirely new phenomenon in the post-war era. The industrialised nations discussed here had already begun using some active measures prior to the "man- 
power revolution" of the 1960s. However, the use of manpower policies across Europe had been sporadic and policymakers typically confined their use to youth and other "special" groups. In the context of virtually full employment, various types of employment exchanges were primarily concerned with assisting jobseekers and employers in filling job vacancies and/or paying out unemployment benefits, rather than delivering active manpower policies. However, during the 1960s, the economic beliefs of two Swedish labour union economists regarding the use of active manpower policy became an attractive reference point for reformminded policymakers. As this brief overview has shown, the OECD Recommendations of 1964 and their dissemination by the Manpower and Social Affairs Directorate served as a motivation for many governments to initiate institutional changes. Meanwhile, a series of OECD follow-up reports, country studies and conferences helped to disseminate best practices, country-specific experiences, and new insights into how to apply these new measures. Unemployment remained fairly low in most European countries during the post-war period, which meant that the main focus of these new instruments were supply-side oriented, i.e., focused on placement and the improvement of the technical skills of the jobseekers. Demand-side programmes such as public works projects were of a smaller scale and used as "social" programmes to provide employment to disadvantaged groups rather than as an instrument to artificially reduce the demand for labour.

In addition to advancing the use of active manpower policy in the five case studies, the OECD promoted the creation of national, tripartite PESs in Denmark, Ireland, and the UK. In the other countries, it encouraged the transformation of PESs into "modern" service providers that offered improved vocational counselling and guidance to jobseekers (OECD 1978b, 46). ${ }^{19}$ Accordingly, many social scientists have attributed this "manpower revolution" to the OECD Recommendations, which "appear to have had considerable weight as major reorganisations of the structure of administrations were carried out by France in 1967, Germany in 1969, and England in 1973, modelled to a very large extent on Sweden's experience in the 196os" (Krautkrämer 1978, xii; Lewis 1978, xii; OECD 1978b, 44; Butschek 1981, 34; Rothstein 1985, 153).

In analytical terms, this can be interpreted as a partial convergence of labour market policy regimes on a common ideal that included a centrally steered PES (addressing frictional unemployment), supply-side active manpower measures (promoting non-inflationary economic growth, while addressing structural unemployment through investments in hu- 
man capital), demand-side measures that created employment opportunities for the most disadvantaged, especially during cyclical downturns, the provision of "adequate" unemployment benefits, and social partner involvement in policy development and implementation (providing expertise, legitimacy, and resources). 



\section{Labour Market Policy Regimes in Crisis: Divergence into Three Distinct Clusters}

\section{IV.1 Labour Market Policy Regimes Under Stress: 1973-1979}

After a period of "institution-building" that included the creation and/ or modernisation of public employment services, the introduction and expansion of active manpower policies, and the general enthusiasm for economic planning, foresight, and management during the mid-196os to the early 1970s, many European policymakers were rudely awakened by the first oil crisis of 1973. As a consequence of quadrupling oil prices and skyrocketing commodity prices, unemployment soared in most OECD countries. Two decades of (near) full employment came to an end and a "cosy world" had abruptly disappeared (British Prime Minister James Callaghan, cited in Hall 1986). Table 5 below shows the changes in unemployment levels for most of Western Europe.

Practically all of the advanced industrial countries initially reacted to this crisis with a typical Keynesian response: they resorted to large-scale deficit spending. However, when unemployment remained stubbornly high throughout the latter half of the 1970s, policymakers and prominent economists increasingly began publicly casting doubts about core Keynesian premises, including the assumptions about the inverse relationship between unemployment and inflation as captured in the Phillips Curve. ${ }^{1}$ Most prominently, it was two US economists - and later Nobel Prize winners - who produced new insights, independently of each other, that challenged policymakers' cognitive ideas about the use of macroeconomic demand management. Edmund Phelps, who was awarded a Nobel Prize in Economic Sciences in 2006, introduced the concept of the expectations-augmented Phillips Curve in the late 196os, which emphasised that high current levels of inflation lead to high future inflation. His analysis thus suggested that it becomes more difficult to achieve price stability in the long run and that "the long-term rate of unemployment cannot be influenced by monetary or fiscal policy affect- 


\begin{tabular}{|c|c|c|c|c|c|c|c|c|c|}
\hline Country & $\begin{array}{c}1960- \\
1973\end{array}$ & 1974 & 1975 & 1976 & 1977 & 1978 & 1979 & $\begin{array}{c}1974- \\
1979\end{array}$ & $\begin{array}{c}\text { Chan- } \\
\text { ge }\end{array}$ \\
\hline Austria (AT) & 1.7 & 1.3 & 1.8 & 1.8 & 1.6 & 2.1 & 2.1 & 1.8 & 0.1 \\
\hline Belgium (BE) & 2.2 & 2.5 & 4.6 & 6.0 & 6.8 & 7.4 & 7.7 & 5.8 & 3.6 \\
\hline Denmark (DK) & 1.4 & 3.6 & 4.9 & 6.4 & 7.4 & 8.4 & 6.1 & 6.1 & 4.8 \\
\hline Finland (FI) & 2.0 & 1.7 & 2.3 & 3.9 & 5.9 & 7.3 & 6.0 & 4.5 & 2.5 \\
\hline France (FR) & 1.8 & 2.6 & 3.7 & 4.1 & 4.6 & 4.8 & 5.4 & 4.2 & 2.4 \\
\hline Germany (DE) & 0.8 & 2.2 & 4.0 & 4.0 & 3.9 & 3.7 & 3.2 & 3.5 & 2.7 \\
\hline Greece (GR) & 4.6 & 2.1 & 2.3 & 1.9 & 1.7 & 1.8 & 1.9 & 1.9 & -2.6 \\
\hline Ireland (IE) & 5.5 & 5.4 & 9.3 & 9.1 & 8.8 & 8.3 & 6.8 & 8.0 & 2.4 \\
\hline Italy (IT) & 5.4 & 5.4 & 5.9 & 6.8 & 7.2 & 7.3 & 7.8 & 6.7 & 1.3 \\
\hline Netherlands (NL) & 1.1 & 2.8 & 5.3 & 5.6 & 5.5 & 5.4 & 5.5 & 5.0 & 3.9 \\
\hline Portugal (PT) & 2.6 & 1.8 & 4.6 & 6.4 & 7.6 & 8.1 & 8.2 & 6.1 & 3.6 \\
\hline Spain (ES) & 1.8 & 3.3 & 4.7 & 4.6 & 5.2 & 7.0 & 8.7 & 5.6 & 3.8 \\
\hline Sweden (SE) & 1.9 & 2.0 & 1.6 & 1.7 & 2.0 & 2.5 & 2.3 & 2.0 & 0.1 \\
\hline United Kingdom (UK) & 1.9 & 2.1 & 3.3 & 4.9 & 5.3 & 5.2 & 4.7 & 4.2 & 2.3 \\
\hline
\end{tabular}

Source: OECD.stat, extracted on 30 June 2009

ing aggregate demand" (Royal Swedish Academy of Sciences 2006, 2). Meanwhile, a group of economists at the University of Chicago, including Milton Friedman (Taylor 1990, 36), presented the idea of a "natural rate" of unemployment. Friedman argued that inflation was caused only by the excessive expansion of the money supply, while excessive unemployment was the result of frictions in the labour market. Friedman, who was awarded the Nobel Prize in Economics in 1976, did not believe that unemployment could be reduced through expansionary demand policy, and that a "natural" level of unemployment was an unavoidable, if not necessary, aspect of every economy. The level of unemployment was mostly a reflection of labour market institutions that were too rigid and wages that were set at levels that exceeded workers' productivity. As a result, Friedman advocated free markets, laissez-faire capitalism, price stability targets and balanced budgets as the most appropriate way to enhance employment. The works of these two economists thus formed the scientific foundation for the economic concept of NAIRU, which would become the guiding principle of the 1994 OECD Jobs Study (see chapter VI.) However, throughout most of the 1970s, the representatives of pure 
"supply-side economics" or "monetarism" would remain in the minority among the political elites. This is to say, while some governments saw themselves as "pragmatists reluctantly taking nasty medicine" (Ruggles and O'Higgins 1987, 160), they had not fundamentally reassessed their causal and normative beliefs and thus had not yet shifted entirely from a Keynesian to a monetarist view.

In search for alternative solutions to address Europe's high levels of unemployment, a ministerial-level meeting was arranged by the OECD Committee for Manpower and Social Affairs, for the first time in OECD history. In this meeting, the Ministers exchanged their ideas regarding measures to address unemployment. But instead of endorsing Friedman's prescriptions, an increase in active manpower policies was seen as the appropriate tool to ameliorate the effects of the economic downturn. At that time, policymakers still believed that increases in unemployment were cyclical by nature - rather than structural as Friedman had proposed - and that an imminent economic recovery would bring unemployment levels back down to, or at least close to, pre-oil crisis levels (OECD 1976, 8). However, as the economic environment had changed from one of labour shortages to one of oversupply, policymakers shifted the focus of active manpower policies. While active manpower policies were seen as predominantly economic instruments to improve the general supply of labour in the 1960 s, policymakers began to utilise them in the 1970 as socially oriented, "offensive" and explicitly counter-cyclical instruments that supported employment during times of a gradual economic recovery. Put differently, active manpower measures were recalibrated and new instruments introduced, including occupational training courses for a large number of the unemployed; public support for the creation of jobs in the context of regional and industrial development; employment subsidies to sustain and increase levels of employment; and the creation of jobs in the secondary labour market, particularly in areas where public services were needed (OECD 1976, 24). These "new" measures were thus intended to stabilise, if not increase, the demand for labour. As such, more state interventionism - in contrast to its retreat as Friedman had envisioned - emerged as the predominant policy strategy of the mid-1970s. ${ }^{2}$ A brief review of country-specific policy responses follows below. [Please note that an appendix to this chapter provides tables with comparative data on the developments described in this section.] 


\section{IV.2 National Policies after the First Oil Crisis: Moderate Optimism and the Expansion of Active Manpower Policies}

\section{Sweden}

In contrast to most European economies, Sweden survived the challenges of the first oil crisis relatively well and unemployment remained under three percent throughout the 1970s. The Social Democratic government's strategy was based on the continuation of interventionist labour market policies, including massive industrial subsidy programmes, stimulating employment growth in the private sector, and the expansion of active manpower policies, which included generous supply-side measures, intended to equip workers with new skills in a changing labour market. Demand-side measures were also vastly expanded, providing work opportunities for laid-off workers (Anxo and Niklasson 2004, 6). These measures included a system of grants for the recruiting of young people in the early 1970s, which were subsequently expanded in several stages. The Swedish government also expanded the use of temporary job opportunities in public employment projects throughout the 1970s. These were arranged by national and local authorities in both public and private firms (Ahlqvist 1979, 49). Moreover, financial incentives were provided to companies "to increase their training programmes during recessions so that they can avoid having to lay off employees" (Larsson 1979, 14). During the early 1970s, demand-reducing measures were also introduced and/or expanded, including a "right" for employees to take an educational leave of absence. These periods of absence fulfilled a dual purpose: while firm employees improved their occupational skills, the temporarily vacant position was filled with an unemployed who could gather some in-firm work experience. Early exit options were also fostered through a relaxation of the access to pensions for older workers in poor health in 1970; the introduction of a disability pension for older unemployed workers, who had exhausted their UB entitlements in 1972; and the issuance of a new support scheme in 1974, with more lenient job-search requirements for older workers (Wadensjö 1991, 303ff). In addition to these labour market policy measures, the Social Democratic government also issued the Job Security Law in 1974, effectively regulating dismissals by new legislation rather than social partnership agreements. The new law institutionalised the so-called "seniority principle", meaning that the longer one was employed with a particular employer, the more difficult it became to get laid off, which is also known as the "first-in-last-out rule" (cf., Wadensjö 2009). 
Interestingly, these interventionist policies were all subsequently extended by the bourgeois coalition government that took office in 1976, ending a 44-year era of Social Democratic rule (Anxo and Niklasson 2004, 6). The new centre-right government (comprised of the agrarian Centre Party, the conservative Moderates, and the liberal People's Party), did not endorse a monetarist paradigm, because they believed that the downturn was temporary, and because they wanted to prove that the "Social Democratic propaganda against them" was incorrect (Huber and Stephens 2001, 241). Mjøset $(1987,429)$ goes even further in his assessment of the politico-economic orientation of the bourgeois parties and argues that "these parties were heavily Keynesian". An additional factor that contributed to the extension of Sweden's policies - which Mjøset (1987, 421, table 4) called "fumbling" - included the strong intra-party conflicts that plagued the three-party coalition government. In other words, the bourgeois government not only refrained from adopting a new set of economic ideas, which could have redirected the traditional "Swedish Model", but the coalition government was also unable to align its own forces on a new course, which, in turn, caused great internal instability. More specifically, during the period 1976-1982, Sweden's centre-right coalition government underwent numerous reshuffles with "no less than five different cabinets" (Benner and Vad 2000, 416). ${ }^{3}$ Not being able to consolidate their political forces, lacking a coherent vision, and rejecting a monetarist reform agenda, the centre-right government - in an attempt to maintain Sweden's international competitiveness and to stimulate employment growth - merely relied on the strategic devaluation of the krona - "twice in 1976 (after 25 years of constant exchange rates) and again in 1977 and 1981" (Anxo and Niklasson 2004, 6).

The 1970 s were, however, characterised not only by "fumbling" and "more-of-the-same-policies", they became a critical era also for the development of what we today refer to as the "Nordic Model": a service-heavy welfare state, high female employment rates, and extremely high tax burdens (cf., Sapir 2006). This is to say, during the first two post-WWII decades, the Nordic welfare states were "not distinctive in terms of the size of public social service employment or, other than in Finland, in the level of women's labour force participation" (Huber and Stephens 2001, 125). However, during the 1960s, and in particular during the 1970s, a distinct set of Nordic labour market characteristics was established. Because the Social Democrats, and to some extent the labour unions, had been reluctant to welcome "guest workers" to compensate for labour shortages, the expansion of the public sector in the areas of childcare, elderly care, 
health care, and education provided additional job opportunities for many women during the 1970s. More specifically, the public sector doubled its size from 700,00o to 1,400, ooo employees in the period 1965-1980 (Benner and Vad 2000, 406).

This drastic expansion of the public sector must - at least in part - be understood as a reaction to a rapidly growing women's movement and the Social Democrats' alignment with their cause. The women's movement emerged as a loud advocacy group "for equal access to the labour market for women, a higher value to be put on caring work, and a more equal division of labour in the household" (Huber and Stephens 2001, 126). The Social Democrats, in turn, quickly incorporated gender equality into their ideology and, together with the Swedish Trade Union Confederation (Landsorganisationen $i$ Svergie, LO), launched the Increased Equality programme in 1969. The government subsequently endorsed the establishment of a "dual-earner household model", which it promoted with its transition to separate taxation in 1971, the appointment of a Delegation for Equal Opportunities to improve women's opportunities in the labour force in $1972,{ }^{4}$ and the expansion and introduction of transfer payments, including increased compensation for maternity leave, a new paternal leave scheme, and more generous sick pay for parents with ill children in 1974 (cf., Thoursie and Wadensjö 1997, 66; Huber and Stephens 2001, 126). The combined effects of the normative reassessment regarding "women and work", the rapid expansion of the public sector, and the introduction of innovative gender-oriented transfer payments, eventually led to dramatic increases in the female employment rate during the 1970s. While women's labour force participation generally improved from 53.8 percent in 1965 to 65.2 percent in 1974, the participation rate for married women rose even more drastically, from 42.2 percent to 63.6 percent during the same time period (Schmid 1975, 60).

\section{Denmark}

In contrast to Sweden, Denmark experienced a strong economic recession after the first oil crisis and saw rapidly accelerating levels of unemployment. Moreover, the 1970 s were characterised by great political volatility and instability. The Liberal Party was in power from 1973 to 1975, followed by two short-lived Social Democratic-Liberal coalition governments from 1975 to 1978 , and 1978-1979, which, in turn, were followed by two minority Social Democratic governments, from 1979-1981 and 1981-1982. In other words, even though the period from 1975-1982 was under Social Demo- 
cratic leadership, the government was weak politically and had to rely either directly or indirectly on the support of other parties.

In 1975, the newly elected Social Democratic coalition government attempted to alleviate skyrocketing unemployment by employing countercyclical Keynesian demand management. However, "increasing publicsector and balance-of-payment deficits forced [them] to abandon this policy" already in 1977 (Torfing 1999, 10). In contrast to the Swedish strategy of currency devaluations, state subsidies, and massive manpower measures, Denmark hesitantly and half-heartedly embraced a monetarist orientation, ${ }^{5}$ and the commitment to full employment was gradually replaced by concerns about the "competitiveness" of Danish firms. In this regard, the government began to interfere in the social partners' wage settlements - much to the resentment of the unions - and since 1976 "disposable real wages ... diminished for all categories of employees" (Lind 1988, 10).

The government reacted to rising unemployment also by gradually expanding labour market measures, but saw no immediate need to dramatically alter their policies as long as the prolonged and generous benefits that had become as generous as those in Sweden - were able to guarantee a decent standard of living for the unemployed (cf., Torfing 1999; Benner and Vad 2000; Knuth et al. 2004). On the supply side, the Danish PES began organising short (seven to ten week) introductory vocational courses (erhvervsforberendende kurser) "for young people in the 16-25 age group and for unemployed women" (Köditz 1990, 34). In contrast to Sweden, however, these courses were very basic and not designed to offer comprehensive vocational training. On the demand side, the government introduced the Job Offer Scheme (Arbejdstilbudsordningen) in 1978, which was the most important and largest employment measure to date (Jørgensen 2002, 173). Through this scheme, jobseekers earned the "right" to employment in a subsidised, public sector job for at least seven months. ${ }^{6}$ That same year, the national government's Extraordinary Local Authority Employment Measures Act also required local authorities to invest a fixed portion of their budgets in the reduction of unemployment and in the development of public works projects (Knuth et al. 2004, 56). Through this act, access to active manpower measures was effectively extended to also include "uninsured" workers and social assistance recipients.

Overall, while the effect of the supply-side and demand-side measures on unemployment reduction was rather limited, it was a new early retirement scheme, introduced in 1978/79 that made "a real dent" in the unemployment statistics (Benner and Vad 2000, 437). The newly intro- 
duced, demand-reducing Post-Employment Wage Scheme (efterløn) allowed workers and unemployed jobseekers who had been UI fund members for at least 20 years to receive a post-employment wage from the age of 60 until retirement. Since the income earned through the efterløn was considerably higher than UB entitlements, older unemployed workers were "incentivised" to enter the scheme, thus withdrawing from the labour market. The following table illustrates the various unemployment measure priorities in Denmark and Sweden.

Table 6 Distribution of Government Spending on Labour Market Policy Measures in Denmark and Sweden, 1979

\begin{tabular}{lcc}
\hline & Denmark & Sweden \\
\hline Cash assistance to the unemployed & $84 \%$ & $10 \%$ \\
\hline Employment policy measures targeted to the individual & $10 \%$ & $45 \%$ \\
\hline Employment policy measures targeted to firms & $1 \%$ & $13 \%$ \\
\hline Labour market training & $4 \%$ & $31 \%$ \\
\hline Increased geographical mobility & $0 \%$ & $1 \%$ \\
\hline
\end{tabular}

Source: Esping-Andersen and Korpi 1987, 65, table 5

Despite these significantly different macro-economic and labour market policy approaches in Denmark and Sweden, both countries shared a commitment to women-friendly labour and social policies and the expansion of welfare services delivered by local authorities. The Danish Child and Youth Care Law of 1964 set the stage for the "very rapid increase in public day care provision" (Huber and Stephens 2001, 144), which led to an increase in female labour force participation. In 1965, the Social Democratic prime minister appointed a commission on the status of women, and in 1975, after the Social Democrats had returned to power, the Equal Status Council was established. These developments further institutionalised childcare and elder care arrangements at the municipal level, which expanded "rapidly in the 1960 os and early 1970s" (Benner and Bundgaard Vad 2000, 411). Finally, by the mid-1970s, Denmark had also caught up to Sweden in the area of maternity leave benefits, and subsequently also introduced a parental leave scheme (Huber and Stephens 2001, 144). In summary, the 1970 in Denmark were characterised by the institutionalisation of a service-heavy, women-friendly welfare state, which led to both increased levels of female labour market par- 
ticipation and the expansion of the public sector, which "grew steadily over the 1970 s and 1980 s, driven by an expansion of services and transfer payments" (OECD 2000, 24).

\section{Germany}

On 28 September 1969, Willy Brandt (SPD) was elected the first nonChristian Democratic Chancellor in Germany's 20-year young post-war history. While the Chancellor was now a Social Democrat, there was only a partial cabinet reshuffle because the SPD - now in a coalition with the smaller Free Democrats (FDP) - had previously been in the Grand Coalition with the Christian Democrats (1966-1969). This meant that the Social Democrats had played an instrumental part in issuing both the Stability and Growth Act of 1967 and the Work Promotion Act (AFG) of 1969, the two most important pieces of legislation with respect to macro-economic and labour market policy. However, rather than being able to coast along on the same policy trajectory, the SPD-FDP coalition faced significant challenges in the early years. On the one hand, Germany began to experience extraordinarily high rates of inflation in early 1973, which was caused by two factors. First, the unions successfully negotiated significant wage increases, which exceeded real increases in productivity. And second, the government had successively increased its public spending in line with the general euphoria regarding economic steering during the early 1970 . After the first oil crisis, inflation continued to increase and reached seven percent in 1974 (Hetzel 2003, 38). On the other hand, the oil crisis triggered an economic recession, which led to a rapid increase in the unemployment rate, which quadrupled from 273,00o in 1973 to over 1,00o,ooo in 1975. Germany, like many other oil-importing countries in Europe at that time, thus experienced a new economic challenge known as stagflation, or simultaneous economic stagnation and high levels of inflation. In the midst of this economic turmoil, Chancellor Willy Brandt resigned in 1974 and Helmut Schmidt, an economist and an ex-economic and finance Minister, became Germany's new chancellor.

This important reshuffle in the Chancellor's Office brought about a substantive course correction in Germany's economic policies. In contrast to Sweden (and Denmark until 1977), Germany abandoned its shortlived commitment to Keynesianism and thereafter pursued a more "selective" monetarist strategy, combining price stability measures (rather than full employment) with an expansion of interventionist labour market measures and increases in benefits. This allowed the German economy 
to survive the first oil crisis relatively unscathed with an economic growth rate of five percent in 1976 and four percent thereafter until 1979. Inflation also declined rapidly to under three percent and seemed to be largely under control (Hetzel 2003, 41, figure 6), which was in stark contrast to other European countries, most notably Denmark and Sweden (see table 10 in the appendix). The price of "sound" economics, however, was sustained levels of unemployment, which the government tried to address through improved access to training for the unemployed and the expansion of a variety of employment promoting projects (Arbeitsbeschaffungsmaßnahmen, $A B M s)$. Rottenecker and Schneider $(1996,171)$ and Schmuhl $(2003,506 \mathrm{f})$ count a total of 18 such programmes launched between 1974 and 1983, many of which were delivered by the national PES (Bundesamt für Arbe$i t, B A$ ). Moreover, unemployment benefits and unemployment assistance payments were increased, partially because the Social Democrats continued to adhere to the Keynesian idea that the sustained purchasing power of the unemployed would maintain domestic demand for goods and services. The Social Democrats were also unwilling to abandon the state's reactive "caretaker" function, which illustrated that the German Social Democrats (like the Danish Social Democrats) had not fully internalised the principles of the still young $A F G$, which would have emphasised active over passive measures. The SPD's smaller coalition partner, however, became increasingly concerned with the costs of the welfare state and favoured a "cleaner" monetarist strategy. Striking an intra-governmental compromise, the FDP was able to push through its restrictions on access to training for those already employed, new regulations that would allow employment officers to regularly check on the unemployed, and a tightening of the criteria of what constitutes a "suitable" job offer (Schmuhl et al. 2003, 520).

\section{Austria}

In 1971, Bruno Kreisky (SPÖ), a staunch Keynesian who had spent the period of the Nazi occupation in Sweden (where he was in close contact with Willy Brandt), became the first Social Democratic Chancellor in Austria with an absolute majority in parliament. The Kreisky era (1970-1983) was characterised by a period of welfare state expansion and - in contrast to Germany - a sincere commitment to full employment. Even though the economy grew significantly less in the second half of the 1970s, the government was able to keep unemployment consistently at around two percent throughout the 1970s, thus outperforming even Sweden, the "model" welfare state. 
This exceptional employment record was due to a number of factors. First, like Sweden, Austria applied Keynesian, counter-cyclical economic policies, leading to a significant expansion of the public deficit, from 1.3 percent in 1973 to 4.5 percent in 1975 (Ostleitner 1997, 102). These measures were further coupled with moderate wage settlements by the social partners (Wilk 1991, 166). Second, Austria pegged its schilling in 1976 to the (low-inflation) German mark, which allowed Austria to "free-ride" on German stability policies because Germany was Austria's main export market (Butschek 1981, 21). ${ }^{7}$ Third, Austria's tertiary sector had remained underdeveloped during the post-war years, but expanded rapidly during the late 1970s, thus creating new employment opportunities (Tálos 1987, 94). Fourth, in 1969, the majority of Austrians voted for the introduction of a 40 -hour workweek in a national referendum initiated by the SPÖ. The gradual reduction in the workweek eased over-supply pressures and by 1 January 1975 Austria had achieved the 40-hour week. And last, Austria had been suffering from labour market shortages since the mid-196os, a situation which had been compensated with the influx of guest workers. In the midst of the economic downturn, these guest workers were then disproportionately affected by job cuts, and so unemployment was simply "exported" after the oil shock in 1973 (cf., Tálos 1987, 94).

While all of these factors significantly contributed to stable employment rates in Austria, active manpower policy was also used, albeit moderately. In particular, support to facilitate regional mobility was expanded, while measures for disabled workers were introduced in 1974 and continuously expanded throughout the 1970s. Spending on apprenticeships for the unemployed and public employment projects also increased, although more modestly in international comparison. Total expenditures on active measures increased from 168 million schillings in 1970 to 1.017 million schillings in 1979 (Wilk 1991, 179, table 2).

Finally, with respect to women and work, Austria did not follow the Danish or Swedish model of expanding welfare services such as child and elderly care. Austria did, however - in stark contrast to Germany - introduce individual taxation in 1972, which is usually considered to be one of the main ingredients in Denmark and Sweden's success in attracting women into the labour force (e.g., Dingeldey 2001). Kreisky also promoted an end to the discrimination of women in the workplace, expanded maternal leave schemes in 1976, equalised financial transfers to all families with children (reaching several hundred thousand families that had previously been excluded from tax breaks due to their low incomes), and pushed through legislation that codified wage equality in 1979 (cf., Cerny 
1997, 111). Despite these efforts, women's employment rates remained very low in Austria and the male breadwinner norm was never seriously questioned by society as a whole or by employers.

\section{United Kingdom}

In 1974, Harold Wilson's Labour party replaced Edward Heath's Conservatives who had been in power since 1970. The Wilson government, inspired by the lessons of Continental and Scandinavian corporatism, quickly promised the labour unions a new Social Contract that included various welfare state expansions in exchange for wage stability and industrial peace. However, when Britain entered a full-scale recession in 1974/75, unemployment rose rapidly, and the expensive new measures (see next paragraph) required tax increases and "cuts and cash limits on all spending programs" (Rhodes 20oob, 35) ${ }^{8}$ Amidst inflation and a lingering currency crisis, the Labour government was forced to abandon its commitment to full employment and reluctantly shifted from a Keynesian strategy to a more conservative fiscal and monetary policy (Hall 1986, 94; Rhodes 20oob, 39). However, when an IMF loan restored market confidence in 1976, unemployment began to stabilise in 1977, while inflation was somewhat reigned in and fell below ten percent in 1978.

During these turbulent but seemingly stabilising times, the Labour government decided to redirect the MSC's mission and create an array of demand-side active manpower measures. Originally, the creators of the MSC had envisioned that the MSC would deliver a "comprehensive manpower strategy", overhauling the entire British voluntarist and ineffective vocational training and education system. In the midst of the crisis, however, the new MSC became an "instrument for the speedy delivery of a series of work experience and training programmes which [the government had] offered to the trade union leaders in exchange for the wage restraint they attempted to impose upon their members in the social contract" (Ainley and Corney 1990, 45). Among the largest programmes were the Job Creation Programme (JCP, renamed the Special Temporary Employment Programme in 1978), the Work Experience Programme (WEP), and the Youth Opportunity Programme (YOP). In addition to these mostly demand-side labour market measures, the Labour government also introduced a new demand-reducing measure, the Job Release Scheme (JRS) in 1977 - albeit at a much smaller scale than the Danish efterløn - which provided British men aged 60-64 with a preretirement pension (Ebbinghaus 2006, 148). 
By 1978, the continuous rise in unemployment rates seemed to be stemmed and 1979 saw a gradual decline in unemployment. However, when the government attempted to keep wage increases under five percent, the labour unions rejected this proposal and industrial strife ensued. The TUC was unable to restore stability and, in the winter of 1978/79, "[m]ilitant public sector workers and private sector workers joined forces and launched the 'Winter of Discontent' - the first to fight falling real incomes, the second to defend wage differentials" (Rhodes 20oob, 35). The result of the unions' militancy sent the Labour Party into disarray, increased public scepticism regarding neo-corporatism, and, ultimately, led to 18 years of Conservative rule.

\section{Ireland}

As an increasingly export-oriented economy, Ireland "suffered disproportionately when the European and world economies went into recession and demand for Irish exports declined" (House and McGrath 2004, 43). Like most other countries in the Western world, Ireland initially reacted with an application of Keynesian demand-management policies and the expansion of the public sector in an attempt to spend their way out of the recession. During the 1970s, this strategy was coupled with a series of nine "corporatist" National Wage Agreements and two National Understandings intended to keep inflation in check (Sexton and O'Connell 1996, 89; O'Donnell and Thomas 1998, 117). This strategy bore some fruit early on and Ireland underwent a significant recovery (O'Donnell 2004, 52). Thus, during the mid-1970s, Irish policymakers remained optimistic and believed that short-term correctives, mainly designed to operate on the demand side, could alleviate the "temporary" labour market imbalance. Meanwhile, a plethora of labour market instruments were introduced to alleviate unemployment among various groups. For instance, AnCO launched the Community Youth Training Scheme in 1975 and the Community Training Workshops for disadvantaged young people in 1977. While the former was designed to provide basic training and work experience to young unskilled jobseekers, the latter was intended to provide basic literacy and numeracy skills. In 1978, AnCO also introduced the Work Experience Programme, a temporary, public employment scheme. The Department of Labour, in turn, introduced a wage subsidy scheme called the Premium Employment Programme in 1975 (which evolved into the Employment Incentive Scheme in 1977). The Department of Environment operated two Environmental Improvement Schemes, while the De- 
partment of Education directed the Temporary Grant Scheme for Youth Employment in 1976 (later called Teamwork). These rapid developments reveal that the Irish government was increasingly placing manpower policies centre stage in the state's strategy to counteract a period of mass unemployment during the 1970 (NESC 1985, 255ff; O'Connell and McGinnity 1997, 25; DETE 1998, chap. 4). There was, however, no overall coherent strategy and a large number of actors were responsible for the implementation of these programmes. Even though a tripartite Manpower Consultative Committee was set up in 1978 to assist the DfL in supervising and monitoring labour market policy, its actual impact was "very limited" (NESC 1985, 54). Nevertheless, counter-cyclical deficit spending, social concertation, and the application of a variety of active manpower policy seemed to keep unemployment somewhat in check, especially when considering the substantive "growth in [Ireland's] labour force" during 1973 and 1980, which was triggered by both net migration inflows and a "natural increase in population" (Kennedy 1993, $5 \mathrm{ff}$ ).

\section{IV.3 Conclusions}

The 1973 oil crisis marked the beginning of a new era of unemployment in most of Europe and, as inflation spiralled upwards, Keynesian economic policies came under increasing scrutiny, especially in Germany, the UK, and, to a lesser extent, in Denmark. Nevertheless, virtually all of Europe turned to more active manpower policies - especially on the demand side - to address high levels of allegedly "temporary" unemployment. The manpower policies outlined in the Swedish Model during periods of rapid economic growth, full employment and technological innovation, were now recalibrated into instruments used to combat cyclical unemployment in times of economic turmoil. Their main goal was no longer to assist firms (and workers) in adjusting to economic restructuring, but to prevent economic hardship and ease the transition back into employment. As such, the goals switched from affecting primarily economic to primarily social outcomes, and the focus of these measures shifted from the supply to the demand side. In addition to the consolidation of active manpower policies as an appropriate instrument to address cyclical fluctuations in the labour market, the early 1970 s also highlighted the beginning of a uniquely Nordic strategy that built on a rapid expansion of the public sector and the promotion of a gender neutral, women-friendly welfare state. 


\section{IV.4 After the Second Oil Crisis: Shattered Illusions and Diverging Pathways}

In the early 1980s, it was generally accepted that the welfare state was "in crisis" (OECD 1981) and unemployment had become an increasingly salient issue. Unemployment continued to rise not only because a second oil crisis in 1979 triggered another global economic downturn, but also because many economies had to accommodate the influx of a new generation of workers as the baby boom generation's children reached working age. Moreover, European manufacturing began to face fierce economic competition from various emerging economies, particularly the Asian Tigers. The table below illustrates the impact of the second oil crisis on unemployment statistics, followed by a brief overview of the OECD's reactions and illustrations of country-specific responses to the crisis.

Table 7 Unemployment as Percentage of Civilian Labour Force, 1980-1990

\begin{tabular}{lrrrrrrrrrrrr}
\hline & 1980 & 1981 & 1982 & 1983 & 1984 & 1985 & 1986 & 1987 & 1988 & 1989 & 1990 & $\begin{array}{l}\text { Average } \\
1980 \text { s }\end{array}$ \\
\hline AT & 1.9 & 2.5 & 3.5 & 4.1 & 3.8 & 3.6 & 3.1 &.. &.. &.. &.. & 3.2 \\
BE & 8.1 & 10.4 & 12.2 & 13.5 & 13.5 & 11.4 & 11.3 & 11.3 & 10.2 & 8.3 & 7.3 & 10.7 \\
DK & 6.9 & 10.4 & 11.1 & 11.6 & 8.6 & 8.0 & 6.1 & 6.2 & 6.6 & 8.3 & 8.5 & 8.4 \\
FI & 4.7 & 4.9 & 5.4 & 5.5 & 5.2 & 5.2 & 5.3 & 5.2 & 4.6 & 3.2 & 3.1 & 4.8 \\
FR & 5.8 & 6.8 & 7.4 & 7.7 & 9.0 & 10.3 & 10.2 & 10.7 & 10.2 & 9.6 & 9.2 & 8.8 \\
DE & 3.2 & 4.6 & 6.5 & 8.1 & 7.2 & 7.2 & 6.5 & 6.3 & 6.2 & 5.6 & 4.9 & 6.0 \\
GR & 2.8 & 4.1 & 5.8 & 7.9 & 8.1 & 7.8 & 7.4 & 7.4 & 7.7 & 7.5 & 7.0 & 6.7 \\
IE & 7.4 & 10.5 & 11.6 & 14.0 & 15.6 & 17.1 & 17.7 & 17.4 & 16.8 & 15.6 & 13.3 & 14.3 \\
IT & 7.7 & 8.0 & 8.7 & 9.5 & 10.1 & 10.4 & 11.2 & 12.1 & 12.1 & 12.1 & 11.5 & 10.3 \\
NL & 6.2 & 8.7 & 11.6 & 12.0 & 12.2 & 13.2 & 12.2 & 9.5 & 9.1 & 8.3 & 7.4 & 10.0 \\
PT & 7.8 & 7.6 & 7.5 & 7.9 & 8.6 & 8.9 & 8.8 & 7.4 & 6.0 & 5.3 & 4.9 & 7.3 \\
ES & 11.5 & 14.2 & 16.0 & 17.5 & 20.2 & 21.6 & 21.1 & 20.3 & 19.3 & 17.3 & 16.3 & 17.8 \\
SE & 2.2 & 2.8 & 3.5 & 3.9 & 3.5 & 3.1 & 2.9 & 2.3 & 1.9 & 1.6 & 1.8 & 2.7 \\
UK & 5.7 & 9.1 & 10.5 & 11.4 & 11.9 & 11.3 & 11.3 & 10.8 & 8.9 & 7.2 & 6.9 & 9.5 \\
\hline
\end{tabular}

Source: OECD.stat, extracted on 30 June 2009

As unemployment continued to rise, long-term unemployment established itself as a common phenomenon and the OECD began publishing its Employment Outlook in 1983, which offered a synopsis of current 
labour market trends in its Member States and investigated the causes of unemployment. In the early to mid-1980s, however, no single explanation prevailed, with at least three theories gaining prominence, including one that stressed the weakness of effective demand, one that highlighted rising labour costs, and one that emphasised the role of rigidities in the labour, capital, and product markets (OECD 1986, 5). In addition to the introduction of greater flexibility, which - at that time - included even more reliance on active manpower measures to make workers more adaptable, the OECD Employment Outlook discussed the restructuring of working time, non-wage labour costs, the positive role the social partners could play in minimising inflation, special measures for youth and the long-term unemployed, and a new "innovative approach of offering long-term unemployed older workers the possibility of opting for early retirement" (OECD 1983, 71; see also, OECD 1984; OECD 1985; OECD 1986). This latter approach was based on the belief that "owing to the depressed state of labour markets in Europe, and the reluctance of many employers to hire older workers, there are often very severe obstacles to the re-insertion of the older long-term unemployed in regular employment" (OECD 1984, 10).

As there were "no magic remedies for lowering unemployment" (OECD 1986, 11), governments picked and chose their preferred prescription or a mix thereof. Consequently, while Keynesianism was largely abandoned, or being phased out - with the exception of a brief attempted revival in France in the early 1980 os (see, e.g., Hall 1986) - divergent responses to labour market policy regimes were institutionalised, which were historically contingent and reflected governments' ideological predispositions, their political strength, i.e., their capacity to (re-)align political coalitions powerful enough to enact transformative changes, and, perhaps most importantly, their underlying assessment of the root causes of, and remedies for, the crisis. While the Nordic countries, especially Sweden, continued to expand their service-heavy and women-friendly welfare states, the Continental welfare states opted for a strategy of demand reduction by adhering to the male breadwinner model and the expansion of labour market exit options. The Anglophone countries, especially the UK under Thatcher, embraced Milton Friedman's monetarist prescriptions and followed a strategy of deregulation, privatisation, and welfare retrenchment since the mid-1980s. By the end of the 1980s, three distinct crisis response patterns had solidified, which were identified as three different "worlds of welfare capitalism" (Esping-Andersen 1990). In what follows, I briefly support this argument with a more detailed look at the national responses. 


\section{IV.5 National Policy Responses: Social-Investment, Labour-Shedding, and Marketisation Strategies}

\section{Sweden}

When the second oil crisis struck, the Swedish bourgeois government struggled with its economic policies. While active manpower policy continued to play an important role, the devaluations of the krona interfered with the increases in real wages, while record levels of inflation reached almost 14 percent in 1980 and remained in double digits throughout 1981. Similarly, the increasingly open economy and the continuous crisis of Swedish industries, especially in manufacturing, strained industrial relations and made the employers association (SAF) - which increasingly adopted an "aggressive neoliberal posture" - less willing to compromise (Huber and Stephens 2001, 241). ${ }^{9}$ When, in the spring of 1980, the government decided to opt for a policy of "full austerity" that included (modest) cuts in public transfers, a reduction in labour market expenditures, and a general acceptance of rising unemployment, the already tenuous situation exploded into the "Great Conflict" between the social partners and between the government and the labour movement (Mjøset $1987,448) .{ }^{10}$

The ongoing struggles regarding the course of the Swedish economy subsequently returned the Social Democrats back to power in 1982. In the face of a new economic reality, the Social Democrats pursued a strategy of partial privatisation, deregulation of the financial sector, and the introduction of market principles to the public sector, including the Swedish PES, which was intended to prevent cuts in welfare state provisions $\mathrm{CH}-$ ber and Stephens 2001, 242). The government devalued the krona yet again, which "actually created an undervalued Swedish currency" (Anxo and Niklasson 2004, 6). When the labour movement realigned itself with the new government by becoming more accommodating and actually accepted "real wage reductions" (Mjøset 1987, 449), the exposed tradable sector experienced a major boost. Within a short period of time, the government overcame the crisis (Anxo and Niklasson 2004, 7), and Sweden's "Third Way" - positioned between the neo-Keynesian approach of the French government during the early 1980 os and the Thatcherite approach of marketisation - was termed a success. Huber and Stephens $(2001,243)$ summarise Sweden's success story as follows: by the end of the 1980s, "[ $t$ ]he budget deficit, which had been 8 percent of GDP when the Social Democrats had come into office, had been eliminated; unemployment was under 2 percent; the balance of trade was in surplus; and 
social policy reforms had been passed". As a result of these improving economic conditions, the Social Democratic government could afford to further expand the public sector and welfare services, including the introduction of a legal "right" to municipal day care (Lehto et al. 1999, 122), ${ }^{11}$ the extension of parental leave, and paid leaves of absence "to take care for ill children [were] expanded from twelve to sixty days" (Huber and Stephens 2001, 243).

Not only were the public sector and women-friendly policies expanded, the use of labour market training and the scope of public relief works were also vastly extended during the $198 \mathrm{os}$. This was done to "catch" the unemployed early, thus preventing them from drifting into long-term unemployment. Moreover, since the late 1980 os, jobseekers who participated in public relief work and other direct job-creation programmes, (re-)qualified for new periods of unemployment benefit payments upon completion of these programmes. As a result, benefit coverage was de facto extended to uninsured workers, who first participated in a municipal programme and afterwards were eligible for regular benefits. Moreover, there was "no limit on the amount of time a jobless person [could] spend outside the regular labour market by switching between training and unemployment compensation" (Forslund and Krueger 1994, 7). Local authorities had also an incentive to place social assistance recipients into ALMP programmes because participants would subsequently qualify for UB and thus be transferred from local welfare offices to the nationally run employment offices. Although some, if not most, economists believed that Sweden's active manpower measures had gone "over the top" during this period, the virtue of the Swedish Model was its resilience - "the Swedish unemployment rate never lingered over 3 per cent [and] long-term unemployment was never allowed to emerge" (Layard et al. 2005, 63).

In summary, the 1980 os were characterised by the reinforcement of a "modified" Swedish Model, in which the government increasingly built on a strategy of currency devaluations, while counter-cyclical spending became less pronounced. ${ }^{12}$ The Nordic welfare trajectory, however was reinforced by further improving women-friendly policies and expanding the public sector, albeit on a smaller scale than in the 1970s (Benner and Vad 2000, 418). The expansion of welfare services was further coupled with public sector modernisation (to make it more efficient), the continued issuance of generous subsidies that kept struggling industries alive, and the expansion of the scope of demand-side ALMPs, effectively making the Swedish welfare state the "employer of last resort". In other words, it was during the 1970 os and 1980 os that a "truly distinct Nordic - and es- 
pecially Swedish - model came into being with the shift towards active labour market policies, social service expansion, and gender equalisation" (Esping-Andersen 1996, 11).

\section{Denmark}

The development of economic and social policies in Denmark during the 1980 os included trends that were similar to those in Sweden (including the expansion of women-friendly family policies and the continued growth of the public sector), and trends that were particular to Denmark (including the endorsement of a hard currency policy and early steps taken towards a compulsory "activation paradigm"). These differences can - at least in part - be attributed to political make-up of Denmark at the time. In contrast to Sweden, where the 1980 os were mostly a "Social Democratic" decade, Denmark saw a Conservative-Liberal coalition government replace the Social Democrats in 1982, who had left office voluntarily as they were not able to align a parliamentary coalition large enough to get their policies passed (Mjøset 1987, 451). The new centre-right government (19821993), under the leadership of conservative Prime Minister Poul Schlüter, quickly made the consolidation of public deficits their major political goal (Lind 1988, 9). The bourgeois government was more convincing than the Social Democrats in its implementation of a hard currency policy, which included forceful interventions in collective wage agreements to keep inflation in check. These government interventions, however, forced the social partners to pull out of wage negotiations at an earlier stage, which then shifted the locus of wage agreements "away from the central level of federations to the lower level of each trade organisation" (PLS Consult and Jensen 1997,88$).{ }^{13}$

While these developments certainly weakened Denmark's social partnership, the centre-right government did not pursue a path of "dismantling" the unions and a decentralisation of wage bargaining, which was the strategy of the Conservative government in Britain during this same period (see below). Instead, the government continued to solicit the support of the social partners in political decisionmaking processes, and, in 1987 , the Conservative-Liberal government was even able to issue a joint "Declaration of Intent" in which the social partners agreed to the "goal of keeping Danish wage increases below those of countries in which Danish companies usually compete" (PLS Consult and Jensen 1997, 89). Nevertheless, the relationship was lopsided in favour of the employers, who the government granted a "long-cherished wish for the removal of 
the automatic cost-of-living adjustment (from wages and unemployment benefits)" (Lind 1988, 12, emphasis added). This adjustment effectively reduced the level of unemployment benefits over time "by stealth", from "a peak of 72 percent in 1979 to 58 percent in 1987", while, however, shielding low-wage workers (Huber and Stephens 2001, 262).

The government's strategy seemed to bear fruit and Denmark experienced rapid economic growth soon after the second oil crisis. Inflation dropped from some twelve percent in 1981 to four percent in 1984 and 1985 (Boje and Madsen 1994, 103, figure 5.1), while unemployment levels also began to decline (see table 7 ). The rapid growth of the tertiary services and the information technology sectors even led to some "bottlenecks in the labour market, particularly in the demand for skilled workers" (OECD 1996c, 13). In reaction to these changing labour market conditions, the unemployed were given the "right" to a second Job Offer in 1983, which was supplemented in 1984 with educational as well as selfemployment subsidies (Knuth et al. 2004, 59). In 1985, the ConservativeLiberal government also began placing increased emphasis on improving the qualifications of the unemployed, which resulted in an expansion of training measures now also available for the unemployed in a systematic and comprehensive way (interview, CARMA).

However, when unemployment began to rapidly rise again in 1987, almost all of the political actors reassessed their beliefs about the causes of Denmark's employment malaise. As policymakers increasingly perceived unemployment as a structural, rather than a cyclical, phenomenon (Knuth et al. 2004, 51), the typical "Danish" use of demand-side measures, which provided alternatives to unemployment such as Job Offers, came under fire, and supply-side concerns became increasingly significant. In the late 1980 s, the provision of skills became a key issue and a new job rotation scheme (Jobrotation) was introduced. This scheme was similar to Sweden's 1970s schemes, which allowed employed workers to leave their jobs to pursue continuing education courses, if there was an unemployed person who could temporarily fill his or her position. The introduction of these schemes was achieved with the collaboration of the labour unions, employers and training programme providers, and received general political support. In 1989, the government also restructured its PES "through the merger of the previous Directorate of Labour and the Directorate for Adult Vocational Training" and renamed it the national Labour Market Authority, Arbejdsmarkedsstyrelsens (AMS) (OECD 1996c, 39). However, the new AMS retained two subdivisions, including the AF (Arbeidsformidlingen), which was responsible for "typical" PES services, and the AMU 
(Arbeidsmarkedsuddannelse), which managed 24 state-owned training centres. The AMU's training centres offered courses to both employed and unemployed semi-skilled workers. Additional training courses were provided for skilled and unskilled workers through technical and vocational schools, supervised by the Ministry of Education (OECD 1996c, 39). ${ }^{14}$ Like Sweden, the Danes also began to develop their first "new public management" reforms, including (a) the introduction of elements of a management-by-objectives system, (b) improved PES collaboration with the business sector, (c) decentralisation by delegation of numerous tasks to the local level, and (d) the introduction of a clearly structured "package of products" (Willemer 2003, 173). Moreover, Denmark opened new placement offices in attractive locations, such as pedestrian zones, to increase access and visibility. Finally, in an attempt to incentivise looking for regular employment, participants in public employment projects received lower wages than those negotiated in public sector wage agreements (Rosdahl and Weise 2001, 170).

In this context of labour market recalibration, PES modernisation, and the expansion of supply-side measures, Danish policymakers also discussed compulsory participation in ALMPs for the first time in Danish history. Throughout the 1970 s and 1980s, participation in ALMPs was seen as a "right" and thus, a privilege rather than an obligation (cf., Rosdahl and Weise 2001). By the late 1980s, however, Danish policymakers realised - a fact that OECD analyses also repeatedly pointed out - that the Danish conceptualisation of "active" labour market policy, which often started only after someone was unemployed for four years, could not prevent long-term unemployment (Knuth et al. 2004, 55). The first compulsory measure was introduced in 1990 - with the support of the Social Democrats - when 18 and 19 year-old social assistance claimants were required to participate in the Youth Allowance Scheme in order to receive benefits. The introduction of this scheme was a critical normative and cognitive break in, and reassessment of how Danish policymakers conceived of unemployment. The Danish, especially the Social Democrats, had previously considered unemployment as "an event outside the control of the individual" and benefits were thus guaranteed for an unlimited period of time (Andersen and Pedersen 2007, 4). The Minister of Social Affairs Aase Olesen was the first to publicly challenge the Nordic principle of a social "right" to state support. By referencing the Swedish "work line" - but also paralleling the development in Britain triggered by Lord Young in the late 1980 os (see below in this chapter) - Olesen successfully reframed the issue in terms of "something for something" (Abrahamson 
2006, 359). This principle would later be an important precursor of many institutional changes first associated with the "active line" in Denmark, ${ }^{15}$ and subsequently with the concept of "activation" across Europe (see chapters V and VI).

In summary, despite the neo-liberal rhetoric of the centre-right government throughout the 1980 os, the Danish welfare state remained intact and no major cuts in the benefits regime occurred. ${ }^{16}$ Generous and prolonged benefits continued to be a "right" for jobseekers - albeit with some signs of conditionality - and supply-side measures were improved and expanded for both insured and uninsured workers. Similarly, while the corporatist arrangements of wage-bargaining underwent a process of decentralisation, the social partners' role in influencing and delivering labour market policy was never questioned and the social partners' found themselves represented on all levels of the newly reorganised AMS. Despite these seemingly "adaptive" rather than "transformative" institutional changes, a major ideational shift across party lines had occurred. As unemployment was increasingly seen as structural rather then cyclical, policymakers started to reassess their normative and cognitive beliefs about the appropriateness of Denmark's entire labour market policy regime, including the very definition of jobseekers' rights and duties. As we will see below, it was this reassessment which subsequently triggered transformative institutional changes associated with "activation" policy and the "PES service model" during the 1990s and 20oos, not only in Denmark but in the EU in general (see chapter V).

\section{Germany}

With the eruption of the second oil crisis in 1979, Germany slipped back into a recession. By 1980, inflation rates rose above five percent and unemployment was rising at a record pace. At the same time, economic growth rates stagnated in 1980 and even reached negative growth levels of some two percent in 1981 and 1982. Facing growing budget deficits, the Social Democratic-Liberal coalition government reduced spending on employment promotion measures, further tightened job-search criteria, and made access to training more restrictive. These retrenchment efforts were mainly promoted by the FDP, while the SPD accepted these cuts because they feared confrontations with their coalition partner, faced CDU accusations of fiscal irresponsibility, and - when push came to shove preferred cuts in labour market measures over cuts in transfer payments (Schmuhl et al. 2003, 520). However, when Economic Minister Otto Graf 
Lambsdorff (FDP) issued a strongly neo-liberal strategy paper on 9 September 1982 - outlining major economic reforms, including an overhaul of labour market policy - the SPD could no longer avoid an open confrontation with the FDP. One week later, Chancellor Schmidt announced that he would call for a vote of confidence in Parliament. Most of the FDP MPs voted against the Chancellor, thus realigning with the CDU/CSU. The Social-Liberal government fell and Helmut Kohl (CDU) became the new Chancellor on 4 October 1982, as part of a centre-right coalition with the FDP.

Chancellor Helmut Kohl almost immediately announced an "intellectual and moral turning point" in German economic and social policy, while proclaiming the vision that the country was to be transformed from a "welfare society to a productive community" (Wohlfahrtsgesellschaft zur Leistungsgemeinschaft) (Kohl 1983). However, while the rhetoric implied a sweeping deregulation of the labour market, the Kohl government avoided radical changes. Instead, the government continued the "recruitment prohibition" of foreign workers initiated by the Social Democrats in the 1970s, while facilitating a flexibilisation of the labour market at the margins through an expansion of fixed-term contracts and part-time employment. The modesty of these institutional changes, however, were not the result of legislative "veto points" (Zohlnhöfer 2003, 139), but a reflection of intra-governmental disagreements on many issues. Failing to find a common position, the centre-right coalition was unable to align a coalition strong enough to successfully advocate (unpopular) reforms. In particular, the more socially oriented wing of the CDU under the leadership of Labour Minister - and member of the powerful metal workers union IG Metall - Norbert Blüm blocked any substantial retrenchment efforts, while Germany's well organised labour unions also stood up for their interests.

This is not to say, however, that little institutional change occurred in the $1980 \mathrm{os}$. The $198 \mathrm{os}$ saw the introduction or expansion of a series of "labour-shedding" policy measures. Because policymakers believed that there "was only so much work to go around", the government, the opposition, employer associations, and the labour movement alike compromised on a series of demand-reducing measures. This compromise included the following: a moderate reduction in the workweek, an extension of early exit options, perpetuation of the male breadwinner model, and the expansion of (demand-side) "active" labour market policy. Taken together, these measures would eventually lead to the Continental path of "welfare without work" (Esping-Andersen 1996), and the emergence of a "high equality, low employment regime" (Streeck 2001, 2). 
More specifically, while France became the vanguard in reducing the workweek to 35 hours, German policymakers and employers feared that a similar reduction, as demanded by the IG Metall, would undermine German competitiveness in global markets. Consequently, Chancellor Kohl and Labour Minister Blüm agreed to smaller reductions in working hours, from 40 hours to 38.5 in 1984 and down to 37 in 1987. Blüm, in turn, promoted "early exit" as an alternative to a 35-hour workweek, which brought some stability to these turbulent years (interview, DGB1). The early exit policy included three pathways: (1) measures that allowed the older, longterm unemployed to receive unemployment benefit payments first, and then "transfer" into early retirement; (2) "regular" early retirement offered to older workers in employment, who had long employment histories; and (3) a disability option for workers in ill health.

Blüm approached the first, "long-term unemployment" pathway by building on a provision originally introduced during the Weimar period whereby white-collar workers who had been unemployed for at least one year were allowed to retire at the age of 6o. This measure was extended by the first post-WWII German Chancellor, Konrad Adenauer (CDU), to blue-collar workers and became known as the "59er rule" (Trampusch $2005,205)$. When the Kohl government extended unemployment benefits from 12 to 32 months in 1986, the "59er rule" effectively became the "57er rule" (Köhler-Rama 2003, 144). The second, "early retirement" option was based on the pension reforms of 1972, which were introduced as a "flexible retirement" provision during periods of considerable economic growth and full employment. This original reform allowed workers who had made old age insurance contributions for at least 35 years to retire at the age of 63 "without an actuarial reduction in benefits" (Manow and Seils 20oo, 141). The Kohl government replaced this scheme with the Pre-Retirement Act of 1984 (in effect until 1988 and subsequently replaced by a part-time scheme), which allowed these workers to already retire by the age of 58 (Ebbinghaus 2006, 151, table 5.5). These workers would receive up to 65 percent of their previous gross wages in benefits (additional top-ups possible through collective agreements), while companies would receive financial rewards from the $B A$ if they hired a young replacement. The third pathway, the "disability" option, in turn, was extended via the 1984 pension reforms. Workers who were only able to work part-time, but for whom no such employment was available, were now allowed to draw a disability pension.

While the pre-retirement scheme was rather short-lived and the disability option was not as extensively utilised as similar schemes available in other European countries, the "57er rule" became the most important 
instrument for larger companies to "shed" an excessive labour force in a "socially responsible" way. While none of these provisions were originally intended as instruments to reduce the labour supply, the Kohl government - with the support of the opposition, employers' associations, and labour unions - purposely recalibrated the functions of these policies. This is to say, through a process of deliberate conversion, the German old age social security pillar became a de facto labour market policy intended to artificially reduce the labour supply. ${ }^{17}$

Moreover, while an early exit option was the "instrument of choice", the low activity regime also included the perpetuation of the male breadwinner model and the extension of demand-side labour market policy measures. Female employment rates, while they showed slight increases during the 1970 os and 1980s, albeit almost exclusively of a part-time nature, remained low in international comparison. The main hurdle for women joining the workforce as full-time employees was the poor availability of childcare facilities (Hagemann 2006, 225), ${ }^{18}$ as well as unfavourable school and store hours. ${ }^{19}$ Moreover, the tax code introduced in 1958 did not (and still does not) promote women's labour market participation. According to the German tax code, incomes of dual-earner households are first added together, the sum is then divided by two, and then taxes are assessed. This means that single-earner households headed predominantly by males have the highest tax savings, while married couples with dual incomes have no such tax advantages. Finally, the continued support of societal norms certainly played a role as well. A "good" mother stayed at home with her children, while a woman with small children working full time was considered a bad, "raven mother". ${ }^{20}$

Labour market measures, in turn, saw a further expansion of demandside instruments. The expansion of public work programmes (ABMs), in particular during the period 1982-1986, was considered an appropriate and necessary response to increased long-term unemployment rates. From 1982 to 1988 , the percentage of long-term unemployed grew from 18 percent to 32.6 percent, while the percentage of very long-term unemployed, i.e., those who had not had a job in over two years, rose from 4.4 percent to 16.5 percent (Schmid and Oschmiansky 2005a, 261).

In summary, German policymakers - in an alignment with all of the major stakeholders - addressed unemployment via a strategy of demand reduction, in particular, "early exit strategies" that were also popular in other Continental welfare states such as Austria (see next section) and the Netherlands (see e.g., Esping-Andersen 1996, 19ff; Visser and Hemerijck 1997). 


\section{Austria}

Austria's government also reassessed their commitment to Keynesianism during the 1980s. While the OECD in 1978 still described Austria as a "remarkable" economy that was able to simultaneously achieve a "progressive reduction of inflation and continued economic growth" (OECD 1978a; see also, Scharpf 1987, 95f), by the early 1980s, the Social Democratic government was confronted by new challenges. The SPÖ's countercyclical policies applied during the Kreisky era had not only been used to suppress unemployment, but they also had a detrimental effect on the national debt, which, in turn, hampered economic growth (Walterskirchen 1991, 13). After Franz Vranitzky (SPÖ), who was Chancellor from 19831997, formed a coalition government with the Liberals in the fall of 1983, and subsequently with the Christian Democrats in 1986, Kreisky's AustroKeynesian policies were gradually phased out. Large portions of Austria's nationalised industries were privatised, and annual budget targets were agreed upon. Importantly, and in contrast to both Denmark and Sweden - which had encountered increasing tensions between the social partners and the government in the early 1980s - the Austrian labour unions continued to support the government's course correction and accepted the stagnation of real incomes in order to make Austrian companies more competitive globally. Throughout the 1980s, Austria experienced almost no labour strife or strikes (Walterskirchen 1991, 50).

However, the government's gradual move toward a hard currency policy triggered a steady rise in unemployment. Unemployment almost doubled from 2.4 percent in 1981 to 4.5 percent in 1983, and continued to grow until the late 1980 , reaching a peak of 5.6 percent in 1987 (Biffl 1989, 139, table 3). ${ }^{21}$ At the same time, the percentage of long-term unemployment also grew from just under 20 percent in 1981 to just over 30 percent by 1987 (Biffl 1989, 140, table 4), while the unemployment numbers among youth grew rapidly from 9,900 in 1980 to 47,026 in 1987 (Biffl 1989, 141, table 5), which was especially alarming for policymakers (Walterskirchen 1991, 33). Ultimately, it became painfully apparent that this rising trend in unemployment was not a temporary, i.e. cyclical, challenge, but rather a structural one that needed extra attention (Wilk 1991, 131). Accordingly, one of the last legislative acts of the Kreisky government was passing an amendment to the $A M F G$ on 9 February 1983, which introduced an "experimental clause" that would broaden (and simplify) the toolbox of labour market policy instruments, while also specifically targeting "problem" groups, such as youth and the long-term unemployed (Wroblewski 
2004, 63). Perhaps the most significant development that arose from the "experimental clause" was the introduction of the Aktion 8000 in March 1985. The Aktion 8000 was designed to create 8 , ooo new jobs, mainly for youth and the long-term unemployed, in the "second labour market", i.e., additional, publicly subsidised jobs that would benefit the community and serve as a "bridge" to the open labour market (interview, IHS1). The $A k$ tion 8000 created more than 10,000 jobs in the next four years and was quite successful as "[m]ore than half of [the participants] found regular jobs afterwards" (Walterskirchen 1991, 34).

Other 1980 os recalibration efforts included the introduction of subsidies paid to firms that offered additional apprenticeships, a rebalancing of public training efforts in favour of the unemployed, ${ }^{22}$ and the extension of unemployment benefits paid to older workers for up to four years in regions experiencing particular hardships (Walterskirchen 1991, 98). However, despite these expansions, labour market policy measures continued to play only a modest role in the Austrian context, and many of these programmes, especially the Aktion 8ooo, were exposed to the constant criticism of employers and other market-oriented actors.

In addition to the government's attempts to tackle problems of unemployment, private industry initiatives also had long-term effects on the Austrian labour market. When the steel company VoestAlpine was forced to lay off a large number of its employees, the management board and the workers council (Betriebsrat) were confronted with the social responsibility of finding new opportunities for "their" workers. Inspired by experiences gathered from an excursion to the German steel company Dillinger Hütte in the Saarland, VoestAlpine established Austria's first outplacement foundation in late 1987. Instead of offering only a severance payment, the foundation would assist laid-off workers in their job-search activities and re-training efforts. In the summer of 1988 , the foundation received its "legal footing" through legislation that amended Austria's employment promotion act. While it was initially only steel mills that relied on these foundations to "smoothen" their restructuring (and privatisation) efforts, additional employment foundations were established - and financially supported by national and regional governments as well as the Austrian PES - also in other sectors.

More important than the still rather modest use of ALMPs was the continued reliance on the male breadwinner model and the expansion of early exit options, which included early retirement and disability pensions during the 1980s. In the period 1973 to 1988 , the number of people who took advantage of early exit schemes almost doubled to some 100,ooo, or 
three to four percent of the total workforce (Walterskirchen 1991, 112). In other words, just as in Germany, Austria preferred a strategy that relied heavily on the extensive use of "exit options" and the perpetuation of the male breadwinner model to keep female employment rates low rather than extensive active labour market measures (Biffl 1996, 71f). As such, even though Sweden had remained a role model for the Ministry of Labour and Social Affairs throughout the 1980s, the policies actually pursued were much closer to the Continental, particularly German, labourshedding strategy (interview, BMWA1).

\section{United Kingdom}

After the Conservatives returned to office in 1979, British labour market, training, and social policies would first be gradually, then later more radically, redirected. The incoming Thatcher administration fully endorsed the monetarist paradigm outlined by Milton Friedman, and shared a "fundamental belief in the need to shift the boundaries of private and public activity" (Ruggles and O'Higgins 1987, 161) with US President Ronald Reagan. Upon taking office, Prime Minister Margaret Thatcher's main concern was to curb rising inflation, reduce the overall tax burden, and limit government interventions and public borrowing.

With respect to labour market policy, this meant that the "state" - and the labour movement - was detrimental to economic growth and creativity. Thatcher preached less public intervention, which would then make way for tax cuts as public expenditures were reduced. While the government succeeded in quickly abolishing 16 of the 23 ITBs "in an attempt to return the full cost of training to employers", while also cutting the MSC's budget for adult training in real terms during the early 1980s (Wikeley 1990, 355f), it was less successful in dismantling labour market measures for the unemployed. Unemployment rates exploded from 5.7 percent in 1979 to 13 percent in 1982, which made the labour market a salient electoral issue. Moreover, the Conservatives still faced a powerful MSC that openly opposed many of the new strategies (cf., Finn 1987, 134). Initially, the MSCs prevented drastic cuts in employment benefits, while it even reversed some Thatcher policies of retrenchment in the area of employee training. This was the case with the Youth Opportunities Programme (later replaced by the Youth Training Scheme, YTS), and the Community Enterprise Programme (CEP, later replaced by the Community Programme, CP). ${ }^{23}$ The CP scheme, which offered employment opportunities to the long-term unemployed, became so popular - reaching a peak of near- 
ly 250,000 participants in the spring of 1987 - that the government had to "reign in its expansions" (Price 2000, 266). The first half of the $1980 \mathrm{os}$ thus saw a surprising combination of market-embracing measures, e.g., the curtailment of the ITBs and anti-inflationary macro-economic policy, and market-eschewing measures, including the rapid expansion of "special measures" such as the CP.

By the mid-1980s, however, the Thatcher administration would embark on a more radical course. When the Conservatives were re-elected in 1983 - in part due to the internal disarray within the Labour Party and the formation of the Social Democratic Party by Labour defectors in 1981 (Hall 1986, 99) - the government confronted the unions more aggressively and the MSC was gradually abolished. In contrast to the Continental and Nordic strategies regarding working with the labour unions to tackle the challenges of rising unemployment and inflation, the British Conservatives confronted the fragmented labour union movement, whose preference for real-wage increases were considered one of the causes of the unemployment crisis. In addition to openly confronting, and eventually defeating, the labour unions in 1984 - which led to daily clashes between picketing miners and police brigades (Hall 1986, 109) - the government also passed the Employment Act of 1984 (expanded in 1990), which substantially weakened the labour unions' strike capacity through the introduction of mandatory pre-strike ballots (Manning 1993, 422).

The MSC's demise, in turn, occurred very gradually and was stalled until after the Conservatives won a third consecutive term in 1987. During the Conservatives' second term, the MSC remained an important, albeit less autonomous, player. A major new actor in the field was David Young, former MSC chairman, who Thatcher appointed in September 1984 as the "Minister without Portfolio" to advise the government on unemployment issues. In September 1985, he then became Secretary of Employment. Young, like the Danes, found inspiration in both the Swedish "work principle" and the Beveridge Report, which stated that "[y]oung people should not get unconditional unemployment benefits" (Beveridge Report cited in Johnson 1991, 242). Rather, unemployment should be seen as an opportunity to provide further education and training to the (young) unemployed (Lord Young 1990, 153ff). While Young faced resistance to the introduction of expensive, high-quality training for young adults from the Treasury, he was successful in introducing his Restart Interviews, which foreshadowed both the Danish "active line" and New Labour's "New Deal for Young People", which were launched in 1993 and 1997 respectively. 
During Restart Interviews, which went national in March 1986, individuals were first asked for the reasons why they were unemployed. Subsequently, the unemployment officer would choose one of the following (low-cost) interventions, including (Price 2000, 242):

- Submission to a job; which might have been assisted by a Job Start payment of $£ 20$ per week for six months to anyone taking a job paying less than $£ 8$ o per week;

- Submission to a job in the Community Programme, which Young wanted to expand further;

- Assistance with setting up a business, through an expanded Enterprise Allowance Scheme;

- Attendance at a Jobclub; ${ }^{24}$

- Or, attendance at a 1-week Restart Course.

In October 1986, Young also announced the piloting of a new Job Training Scheme, which offered "full-time training and work experience for an average of 6 months to people who had been unemployed for 6 months or more. Priority went to $18-25$ year olds" (Beale 2005, 73). The participants were paid a small training allowance of $£ 25$, the equivalent of their current benefits. The TUC vociferously resisted this programme, which they perceived as a means to force the unemployed to simply work "for dole money" and as a PR move for the upcoming elections (The Guardian, 27 December 1986). Because of the TUC's resistance, the scheme, which was launched in 1987 as a new element in the Restart menu, remained voluntary for young jobseekers, which was different from the Danish Youth Allowance Scheme as well as American "workfare schemes". Because of ongoing quarrels between the government and (parts of) the MSC, Young became increasingly interested in circumventing the MSC's powers. But rather than dismantling the MSC, which would have been the preferred course for many Conservatives, Young proposed other ways to keep the MSC in check. He suggested moving the Job Centres out of the MSC and to the Department of Employment, and he wanted to increase the representation and influence of employers on the Commission, who would then be more concerned with training than employment. This proposal was presented in the Tories' Manifesto of 1987.

After winning a third term and with a booming economy, the Conservatives felt confident enough to endorse further reforms to the employment system. The government limited the MSC's remit to training, while respon- 
sibility for the Job Centres and labour market policies was returned to the Department of Employment. The MSC was renamed the Training Commission with consensual policy decisionmaking further compromised with the introduction of six more employer representatives (without consulting the CBI) (Wikeley 1990, 357). The restructured Department of Employment, in turn, was further strengthened by the launch of a Stricter Benefits Regime (SBR), which was designed to "police" dubious benefit recipients. More specifically, with the introduction of the 1989 Social Security Act, the unemployed were required to actively seek work, which would be checked at the Restart Interviews and elsewhere, and could result in sanctions if officials thought their job-search activities were inadequate. It further abolished the concept of "suitable work" and introduced a 13-week period during which the unemployed could refuse job offers below the normal wages for their occupations. Thereafter, claimants were expected to broaden their search and the refusal of job offers could result in sanctions.

The new Secretary of State, Norman Fowler, also combined a range of training and employment programmes ( 37 in total), including the Community Programme and the Job Training Scheme, into a new framework, called Employment Training (ET). The ET, which involved no new resources, was initially intended to accept 300,00o participants (that figure was later reduced to 200,00o), offering (low-cost) training for about six months, work experience to the long-term unemployed, and assistance with job-search activities (Fowler 1991, 298). The participants were often referred to the ET through the Restart Interviews and would get paid £10 plus benefits, which left most participants worse off than they would have been under the Community Programme (Wikeley 1990, 365). While Fowler was willing to retain the voluntary nature of the programme, he threatened to reduce or withdraw benefits from those unemployed who "did absolutely nothing to find work" (Fowler 1991, 298).

The TUC once again opposed the government's policies and narrowly voted to withdraw its support from the ET, even though Labour Party leader Neil Kinnock had called upon its leaders not to boycott the scheme, but rather to continue "resist[ing] the slide to workfare [... and] to expose the falsehood of the scheme" from within (Financial Times, 7 September 1988). Only eight days later, Fowler dissolved the Training Commission, created a successor entity, the Training Agency, and recommenced with the programme. The dissolution of the Training Commission was the "final break" with British corporatism that had governed labour market policies throughout the 1970s (Wikeley 1990, 357). Within less than a year, the TUC and the CBI were no longer formally or automatically em- 
bedded in employment policy formation or implementation. Instead, the newly empowered Department of Employment relied on local, privatesector employers as their partners and market mechanisms, as opposed to public institutions, to provide training (Financial Times, 16 September 1988). The unions' last formal role in government training programmes was subsequently abolished with the gradual replacement of the Training Agency by some 80 employer-led, self-governing Training and Enterprise Councils (TECs). Central funding for training, in turn, was cut the following year - and was not restored even during the early 1990 o economic recession - "effectively placing the privatisation of training in the hands of local employers" (Whiteside 2003, 107).

To summarise, the Conservative years were characterised by a "move away from training and work programmes towards initiatives run by the Employment Service", in particular job-search assistance (Robinson 1997, vii). The variety of programmes introduced under the "training" label were "inextricably entangled with the instillation of work discipline, and with alleviating public irritation at the prospect of the unemployed claiming benefits indefinitely" (Whiteside 2003, 106). Only the very young, unemployed school-leavers, aged 16-17, still maintained their "right to training" (Lindsay and Mailand 2004, 136). In addition to gradually reducing the scope of both supply-side and demand-side ALMPs during the 1980 , the British demand-reducing pre-retirement scheme (the Job Release Scheme) was also closed down entirely in 1989, while its part-time variant had already been closed down in 1986 (Ebbinghaus 2006, 219, fn. 8 ). The Tories were clearly influenced by a monetarist paradigm, which entailed a focus on containing costs, minimising benefit fraud, and counteracting individual "welfare dependency". In turn, the Restart Interviews and the Stricter Benefit Regime were launched as important precursors of New Labour's "activation" paradigm. Finally, but possibly most importantly, the social partners were gradually excluded from the policymaking process, while the department was empowered and local, employer-led Training and Employment Councils created, reinstituting British "voluntarism" in the provision of vocational training. Taken together, these 198 os developments gave rise to a unique - at least in the European context - combination of economic and labour market institutions, which constituted a liberal welfare regime (Esping-Andersen 1996, 15ff; see also, Ferrera and Hemerijck 2003, 101ff) and a liberal market economy (Hall and Soskice 2001). 


\section{Ireland}

When the second oil crisis shook the global economy in 1979, its aftermath severely undermined Ireland's Keynesian strategy. National debt skyrocketed while the associated costs of counter-cyclical deficit spending resulted in income tax hikes, which had to be pursued in order to service the rising debt. A profound economic, social and political crisis followed, which O'Donnell $(2004,52)$ describes as follows: “The period 1980-87 was one of recession, falling living standards and a dramatic increase in unemployment. Total employment declined by almost 6 per cent and employment in manufacturing by 25 per cent". Making things worse, the industrial decline, high levels of unemployment, and outward migration meant even less government revenues, which necessitated even higher income tax hikes, and a further deflation of the economy. The crisis was so severe that "there was talk of the International Monetary Fund stepping in, and there were even questions about whether or not the Republic could last as an independent country" (House and McGrath 2004, 43). Industrial relations during this period rapidly deteriorated, as they did in Britain, and so national wage agreements were suspended in 1980. However, the devolution of wage negotiations from the national to the firm level did not bring any real benefits to the vast majority of businesses. It did, however, increase unemployment and inequality. During these times of deep despair, expectations for economic recovery on all sides were extremely pessimistic, which, in turn, had "encouraged rent-seeking and profit-taking behaviour" (O’Donnell 2004, 52).

In an attempt to address spiralling levels of national debt and unemployment, the centre-left Fine Gael (FG) and Labour coalition governments (1981-1982 and 1982-1987) cut social services and health care benefits (which the FG favoured) and expanded active labour market measures (which Labour favoured). Labour Minister Ruairi Quinn (Labour Party) set up a separate Youth Employment Agency (YEA) for those under 25 years of age in 1982, and launched the Alternance and the Social Employment Scheme (SES) in 1984 and 1985 respectively. While the former offered training to the older, long-term unemployed, the latter provided "temporary, part-time work experience in the not-for-profit sector for those aged over 25 years who had been on the Live Register [Ireland's social assistance scheme] for more than twelve months" (Duggan 1999, $3)$. In response to the plethora of ALMPs used in the Irish context, the multipartite National Economic and Social Council (NESC) published a report in 1985 that strongly advocated a more coherent and streamlined 
approach to the governance of the labour market. These recommendations were subsequently included in the White Paper on Manpower Policy issued by the FG-Labour government in 1986. It outlined the creation of a tripartite National Training and Employment Authority called Foras Aiseanna Saothair (FÁS), which was then codified in the Labour Services Act of 1987 .

In the 1987 general elections, Labour lost four seats in the Dáil, receiving the brunt of the blame for unpopular cutbacks, while voter dissatisfaction also led to an increase in votes for the far more radical Workers Party and the newly established, centre-right Progressive Democrats (PD). As a result, Fianna Fáil (FF) emerged with the most votes and was able to form a minority government. Fianna Fáil built on their predecessor's work and introduced FÁS on 1 January 1988 as a "one-stop" service centre, where employed and unemployed workers could get job-search assistance and training. FÁS streamlined the functions of AnCO, the National Manpower Service, and the Youth Employment Agency, and took over the Social Employment Scheme. In other words, in the period during which Britain fully endorsed marketisation, union confrontation, and the dismantlement of the MSC, Ireland launched the tripartite FÁS and made state-supported, in contrast to voluntarist, training a key priority. The creation of FÁS, however, was only one of the two major differences between Ireland and Britain. The second, perhaps more dramatic change began when the NESC "hammered out" a report in 1986, entitled Strategy for Development (O'Donnell 2004, 54). While the FG-Labour government had been sceptical about the report's recommendation in favour of "competitive corporatism" (cf., Rhodes 2003), in which the labour movement was to agree to moderate wage increases in exchange for tax cuts, the NESC recommendations were utilised by the new Taoiseach (Ireland's prime minister) Charles Haughey (FF). Accordingly, the new FF government abandoned the system of decentralised wage setting and successfully passed the first national social partnership agreement, the Programme for National Recovery (PNR), which outlined an agreement among the government, the social partners, and other key civil society actors on wage restraint, fiscal austerity and welfare state recalibration.

Fianna Fáil's new strategy would not have been possible, however, without a reshuffle in the FG leadership and a realignment of Ireland's political forces after the elections. More specifically, as the FF minority government was dependent on the support of the opposition to pass their unpopular fiscal restraint bills, it was critical that the new FG party leader, Alan Dukes, had decided not to oppose the measures outlined in the PNR. 
Rather, in a selfless move that would become known as the Tallaght Strategy, Alan Dukes sacrificed a political opportunity, which he could have exploited to weaken the government, in an attempt to assist overcoming the national crisis (House and McGrath 2004, 44).

The other critical player that needed to be aligned with the government was the labour movement (cf., Baccaro 2003). The labour unions, while initially sceptical about a programme that outlined wage moderation, despite spiralling inflation, eventually accepted the terms outlined in the partnership agreement. One the one hand, the unions' support was solicited by assuring that "the value of social welfare payments would be maintained, and income tax would be reformed to reduce the burden on workers" (O’Donnell 2004, 54). Perhaps more importantly, however, decreases in union membership and the harsh experiences the British unions faced during Thatcher's reign had also increased union fears of further marginalisation. Moreover, the emergence of a new political party, the "avowedly neo-liberal" Progressive Democrats, alerted the labour "union movement to the possibility of ideologically informed party politics in Ireland, and such a prospect cannot be underestimated as a likely factor in prompting their early enthusiasm for co-operating with a national wage agreement in 1987" (Sexton and O'Connell 1996, 75). .25

In summary, the 1987 elections represent a crucial moment in Irish history, because they reflect a reassessment of economic thought, i.e., the acceptance of fiscal conservatism, albeit with a consensual, rather than conflict-oriented, outlook. They also produced new leadership, not only at the governmental level, but the election results also forced a reshuffle of the leadership in the main opposition party, brought a new voice on the political right, the Progressive Democrats, and realigned the voices within the social partners in support of a national partnership agreement.

\section{IV.6 Conclusions}

Part I was divided into three historical phases, each with a particular argument about institutional evolution. In chapter III, I argued that European welfare states, while having unique historical trajectories and diverse sets of labour market and social policy prerogatives and instruments, partially converged on particular elements of the Swedish Model. More specifically, after the OECD began disseminating certain ideas associated with active manpower policy and a national, tripartite PES, many European welfare states incorporated these elements into national policies. Important ex- 
amples included the German Work Promotion Act and the Austrian Labour Market Promotion Act, both of which were enacted in 1969. Other examples include the creation of a modern, tripartite PES in Denmark, Ireland, and the UK in 1969, 1971, and 1973 respectively, and the gradual introduction and expansion of active manpower policies in these three countries.

In chapter IV, I argued that European policymakers' reactions covaried in response to the first oil crisis of 1973. Virtually all of the cases discussed here endorsed active manpower policies, now of the demand-side type, to cushion the effects of what was considered a cyclical economic downturn. It was only after 1979 that governments started to take persistent unemployment more seriously as a structural phenomenon. Price stability became the primary political objective for most governments, while the commitment to full employment was largely abandoned. By the mid-1980s, diverging labour market strategies had become apparent and the OECD lacked a clear-cut solution to the dual challenge of persistent unemployment and high inflation that would be acceptable to all of the involved governments. By the end of the $1980 \mathrm{os}$, three diverging strategies had been put forward, including a Nordic (mainly Swedish), a Continental (mainly German), and an Anglophone (mainly British) version. ${ }^{26}$

In the Nordic cluster, the 1970 and 1980 os were characterised by important developments, including the expansion of the public sector, extending welfare services and enabling female employment, the consolidation of a dual breadwinner norm, and continued reliance on (not always entirely consensual) social partnership. One of the most critical developments in the Nordic cases was the provision of child and elderly care, which enabled a reconciliation of work and family life, while providing (flexible) employment opportunities for women. These developments were further supplemented by an accommodating tax regime, expanding maternity and paternity leave schemes, and school hours that allowed mothers to engage in full-time employment. As a consequence, female employment grew significantly during those decades. Even though wage negotiations in both Sweden and Denmark became more tenuous, social partnership remained a staple ingredient in the Nordic welfare states. The governments continued to seek the social partners' collaboration, not only because of the social partners' resources and expertise, but also to legitimise policy choices and programmes. Both welfare states also maintained high levels of general taxation to finance their welfare states with the goal of achieving high levels of equality and social homogeneity (adherence to the equity principle). ${ }^{27}$ Sweden and Denmark 
continued to differ, however, in the importance they placed on various labour market measures. While Sweden favoured "active" over "passive" measures, Denmark "tolerated" unemployment more than Sweden and, accordingly, emphasised passive measures in order to prevent economic hardship during periods of joblessness. Nevertheless, the role of active measures in Denmark, accessible to both insured and uninsured workers, became gradually more significant and expenditures continued to increase throughout the 1980 os.

In the Continental cluster, the method of choice for addressing unemployment was through demand-reducing measures such as early exit, protracted education opportunities, and a reduction in working hours. Similarly, the consolidation of the male breadwinner principle kept female employment rates low. Active labour market policies, in turn, were recalibrated throughout the 1970 os and 1980 os to address problems associated with long-term unemployment. However, the relative weight of active measures, typically only available to insured workers, was moderate in comparison to passive expenditures (i.e., cash transfer payments). As the Continental countries relied more on payroll contributions (insurance principle) than on general taxation to finance their labour market programmes, governments had to gradually increase these payments during the 1970 and 1980 os when unemployment increased. As such, labour market measures were often used in pro-cyclical ways: when unemployment decreases, more funds become available and programmes are expanded. Because much of the Continental economies' success in keeping unemployment low relied on prioritising the employment of prime-aged male workers at the expense of other groups, the Continental welfare states became known as a system that suffered from "welfare without work" (Esping-Andersen 1996). This strategy was largely agreeable to all stakeholders, including the social partners, as long as the beneficiaries were insured workers and their families. Accordingly, in the 1980s, the Continental welfare states seemed to successfully keep inequality low, while also preserving the social status of the unemployment (equivalence principle).

In the Anglophone cluster, especially Margaret Thatcher's Britain, a strategy of deregulation, privatisation, and marketisation based on Friedman's monetarist paradigm was chosen. This path included the dismantling of unions and the removal of labour market "rigidities" such as employment protection legislation and administrative "red tape" inhibiting job creation. The social partners were thus expelled from welfare state governance in general and the labour market in particular, while 
benefits became more residual and flat rate. The guiding principle was not equivalence like in the Continental cases or equity as we saw in the Nordic cases, but ending the "culture of dependency" by advancing market principles and reducing the role of the state. Ireland shared many characteristics with the UK, including the provision of limited social services, a flexible labour market, and a tradition of poor relief to those in need. Moreover, during the economic crises of the 1980s, Ireland's policymakers also followed the British example of decentralised wage setting. However, by the end of the 1980 s, Ireland had begun to diverge from Britain's more radical path and began to rebuild social partnership features by creating a tripartite Training and Employment Authority (FÁS) and arranging national wage-setting agreements, embedded in a larger "planning" context. As such, the Irish case is not a "pure" example of the Anglophone welfare state, even though it shares many features with its British counterpart.

Table 8 summarises the key principles that are shared in the respective welfare state clusters, which is followed by supplementary tables in the appendix, which summarise the economic, employment, and labour market policy characteristics of the three welfare clusters for the period 1974-1989.

Table 8 Core Principles, Common Outcomes, and Tradeoffs in Three Welfare Clusters in the 1980s

\begin{tabular}{|c|c|c|c|}
\hline $\begin{array}{l}\text { Welfare } \\
\text { Cluster }\end{array}$ & Principles & Outcomes/Effects & $\begin{array}{l}\text { Equity-Employment-Tax } \\
\text { Trade-off }\end{array}$ \\
\hline \multirow{5}{*}{$\begin{array}{l}\text { Nordic } \\
\text { (Sweden, } \\
\text { Denmark) }\end{array}$} & $\begin{array}{l}\text { Dual breadwinner } \\
\text { principle }\end{array}$ & $\begin{array}{l}\text { Large public sector } \\
\text { (increasing in size) }\end{array}$ & $\begin{array}{l}\text { Female employment } \\
\text { rate: high }\end{array}$ \\
\hline & $\begin{array}{l}\text { Universality principle } \\
\text { (general taxation) }\end{array}$ & $\begin{array}{l}\text { Service-heavy \& } \\
\text { women-friendly welfare } \\
\text { state (delivered mainly }\end{array}$ & $\begin{array}{l}\text { General level of activity: } \\
\text { high }\end{array}$ \\
\hline & $\begin{array}{l}\text { Equity principle (social } \\
\text { homogeneity) }\end{array}$ & through public actors) & Inequality: low \\
\hline & $\begin{array}{l}\text { Consensus-style } \\
\text { policymaking }\end{array}$ & $\begin{array}{l}\text { Generous active and } \\
\text { passive labour market } \\
\text { measures for all citizens }\end{array}$ & Taxation: high \\
\hline & & $\begin{array}{l}\text { Social partners involved } \\
\text { in labour market } \\
\text { institutions (based on } \\
\text { tradition) }\end{array}$ & \\
\hline
\end{tabular}


Table 8 Core Principles, Common Outcomes, and Tradeoffs in Three Welfare Clusters in the 1980s

\begin{tabular}{|c|c|c|c|}
\hline $\begin{array}{l}\text { Welfare } \\
\text { Cluster }\end{array}$ & Principles & Outcomes/Effects & $\begin{array}{l}\text { Equity-Employment-Tax } \\
\text { Trade-off }\end{array}$ \\
\hline \multirow{5}{*}{$\begin{array}{l}\text { Continental } \\
\text { (Germany, } \\
\text { Austria) }\end{array}$} & $\begin{array}{l}\text { Male breadwinner } \\
\text { principle }\end{array}$ & $\begin{array}{l}\text { Medium public sector } \\
\text { (increasing in size) }\end{array}$ & $\begin{array}{l}\text { Female employment } \\
\text { rate: low }\end{array}$ \\
\hline & $\begin{array}{l}\text { Insurance principle } \\
\text { (payroll contributions) }\end{array}$ & $\begin{array}{l}\text { Transfer-heavy welfare } \\
\text { state; weak child/elder } \\
\text { care institutions }\end{array}$ & $\begin{array}{l}\text { General level of activity: } \\
\text { medium }\end{array}$ \\
\hline & $\begin{array}{l}\text { Equivalence principle } \\
\text { (status preservation) }\end{array}$ & Generous transfers to & Inequality: low \\
\hline & $\begin{array}{l}\text { Consensus-style } \\
\text { policymaking }\end{array}$ & $\begin{array}{l}\text { insured workers } \\
\text { Social partners } \\
\text { involved in labour } \\
\text { market institutions } \\
\text { (legitimised by payroll } \\
\text { contributions) }\end{array}$ & $\begin{array}{l}\text { Taxation: medium; } \\
\text { (but high payroll } \\
\text { contributions) }\end{array}$ \\
\hline & & $\begin{array}{l}\text { Not-for-profit actors } \\
\text { and social partners } \\
\text { involved in social policy } \\
\text { delivery }\end{array}$ & \\
\hline \multirow{5}{*}{$\begin{array}{l}\text { Anglophone } \\
\text { (UK and to } \\
\text { some extent } \\
\text { Ireland) }\end{array}$} & $\begin{array}{l}\text { Male breadwinner } \\
\text { principle (very strong in } \\
\text { Ireland) }\end{array}$ & $\begin{array}{l}\text { Medium public sector } \\
\text { (stagnant/declining) }\end{array}$ & $\begin{array}{l}\text { Female employment } \\
\text { rate: medium (low in } \\
\text { Ireland) }\end{array}$ \\
\hline & $\begin{array}{l}\text { Weak universality } \\
\text { principle (general } \\
\text { taxation) }\end{array}$ & $\begin{array}{l}\text { Transfer-biased welfare } \\
\text { state; weak child/elder } \\
\text { care institutions }\end{array}$ & $\begin{array}{l}\text { General level of activity: } \\
\text { medium/high in UK, } \\
\text { low in Ireland }\end{array}$ \\
\hline & $\begin{array}{l}\text { Market principle } \\
\text { (welfare seen }\end{array}$ & $\begin{array}{l}\text { Residual, flat-rate } \\
\text { benefits }\end{array}$ & Inequality: high \\
\hline & $\begin{array}{l}\text { as individual } \\
\text { responsibility) }\end{array}$ & $\begin{array}{l}\text { Not-for-profit actors } \\
\text { involved in social policy } \\
\text { delivery }\end{array}$ & Taxation: low \\
\hline & $\begin{array}{l}\text { Weak social partnership } \\
\text { (improving in Ireland in } \\
\text { late 1980s) }\end{array}$ & & \\
\hline
\end{tabular}




\section{Appendix to Part I, Chapter IV: Comparative Data}

Table 9 Real Gross Domestic Product (GDP); Percentage Change from Previous

Period, 1974-1989

\begin{tabular}{lcccccc}
\hline & Average & & & & & \\
& $1974-1984$ & 1985 & 1986 & 1987 & 1988 & 1989 \\
Denmark & 2.1 & 4.3 & 3.6 & 0.3 & 1.2 & 0.2 \\
Sweden & 1.6 & 2.2 & 2.7 & 3.3 & 2.6 & 2.7 \\
Austria & 2.1 & 2.4 & 2.1 & 1.6 & 3.4 & 4.2 \\
Germany & 1.9 & 2.0 & 2.3 & 1.5 & 3.7 & 3.6 \\
Ireland & 3.8 & 3.1 & -0.4 & 4.7 & 5.2 & 5.8 \\
UK & 1.5 & 3.8 & 4.2 & 4.2 & 5.2 & 2.2 \\
\hline
\end{tabular}

Source: OECD 2002, 207, table 1

Table 10 Inflation Rate (Consumer Price Index); Percentage Change from Previous Period, 1974-1989

\begin{tabular}{lcccccc}
\hline & $\begin{array}{c}\text { Average } \\
\text { 1974-1984 }\end{array}$ & 1985 & 1986 & 1987 & 1988 & 1989 \\
\hline Denmark & 9.7 & 4.7 & 3.7 & 4.0 & 4.5 & 4.8 \\
Sweden & 10.0 & 7.4 & 4.2 & 4.2 & 5.8 & 6.4 \\
Austria & 5.5 & 6.7 & 9.1 & 8.5 & 7.3 & 7.5 \\
Germany & 4.3 & 2.1 & -0.1 & 0.2 & 1.3 & 2.8 \\
Ireland & 14.7 & 5.5 & 3.8 & 3.1 & 2.2 & 4.0 \\
UK &.. & 5.2 & 3.6 & 3.7 & 4.6 & 5.9 \\
\hline
\end{tabular}

Source: OECD 2002, 225, table 19

Table 11 General Government Gross Financial Liabilities as Percentage of Nominal GDP, 1985-1989

\begin{tabular}{llcccl}
\hline & 1985 & 1986 & 1987 & 1988 & 1989 \\
\hline Denmark & 74.9 & 71.8 & 68.6 & 66.7 & 65.0 \\
Sweden & 64.7 & 64.1 & 57.0 & 51.2 & 46.5 \\
Austria & 49.1 & 53.6 & 57.5 & 58.9 & 58.1 \\
Germany & 40.6 & 40.6 & 41.6 & 42.1 & 40.8 \\
Ireland & 99.5 & 110.6 & 111.8 & 108.2 & 98.9 \\
UK & 59.2 & 58.4 & 56.1 & 49.7 & 43.0 \\
\hline
\end{tabular}

Source: OECD 2002, 239, table 33 
Table 12 Overall Marginal Tax Wedge, 1978-1989

\begin{tabular}{lcccc}
\hline & 1978 & 1981 & 1985 & 1989 \\
\hline Denmark & 69.7 & 72.1 & 75.1 & 72.5 \\
Sweden & 75.4 & 75.3 & 71.2 & 70.5 \\
Austria &. &. &. &. \\
Germany & 66.0 & 64.3 & 67.5 & 66.3 \\
Ireland &.. &.. &.. &.. \\
UK & 44.3 & 50.4 & 48.1 & 38.2 \\
\hline
\end{tabular}

Source: OECD 1994, 241, table 9.1

Table 13 Labour Force Participation Rate, Total, 1973-198928

\begin{tabular}{llllll}
\hline & 1973 & 1979 & 1983 & 1987 & 1989 \\
\hline Denmark & 75.9 & 79.8 & 80.9 & 84.0 & 84.3 \\
Sweden & 75.5 & 80.5 & 81.3 & 81.7 & 83.3 \\
Austria & 65.1 & 64.9 & 65.6 & 67.0 & 67.2 \\
Germany & 68.8 & 66.8 & 65.1 & 68.6 & 68.2 \\
Ireland & 63.5 & 62.4 & 62.7 & 61.6 & 60.3 \\
UK & 73.0 & 74.3 & 72.4 & 74.9 & 76.0 \\
\hline
\end{tabular}

Source: OECD 1990a, 200, table G

Table 14 Labour Force Participation Rate, Female, 1973-1989

\begin{tabular}{llllll}
\hline & 1973 & 1979 & 1983 & 1987 & 1989 \\
\hline Denmark & 61.9 & 69.9 & 74.2 & 78.6 & $78.3^{\mathrm{a}}$ \\
Sweden & 62.6 & 72.8 & 76.6 & 79.4 & 81.0 \\
Austria & 48.5 & 49.1 & 49.7 & 53.0 & 54.3 \\
Germany & 49.6 & 49.6 & 49.7 & 54.4 & $54.4 \mathrm{a}$ \\
Ireland & 34.1 & 35.2 & 37.8 & 38.5 & $37.6 \mathrm{a}$ \\
UK & 53.2 & 58.0 & 57.2 & 62.4 & 65.2 \\
\hline
\end{tabular}

$\mathrm{a}=1988$

Source: OECD 1990a, 200, table H 

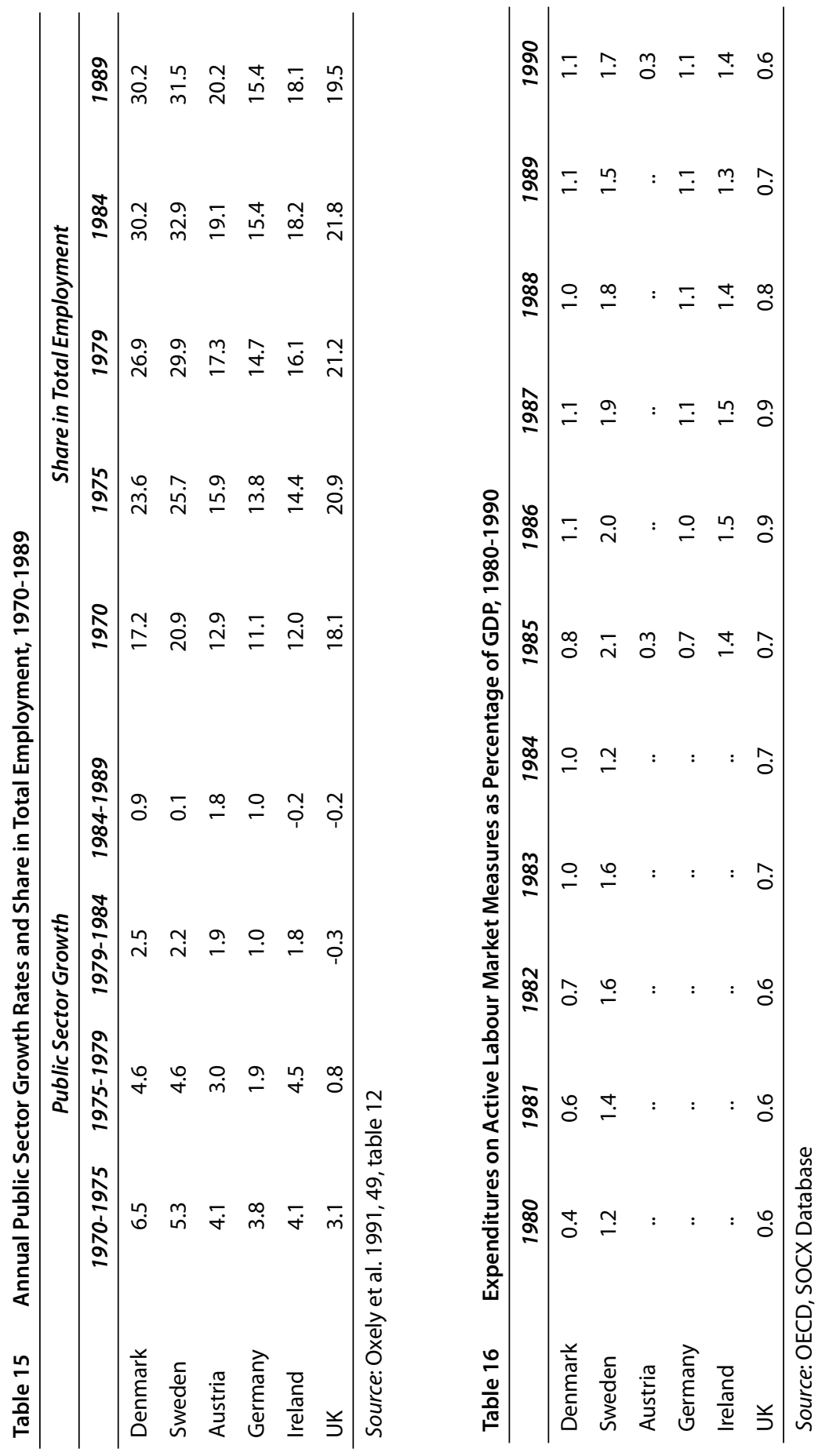
Table 17 Expenditures on Specific Labour Market Measures as Percentage of GDP, 1987

\begin{tabular}{|c|c|c|c|c|c|c|}
\hline & Denmark & Sweden & Austria & Germany & Ireland & UK \\
\hline PES & 0.13 & 0.21 & 0.11 & 0.23 & 0.17 & 0.16 \\
\hline Training & 0.52 & 0.49 & 0.13 & 0.29 & 0.56 & 0.11 \\
\hline $\begin{array}{l}\text { Youth } \\
\text { Measures }\end{array}$ & 0.21 & 0.15 & 0.02 & 0.06 & 0.40 & 0.27 \\
\hline $\begin{array}{l}\text { Direct Job } \\
\text { Creation/ } \\
\text { Employment } \\
\text { Subsidies }\end{array}$ & 0.03 & 0.26 & 0.12 & 0.20 & 0.32 & 0.31 \\
\hline Disabled & 0.25 & 0.75 & 0.03 & 0.21 & .. & 0.04 \\
\hline Cash Transfers & 2.64 & 0.70 & 0.91 & 1.33 & 3.66 & 1.66 \\
\hline $\begin{array}{l}\text { Early } \\
\text { Retirement }\end{array}$ & 1.25 & 0.10 & 0.16 & 0.02 & .. & 0.02 \\
\hline $\begin{array}{l}\text { Sum (total } \\
\text { expenditures) }\end{array}$ & 5.03 & 3.77 & 1.48 & 2.34 & 5.12 & 2.57 \\
\hline $\begin{array}{l}\text { Active: Passive } \\
\text { Ratio (w/o } \\
\text { spending on } \\
\text { the disabled) }\end{array}$ & 0.23 & 1.39 & 0.36 & 0.58 & 0.40 & 0.51 \\
\hline
\end{tabular}

Source: OECD 1988, 86, table 3.1 

Part II

The Emergence of the Activation Paradigm 



\section{The OECD's Repeated Reassessments and the EU as a Proliferator of New Ideas}

Chapter III examined the emergence of active manpower policy - inspired by the Swedish Model and diffused by the OECD - across most of the industrialised world. Chapter IV outlined the expansion, recalibration, and - in most cases - gradual expansion in the use of active manpower policy in response to the employment challenges that arose after the two oil crises in the 1970s. In this chapter, I will trace how the OECD has reacted to - and repeatedly adjusted its position on the causes of, and remedies for, unemployment since the late 1980s. I will juxtapose the OECD's recommendations to those of the EU, which emerged in the mid-1990s as an additional "ideas proliferator" and locus for new policy agendas. I argue that while the authors of the OECD and EU statements initially offered competing sets of recommendations - based on different normative and cognitive underpinnings - a gradual phase of normative and cognitive recalibrations has subsequently led to programmatic convergence on a common paradigm based on activation policies.

\section{V.1 The New Aspiration for an "Active Society" and the Road to the OECD Jobs Study}

Possibly one of the most striking developments in OECD countries during the 1980 s was the diversity in both the level and structure of unemployment. While unemployment began to decline in some European countries as part of a general economic upswing in the mid-1980s, in many others, unemployment remained a salient issue. Moreover, many countries shared - even those with a better record such as Austria the phenomenon of persistent and long-term unemployment, which was concentrated in particular groups, especially youth. At the same time, employers in many countries began to report skills shortages, which highlighted the increasing mismatch of jobseekers' skills and employers' 
demands (for an excellent review, see Blanchard 2006). These economic, political, and social challenges were further amplified by demographic developments that suggested that economic old-age dependency ratios would significantly rise (as birth rates declined and people grew older), which, in turn, increased concern about the sustainability of old age social security systems.

When a cyclical economic upswing contributed to continuously falling average levels of unemployment from 1984 to $1990,{ }^{1}$ the OECD seized this opportunity to propose a New Framework, endorsing an "active society" (OECD 199ob) that was welcomed by the Ministerial Council. The New Framework articulated a major reassessment of many previously held recommendations. The diversity in unemployment levels, the growth in youth unemployment, and the emergence of long-term unemployment - despite sustained economic growth - led the OECD to consider unemployment as a predominantly structural phenomenon. Thus, the OECD concluded, in stark contrast to previous assessments, that there remained "little scope for addressing unemployment by aggregate demand measures" (OECD 1990a, vii). It also outlined a new political agenda. At the heart of the OECD's reorientation toward an "active society" was a cognitive shift in the cause-and-effect relationship between levels of unemployment and employment. It was argued that the mobilisation of passive reserves would improve the productive capacity of an economy, raise income levels (while easing pressures on the public budget), enhance social progress, and thus contribute to the creation of new jobs. In other words, this New Framework welcomed, rather than rejected, the expansion of general employment levels through the mobilisation of women, lone parents, disabled workers, and other economically inactive, but not necessarily unemployed, people. To achieve this goal, the expansion of "non-standard" forms of employment, such as part-time, weekend and homework, and self-employment, and the associated segmentation of the labour market was tolerated, if not embraced. In this context, "adequate training and other mobility-enhancing" measures were considered necessary to turn these non-standard jobs into "stepping stones" to regular employment (OECD 1989, 10). The associated policy recommendations included: (1) a "swing from 'passive' to 'active' labour market policies"; ${ }^{2}$ (2) a renewed focus on guaranteeing a "solid background of basic education" and improving workers' adaptability through "lifelong learning"; and (3) a reorientation of PESs' functions away "from bureaucratic control" toward a "view to the active facilitation of labour market processes" (OECD 1990a, ix). The latter promoted a spirit of active job searching by improving place- 
ment and counselling services, more frequent contact with the PES, and potentially benefit conditionality. Targeted and selective training measures and employment subsidies should be considered if, and only if, all other measures failed. Coupled with an increase in the pressure on jobseekers to find and accept jobs, the OECD foresaw tax and benefits reforms early on. Tax and benefits reforms should make employment financially more attractive than "a life on benefits". Additional hurdles to gainful employment, especially the lack of childcare, also needed to be addressed.

While the OECD's recommendations and rhetoric thus foreshadowed much of the contemporary European discourse, little substantive policy change occurred in the early 1990 os. In fact, when the economic recession of the early 1990 s affected European labour markets, most governments were more interested in "managing" rising levels of unemployment than pushing more people into atypical employment. In response, the OECD symbolically entitled their 1991 Employment Outlook "Labour Market Reform: Staying the Course" and in 1992, the OECD articulated the fear that the additional layer of cyclical unemployment might turn into structural unemployment if governments failed to pursue the recommendations outlined in the New Framework. To overcome many Member States' reform apathy, the OECD Labour Ministers agreed in May 1992 to launch a comprehensive research effort "on the reasons for and the remedies to the disappointing progress in reducing unemployment" (OECD 1992, ix). That same year, the Manpower and Social Affairs Committee was renamed the Employment, Labour and Social Affairs Committee, capturing the OECD's far-reaching normative and cognitive reassessments. The term "manpower policy" was also gradually replaced with "active labour market policy". Two years later, the 1994 Jobs Study (JS) was published, which would become the focal point for all subsequent OECD labour market reform proposals. The JS articulated nine (later ten) broad policy guidelines and more than 70 detailed policy recommendations specific to its Member States (Martin 2006, 1).

\section{Box 31994 OECD Jobs Study Recommendations}

1. Macro-economic policy, in conjunction with good structural policies, should encourage sustainable (i.e., non-inflationary) growth

2. Improve frameworks to enhance the creation and diffusion of technological knowhow

3. Increase flexibility of working time 
4. Eliminate impediments to the creation and expansion of enterprise

5. Make wages and labour costs more flexible to reflect local conditions and individual skill levels, in particular of younger workers

6. Reform employment security provisions that inhibit the expansion of employment in the private sectors

7. Strengthen the emphasis on active labour market policies and reinforce their effectiveness

8. Improve workforce skills and competences through wide-ranging changes in education and training systems

9. Reform unemployment and related benefit and tax systems so that equity is not pursued at the expense of efficient labour markets

10. Enhance product market competition to reduce monopolistic tendencies and weaken insider-outsider mechanisms.

Source: OECD 1999, 9

While the language in the recommendations is fairly neutral and not explicitly "anti-welfare", the Jobs Study has typically been interpreted as an "American" or "neo-liberal" prescription in which social policy is viewed as a "brake" to economic development and a "burden" to employers, individuals, and the public purse (Casey 2004, 330). This particular interpretation has typically been explained by (a) the specific policy recommendations that were developed in the subsequent country assessment processes, and (b) the relative weight given to the ten policy areas with a clear bias against five labour market institutions, including minimum wages, employment protection legislation (EPL), unemployment and other benefits, the tax wedge, and wage-setting arrangements (Watt 2006, 2). In other words, the OECD recommendations were heavily focused on improving labour market flexibility, which was regarded as the key ingredient of economic growth and job creation. ${ }^{3}$ The very definition of flexibility, however, had taken on an entirely new meaning. While up until the early 1980 s, achieving flexible labour markets was predicated on the use of ALMPs - which were assumed to make the labour market flexible by improving the occupational and regional mobility of workers - the JS's interpretation of flexibility was based on removing "rigidities" caused by labour unions and governmental regulations. Accordingly, the scope for "active" labour market policy became more limited and was envisioned as a mixture of positive, non-financial incentive measures, mainly efficient and effective job-matching and placement services, and their negative counterpart, i.e., the enforcement of work and job search requirements. ${ }^{4}$ While the targeted use of 
supply-side measures was still seen as a desirable component of labour market policy, demand-side measures were seen as mostly inappropriate instruments that should only be used for the most disadvantaged jobseekers and only for limited periods of time.

Finally, the JS also built on the older notion of an "active society" - even though this term was no longer used - by encouraging, rather than suppressing, labour market participation of all groups in society. This prescription still included the expansion of "atypical" employment, which continued to be seen as an appropriate instrument for addressing unemployment and social exclusion. This preference is articulated well in the statement by the OECD Secretary General Jean-Claude Paye: "It is much better to have people on a salary, perhaps not a very high one, than to have people unemployed" (citation in, Riding 1994).

In summary, while the wording of the JS remained neutral - after all, it had to be endorsed by all Member States - its message was that (Continental) Europe needed to adjust its labour markets along US lines to sustain competitiveness and improve its employment performance. This reorientation must therefore be understood in part as a reassessment and, in other cases, as a confirmation of market-oriented political actors' beliefs about the adequacy of the deregulatory approach to the unemployment malaise. The large "over-regulated" economies including France, Germany, and Italy in particular suffered from largescale, often long-term unemployment, which strongly contrasted with a well-performing, "unregulated" US with its steady job increases. While this problem assessment was not fully shared by left-leaning actors, it was nevertheless internalised in the OECD recommendations as the Jobs Study was conducted, evaluated and published during a politically "conservative moment". In other words, not only was the OECD agenda mainly driven by the US's superior economic performance and the UK's endorsement of deregulatory labour market policies, but also by centreright governments in most European countries. While Germany was governed by a Christian-Liberal coalition government under Helmut Kohl, Denmark and Sweden were headed by Poul Schlüter (Conservative People's Party) and Carl Bildt (centre-right Moderates) respectively, and Socialist François Mitterrand faced a Gaullist majority in parliament and was thus forced to appoint Édourd Balladur as prime minister in March 1993. 


\section{V.2 The European Union as a Proliferator of New Ideas: From Delors' 1993 White Paper to the European Employment Strategy}

During the first four post-WWII decades, the OECD enjoyed an almost "monopoly-like situation" with regard to the exchange, deliberation, and diffusion of ideas and recommendations in the fields of social and labour market policy in Europe (Noaksson and Jacobsson 2003, 34). The EU, in turn, had little influence in this field and the impact of European integration was typically described as "negative integration", or the retrenchment of national regulatory capacity, rather than "positive integration" associated with European-level capacity building (Leibfried and Pierson 1995; Scharpf 20oob). Accordingly, the EU's achievements in European social policy making were considered "at best - weak" (Pochet 2005, 37), and "EU social policy remained limited and secondary" (Geyer 2000, xiii). However, throughout the 1990s, the EU would gradually emerge as an important new actor in the dissemination of new ideas related to employment and social policy. The first step toward "positive integration" in the realm of labour market policy was the conclusion of the Treaty on the European Union (henceforth Maastricht Treaty), signed in Maastricht on 7 February 1992. The Maastricht Treaty not only codified Europe's hard currency path, i.e., "a harmonious and balanced development of economic activity, [and] sustainable and non-inflationary growth", but also set out "a high level of employment and social protection, the raising of the standard of living and quality of life, and economic and social cohesion and solidarity among Member States" as core EU principles and priorities (cf., Art. 2).

Unemployment, in turn, was first discussed as a European rather than a national problem after the currency crisis of September 1992, which forced Britain, Italy, and Sweden (a soon-to-be EU member) out of the European Exchange Rate Mechanism (ERM). The EU Member States realised that the Union did not have the tools to adequately deal with macro-economic shocks, which in turn, could potentially endanger the prospects of the Economic and Monetary Union (EMU) and the introduction of a common currency as outlined in the Maastricht Treaty. Thus, on 1 June 1993 the Commission presented a Community-wide Framework for Employment in which a high level of employment across all Member States was prescribed as "a fundamental objective of the Community". The Commission also underlined the need for Member States' policy coordination and common action at the Community level, while identifying Scandinavia as a good example for the achievement of high employment rates (Commission of the European Communities 1993a). Later that same 
month, the chiefs of government (CoGs) conceded at the Copenhagen Council that a comprehensive European strategy was needed to "restore sustainable growth, reinforce the competitiveness of European industry and reduce unemployment" (Council of the European Union 1993, 3). For this purpose, the Copenhagen Council invited the Commission to present a White Paper on a medium-term strategy for growth, competitiveness and employment. This White Paper would become Social Democratic Commission President Jacques Delors' window of opportunity to outline his vision of a Europe that would include an explicit social dimension as a counterweight to the EU's fundamentally "neo-liberal thrust" (Pollack 1999, 268). While the White Paper agreed with many of the OECD's findings published in the 1994 Jobs Study, including the diagnosis that most of Europe's unemployment was caused by structural impediments, it proposed significantly different remedies. More specifically, Delors placed less emphasis on enforcing market mechanisms and the removal of "rigidities" through labour market deregulation, welfare state retrenchment, and decentralisation of wage negotiations, and more emphasis on capacity-building state interventions, social partnership, and the proliferation of a "sustainable developmental model" (cf., Commission of the European Communities 1993b).

The White Paper did, however, share the OECD's vision of an "active employment policy" that reflected the cognitive and normative shifts that had also reached the European Commission. Accordingly, the Commission began to "persuade" national governments about the merits of an active labour market policy regime that entailed mutual obligations to jobseekers and the state alike. Accordingly, the White Paper called for a "complete reversal of attitudes" with the aim of preventing rather than managing long-term unemployment (Commission of the European Communities 1993b, 18). For this purpose, the unemployed should, based on the duration of their unemployment spell, first be offered "training leading to meaningful qualifications, then the possibility of working, possibly in the public sector for a number of months" (Commission of the European Communities 1993b, 18f, emphasis added). The more difficult cases, in particular the long-term unemployed, should be monitored personally by the same employment adviser, while young jobseekers, especially early school leavers, should be guaranteed a "Youthstart", leading to a meaningful vocational certification. Jobseekers were thus offered "real assistance", which would also carry, however, an obligation to make a "personal investment in this training and employment" (Commission of the European Communities 1993b, 18f). 
Inspired by Delors' White Paper, the CoGs' meeting in Essen in December of 1994 - the last European Council attended by Delors as President of the Commission - introduced a new focus on the labour market, echoing many of the recommendations of both the Jobs Study and the White Paper. The Essen Council took place at a time of economic recovery, which had the potential to "set free" new financial means in the fight against unemployment. However, Essen also took place while further steps toward the consolidation of the EMU were occurring, which required the tightening of national budgets and the creation of more efficient public sectors. As such, a strategy was needed that could tackle the unemployment problem without turning to inflationary growth and growing budget deficits. The Council then agreed on the following five guidelines, consolidating, broadening, and further specifying previously outlined measures:

\section{Box 4 Five Guidelines Proposed at the 1994 Essen Council}

1. Improving employment opportunities for the labour force by promoting investment in vocational training. [...]

2. Increasing the employment-intensiveness of growth, in particular by:

- more flexible organization of work [...]

- a wage policy which encourages job-creating investments and in the present situation requires moderate agreements below increases in productivity, and

- finally, the promotion of initiatives, particularly at the regional and local level that create jobs [...]

3. Reducing non-wage labour costs [...]

4. Improving the effectiveness of labour-market policy [...] by moving from a passive to an active labour market policy. [...]

5. Improving measures to help groups which are particularly hard hit by unemployment:

- Particular efforts are necessary to help young people, especially school leavers who have virtually no qualifications, by offering them either employment or training.

- The fight against long-term unemployment must be a major aspect of labourmarket policy. [...]

- Special attention should be paid to the difficult situation of unemployment women and older workers.

Source: Council of the European Union 1994, $2 f$.

When we compare the Essen guidelines to the JS recommendations, the difference between their orientations and their conclusions are quite striking. Not only are the Essen guidelines clearly oriented toward en- 
hancing the employability of workers through a strong focus on vocational training, while assisting the weakest groups in the labour market, including older workers, early school leavers, women and the long-term unemployed, but they also do not address EPL standards or benefit levels. Likewise, instead of calling for the devolution of wage setting to the firm level, the Essen guidelines called for "moderate agreements below increases in productivity", which were best achieved by concerted actions at the national or sectoral level. As such, addressing "structural" problems and moving from "passive" to "active" labour market policy meant something very different in the Essen guidelines compared to the OECD recommendations.

In order to institutionalise a peer-review process, all of the Essen guidelines were to be translated by the Member States into multi-annual programmes, while having regard "to the specific features of their economic and social situation" (Council of the European Union 1994, 3). Starting in December 1995, the Labour and Social Affairs Council, the Economic and Financial Affairs Council, and the Commission would monitor the Member States' policies and report back to the European Council. While the newly launched Essen Process therefore represented a first step in creating a common European framework for the exchange of economic ideas and good practices, mutual surveillance, and benchmarking, it was rather unclear whether any permanent structure would emerge at the European level (cf., Commission of the European Communities 2004). This institutional uncertainty was mainly due to the scepticism to these developments by the centre-right parties. At this point in time, the British, French and German governments as well as the Union of Industrial and Employers' Confederations of Europe $(\mathrm{UNICE})^{5}$ all opposed any transfer of real policymaking competences to the EU level.

However, the year 1995 would see new players emerge, advancing the agenda for the European co-ordination of employment policies. On the one hand, the EU welcomed three new members on 1 January 1995: Austria, Finland, and Sweden. All three countries had strong corporatist traditions and generally favoured labour market interventions over "free" markets. Accordingly, the inclusion of these governments in the Union significantly strengthened the alignment of players in favour of the Essen Process. Especially the Swedish government quickly turned out to be a major advocate for European-level employment co-ordination, mainly because of domestic pressures. Shortly before its accession to the EU, the Swedish right-of-centre Moderates lost the national elections and the 
Social Democrats were returned to office. Newly elected Premier Ingvar Carlsson, who had already been actively involved in pushing the agenda for the inclusion of an employment title in subsequent European treaties prior to Sweden's accession (Financial Times 1993), faced a sceptical Swedish electorate, in particular among Social Democratic voters. His worst fears were realised when the Swedes elected their first set of MPs to the European Parliament on 17 September 1995. While the parties that campaigned on a broadly anti-EU platform, including the Greens and the Left Party, won 17.2 percent and 12.9 percent of the vote, respectively, up from five percent and 6.2 percent in the 1994 general elections, the Social Democrats plummeted from 45.4 percent to 28.1 percent support (Ferrara and Weishaupt 2004, 284). Nine months after Sweden had joined the EU, these outcomes strikingly confirmed what polls had warned: "Sweden is thoroughly disillusioned with membership, and last November's referendum would be lost if it was held again now" (The Times, 1995). As such, by the end of 1995, it became increasingly essential for the Swedish government to find ways to ease voters' concerns over EU membership and its impact on the Swedish welfare state.

Moreover, as a consequence of a reshuffle within the Commission in 1995. Allan Larsson became the new Director General for Employment and Social Affairs. Larsson, who had served as Director General of the Swedish Labour Market Board (1983-1989), Swedish Finance Minister (1990-1991) and Chairman of the European Employment Initiative (EEI), ${ }^{6}$ was a "very influential" man whose opinions "carried a lot of weight" (interview, DGEmpl2). Although Larsson needed to be an independent candidate, his political beliefs reflected Swedish policy priorities, especially Swedish notions of active labour market policy (cf., Pochet and Jenson 2006). Carlsson quickly invited Larsson to write a paper entitled "A Vision for IGC 1996: A European Employment Union - to Make EMU Possible" and submitted a first, detailed proposal for an "employment title" to be included in a new EU treaty to the Westendorp Reflection Group, which prepared the contents for the upcoming Intergovernmental Conference (IGC) in 1996 (cf., van Riel and van der Meer 2002). ${ }^{7}$ Subsequently, during an informal meeting in Cordoba at the end of October, EU Employment Ministers under Swedish leadership, worked hard to lay the groundwork for a European employment strategy, which would be put before the Council for ratification in Madrid on 15-16 December 1995. The proposal for institutionalising a European employment policy, however, failed at the Madrid Council as the "big three" Member States were still opposed to it (Johansson 1999, 9). 
Nevertheless, even though the Madrid European Council did not ratify the proposed European employment policy, it reaffirmed that the fight against unemployment should remain a priority of the Community and the Member States. Moreover, the Madrid Council approved a Single Report on Employment, which was prepared jointly by the Economic and Financial Affairs Council (EcoFin), the Social Affairs Council, and the Commission. This 1996 report gave the Member States and the Commission a detailed agenda for action. The Council furthermore encouraged the Commission to work with the Member States to develop proper indicators to evaluate the successes of various measures and policies and to intensify the exchange of information and experience (Council of the European Union 1996). These developments were thus considered major successes for the proponents of a European employment agenda because the Maastricht Treaty had not foreseen that employment would be on the agenda for the 1996 IGC.

While the IGC negotiations of 1996 did not lead to a breakthrough, the strength of the "anti-employment co-ordination coalition" declined substantially in 1997. First, the French resistance to an employment title dissipated after the election of Socialist Premier Lionel Jospin. The new French government not only became an outspoken supporter of a European employment strategy, but actually demanded that the EU addresses employment policy, threatening not to sign the Stability and Growth Pact if nothing was done (interview, DGEmpl3). Second, German Chancellor Kohl faced increasing domestic pressure to deal with the issue of unemployment, which had surpassed (based on national figures) the four million threshold in 1996, the highest level in the history of the Federal Republic. The labour unions in particular put intense pressure on Kohl to abandon his opposition to a European employment policy. Third, the "pivotal event was the change of government in Great Britain on 1 May 1997" (van Riel and van der Meer 2002). Newly elected Prime Minister Tony Blair (Labour Party) was eager to show that everything in Britain had changed. Accordingly, Blair wanted to present himself as a "good European" by showing that Britain would no longer be a stumbling block regarding an employment policy amendment to the treaty (personal communication, DGEmpl1; interview, DGEmpl 3 ).

In short, the reshuffling of governments in Britain and France, and increasing domestic pressures in Germany to soften its categorical opposition to a European response to unemployment, allowed for the forging of a "careful political compromise" between those Member States in favour of delegating powers to the EU and those who were more re- 
luctant to transfer those policymaking powers to the EU (Mosher and Trubek 2003, 67). This compromise formally created the European Employment Strategy (EES) at the Amsterdam Summit in June 1997, which institutionalised a multilateral surveillance process and established a permanent, treaty-based Employment Committee (EMCO), promoting policy co-ordination among Member States' employment and labour market policies. The precise institutional design of the EES, in turn, was to be decided later that year. At first, the proposals of the Commission were unacceptable to the Council, ${ }^{8}$ while the Economic, Finance, and Labour ministers were also unable to agree on a common formula during their October meetings. Eventually, however, it was the then President of the Council, Jean-Claude Juncker, who offered a "realistic" proposal that became the blueprint for the EES (interview, EMCO1). Jean-Claude Juncker, a highly respected Christian Democrat, successfully persuaded the sceptics, including Helmut Kohl, about the adequacy, necessity, and prospects of an employment title to be included in the new Treaty of Amsterdam (Pochet 2005, 49). At an extraordinary European Council meeting held on 26-27 November 1997, prior to the ratification of the Amsterdam Treaty, a compromise was ultimately reached and the socalled Luxembourg Process was passed. This new process rested on four policy pillars, each with a set of commonly agreed upon guidelines, outlining the direction of national institutional reforms, and a set of institutionalised mutual monitoring, reporting, and feedback mechanisms.

\section{Box 5 Institutional Components of the EES (Luxembourg Process)}

- Employment Guidelines (EGL): following a Commission proposal, the Council shall agree annually to a series of guidelines that establish common priorities for Member States' employment policies;

- National Action Plans (NAPs): every Member State shall draw up an annual National Action Plan that describes how these guidelines are put into practice on a national level;

- Joint Employment Report (JER): The Commission and the Council shall jointly examine each National Action Plan and present a Joint Employment Report. The Commission shall present a new proposal to revise the Employment Guidelines accordingly for the following year;

- Recommendations: The Council may decide, by qualified majority, to issue countryspecific recommendations upon a proposal by the Commission.

Source: European Parliament 2007 


\section{Employability Pillar}

Guidelines 1 and 2: Implementing preventative and employability-oriented strategies, building on the early identification of individual needs and ensuring that young/long-term unemployed persons are offered a new start in the form of training, retraining, work practice, a job or other employability measure after six/12 months respectively.

Guideline 3: $\quad$ Shifting people from welfare dependency to work and training by increasing the number of unemployed people in ALMP measures, gradually achieving the average of the three most successful Member States, and at least 20 percent.

Guidelines 4 and 5: Developing partnerships as a framework for the provision of training and lifelong learning.

Guidelines 6 and 7: Facilitating the transition from school to work.

\section{Entrepreneurship Pillar}

Guidelines 8-10: Reducing overhead costs and removing the administrative burden to promote business activities, especially for small and mediumsized enterprises, exploiting all of the available opportunities for job creation, including the social economy; encouraging self-startups.

Guideline 11 and 12: Making the tax system more employment friendly by reducing labour and non-wage labour costs, in particular for unskilled and low-paid work.

\section{Adaptability Pillar}

Guidelines 13 and 14: Inviting the social partners to negotiate flexible working arrangements and to examine the possibility of more adaptable types of work contracts.

Guideline 15: $\quad$ Re-examining the obstacles to investment in human resources and possibly provide for tax or other incentives for the development of in-house training.

\section{Equal Opportunities Pillar}

Guideline 16: $\quad$ Reducing the gap in unemployment rates between men and women and actively supporting the employment of women.

Guideline 17: $\quad$ Improving access to care services.

Guideline 18: $\quad$ Facilitating the return to work after child bearing.

Guideline 19: Giving special attention to people with disabilities.

Source: Council of the European Union 1997, annex 
While in principle all four pillars were of equal importance, the focal point of the EES was clearly the Employability Pillar, which was seen as a "real watershed at the time" (interview, DGEmpl2). Not only was it the only one of the four pillars with hard targets, including a "new start" within six and twelve months for the young and adult unemployed respectively and the participation of at least 20 percent of the unemployed in training or equivalent programmes, but it identified early and individualised interventions, skills and training as key issues. As such, the EES had a real effect on Member States' domestic policy making (interview, $\mathrm{EMCO}_{2}$ ), while the idea of "activation" - especially for young jobseekers - through offers of positive, non-financial incentives and the introduction of individual actions plans were "at the core of the EES" right from its inception (interview, DGEmpl3).

To summarise, the 1997 realignment of actors in favour of Europeanlevel concerted action on unemployment - including Allan Larsson, advocating a Swedish model and new Prime Minister Tony Blair, who had just launched his New Deal in the UK (see box 7, below) - made the institutionalisation of the EES possible. Successfully delivering the EES was not only a significant breakthrough for the European Union to influence national labour market and social policy for which previous treaties had little room, but it encapsulated the formalisation of a major normative reassessment that had been initiated by Jacques Delors in 1993. In other words, the EES embodied the normative view that "good" social policy is an activating policy that prevents long-term unemployment through early, individualised interventions and investments in people, while consolidating the cognitive assumption that supply-side labour market policy interventions lead to structural improvements. The EES also placed a much higher priority on raising employment levels as the key to economic performance, while the OECD in its Jobs Study applied the concept of NAIRU as the main benchmark (Eichhorst and Hemerijck 2008). As such, the EES emerged as a real alternative to the prescription of the OECD Jobs Study and offered a new perspective on the causes of, and remedies for, Europe's unemployment problems. Finally, the EES was also a symbolic victory for its proponents, because it received its own title in the Amsterdam Treaty, rather than just a chapter, which indicated that employment policy objectives were equally as important as macro-economic objectives. 
When Tony Blair and Gordon Brown came to office in Britain in 1997, they almost immediately launched their flagship programme, the New Deal for Young People (NDYP), for young adults aged 18 to 24 . The NDYP's core element included the activation of jobseekers after a period of six months, when jobseekers first entered a four-month period of intensive counselling and job-search support (the Gateway period), and subsequently moved on to the New Deal phase. The NDYP included four options, ranging from subsidised employment in the private sector, subsidised and temporary work in the voluntary or environmental sectors, to full-time education or training. In line with the normative foundation of "no rights without responsibilities", there was no "fifth option" to continue a (passive) life on welfare. Within months, the NDYP was extended to the "New Deal for Long-Term Unemployed" (ND25+) with similar options, and subsequently, other types of New Deals were offered to single parents (April 1998), their partners (April 1999), chronically disabled persons (April 1999), older workers (April 2000), partners of childless NDYP participants (2001) and partners of childless ND25+ participants (2002). With the exception of the NDYP and the ND25+, participation was voluntary apart from an interview with a personal advisor. In 1999, the government then initiated a series of other policies that supplemented the New Deals in an attempt to prevent particular hardships by "making work pay". Most importantly, a national minimum wage was introduced in April 1999 and was subsequently raised a number of times. In October 1999, the Conservatives' Family Credit, an in-work benefit, was replaced by a more generous Working Families Tax Credit (WFTC) (Glyn and Wood $2001,205)$. The new system resulted in an almost ten-fold increase in tax credits, which skyrocketed from $£ 1.4$ billion in 1999 to $£ 11.5$ in 2004 (Nachtwey and Heise 2006, 6).

\section{V.3 The Consolidation of Activation and the Emergence of the PES Service Model}

The OECD from 1995 to 1999: A Period of Reflection

Parallel to the launch of the EES and the emergence of activation as the guiding policy principle, the OECD continuously assessed and evaluated Member States' labour market programmes and their application of the JS. Numerous studies conducted between 1995 and 1999 provided further evidence for the need to recalibrate existing measures. In particular the need for activation was repeatedly stressed also by the OECD, while traditional ALMPs, including supply-side and demand-side oriented measures, were scrutinised and their use questioned both in terms of efficiency (i.e., costs) and effectiveness (i.e., achieving the desired outcome, which would be in most cases employment). More specifically, the OECD published the following results, which concentrated on three areas. 
First, job-placement and matching services are generally considered efficient and effective measures. Best results are achieved when benefit claimants are kept "active" through frequent contacts with the PES (OECD 1996b; OECD 1996e, 8). Within this context, good examples for maximising the PESs' effectiveness include "profiling" for new benefit claimants to identify those at risk of becoming long-term unemployed (e.g., Denmark), the use of "availability for work" tests (e.g., UK), and the "conditionality" of transfer payments on participation in ALMP measures after six to eight months of unemployment (e.g., UK). The introduction of individual action plans (individual handlingsplan) which were part of Denmark's 1994 labour market reform (see box 8 at the end of this section) were herein identified as a "virtuous" reform (OECD 1995a, 111; OECD 1995b, 29).

Second, supply-side measures such as training showed mixed results. Broad-based training seemed ineffective in helping participants find and retain employment, while targeted training courses, offered to specific groups and sensitive to employers' needs, tended to yield better results. Similarly, with respect to demand-side measures, targeted employment subsidies tended to yield more positive, long-term effects because the unemployed retain their motivation and skills. Direct job creation, however, did not yield the same positive effects because most of these jobs were not in the private sector and the associated acquired skills did not correspond to employers' needs (OECD 1995a; OECD 1995b).

Third, benefit/tax regimes must be restructured to provide proper incentives for those seeking and accepting (low-wage) employment. As such, the OECD encouraged its Member States to address inactivity traps (when benefits are high relative to expected net earnings) and poverty traps (when increases in time and work effort yield little prospect of higher earnings). In this context of "making work pay", non-wage labour costs such as payroll contributions were also identified as potential disincentives for employers to invest in new jobs (OECD 1996a).

In 1999, the OECD published a second, comprehensive progress evaluation and review of the JS. In this study, the OECD stressed the synergetic effects of combining a variety of structural reforms, while confirming that "countries with a good record on unemployment tend to have rising employment, relatively high participation, a relatively better position of marginal groups, a higher share of those working part-time doing so voluntarily and less of a long-term unemployment problem" (OECD 1999b, 10). ${ }^{9}$ Accordingly, the OECD explicitly encouraged its members not to use early retirement schemes and low female participation rates as a way of tackling youth unemployment, while shifting special attention to people 
on the margins of the labour market, including single mothers and non or low-skilled workers. In this context, the OECD recommended boosting these workers' incomes through in-work benefits and/or employment/ wage subsidies without however increasing costs to employers. More generally, the OECD's broadened scope of interest in the 1999 study, which explicitly included issues related to gender equality, the special needs of marginalised groups, and social equity concerns more generally, was considered a significant course correction and a step toward the European mainstream (Noaksson and Jacobsson 2003, 54).

The OECD and the Modernisation of Public Employment Services

In line with the findings published in the JS Implementation Reviews and various Employment Outlooks, the OECD began to also increasingly focus on reforming national PESs. PES reform had become necessary in order to adequately address "further ways and means of achieving the efficiency objectives of active labour market policies, while continuing to meet their equity objectives" (OECD 1997a, 6). To this end, the OECD not only produced a series of (descriptive rather than prescriptive) PES country reports (e.g., OECD 1993C; 1996c; 1996d; 1997C; 1998), but also advocated "testing" or "pioneering" a new PES model (OECD 1997a, 26). At a meeting of the Employment Labour and Social Affairs (ELSA) Committee in October 1997, four "promising avenues" were discussed, and subsequently published as an Occasional Paper..$^{10}$ They included: first, PES core functions, including job brokerage, unemployment benefit administration, and referral of the unemployed to ALMP programmes should be integrated - ideally but not necessarily - by setting up "one-shop offices". The integration of these services was seen as desirable because (a) close co-operation between placement and benefit work allows for an effective application of work tests; (b) the co-ordination of job brokerage and the ALMPs can assure that jobseekers acquire the skills needed to fill available job vacancies; and (c) the co-operation between benefits administration and the ALMPs is needed to avoid long-term dependency on cash transfers (OECD 1997a, 6f).

Second, since the 1996 study showed that job brokering at an early stage of joblessness and targeted and individualised supply-side ALMPs are effective in preventing long-term unemployment, their use was recommended to all members. However, as such instruments are costly and the availability of staff is limited, not all jobseekers can (and should) have access to these public services. Accordingly, reliable profiling techniques 
could help to properly select qualified clients by grouping jobseekers into three categories: $(i)$ those who are job-ready and not at risk of becoming long-term unemployed; (ii) those at risk but judged to be job-ready; and (iii) those at risk and judged to be not job-ready. The first group might be "left to fend for themselves except for normal placement services. Group (ii) should be assisted immediately with job-search assistance measures such as résumé writing, provision of telephone and fax facilities, jobs clubs etc. ... Only group (iii) might be considered for immediate referral to training and employment programmes" (OECD 1997a, 13). At what stage this intervention should begin, i.e., immediately, or after three, six, or 12 months, largely depended on the availability of staff and resources, but a first contact with the PES should not occur any later than three months after someone becomes unemployed. After six months, individualised action plans (IAPs), more intensive interviews, and stricter "suitable work" criteria should be applied. Participation in public work programmes (and wage subsidies) should only be considered an option after twelve months, when all the groups are combined.

Third, the use of performance targets and "management-by-objective" techniques were considered "good practices" because PES offices are then "no longer bound by rigid budget lines, staffing regulations and other formal constraints" (OECD 1997a, 16). MBO techniques further allow PESs to become more decentralised - thus giving more leeway to front-line officers, who could respond better to local labour market and individual jobseeker needs - while ensuring that "broad national policy orientations are followed" and government budgets managed in a transparent way (OECD 1997a, 16). Performance targets should "generally [be] applied on the basis of negotiations, mutual agreements, regular follow-up meetings, etc. rather than in the form of rigid administrative procedures to avoid undesirable - and potentially counterproductive - results" (OECD 1997a, 17).

Fourth, the OECD argued that the introduction of market signals to PES operations could possibly further enhance their efficiency, while creating a real "benchmark" against which performance targets could be assessed. Market-type mechanisms could include "contracting out", i.e., awarding delivery service contracts to private actors through competitive bidding processes, and organisational reforms that separate buyers from providers of public goods. Another way to increase market competition was the liberalising of rules and regulations that governed private employment agencies (PREAs). While the experience with the introduction of market mechanisms in some countries, including Sweden, had pro- 
duced decreases in unit costs for training by about 20 percent (and a loss of market share by almost 50 percent for the public labour market training centres in Sweden), the OECD urged its Member States to be cautious about contracting their services out because cost savings were not realised in numerous other cases. Furthermore, there had been no systematic evaluations to test whether contracting out had negative effects on the quality of the services (OECD 1997a, 18f).

Since the OECD Member States had requested a follow-up conference on the PES in 1997, a large-scale meeting was organised in Prague in July 20oo. At this conference titled "Labour Market Policies and the Public Employment Service", labour market experts not only identified a "sea change in PES working methods" but also recognised a set of good practices. In addition to repeatedly stressing activation as the most appropriate way forward, the PESs also needed to adopt "private sector practices and develop modern management methods", while retaining however, a "public service ethos". The most frequent themes included (OECD 2001, 61):

- Customer service. Like the customers of private business, jobseekers and employers seek rapid, easily accessible services, without queues, misdirection or red tape. This focus has been typified by the use of customer satisfaction surveys, one-stop shops and the expansion of telephone services and information technology.

- Information technology. Internet vacancy banks are only the most obvious among a number of IT-related developments, which include $\mathrm{CV}$ data banks, on-line training, improved electronic exchange of information between different organisations and providers, and fast entry of, and access to, register information by PES staff.

- PES performance indicators and jobseeker classification instruments. The use of placement rates and a variety of other indicators for assessing performance at local, regional and national level of the PES has become relatively commonplace. ...

- Contestability and financing mechanisms. The purchase of some proportion of intensive job-search assistance services and labour market training from private sector providers has become relatively commonplace.

In summary, the reform ideas first proposed in the 1994, which were strengthened and streamlined by the ELSA Committee meeting in 1997, and subsequently reaffirmed in 2000 at the Prague Conference, focused on "modernising" PES governance structures by embracing a service and 
market orientation akin to the private sector. The OECD's "ideational turn" thus incorporated important aspects of the philosophy of New Public Management, which had generally become popular in public sector reform. In fact, the OECD played a crucial role in spreading NPM ideas, most importantly by setting up its Public Management Service (PUMA) in 1989 (Mathiasen 2005, 651), which subsequently produced key documents in favour of public sector reform along NPM lines (e.g., OECD 1993b; OECD 1993ff; OECD 1997b). ${ }^{11}$ While there are countless definitions of NPM, they all share some common ideas and principles, centred on the goal of transforming state bureaucracies - rightly or wrongly associated with inefficiency, red tape, and ineffective use of public programmes - into modern management agencies, emulating private business best practices. As such, the key message of NPM - then taken over into PES reform - was to "reinvent government" and to recalibrate "public governance" through (partial) privatisation, ${ }^{12}$ deregulation, and decentralisation, while increasing competition, promoting new partnerships and introducing new incentive structures to both public employees and customers (cf., Osborne and Gaebler 1993; Pollitt and Bouckaert 1995; 2000; 2004; Weishaupt 2010a).

\section{Box 8}

The Danish “Active Line"

Based on the findings of the multi-partite Zeuthen Commission, assembled in 1991, and the positive experiences made with the Youth Allowance Scheme introduced in 1990 (see Chapter IV), the Danish Social Democrats gradually and sequentially introduced comprehensive changes to the Danish labour market under the heading of an "Active Line". The two main elements of structural changes included (a) the modernisation of the Danish PES (see chapter VI), and (b) a shift away from traditional ALMPs toward activation. The shift toward activation in Denmark was based on the "revival" of the constitutionally anchored "right and duty to work" (Greve 2000, 329), echoing Delors' "mutual obligations" and foreshadowing New Labour's "rights and responsibilities" rhetoric. The labour market reforms, successively introduced in between 1994 and 1999, substantially recalibrated almost the entire set-up of negative and positive incentive structures in Denmark. While access to unemployment benefits was gradually reduced from nine to four years - leaving the generosity of benefits intact - "compulsory" activation was gradually introduced, timetables were tightened, and participation in ALMPs no longer (re-)qualified for UB. The "threshold" for activation was decreased to two years in 1996 and to 12 months in 1999. The young unemployed could be activated earlier during periods of joblessness, typically after six months (Lindsay and Mailand 2004,133 ). There was also an option for "early activation" at three months for clients at risk of becoming long-term unemployed. Compulsory activation typically went 
hand in hand with the drawing of individual action plans that were primarily seen as "moral contracts", codifying the rights and duties of jobseekers and the state. With regard to positive incentives, the Danish government mainly focused on a wide range of non-financial incentives, including high-quality training, which remained a "public" responsibility, and a plethora of other supply-side and demand-side programmes (e.g., Jobtraining, Jobrotation, Pool Jobs, Flexjobs and a variety of "leave" programmes, including a Childcare Leave, Sabbatical Leave, and an Educational Leave scheme).

\section{The EU and the Modernisation of Public Employment Services}

With an operational shift of labour market policy toward early interventions, preventative strategies, and the individualisation of services, the EU recognised the need for the modernisation of the national Public Employment Services along NPM lines ${ }^{13}$. During the launch of the EES, PES reform was considered a key goal, even though it was not explicitly formulated in the Guidelines as such (interview, especially DGEmpl3, but also BMAS6). ${ }^{14}$ Put differently, achieving the quantified targets with respect to early, customised interventions and ALMP participation rates required a modernised, and more efficient, PES capable of delivering such services adequately and without requiring additional funding. Moreover, in the spring of 1997, shortly before the launch of the EES, the DG for Employment, Social Affairs and Equal Opportunities (henceforth DG Employment) also set up a Network of the Heads of Public Employment Services (HoPES), within which the heads of national PESs would meet bi-annually to promote ideational exchange and co-operation (cf., Weishaupt 2010a). ${ }^{15}$ HoPES was designed to provide an effective forum for mutual learning and to serve as a supporting structure to initiate, foster, and enhance national PES modernisation efforts (interview, DGEmpl 3 ). ${ }^{16}$ The Commission, in turn, placed itself in a "driving seat" in the PES network, where it early on identified four common priority areas for institutional advancement in support of the EES:

PES should (a) obtain substantial access to vacancies, (b) develop arrangements for the systematic case management of all registered unemployed jobseekers, (c) contribute to the co-ordinated delivery of all public services to jobseekers, focused on their reintegration, and (d) develop strong partnerships with other relevant actors on the market. In addition, there is a need for a more active approach to the promotion of occupational as well as regional mobility in Europe as a means of increasing job opportunities and improving job matching (Commission of the European Communities 1998, 14, emphasis added). 
Subsequently, the European Commission issued a series of more specific recommendations, including: (1) the development of service enterprise features, (2) the use of modern information and communication technology to improve client services, (3) case management and early interventions, (4) continuous monitoring and in-depth analysis of labour market conditions and trends, (5) the co-ordination of various PES functions, and (6) the building of partnerships with other stakeholders in the labour market (Commission of the European Communities 1999a, 26f).

In other words, like the OECD, the European Commission fully incorporated - without using the name (interview, DGEmpl3) - the NPM philosophy. The Commission hoped that when Member States would translate these new priorities and recommendations into action, PESs would be transformed into outward-looking, efficient and effective, modern "service providers", capable of delivering "individualised service packages" in the form of "individual action plans" to jobless clients. By turning PESs into "one-stop shops at the local level", these public agencies would thus become more attractive to both jobseekers and employers, while generating new synergies through the active engagement with all relevant stakeholders, including the social partners, vocational training centres, private placement services, and institutions that assist other inactive people who are not registered as unemployed (Commission of the European Communities 1998, 16ff).

In addition to key concepts such as case management, individual action plans, early interventions, and local partnerships, the concept of "quality" became part of the European PESs jargon in 1999 (Commission of the European Communities 1999b, 1). While some EU Member States, including Austria, Ireland, the Netherlands, Sweden and the United Kingdom, had already undergone reforms to improve the quality of their service delivery in the early 1990s, other EU Member States now recognised the need to follow suit. Accordingly, "customer satisfaction", "minimum quality standards" and "higher staff productivity" became new buzzwords. In a follow-up study conducted by the Commission and published in June 2000 , the success of the "service model" was praised and the use of individual case management, including the use of activation, preventative measures and, in particular, the individual action plans as instituted by Austria, Denmark and France, were singled out as particularly virtuous practices (Commission of the European Communities 2000, 5). In addition to the new focus on developing customer orientation and quality control, the Commission subsequently also endorsed "performance management" through the introduction of management-by-objective (MBO) 
systems. While Allan Larsson had been an early advocate for moving from "management by regulation to management by objectives" (e.g., Larsson 1999a; 1999b), a comprehensive study of EU Member States' PES governance systems published in December 2000 now formally recommended the "introduction of MBO in the PES of countries without performance management systems" (Mosley et al. 2000, viii). ${ }^{17}$ This conclusion was reached because $\mathrm{MBO}$ systems:

- help to clarify priorities in labour market policies

- set clear standards in terms of which PES performance can be fairly assessed

- shift emphasis from the inputs of ALMP to policy outputs and impacts, providing an instrument for improving both the efficiency and effectiveness of policies

- are an appropriate tool to support the implementation of the European Employment Strategy (Mosley et al. 2000, viii).

In short, by the turn of the millennium, the heads of PES and most Western policymakers had agreed upon and committed to the modernisation of labour market services and offices in line with a new "service model" that was built on key features such as (a) activation, i.e., a more rigorous and earlier application of job search requirements; (b) case management, i.e., individualised, tailor-made services for PES customers; (c) performance management, i.e., the introduction and/or strengthening of MBO governance techniques to advance the centres' steering capacity, ensure programme cohesion, and improve transparency; and (d) decentralisation, i.e., the promotion of local level flexibility and the expansion of local partnerships. In other words, the Commission and HoPES promoted institutional reforms that were largely based on the NPM philosophy and almost identical to the recommendations put forward by the OECD in 1997.

\section{V.4 Further Ideational Convergence: The Reassessed OECD Jobs Study and the Revised Lisbon Agenda}

Lisbon and Beyond

The Lisbon Strategy launched in March 2000 during a rather unique alignment of almost exclusively Social Democratic governments - 11 of the 15 Member States were governed by centre-left parties, including the big three, Britain, France and Germany - marked a "double departure for the 
EU" (Zeitlin 2008b, 436). On the one hand, the EU committed itself to becoming "the most competitive and dynamic knowledge-based economy in the world, capable of sustainable economic growth with more and better jobs and greater social cohesion" (Council of the European Union 2000). At the heart of the so-called Lisbon Agenda lay a modernised European Social Model with three elements, including "making more investments in people, activating social policies and strengthening action against old and new forms of social exclusion" (Rodrigues 2003, 17). As such, the "Lisbon Summit in 2000 marked a 'true watershed' in employment and social policy by bringing together economic and social policy in a longterm perspective" (Larsson 2001, 51). On the other hand, the EES was strengthened and the Open Method of Co-ordination (OMC) formalised as a framework within which national governments could improve their economic and social performance. The EU outlined that the OMC would be used in a variety of social policy areas, including social inclusion, pensions, and health care, this is to say, in domestically sensitive areas where mutual learning promised to be an appropriate tool to overcoming uncertainties (Zeitlin 2005b). Lisbon also substantially strengthened the EES by arming it with additional "hard targets" - to be reached by 2010 - such as an overall European employment rate of 70 percent and an employment rate for women of more than 6o percent (Council of the European Union 2000, 10). Subsequently, the Stockholm European Council in March 2001 introduced a 50 percent employment target for older workers aged 55-64 (Council of the European Union 2002, 12).

While the Commission praised the success of the EES in its Five-Year Review in July 2002 - especially because EU members had increasingly moved from "managing unemployment to managing employment growth" - there was also a perceived need to revise the EES (Commission of the European Communities 2002, 8). As a result, in April 2003, the Commission proposed, and the Council endorsed, a simplification of the EES by consolidating the four pillars and corresponding guidelines into three overarching objectives, including (1) full employment, (2) quality and quantity of work, and (3) social inclusion and an inclusive labour market. The overarching objectives were then supported by "ten commandments" that were coupled, at least in some areas, with associated quantifiable targets. Finally, with respect to policy implementation and governance, the revised EES stressed the need for more effective public employment services, more involvement of the social partners, and the allocation of suitable financial resources (OPTEM 2007, 111). The following two boxes summarise the "ten commandments" and their targets. 
1. Active and preventative measures for the unemployed and inactive

2. Job creation and entrepreneurship

3. Address change and promote adaptability and mobility in the labour market

4. Promote development of human capital and lifelong learning

5. Increase labour supply and promote active ageing

6. Gender equality

7. Promote the integration of and combat discrimination against people at a disadvantage in the labour market

8. Make work pay through incentives to enhance work attractiveness

9. Transform undeclared work into regular employment

10. Address regional employment disparities

Source: Watt 2004, 126, table 1

\section{Box 10 Quantified Targets in the 2003 Guidelines}

1. Every unemployed person to be offered a new start (job or other employability measure) within 6 months of unemployment in the case of young people and 12 months in the case of adults

2. By 2010,25 percent of the long-term unemployed to participate in an active measure, with the aim of achieving the average of the three most advanced member states

3. By 2010 , at least 85 percent of 22 year olds in the European Union should have completed upper secondary education

4. The European Union average level of participation in lifelong learning should be at least 12.5 percent of the adult working-age population (25-64 age group)

5. By 2010, achieve an increase, at EU level, of the effective exit age from the labour market from 60 to 65

6. Provide childcare by 2010 to at least 90 percent of children between 3 years and the mandatory school age and at least 33 percent of children under 3 years of age

7. Achieve by 2010 an EU average rate of no more than 10 percent early school leavers

8. All job vacancies advertised by national employment services should be accessible and be able to be consulted by anyone in the EU by 2005

Source: Watt 2004, 128, table 2

Parallel to the revision of the EES, during the March 2003 Spring Council meeting, an eight-person strong taskforce was set up to prepare additional recommendations before the following year's Spring Council meeting. This taskforce, which was led by former Dutch Prime Minister Wim Kok, ${ }^{18}$ presented its conclusions in November 2003 in a report entitled 
"Jobs, Jobs, Jobs: Creating More Employment in Europe". The results presented in this report were generally seen as a warning: the Lisbon objectives will not be met unless Europe reforms its labour markets (European Report 2004a). The group further concluded that the EES should focus on three reform priorities, including (1) improving the supply of labour (i.e., increasing the active population and modernising social protection systems); (2) enhancing the adaptability and flexibility of labour markets, and (3) making more investments in human resources (OPTEM 2007, 110).

The 2004 Spring Council then requested an additional, follow-up report by a High Level Group, chaired again by Wim Kok, to "instil new life into the failing Lisbon Strategy" (European Report 2004b). This second report concluded that the Member States' progress was too slow and/ or limited to meet the 2010 objectives. For that reason, the EES needed to refocus on "growth and jobs, supported by intensified peer pressure on Member States through a process of 'naming, shaming, and faming"' (Zeitlin 2008b, 436). This focus on "growth and jobs" was warmly welcomed in 2005 by the newly appointed Commission President José Manuel Durão Barroso, who quickly changed the "mood and direction" of the Lisbon Process (interview, EMCO2). While Barroso rejected the revision of the Lisbon Strategy through a process of naming, shaming, and faming, his Commission introduced a new institutional design that combined the European Employment Guidelines and the Broad Economic Policy Guidelines into a single set of 24 Integrated Guidelines for Growth and Jobs. The EES was thus integrated into the revised Lisbon Strategy, in which employment received its own chapter, based on eight guidelines. This integration, however, effectively ended the "equilateral triangle" envisioned by the original Lisbon Agenda, namely equally weighing economic, labour market, and social policy, which were then seen as mutually reinforcing. By reducing employment policy to a chapter, the policy domain also lost some of its status, both symbolically and in terms of visibility. The comprehensive National Action Plans were now not only subsumed into the less detailed - with respect to labour market policy - National Reform Programmes, but the Joint Employment Reports became part of the single Annual Progress Report, addressing the entire area of reforms. Inserting employment into the greater BEPG was an indication that economic goals were going to be the number one priority of the newly relaunched Lisbon Strategy, while the social ambitions disappeared entirely for the time being (cf., also Zeitlin 20o8b, 438-41). However, "following an effective EU-level campaign led by social 
NGOs with support from key Member States and the European Parliament, social cohesion objectives, including the commitment to a decisive reduction of poverty and social inclusion, were formally reinstated in the Lisbon Strategy by the 2005 Spring European Council, a decision reaffirmed by successive Spring European Councils in 2006 and 2007" (Zeitlin 2008b, 437).

Despite - or maybe because of - its "neo-liberal turn", most, if not all, European policymakers continued to adhere to the idea of a European Social Model. ${ }^{19}$ Searching for new ways to promote economic and employment growth without abandoning long-standing norms and structures of social protection, the concept of "flexicurity" emerged as a possible avenue. While flexicurity was first only debated in elite and expert circles such as EMCO in the early $2000{ }^{20}$ it rose to the top of the European agenda at the Summit Meeting in Hampton Court in October 2005. ${ }^{21}$ The Commission, and the subsequent Austrian and Finnish presidencies (spring and fall of 2006 respectively), have continued to advance the concept. Many EU Member State governments, the European Parliament, the main European trade union associations (more hesitantly) and employers' organisations (more enthusiastically) also showed great interest in it (Keune and Jepsen 2007, 8). Moreover, an EMCO working group on flexicurity was set up under the Austrian presidency, which produced a report intended to develop a consensus on a set of common principles of flexicurity (EMCO 2006). ${ }^{22}$

While flexicurity is rooted in the Dutch Flexibility and Security Act of 1999, coupling a relaxation of dismissal laws and the rules for setting up temporary work agencies with higher levels of security in atypical work (Visser 2005), the current debate mainly centres on the Danish variant, typically encapsulated by the "Golden Triangle" of lax employment protection standards coupled with generous unemployment benefits and extensive ALMPs (e.g., Madsen 2005; Wilthagen 2005). The core idea is that employers can "hire and fire" employees with relative ease, while workers are not only protected by generous unemployment benefits (which allow them to sustain their economic well-being), but also have access to ALMPs, which enable them to more easily transfer into new areas of employment. As a result, Danish job mobility is among the highest in Europe, while economic productivity is also high and relative poverty low.

It was quite apparent, however, to the EMCO members in charge of producing common principles of flexicurity - and interviewees reiterated this repeatedly - that the Danish version of flexicurity not only required 
substantial financial resources to provide both active and passive LMPs, but it also built on a long tradition of social partnership (see chapter III and IV). But because either - or perhaps even both - of these factors may not be readily available in other Member States, a wide variety of different mixes of employment security and labour market flexibility had to be included that could serve as functional equivalents. In June 2007, the Commission circulated a Communication suggesting eight common principles - subsequently adopted by the Council in December 2007 - reflecting the results of the EMCO working group.

\section{Box 11 Common Principles of Flexicurity}

1. Flexicurity is a means to reinforce the implementation of the Lisbon Strategy, create more and better jobs, modernise labour markets, and promote good work through new forms of flexibility and security to increase adaptability, employment and social cohesion.

2. Flexicurity involves the deliberate combination of flexible and reliable contractual arrangements.

3. Flexicurity approaches are not about one single labour market or working life model, nor about a single policy strategy: they should be tailored to the specific circumstances of each Member State.

4. Flexicurity should promote more open, responsive and inclusive labour markets overcoming segmentation. It concerns both those in work and those out of work.

5. Internal (within the enterprise) as well as external flexicurity are equally important and should be promoted. Sufficient contractual flexibility must be accompanied by secure transitions from job to job.

6. Flexicurity should support gender equality.

7. Flexicurity requires a climate of trust and broadly-based dialogue among all stakeholders, where all are prepared to take the responsibility for change with a view to socially balanced policies.

8. Flexicurity requires a cost effective allocation of resources and should remain fully compatible with sound and financially sustainable public budgets.

Source: http://ec.europa.eu/employment_social/employment_strategy/flex_ingredients_ en.htm, last accessed on 3 August 2008

The language used to describe flexicurity - and thus the normative and cognitive underpinnings - has explicit "third way" characteristics. Just like activation and the "PES service model", it seeks to combine "free market" elements - in particular the reduction of EPL standards with state-induced "capacity-building" and "social cohesion" elements, by stressing "comprehensive lifelong learning", "effective ALMPs" and 
"modern social security systems" (Commission of the European Communities 2007,5$){ }^{23}$

In summary, while labour market policy has lost "visibility" and economic issues seem to outweigh equity concerns due to the reshuffle of the European Commission, the effective alignment of socially oriented actors has led to the continuation of a lively debate about, and programmatic focus on, social and labour market policies. However, a risk remains that the new governance architecture may lead to less, not more, policy co-ordination (as the range of objectives has narrowed); more unilateralist, in contrast to co-ordinated, reform endeavours (because "process ownership" has been lost); and the emergence of dual-track, parallel "jobs and growth" and "greater social cohesion" processes, replacing the mutually reinforcing triangle of economic, employment, and social policies (for a similar assessment, see Zeitlin 2008a, 438f).

\section{Toward the OECD Jobs Study Reassessment}

The OECD has also gone through a long period of reflection, evaluation, and reorientation. By 2003, the OECD was echoing the Lisbon Strategy's ambitions by calling for "more and better jobs" and for the mobilisation of all under-represented groups. The OECD, similar to the Lisbon employment targets, also began advocating reductions in nonemployment and a focus on "policies that help people move up career ladders", while recalibrating benefits and tax regimes so that they "make work pay". The OECD specifically reiterated that "activation" policies, including benefit conditionality, individualised services, and the maintenance of effective contact with the PES, were a necessary component in moving beneficiaries of unemployment and other non-employment benefits into jobs (OECD 2003, 14). In light of the efforts to modernise PESs and the explicitly expressed shift toward creating more and better jobs, the OECD Employment and Labour Ministers concluded in September 2003 that the almost decade-old Jobs Study needed to be reassessed. Three years later, the OECD published its reassessment in the 2006 Employment Outlook, which included substantial revisions to its previous recommendations, based on "new insights and policy lessons" (OECD 2006a, 13). The following table summarises these seven new insights, in the same order they were presented in the Employment Outlook. 
1. Activation or mutual obligations approaches can co-exist with relatively generous unemployment benefits when providing strong incentives for the unemployed to seek and accept work;

2. It is vital to remove existing barriers to labour force participation among women (e.g., through the introduction/expansion of flexible working patterns, appropriate tax incentives, adequate, but not overly long, paid parental leave, access to good quality and affordable childcare, and more sharing responsibilities between men and women), older workers (e.g., by phasing out remaining disincentives to continued work and various pathways into early retirement) and under-represented groups more generally;

3. A better alternative to merely easing the conditions of temporary jobs while leaving those governing permanent jobs unchanged - which results in a growing duality in labour markets and hinders investment in growth - is flexicurity;

4. Expand labour demand by pricing back into employment the lower-skilled who are excluded by tax, social contribution or institutional arrangements. Moreover, policies that stimulate product market competition will create new jobs, especially in the service sector;

5. Effective lifelong learning has great potential to help workers adjust to changing skills demands;

6. Stability-oriented macro-economic policy reduces cyclical output fluctuations and positively interacts with structural reforms;

7. There is no golden road to better labour market performance, but both the Englishspeaking and Scandinavian countries, especially Denmark, score high in this area.

Source: OECD 2006a, $13 f$.

The revised JS shows that the OECD has fundamentally reassessed many of its core cognitive beliefs. To some extent, the RJS even spelled out a gradual move toward - or at least positive acknowledgement of - something akin to a European Social Model. The Anglo-American deregulation of labour market institutions and decentralisation of wage-setting arrangements is no longer the (only) best-practice model and dominant message. Instead, partnership-based wage co-ordination, activation, (state-sponsored) lifelong learning and family policy, and making-work-pay measures are seen as potential remedies for high unemployment and appropriate measures for increasing employment. The shift in prescriptions from market forces to innovative public policy mixes is also evident in the listing of product market competition and stability-oriented macro-economic policy as the fourth and sixth policy lessons respectively, while new state-of-theart concepts such as "activation" and "flexicurity" are introduced first and 
third. In other words, the new OECD prescriptions contain "more carrots and fewer sticks" (Watt 2006, 11), and the tone of the prescriptions-compared to the original JS of 1994 - is significantly less "neo-liberal".

This endorsement of some state-led capacity building, in contrast to "negative" market making, has also been supported by a series of thematic reviews, including important Country Notes on early childhood education and care, conducted from 1998 to $2004,{ }^{24}$ an ongoing series of country studies on the reconciliation of work and family life, entitled Babies and Bosses, which was launched in 2002 , and a new project on ageing and employment policy, covering 21 OECD countries, which has led to a series of publications entitled Live Longer, Work Longer. These studies complement the EU's calls for innovative state interventions, in particular the state-led expansion of childcare facilities and lifelong learning measures, which are designed to achieve higher participation rates among women and older workers, less discrimination based on age or gender, and the provision of work and learning opportunities throughout the life-cycle.

To summarise, the OECD and the EU have arguably moved closer together with respect to their prescriptions: the EU has become more marketoriented and more concerned with growth, while the OECD has become more equity and partnership oriented and less concerned with labour market "rigidities". The reorientation of the OECD is probably more noticeable. The OECD now not only criticises the expansion of "precarious" jobs, leading to insecurity, poverty and under-achievement, but also admits "there is no robust evidence for a significant direct effect of EPL on unemployment" (OECD 2006a, 96). ${ }^{25}$ Likewise, the OECD "core" prescription of a general move toward a decentralisation of wages has been replaced by the (somewhat reluctant) suggestion that "high corporatism bargaining systems tend to achieve lower unemployment than do other institutional set-ups" (OECD 2006a, 86). In other words, the RJS accepts the virtues of Nordic labour market models and has become more sceptical about the merits of entirely "free" labour markets. The EES, in turn, more fully embraces labour market flexibility (previously only referred to as adaptability) and has relegated employment to a chapter within the new NRPs. While this reorganisation was intended to "streamline" the parallel processes of the EES and the BEPG, it certainly favours efficiency over equity goals.

This process of convergence seems to have become possible due to (a) the frequent and institutionalised exchange of ideas and practices between the EU and the OECD since 1996 (Noaksson and Jacobsson 2003, 52); (b) the conduction and publication of empirical studies that provided hard evidence for the vibrancy of the Nordic models, especially Denmark's, and the 
lack of evidence to substantiate some of the key recommendations in the 1994 JS, especially with respect to the effects of EPL and wage bargaining on unemployment levels; and (c) the emergence of "bridging" concepts such as activation, the "PES service model", and more recently flexicurity that all combine rights with obligations, public services with private market mechanisms, and individual (employment rather than job) security with labour market flexibility in virtuous circles. The table below summarises the key developments of the last decade and a half in both the EU and the OECD.

\section{The EES and the OECD Peer-Review Processes: Birds of a Feather?}

Before concluding this chapter, I would like to raise the following questions: Are the EU and OECD peer-review and policy diffusion processes similar creatures, and if not, do we have reason to believe that one process may be superior to the other? Quite certainly, the OECD processes of peer review, i.e., the exchanging of ideas and best practices, promoted and monitored by an executive body, while leaving policy implementation to the members, was a great source of inspiration for the EES (Noaksson and Jacobsson 2003; Visser 2005, 181). Accordingly, both the OECD peer-review process and the Luxembourg Process are based on a method of "soft" co-ordination and not on "hard", justiciable laws (e.g., Zeitlin and Trubek 2003; Trubek and Trubek 2005; Zeitlin et al. 2005). Despite these apparent similarities, the actual peer-review processes associated with the EES are much more frequent, more rigorous, and more institutionalised than those of the OECD. More specifically, the EU Member States are examined annually through Joint Employment Reports, (now Annual Progress Report, $A P R$ ) in contrast to every one-and-a-half to two years by the OECD. ${ }^{26}$ Moreover, EU members are required to draft National Action Plans for Employment (now National Reform Programmes), for which there is no functional equivalent in the OECD peer-review process. ${ }^{27}$ Third, and perhaps most importantly, in the context of EU peer review exercises, a wide variety of actors, including the social partners and government representatives from labour and social affairs departments are involved in the process, which is in contrast to the primarily technocratic actors involved in the OECD process, whose contacts are mostly limited to national representatives in the finance and economics ministries. Fourth, the newly established Employment Committee (EMCO), replacing the Employment and Labour Policy Committee of 1996, is constitutionally anchored in the Amsterdam Treaty (Art. 130) and represents the key forum for ongoing, regular, and systematic deliberations on labour market and social policy developments in the 


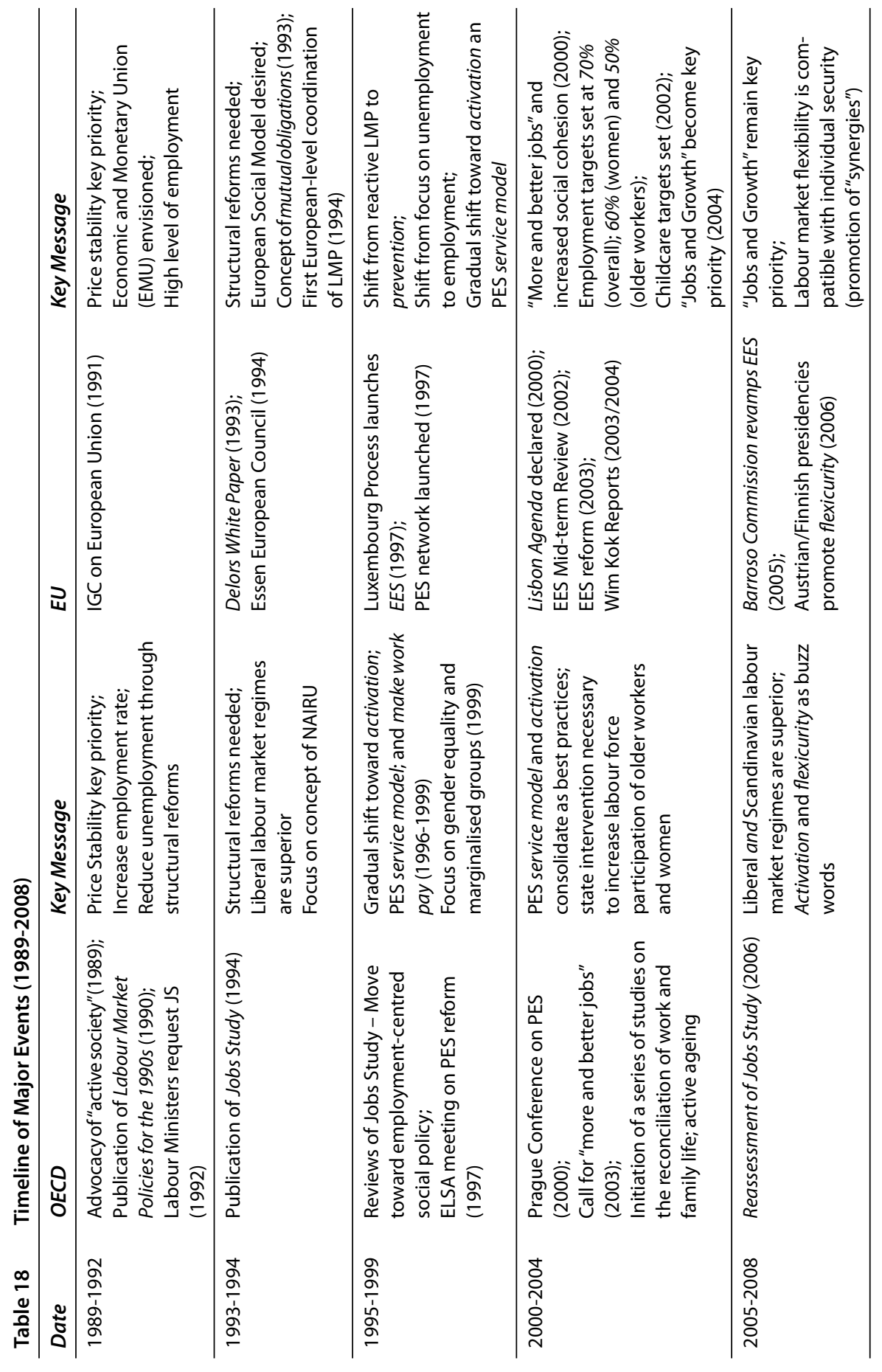


EU. Moreover, EMCO hosts the debates and negotiations regarding Employment Guidelines and EMCO's conclusions are almost always accepted without any substantive changes by the Council, making EMCO a very powerful forum (Interview, BMAS2). And finally, in addition to the regular peer-review exercises, the Commission also introduced a new peer-review mechanism, the Mutual Learning Programme (MLP) in 2005. The MLP replaces the Peer Review Programme, first launched in 1999, and brings together national experts and a variety of stakeholders with the aim to encourage mutual learning and to assist in transferring good practices. The core goal of the review process recalibration is to "achieve a higher level of dissemination and coherence" (MLP 2005). MLP participants now conduct "thematic" research in biannual cycles in areas of key policy priority, arrange meetings with the Member States to review the reports and findings, and disseminate the information to a wide range of actors. EMCO is closely involved in this process. In summary, the EES's methodology goes beyond what the OECD can produce, and the possibility of "mutual learning" is greater. The EES process has thus been described by many observers as "contextualised", allowing consultation and ongoing feedback, in contrast to the OECD's process, which is seen as "decontextualised" and a "one-size-fits-all" approach (Hemerijck 2002; Zeitlin 2003, 15; Visser 2005, 181). As such, the OECD is often perceived as a "teacher" - typically an economist or lawyer - telling member countries how they ought to behave. The EES, in turn, is perceived as a "joint endeavour" of a large variety of actors (Eichhorst and Hemerijck 2008, 31). The EES's real advantages therefore lie in the fact that participants may claim "ownership" over its processes, it may mobilise a wide(r) variety of participants and stakeholders, it has the potential to "persuade" actors about the appropriateness of reforms, and, last but not least, it may even provide some financial incentives because the implementation of reform proposals may be subsidised through the European Social Fund (ESF) (e.g. Weishaupt 2009).

Despite, the EES's superior "learning" context, I argue that it is precisely the OECD's "decontextualised" and "efficiency-oriented" approach that sometimes makes its recommendations more attractive to policymakers. This is the case because OECD recommendations are seen - or can be presented to electorates - as "hard facts" rather then (watered down) political compromises. The highly politicised 1994 JS, however, may be the exception. This means that the OECD is less useful as a "learning tool" and more practical as an instrument to convince other, perhaps more hesitant, actors or society in general about institutional changes that are deemed necessary to policymakers. In other words, in these contexts OECD recommenda- 
tions become an element of "powering" rather than "puzzling". Hence, if and when the conclusions of the EES and the OECD are consistent, they can become powerful, mutually reinforcing instruments for policymakers, offering a context for reflexive learning and the gathering of "hard evidence" with which analytical solutions can be turned into real policy outputs.

Finally, it is also important to mention that there is a substantial amount of overlap in the memberships of the two organisations, and experts are engaged in regular and institutionalised meetings, joint work in common projects, and ad hoc discussions. As such, learning across institutional boundaries is certainly also possible, or even probable, because the EU and the OECD have a relationship, which is characterised by both "emulation and competition" (interview, DGEmpl3).

The following graph illustrates the process of policy diffusion and mutual learning, while differentiating the various focuses and processes in the OECD and the EU.

Figure 3 The Processes of Peer Review in the EU and the OECD

\begin{tabular}{|c|c|c|}
\hline Process & $E U$ & $O E C D$ \\
\hline $\begin{array}{l}\text { Definition of Problem } \\
\text { (Cause and Effect) }\end{array}$ & $\begin{array}{l}\text { Structural unemployment; } \\
\text { low employment }\end{array}$ & $\begin{array}{l}\text { Structural unemployment; } \\
\text { low employment }\end{array}$ \\
\hline$\downarrow$ & $\downarrow$ & $\nabla$ \\
\hline $\begin{array}{l}\text { Definition of Common } \\
\text { Goals }\end{array}$ & $\begin{array}{l}\text { Full Employment (70\% - 60\% } \\
\text { - 50\% Employment Targets) }\end{array}$ & $\begin{array}{l}\text { "Active Society" and "more } \\
\text { and better jobs" }\end{array}$ \\
\hline $\begin{array}{l}\text { Monitoring and } \\
\text { Reporting of national } \\
\text { Implementations }\end{array}$ & $\begin{array}{l}\text { Commission drafts } A P R / E G L ; \\
\text { Committees review; Council } \\
\text { approves; Member States } \\
\text { write NRPs }\end{array}$ & $\begin{array}{l}\text { Country Desk prepares } \\
\text { Country Report and visits } \\
\text { Country; Drafting of Country } \\
\text { Report }\end{array}$ \\
\hline$\downarrow$ & $\nabla$ & $\downarrow$ \\
\hline $\begin{array}{l}\text { Multilateral } \\
\text { Deliberation }\end{array}$ & $\begin{array}{l}\text { Cross-examination of } \\
\text { NRPs; Discussion in } \\
\text { EMCO; Consultation with } \\
\text { Social Partners; Bilateral } \\
\text { discussions between MS and } \\
\text { Commission }\end{array}$ & $\begin{array}{l}\text { Discussion in Economic } \\
\text { Development and Review } \\
\text { Committee (EDRC) }\end{array}$ \\
\hline$\nabla$ & $\nabla$ & $\nabla$ \\
\hline $\begin{array}{l}\text { Recommendations and } \\
\text { Publication }\end{array}$ & $\begin{array}{l}\text { Publication of Annual } \\
\text { Progress Report (annually) }\end{array}$ & $\begin{array}{l}\text { Publication of Economic } \\
\text { Survey (every } 1 \frac{1}{2} \text { to } 2 \text { years) }\end{array}$ \\
\hline
\end{tabular}

Sources: Noaksson and Jacobsson 2003; Casey 2004; Dostal 2004; Schäfer 2006; Zeitlin 2008b; Interview, BMAS2 


\section{V.5 Conclusions}

In contrast to the 1960 s, there was no single point of reference (i.e., Sweden) and no single "voice" for the dissemination of good practices with respect to labour market measures in the 1990s. Instead, various countries such as Denmark and the Netherlands emerged as "good examples" in the mid-1990s (e.g., Auer 2000), ${ }^{28}$ and the UK toward the second half of the 1990s. These "good practice exemplars", however, had their own particular sets of strengths and weaknesses. ${ }^{29}$ Likewise, while the US seemed effective in achieving high levels of economic and employment growth during times when most of Europe was struggling - and thus served as a focal point in the 1994 OECD Jobs Study - the US's model of "free" labour markets remained, with few exceptions, the antithesis to the European Social Model, which was promoted by the EU. The agreement on neo-liberal prescriptions remained thus incomplete, many actors did not follow the OECD's recommendations, and no single country seemed to embody an institutional mix entirely desirable or transferable. Moreover, when the EU emerged as an "ideational agent" in addition to the OECD in the mid- to late 1990s, two partially overlapping and partially competing sets of recommendations were issued. While the OECD Jobs Study prioritised reducing unemployment through deregulatory structural reforms, with a focus on labour market "rigidities" such as organised wagesettlements, strict employment protection, and generous unemployment benefit regimes, the European Employment Strategy focused mainly on "positive" supply-side measures, such as individual case management and vocational training, while stressing the improvement of employment rates as the main focal point. As such, throughout the 1990s, there was no one clear country model to emulate and the EU and OECD presented two sets of - at times competing - recommendations.

However, in the second half of the 1990s, the OECD gradually reassessed many of its core beliefs, while the EU further developed its influence in the social sphere with the launch of the Lisbon Agenda in 2000 and the quantification of various performance indicators and targets. In the early 2ooos, an increasingly coherent set of recommendations emerged and a common normative and cognitive framework became gradually identifiable. This new labour market policy paradigm was based on (a) "activation" (i.e., early and systematic interventions, case management, and benefit conditionality); (b) a PES "service model" informed by NPM philosophy (i.e., customer orientation, sensitivity to efficiency and effectiveness of public programmes, and a governance architecture emulating 
private management structures); and (c) the promotion of employment through the use of "positive" capacity-building public policies, supporting a more inclusive labour market, especially with respect to women and older workers. More recently, the concept of flexicurity was added as a new supplementary element. This concept is still in its infancy, however, and it is thus too early to identify how precisely it will be translated into public policy recommendations. 


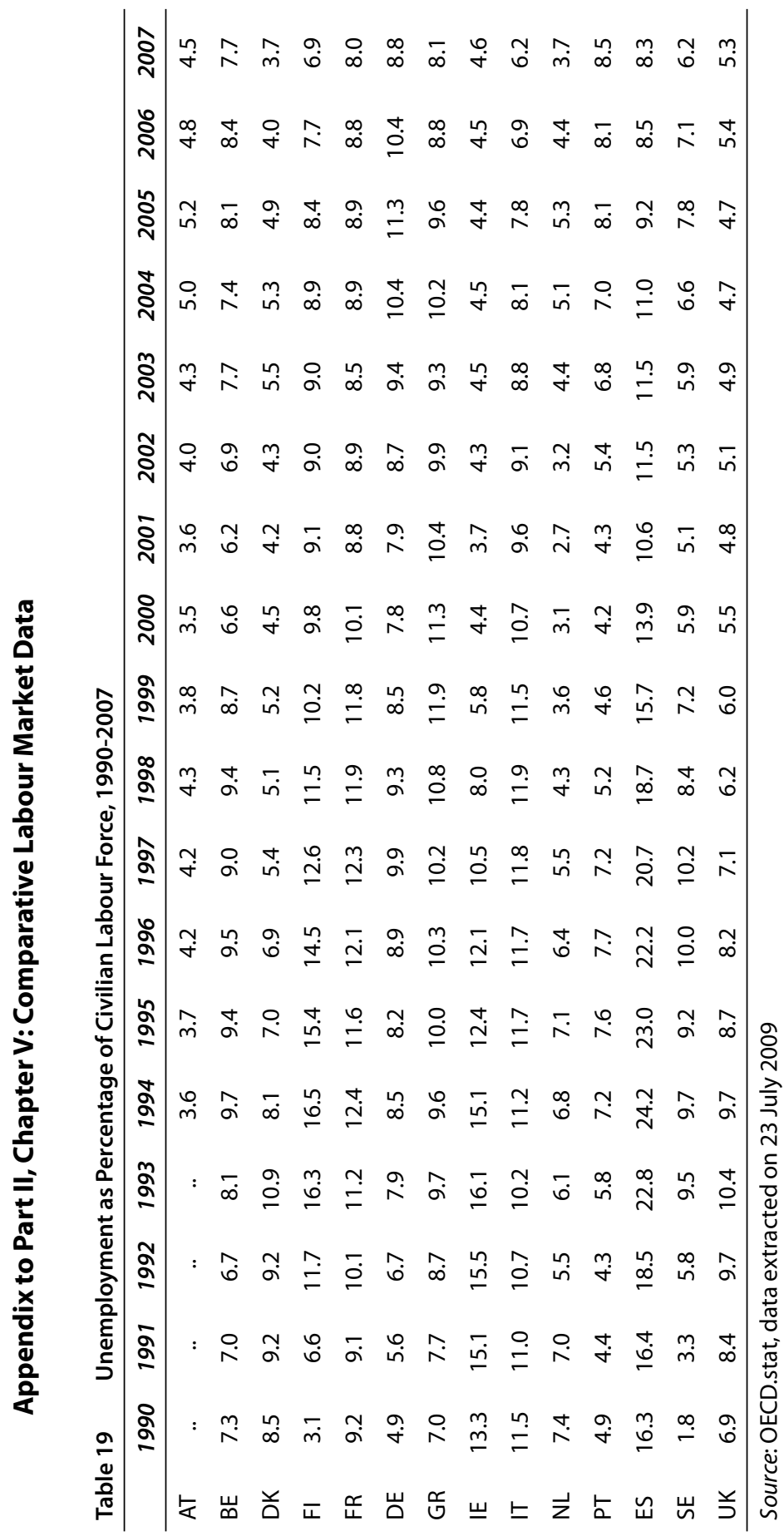




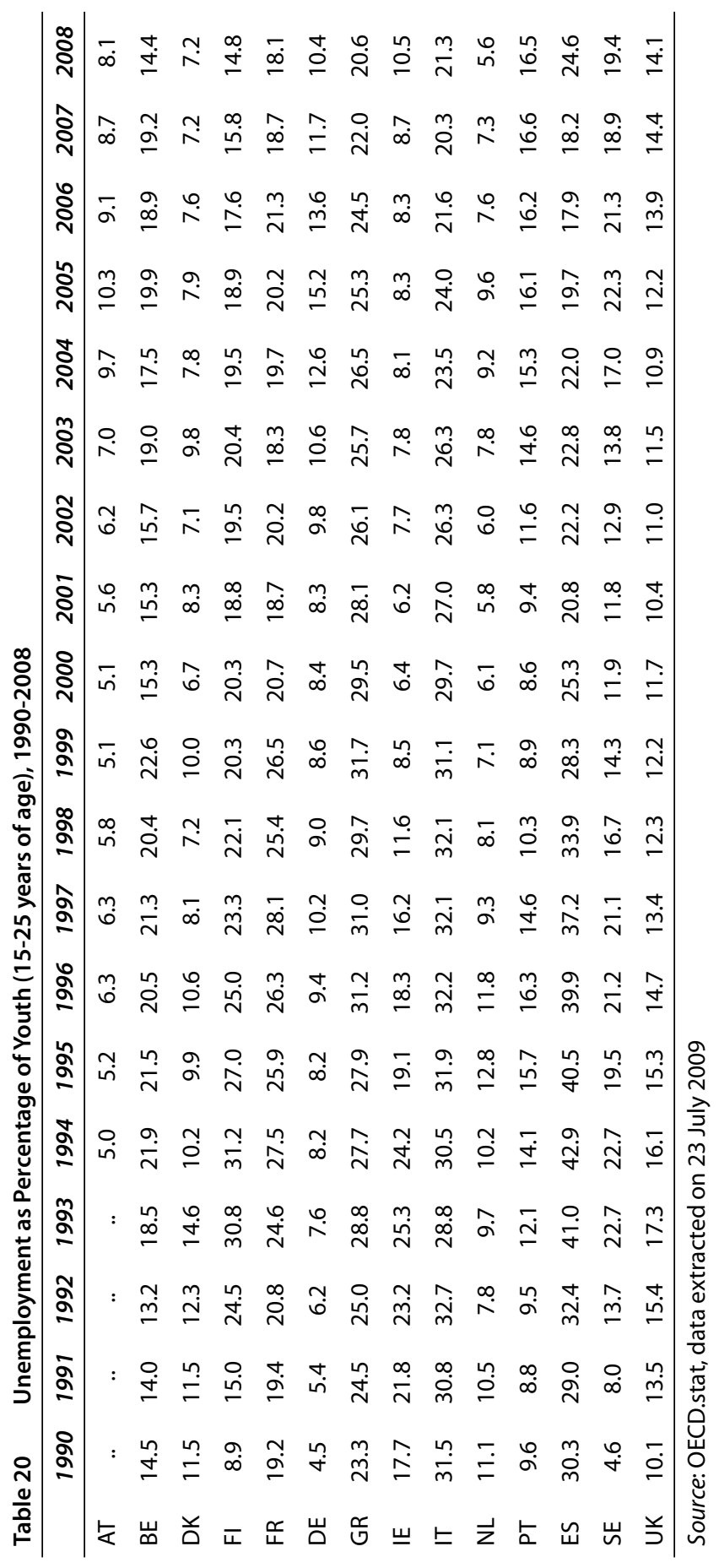




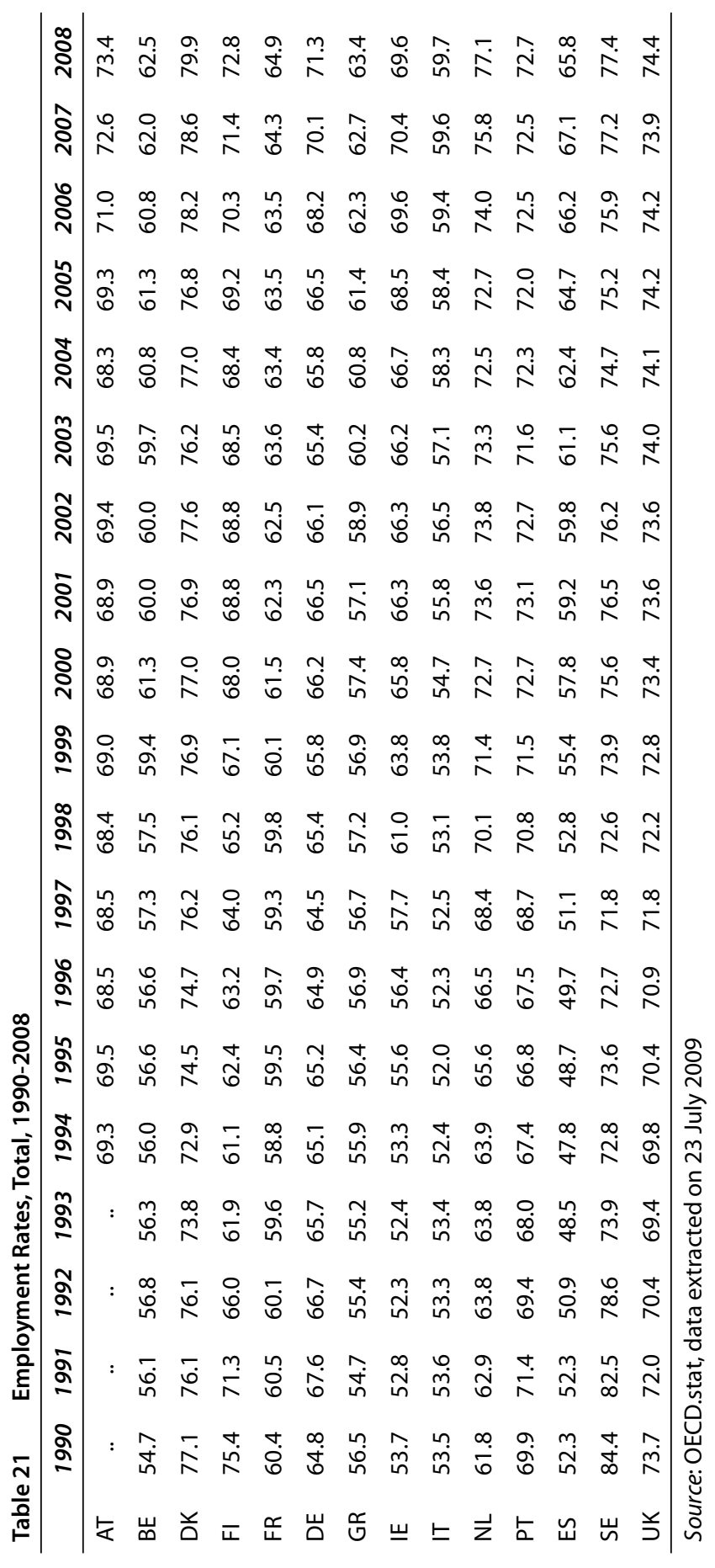




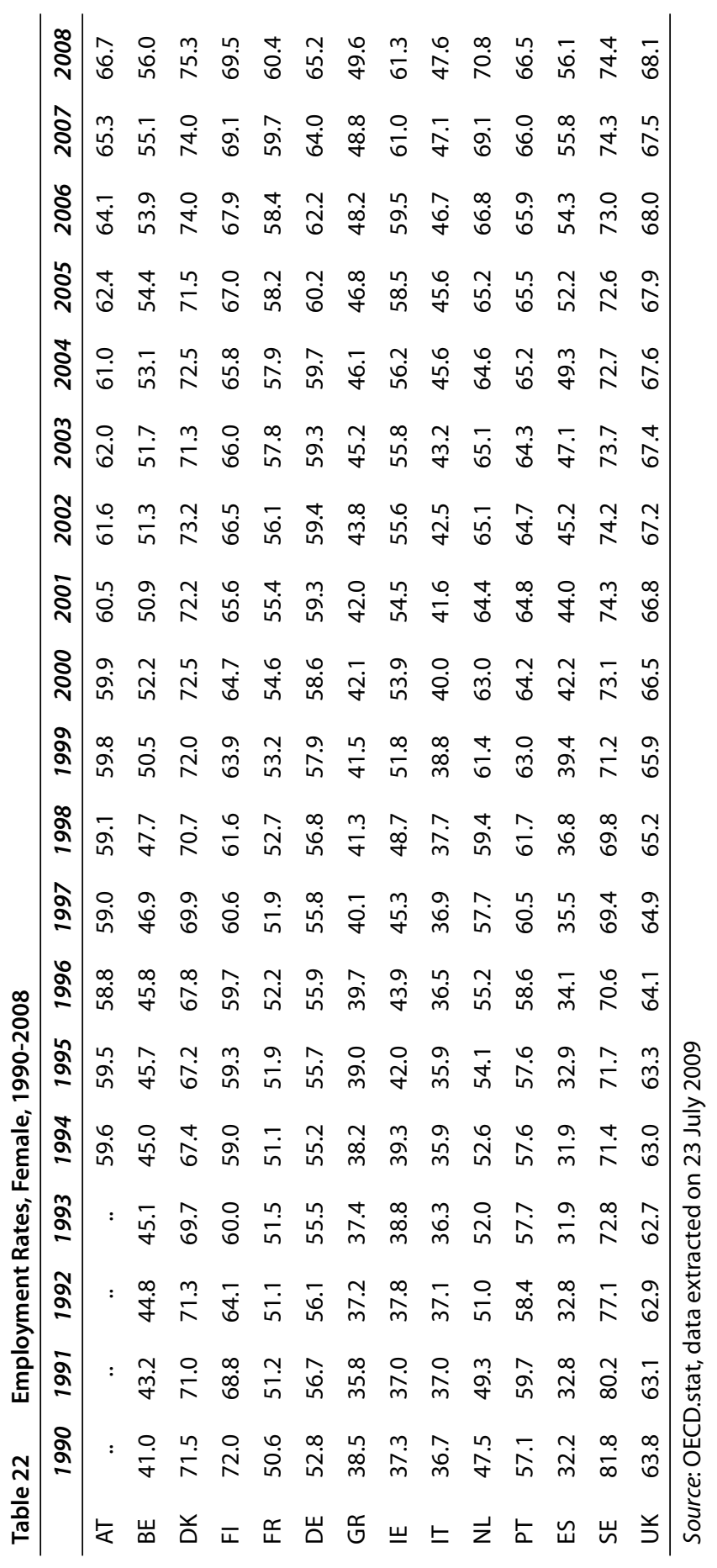




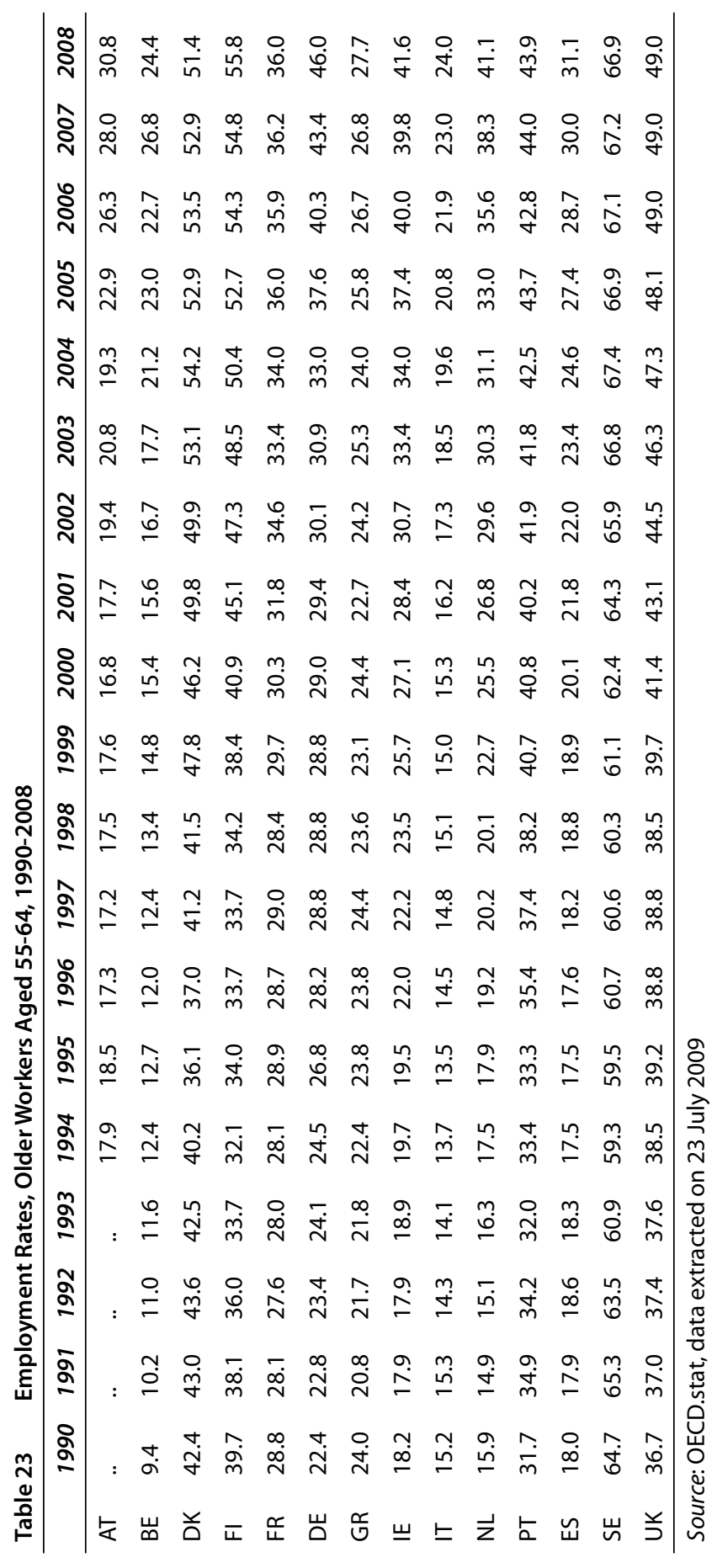




\section{The Emergence of the Activation Paradigm: Analysing Institutional Hybridisation}

The previous three empirical chapters have illustrated three phases of cognitive and normative shifts, leading to new policy agendas and institutional changes. The first, institutional consolidation phase, lasting from the mid-1960 to the early 1970s, was characterised by an ideational convergence on the conceptual and normative merits of the Swedish concept of active labour market policies, which were seen as an adequate instrument to simultaneously improve the adaptability of national economies and the mobility of individual workers. These ideas were spearheaded by the OECD, especially Director of Manpower and Social Affairs Gösta Rehn, and resulted in a "manpower revolution", associated with substantive national legislative changes, introducing or strengthening national public employment services and active manpower measures. The second "crisis" phase, lasting from the mid-1970s to the mid-1980s, was characterised by a major reorientation by national governments and the OECD alike. Keynesianism and other attempts to manage demand were gradually phased out and, in parallel, monetarist theory emerged, focusing on supply-side economics and inflation. With respect to labour market policy, there was no longer a clear point of reference for emulation and the OECD issued a variety of "theories" about the causes of, and remedies for, unemployment. This lack of a focal point reflected the dissent within the OECD about the most appropriate way to move forward as well as the existence of competing ideas about the role of labour market policies and institutions. It was during the 1980 os that country trajectories increasingly showed divergence along three reform strategies: Anglophone marketisation, Continental labour shedding, and Nordic social investment. Chapter V, in turn, outlined the emergence of an "activation paradigm" with a uniquely Anglo-Nordic focal point.

The remainder of this book seeks to delve deeper into two sets of questions: First, this chapter asks what caused certain countries to become trendsetters in activation policy, and to what extent these changes have led to a convergence of national models. For this purpose, an analytical 
overview of recent developments is presented, which includes an assessment of the four dimensions of labour market policy regimes as outlined in chapter II. The primary focus is placed on the same six cases analysed in chapters III and IV. Descriptive statistics, however, are presented and occasional references are made to other European cases throughout this chapter. Chapter VI concludes with a comparison of contemporary labour market policy regimes with those present in the mid-1980s. Subsequently, chapter VII asks how these institutional changes have come about in the context of national politics. For this purpose, the evolution of labour market policy from the mid-1990s to today is carefully traced in Germany and Ireland as two illustrative cases.

\section{Vl.1 Normative/Cognitive Dimension}

In chapter V, I argued that both the EU and the OECD embraced new outlooks on unemployment and the most appropriate institutional mix of policies located at the work-welfare nexus. The associated changes in the recommendations for their members in both international organisations are far-reaching, especially as both institutions have gradually converged on the "activation paradigm" and the associated focal points of a "PES service model" and a more inclusive labour market. These converging recommendations need to be interpreted as a reflection and consolidation of the members' new collective outlook - or at least an agreeable compromise - on the key notions regarding labour market institutions and instruments. The emergence of, and developments in, the EES in particular represent a real watershed. In contrast to the more technocratic and often prescriptive recommendations of the OECD, the EES Guidelines are produced after deep deliberations and negotiations in EMCO, the approval of the Council and the Commission, and the input of a wide variety of non-governmental organisations, the social partners, and a multiplicity of governmental departments and ministries. Accordingly, because reaching a compromise with such a large number of actors is a very "cumbersome" process, the results carry "great weight, because one can say that they represent the consensus of all EU Member States and the Commission" (interview, BMAS2, my translation).

Reaching such "cumbersome compromises" means that the formulation of EES Guidelines is a highly political process that entails elements of both "powering" and "puzzling". One the one hand, Member States bring their own, home-grown political agendas to the EU table. This means that they 
seek to advocate "their" models for domestic political gain, and they worry about the effects of EU Guidelines on national policies, e.g., reputational harm and financial costs. Quite clearly, however, Members States cannot simply "upload" their exact national models to the European levels and concessions must be made. On the other hand, the EES provides a forum through which policymakers are exposed to thought-provoking new ideas about common problems, which they can utilise in their respective national reform efforts. The same interviewee, who is also a member of EMCO, used the apt analogy of a "ping-pong game" to describe how ideas travel from national capitals to Brussels, bounce back to the national capital, and then back again to Brussels and so on (for a similar assessment, see Zippel 2004). Over time, Member States and the Commission take on just a little bit of the others' ideas, and eventually "one can trace ideational changes in party manifestos, as grounds for justification for new legislation, in cabinet resolutions and the like" (interview, BMAS2, my translation). As such, capturing the main common features in the EES (and OECD recommendations) can serve as a good approximation with respect to the ways in which policymakers think about problems and solutions in their labour markets. The cognitive and normative changes that run like a "golden thread" through the EES as well as the JS are best encapsulated in two dimensions, including a renewed focus on (1) the supply side of the labour market through obligatory activation measures, and (2) raising overall employment levels rather then merely reducing unemployment rates.

\section{Supply-side Orientation and Activation}

As we saw in chapter III, during the 1960 os and 1970s, the birth years of active labour market interventions, policymakers assumed that the labour market was - within the hierarchy of markets - subordinated to financial and product markets. Accordingly, the ALMPs were seen as a supplement to macro-economic demand management and as an economic tool to boost productivity and enhance individual mobility. At that time, macroeconomic rather labour market policy did the "heavy lifting" in addressing questions pertaining to unemployment. However, as unemployment, especially its long-term version, established itself as a continuous challenge throughout the 1980 os - often despite rapid economic growth - European policymakers began to increasingly move away from locating the root causes of unemployment in insufficient demand (i.e., cyclical causes of unemployment) and moved toward seeking solutions on the macro and micro level (i.e., structural and indiviual causes of unemployment). This 
new focus on the structural causes of unemployment included both labour market and welfare institutions that "hindered" the free workings of the market and shortcomings in workers' skills and education. The political shift away from economic demand-management strategies was further accentuated across Europe by the rapid steps taken toward establishing a common European market in the early 1990 os and introducing a single $\mathrm{Eu}-$ ropean currency at the turn of the millennium. The institutionalisation of the Economic and Monetary Union not only forcefully placed a "hard currency" paradigm at the centre of economic policy making through strict targets on national debt and inflation, but also meant that the European Central Bank (ECB) would determine the interest rates for the entire $\mathrm{Eu}$ rozone, and by extension, also affect the non-EMU members' room for manoeuvre. As such, policymakers lost an important means to manage national economic growth, and labour market policy became the main tool left to national governments to address unemployment besides adjusting levels of personal and corporate taxation to stimulate investment and growth. Hence, while the labour market was still seen as being dependent on the developments in the financial and product markets, it was now "of equal ranking" (interview, BMAS1), and had matured to a market with its own laws and regulations (interview, HBS). ${ }^{1}$

This pragmatic shift toward a focus on the supply side was also a reflection of growing concerns over welfare abuse, thus locating the root causes of unemployment in individual idleness. Intellectually, the US was on the forefront of these normative reassessments during the 1980s. On the one hand, academic writings suggested the dismantling of the entire US welfare state as the best way to fight poverty (e.g., Charles Murray's Losing Ground), or explained the existence of an "underclass" by referring to welfare programmes that allowed recipients to remain passive (e.g., Lawrence Mead's Beyond Entitlement). Meanwhile, political and media attacks were launched on supposed African-American "welfare queens" who were driving Cadillacs while collecting welfare (cf., Daguerre 2007). Similar assessments about the inactivity-enabling role of welfare institutions and the associated abuse of taxpayers' money were also very evident in the UK during the late Thatcher era, where conservative think tanks massively attacked existing welfare structures. Popularising concerns about the welfare state was not, however, limited to the Anglo-Saxon world, but emerged as a salient, albeit not as hostile, topic in Denmark (see chapter IV for more details), Austria - mainly through the daily tabloid newspaper Die Krone (cf., Atzmüller 2009) - Germany and Sweden (for Sweden, personal conversation with VÄXJÖ). Ireland, in turn, was somewhat different 
because the 1980 os and early 1990 os was a period of such massive unemployment that almost everybody had some personal connection to being unemployed. Due to this direct or indirect, yet almost always personal, exposure to unemployment, reducing alleged welfare abuse was not part of Ireland's political agenda (interview, YOUTH).

This Europe-wide new public discourse and political concern ultimately altered many policymakers' views on unemployment. While the unemployed during the 1960 os and 1970 s were seen as the "victims" of unfavourable economic developments, unemployment during the late $1980 \mathrm{os}$ and 1990 os was increasingly interpreted - at least in part - as "voluntary". Earlier "rights" to participation in active measures gradually turned into "obligations", i.e., measures to test whether jobseekers were actively seeking and remaining available for work. Interestingly, it was not only fiscally conservative actors who adopted these views, but also Social Democrats who embraced the concept of "mutual obligations", including Commission President Jacques Delors in the early 1990 os at the EU level. Prominent national examples, in turn, include Denmark's Social Democratic government that introduced a "right and duty" to activation in the early 199os; the UK, where left-leaning New Labour launched its famous New Deals in 1997/98 that were predicated on the norm of "rights and responsibilities" for both the state and jobseekers; and Germany, where Social Democratic Chancellor Gerhard Schröder embedded his 2001 JobAqtiv reforms in a context of "demanding and promoting" (fordern und fördern) while the 2002 Hartz proposals were advanced with the slogan "promoting self-initiatives and redeeming new securities" (Eigeninitiative auslösen - Sicherheit einlösen). Even though an explicit rights and responsibilities rhetoric was less pronounced in Austria and Ireland, both Austrian and Irish policymakers referred to the principle that the state offered "something-forsomething" (interviews, IHS2; YOUTH; see also Weishaupt 2009).

For many Social Democrats who relied on the rhetoric of mutual obligations to justify deep reforms of their welfare states, the newly emerging idea of "activation" was seen as a necessary instrument to reduce (long-term) unemployment and to address the legitimacy of the welfare state; appropriate because work alleviates poverty and social exclusion; and politically viable as it was seen as a compromise between centre-left actors, prioritising citizens' rights to public assistance, and centre-right actors, demanding that jobseekers act responsibly, which should be enforced through supervision and sanctions. Thus, many European actors hoped that activation would prove to be a real alternative to the purely neo-liberal "workfare" strategy offered in the 1994 OECD JS that simply 
"downgraded" expectations by cutting benefits and lowering wage floors. The main goal of these activation reform efforts was to sustain a European welfare model by cutting welfare costs without cutting services (interviews, BMAS1, DGB1). Welfare conditionality, in turn, was acceptable as the unemployed had real options to choose from and were not simply pushed into available (but perhaps inappropriate) work (interview, TUC1).

Even though this discourse seemed somewhat superfluous in Sweden - because the decades-old "work line" had always included both sticks and carrots (personal conversation, IFS) - similar trends were visible. On the one hand, the "rediscovery" of a rights and responsibility discourse was based on the popular view that the Swedish welfare state had become overly passive during the $198 \mathrm{os}$. This impression was based on the expansion of disability pensions, less stringent work requirements for older workers, and persistent levels of youth unemployment. On the other hand, the rapid rise of unemployment in the early 1990 os led to a massive increase in social assistance claimants, whose "only" problem was that they were unemployed (personal conversation, VÄXJÖ). In an attempt to tackle the growing numbers of welfare recipients, many municipalities launched their own activation schemes in the mid 1990s, which, in turn, entailed obligations for SA recipients to participate in various programmes in exchange for their benefits. In reaction to this "bottom-up" development, the Social Democratic central government then instituted a legal base by revising the Social Service Act in 1998 (Sproß and Lang 2008, 61; Thorén 2008, 47ff). An even more explicit rights and duties discourse then emerged in the run-up to the 2006 election. The bourgeois alliance of four centre-right political parties capitalised on this issue by claiming that the Social Democrats had lost touch with the Swedish "work line" and that they represented the real Swedish model that had always entailed a right and duty to work (Magnusson 2007, 4).

\section{Raising Employment Levels: Building More Inclusive Labour Markets}

In conjunction with the cognitive shift regarding the main causes of, and remedies for, unemployment and the normative shift toward welfare conditionality and mutual obligations, a new policy agenda emerged during the 1990s. While the NAIRU concept and the associated OECD recommendations made unemployment reduction the central focus of reform, the new policy goal increasingly became the raising of overall employment levels, thus bringing more people into the workforce, regardless of their benefits status. The first steps toward focusing on employment 
rather than unemployment were already being articulated in the mid1990 os with the inception of the Essen Process. This new goal was then quantified through the Lisbon targets in 2000. As outlined in chapter V, national governments committed themselves to reach jointly agreed-upon targets, including an overall employment rate of 70 percent, a female employment rate of 60 percent, and an employment rate of 50 percent among older workers. This new political agenda strongly reflected the fact that policymakers no longer believed that raising employment levels and shrinking unemployment levels were mutually exclusive (e.g., Boeri et al. 200o). Instead, it was now commonly accepted that if and when governments increase the supply of (skilled) labour, more people will earn money, incomes rise, productivity improves, and thus the demand for labour increases as more money is spent and new services are needed. This also means that when more people are working, tax revenues increase as the tax base is broadened, while individual dependence on the state is reduced. Both of these trends then allow governments to either reduce corporate, income, and/or payroll taxes, which stimulates future job growth, or to make additional investments in the economy, the public sector, and/or human capital development. However, the raising of employment levels was not only desirable in socio-economic terms, it also presented itself as (the only) solution to the "dual" challenges of globalisation and societal changes. More specifically, while economic globalisation pressures forced policymakers to reduce welfare costs in a race to stay competitive, internal challenges associated with ageing societies, demographic shifts, new family structures, and long-term, often persistent un- and underemployment, increased the demands on the welfare state, while also shrinking its very revenue base. As such, because policymakers had to find ways to do "more with less", higher levels of employment became not only desirable, but also a necessary condition for the sustainability of European welfare models.

The new policy agenda to increase employment levels was translated into an empirically observable upward trend in employment levels in the EU-15 Member States. Overall employment levels increased from 60.7 percent in 1997 to 66.9 percent in $2007 .{ }^{2}$ Even more remarkable, the employment rate for women went up from 50.8 percent in 1997 to 59.7 percent in 2007 and the employment level for older workers rose from 36.4 percent in 1997 to 46.6 percent in 2007, respectively (Eurostat 2008). EMCO Chair Maarten Camps saw these trends as "clear evidence" that European policymakers had "put their mind" to this issue (Camps 2006, 3).

Perhaps more tellingly, many national governments have openly embraced the goal of raising employment levels in their domestic arenas. 
Perhaps the clearest and most ambitious move toward rising employment rates was propagated by British Prime Minister Tony Blair on 11 October 2004. In a speech to the Institute for Public Policy Research (IPPR) and Demos, the Prime Minister declared that the government should not rest until everyone who wants a job has a job, while further aspiring to attain the highest employment rate in the world. While an official target was not set, achieving the highest employment rate in the world de facto meant an ambitious target of about 80 percent (cited in Bivand 2004, 20). Sweden also set an 80 percent employment rate target in their National Reform Programme in 2006, while Denmark, which already had the highest employment rate in Europe, launched a labour market reform programme entitled "More People at Work" in November 2002 to maintain its high levels of employment. Other Member States such as Germany returned to their official goal of reaching full employment, a goal they had abandoned more than 20 years ago. Similarly, the focus on women and older workers also came to the forefront in both Austria and Ireland. Civil servants in these two countries explained that they were not only being pressured to increase employment levels by domestic employers who complained about skills shortages, but also from Brussels. Accordingly, the focus of the labour mobilisation was on older workers, who had already acquired work-related skills, and women, who were often well educated, but failed to return to work after having children due to an insufficient public infrastructure or counterproductive benefit and wage systems (consensus view among interviewees in Austria and Ireland).

To summarise, the new agenda of raising employment levels, the belief in the capability to steer the level of (un-)employment through supplyside instruments, in particular activation, and the normative foundation of mutual obligations, moved reform debates in a common direction across Europe. Work was increasingly seen as the best form of welfare for the individual and more work was also the best means to sustain the functioning of the European welfare states. As such, a common discourse on self-reliance through activation became predominant, albeit in a context in which the state should continue to play a supportive or enabling role. Moreover, the change in the political agenda to achieve high levels of employment directly affected the workings of many government ministries (interview, BMAS4). Once the goal to raise employment levels was declared - which cannot be reached solely by reducing unemployment - the state machineries began searching for "untapped" sources, which often included the activation of previously passive groups such as older workers, lone parents, 
the disabled, or immigrants (interview, CESI). This search for new labour pools, in turn, then provided feedback to the "activation paradigm" and its normative foundation of mutual obligations. ${ }^{3}$

\section{VI.2 Organisational Dimension}

As chapter VI outlined, both the EU and the OECD, beginning in the mid-199os, placed the modernisation of European PESs at the centre of attention. For an assessment of the procedural changes anticipated by the development of a "service model" and to answer the question of whether European PESs have converged on a similar institutional framework, it is necessary to understand their organisational structures. For this purpose, I will first briefly review their institutional make-up and outline their organisational differences, including (a) their position vis-à-vis the government, i.e., their legal status, (b) the role of social partnership within PES governance structures, and (c) their source of revenues.

\section{VI.2.a Organisational Structures: Legal Status, Corporatist Governance, and Sources of Revenue}

\section{Legal Status}

As outlined in chapter II, there are various ways to organise PESs. The majority of European PESs could be described as "semi-autonomous", or institutions created under public law which, however, are not run directly by a governmental ministry. Put differently, while PESs operate relatively independently from government control on a daily basis, they have to follow laws adopted by their respective parliaments and adhere to governmental regulations; receive broad instructions about the direction of labour market policy from a respective ministry; rely - at least partially - on funding from the government; and have governmental appointees sitting on, or even chairing, their executive and/or supervisory boards. This model is therefore distinct from an entirely state-run model, where the PES is an integral part of a ministry for employment, as is the case in Japan (and Austria until 1994), the entirely privatised model, introduced in countries such as Australia and New Zealand, or a regionally or locally run PESs with no or very little direct steering by the national government and no national PES headquarters (e.g., Italy, Poland, and the US).

Among the six cases reviewed here, the British PES comes closest to a PES with a state-led governance system because Job Centres Plus (JCP) 
is located within the DWP and its entire board is directly appointed by the government. However, the JCP enjoys "agency status", which gives it some degree of independence from the Ministry (OECD 1993c). Historically, Germany and Sweden are archetypical representatives of a public, yet tripartite-run employment service, established in 1927 and 1947 respectively. As outlined in chapter III, most other European countries followed the German and Swedish models, thus moving away from membership-based, primarily locally operated or social partner-operated models. For instance, in $1969 / 70$, Denmark established a modern, tripartite PES with a monopoly on job-placement and matching services and an enhanced remit to provide training and further education, ending the labour unions' dominance in this area. Similarly, the government in Ireland also created a PES, the National Manpower Service (NMS), in 1971, streamlining the activities of locally run PES offices. In 1987, the NMS was replaced by FÁS, Ireland's tripartite Employment and Training Authority, responsible for job-placement and matching services as well as training measures that were offered to both the employed and unemployed. Finally, Austria removed its PES from the Ministry of Labour in 1994/95 and established a tripartite-run agency with significantly more autonomy, similar to the German or Swedish versions.

\section{Corporatist Governance}

Most European PESs can look back at long periods of social partnership during which the employer and employee representatives were closely involved in PES governance, including programme design, monitoring, and delivery. In 2009, however, among the six countries discussed here, only Austria and Ireland have been able to retain a strongly tripartite governance structure. In both of these countries, social partnership is the norm "all the way down" and employee and employer representatives are present in the national executive boards as well as the regional and local levels. The social partners also take part in most, if not all, major policy committees to develop labour market policies (interviews, AMS1, FÁS 3 , FÁS4). PES officials in both Austria and Ireland, and the social partners themselves, have described social partnership as positive and valuable, particularly due to its ability to resolve conflicts internally, which allows for pragmatic rather than ideological solutions (consensus view in interviews with Austrian and Irish PES representatives).

This positive assessment of the social partners' involvement is not a uniform experience across Europe. The long tradition of full participation of the social partners at all levels of PES governance was ruptured in the late 1980 os in the UK, in the early 1990 os in Sweden, in the early 2000 s 
in Germany, and between 2005 and 2009 in Denmark. In the UK, the social partners lost their direct representation on both the national steering board and in the regional and local branches in 1987 when the MSC was dismantled. After years of political isolation during the Conservative years, the New Labour government began to consult the social partners on a variety of issues, while the DWP organised regular meetings with both the TUC and the CBI (interview, DWP1). DWP officials described the engagement with the social partners and other stakeholders as a "good practice" (interview, DWP2). However, even though the social partners were consulted by the DWP, their actual impact on both policy initiation and design remained minimal (interview, IES2). Nevertheless, providing their "tacit" or "permissive" support was an important element in successfully launching many of New Labour's reform packages and the TUC was influential in introducing certain provisions that prevented the exploitation of vulnerable jobseekers (interview, TUC1).

In Sweden, social partnership on the executive level formally ended in 1991, when the Swedish Employers Confederation (SAF) withdrew from the governing boards of almost all government agencies, including the PES. The government had to subsequently expel the labour unions because their participation was no longer considered legitimate (Lindvall and Sebring 2005, 1061). However, despite their absence from the PES Executive Board, the social partners are still represented in the Stakeholders Council, a national advisory body. Moreover, the social partners advise regional PES offices, albeit as regional stakeholders and experts rather than representatives of a particular organisation (interview, PES-Sweden).

Meanwhile, the social partners in the German PES were formally weakened, but not entirely expelled, in 2002. While their presence on the executive board (Verwaltungsrat) at the national level was preserved, the social partners were effectively removed from the boards at the regional level (Regionaldirektionen) and play only an advisory role in the local employment agencies (Arbeitsagenturen). With the benefit reforms that came into force in 2005, the social partners also lost their institutionalised input concerning the services for the long-term unemployed, who now fall under the auspices of ARGEn (Arbeitsgemeinschaften) and Opt-out Communes (Optionskommunen) (see below in this chapter). Nevertheless, the daily workings of social partnership in the Executive Board was described as "lively, important, and largely consensual" (interview BA1; confirmed by BDA1, but seen more sceptically by DGB1).

Social partnership in Denmark is typically described as a system that functions well (see Hendeliowitz and Woollhead 2007; Hendeliowitz and 
Hertz 2008). However, recent developments are often interpreted as a disruptive break. While the Danish Social Democrats instituted a system of PES governance that mainly concentrated on the regional level, where the social partners were key decisionmakers (Knuth et al. 2004), the recent changes to the governance structures of the Danish PES pushed decision-making responsibility "upwards" and "downwards". Governance responsibility was pushed upwards when the government empowered the national ministry by increasing the use of more specific performance targets, which directly affect local priorities, strategies and the choice of instruments. Likewise, responsibility was pushed downwards when municipal authorities were empowered with the full responsibility for programme implementation. At both the national and local level, the social partner retained only an advisory function and, increasingly, they are being relegated to the role of being "contractors" recruited for the delivery of some, but not all, programmes. Accordingly, many analysts interpreted the centre-right government's reform as "an outright attack on the labour market parties' influence on policy" (Larsen 2005, 129), which led to the formal dismissal of corporatism in 2007 (Jørgensen 2009, 16).

\section{Sources of Revenue}

In addition to a PES's legal status and the degree of the social partner's involvement in programme design and implementation, PESs' sources of revenue are yet another important element in determining their degree of autonomy from respective governmental departments. In the case of Germany, the PES budget is traditionally allocated almost entirely through specific payroll contributions, i.e., obligatory unemployment insurance payments, with its own financial circuit. This pattern provides the German PES with further autonomy from the state because its services are largely self-financed and its budgets is clearly distinguishable from other social security funds. While Austria relies on payroll contributions to finance its labour market policies, the generated revenues are collected by the Ministry of Finance and thus become part of the general budget. In Ireland, the budget of FÁS is also predominantly comprised of payments into the Pay-Related Social Insurance (PRSI) fund and an employers' levy, which generates funds for the training of employed workers. The state, however, provides a small subsidy (OECD 1998, 77). The budgets in Denmark, Sweden, and the UK, in turn, are mainly tax-financed. There are also some general payroll contributions to the social security system in the cases of Sweden and the UK, but these are fairly nominal with respect to unemployment insurance and have no direct effect on their PESs' bud- 
gets (OECD 1996d, 26). In both Denmark and Sweden, employees can also voluntarily sign up for unemployment insurance (UI) for a small fee. UI funds are administered by recognised funds, typically associated with labour unions. The UI funds approve the payments of benefits - paid out by the local employment office - as well as the sanctions recommended by case managers.

In summary, the description of these six PESs shows there is a great deal of variety among national organisations with respect to their organisational and legal structures, the degree of social partner involvement, and predominant funding patterns. Despite this heterogeneity, most European PESs have gradually converged in how they govern and deliver their services (cf., also Weishaupt 2010a). In particular, explicit attempts have been undertaken to turn the PESs into modern "service providers", governed by a business rather than a bureaucratic philosophy. In this context, central ideas of NPM theories - as advanced by the OECD Secretariat, the European Commission, and HoPES - have guided institutional reforms (e.g., interviews, DGB1, DWP 5 , DGEmpl3). Four reform trajectories are most evident, including (a) a strengthening of the state's steering capacity through the introduction of management-by-objectives systems and comprehensive programme evaluations, conducted by independent third parties; (b) responsibility-sharing through the encouragement of local flexibility, local partnerships, and closer co-operation, if not merger, of employment and welfare offices; (c) increased competition through the lifting of state monopolies for the delivery of job-search and matching services and the introduction of quasi-markets through contracting out specific tasks and programmes; and (d) the contractualisation of the relationship between the state and jobseekers through individual case management and individual action plans.

\section{VI.2.b Management-by-Objectives and Independent Review: Strengthening PES Steering Capacities}

\section{Management-By-Objectives}

In the European context, the two countries that spearheaded PES reforms in line with NPM ideas were Sweden and the United Kingdom (Forssell 2001, 269ff; McLaughlin and Osborne 2002, 1). Sweden's PES had already formally introduced far-reaching organisational reforms in 1985, when Allan Larsson was its General Director (1983-1989), including a management-by-objectives (MBO) and a more decentralised decisionmaking structure. A rigorous use of $\mathrm{MBO}$ techniques only became possible, how- 
ever, with the full computerisation of the management operation system in 1996/97 (Mosley et al. 2000, 73). This system enabled real-time performance comparisons of individual PES offices with set targets and is accessible to all staff members. The government and parliament, however, guide the operations of the Swedish PES through budget bills, which include broad national objectives. The national PES headquarters then sets specific goals and targets for the 68 regional offices, which, in turn, pass them on to their local branches (cf., Visser and Kouw 2006, 9).

Similarly, the UK significantly expanded and streamlined the use of $\mathrm{MBO}$ in the mid to late 1980 os and complemented these changes with the introduction of new local agencies and a stronger customer orientation. More specifically, the government replaced local employment offices with Next Step Agencies (NSAs), and divorced policy design from delivery. By doing so, the government clearly defined what the role of the newly introduced NSAs was and what the role of the department was (interview, DWP5). ${ }^{4}$ Moreover, Prime Minister John Major introduced the Citizen's Charter in 1991, establishing what customers could expect from the British PES and other public services. In this context, MBO techniques were believed to improve transparency and to encourage benchmarking exercises between Next Step Agencies, which, in turn, were expected to promote the delivery of better services. However, the originally rather strict "top-down" management-style in the British context led to some counterproductive and unintended consequences. The most commonly named examples include the (too hasty) placement of jobseekers into inappropriate jobs in order to reach certain performance targets and high staff turnover caused by the pressure to reach targets that were just too ambitious (Finn and Blackmore 2001, 298). Consequently, the incoming New Labour government amended British performance targets so that they also focused on "higher-quality job outcomes" and made staff retention as well as jobseekers and employers' satisfaction key organisational goals (Finn and Blackmore 2001, 303). While about 9o percent of all surveyed jobseekers were very satisfied with the services provided by the PES in 2008 (interviews, JCP1, 2; DWP 5 ), there was still an ongoing debate about the appropriateness of the use of overly ambitious job-placement targets rather than - or perhaps in addition to - targets for job retention. ${ }^{5}$

Subsequent to the British and Swedish organisational reforms, the enthusiasm for MBO techniques gradually expanded across Europe, reaching France and the Netherlands in the early 1990s (OECD 1993a; Mosley et al. 2000). While both Austria and Denmark had also "experimented" with MBO systems in the late 1980 s, they fully launched their version 
as part of their major organisational reforms in 1994/1995. In Denmark, these reforms led to the empowerment of regional PES offices, while in Austria, the PES was formally separated from the ministry and a semiautonomous, tripartite PES was established. Ireland, in turn, began introducing and gradually expanding the use of MBO techniques in $1996 .{ }^{6}$ Eventually Germany, the largest continental welfare state, which typically resists most NPM-inspired reforms, also followed suit.7 While the German PES implemented first reforms in the late 1990s, the major overhaul of the German PES occurred in 2002, as part of the Hartz reform process. ${ }^{8}$

These converging trends on NPM steering techniques must be understood not only as endogenous modernisation processes, but also as a consequence of the Commission's Director General for Employment and Social Affairs Allan Larsson's advocacy and the launch of the EES. More specifically, Larsson, a highly respected and influential man, who had already been instrumental in introducing MBO techniques in the Swedish PES during the late 1980 s, continuously advocated for a shift from management-by-regulation to management-by-objectives at the European level (e.g., Larsson 1998; 1999a; 1999b). Moreover, the very launch of the EES promoted, if not necessitated, the use of hard, quantifiable output targets because of three interrelated factors (cf., Mosley et al. 200o, viii; Mosley et al. 2003, 20). First, the EES required EU members to write annual action plans, which summarise national reform efforts. This, in turn, led to the institutionalisation of regular benchmarking exercises, which necessitated the collection of comparative labour market data and the establishment of common indicators (through EMCO's Indicators Group). Finally, the EES compelled members to reach a set of commonly agreed-upon guidelines, which include quantitative performance targets, such as offering "a new start" before young (adult) jobseekers have been unemployed for six (12) months, and to increase the number of unemployed people who receive training or take part in similar programmes. As such, the EES amplified the perceived need for PES modernisation and encouraged the heads of PES to (re-)evaluate their "institutional setting and management methods" (Commission of the European Communities 1998, 4).

\section{INDEPENDENT REVIEW}

In addition to improving the steering capacity of governments and central PESs through the introduction of MBO techniques, policymakers increasingly sought to achieve higher levels of programme quality. In line with NPM theory and OECD/EU recommendations, a critical element in PES reforms included a continuous and comprehensive evaluation of la- 
bour market instruments, conducted by independent third parties. While the Anglophone countries, including Ireland and the UK, share a long tradition of independent reviews (interview, FÁS1), countries with Nordic or Continental regimes, followed suit only in recent years. For instance, Sweden created the Institute for Labour Market Policy Evaluation (IFAU) in 1997, as a relatively autonomous, national evaluation body (Visser and Kouw 2006, 9). Since then, all of its labour market policies have been "subjected to a large number of rigorous evaluation studies" (Calmfors $2004,4)$. Germany has in recent years also undergone a series of wideranging evaluations, conducted for the most part by independent third parties. These developments have been described as a "major step forward" and a truly path-breaking development (interview, INFAS). Similarly, leading Austrian policy experts argue that - due to EU membership and the launch of the EES - Austria has developed an "evaluation culture" and labour market policy monitoring has been vastly improved as EU targets are taken "very seriously" (interviews, IHS1; IHS2 respectively). Denmark has, however, emerged as somewhat of an outlier. While the Social Research Centre in Copenhagen conducts labour market policy evaluations on a contractual basis, its close ties to the ministry are seen as somewhat compromising its claim of "independence". Other institutions are occasionally contracted. These contracts are, however, on a much smaller scale and on an ad hoc basis (personal conversation, CARMA).

\section{VI.2.C Centralised Decentralisation and Bridging Employment and Welfare Services: Strengthening Local Rowing Capacities}

\section{Centralised Decentralisation}

As outlined above, most European governments reorganised their PES governance systems away from "management-by-regulations" and toward "management-by-objectives". The rationale was, on the one hand, to empower PES headquarters by giving them the capacity to articulate, transpose, monitor, and enforce clearly articulated and transparent objectives. On the other hand, it was argued that traditional regulatory approaches had become increasingly obsolete, especially in areas with particular economic hardships or among "non-standard" groups who were more difficult to place into work. Accordingly, PES officials sought - and were often granted - a reduction in bureaucratic structures which would enhance local flexibility. The idea was that local offices could then deliver more customised responses, adequate for their clients and their local labour markets, within, however, a clear set of operational parameters. 
The extent and form of decentralisation varies rather strongly across countries, and within countries, across clienteles (i.e., insured versus uninsured workers or the short-term versus long-term unemployed, etc.). Generally speaking, local employment offices have been granted more flexibility since the introduction of MBO systems. However, this de jure flexibility does not necessarily translate into practice. This is mainly due to the pressure placed on local offices to reach ambitious quantitative performance targets. As long as local employment offices are able to reach their targets, the centre allows them a great deal of flexibility. If they fail to reach their targets, however, the centre puts pressure on them to follow its suggestion of what represents "good practice". Therefore, the fear of failure by local office managers may impede local flexibility as they choose to follow protocol in the first place. This issue has been raised especially in the UK (interviews, JCP1; 2), but has also been mentioned in the German context (interview, BA1). To overcome these shortcomings associated with a strictly "top-down" approach - applied to various degrees in Austria, Germany, Ireland, Sweden, and the UK - the centre negotiates the targets with both regional PESs, functioning as "transmission belts", and the local offices, delivering the results. By doing so, the PES headquarters try to formulate targets in ways that take local particularities into account, while continuous feedback and consultation on all governance levels is intended to assess the appropriateness of targets throughout the business cycle (interviews, JCP1,2; FÁS1; BA2). Regional and/or local targets are often added, fine-tuned to local specificities and local labour markets. This consultative mechanism, however, appears to work somewhat better in smaller countries (Austria, Ireland and Sweden). ${ }^{9}$

As indicated above, a more dramatic U-turn is observable in Denmark. After the labour market reforms in the mid-199os, Denmark was characterised by its strong focus on regional governance and the fact that real decisionmaking authority was handed over to the social partners. The multipartite regional bodies devised regionally specific programmes and enjoyed high levels of discretion in translating national targets and setting additional ones for their local offices (Mosley et al. 20oo; Hendeliowitz 2005). The Danish centre-right government that came into office in 2001, however, showed its dissatisfaction with the mid-level steering model early on. Embedded in a larger reform of its regions, the regional PES offices were first reduced to four and gradually lost their steering power. The government believed that the regional authorities "lacked [the] adequate capacity to ensure optimal sector planning" (Hendeliowitz and Hertz 2008, 11). Over time, the regional PESs were reduced to mere 
monitoring bodies (Jørgensen 2009), while municipal authorities were empowered instead. With the reforms of 2007 , the steering emphasis was further shifted both downward to the local level through more emphasis on "management by results", and upward by streamlining and standardising the system of performance indicators. As of the fall of 2009, municipal authorities are now solely responsible for all of the labour market services. While it is too soon to properly judge the outcomes of this reform, I concur with Colin Lindsay $(2007,16)$, who writes:

[W] hile the government has characterised this reform as promoting de-centralisation, the clear 'central line' that has always defined Danish employment policy is stronger than ever. By abolishing partnership bodies that had a genuine decision-making authority, the government has arguably strengthened its own ability to direct policy from the top down, while allowing some freedom in the local implementation programmes. Lødemel and Trickey (2001), considering the UK's activation services, have described this approach as a form of 'centralised localism' - promoting localised delivery arrangements, but retaining ultimate and near total power over the aims, general content and direction of policy within central government.

In summary, while PES governance systems continue to differ with respect to the degree of top-down management, there seems to be an overall trend toward a "centralised" decentralisation. In other words, while local PES offices tend to have more autonomy with respect to programme and partner choices, the respective ministries simultaneously seek to hold local PES offices accountable through ambitious performance targets and continuous monitoring.

\section{Bridging Employment and Welfare Services}

Tight central or regional steering through output targets is most common for local employment offices, delivering services to "typical" jobseekers, i.e., the short-term unemployed who receive unemployment benefits. Local discretion is much higher, and therefore local diversity is more pronounced, for clienteles further from the labour market, including long-term unemployed jobseekers, social assistance recipients, and other "atypical" groups, such as lone parents or immigrants. This is the case, because these types of clients often fall under the authority of local municipalities, in contrast to centrally organised offices of the PES, that, in most countries, enjoy some independence from the central employment ministries. How- 
ever, because most national governments are in line with the new political agenda to raise overall employment levels, local authorities have been encouraged to approach "their" clients in new ways. In many cases, localised activation of difficult-to-reach clients included (a) the establishment of one-stop centres for all jobseekers, thus streamlining the ways in which all types of benefits recipients are approached, (b) the creation of new agencies, specifically designed to address the needs of these clients, and/or (c) the tighter collaboration of employment and welfare offices.

This is to say, while all governments increasingly seek to "activate" benefit recipients in a more coherent, unified way, the actual institutionalisation of these attempts remains varied. For instance, the New Labour government, following a pilot phase that lasted from June 1999 to October 2001, created the one-stop JobCentres Plus (JCP) in 2002. With the creation of the JCP, the Benefits Agency, formerly responsible for the issuance of welfare benefits, and the Employment Service that assisted jobseekers in their jobsearch and application efforts, ceased to exist as separate institutions and all jobseekers, irrespective of their benefits status, are catered for by JCP officers (Davern 2008, 116). Training courses for the unemployed, in turn, are delivered - if at all - by contractors rather then the JCP. The rather centralised system of JCP - which is associated with a variety of governance shortcomings that were described above - has been supplemented by a network of 15 Employment Zones (EZ), which have been established in areas of high unemployment. The EZ are privatepublic-voluntary sector collaboratives, charged with the remit to address local disparities and to assist the most disadvantaged and marginalised jobseekers in experimental, innovative ways. All EZs are characterised by high intensity, more individualised placement/coaching services and intensive collaboration with local employers. The recently published Leitch Review (2006) stimulated the launch of a revised Jobseekers' Allowance and Flexible New Deal programme, which was introduced in the fall of 2009 , in which jobseekers are referred from the JCP office to private service providers after a 12-month unemployment period. It is expected that these specialised providers will have new, more innovative techniques to offer. Building on the experiences of the EZ, these providers enjoy greater autonomy to design individual support, "prime contractors" are given longer contracts, and their payments are based on outcomes (McNeil 2009, 15). Since 2004, there has also been more collaboration between JCP and the Learning and Skills Council (LSC), responsible for adult education. Pilot projects were also launched in 2009 to test the merits of the two institutions' efforts to collaborate. A newly Integrated Employment and 
Skill system will then be introduced in 2010, in which benefit claimants will undergo an extensive skills health check (McNeil 2009, 15).

Inspired by British JCP, the original Hartz proposals, which the German Social Democratic government had requested to inform their labour market reform efforts (see chapter VII), also included the establishment of a "single gateway" job centre for all jobseekers (cf., Hartz Commission 2002; also interviews, $\mathrm{BMAS}_{2}$, DWP5). While a significant political gridlock prevented these plans from being fully implemented, the government nevertheless revamped the delivery of labour market services at the local level. The traditional employment offices (Arbeitsämter) were remodelled into modern "customer centres" (Kundenzentren) and renamed employment agencies (Arbeitsagenturen). These new employment agencies would provide all benefits, job-search and counselling services to all insured, short-term unemployed and refer qualified jobseekers to skills training, provided by external service providers. All of the other clients, i.e., the long-term unemployed and those previously receiving social assistance payments, are serviced in one of two offices, either so-called $\mathrm{Ar}$ beitsgemeinschaften (ARGEn), job centres jointly run by federal PES staff and local authorities, or Opt-out Communes (Optionskommunen) that chose not to cooperate with the federal PES and are solely under the aegis of local authorities. While in some instances these offices are "under one roof", most of them are in separate buildings, or even different parts of the city. Each of the three institutional arrangements, however, is organised as a "one-stop shop" where jobseekers receive job-search assistance, benefit payments, and referrals for training and other services. ${ }^{10}$ Performance targets for the ARGEn - but not for the Opt-out Communes - are set by the Ministry for Employment and Social Affairs (BMAS) in consultation with the national PES - albeit, in a more deliberate and less binding way than for the federal employment agencies. One PES representative described this process as "top-down-bottom-up-top-down" rather than strictly "top-down" (interview, BA2).

When the centre-right Danish government launched a comprehensive reform package entitled "More People in Work" in 2003, Denmark also moved toward a "one-stop shop" model. This reform streamlined all of the rules and regulations for insured and uninsured jobseekers to the effect that both groups are now subjected to the same procedures and have access to the same instruments (Dingeldey 2005, 20). Since 2007, newly established "one-stop" job centres have been delivering job-placement and benefit services, as well as making referrals to training and other services under one roof (Lindsay and McQuaid 2008). ${ }^{11}$ Like in Germany, Den- 
mark relied on two types of job centres from 2007 to 2009: in one type, central PES staff and local authorities co-managed all jobseekers, and in the other, municipal authorities worked without the assistance of federal PES staff. Following a government decision, the joint centres ceased to exist, much against the protest of the social partners and the opposition parties. Since the fall of 2009 , only local municipalities have been responsible for all services, incorporating and hiring previous PES staff members (personal conversation, CARMA).

While Denmark, the UK, and Germany have introduced a variety of one-stop shops for all jobseekers, the other three countries in this study continue to have institutionally separate offices for employment and welfare services. The Swedish government has made very little effort to institutionally merge municipal activation with the PES. There is, however, close co-operation between welfare and employment offices since SA recipients are not only expected to sign up with the local employment office to prove that they are actively seeking work, but ALMP measures offered by the PES can also be made available to them. The revised Social Service Act of 1998 even specifies that the "Social Service Board shall consult with the local Employment Services" about suitable programmes prior to SA recipients participating in municipal programmes (Thorén $2008,51)$. This collaboration between employment and welfare intensified during the 1990s, in particular with the launch of the Youth Guarantee (Ungdomsgarantin) for young, disadvantaged jobseekers (1998) and the Activation Guarantee (Aktivitetsgarantin) for the long-term unemployed (200o). ${ }^{12}$ More specifically, municipalities can send jobseekers to the PES to participate in various measures, while the PES can seek assistance from municipalities, in particular when it comes to the long-term unemployed who have gone through various stages of activation. These PES clients are then often placed into work-experience and practical-training programmes, organised by local municipalities (interview, DEMPL).

In Austria, the co-operation between local welfare offices, which service social assistance recipients, and employment offices in charge of both UB and UA recipients, has also increased substantially. In recent years, especially when the Social Democrats reclaimed power, the possibility of establishing "one-stop" centres became a salient political issue (interview, CDA). However, the reluctance by the Christian Democratic coalition partner and the resistance of various Länder governments, especially Kärnten, has prevented a real merger of PES and welfare offices along German lines. It has, however, been agreed that social assistance recipients who are deemed "capable of working" will be sent to the nearest lo- 
cal employment office, where they will be exposed to the same activation measures as any other jobseeker (interview, AMS).

Finally, Irish local welfare offices still issue unemployment benefits and other assistance payments, while FÁS offers job-placement, counselling and training services to jobseekers (insured and uninsured) and employed workers alike. However, the mutual collaboration and contact between welfare offices and FÁS has greatly intensified in recent years. In fact, one observer has described this trend as "the most important change" in the organisation of the Irish labour market regime (interview, CDI). Welfare and FÁS staff engage in frequent exchanges, share data, and refer customers to each other's offices. In contrast to most other European countries, neither the FÁS nor the welfare office are sufficiently equipped with the resources or staff to adequately assist the most disadvantaged jobseekers. This is why a network of additional and institutionally separate Local Employment Services (LESs) was established in the mid-199os during a period of massive (long-term) unemployment (see chapter VII for more details). ${ }^{13}$ FÁS employment officers can refer "disadvantaged" customers to the LES, where they receive special services and staff-client ratios are much lower. The LES are embedded in a dense network of stakeholders, including local employers, local voluntary and community sector groups, and union-run employment centres. One interviewee described this division of labour by referring to FÁS as the "primary doctor" and the LES as the "specialist" (interview, FÁS5).

\section{VI.2.d Private Placement Agencies and Competitive Tendering}

Consistent with the New Public Management philosophy, many governments have also sought to increase external competition in the provision of services. An important step in this direction includes the abandonment of long-held placement monopolies, which has not only allowed new private sector actors to enter the market but also forced PESs to modernise. While the UK never ratified the 1949 ILO Convention 96, which prohibited employment services that charge fees, many European governments only allowed private employment agencies (PREAs) to operate during the $199 \mathrm{os}$, including Denmark (1990), the Netherlands (1991), Sweden (1993), Austria, Germany and Finland (1994). In 1997, the ILO then adopted the Employment Agencies Convention C181, which formalised the end of the PES monopoly (Phan-Thuy et al. 2001, 152). The scope of activities of private placement agencies remains varied, ranging from less than one percent market penetration (daily full-time equivalent as a percentage of total employ- 
ment) in Denmark and Sweden, to one to two percent in Austria, Germany and Ireland, and more than four percent in the UK in 2006 (Report Commissioned by Eurocitt 2007, 8). Despite their limited role, collaborations between public and private employment services are often encouraged by governments, especially with respect to labour market data exchange. Some PESs have even begun to contract PREAs as programme providers for specific clients. For instance, the centre-right government in Denmark began involving private placement providers for "weak groups" such as "seniors, refugees or immigrants" in 2001 (Bredgaard and Larsen 2007, 9). Germany introduced an "entitlement" as part of the Hartz reforms so that unemployment benefit recipients receive a placement voucher with which they can purchase PREA services after they are unemployed for over three months. Likewise, in 2009, the bourgeois Swedish government introduced a new "coaching" tool that allows jobseekers to consult private providers, who are then reimbursed by the Swedish PES.

Beyond liberalising private placement services, PESs have generally become more "outward-looking actors" seeking to collaborate closely with private businesses, employers, and providers of a variety of services. Working closely with businesses and employers is part of the PESs' new "customer-service orientation" that includes maximising the efficiency and the quality of matching vacancies with qualified applicants. Increased reliance on and collaboration with private service providers, in turn, has not only increased the number of actors involved in the labour market, but has also increased the reliance on more competitive tendering processes. While service "contestability" has a long tradition in the UK, the Nordics have also begun to rely on external providers to deliver soft and occupational skills courses (personal conversation, SOFI). While Sweden had already begun introducing steps to shift services from public to private providers in the 1990s, Denmark followed suit in 2002 as part of the "More People in Work" reform process. Since then, external actors, including labour unions, UI funds, education institutions etc., have been involved in competitive bidding procedures, establishing a "quasi-market" for the provision of these services for the first time in Danish history (Bredgaard and Larsen 2007, 8; Hendeliowitz and Woollhead 2007, 130). This trend toward including for-profit, private actors has gradually expanded since then, and peaked with the decision to "municipalise" all employment services (Jørgensen 2009). The not-for-profit voluntary and community sectors, in turn, continue to play a small role in the Nordics, mainly because of the long tradition of public sector predominance in welfare service delivery (personal conversation, SOFI, see also Thorén 2008, 53f.). 
In the Continental cases, the delivery of training courses has always been "outsourced" to private training providers, traditionally linked to or entirely operated by either the labour unions or employer associations. Because the social partners were represented on PES management boards that are in charge of the bidding, accusations of favouritism arose over time and the PESs were accused of mismanagement and inefficiency (for Austria, interviews, BMWA1, 2; for Germany, DGB1; Metall NRW). Austria began to first use open, competitive bids with the creation of its "new" PES in 1994, a trend that was strengthened in 2001. Germany followed suit in 2002/3 as part of the Hartz package. Finally, the Irish PES has also "become a very outward-looking organisation with their own contacts" (interview, CDI), and in particular, Specific Skills Training courses are increasingly provided by private actors. But in Ireland the motivation was not to generate "better and cheaper" services (like in Denmark or Sweden) or to avoid accusations of favouritism (like in Austria and Germany). Instead, it was a pragmatic response to the drastic expansion of the demand for apprenticeships, which filled the training facilities, and rapidly changing course curricula to which private providers seemed to be able to respond to quicker (interviews, FÁS 1, 3, and 4).

\section{VI.2.e Case Management and New Contractualism}

The NPM philosophy that has underpinned much of these institutional developments has also trickled down to the daily workings of the PES. Far-reaching changes have occurred, particularly in the relationships between individual jobseeker and employment officers, now typically referred to as "customers" and "case managers" respectively. Individual case management, i.e., the delivery of individually tailored employment services, codified through individual action plans are now in use in all EU countries, and early intervention schemes are part and parcel of this new common paradigm. In this context, the negotiation of IAPs symbolises the reliance on a new, moral rather than legal, contract between the state and its citizens (cf., Sol and Westerveld 2005). While many countries were already using IAPs in the late 1980 os and early $1990 \mathrm{os}$, their use has expanded from youth and the long-term unemployed to almost all customers, regardless of their benefits status. These contracts serve multiple functions, including the reduction of the moral hazards associated with the receipt of allegedly passive benefits, the increase in PES operations' transparency, and the clear delineation of the rights and 
responsibilities for both the state and the individual. In other words, the IAPs are seen not only as a "policing" tool, but also as a means for improving the jobseekers' level of personal initiative and the quality of state assistance.

The production of IAPs is a time-consuming and costly exercise. As a result, not all PES customers can expect a fully detailed plan. In order to identify those clients that benefit most from IAPs, the "profiling" of jobseekers into different categories has become a central element in case management. This profiling may take place formally (through standardised, "objective" procedures) or informally (based on the "subjective" observations of a case manager). ${ }^{14}$ In most cases, clients are categorised according to their "distance" from the open labour market, and, as a result, specific instruments become available or are discarded. Profiling takes place, for instance, in Austria, Denmark, Germany, and Ireland and is currently being discussed in many other European countries, including the UK. Following the OECD recommendations of 1997, profiling in the aforementioned countries means that the jobseekers who are deemed "job ready" will not receive detailed IAPs. Case managers expect that most "job ready" clients will find employment on their own within a short period of time. When, however, a "crisis point" is reached - typically after three or six months, depending on the person's age and qualifications - the jobseeker is invited for a longer interview and an IAP is created. Jobseekers, in turn, with initial profiles that indicate the need for PES assistance will typically receive an IAP early in their unemployment period.

Another crucial development was the introduction of a tiered structure of services and an expansion of self-service modes of delivery (Watts and Sultana 2005, 61). These reforms - which were also encouraged by the OECD and HoPES - have been required to reduce the tension between the need to deliver more individually tailored services, which necessitate more time and effort, and the simultaneous requirement to cater to an ever-increasing number of customers, which is caused by the activation of previously passive groups and the increased inflow of social assistance recipients to employment offices. In response, most local employment offices have been reorganised so that clients without appointments can access job vacancies, use free phone help lines, and other informational services in the office lobby, while clients with appointments are assisted more formally at customer desks. Some PESs are increasingly also making use of a variety of online services accessible from home, a service that is highly developed in the Scandinavian countries. 


\section{VI.2.f Conclusions}

Most PESs have undergone a wave of reforms inspired by (or are at least in line with) the philosophy of NPM and the EU/OECD recommendations, including the following common trends: First, all six PESs under discussion have moved from a system of "management-by-regulation" to one of "management-by-objective". ${ }^{15}$ This has also increased concerns about the overall performance of PES programmes, triggering a shift from input to output targets, on the one hand, and an increased emphasis on customer and staff satisfaction, on the other. Quality, meanwhile, is "enforced" through independent, third-party evaluations, which scrutinise the operations of individual programmes. Second, the new political agenda to raise overall employment levels and the normative underpinnings of mutual obligations has broadened the scope of activation to include social assistance recipients and other "inactive" people. As a result, either "one-stop centres" were created, which combine welfare and employment offices under one roof (e.g., Denmark, Germany, and the UK), or, if the institutional separation has been preserved, welfare and employment offices have begun to work more closely together, sharing customers, programmes, and partners (e.g., Austria, Ireland, and Sweden). Third, the vast majority of European countries now permit private employment agencies to enter the market. In some cases, PESs co-operate with PREAs though the exchange of data, labour market information, etc. In others, PESs enter into contracts with PREAs that then deliver specialised tasks. Most PESs also increasingly rely on quasi-market mechanisms, primarily competitive bids, to select their service providers. The introduction of quasi-market mechanisms is, however, limited to skills provision, while other social services continue to be delivered mostly by not-for-profit actors. Generally speaking, European PESs have become outward-looking organisations that are more actively engaged in building new local partnerships and networks. ${ }^{16}$ Finally, all of the PESs now rely on IAPs for large segments of their customer base in order to establish a contractual basis. This benefits jobseekers and the PES employees alike, because IAPs individualise and customise services, make labour market programmes more transparent, and increase the accountability of both the case managers and PES clients. 


\section{VI.3 Financial Dimension}

Vl.3.a Sources of Revenue: Frozen Imagery

A necessary condition for the success of activation strategies is the availability of employment opportunities. In this context, both the OECD and the EU have discussed labour market institutions and labour costs as potential impediments to employment growth. The debates about labour market institutions (LMI), such as employment protection legislation, statutory minimum wages, and co-ordinated wage-setting arrangements, have remained largely ideologically driven and statistical findings continuously show ambiguous results. At the risk of oversimplification, I argue that right-leaning actors typically favour the flexibilisation of wagesetting agreements and labour market deregulation, and left-leaning actors generally favour the observance of existing regulations that protect already employed workers' wages and employment contracts. Similarly, left-leaning actors prefer high minimum wages that offer a decent standard of living, while right-of-centre actors favour no, or very low minimum wage floors to reach market-clearing levels. As outlined in chapter $\mathrm{V}$, economists have yet to provide clear evidence for the (interactive) effects of any of these labour market institutions on employment levels and growth. Recent studies suggest, for instance, that high EPL standards on their own do not necessarily have a negative impact on the overall level of unemployment, but may only affect particular groups (cf., Commission of the European Communities 2006; OECD 2006a). Similarly, if union coverage is high and trade union confederations strong, co-ordinated wagesetting mechanisms may even promote job growth if and when moderate, binding wage increases can be agreed upon (cf., OECD 2006a). ${ }^{17}$

This brief overview shows that neither the EU nor the OECD can offer a clear prescription for core LMIs. However, both international organisations agree that reducing non-wage labour costs is a compelling way for governments to foster investments in jobs by firms and thus spur employment growth. In other words, shifting the allocation of revenues for labour market and social policies from payroll contributions to general taxation is seen as a feasible method to increase the international competiveness of firms and to stimulate investments in new jobs. How to compensate for the lost revenues that accompany payroll reductions remains controversial and thus issuing changes may prove to be a difficult political endeavour. On the one hand, raising taxes elsewhere - even when presented as a trade-off may remain very problematic as no political party wants to be seen as being responsible for tax increases. On the other hand, simply reducing payroll 
contributions by cutting services and/or benefit levels may not be acceptable to left-leaning voters, labour unions, and other socially oriented actors.

The following table illustrates non-wage labour costs for full-time workers for the years 2000 and 2006. The table illustrates that the Anglophone welfare states and Denmark in particular have lower levels of payroll taxation. However, despite the expectations outlined above, there has been no radical shift toward a substantial reduction in non-wage labour costs, for neither workers nor employers. One can observe only a slight reduction of non-wage labour costs for employers in Austria, Finland and Italy, but also substantial increases in France and the Netherlands. There have been barely any changes to average workers' (AW) burdens, and if so, these changes point in the opposite direction in some of the cases to what would result from the EU and OECD's the recommendations.

\section{Table 24 Workers and Employers' Social Security Contributions (SSC),} 2000 and $2006^{18}$

\begin{tabular}{llccccc}
\hline & \multicolumn{2}{c}{2000} & \multicolumn{2}{c}{2006} & \multicolumn{2}{c}{ Change in \% points } \\
\hline & $\begin{array}{l}\text { Employee } \\
\text { SSC }\end{array}$ & $\begin{array}{c}\text { Employer } \\
\text { SSC }\end{array}$ & $\begin{array}{c}\text { Employee } \\
\text { SSC }\end{array}$ & $\begin{array}{c}\text { Employer } \\
\text { SSC }\end{array}$ & $\begin{array}{c}\text { Employee } \\
\text { SSC }\end{array}$ & $\begin{array}{c}\text { Employer } \\
\text { SSC }\end{array}$ \\
\hline Austria & 18.1 & 31.63 & 18.1 & 28.86 & 0 & -2.77 \\
Belgium & 13.1 & 34.7 & 13.1 & 34.72 & 0 & 0.02 \\
Denmark & {$[1]^{\mathrm{a}}+8+$} & $0.6 \% \mathrm{AW}$ & $8+$ & $0.6 \% \mathrm{AW}$ & {$[-1]$} & 0 \\
& $3 \% \mathrm{AW}$ & & $3 \% \mathrm{AW}$ & & & \\
Finland & 7.2 & 26 & 7 & 24 & -0.2 & -2.0 \\
France & 13.52 & 35.95 & 13.6 & 41.05 & 0.08 & 5.1 \\
Germany & 20.5 & 20.5 & 21.4 & 21.4 & 0.9 & 0.9 \\
Greece & 15.9 & 27.96 & 16.0 & 28.06 & 0.1 & 0.1 \\
Ireland & 4.5 & 8.5 & 4.0 & 8.5 & -0.5 & 0 \\
Italy & 9.19 & 34.08 & 9.19 & 32.08 & 0 & -2.0 \\
Netherlands $\mathrm{b}$ & $31.15+$ & 7.4 & $31.7+$ & 14.36 & $0.55+$ & 6.96 \\
& $0.6 \% \mathrm{AW}$ & & $2.44 \% \mathrm{AW}$ & & $1.84 \% \mathrm{AW}$ & \\
Portugal & 11.0 & 23.75 & 11.0 & 23.75 & 0 & 0 \\
Spain & 6.4 & 30.6 & 6.4 & 30.6 & 0 & 0 \\
Sweden & 7.0 & 32.92 & 7.0 & 32.28 & 0 & -0.64 \\
UK & 10 & 12.2 & 11 & 12.8 & 1.0 & -0.6 \\
\hline
\end{tabular}

a Mandatory contribution to institutions outside the government sector (not considered a tax in the OECD Taxing Wages report).

b The majority of these contributions is levied on taxable income. In the Netherlands, these aspects of social contributions are commonly considered part of the income tax.

Source: OECD Special Feature: Tax Reforms and Tax Burdens 2000-2006, 47ff, own calculations 
Based on the findings in table 24, one could argue that there has been very little institutional change, corroborating the above theorised difficulty in reducing or shifting tax burdens. The differences across and within regime types remain pronounced, and no overall trend of convergence in regards to payroll contributions can be identified.

\section{Vl.3.b Expenditures - A Cost Reduction Trend?}

With respect to labour market policy expenditures, clear country-specific differences are identifiable. As expected, the Nordic countries (plus the Netherlands) are the most generous, the Continental ones plus Ireland occupy a middle position, and the Mediterranean states and the UK are the least generous in the late 1990 s. Since then, however, a slight trend of convergence is visible. Belgium as well as the least generous countries have tended to increase their spending (e.g., Austria, Spain and the UK), while the most generous have, at times significantly, reduced their spending efforts (e.g., Germany, Finland, France, Ireland, Netherlands, and Sweden). As a result, absolute spending patterns became more homogenous and the difference between the highest and lowest spenders had narrowed substantially by 2007 .

Table 25 Public Expenditures on ALMP as Percentage of GDP in West European Countries, 1997-2007

\begin{tabular}{|c|c|c|c|c|c|c|c|c|c|c|c|c|}
\hline & 1997 & 1998 & 1999 & 2000 & 2001 & 2002 & 2003 & 2004 & 2005 & 2006 & 2007 & $\begin{array}{l}\text { Change } \\
1997- \\
2007\end{array}$ \\
\hline AT & 0.45 & 0.46 & 0.55 & 0.52 & 0.57 & 0.56 & 0.62 & 0.60 & 0.62 & 0.71 & 0.68 & 0.23 \\
\hline $\mathrm{BE}$ & 1.10 & 1.27 & 1.23 & 1.08 & 1.14 & 1.03 & 1.14 & 1.15 & 1.08 & 1.09 & 1.30 & 0.20 \\
\hline DK & 1.71 & 1.81 & 1.99 & 2.02 & .. & 2.02 & 1.91 & 1.85 & .. & .. & 1.31 & -0.40 \\
\hline $\mathrm{FI}$ & 1.41 & 1.15 & 1.06 & 0.89 & 0.82 & 0.84 & 0.90 & 0.95 & 0.89 & 0.89 & 0.86 & -0.55 \\
\hline FR & 1.22 & 1.16 & 1.22 & 1.19 & 1.15 & 1.11 & 1.05 & 0.95 & 0.90 & 0.92 & 0.92 & -0.30 \\
\hline $\mathrm{DE}$ & 1.10 & 1.16 & 1.27 & 1.19 & 1.15 & 1.25 & 1.25 & 1.15 & 0.97 & 0.88 & 0.77 & -0.33 \\
\hline GR & 0.30 &.. & .. & .. & .. & .. & .. &.. & .. &.. & .. & $\mathrm{n} / \mathrm{a}$ \\
\hline IE & 1.26 & 1.15 & 1.06 & 0.95 & 0.88 & 0.80 & 0.71 & 0.65 & 0.63 & 0.61 & 0.62 & -0.64 \\
\hline IT & .. & .. & .. & .. & .. & .. & .. & 0.63 & 0.57 & 0.50 & 0.46 & $\mathrm{n} / \mathrm{a}$ \\
\hline $\mathrm{NL}$ & 1.42 & 1.48 & 1.51 & 1.51 & 1.54 & 1.60 & 1.56 & 1.40 & 1.33 & 1.22 & 1.09 & -0.33 \\
\hline PT & 0.51 & 0.57 & 0.56 & 0.61 & 0.61 & 0.59 & 0.66 & 0.68 & 0.69 & 0.61 & 0.53 & 0.02 \\
\hline ES & 0.40 & 0.56 & 0.85 & 0.79 & 0.74 & 0.72 & 0.71 & 0.75 & 0.78 & 0.80 & 0.80 & 0.40 \\
\hline SE & 2.12 & 2.47 & 2.24 & 1.76 & 1.66 & 1.58 & 1.25 & 1.22 & 1.29 & 1.36 & 1.12 & -1.00 \\
\hline UK & 0.25 & 0.23 & 0.24 & 0.25 & 0.33 & 0.30 & 0.46 & 0.46 & 0.45 & 0.42 & 0.32 & 0.07 \\
\hline
\end{tabular}

Source: OECD.stat, extracted on 30 June 2009 
A somewhat different picture emerges, however, when we also consider the level of unemployment in each country. In other words, when controlling for the number of jobseekers, the relative spending of Denmark, Finland, France, and Ireland has increased rather then decreased, which thus changes the impression presented above. Only Germany, Sweden and now also Portugal emerge as countries that have actually cut expenditures. Moreover, while Denmark and the Netherlands, and further behind, Sweden, remain the most generous countries, the distinction between the Liberal and the Continental countries has become less pronounced. Based on these calculations, the laggards include not only the Mediterranean countries and the UK, which was to be expected, but surprisingly also Germany in recent years. ${ }^{19}$

Table 26 Spending on ALMP as Percentage of GDP Divided by the Standardised Rate of Unemployment in West European Countries, 1997-2007

\begin{tabular}{|c|c|c|c|c|c|c|c|c|c|c|c|c|}
\hline & 1997 & 1998 & 1999 & 2000 & 2001 & 2002 & 2003 & 2004 & 2005 & 2006 & 2007 & $\begin{array}{l}\text { Change } \\
1997- \\
2007\end{array}$ \\
\hline AT & 0.11 & 0.11 & 0.15 & 0.15 & 0.16 & 0.14 & 0.14 & 0.12 & 0.12 & 0.15 & 0.15 & 0.04 \\
\hline $\mathrm{BE}$ & 0.12 & 0.14 & 0.14 & 0.16 & 0.18 & 0.15 & 0.15 & 0.16 & 0.13 & 0.13 & 0.17 & 0.05 \\
\hline DK & 0.31 & 0.36 & 0.39 & 0.45 &.. & 0.47 & 0.35 & 0.35 &.. &.. & 0.36 & 0.05 \\
\hline $\mathrm{FI}$ & 0.11 & 0.10 & 0.10 & 0.09 & 0.09 & 0.09 & 0.10 & 0.11 & 0.11 & 0.12 & 0.12 & 0.01 \\
\hline FR & 0.10 & 0.10 & 0.10 & 0.12 & 0.13 & 0.12 & 0.12 & 0.11 & 0.10 & 0.10 & 0.12 & 0.02 \\
\hline $\mathrm{DE}$ & 0.11 & 0.12 & 0.15 & 0.15 & 0.15 & 0.14 & 0.13 & 0.11 & 0.09 & 0.08 & 0.09 & -0.02 \\
\hline GR & 0.03 &.. & .. & .. & .. &.. &.. & .. & .. & .. &.. & $\mathrm{n} / \mathrm{a}$ \\
\hline IE & 0.12 & 0.14 & 0.18 & 0.22 & 0.24 & 0.19 & 0.16 & 0.15 & 0.14 & 0.14 & 0.13 & 0.01 \\
\hline IT &.. &.. &.. &.. &.. & .. &.. & 0.08 & 0.07 & 0.07 & 0.07 & $\mathrm{n} / \mathrm{a}$ \\
\hline $\mathrm{NL}$ & 0.26 & 0.34 & 0.43 & 0.49 & 0.57 & 0.51 & 0.36 & 0.27 & 0.25 & 0.28 & 0.30 & 0.04 \\
\hline PT & 0.07 & 0.11 & 0.12 & 0.15 & 0.14 & 0.11 & 0.10 & 0.10 & 0.09 & 0.08 & 0.06 & -0.01 \\
\hline ES & 0.02 & 0.03 & 0.05 & 0.06 & 0.07 & 0.06 & 0.06 & 0.07 & 0.08 & 0.09 & 0.10 & 0.08 \\
\hline SE & 0.21 & 0.29 & 0.31 & 0.30 & 0.33 & 0.30 & 0.21 & 0.18 & 0.17 & 0.19 & 0.18 & -0.03 \\
\hline UK & 0.04 & 0.04 & 0.04 & 0.05 & 0.07 & 0.06 & 0.09 & 0.10 & 0.10 & 0.08 & 0.06 & 0.02 \\
\hline
\end{tabular}

Source: OECD.stat, extracted on 30 June 2009

When analysing the spending priorities of these countries in greater detail, one begins to recognise significant differences within and across regime types. As the following two tables illustrate, Denmark (prior to 2007), Sweden and the Mediterranean countries spent more money on employment or work subsidies than other European countries (except Belgium in 2007), 
while most of the Continentals (plus Ireland) tend to rely on publicly funded works projects at the local level..$^{20}$ It is evident, however, that there is a clear trend in all European countries (except Spain) to cut expenditures involving direct job creation. These cuts are in line with OECD and other programme evaluations that suggest that direct job creation has generally experienced little success in assisting participants in their progression into the open labour market. The maintenance of (some level of) direct job-creation measures remains an appropriate tool, however, when policymakers seek to provide job opportunities to jobseekers facing severe hurdles. Examples of these programmes include the Community Employment scheme in Ireland, work in so-called social-economy firms (sozio-ökonomische Betriebe) in Austria, and the new JobPerspektive in Germany (see below in this chapter).

With regard to spending on active labour market training, the Nordic countries, this time including Finland, emerge as the most generous countries. But also here, one finds a discernable trend toward reducing expenditures in the Nordic cluster as well as in other relatively generous countries such as France and Germany. Large-scale increases, in turn, are visible mostly in Austria. Overall, Britain, Greece, and surprisingly, the Netherlands appear as the countries with the lowest spending levels on pre-employment training. The following tables summarise these findings.

Table 27 Total Public Expenditure on Employment/Work Subsidies as Percentage of GDP in Western European Countries, 1997-2007

\begin{tabular}{|c|c|c|c|c|c|c|c|c|c|c|c|c|}
\hline & 1997 & 1998 & 1999 & 2000 & 2001 & 2002 & 2003 & 2004 & 2005 & 2006 & 2007 & $\begin{array}{l}\text { Change } \\
1997- \\
2007\end{array}$ \\
\hline AT & 0.04 & 0.04 & 0.06 & 0.06 & 0.08 & 0.06 & 0.06 & 0.06 & 0.05 & 0.05 & 0.06 & 0.02 \\
\hline $\mathrm{BE}$ & 0.12 & 0.26 & 0.18 & 0.17 & 0.17 & 0.17 & 0.21 & 0.20 & 0.21 & 0.21 & 0.42 & 0.30 \\
\hline DK & 0.45 & 0.45 & 0.50 & 0.50 & 0.53 & 0.53 & 0.50 & 0.47 &.. &.. & 0.13 & -0.32 \\
\hline $\mathrm{FI}$ & 0.07 & 0.06 & 0.10 & 0.12 & 0.11 & 0.11 & 0.13 & 0.12 & 0.11 & 0.10 & 0.08 & 0.01 \\
\hline FR & 0.30 & 0.23 & 0.23 & 0.19 & 0.17 & 0.14 & 0.11 & 0.12 & 0.12 & 0.12 & 0.13 & -0.17 \\
\hline $\mathrm{DE}$ & 0.06 & 0.06 & 0.08 & 0.08 & 0.09 & 0.10 & 0.11 & 0.08 & 0.05 & 0.06 & 0.06 & 0.00 \\
\hline GR & 0.04 & 0.06 & 0.09 & 0.06 & 0.21 & 0.07 & 0.04 & 0.05 & 0.02 & 0.06 &.. & $\mathrm{n} / \mathrm{a}$ \\
\hline $\mathrm{IE}$ & 0.12 & 0.12 & 0.13 & 0.13 & 0.09 & 0.12 & 0.10 & 0.07 & 0.05 & 0.03 & 0.04 & -0.08 \\
\hline IT & 0.10 & 0.16 & 0.19 & 0.23 & 0.31 & 0.42 & 0.37 & 0.25 & 0.21 & 0.18 & 0.15 & 0.05 \\
\hline NL & 0.06 & 0.08 & 0.07 & 0.06 & 0.06 & 0.05 & 0.03 & 0.03 & 0.02 & 0.01 & 0.00 & -0.06 \\
\hline PT & 0.09 & 0.12 & 0.15 & 0.16 & 0.18 & 0.17 & 0.16 & 0.17 & 0.16 & 0.13 & 0.12 & 0.03 \\
\hline ES & 0.08 & 0.21 & 0.34 & 0.32 & 0.28 & 0.29 & 0.28 & 0.29 & 0.29 & 0.32 & 0.32 & 0.24 \\
\hline SE & 0.48 & 0.45 & 0.49 & 0.46 & 0.44 & 0.44 & 0.39 & 0.41 & 0.44 & 0.51 & 0.48 & 0.00 \\
\hline UK & 0.01 & 0.02 & 0.02 & 0.03 & 0.03 & 0.02 & 0.01 & 0.01 & 0.01 & 0.01 & 0.01 & 0.00 \\
\hline
\end{tabular}

Source: OECD.stat, extracted on 30 June 2009 
Table 28 Total Public Expenditures on Direct Job Creation as Percentage of GDP in Western European Countries, 1997-2007

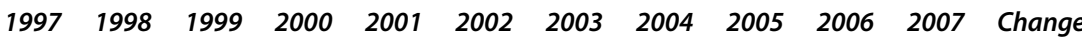

1997-

2007

\begin{tabular}{llllllllllllr}
\hline AT & 0.04 & 0.04 & 0.04 & 0.04 & 0.04 & 0.04 & 0.04 & 0.04 & 0.04 & 0.04 & 0.04 & 0.00 \\
BE & 0.45 & 0.46 & 0.49 & 0.34 & 0.38 & 0.36 & 0.42 & 0.43 & 0.34 & 0.35 & 0.34 & -0.11 \\
DK & 0.18 & 0.16 & 0.12 & 0.06 & 0.00 & 0.00 & 0.00 & 0.00 &.. &.. & 0.00 & -0.18 \\
FI & 0.35 & 0.25 & 0.18 & 0.11 & 0.10 & 0.10 & 0.09 & 0.08 & 0.07 & 0.09 & 0.08 & -0.27 \\
FR & 0.24 & 0.30 & 0.37 & 0.40 & 0.40 & 0.40 & 0.34 & 0.23 & 0.18 & 0.19 & 0.20 & -0.04 \\
DE & 0.25 & 0.31 & 0.34 & 0.26 & 0.20 & 0.19 & 0.14 & 0.13 & 0.10 & 0.09 & 0.07 & -0.18 \\
GR & 0.00 & 0.00 & 0.00 & 0.00 & 0.00 & 0.00 & 0.00 & 0.00 & 0.00 & 0.00 &.. & n/a \\
IE & 0.56 & 0.50 & 0.45 & 0.40 & 0.35 & 0.29 & 0.24 & 0.20 & 0.21 & 0.21 & 0.21 & -0.35 \\
IT & 0.05 & 0.06 & 0.07 & 0.05 & 0.04 & 0.03 & 0.03 & 0.01 & 0.01 & 0.01 & 0.01 & -0.04 \\
NL & 0.24 & 0.29 & 0.30 & 0.30 & 0.31 & 0.27 & 0.23 & 0.18 & 0.15 & 0.12 & 0.11 & -0.13 \\
PT & 0.05 & 0.05 & 0.05 & 0.05 & 0.04 & 0.04 & 0.04 & 0.04 & 0.03 & 0.03 & 0.02 & -0.03 \\
ES & 0.06 & 0.08 & 0.11 & 0.13 & 0.13 & 0.12 & 0.11 & 0.11 & 0.09 & 0.08 & 0.08 & 0.02 \\
SE & 0.41 & 0.35 & 0.19 & 0.07 & 0.00 & 0.00 & 0.00 & 0.00 & 0.00 & 0.00 & 0.00 & -0.41 \\
UK & 0.01 & 0.01 & 0.01 & 0.01 & 0.01 & 0.01 & 0.01 & 0.00 & 0.00 & 0.00 & 0.01 & 0.00 \\
\hline SOUTCe
\end{tabular}

Source: OECD.stat, extracted on 30 June 2009

Table 29 Total Public Expenditures on Training as Percentage of GDP in Western European Countries, 1997-2007

\begin{tabular}{|c|c|c|c|c|c|c|c|c|c|c|c|c|}
\hline & 1997 & 1998 & 1999 & 2000 & 2001 & 2002 & 2003 & 2004 & 2005 & 2006 & 2007 & $\begin{array}{l}\text { Change } \\
1997- \\
2007\end{array}$ \\
\hline AT & 0.21 & 0.22 & 0.28 & 0.25 & 0.27 & 0.27 & 0.31 & 0.29 & 0.33 & 0.40 & 0.37 & 0.16 \\
\hline $\mathrm{BE}$ & 0.16 & 0.16 & 0.15 & 0.16 & 0.17 & 0.18 & 0.18 & 0.19 & 0.20 & 0.20 & 0.18 & 0.02 \\
\hline DK & 0.68 & 0.74 & 0.84 & 0.77 & 0.74 & 0.70 & 0.62 & 0.54 & .. & .. & 0.33 & -0.35 \\
\hline $\mathrm{FI}$ & 0.66 & 0.53 & 0.47 & 0.37 & 0.31 & 0.33 & 0.35 & 0.40 & 0.37 & 0.37 & 0.37 & -0.29 \\
\hline FR & 0.44 & 0.41 & 0.39 & 0.37 & 0.33 & 0.29 & 0.30 & 0.31 & 0.29 & 0.29 & 0.27 & -0.17 \\
\hline $\mathrm{DE}$ & 0.44 & 0.43 & 0.46 & 0.45 & 0.46 & 0.52 & 0.44 & 0.36 & 0.24 & 0.33 & 0.28 & -0.16 \\
\hline GR & 0.14 & 0.2 & 0.13 & 0.15 & 0.04 & 0.09 & 0.02 & 0.03 & 0.04 & 0.05 &.. & $\mathrm{n} / \mathrm{a}$ \\
\hline IE & 0.30 & 0.28 & 0.27 & 0.25 & 0.25 & 0.25 & 0.24 & 0.24 & 0.24 & 0.24 & 0.25 & -0.05 \\
\hline IT & 0.23 & 0.26 & 0.27 & 0.25 & 0.21 & 0.23 & 0.25 & 0.22 & 0.2 & 0.18 & 0.18 & -0.05 \\
\hline $\mathrm{NL}$ & 0.19 & 0.19 & 0.20 & 0.14 & 0.16 & 0.19 & 0.22 & 0.14 & 0.14 & 0.13 & 0.10 & -0.09 \\
\hline PT & 0.17 & 0.23 & 0.20 & 0.22 & 0.19 & 0.17 & 0.27 & 0.29 & 0.29 & 0.25 & 0.20 & 0.03 \\
\hline ES & 0.13 & 0.15 & 0.22 & 0.19 & 0.17 & 0.14 & 0.14 & 0.15 & 0.17 & 0.16 & 0.15 & 0.02 \\
\hline SE & 0.57 & 0.95 & 0.90 & 0.66 & 0.67 & 0.60 & 0.36 & 0.32 & 0.33 & 0.33 & 0.20 & -0.37 \\
\hline UK & 0.07 & 0.05 & 0.05 & 0.04 & 0.03 & 0.03 & 0.03 & 0.03 & 0.03 & 0.02 & 0.02 & -0.05 \\
\hline
\end{tabular}

Source: OECD.stat, extracted on 30 June 2009 
To summarise, while traditional country cleavages remain with respect to spending generosity, theses differences have become less pronounced over time. When we consider spending priorities, however, it has become apparent that different countries prefer different measures. As the literature on path dependency predicts, the Nordics tend to be the most generous in overall spending terms and with respect to public funding of training for the unemployed, which is often seen as the most prominent instrument associated with ALMPs. The Nordic countries are also the most generous in terms of employment subsidies, which are paid to employers upon hiring particular unemployed persons. The Continental welfare states and Ireland occupy a position in the middle and tend to promote publicly funded employment in local communities as well as wage subsidies paid to workers. The UK and the Mediterranean welfare states tend to spend the the least overall and especially with respect to training programmes for the unemployed.

\section{VI.4 Work Incentive Dimension}

\section{VI.4.a Negative Non-Financial Work Incentives}

In accordance with the expectations articulated in the section on the normative and cognitive labour market dimension, the following overview will show that there has been a convergence on an "activating" benefits regime through a mix of both positive and negative non-financial work incentives. Quite systematically, countries across all regime types have applied non-financial negative incentives to tighten access to state benefits through stricter availability criteria. These criteria include benefits targeting, which is typically achieved through more selectivity (fewer people qualify for benefits), and a combination of a higher density of contacts, coupled with the verification of work availability through regular sign-ins with the local employment and welfare agencies, which are intended to reduce benefit abuse. Moreover, active job-search requirements are applied earlier and more systematically during an individual's period of unemployment. For instance, in some countries, unemployed jobseekers can be directly placed into a new job during the time of initial registration for benefits payments or during intensive follow-up interviews (e.g., Austria, Germany, Greece, and Portugal). In other countries, jobseekers have to underwrite their work availability and job-search commitment before benefits payments begin, which is then further tested in post-registration intensive interviews (e.g., Denmark, Finland, Ireland, the Netherlands, Spain, and the UK). In the case of Sweden, benefits can be curtailed retro- 
spectively if there is doubt about the applicant's availability for work and whether she is actively seeking work (OECD $2007 \mathrm{c}, 7 \mathrm{ff}$ ).

Availability criteria also include tighter definitions of "suitable job offers", e.g., how long workers can be expected to travel to work, or what an appropriate reduction in wage expectations might be. The definition of suitable job offers has frequently been widened or even completely abolished (OECD 2007c, $7 \mathrm{ff}$ ). For instance, Denmark makes no reservations for jobseekers, meaning they must theoretically accept any "appropriate" job offer they qualify for. In most of the other countries, jobseekers have a limited period of time at the beginning of one's unemployment during which they can refuse offers outside of their field or when wages are below their typical earnings (e.g., 13 weeks in the UK, 100 days in Austria and Sweden, three months in Ireland and Finland). Similarly, some countries, including Sweden, Belgium, Austria and Denmark, require the unemployed to be willing to travel up to three or four hours to work daily, effectively requiring them to relocate. In most cases, the highest demands for mobility are on young, single jobseekers, while families with children are typically not required to move.

Requiring greater mobility from jobseekers not only increases the pool of workers available to employers, thus making vacancies easier to fill, but it also reduces overall wage pressures. Lower wages and a reduction in job vacancies, in turn, can have a positive impact on structural unemployment levels. However, pressuring jobseekers too quickly into inappropriate jobs may reduce productivity levels (as highly qualified workers will not reach their full potential) or increase dissatisfaction in the workplace (also reducing productivity and potentially encouraging industrial strife and/or high turnover). Therefore, finding the appropriate balance between labour market efficiency and productivity is difficult and countries tend have their own definitions about what constitutes a "suitable" job for their jobseekers. While it is difficult to "quantify" changes in these regulations over time, qualitative reviews show that almost all of the EU15 countries have tightened their availability criteria, with Austria and Ireland in the forefront (cf., Hasselpflug 2005).

\section{VI.4.b Negative Financial Work Incentives}

The extent to which negative financial incentives are used is much more varied. There are still great differences in the generosity of cash transfers and the use of "exit options". The following table provides an overview of initial unemployment benefits (UB) levels (as a percentage of the previous average 
wage) in 2001 and 2006 for three types of workers: a low-income, average and high-income worker, averaged across various income types, including single persons, one and two-earner households, with and without children.

Table 30 Average Net Replacement Rates for Unemployed Persons at the Initial Stage of Unemployment at Different Earning Levels, 2001 and 2006

\begin{tabular}{|c|c|c|c|c|c|c|c|c|c|}
\hline & \multicolumn{3}{|c|}{$\varnothing 67 \%$ of $A W$} & \multicolumn{3}{|c|}{$\varnothing 100 \%$ of $A W$} & \multicolumn{3}{|c|}{$\varnothing 150 \%$ of $A W$} \\
\hline & 2001 & 2006 & Change & 2001 & 2006 & Change & 2001 & 2006 & Change \\
\hline Austria & 70 & 70 & 0 & 68 & 67 & -1 & 56 & 53 & -3 \\
\hline Belgium & 76 & 75 & -1 & 61 & 60 & -1 & 47 & 47 & 0 \\
\hline Denmark & 91 & 90 & -1 & 73 & 71 & -2 & 60 & 58 & -2 \\
\hline Finland & 83 & 80 & -3 & 74 & 70 & -4 & 61 & 58 & -3 \\
\hline France & 80 & 81 & +1 & 74 & 71 & -3 & 72 & 71 & -1 \\
\hline Germany & 77 & 77 & 0 & 74 & 74 & 0 & 71 & 69 & -2 \\
\hline Greece & 60 & 60 & 0 & 45 & 47 & +2 & 34 & 35 & +1 \\
\hline Ireland & 63 & 67 & +4 & 51 & 56 & +5 & 39 & 44 & +5 \\
\hline Italy & 62 & 70 & +8 & 63 & 72 & +9 & 58 & 57 & -1 \\
\hline Netherlands & 82 & 82 & 0 & 72 & 74 & +2 & 61 & 61 & 0 \\
\hline Portugal & 81 & 84 & +3 & 83 & 85 & +2 & 87 & 84 & -3 \\
\hline Spain & 80 & 81 & +1 & 74 & 73 & -1 & 56 & 54 & -2 \\
\hline Sweden & 88 & 88 & 0 & 74 & 71 & -3 & 58 & 56 & -2 \\
\hline $\begin{array}{l}\text { United } \\
\text { Kingdom }\end{array}$ & 58 & 63 & +5 & 46 & 50 & +4 & 34 & 37 & +3 \\
\hline Average & 75 & 76 & +1 & 66 & 67 & +1 & 57 & 56 & -1 \\
\hline
\end{tabular}

Source: http://www.oecd.org/els/social/workincentives, last accessed on 2009/04/14, own calculations

While no clear pattern is immediately discernable from this table, it is apparent that Greece, Ireland, Italy and the UK are among the least generous countries regarding low-income jobseekers, while Belgium, Greece, Ireland and the UK are among the least generous for average and high-income clienteles. Denmark, Finland, the Netherlands and Sweden, and surprisingly Portugal and Spain, are the most generous regarding low-income jobseekers, while Germany, France and Portugal are the most generous for highincome earners. Perhaps more striking than the regime-atypical diversity is the lack of welfare "retrenchment" in entitlement levels. With the exception of the Nordic countries, where a moderate cut across clienteles is noticeable, benefits have remained stable and maybe even increased (most notably in Ireland and the UK as well as Italy for low- and average-income workers). 
The following table provides a similar snapshot of cash-transfer levels to the long-term unemployed, that is, the averages for the same family types after 60 months of unemployment. This table shows a somewhat different pattern and some regime-specific trends are discernable. The percentages indicated here include, if applicable, a combination of unemployment benefits, social assistance payments, family allowances and housing subsidies after tax.

Table 31 Average Net Replacement Rates for Long-term Unemployed Persons at Different Earning Levels, 2001 and 2006

\begin{tabular}{llllllllll}
\hline & \multicolumn{3}{c}{$\varnothing 67 \%$ of AW } & \multicolumn{3}{c}{ Ø100\% of AW } & \multicolumn{3}{c}{$\varnothing 150 \%$ of AW } \\
\hline Austria & 2001 & 2006 & Change & 2001 & 2006 & Change & 2001 & 2006 & Change \\
Belgium & 71 & 62 & -5 & 57 & 55 & -2 & 47 & 36 & -11 \\
Denmark & 79 & 73 & +2 & 58 & 58 & 0 & 45 & 39 & -6 \\
Finland & 76 & 73 & -3 & 62 & 59 & -3 & 48 & 39 & -9 \\
France & 60 & 60 & 0 & 45 & 44 & -1 & 32 & 30 & -2 \\
Germany & 72 & 67 & -5 & 63 & 53 & -10 & 61 & 38 & -23 \\
Greece & 18 & 18 & 0 & 15 & 15 & 0 & 12 & 10 & -2 \\
Ireland & 71 & 76 & +5 & 57 & 62 & +5 & 43 & 41 & -2 \\
Italy & 20 & 20 & 0 & 17 & 17 & 0 & 14 & 11 & -3 \\
Netherlands & 71 & 74 & +3 & 53 & 59 & +6 & 40 & 39 & -1 \\
Portugal & 50 & 50 & 0 & 38 & 38 & 0 & 28 & 26 & -2 \\
Spain & 47 & 46 & -1 & 36 & 35 & -1 & 27 & 24 & -3 \\
Sweden & 72 & 69 & -3 & 54 & 52 & -2 & 42 & 35 & -7 \\
United & 62 & 63 & +1 & 49 & 50 & +1 & 37 & 34 & -4 \\
Kingdom & & & & & & & & & \\
\hline Average & 60 & 59 & -1 & 48 & 47 & -1 & 38 & 32 & -6 \\
\hline
\end{tabular}

Source: http://www.oecd.org/els/social/workincentives, last accessed on 2009/04/14, own calculations

Table 31 clearly indicates that the Continental welfares states of the Mediterranean variant, including Greece, Italy and to some extent Spain offer little or no assistance to long-term unemployed jobseekers and otherwise inactive citizens, reflecting their family-based welfare support systems. The Nordic welfare states along with Belgium, the Netherlands and Ireland are above the average for all income clienteles. The UK is also consistently right around the average, which shows that regime type is a very crude indicator, albeit, somewhat better than for initial unemployment 
benefits payments. Perhaps most strikingly, literally all of the countries have reduced transfers for the high-income bracket with the most significant cuts institutionalised in Germany, followed by Denmark, Finland and Sweden. Increases, in turn, are rare and mostly noticeable in Ireland and the Netherlands for low and average incomes only.

While it has been established that there is great diversity regarding the generosity of negative financial incentives, there is also continued diversity regarding the duration of benefits payments, both within and across regime types. However, many governments have shortened the eligibility duration for unemployment benefits, in some cases, quite dramatically. Examples include the UK, where the UB duration was reduced from 12 to six months in 1996; Germany, where UB payments were cut from 32 months to 12 months in 2005 for adult jobseekers (older workers with long work biographies may receive benefits for up to 24 months); Ireland, where UB payments were reduced from 15 to 12 months in October 2008; Denmark, where the duration of UB was gradually reduced from nine to four years, albeit with compulsory activation that may start as early as after three months after becoming unemployed; and Sweden, where the centre-right government reduced the duration of benefits payments in early 2007 to 60 weeks total, albeit with a reduction in payment generosity after 40 weeks already (OECD 2007b). In this context, another common trend in many European countries has been the abolition of the possibility of re-qualifying for UB payments after participation in active labour market programmes (e.g., Denmark, Germany, and Sweden). The following box illustrates unemployment insurance benefit durations along regime lines.

Box 13 Maximum Unemployment Benefits Duration in Months for Prime-Aged Workers, Indicating Changes in the Duration of UB Benefit Payments from mid-1990s to 2008

\begin{tabular}{ll}
\hline Anglophone Europe & Nordic Europe \\
- Ireland $(15 \rightarrow 12)$ & - Denmark $(108 \rightarrow 48)$ \\
- UK $(12 \rightarrow 6)$ & - Finland $(23)$ \\
& - Sweden $(28 \rightarrow 14)$ \\
\hline Continental Europe (centre) & Continental Europe (south) \\
- Austria (9) & - Greece (12) \\
- Belgium (indefinite) & - Italy (6) \\
- France $(23)$ & - Portugal (24) \\
- Germany $(32 \rightarrow 12)$ & - Spain (24) \\
- Netherlands (24) & \\
\hline Source: OECD, 1997d, 2007a &
\end{tabular}


In summary, while differences remain significant, recent developments suggest that there is a rather common trend toward reducing the duration of benefit payments, and no country in Western Europe has actually increased the duration of benefit payments. This trajectory is in line with empirical studies that suggest that unconditional UB payments paid over a prolonged period of time contribute to higher levels of long-term unemployment (e.g., Esping-Andersen 200ob; Gangl 2002). ${ }^{21}$ It also seems to suggest that it is politically a more viable option to reduce benefit payment duration rather than its generosity.

A final aspect that is closely related to the generosity and duration of unemployment benefits and other assistance payments is the availability of "exit options". Chapter IV has shown that during the early to mid$198 \mathrm{os}$, the OECD promoted - under certain circumstances - the use of early retirement options as a way to alleviate high levels of unemployment and to "open up" job opportunities for younger workers. This advice was taken to heart by many Continental countries, including both Austria and Germany. But also the Nordics and to a lesser extent the Anglophone countries made use of this instrument. With the new political agenda of raising employment levels - and the experience in many countries that early retirement did not lead to the intended effect of lowering youth unemployment - this instrument has increasingly come under criticism and both the OECD and the EU now call for the abolishment of these schemes and the parallel expansion of "lifelong learning" instruments to retain older workers in the workforce. Many European countries have subsequently begun to phase out or severely curtail early retirement schemes, including, for instance, Ireland, Germany, the Netherlands, Sweden, and the UK. More specifically, in Sweden, the option for early retirement for labour market reasons was abolished in 1991, and the Partial Pension Scheme was phased out in 2001 (Anxo and Niklasson 2004, 30). Similarly, in Ireland, the government has been gradually phasing out the Pre-retirement Scheme since 2006. Instead, older workers receive a UA payment, which means, however, that they need to fulfil regular work availability requirements. Germany also introduced substantive legislative changes in the fall of 2005. Access to early retirement schemes has been limited and the early retirement age is being gradually raised from 60 to 63 years of age, while the regular retirement age will gradually rise from 65 to 67 years of age.

Smaller path corrections have also been undertaken in Austria and Denmark. In June 2006, as part of a Welfare Agreement between the social partners, the Danish government and the main opposition parties 
agreed to retain the "right" to an early exit, but raised the entry age from 60 to 62 , in line with the increase in the age of regular retirement from 65 to 67. Moreover, the special rule for older workers, which "forced" older workers who had been unemployed for more than two-and-a-half years into early retirement, was also abandoned, while a "right" to a senior job offer on conditions reached by the social partners was introduced, effective 1 January 2008. Similarly, in Austria, the use of early exit options has a long tradition and Austria has been the "taillight" with respect to employment rates for older workers (see figure below). As late as 1 January 2000, the Austrian conservative-populist government managed to introduce a new "old-age part-time" law (Altersteilzeit), which allowed older workers with long working biographies to reduce their working hours by 40 to 60 percent, while receiving wage compensation from the Austrian PES in return. The goal of the programme was to encourage older workers to actually work longer by allowing them to adjust their own working hours. As the uptake of the programme rapidly exceeded the government's expectations, access was tightened in 2004 by gradually raising the age threshold from 50 to 55 years of age for women and from 55 to 60 years for men.

Moreover, in line with reducing the use of early retirement schemes, most European governments have made significant attempts to cur-

Figure 4 Employment Levels Among Older Male Workers Aged 60-64 in Percent, 1996, 2002, and 2008

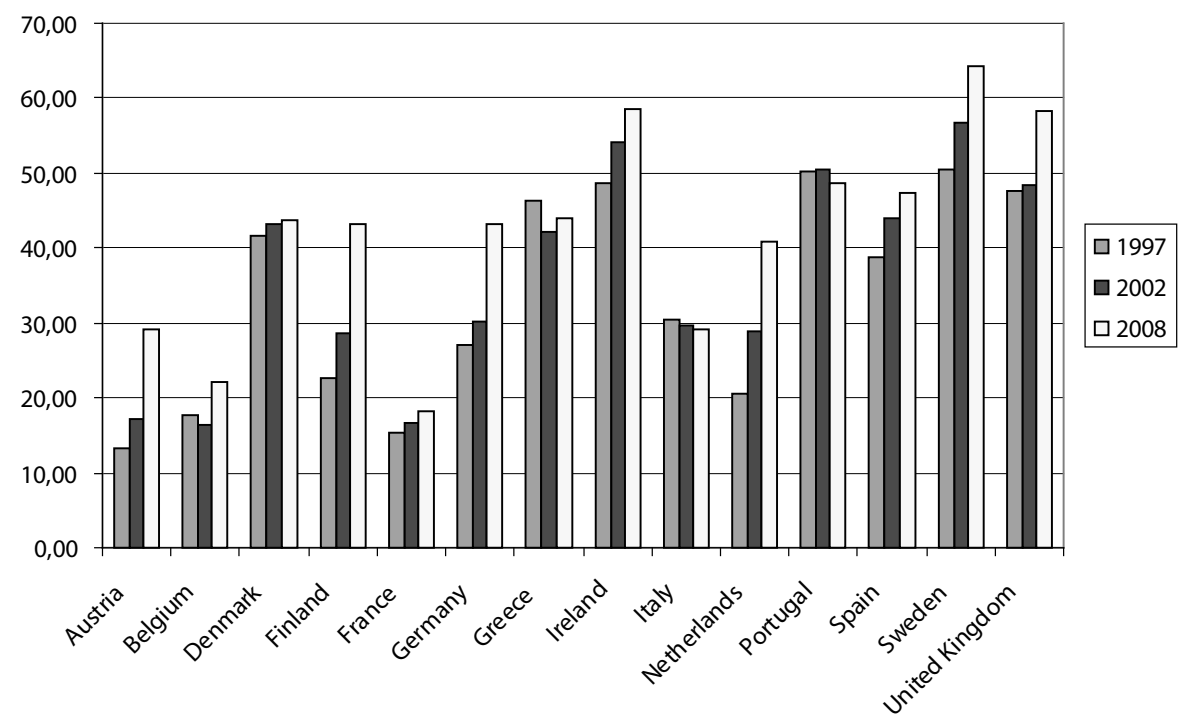

Source: OECD.stat, extracted on 30 June 2009, own graphic illustration 
tail the excessive use of disability pensions. Access has been tightened, cases re-reviewed, and programmes closed off to new entrants. Prominent examples of these developments include the Netherlands and the UK, but recalibration efforts have also been made in Austria, Denmark, Ireland and Sweden, while Germany already has a rather strict disability benefits system. As it is difficult to find reliable and comprehensive comparative data on the use of exit options, including early retirement, disability pensions and even other forms such as prolonged UB payments or social partnership arrangements, the employment rate of older, male workers aged 60 to 64 is used here as an approximation of the availability of such measures. While the data does not control for fluctuations in overall unemployment or improved health of the workers, it can nevertheless provide an indication of the change in activity levels of older workers, which are directly affected by the availability of exit options.

As expected by the described policy changes above, figure 4 shows that there has been a rather significant increase in the employment levels of older, male workers in most European countries, especially Finland, Germany, and the Netherlands. The main exceptions include Belgium, France, Italy and Portugal. In Portugal, however, the level of employment has been fairly high over the past number of years.

In summary, the data and empirical analyses suggest that the "negative" work incentives category displays a somewhat mixed picture. On the one hand, there has been an increase in the emphasis on non-financial negative incentives, including benefits conditionality and a tighter, more targeted access to benefits. This means that periods of joblessness are interrupted earlier by state authorities, job-search requirements have been tightened, and the definition of "suitability" has often been loosened. Thus, the expectations for jobseekers have increased, which is consistent with the normative shifts built on the predominant "mutual obligations" philosophy. On the other hand, with regard to financial negative incentives, major country differences - although no regime-specific ones - remain especially when considering the generosity of state transfers. Likewise, while benefits levels have been stable in some countries, others have seen decreases, which were often made possible indirectly through new indexation methods such as ending automatic benefits adjustments to inflation. In turn, with respect to the duration of benefits payments, many countries have reduced the length of time jobseekers have access to benefits, abolished the possibility to re-qualify for UB payments through participation in ALMPs, and introduced compulsory activation at an ear- 
lier stage of the joblessness period. Similarly, while there is no uniform trend across Europe, most countries have abolished or severely reduced the availability of early exit options.

\section{VI.4.C Positive Non-Financial Work Incentives}

\section{Individual Action Plans}

While the previous section pointed out that jobseekers are under more pressure today to actively seek jobs, there has also been more pressure on welfare and employment offices to support these efforts in a more positive, client-oriented way. One trend is that jobseekers are assigned a personal case manager or supervisor, who motivates and guides jobseekers in their search efforts. PES case managers in all EU-15 countries now formulate an IAP for most of their jobseekers, codifying both parties' rights and responsibilities. In most countries, exceptions for drawing up an IAP are made only when clients are considered immediately job-ready and therefore are expected to find in the near future a job without much PES assistance. Despite the extended use of IAPs, the timing differs for the various countries. In some countries, e.g., Austria, Germany, Sweden, and the UK, IAPs are formulated during the initial registration interview or during a second intensive follow-up interview, which is typically held within the first four weeks of unemployment. In these countries, the initial IAPs are less detailed. More elaborate ones follow when a "crisis point" is reached (typically after three months of joblessness) or when jobseekers are "flagged" as being at risk of drifting into long-term unemployment. In other countries, including Denmark, Ireland, Portugal, or Spain, an initial IAP is formulated only after a crisis point is reached, again, depending on the jobseekers' age and profiling category after three, six, or nine months of unemployment (OECD $2007 \mathrm{C}, 56 \mathrm{ff})$.

\section{Provision of Occupational and "Soft" Skills Courses}

Regarding the instruments applied, or the content of the IAPs, all six European countries in this study have improved and expanded vocational guidance and job-counselling services in recent years. A critical part of the job-counselling services is the increased use of "soft skills", which are often group-based courses that typically aim to improve the basic jobsearch, motivational and presentational skills. This focus goes hand-inhand with the overall "work-first" orientation, i.e., the goal to match jobseekers with available vacancies more quickly and more effectively. The PESs also increasingly offer more and better opportunities for non- and 
low-skilled individuals to acquire basic literacy and numeracy skills, or to complete a diploma equivalent to a secondary-level school degree.

With respect to more costly, high-end training courses, there has been a trend toward shortening the duration of these courses - especially in Austria and Germany - and to deliberately select only qualified jobseekers, who are more likely to progress into gainful employment after course completion (for Austria, see Lutz and Mahringer 2007, 206). In both Austria and Germany, labour unions and other stakeholders are concerned that their systems have become somewhat unbalanced in favour of shortterm "soft skill" courses at the expense of traditional training courses (interviews, $\mathrm{AK}, \mathrm{DGB} 1, \mathrm{DGB} 2, \mathrm{OGB})$. It is important to note, however, that Austria is still operating within a general trend of increasing spending on ALMPs, including training, while Germany has gone through major organisational reforms following the Hartz IV reforms, which temporarily inhibited the full delivery of training courses. Accordingly, there was a sense that both governments in office in 2009 were trying to "course correct" and to make access to training more balanced. Both Nordic countries in this study have experienced significant cutbacks in high-level training under their centre-right governments. For instance, the Danish government has significantly reduced its skills upgrading efforts for jobseekers since 2001, while they have boosted job-search requirements, which has been described as a shift "from a significant focus on social integration to a much greater emphasis on social disciplining" (Larsen and Mailand 2007, 99). Similarly, the Swedish government has more openly embraced a "work-first" approach and has, as a consequence, also reduced labour market training options (Fiscal Policy Council 2009). As both of these countries started at very favourable levels, they continue to remain generous compared to the rest of Europe.

Developments in occupational skills training are somewhat different in the Anglophone countries. While Ireland has continued to offer highlevel training to qualified jobseekers (Specific Skills Training, SST), a variety of preparatory courses for jobseekers who are not quite ready to participate in SST courses, as well as a wide range of apprenticeships, the UK has improved its support for low-skilled people in work instead. The UK's unique strategy is based on one empirical finding and one normative conviction. With respect to the latter, policymakers in Britain firmly believe that the main task of the PES is to find work for jobseekers and not to equip them with occupational skills (which is an individual responsibility). As regards the former, empirical studies suggested that adults learn better in a work setting than in PES training centres. Studies also 
showed, however, that employers are more likely to invest in workers who already have skills than in those who do not (interview, DWP5). In consequence to these findings, UK policymakers concluded that jobseekers needed first and foremost assistance with their job searches, and then, once in employment, they should be offered ways to improve their qualifications to the point where further skills investments become attractive to employers. New Labour's flagship programme, Train to Gain, which was launched in 2006, seeks to achieve precisely these outcomes by offering low-skilled workers fully-paid access to training (both on and off the job), while also offering employers subsidies to compensate for the lost man-hours (Page and Hillage 2006). Training, which is delivered through Learning and Skills Councils, can include literacy and numeracy skills, vocational qualifications, and leadership and management training. With Train to Gain, the government effectively introduced an Adult Level 2 Entitlement to adult workers, i.e., a legal "right" to attain first full Level 2 qualifications free of charge. As of 1 August 2007, there is also an Adult Level 3 Entitlement for young adults between the ages of 19 and 24. The government also expanded the number of available apprenticeship positions to 250,000 , with a goal of 400,000 , and abolished all age restrictions, thus making apprenticeships also available to older workers. Last, the Leitch Review, requested by Gordon Brown and published in 2006, has challenged the purely "work-first" strategy of the JCP and triggered a debate within government and corresponding ministries of how to link employment and training services. These debates have led to pilot programmes in which local JCPs work closely with the Learning and Skills Councils to provide jobseekers joint employment and skills advice services (interview, DfES).

In summary, great variations in skills enhancement remain across regime types. There is a trajectory, however, among the "high spenders" (Denmark, Germany, and Sweden) to cut costs through customer targeting and focusing more strongly on vocational guidance rather than on training. In turn, there is also a trajectory among the "low spenders" (Austria and the UK) to increase expenditures on training. In the case of Austria, the focus has been on the unemployed, while the UK has opted to make basic skills training more accessible to low-skilled workers.

\section{The Provision of Childcare}

Probably the most regime-typical diversity - and yet gradual convergence - can still be found with regard to additional employment-related services such as childcare. While the issue of childcare has become salient in all 
European countries - and the 2002 Barcelona European Council enshrined the goal of providing childcare to 90 percent of all children between three years of age and the mandatory school age - as well as to at least 33 percent of children under three years by the year 2010, few Member States are equipped to reach this ambitious target..$^{22}$ In particular, countries with very limited access to childcare, such as the Mediterranean welfare states including Italy or Spain show correspondingly low levels of female employment. In turn, it is the Nordic countries, including Denmark, Finland, and Sweden that continue to provide exceptional services for parents in general and female jobseekers in particular (European Foundation for the Improvement of Living and Working Conditions 2004). An important legislative change took place, however, in Denmark in 1995, when the Social Democrats followed the Swedish example set in 1985, and introduced a statutory "right" to high-quality, accessible, and affordable childcare. While the responsibility to offer these childcare places has continued to rest with local authorities, the government's legislative mandate has been seen as a step toward re-centralisation of the Danish welfare system.

In other words, while Danish and Swedish institutional developments predate the EES and the Barcelona Summit, and thus serve as inspiration, much political activity has occurred in the "Anglophone" welfare states since the late 1990 os and in the "centre" Continental welfare states, particularly since the mid-2ooos. In both of these regions - with the exception of France and Belgium - childcare facilities are sparse and the traditional male breadwinner model is still deeply ingrained in society. However, in recent years, governments from both ends of the political spectrum have increasingly addressed childcare needs. For instance, the governments of Austria and Germany have pledged to significantly improve the infrastructure of childcare facilities for children under the age of three. In Germany, it was the Red-Green government, that first addressed this issue on 1 January 2005 with the issuance of the childcare expansion act (Tagesbetreuungsausbaugesetz, TAG), which envisioned the creation of 230,00o new childcare places by the year 2010. The successive Christian Democratic Minister further pushed this agenda and, in April 2007, the federal government, the Länder, and the local authorities committed themselves to providing either a childcare place or access to a childminder for 35 percent of children under the age of three, which means 750,000 childcare places by 2013 (for more details, see chapter VII). In Austria, in turn, the right-wing coalition government, which was in power from 2000 to 2006 , showed little interest in expanding childcare provisions. Instead, the government significantly increased child benefits with the explicit goal of encouraging low-skilled 
women to exit the labour market (interview, IHS1). ${ }^{23}$ However, when a Social Democratic-Christian Democratic coalition government returned to office in late 2006, Austria made the provision of childcare a key issue (Weishaupt 2009). The government, inspired by German developments, promised to subsidise the creation of 5,000 places annually, with a total target of 50,000 places (interviews, WKÖ2, WIFO).

The UK and Ireland have also seen a dramatic increase in both the salience and political will to provide more and better access to childcare. Although they started out with very limited institutional capacities, both countries recently initiated and delivered national childcare strategies to expand the provision of childcare places and improved the assistance offered to single parent jobseekers with unfulfilled care needs. More specifically, the Irish government launched a series of programmes, including the 1998 Equal Opportunities Childcare Programme (EOCP I), the Equal Opportunities Childcare Programme 2000-2006 (EOCP II), and the National Childcare Investment Programme (NCIP) 2006-2010. While the EOCP I and II were intended to tackle child poverty through improving employment opportunities for low-income, often single-parent families to whom private childcare was unaffordable, the NCIP targeted the general population by creating an additional 50,000 places nationwide by 2010 (for more details, see chapter VII). The UK's New Labour government made access to affordable childcare one of its key promises in as early as 1998 and subsequently initiated a comprehensive ten-year Childcare Strategy in 2004. The Strategy is intended to provide financial support and co-ordinate the activities of local authorities and their partners in delivering high-quality, affordable childcare to parents with children up to the age of 14. Furthermore, parents with children aged three or four are now "entitled" to 15 hours of childcare (interview, $\mathrm{TUC}_{2}$ ).

To summarise, while both Continental and Liberal welfare states (except for France and perhaps Belgium) are still characterised by a general lack of affordable, high-quality childcare providers, the state-led provision of childcare has gained in salience and substantial legislative initiatives have followed. While emerging skills shortages in many industries was certainly an important element in fostering this agenda ${ }^{24}$ - policymakers hoped that qualified, young mothers would return to work more quickly when childcare needs were fulfilled - most observers argued that the EU has also made a positive contribution toward this goal. (Interviewees in Austria, Germany, and Ireland acknowledged the EU's role, while interviewees in the UK did not mention the EU as a reason why the government pursued childcare initiatives). 


\section{VI.4.d Positive Financial Work Incentives}

While this brief overview of non-financial positive incentives suggests a general trajectory toward the provision of individually tailored services, coupled with continued, but narrowing differences in regard to occupational training measures and an EU-wide effort to expand the provision of childcare places, the following section will show that there is very little evidence of convergence with respect to financial incentives. In the financial context, the EU and the OECD have often advocated recalibration of national policies to incentivise accepting low-wage employment over collecting benefits. Indicators for the existence of appropriate financial work incentives include (a) the level of taxation for low-wage and average-wage employment, (b) the generosity of statutory minimum wages (SMW) and other regulations that guarantee a wage floor above social benefits, and (c) in-work and/or negative income tax credits available to compensate for low incomes. The following two tables summarise the average tax rates (personal income tax plus social security contributions) and gross statutory minimum wages (per hour, US dollars at 2005 market exchange rates and constant prices) in 14 European countries.

Table 32 Average Tax Rates for Full-time Workers at Two Wage Levels, 2000 and 2005

Personal Income Tax plus Employee Social Security Contributions

\begin{tabular}{lcccccc}
\hline & 2001 & 2006 & Change & 2001 & 2006 & Change \\
\hline Austria & $67 \%$ APW & $67 \%$ APW & $2000-2005$ & APW & APW & $2000-2005$ \\
Belgium & 25.6 & 26.6 & +1.0 & 31.0 & 32.7 & +1.7 \\
Denmark & 35.8 & 34.8 & -1.0 & 35.8 & 41.9 & +6.1 \\
Finland & 40.8 & 38.7 & -2.1 & 44.1 & 40.8 & -3.3 \\
France & 28.1 & 25.0 & -3.1 & 34.2 & 31.3 & -2.9 \\
Germany & 25.7 & 26.0 & +0.3 & 28.8 & 29.0 & +0.2 \\
Greece & 38.1 & 36.4 & -1.7 & 44.5 & 42.5 & -2.0 \\
Ireland & 17.4 & 16.5 & -0.9 & 21.1 & 23.7 & +2.6 \\
Italy & 11.1 & 7.9 & -3.2 & 20.3 & 15.3 & -5.0 \\
Netherlands & 23.7 & 22.4 & -1.3 & 28.2 & 27.3 & -0.9 \\
Portugal & 17.6 & 31.9 & -0.7 & 33.2 & 32.5 & -0.7 \\
Spain & 14.7 & 15.6 & -1.7 & 22.4 & 21.2 & -1.2 \\
Sweden & 31.7 & 29.2 & -2.5 & 33.7 & 31.3 & +2.4 \\
UK & 22.2 & 23.5 & +1.3 & 25.5 & 26.6 & +1.1 \\
\hline Average & 26.1 & 25.0 & -1.1 & 30.2 & 29.7 & -0.5 \\
\hline
\end{tabular}

Source: http://www.oecd.org/els/social/workincentives, last accessed on 2009/04/14, own calculations 
Table 33 Gross Statutory Minimum Wages (if applicable), 2000 and 2005

Per hour, USD at 2005 Market Exchange Rates and Constant Prices

\begin{tabular}{lccc}
\hline & 2000 & 2005 & Change \\
\hline Belgium & 9.24 & 9.21 & -0.03 \\
France & 8.62 & 9.72 & 1.10 \\
Greece & 4.67 & 5.03 & 0.36 \\
Ireland & 8.26 & 9.24 & 0.98 \\
Netherlands & 10.43 & 10.60 & 0.17 \\
Portugal & 3.11 & 3.13 & 0.02 \\
Spain & 4.12 & 4.27 & 0.15 \\
United Kingdom & 7.88 & 9.47 & 1.59 \\
\hline
\end{tabular}

Source: Immervoll 2007, 9

Tables 32 and 33 clearly indicate that Liberal economies, especially Ireland, and the Continental welfare states of the southern variety, including Greece, Portugal, Spain and to some extent Italy, i.e., countries that provide the lowest cash transfers to the long-term unemployed, also emerge as the countries with the lowest tax rates on low-wage work. It is however, only the two Liberal countries that also offer a rather generous statutory minimum wage, while Italy has no SMW and the existing SMWs in Greece, Portugal, and Spain are comparatively low. Therefore, the incentives to pick up gainful but low-wage work are significantly higher in Ireland and the UK than in the southern Continentals. Moreover, both Ireland and the UK combine generous SMW with additional in-work tax credits that make almost any type of low-wage work more attractive than a "life on benefits". More specifically, the New Labour government replaced the Conservatives' Family Credit with a more generous Working Families Tax Credit (WFTC), while the Irish government effectively exempted everyone earning the national minimum wage from income taxation. Accordingly, both countries - the UK more systematically than Ireland - place considerable weight on "making work pay" and the governments in both countries have promoted "work by payment through the tax rather than the benefit system" (Wells 2001, 244).

In turn, the countries with the highest tax burdens on low-wage income are found in Denmark, Germany, Belgium, the Netherlands, and Sweden in that order. This latter group is thus composed of those countries that also tend to pay above-average cash transfers to the long-term unemployed. Two countries, Belgium and the Netherlands, offer gener- 
ous SMWs, while Germany, Denmark and Sweden do not offer this legally established minimum wage. If the latter three countries want to improve the incentives to seek and accept low-wage work, they are confronted with four choices: (1) reduce benefit levels, (2) pay subsidies to workers, (3) reduce tax levels, and/or (4) introduce a minimum wage above benefit levels. While the vast majority of workers in Denmark and Sweden remain covered by collective wage bargaining agreements, which effectively serve as a "functional equivalent" to a minimum wage, German workers in the low-wage sector are increasingly left out. Accordingly, the German Social Democrats, while in office from 1998 to 2009, focused on the introduction of a national minimum wage. As the Social Democrats needed the support from the CDU/CSU to pass legislation through the Parliament's upper chamber, only a compromise could be reached with which the government could make certain sectors' collective wage agreements generally binding (cf., Weishaupt 2010b). On the one hand, the Social Democrats extended the "posting workers act" (Arbeitnehmer-Entsendegesetz, $A E n t G)$ to a number of new sectors, including the commercial cleaning services and numerous other industries, covering some 1.8 million workers. On the other hand, the Social Democrats "revived" the dormant 1952 "minimum labour conditions act" (Mindestarbeitsbedingungengesetz, $M i G)$, allowing the federal ministry for employment to impose minimum wage regulations in sectors that are not sufficiently covered by collective bargaining agreements and pay extremely low wages.

The centre-right governments in Denmark and Sweden, in turn, have focused more heavily on tax reductions in recent years. In Denmark, the Liberal-Conservative government first introduced a general tax freeze in 2001 to discipline public spending. In 2004, an in-work tax credit (beskaftigelsesfradraget) was introduced and the threshold "for the first progression step, the so-called middle tax, was raised" (OECD 2008b, 110). The explicit aim of these reforms was to "reduce the distortions on the labour market and to improve incentives to work" (Skatteministeriet 2004, 2). In 2007 , an additional agreement on lowering taxes on earned incomes was reached and a Tax Commission established to present ideas for further tax cuts by 2009. Similarly, the Swedish bourgeois coalition government issued various tax reforms in between 2007 and 2009, lowering the marginal tax rates for low and middle income workers, and introducing and subsequently enhancing and simplifying an in-work tax credit (Government of Sweden 2008, 71). The Swedish government's explicit aim of tax reforms was similar to Denmark's: to "restore the work-first principle and fight labour market exclusion" (Government of Sweden 2008, 1). 
In addition to advancing "making work pay" initiatives through lowering tax burdens, in-work tax credits, and appropriate (minimum) wages, the payment of employment/wage subsidies and participation in public works projects for the unemployed are often seen as alternative ways to provide employment opportunities to jobseekers facing severe hurdles. During the 1970s-1990s almost all of the European governments offered some type of "work experience" scheme and thus often functioned as the "employer of last resort". However, since the mid- to late 199os, most governments have reduced or entirely phased out these types of schemes. This trend was most pronounced in the UK, the Nordics and some Continental welfare states, while Ireland retained a large-scale programme and Austria a smaller version. More specifically, Sweden relied on direct job creation during the 1970 s and 1980 os and even expanded its use in the early 1990 s, when unemployment skyrocketed from about two to eight percent (excluding jobseekers in ALMPs) and employment dropped from over 80 percent in 1989 to some 70 percent in the mid-1990s (Timonen 2003, 5). During the mid-199os, the Swedish government used largescale work experience projects to keep jobseekers "active" and almost 15 percent of the workforce took part in some version of ALMPs (Timonen 2003, 99). While the traditional "relief work" projects were mainly organised by local authorities for social assistance recipients, a new work experience programme called "working-life development" (ALU) was introduced to employment offices in 1993, primarily focusing on environmental and cultural employment (OECD 1996d, 91). ALU attracted a large number of not-for-profit organisers, including labour unions, as the workers came at no cost and it targeted mainly people who were at risk of falling into long-term unemployment. However, with a general reduction in unemployment since the late 1990s, Sweden's Social Democratic and the more recent centre-right governments have gradually phased out direct job-creation measures, retaining such options only for the very long-term unemployed. Denmark has also shifted its emphasis away from direct job-creation measures. While the Social Democratic government introduced a new scheme called Pool Jobs as recently as 1996 (PLS Consult and Jensen 1997, 57), the subsequent centre-right coalition government prioritised private job growth. Accordingly, the centre-right government abolished all of its public employment measures, including Pool Jobs and Individual Job Training (Knuth et al. 2004, 61), and streamlined its previously 32 different labour market schemes into three covering both insured and uninsured workers: (1) guidance and upgrading of skills and qualifications (50 percent); (2) practical work 
training in enterprises (five percent); (3) employment subsidies (45 percent, of which 30 was paid to public and 15 private employers) (Hansen 2007, slide 5).

The UK government has also almost entirely phased out the use of direct job-creation schemes when compared to their peak in the late 1980 os. At that time, the Conservatives' flagship programme was called Employment Training, which offered work experience opportunities to young and disadvantaged jobseekers. While the Conservative government planned - if elected - to introduce a new "workfare" programme dubbed Project Work, the newly elected Labour government launched their New Deal instead. Direct job creation in the social and environmental sectors as well as employment subsidies paid to employers were retained as three of the four "options" in the New Deal - the fourth being full-time education. While temporary work in the voluntary and community sectors was a response to societal actors demanding this option, participation in the environmental task force was mainly seen as an instrument to "test" the willingness of benefit recipients to fulfil their "duties" (interview, DWP1). However, due to the DWP's strong focus on "work first" and the generally positive economic performance of the British economy since the late 1990 s, the use and availability of direct job creation has remained relatively limited, while employers only hesitantly used employment subsidies.

The German government has also reduced the use of direct job creation, but has refrained from entirely abolishing such schemes. With the Hartz reforms, Germany's classic direct job-creation programme (ABMs) has been drastically reduced and, more recently, it was decided that ABMs will eventually be completely phased out. Newly introduced "employment opportunities", commonly known as One-Euro Jobs, now offer some work experience to many long-term unemployed. However, these "employment opportunities" are much shorter in duration (typically six months), offer only marginal financial incentives (about $€ 1$ per hour as a "top-off" to assistance payments), and do not have a built-in training component. Moreover, jobseekers are increasingly expected to accept "atypical", often precarious, employment, including temporary employment, part-time work, and so-called "mini-jobs". Because participants are allowed to keep some of their transfer payments, this development can be described as a de facto wage subsidy, which has been utilised by some 650,00o workers. On a much smaller scale, the government also offers "job integration subsidies" (Eingliederungszuschüsse and Entgeltsicherung) for "weaker" candidates, such as the long-term unemployed, the low skilled, older work- 
ers, or women returnees, who gain full-time employment. More recently, the Social Democratic ministry for employment also introduced a new scheme called JobPerspektive, which subsidises employers' wage costs by up to 75 percent when job opportunities for very long-term, highly disadvantaged, unemployed jobseekers are created.

In Ireland, the largest direct job-creation scheme, Community Employment $(\mathrm{CE})$, is still popular and widely used. CE offers part-time work experience and various training elements to disadvantaged workers. Mostly single mothers are attracted to the scheme as it offers flexible working hours and often includes childcare options. It is community and voluntary sector actors who run these CE projects, which are approved and monitored by FÁS to ensure quality standards (interviews, FÁS1; INOU1). However, in line with a general reduction in unemployment - but not without some loud protests - the Irish government has gradually reduced CE places from a peak of 40,000 in the mid-1990s to 20,000 places in 2008 (for more details, see chapter VII). Wage subsidies, in turn, are mainly paid through the Back to Work Allowance (BWA) scheme and the Family Income Supplement (FIS). BWA allows the unemployed to retain part of their welfare benefits for up to three years upon acceptance of a job. BWA is now available after two years of unemployment (previously five). FIS, in turn, is an allowance for low-income households with parents engaged in low-wage work.

In Austria, social-economy firms (sozial-ökonomische Betriebe) enjoy a similar level of popularity among participants and are strongly supported by the Social Democrats, the labour unions, and the Chamber of Labour (Arbeiterkammer). The social-economy firms offer work experience to insured jobseekers with particularly difficult backgrounds, including former drug addicts, alcoholics or ex-convicts. The majority of costs for social-economy firms are covered by the PES and participation in the scheme is typically six months, but can in rare cases be extended to one year. Workers in social-economy firms receive professional, pedagogic support and assistance with their job-search efforts. Other instruments that target "weaker" jobseekers, such as older workers and the long-term unemployed, include employment subsidies (Eingliederungsbeihilfen), which are paid to employers for a limited period of time to offset the lower productivity levels of these workers. ${ }^{25} \mathrm{New}$ instruments have also been introduced for women returnees after their child-bearing years to help them re-elevate their skills.

A final measure for jobseekers is the provision of business start-up subsidies, which are available in almost all EU countries. However, their 
use is often limited, and often restricted to qualified unemployment benefits recipients. Even among those countries that, comparatively speaking, spend the most on business start-up subsidies, the spending levels are below one-tenth of one percent of GDP. The following table illustrates this trend. Spending levels below 0.005 of GDP are indicated as 0 .

Table 34 Public Expenditures on Business Start-up Subsidies as Percentage of GDP in Western European Countries, 1997-2007

\begin{tabular}{|c|c|c|c|c|c|c|c|c|c|c|c|c|}
\hline & 1997 & 1998 & 1999 & 2000 & 2001 & 2002 & 2003 & 2004 & 2005 & 2006 & 2007 & $\begin{array}{l}\text { Change } \\
1997- \\
2007\end{array}$ \\
\hline AT & 0.00 & 0.00 & 0.00 & 0.00 & 0.00 & 0.00 & 0.00 & 0.00 & 0.01 & 0.01 & 0.01 & 0.01 \\
\hline BE & 0.00 & 0.00 & 0.00 & 0.00 & 0.00 & 0.00 & 0.00 & 0.00 & 0.00 & 0.00 & 0.00 & 0.00 \\
\hline DK & 0.05 & 0.04 & 0.02 & 0.00 & 0.00 & 0.00 & 0.00 & 0.00 &.. & .. & 0.00 & -0.05 \\
\hline $\mathrm{FI}$ & 0.02 & 0.02 & 0.01 & 0.01 & 0.01 & 0.01 & 0.01 & 0.01 & 0.02 & 0.02 & 0.02 & 0.00 \\
\hline FR & 0.00 & 0.00 & 0.00 & 0.00 & 0.00 & 0.00 & 0.01 & 0.00 & 0.00 & 0.01 & 0.03 & 0.03 \\
\hline $\mathrm{DE}$ & 0.03 & 0.03 & 0.04 & 0.04 & 0.04 & 0.05 & 0.09 & 0.13 & 0.09 & 0.12 & 0.08 & 0.05 \\
\hline GR & 0.02 & 0.02 & 0.02 & 0.02 & 0.01 & 0.01 & 0.04 & 0.05 & 0.00 & 0.02 & .. & $n / a$ \\
\hline IE & 0.04 & 0.06 & 0.05 & 0.03 & 0.05 & 0.00 & 0.00 & 0.00 & 0.00 & 0.00 & 0.00 & -0.04 \\
\hline IT & 0.00 & 0.01 & 0.02 & 0.04 & 0.07 & 0.03 & 0.05 & 0.05 & 0.05 & 0.04 & 0.03 & 0.03 \\
\hline $\mathrm{NL}$ & 0.00 & 0.00 & 0.00 & 0.00 & 0.00 & 0.00 & 0.00 & 0.00 & 0.00 & 0.00 & 0.00 & 0.00 \\
\hline PT & 0.04 & 0.03 & 0.01 & 0.01 & 0.01 & 0.00 & 0.00 & 0.00 & 0.00 & 0.00 & 0.00 & -0.04 \\
\hline ES & 0.03 & 0.03 & 0.05 & 0.05 & 0.05 & 0.05 & 0.05 & 0.04 & 0.06 & 0.08 & 0.09 & 0.06 \\
\hline SE & 0.07 & 0.08 & 0.06 & 0.05 & 0.04 & 0.04 & 0.04 & 0.03 & 0.03 & 0.03 & 0.02 & -0.05 \\
\hline UK & 0.00 & 0.00 & 0.00 & 0.00 & 0.00 & 0.00 & 0.00 & 0.00 & 0.00 & 0.00 & 0.00 & 0.00 \\
\hline
\end{tabular}

Source: OECD.stat, extracted on 30 June 2009

To summarise this section on positive work incentives, we find that governments have generally improved non-financial work incentives by modernising job-counselling services and extending the use of "soft skill" courses intended to prepare jobseekers to more quickly re-enter the workforce. There has also been a trajectory towards reducing the costs of occupational skills training courses in most of the Continental and Nordic countries by selecting participants more carefully and by shortening the duration of these courses. The Liberal economies, however, have moved in the opposite direction. Ireland has continued its invest- 
ments in occupational skills training for the unemployed, while the UK engaged in strategies to improve the skills of workers with no or low skills, once they found employment. A strong trajectory toward convergence - albeit, with significant differences remaining - has also been visible in addressing the issue of childcare through state-led initiatives and strategies. Most notably, central governments are increasingly subsidising and steering the activities of local governments, thus effectively recentralising authority.

With respect to financial work incentives, there is a slight trend toward reducing the tax burden for low-wage work, while most countries have also begun to reduce the availability of public works projects (Denmark, Germany, Sweden and the UK). In turn, "making work pay" strategies show a distinct, regime-typical pattern. The liberal countries employ a combination of relatively generous SMWs, low taxation, and in-work tax credits, while the Nordics have increasingly relied on tax cuts, combined with employment subsidies and tight activation measures. Finally, the Continentals seem to struggle the most when trying to provide an appropriate mix of financial work incentives that combines elements of lower taxation with wage/employment subsidies and/or appropriate minimum wages.

\section{VI.5 Conclusions}

This long and yet necessarily simplified comparison of the experiences in Western Europe in general and in Austria, Denmark, Germany, Ireland, Sweden, and the UK in particular, leaves us with two questions. First, are labour market policy paradigms converging? And second, how do the observed changes affect the three regime clusters outlined in chapter IV, i.e., do the models associated with competing "worlds of welfare capitalism" still fit with their descriptions? This final section addresses these two questions.

\section{Vl.5.a Convergence or Persistent Diversity?}

This overview has shown that there has been a trend toward convergence, which is most pronounced on the ideational dimension. EU Member States, facing common challenges associated with economic globalisation, the rise of the service industry, demographic change, and changing family structures, and being constrained by the common European mar- 
ket and a single currency, increasingly define both causes of, and remedies for, unemployment in structural and individual terms. By attributing joblessness to jobseekers' motivation and qualifications, policymakers increasingly believe in their ability to affect the level of unemployment through supply-side labour market policies. This cognitive shift has been accompanied by a normative reorientation and a new political agenda. Work is now seen as the best form of welfare, and policymakers from almost all political spectrums openly embrace the concept of "mutual obligations". With this turn to activation, the political agenda is no longer to merely reduce unemployment, but to activate all "able-bodied" persons, through which individual achievement and self-reliance is maximized, welfare state dependency reduced, and the sustainability of the European Social Model attained.

This ideational convergence, in turn, has led to a reorganisation of Europe's Public Employment Services in line with the prescriptions of NPM theories and the recommendations articulated by the OECD and the EU. EU-wide reform trajectories with regard to the organisational dimension include (a) the introduction of management-by-objective systems (and herein, a shift from input to output targets); (b) independent, third-party programme evaluations; (c) the introduction of "one-stop centres" or, alternatively, the closer collaboration between local welfare and employment offices, which also increasingly blurs the line between the rights and responsibilities of UB and SA recipients; (d) the encouragement of local partnerships and attempts to mobilise all relevant stakeholders; (e) the promotion of quasi-markets and contestability in service provision, in particular for the delivery of soft and occupational skills courses, and finally; (f) the contractualisation of the relationship between individual jobseekers (clients) and employment officers (case managers) through the widespread use of individual action plans.

The ways in which these ideational and organisational changes have affected the financial and the work-incentives dimension are less pronounced, and therefore, convergence is less visible. On the one hand, with respect to the financial dimension, there is a general trend toward reducing some ALMP expenditures, particularly for direct job-creation measures, and for occupational skills training courses in those countries that traditionally spend heavily in this area. With respect to financing ALMP measures, however, there is as of yet no clear trend toward shifting away from payroll to general taxation as advocated by the EU and OECD. 
The work-incentive dimension, in turn, offers a rather mixed picture, with elements of both convergence and persistent diversity. With respect to the generosity of benefits, there has been little or no change and significant country specific differences remain. There has been, however, a trend toward reducing the duration of benefits payments across regime types, including, for instance, Denmark, Germany, Ireland, Sweden, and the UK. In turn, great differences remain with respect to the strategies that individual countries employ to "make work pay" and regime-specific trajectories are clearly noticeable. While the Anglophone countries rely on a combination of in-work tax credits and relatively high statutory minimum wages, the Nordics are willing to subsidise private and public employment, while raising work incentives through general tax reforms. The Continental welfare states have meanwhile struggled with the delivery of a comprehensive "making work pay" strategy and significant inactivity traps have remained. Moreover, while many countries have dramatically reduced or even completely phased out the availability of early exit options for labour market reasons, such options are still accessible and attractive in both Austria and Denmark. In other words, with respect to both negative and positive financial incentives, national and regime-typical differences remain significant.

Moreover, in all of the countries included in this study, the use of positive and negative non-financial incentives has been accelerated and countries increasingly use similar measures. Convergence is clearly noticeable, reflecting the impetus that comes with the "activation paradigm" and the associated "PES service model" that transcends regime trajectories. On the one hand, benefits have become more targeted, eligibility has been tightened, and job-search and suitability criteria have been strengthened. On the other hand, job-placement and counselling services have been expanded and improved, a wider variety of providers offer (more specialised) services, and access to additional services has been widened. Most notably - and again, strongly promoted by both the EU and the OECD - such services include expanded access to affordable childcare, even in those countries with traditionally strong male breadwinner models. The following table shows the main similarities and differences in the six primary cases of this study. 


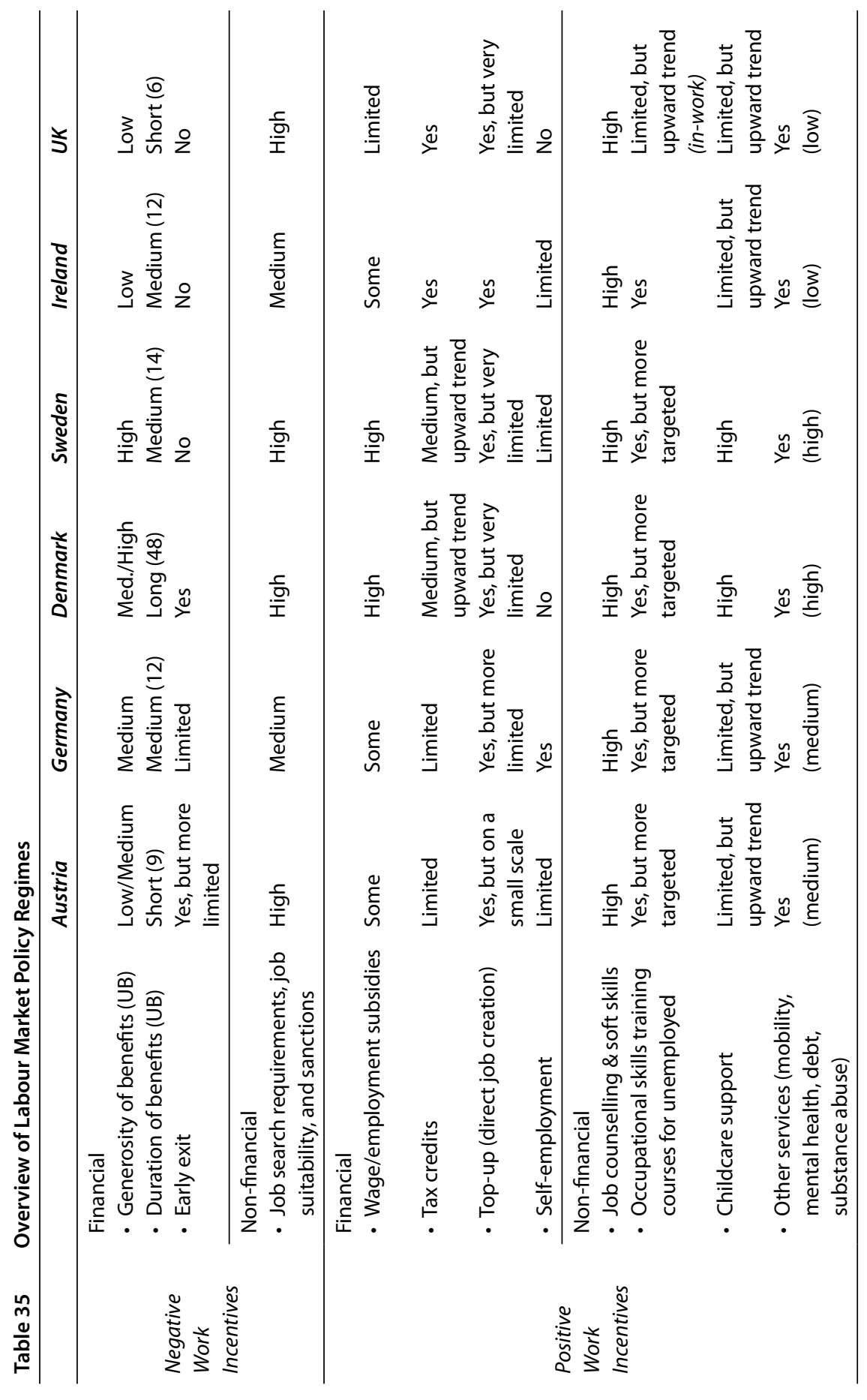




\section{VI.5.b Three Worlds of Welfare or Just One?}

Before I address the final question about the continued usefulness of the "three worlds of welfare capitalism", I would like to reiterate that this chapter has focused only on a particular section of labour market policy regimes, namely labour market governance and policies, while deliberately disregarding other labour market institutions, such as employment protection legislation and wage-setting arrangements. With this in mind, the message of this chapter is clear: there has been a trajectory of convergence across regime types, which is stronger in some areas, i.e., those associated with activation policies and the "PES service model", and weaker in others, i.e., those associated with the generosity of benefits, expenditures, the financing of labour market policies, and the actual toolkit of measures. This trajectory is therefore generally associated with particular institutional mixes found in two regime types: the Nordic model (high levels of activation, high levels of economic activity, and state-led childcare provision) and the Anglophone model ("making work pay", more individual responsibility, and more market mechanisms).

The developments described in this chapter have shown that the Nordic cases - especially after centre-right governments took office - have increasingly become concerned with cost containment and the effectiveness of their labour market programmes. In both cases under discussion, governments have fully embraced "making work pay" strategies, while downsizing their occupational training efforts and phasing out direct job-creation schemes (cf., Larsen and Mailand 2007, 99). They have also stressed a discourse of self-reliance, in contrast to one based on safety nets for the vulnerable (Marston et al. 2005, 144). Lastly, they have introduced quasi-market mechanisms for the provision of employment and training services, while reducing the influence of the social partners (Larsen 2005, 129). All of these developments have moved the Nordics a small but significant step closer to the Anglophone ideal, where one expects to find such institutional preferences.

In turn, the Anglophone cases have implicitly (Ireland) or explicitly (UK) endorsed a "rights and duty" rhetoric, have actively sought to increase activity levels and employment rates, and have launched national strategies to make childcare more readily available to families, effectively challenging male breadwinner norms. Moreover, Ireland launched a comprehensive array of ALMPs, including a variety of high-quality occupational skills training courses. Similarly, the UK has recently been engaged in a national strategy to tackle skills shortages in large segments of the 
population and introduced "entitlements" to second and third level qualifications. All of these developments suggest that the Anglophone countries, with Ireland in the lead, have moved incrementally but significantly toward "more state" rather than "more market" policies and as such, have embraced important elements of the "service-centred" Nordic welfare states.

Lastly, the Continental regime types have also been in flux, aspiring to elements of both the Nordic and the Anglophone ideal types. By seeking to achieve the Lisbon employment targets, the two Continental countries examined here have increasingly adopted activation measures for insured workers and social assistance recipients alike, have engaged in attempts to bring employment and welfare services closer together - thus moving toward a more universal approach - introduced quasi-market mechanisms for the selection of providers delivering occupational skills courses, expanded their low-wage sectors, and most recently, began to offer state assistance and leadership in providing childcare facilities. These developments therefore include both a stronger reliance on market forces (the Anglophone expectation) and a more interventionist role for the state (the Nordic expectation), effectively challenging core elements of Continental welfare states, including the subsidiarity principle (the central government has taken on responsibilities normally assumed by municipalities), the insurance principle (the long-term unemployed and social assistance recipients now receive identical treatment), and the male breadwinner model (important steps toward reconciling work and family life have been taken). In other words, the two Continental case studies have moved a significant step closer to both the Nordic and the Anglophone models, effectively leading to a hybridisation of their regime type. As such, I argue that the new labour market policy paradigm that is emerging across all regime types effectively combines both old and new institutional premises, i.e., Nordic and Anglophone traditions, incorporates new institutional elements often found in the NPM literature, while, however, retaining important elements of historically grown labour market instruments. In other words, institutional hybridisation is most pronounced in the Continental welfare states, but the Nordic and Anglophone countries have also borrowed elements from one another. The common elements that run like a "golden thread" through reform efforts in all of the six countries can be best captured by referencing the "activation paradigm" and the associated "PES service model". This trajectory, in turn, can be understood as a clear indication of the influence of the EU and the OECD and labour market reform processes. The following figure illustrates this argument. 
Figure 5 The Core Elements of the Activation Paradigm

\section{Activating Labour Market Policy}

- Early interventions

- Individually-tailored case management

- Benefits conditionality

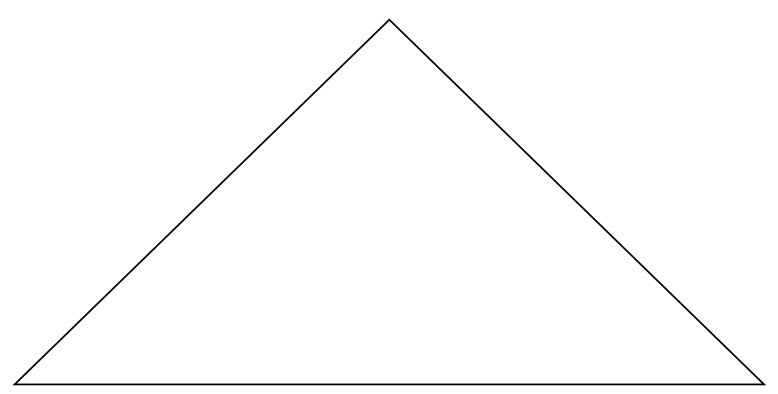

\section{Employment Promotion}

- Enlarged scope of PES activities

- Work first (focus on soft skills)

- Expansion of state-led childcare provision \& active ageing

- Rewards for work ("making work pay")

\section{PES Service Model}

- Management-by-objectives

- Independent review/quality management

- Fusion of employment and welfare agencies

- Introduction of quasi-markets

- Customer orientation 



\section{Explaining Transformative Change in Two Crucial Cases}

While chapter VI has offered an empirical overview of the institutional changes that have taken place in Western Europe over roughly the past decade, this chapter will shed light on the political processes underlying these institutional changes. The analytical focus thus shifts from policy to politics and from institutions to actors. Since an in-depth analysis of six country cases goes beyond the scope of this book, I will focus on two of the six cases. Germany and Ireland have been selected as "crucial" cases, or cases "particularly informative for theory development" (George and Bennett 2005, 253). Germany is the archetypical Continental welfare state and co-ordinated market economy (CME), which makes it a "most likely" case for a path-dependent trajectory. Germany is also, however, one of the world's largest economies and the economic "engine" of the European Union. As such, pressures raised by proponents of the Globalisation Thesis should therefore be particularly prominent there. However, in chapter VI, we saw that Germany's institutional trajectory significantly deviates from the path-dependency hypothesis, and it also fails to clearly conform to a trajectory toward a US-style endpoint. As such, an actor-centred analysis becomes crucial to explain why and how Germany's transformative institutional changes occurred, leading to the hybridisation of its labour market policy regime.

Ireland represents an empirically interesting case because it has become a source of inspiration for many of the Central and Eastern European countries that recently acceded to the EU. This is to say, the "Irish example is important because it shows how an output boom, supported by sensible changes in labour market structures and policies, turned one of Europe's worst performing labour markets into one of the best in less than a decade" (Walsh 2004, 19, emphasis added). Analytically, Ireland is interesting because it has significantly diverged from its British counterpart in many (but not all) respects. While this trajectory has already been labelled as hybridisation by leading scholars in the field (e.g., Zeitlin 2003; NESC 2005a) - an assessment, that I corroborated in chapter VI - 
in this chapter, I seek to explain when, how, and why Irish policymakers have introduced these "sensible changes". My goal is to shed light on the circumstances and motivations that have led Irish policymakers to "mix and match" policies and structures from various regime types, which, in turn, allows me to explain how this process of hybridisation has become possible politically.

\section{VII.1 Explaining the Process of Hybridisation in Continental Europe: Germany as a "Least Likely" Case}

VII.1.a The Kohl Era: From Collective Optimism to Tightening the Screw through "Powering"

When the Berlin Wall collapsed on 9 November 1989, the German government faced unforeseen economic, political, and social challenges. German reunification and the subsequent Monetary, Economic and Social Union on 1 July 1990 brought about the near collapse of the entire East German industrial infrastructure, triggering an "employment catastrophe" (Schmuhl et al. 2003, 538). The most dramatic aspect was the situation of "marginal" groups such as women, who had previously been employed in sectors that were hit hardest by unification; school leavers, because there were far too few apprenticeships available; and unskilled workers, who had become redundant in the new market economy. While the government continued to artificially reduce unemployment through the generous provision of early exit options to older East German workers and governmentally subsidised "short-time work" (Kurzarbeit), the vast majority of jobless East Germans participated in programmes organised by the German PES, such as work promotion projects (Arbeitsbeschaffungsmaßnahmen, $A B M s$ ) and (re-)training measures. During the period between November 1989 and November 1994, "56\% of all East Germans participated - often more than once- in BA programmes" (Schmuhl et al. 2003, 541, my translation). At its peak in the first quarter of 1991, more than two million (about one in four) East Germans were employed in this so-called second labour market. Therefore, it was "active" labour market policy that prevented social unrest and unemployment rates from reaching levels as high as 35 percent (Schmuhl et al. 2003, 541).

During these initial months after reunification, all of the involved actors shared the belief that massive state interventions were necessary to jumpstart the East German economy and that labour market policy could and would contribute to another "economic miracle" (Schmuhl et 
al. 2003, 557). In particular, ABMs were considered important "bridges" to regular employment, and the government and the social partners jointly called upon city and local authorities, churches, and charities to create employment opportunities in the second labour market. This massive use of ALMPs - which was coupled with a generous and widely available early retirement option - led to a cost explosion, which would require additional revenue. The Kohl government was, however, not interested in shifting the costs of labour market policies away from payroll contributions and toward general taxation, which meant that payroll contributions had to be dramatically increased. Accordingly, on 1 April 1991, unemployment insurance contributions were raised from 4.3 percent to 6.5 percent (Streeck and Trampusch 2005, 177, table 1).

By the end of 1992, the initial optimism had given way to cost and efficiency concerns and the prevailing concepts on "active" labour market policy were increasingly seen as inadequate. In response, the government "tightened the screw" on the benefits regime, while it also tried to contain expenditures on active measures. One of the most important cost containment efforts included the reduction of the scale of both the ABM and training measures in 1993 and then again in 1994. Moreover, the "substitute" (originäre) unemployment assistance (sUA) payments, paid to workers who did not qualify for unemployment benefits but had a contribution record of at least five months, was limited to one year; training allowances became optional rather than rights-based payments; allowances paid during participation in $\mathrm{AMB}$ were reduced; and professional development courses were terminated. On 1 January 1994, for the first time since 1982/83, unemployment benefits and unemployment assistance payments were also reduced, this time by one percent for the unemployed with children and three percent for those without. These cost containment measures were further supported by the promotion of part-time work, selfemployment, and the opening of job-placement and matching services to private actors (Schmuhl et al. 2003, 578ff).

With respect to social assistance recipients, the government gradually introduced workfare-style measures. Even though social assistance had de jure always been conditional on participants' willingness to work, this "workfare condition remained dormant" since most SA recipients were considered not ready to assume employment (Voges et al. 2001, 71). However, when more and more "employable" persons were in receipt of SA payments during the 1980 s, local authorities began to offer a range of active labour market measures under the label of Help towards Work (Hilfe zur Arbeit, $H z A)$. While participation remained predominantly voluntary, the SA re- 
cipients' options included (a) participating in public employment projects, offered by public, charity, or church-based organisations, that were "additional" (i.e., they did not interfere with private investment in employment) and of community interest; (b) access to some education and training; and (c) wage subsidies. Due to the costs associated with these measures, their coverage was uneven and "offers" varied significantly across localities and regions (Voges et al. 2001, 83). The character of the HzA changed substantially in 1993, when the government recalibrated this framework by loosening the restriction for the creation of public works projects - HzA jobs could now also be offered by private employers - and by requiring local authorities to apply (the threat of) sanctions to "uncooperative" SA recipients. ${ }^{1}$ A subsequent law issued in 1996 further specified sanctions for SA recipients declining "activation" offers. In particular, young jobseekers were exposed to more conditionality during the 1990s, which resembled the British, Danish, and Swedish experiences during this same period.

Despite these measures, unemployment, which had exceeded the symbolic three million mark in 1993, continued to rise and rapidly approached the four million mark in 1997. At the same time, public debt as a share of GDP increased by more than 20 percent from 41.3 percent in 1991 to 63 percent in 1996, while the annual budget deficit breached three percent in 1991, 1993, 1995 and 1996 (Manow and Seils 2000, 151, table 4). As such, Germany was on its way toward missing two key European budgetary targets established in the Stability and Growth Pact (SGP) - 6o percent and three percent respectively - which were prerequisites for the adoption of the euro. Accordingly, the government deemed more cost containment measures necessary and a more radical overhaul of the German labour market policy regime appeared desirable. How to reform the system, however, remained a controversial issue. Not surprisingly, these politically difficult times led to massive divisions and realignments within the social partners. While labour market policymaking had been largely consensual throughout the entire post-war period and characterised by negotiated package deals, the immediate period after the mid-199os would be marked by a series of conflicts in which one party's gain was the other's loss. At the same time, the very pillars on which the social partners' success was built began to crumble. On the one hand, labour union membership declined dramatically throughout the 1990 os, while labour union leaders - sometimes helplessly - watched "the de facto decentralisation of collective bargaining" (Streeck and Hassel 2003, 113). ${ }^{2}$ These developments effectively weakened the unions' political clout, intensified insider-outsider cleavages, and led to disagreements over the best way forward within the 
labour movement. Employers, on the other hand, were increasingly divided by their size. Small and medium-sized businesses (the Mittelstand) voiced their discontent with the growing non-wage labour costs and high wage settlements, while large companies were willing to cave in to these pressures in exchange for peaceful industrial relations (Streeck and Hassel 2003, 108). ${ }^{3}$ Moreover, the Federal Confederation of German Employers' Associations (Bundesvereinigung der Deutschen Arbeitgeberverbände, BDA), which negotiates wage agreements with the Confederation of German Trade Unions (Deutscher Gerwerkschaftsbund, DGB) and therefore traditionally takes more moderate, consensus-oriented positions, was increasingly at odds with the powerful Federation of German Industries (Bundesverband der Deutschen Industrie, BDI), which demanded more radical, neo-liberal path corrections.

In the midst of these competing interests, which did not leave any room for the formation of actor realignments strong enough to find a consensual solution, Klaus Zwickel, leader of IG Metall, approached the government with a compromise offer. Zwickel proposed wage concessions in exchange for a pledge by employers to create more jobs and the government's promise to give up on further cuts in social programmes. However, this realignment of political forces - potentially giving way to a German version of "competitive corporatism" - did not materialise when in early 1996 the FDP in alliance with the BDI's President Hans-Olaf Henkel raised the stakes and demanded a complete overhaul of the German welfare state, rejecting the current proposals as too modest. The FDP, which had made dramatic electoral gains in three regional (Länder) elections in early 1996, saw their increasingly neo-liberal position confirmed and further promoted a consolidation of the federal budget and tax cuts, which would only be feasible if the welfare state was substantially reduced (cf., Bispinck 1997; Streeck and Hassel 2003). When Kohl failed to reject these claims, the fragile alliance collapsed before it had even started and left behind a painful rift between the government and the unions (Streeck 2003). In September 1996, the government introduced a series of cuts to the German welfare state, including a curtailment of sick pay, an increase in the retirement age for women, and a loosening of German employment protection standards. While these cuts sparked massive demonstrations and were opposed by the labour unions and the Social Democrats, they were loudly praised by the employers' associations.

On 24 March 1997, the Third Book of the Social Code (Sozialgesetzbuch, SGB III) ${ }^{4}$ was introduced, which represented a "profound turnaround in German labour market policy" (Rabe and Schmid 1999, 21, my 
translation). The SGB III represented a departure from the original labour market course enshrined in the AFG of 1969 in many ways. On the one hand, the goal of reaching full employment was no longer endorsed, nor was the state considered a strong intervening force. Instead, the focus shifted to market force and labour market policy would thereafter only play a marginal role (Schmuhl et al. 2003, 584). Furthermore, the employment offices would intervene earlier in cases of unemployment, i.e., after six months, and more responsibilities were shifted to the individual jobseeker. More specifically, the criteria "under which recipients of benefits could refuse a job" were further tightened, while "particular benefits of passive labour market policy" were cut and "active labour market policy" curbed (Zohlnhöfer 2003, 146). At the same time, social assistance offices were also encouraged to enlist long-term unemployed SA recipients in workfare-type employment programmes (cf., Voges et al. 2001).

In summary, even though social scientists typically argue that the "relevance of these reforms to labour market outcomes is indirect and limited" (Wood 2001, 389), the 1990 os were, nevertheless, characterised by a major political reassessment, which resulted in substantial cutbacks in the Bismarckian welfare state, representing significant challenges to core elements of Continental labour market policy regimes. On the one hand, the insurance principle (workers who have contributed to the insurance system enjoy certain privileges, such as access to high-quality ALMPs) and the equivalence principle (the preservation of one's social status in case of unemployment) were under pressure, while open confrontation with the labour movement had become an acceptable reality. ${ }^{5}$ On the other hand, the CDU/CSU-FDP coalition government had clearly taken a "neo-liberal" path, prioritising free market forces, while increasingly perceiving ALMPs as a threat to the creation of new employment opportunities (Schmuhl et al. 2003, 584f). Accordingly, atypical and precarious employment opportunities were promoted, the eligibility and generosity of benefits tightened, and a growing number of jobseekers were shifted into social assistance, which in turn, was increasingly linked to work obligations. ${ }^{6}$

VII.1.b The Schröder Era: Moving from "Active" to "Activating" Labour Market Policy

"If we don't manage to reduce the unemployment rate significantly, then we neither deserve to be re-elected nor will we be re-elected" GERHARD SCHRÖDER, 1998 (my translation) 
Initial Success and the Introduction of an Activation Pillar On 27 September 1998, after 16 years in the opposition, the Social Democrats reclaimed the Chancellor's Office, now in a coalition with the Green Party, ${ }^{7}$ effectively reshuffling the composition of the entire government for the first time since the creation of the Federal Republic of Germany. The Social Democrats' late victory was at least partially due to Gerhard Schröder's promise to significantly reduce unemployment levels. It was also built on SPD party leader Oskar Lafontaine's efforts to unite the Social Democrats in the Bundesrat in the years leading up to the general election. For this purpose, Lafontaine had actively solicited the support of the labour unions, who had become disgruntled with the cuts in the German welfare state. It was not surprising then, that one of the first legislative acts of the new Red-Green government - now with a legislative majority in the Bundesrat and thus facing few veto points - was the reversal of some of the most controversial reforms introduced by the previous government. Most importantly, the reductions in sick pay were annulled and employment protection legislation reinstituted to be enforced in firms with a minimum of five (previously ten) employees. In addition to reversing some of Kohl's most controversial reforms, the government also almost immediately launched a special programme for youth (Jugend mit Perspektive, JUMP) as it had been outlined in the SPD party manifesto. ${ }^{8}$ JUMP represented the first de facto "activation" policy introduced by the new Red-Green government, aimed at finding/creating jobs for 100,000 young people. Like the New Deal for Young People launched in Britain and the youth activation efforts initiated by the French Social Democrats during this period, young jobseekers received "an offer to participate in the programme and to agree on an appointment for consultation" (Heidemann and Rademacker 2004, 362). ${ }^{9}$ Weak sanctions were imposed on those who did not sign up for the programme or failed to agree on an individual action plan. JUMP quickly exceeded its target of 100,ooo young people, as "the offer of involvement was taken up in the very first year by 200,000" (Heidemann and Rademacker 2004, 363). As such, the activation of young jobseekers through "soft" measures, or the application of primarily positive work incentives, was in line with the first pillar of the recently launched EES, which the Social Democrats - in stark contrast to the Christian Democrats - had openly endorsed.

In addition to prioritising the fight against youth unemployment, the Red-Green government also promoted a series of gender-equality measures, reflecting the priorities of the EES's fourth pillar. The government launched a new programme "Women and Work" in 1999, which was set 
out to challenge the persisting norms of the male breadwinner model. The programme included a series of special measures to reduce youth unemployment among female jobseekers, including incentives for school leavers to seek employment in male-dominated areas, appeals to firms to hire women, and financial support for business start-ups. The government's gender-equality efforts subsequently received an "external" boost in 2000 , when the Lisbon Summit enshrined the European employment target for women of 60 percent (Ostheim and Zohlnhöfer 2004, 394). The Social Democrats, however, failed to address the issue of childcare provisions during their first term. Instead, the government followed the regime-typical response and expanded universal childcare benefits (for more details, see Korthouwer 2008; Weishaupt 2010b).

Discussions about more substantive labour market reforms, in turn, were passed along to the tripartite "Alliance for Jobs, Training and Competitiveness" (Bündnis für Arbeit, Ausbildung und Wettbewerb). The government initiated these high-level meetings with representatives from the unions and employers associations almost immediately after the new government came into office. The Alliance's first official meeting took place in December 1998. The government hoped to renew the consensual spirit of German corporatism, while the Alliance was deemed the most appropriate forum to discuss potentially sensitive issues such as labour market reform. Within the context of the Alliance, the Chancellor envisioned a successful conclusion of moderate wage increases to boost employment, while the strengths and weaknesses of the German labour market were to be assessed in a report that placed the German system in a comparative context. Accordingly, the working group Benchmarking Germany was created to compile comparative data and write a report that would guide Germany's labour market reforms. However, the Red-Green government's attempts to promote a tripartite solution in the context of wagesettlement agreements similar to the Irish and Dutch examples were built on shaky foundations from the start. On the one hand, the roundtable's success depended on the goodwill of the social partners because German governments were prohibited by law from intervening in wage negotiations (Bertelsmann Stiftung 1999, 45). More specifically, the German constitution (Article 9, $\mathbb{S} 3$ ) enshrines the right of the social partners to negotiate wage agreements without state interference (Tarifautonomie). On the other hand, and more importantly, disagreement over wage settlements within the government would quickly become a sore spot for the negotiators. Chancellor Schröder had not expected Finance Minister and Party Chair Oskar Lafontaine and his Secretary of State to "encourage 
high union wage claims which, they argued, were needed to increase demand and thereby improve employment" (Streeck and Hassel 2003, 115). The return to traditional Keynesian thinking in the Finance Ministry, and the corresponding high wage demands by the unions, created rifts within the Social Democrats, while the reversal of the Kohl reforms had already frustrated the employers association and the business community. In other words, the Alliance was built on a fragile political foundation consisting of feuding coalitions, which effectively undermined the half-hearted attempt to institutionalise a German version of "competitive corporatism" from the start. ${ }^{10}$ The Alliance quickly turned into a bilateral forum between the government and either the employers or the unions instead of a tripartite roundtable. Negotiations stalled and - at least initially - the Alliance produced little of substantial value (cf., Streeck 2003).

Despite the gridlock in the Alliance, the economy continued to improve throughout 1999, which the government hoped would alleviate the unemployment problem on its own. Chancellor Gerhard Schröder saw no need to rush into major labour market reforms, ${ }^{11}$ and Labour Minister Walter Riester, a more traditional Social Democrat, chose to concentrate on - and successfully concluded - a substantial pension reform (interviews, BMAS1, SPD 3 ). These three factors, i.e., the improving economy, the Chancellor's lack of initiative, and the Ministry's priority to reform the German pension system rather than the labour market, are particularly significant when we try to understand the slow pace of progress during Schröder's first term. This deliberate inactivity with regard to labour market reform throughout 1998 and 1999 - despite Schröder's electoral promise - represented a missed "window of opportunity" for at least four reasons. First, the Red-Green government controlled the majority of seats in the Bundestag and thus would have been in a situation to successfully pass its own policies. Second, the economy experienced an upward trend, thus generating new jobs, which would have made the introduction of "activation" measures less controversial. Third, Hans Eichel (SPD) replaced Oskar Lafontaine as Finance Minister in March 1999, who had resigned after numerous clashes with Chancellor Schröder. Eichel, in turn, quickly abandoned Lafontaine's neo-Keynesian policies and made debt consolidation and price stability his first priorities. And finally, Gerhard Schröder was elected chair of the SPD, thus uniting the Chancellorship and party leadership for the first time since Willy Brandt. The "removal" of the traditionalist leadership within the SPD could have been exploited to successfully realign the SPD internally and lead backbenchers along a new path of modernisation. 
Despite the government's slow-moving approach to labour market reform and the Chancellor's lack of leadership on this issue - which sets the German Social Democrats apart from the developments in Denmark and the UK - the Alliance prompted not only moderate wage increases for many years, but also the launch of various pilot programmes including the Mainzer Modell, which assessed the employment-generating effects of subsidies for low-wage employment in the private sector. More importantly, however, the government was eventually able to forge an agreement within the Alliance on a second, comprehensive activation effort, the JobAQTIV Act in $2001(\mathrm{~A}=$ activation, $\mathrm{Q}=$ qualifications, $\mathrm{T}=$ training, $\mathrm{I}=$ (self) initiative, and V = Placement). The Job-AQTIV Act reflected the government's ambition to continue with the creation of an "activating" welfare state by institutionalising an additional "fourth" labour market pillar, layered on top of the existing framework (interview, DGB1). This activation pillar included early interventions, client profiling, and individualised integration contracts for jobseekers, while the pre-existing supply-side pillar was enhanced through earlier and wider access to (re-)training measures, and the demand-side pillar was expanded through more publicly funded employment. This new "four-pillar" framework - demand-reducing "early exit" options being the fourth pillar - was supplemented through a more rigorous promotion of gender equality, improved labour market monitoring and evaluation measures, and an explicit commitment to reach full employment. The government's reorientation toward "soft" proactive and preventative measures therefore represents not only an explicit incorporation of the European Employment Strategy's guidelines and recommendations, but also a revival of AFG principles, which the previous government had officially abandoned (i.e., an interventionist state that can proactively steer both the level and structure of unemployment). The government's Job-AQTIV Act deliberately left out, however, the most controversial issues at the time, including a reform of the benefits system, the expansion of "atypical" work such as temporary work contracts, a reduction of nonwage labour costs, and the expansion of a (private) low-wage sector.

In summary, despite the government's failure to prioritise labour market reform - which had been expected, based on the 1998 election campaign promises - the Red-Green government's first term still represents an important course correction. The orientation of labour market policy under the Social Democrats was significantly less "neo-liberal" in character than what the CDU had envisioned (i.e. local workfare policies, more flexibility, and more atypical work). Instead, the SPD endorsed a "soft" activation of young jobseekers in 1998, mobilised the social partners in 
a tripartite Alliance (1998-2002), promoted gender equality (1999, 2001), and passed the proactive Job-AQTIV Act (2001), effectively institutionalising a shift from active to activating labour market policy. Since the SPD manifesto of 1998 already largely agreed with the EES's main thrust, it is difficult to argue that the EES "caused" the government's policy decisions. However, the EES most likely served as a "catalyst", which sped up institutional developments (cf., Büchs and Friedrich 2003). It also "empowered" actors in favour of these concepts to advance their positions, and allowed the Red-Green government to legitimise its proposals by referring to the EES and National Action Plans (NAPs). Perhaps more importantly, the Red-Green government's attitude toward the EES was certainly different from that of its predecessors. Both the SPD and the Greens welcomed a European Employment Pact and binding targets for the reduction of unemployment, and both parties embraced "soft" activation, i.e., supply-side instruments that enhance jobseekers' employability in contrast to "hard" sanctions that force jobseekers to accept employment of any kind (cf., Ostheim and Zohlnhöfer 2004, 388f).

\section{Failed Realignments and the Demise of the Schröder GOVERNMENT}

Despite the (limited) progress produced by the Alliance, the government continued to face a divided political landscape toward the end of its first term, while the political constellation in the Bundesrat had shifted in favour of the CDU/CSU and FDP. The opposition parties continuously challenged the government on its labour market reform choices and called the Job-AQTIV Act a "hotchpotch" of incoherent instruments, while demanding much more dramatic measures, including a reduction of nonwage labour costs and stricter controls over jobseekers. More generally, political stakeholders remained aligned roughly along ideological lines with diametrically opposed positions on almost all of the important political decisions, including the effects of employment protection legislation, the role of an expanded low-wage sector and atypical work, and the future of Germany's generous benefits system. The latter issue would become a particularly salient topic. With an election rapidly approaching, the CDU/CSU argued that unemployment assistance payments needed to be reduced to the level of social assistance, while the FDP favoured a merger of unemployment and social assistance in addition to a limitation of unemployment benefits payments to a maximum of one year. At that time, even the Greens promoted the idea of an amalgamation of unemployment and social assistance (FAZ 2001). This mismatch of interests 
was further aggravated by disagreements over wage settlements, which effectively produced gridlock in Alliance negotiations and brought a December 2001 meeting to a halt, while the bursting of the "dot.com bubble" and the terrorist attacks of 11 September 2001 triggered a global economic downturn and a domestic reversal of unemployment trends.

When Labour Minister Riester promised to tackle these controversial issues after the 2002 federal elections, many political analysts anticipated a continuation of Germany's infamous Reformstau, or reforms on a very small scale and at an extremely slow pace. However, Chancellor Schröder decided to pursue a different, unilateral route in early 2002. Rather than "muddling through" these divisive times, Chancellor Schröder strategically seized a moment of political turmoil when, in January 2002, five employment offices were accused of having misreported job placements in 70 percent of a total 5,100 cases (Collier 2004, 12). On 22 February, in response to this "placement scandal", Chancellor Schröder announced the creation an independent "Commission for Modern Labour Market Services" (Kommission für Moderne Dienstleistungen am Arbeitsmarkt) to address the lingering problems of the German labour market. Schröder appointed Dr. Peter Hartz, Labour Director on the Board of Management of Volkswagen (VW) to chair the commission. Peter Hartz, an SPD and IG Metall member, was well known for his successes in restructuring VW without having to lay off employees while actually opening new VW production plants in former East Germany rather than elsewhere in Eastern Europe. The other 14 members of the so-called Hartz Commission included at least one from every major social group, except the opposition parties. The labour unions were represented by Isolde Kunkel-Weber (Ver.di) and Peter Gasse (IG Metall), the employers by Hanns-Eberhard Schleyer (Zentralverband des Deutschen Handwerks, ZDH), the public employment service by Wilhelm Schickler (Hessian regional employment office), the local authorities and former East Germany by Wolfgang Tiefensee (Mayor of Leipzig, SPD), and the Länder by Harald Schartau (Labour Minister in North-Rhine Westphalia, SPD). Moreover, various CEOs represented business interests, while management and consultant strategists from Goldman Sachs and McKinsey were brought in to assist in reforming the Bundesamt für Arbeit. ${ }^{12}$ Two senior academics, Günther Schmid and Werner Jann, were also included. Meanwhile, the Minister for Labour and Social Affairs in Berlin served as the host of the meetings (Hartz and Kloepfer 2007, 208f). ${ }^{13}$

On 17 August 2002, only weeks before the upcoming federal elections, the Hartz Commission presented its final report to the Chancellor, which was written after numerous visits to various "best practice" sites includ- 
ing, inter alia, Britain, Denmark, and the Netherlands (interview, WZB1). As the elections were approaching rapidly, the unions and the traditionalist wing of the Social Democratic party had quickly been manoeuvred into a position in which they had to go along with the proposed reforms, since open dissent would only aid the opposition in the elections (Streeck and Hassel 2003, 119). ${ }^{14}$ While the unions offered their "tacit" support, Chancellor Schröder had also hoped for the support of the business community for the Hartz reforms report. However, despite their approval of the reforms, the business community sided with opposition candidate Edmund Stoiber (CSU) in the run up to the federal elections and BDA President Dieter Hundt, BDI President Michael Rogowski, and Hartz Commission member Hanns-Eberhard Schleyer (ZDH) all failed to attend the ceremonial presentation of the Hartz report (Hauschild and Noe 2002).

The first two - less controversial - legislative packages, the I and II Acts for Modern Labour Market Services, henceforth Hartz I and II, were presented to the Bundestag ten days prior to the federal elections. ${ }^{15} \mathrm{Hartz}$ I was designed to promote and expand temporary employment contracts through the establishment of Personal Service Agencies (PSAs). ${ }^{16}$ These PSAs were supposed to be introduced in new "one-stop public employment centres" (zentrale Anlaufstellen), which were to be established for all jobseekers. The use of PSAs was inspired by the Dutch experience with temporary jobs and the government hoped that they would serve as real stepping stones to regular employment (interviews, WZB1, Ver.di2). Hartz I also aimed to improve the quality and speed of job placements, while requiring workers to immediately inform their local employment offices upon receiving a notice of job termination. Hartz II, in turn, was designed to expand the low-wage sector through the introduction of "mini" and "midi" jobs, which expanded exemptions/reductions for employees' payroll taxes up to a ceiling of $€ 400 / 800$ respectively. Hartz II further introduced business start-up subsidies to unemployment benefits recipients (Ich AG). ${ }^{17}$ Both of these measures were meant to activate jobseekers, especially those who had experienced long periods of unemployment, by easing their reentry into the workplace and by restoring their self-worth and confidence (Hartz and Kloepfer 2007, 224).

Despite the creation of the Hartz Commission, the Social Democrats - but not the Greens - had called for the continuation of the Alliance in their manifesto, hoping that the strained relationship with the unions could eventually be mended. Soon after the elections - which Schröder's Red-Green coalition won with a razor-thin majority - a new impetus for tripartite talks came from Hubertus Schmoldt, chair of the Mining, 
Chemicals, and Energy Union (Industriegewerkschaft Bergbau, Chemie, Energie, IG BCE) who called for new negotiations. The presidents of representative business organisations, including the German Association of the Chambers of Commerce (Deutscher Industrie- und Handelskammertag, DIHK), the BDI, and the $\mathrm{ZDH}$, welcomed the initiative as long as the talks could "take place in a climate without 'taboos' and [were] not open to the public" (Behrens and Niechoj 2003). On 10 December 2002, Wolfgang Clement (SPD), the new reform-oriented "super" Minister for the Economy and Labour Affairs (Bundesministerium für Wirtschaft und Arbeit, BMWA), met with DGB President Michael Sommer and the BDA President Dieter Hundt BDA to discuss a revival of the tripartite talks and scheduled a top-level meeting for the spring of 2003. However, by February 2003, the meetings already seemed increasingly unlikely after the labour unions concluded that there were "unbridgeable differences between themselves and employers' organisations" (Funk 2003c). Earlier that month, after an unexpectedly sharp rise in the unemployment figures, Dieter Hundt had offered a - in the eyes of the unions lopsided - six-point job-creation plan. Hundt suggested that employers would provide vocational training to every qualified young person in exchange for wage moderation, 'opening clauses' in collective agreements, less stringent job protection, lower social security contributions, and no tax increases in the near future.

Even though Chancellor Schröder had been warned by leading German economists that sweeping labour market reforms could not be reached without the support of the unions, Schröder decided to continue his confrontational course and announced his Agenda 2010 on 14 March 2003. The Agenda 2010 comprised an ambitious policy package aimed at "achieving full employment in Germany by the end of the first decade of the $21^{\text {st }}$ century, reviving economic growth and re-establishing financial sustainability for German social insurance institutions" (Collier 2004, 22). With respect to the labour market, the Agenda explicitly limited the government's manoeuvrability to economic supply-side measures, including the promotion of a more flexible labour market by "reversing the reversal" to ten employees at which employment protection legislation would be enforceable, and the issuance of personal income and corporate tax cuts, stimulating private consumption and economic activity. The Agenda also outlined a major overhaul of the benefits system, including the limitation of statutory unemployment benefits to twelve months ( 18 months for workers over 55 years of age) and the introduction of a single, means-tested assistance payment that would be paid after the expiration 
of statutory unemployment benefits, replacing the dual system of unemployment and social assistance payments. The drastic changes in the benefits system went beyond the proposals outlined in the Hartz Commission. Indeed, they closely resembled the proposals that the FDP had presented during their 2002 election campaign. When Schröder threatened to step down, the Agenda was subsequently approved by 90 percent of the Social Democratic delegates during an extraordinary party conference on 1 June and by over 90 percent of the Green delegates on 14/15 June (Stuttgarter Zeitung 2003).

The reaction to the Agenda was mixed. On the one hand, the employers' organisations offered broad support for what they perceived to be long overdue reform policies, calling it an "important step in the right direction". Similarly, leading economists and the CDU supported the Agenda, while siding with the employers' concerns that the reform proposal did not go far enough..$^{18}$ On the other hand, the unions rejected the package as too socially unbalanced. Some union leaders were literally outraged by the Agenda, calling it "immoral", "completely incomprehensible and superfluous" while "shifting wealth from the bottom to the top" (Funk 2003a). While the merger of the UA and SA did not universally lead to benefit cuts - indeed, the overall retrenchment was rather modest for many jobseekers ${ }^{19}$ - the message sent to the German people was a different one: after twelve months of unemployment, jobless workers regress into $A L G-2$, a flat-rate, means-tested, and highly stigmatising income support. As such, the reforms constitute a significant shift away from the Bismarckian ideal of status preservation via a receipt of generous benefits based on merit toward a Beveridgian ideal of income support for those in need (cf., Eichhorst et al. 2006; Knuth 2006).

Despite union dissatisfaction, the cabinet passed Hartz III and IV on 13 August 2003. On 26 September 2003, the federal government passed a seperate bill with a Red-Green majority reducing the duration of unemployment benefits from 32 to 12 months ( 18 for workers over the age of 55) and introducing a reform aimed at more flexible hiring/firing practices. On 17 October 2003, the Bundestag passed Hartz III and IV. Hartz III, as outlined in chapter VI, introduced the massive reorganisation of the Federal Labour Office "remodelling it after private job-placement agencies and renaming it the Federal Job Agency [Bundesagentur für Arbeit, BA]" (DW-world.online 2003). On 19 December, the Hartz III act passed both houses and was thus signed into law. The new Hartz III Act, however, no longer matched the Commission's vision. The Commission wanted a onestop centre for all of the unemployed, regardless of their previous employ- 
ment history under the direct administration of the BA. The regionallevel PES, in turn, were pictured as Competency Centres, charged with promoting and fostering regional economic activity and structural innovation, which, in turn, would stimulate new job growth (cf., Hartz Commission 2002). The opposition parties, however, under the leadership of Roland Koch (CDU), Edmund Stoiber (CSU) and Christian Wulff (CDU), opposed not only the de facto abolition of the regional PESs, but also favoured local authorities as delivery agents for local labour market policy (Handelsblatt 2003). As such, the CDU revived their preference for local workfare, which was then reflected in the compromise reached between the CDU/CSU and the SPD. Accordingly, the clientele of "able-bodied" jobseekers was split into two separate groups (the insured, short-term vs. the uninsured and/or long-term unemployed), with two separate sets of codified rules and instruments (Social Code Book II vs. Social Code Book III), two different sources of financing (payroll vs. general taxation), two principals (the federal PES vs. the BMAS/local authorities), two guiding principles (an "enabling" work-first approach vs. basic income support), and two separate service providers (employment agencies and ARGEn/ local authorities). In short, while the Hartz Commission had envisioned and thus followed the 1997 OECD recommendations (see chapter V) - a "single gateway" for all jobseekers, delivering a coherent set of policies for all jobseekers under one roof, the newly introduced system created two sets of "one-stop centres" with different sets of logic and goals. An important unintended consequence of the system was that the PES had a built-in incentive to "park" insured clients with little prospect of finding employment within 12 months. More specifically, as the PES knows that customers who are not successfully placed into employment will be transferred to an $A R G E$ or Opt-out Commune after 12 months, they have incentives to select only customers who are likely to benefit from ALMPs for more expensive activation measures. Municipalities also had an incentive to classify as many people as possible as "able-bodied" since they would then receive more federal funding. Persons who are not considered to be able to work, in turn, continue to receive SA payments which must be financed from municipal budgets. The "revised" Hartz III Act therefore failed to achieve one of the core ambitions of the Hartz Commission, namely the abolition of Germany's infamous "switchyards" (Verschiebebahnhöfe), where responsibility for various benefits recipients is shifted from one authority - and budget - to the next (e.g., Trampusch 20oob). ${ }^{20}$

Finally, on 2 July 2004, the Bundesrat passed the remaining parts of the previous bills, which introduced the controversial "unemployment 
compensation II" (Arbeitslosengeld II, ALG-2). This policy was at the core of the sensitive sections in Hartz IV, i.e., the consolidation of unemployment assistance and social assistance. As envisioned in the Agenda 2010 - but not the Hartz report - the bill stipulated that the unemployed would only receive the newly designated ALG-2 after 12 months of unemployment. The long-term unemployed received a flat-rate benefit, which was means-tested and paid only to those who "seriously" sought work. On average, cash benefits for single people living in West Germany were set at $€ 345$ (for those in the east, the level was $€$ 331), which were further supplemented by rent and heating allowances.

Despite - or rather because of - the "success" of the reform-minded Social Democrats in pushing through the most significant reforms since the introduction of the $A V A V G$ in 1927 , this last bill strained the party internally, while highlighting old, inner German divisions: all five East German states, including those governed by the SPD, voted against the legislation, while all 11 West German states, including those governed by the CDU, voted in favour of Hartz IV. As such, the years 2003 and 2004 marked the height of an "informal Grand Coalition" between the Social Democrats and the CDU/CSU, jointly overcoming institutional hurdles, while deepening the rift between the SPD and the unions. It also marked a low point for unions themselves, who were publicly conceived as the main stumbling block to reforms. Opinion polls held in early 2003, showed that 42 percent of respondents wanted unions to have less influence on government policies and only 28 percent wanted them to have more. In 1999, the numbers were reversed: 21 percent in favour of less and 49 percent in favour of more union influence (Funk 2003b). ${ }^{21}$ Business and employers' associations, in turn, adopted a joint declaration in March 2004 on the government's reforms, which underscored their relentless pressure to continue the reform process. The BDA, BDI, DIHK and ZDH declared: "We will support the government as long as, first, the necessary structural reforms improve ... the climate for investors and consumers and, second, the burdens - taxes, social security contributions and bureaucratic burdens - on individuals and firms are lessened" (Funk 2004). While the CDU/CSU, employers, and businesses temporarily aligned with the Chancellor, disenfranchised voters - primarily in former East Germany where unemployment remained concentrated - began to organise mass demonstrations, which were quickly supported by the labour movement. Despite this popular uprising, the government did not renege on its reforms and Hartz IV was enacted on 1 January 2005. 
After the successful launch of Hartz IV, the Social Democrats plunged into a deep crisis as voters blamed the Schröder government for dismantling the German welfare state, breaking with traditional social democratic values, and causing unnecessary economic hardship for countless benefits recipients. SPD membership rapidly declined and public approval ratings were at an all-time low. When the Social Democratic government of North-Rhine Westphalia lost to the CDU in regional elections on 22 May 2005 - after forty years in government - the Chancellor announced early federal elections. New elections seemed to be the only option left to legitimise the Chancellor's government. Schröder hoped that voters would renew his mandate, which would then help him reign in the dissenting voices within his own party. However, despite a surprisingly close election - the SPD received 34.2 percent, while the CDU received 35.2 percent - the Chancellor had, once again, underestimated the political clout of his former SPD colleague Oskar Lafontaine. Lafontaine had founded his own party, the Elections Alternative Work and Social Justice (Wahlalternative Arbeit und Soziale Gerechtigkeit, WASG) in early 2005 and re-emerged as a prominent political figure in the anti-Hartz IV, antiAgenda 2010 movement. WASG subsequently formed an formal alliance with the Party of Democratic Socialism (PDS), the successor of the East German Socialist Unity Party (SED). ${ }^{22}$ The emergence of a party with a clear anti-reform agenda that was to the left of the Social Democrats dramatically affected the SPD's ability to manoeuvre, not to mention the entire German political landscape. Now, there was not only an electoral option for voters, including union members, who were dissatisfied with the nature of the reform, but with five political parties gaining seats in Parliament, it became increasingly difficult to form a "traditional" coalition on the centre left (SPD and Greens) or the centre right (Christian Democrats and Liberals). On 18 September 2005, the SPD and Green Party then failed to win a mandate to govern, Schröder resigned, and Germany's second Grand Coalition under the leadership of Angela Merkel (CDU) was sworn into office. ${ }^{23}$

While the divisive benefits system reform certainly overshadowed the Social Democrats' second term, the government did manage to address other policies within the "work-welfare nexus", including gender issues. With respect to "negative" work incentives for women, the Hartz reforms compelled the spouse of an unemployed worker to actively seek work. Put differently, the male breadwinner norm had been successfully challenged from "below", as previously "inactive" partners are now obliged to register as unemployed (with all its consequences) to receive benefits. However, 
the male breadwinner norm remained intact for women with a working partner. Inactive spouses (typically women) of working partners continued to enjoy tax privileges, receive "free medical care by virtue of the contributions paid by her husband and enjoy a widow(er)'s pension if the breadwinner dies" (Knuth 2006, 11). With respect to "positive" incentives intended to enable family life and work, the Social Democrats triggered a new public debate that focused on the lack of childcare places in (West) Germany. This shift, however, came very late in the Social Democrats' second term, i.e., only after being in office for six years. While the issue of childcare provisions had been "very controversial" during the Social Democrats' first term (interview, $\mathrm{SPD}_{3}$ ), the environment became slowly less unsympathetic during the course of their second term. On the one hand, the EU's childcare targets set at the Barcelona Summit in March 2002, and the preparation and subsequent publication of an OECD country note that had criticised the poor childcare infrastructure in Germany (OECD 2004b), empowered the new Minister for Family Affairs Renate Schmidt (SPD) and legitimised her efforts to promote the expansion of childcare in Germany (cf., Siems 2004a). ${ }^{24}$ On the other hand, the media increasingly referred to Sweden and France as family-friendly nations, while identifying Germany's low fertility rates and its shrinking population as looming dangers for Germany's economic competitiveness and the sustainability of its welfare state (Henninger et al. 2008; Ahrens and Blum 2009). Nevertheless, when the Minister brought her proposal to the Bundestag, the CDU, local authorities, and various socially conservative groups quickly protested against her plans to create 230,00o childcare places by 2010 (Siems 2004b). While the CDU opposed the proposal because it "discriminated" against women outside the workforce, the local communities feared the government's "breach" of the subsidiarity principle. When Schmidt subsequently split the legislative proposal into two parts, she was able to pass an important childcare expansion act (Tagesbetreuungsausbaugesetz, TAG) on 1 January 2005 because the new version did not require the approval of the CDU-dominated Bundesrat (Schmitt 2004). ${ }^{25}$

Inspired by Swedish policy, Schmidt also proposed a new parental allowance (Elterngeld). The goal was to provide incentives for (well-off) parents to have children and stimulate the father's involvement in the upbringing of his children (Soldt 2004). While quarrels about the actual design of the Elterngeld and the early elections triggered by the Chancellor prevented its swift enactment, it became law on 1 January 2007. Since then, a parent on leave after the birth of their child receive 67 percent of 
their previous income for 12 months, with a ceiling of $€ 1,800$ and a minimum payment of $€ 300$. The parental leave duration can be extended to 14 months, if the other spouse, typically the husband, opts to stay at home for two months as well. Single parents receive the parental allowance for 14 months, as they fulfil the dual role of father and mother. As such, the new act was intended to promote gender equality, incentivise having babies, and improve the reconciliation of work and family life by providing financial stability to young parents. Taken together, the parental allowance and the childcare acts are supposed to complement each other by easing the transition from work to family life and back to work, through the provision of a (shorter, but financially more attractive) leave option and the subsequent access to a childcare facility, if the family chooses to do so (interview, SPD4).

In addition to promoting access to childcare facilities, the Social Democrats and Greens had also begun to advocate "all-day" schools, i.e., schools that would not end mid-afternoon and would thus provide a safe place for school children while both parents were at work. Since education policy, like childcare policy, is firmly in the hands of the Länder governments, the federal government could not just institute a national programme. Instead, the government needed to offer financial support and agree on nationwide outcomes with the Länder. Accordingly, in 2003, the government began offering multi-billion euro federal subsidies to enable the creation and operation of all-day schools throughout Germany in the coming years.

In summary, the Social Democratic period can certainly be characterised by a substantial reassessment of labour market policy toward activation and a commitment to introduce a modern "PES service model". However, the degree of reassessment with respect to family policy, that is, the acceptance and promotion of a dual breadwinner model was more modest and incorporated (too) late. However, important legislative steps were taken that paved the way for the development of a more "womenfriendly" welfare state, including a substantial increase in childcare places. These steps, however, only became possible because of the publication of an OECD report, the issuance of the Barcelona targets, and the media, all of which "de-legitimised" the traditional German model and provided political leverage to push through reforms that ran against the interests of a powerful opposition. Other EU and OECD "recommendations" associated with lifelong learning and flexicurity remained largely absent in the German discourse. This development therefore suggests that some of the OECD recommendations, and in particular, the "hard" EU targets on 
activation policy, childcare places, and employment rates, had a real impact on policy design, while others did not (yet). I would argue that it was precisely this deliberate "selectivity" by the Social Democrats that may have sealed the Chancellor's electoral fate. In other words, while the Hartz reforms required significant sacrifices from a portion of the Social Democrats' core constituency, an earlier and/or more systematic introduction of "positive" features associated with "make work pay" (as in the British context), or "lifelong learning" and the "gender mainstreaming" (as in the Danish and Swedish context), or the matching of flexibility with security (as in the Danish and Dutch context) could have allowed the Chancellor to reconcile the newly emerging divisions. However, the rather confrontational course of the Chancellor after the 2002 elections effectively alienated large parts of the left-leaning electorate, including the labour movement. In particular, the Chancellor's failure to persuade his own party of the appropriateness and necessity of the Hartz IV Act, which effectively undermined Germany's longstanding equivalence principle, while failing to convincingly introduce elements of a Nordic equity principle, became an electoral liability. For many voters, all that was left was a perceived trajectory toward Anglophone marketisation, associated with (unnecessary) economic hardship, particularly in the east parts of Germany. Accordingly, deep intraparty divisions, a disgruntled labour movement, and the rise of the Left Party on the far left gave way to the alignment of a powerful "anti-Hartz" coalition, a constellation of political forces that effectively undermined the modernisers in government and subsequently brought about Schröder's demise.

The Grand Coalition - Two Steps Forward, One Step Back While it may be too early to reach definitive conclusions about the effects of the partial reshuffle that brought the CDU back to the Chancellor's office in 2005 - albeit with the SPD as the junior partner - three important developments under the grand coalition need to be highlighted (for a more detailed overview, see Weishaupt 2010b). First, the Ministry for Family Affairs, Senior Citizens, Women and Youth (BMfSFJ), headed by Ursula von der Leyen (CDU), mother of seven children, built on and exceeded the Social Democrats' approach to the provision of childcare places in Germany by proposing an even more rapid and radical expansion. While her proposal was only half-heartedly supported by the more conservative wing of her party - and loudly opposed by leading Catholic Church leaders - the Social Democrats and Chancellor Merkel supported her push forward. ${ }^{26}$ At a childcare summit in April 2007, the 
federal government, the Länder, and the local authorities committed to reaching the EU's Barcelona targets by providing either childcare places or access to a child minder for 35 percent of children under the age of three, equal to 750,000 childcare places by $2013 .{ }^{27}$ Based on a cabinet resolution, the federal government earmarked four billion euro to reach this target, which was expected to cover about one-third of the costs (interview, BMAS5). In September 2007, the Cabinet decided that - in the long run - parents should have a "statutory right" to a childcare place, therefore following the Danish and Swedish examples. As such, a conservative-led government pursued a "progressive" strategy that is traditionally at odds with the traditional male breadwinner model. This policy choice thus reflects a gradual, but significant normative reassessment at least on part of the Christian Democrats, who were in a de facto alignment with their Social Democratic coalition partners (Ahrens and Blum 2009). This is not to say, however, that this course correction has not gone uncontested. Mainly the more conservative CSU under the leadership of Edmund Stoiber insisted that they not "discriminate" against women who choose to mind their children at home. In a political compromise, Chancellor Merkel then promised to introduce additional cash benefits (Betreuungsprämie) by 2013. These cash benefits would then be paid to parents who prefer raising their children at home, thus forfeiting the use of a public childcare place (am Orde and Schmitt 2008). ${ }^{28}$

Second, the short-lived "super ministry" established in 2002 was broken up into its original parts: a Ministry for Economics and Technology (BMWi) and a Ministry for Labour and Social Affairs (BMAS). The new BMAS was headed by Franz Müntefering (SPD), a "strong supporter of, and believer in, the EES" (interviews, BMAS5, BMAS6, SPD2, SPD 3 ). Müntefering continued to push through significant changes to the pension regime, which had direct consequences on the labour market. The pension reform will gradually raise the regular retirement age from 65 to 67 , while the early retirement age will gradually raise from 60 to 63 . Both of these "hard" legislative changes are intended to increase the average retirement age of German workers, and were accompanied by "softer" measures, including the Initiative 5o-plus and the Perspektive 5o-plus. An employers' association representative (interview, Metall NRW) explained that these "hard" legislative changes were a major breakthrough that would have "a real impact on business behaviour". This was the case because in the past, large firms (and their employees) seldom expected anyone to work beyond the age of 57 . Thus employers stopped investing 
in the skills of their older workers, who were often just in their mid-4os. Now that companies expect to retain their employees until the age of 63 , if not 67 , the incentives structure had changed, and investments in older workers' skills would become much more likely.

The "soft" Initiative 5o-plus, in turn, introduced new "active" measures to supplement the pension reform and to further promote a normative shift away from early exit. The Initiative 5o-plus includes both wage and employment subsidies to employers and employees, thus providing incentives to take on work/hire older workers. It also includes the creation of additional, long-term employment opportunities in the "second labour market" for workers 58 and older. Under the heading of "life long learning", the access to in-firm training opportunities was also expanded: Workers aged 45 and older (previously 50 years) in firms with less than 250 employees (previously 100 employees) can now receive a "training voucher" with which they can "buy" further qualifications, leading to a certification. In addition to the Initiative 5o-plus, Müntefering initiated the Perspektive 5o-plus which is targeted at older, often long-term unemployed jobseekers (aged 50-64). More specifically, through the Perspektive 50-plus, the BMAS supported the launch of 62 regional employment pacts in which employers, local PESs, ARGEn/Optionskommunen, and other stakeholders joined forces in an effort to provide older workers with a fair chance for decent employment.

Third, while both the Social Democratic BMAS and the Christian Democratic BMfSFJ pursued reform strategies that conformed to the EES and the revised OECD Jobs Study, there was also one legislative "setback". In an attempt to "sharpen their social profiles" (personal conversation, SPD Parliamentary Group), both Chancellor Angela Merkel and SPD Chair Kurt Beck agreed to reverse parts of the controversial Hartz reforms by (re-)extending the benefit duration for older. Based on a compromise between the CDU and the SPD, the German PES then offered a staggered receipt of $A L G-1$ between 15 and 24 months, depending on the recipients' age. Beck and Merkel defended this "minor adjustment" by reference to the equivalence principle, which suggests that workers who had contributed to the system for decades should have the "right" to draw on benefits for an extended period of time. While this strategy was well received by voters, it ran counter to the "paradigm shift" that Franz Müntefering had attempted to initiate, and directly affected the very incentive structures he wanted to create. When Franz Müntefering failed to prevent this politically motivated manoeuvre, he resigned his post as minister. ${ }^{29}$ 
To summarise, this brief overview of the Grand Coalition years has shown that institutional evolution is a complex game in which policymakers are engaged in "puzzling" and "powering", or trying to find new solutions to existing problems and maximising electoral support. The EES has certainly inspired - and helped to legitimise - Germany's path-altering legislative initiative that will create a dense, nationwide network of childcare facilities. Similarly, the EES has been a major source of inspiration for Franz Müntefering's pension reform that will increase the average age at which workers exit the labour market, closes early exit corridors, and promotes life-long learning and older workers' activities through the launch of the Initiative 5o-plus and the Perspektive 5o-plus. However, the EES could not prevent "politics as usual" from taking place. In a vote-maximising manoeuvre - which could draw legitimacy from socially engrained norms and long-standing traditions - legislative proposals extending the duration of UB payments for older workers were pursued, and supported by large factions in both the CDU and SPD.

\section{VII.2 Explaining Hybridisation in the Liberal World: Turning Vice into Virtue in Ireland}

While German institutional developments have been characterised by the gradual, and at times rather late, influence of European ideas - including activation (1998/2001), state-led public childcare provision (2005), and an active ageing strategy (2006) - and intense political struggles along ideological lines, the Irish trajectory comprises a largely consensual (albeit, not necessarily harmonious) development of institutional capacity building, in the absence of large-scale ideological divisions. The Celtic Tiger experience can roughly be divided into two episodes: a first era, lasting from 1987 to 1997 , which was characterised by (a) the establishment of a social partnership norm, which has been labelled "competitive corporatism" (Rhodes 2000a; Hardiman 2002), leading to moderate wage deals, industrial peace, and employment growth; and (b) the (massive) expansion of ALMPs (with the help of ESF money), in particular of the demand-side variety (e.g., the Community Employment Scheme). During this first phase, Ireland was not only able to substantially reduce high levels of unemployment, but also consolidated its budget and reined in inflation, which were necessary preconditions to becoming a member of the Eurozone.

The subsequent era - up until the 2008 global financial crisis - saw the maturation of a "developmental welfare state" (NESC 2005a), designed to 
overcome Irish institutional shortcomings, such as the "negative" effects associated with the Anglophone welfare cluster (inequality, poverty, and underachievement) and the male breadwinner norm, which had led to low female employment rates and gender inequality. During this second period, the EU/ESF gradually lost its financial importance. The recommendations of the EES and the OECD, in turn, served as an institutional compass and a political lever for civil servants and societal actors alike to recalibrate Ireland's passive and minimalist welfare state through the introduction of an activating labour market policy that rewards (low-wage) work, a national childcare strategy that enables more women to retain their participation in the workforce, and attempts to address the concerns of older workers in the Irish knowledge economy.

\section{VII.2.a The Genesis of the Celtic Tiger: Negotiated Partnership}

As shown in chapter IV, Ireland's policymakers decided to opt for a negotiated partnership route rather than a marketisation approach in 1987. This approach was a conscious decision by the (minority) Fianna Fáil (FF) government, building on a National Economic and Social Council's strategy paper, which had been developed jointly by the NESC secretariat, employer representatives and union leaders (O'Donnell and O'Reardon 1997; O'Donnell and Thomas 1998; Hardiman 2002). The subsequent first partnership round was concluded with the issuance of the Programme for National Recovery (PNR), which was mainly concerned with reaching a deal on wage moderation, securing industrial peace, ${ }^{30}$ and moving toward the consolidation of the public budget in an attempt to tackle the overwhelming economic distress. While the unions were at that time not surprisingly - rather sceptical about the PNR's goals to keep wage increases down, their decision to participate would become the foundation of the Celtic Tiger economy, and subsequently strengthened and institutionalised Irish social partnership. ${ }^{31}$

The second round of social partnership negotiations, which were again - as all subsequent negotiations - based on a strategic framework established by the NESC, was then concluded in January 1991 with the Programme for Economic and Social Progress (PESP). While the PNR had contributed to increasing levels of economic growth, it failed to significantly reduce unemployment. Accordingly, in addition to securing wage moderation, which was hoped to stimulate employment growth, PESP proposed an area-based approach to unemployment and social exclusion. The most important new labour market policy measure in this con- 
text was an "advanced" version of the demand-side Social Employment Scheme, entitled Community Employment Development Programme (CEDP).

When unemployment began to increase again in 1991, the general elections held in November 1992 were primarily fought on the issue of unemployment, in particular its long-term variant. More than doubling its seat share, the Labour Party emerged as a confident actor, and the FF reached out to Labour to form a coalition government under the leadership of Albert Reynolds (FF) as Taoiseach, or Prime Minister. Ruairi Quinn (Labour Party), the "founding father" of the SES, became - once again - Minister for Enterprise and Employment (DEE) from 21 January 1993 through 17 November 1994 (cf., Quinn 2006). Under Labour's watch the multipartite National Economic and Social Forum (NESF) was set up in 1993 to monitor, analyse and evaluate labour market programmes and social policy measures and to propose alternative ways of moving forward. The NESF operated parallel to the NESC and was also given the task of co-ordinating "a variety of community and voluntary interests including activists for the unemployed, disability rights, poverty issues, the elderly, and others" (Hardiman 2005a, 4).

During the subsequent social partnership negotiations of January/ February 1994, leading to the Programme for Competitiveness and Work (PCW), the government committed itself "to introducing a new Community Employment $(\mathrm{CE})$ venture that would enable the unemployed to undertake work of public or social value while it provided work experience and development training" (Taylor 2005, 41). In preparation for the launch of the new CE, the DEE eliminated the distinction between black spots and other areas in the CEPD, streamlined the programme and co-ordinated it for its nationwide operations (interview, MIN). The newly launched $\mathrm{CE}$ then created 40,000 job opportunities in local communities, replacing the SES, the CEDP, and Teamwork. ${ }^{32}$ The CE's massive size represented a net increase of some 20,000 places within less than a year, making it Ireland's most important ALMP measure. Starting in 1994, the government gradually phased in training modules to the $\mathrm{CE}$ - which were mainly financed by ESF money - and increased the size of local CE projects. Larger CE projects were then eligible for the appointment of supervisors assisting CE participants. While the Progressive Democrats criticised the fact that the CE was a voluntary programme, the vast majority of politicians endorsed the scheme due to its "double dividend" nature (NESC 2005a, 75), or its ability to offer meaningful work to disadvantaged groups and its function as "the backbone of thousands of voluntary organisations and communi- 
ty groups" (Fitzgerald 2005, 129). In addition to recalibrating the $\mathrm{CE}$, the government introduced the Back to Work Allowance scheme (BTWA) in 1993. The BTWA allowed long-term unemployed persons over the age of 23 "to retain 75 per cent of their existing benefits for the first year, 50 per cent for the second and 25 per cent for the third and final year" (Fitzgerald 2005; Taylor 2005, 65). As such, participation in BTWA made virtually any low-wage employment more attractive than remaining on unemployment benefits (Tansey 1998). Besides the CE, BTWA quickly become the secondlargest programme, culminating in 2000 with 39,000 participants (Walsh 2004, 17).

In November 1994, the Fianna Fáil-Labour coalition government unexpectedly collapsed when Labour withdrew its support after a series of FF scandals, which also led to the resignation of Reynolds and the appointment of Bertie Ahern as the new party leader (Kavanagh 2001, 155f). Subsequently, a "Rainbow Coalition" consisting of Fine Gael (FG), Labour, and the Democratic Left emerged without having to hold new elections. ${ }^{33}$ This (partial) governmental reshuffle, however, did not lead to a major departure from the previous course on labour market policy. Neither did it affect the prevailing partnership norm, as a "consensus on the desirability of this approach" had been established also among the more sceptical political parties, including FG (Hardiman 2002, 6). But, not only had national partnership become a constant feature in Irish policymaking, compliance with this - in principle voluntary - wage-setting mechanism had also been surprisingly high. In other words, even the non-unionised sector, which includes many foreign companies, closely followed the wage agreements (Sexton and O'Connell 1996, viii). As such, the social partnership approach helped Ireland to reverse its previous path of spiralling budget debts, inflation, and unemployment, while also offering a forum in which external constraints that emerged with the European Union's rapid developments to establish a common currency could be "internalised" (Hardiman 2005a, 25).

In 1996, following the recommendations offered by the multi-stakeholder Task Force on Long Term Unemployment, set up in 1994 to assess two NSEF reports published in December 1994 and 1995, the government created a series of additional labour market instruments, including (a) the Pay Related Social Insurance (PRSI) exemption scheme, which offered subsidies to employers in an attempt to encourage recruitment of certain benefit recipients; (b) the Jobs Initiative Programme (JIP), designed to provide full-time employment for a "hard core" of long-term unemployed people aged 35 or older; and (c) the Youth Progression Programme (YPP), 
targeting the younger unemployed, 18 to 19 years of age. The YPP was a direct response to those critics who had argued that the CE "deliberately exclude[ed] young people" (Irish Times 1994). The YPP targeted up to 500 young jobseekers and was Ireland's first step toward activation as it offered individual, intensive support plans to prevent the young on the Live Register from drifting into long-term unemployment (Irish Times 1996). In 1996, upon the recommendation of the NESF, the Local Employment Services (LESs) were launched. The LESs were to collaborate closely with local employers and provide "more in-depth engagement over time with unemployed clients who are further from the labour market" (Fitzgerald 2005, 128).

In summary, the first half of the 1990 os were characterised by (a) the establishment of a peaceful and financially attractive economic environment for foreign investors; (b) a realignment of all political parties and stakeholders in favour of national partnership deals in which wage moderation served as "the glue"; and (c) an intensification and expansion of a wide variety of active labour market measures, in particular, but not exclusively the demand-side oriented CE and the supply-side oriented BTWA.

\section{VII.2.b Ireland the Good - but Occasionally Reluctant - European Pupil: Introducing Activation, Childcare, and Active Ageing}

When Fianna Fáil returned to office in 1997, now in a coalition with the more market-liberal Progressive Democrats, the Irish economic crisis was a relic of the past. The Irish economy had grown at an annual rate of 8.5 percent per annum since 1994, almost four times as fast as the EU-15 (Hardiman 2002, 10). Likewise, overall employment rose by more than five percentage points from 1992 to 1997 - from 50.9 to 56.2 percent while unemployment had fallen from over 15 percent to some ten percent since 1993 (OECD 2006a). However, despite these rapid improvements, the "single greatest problem facing Irish society remain[ed] the high proportion of long-term unemployment and the associated poverty and social exclusion" (O'Donnell and Thomas 1998, 124). Accordingly, promoting employment growth and tackling entrenched unemployment problems were key issues for the incoming government. For this purpose, the FF-PD government sequentially introduced a variety of measures, including (a) "soft" activation and a recalibration of Irish ALMPs, (b) "making work pay" through a reduction of income tax burdens, coupled with a (generous) statutory minimum wage, (c) expanding the female workforce through the individualisation of taxation and im- 
proved access to (public) childcare; and (d), most recently, active ageing and lifelong learning measures, which allow older workers to improve their (basic) skills. Many of these reforms were addressed in the context of partnership negotiations, which became both more inclusive as the voluntary and community pillar was invited in 1997 - this had been initiated by the previous government under Labour's watch - and broader in scope by addressing more social issues (cf., O'Donnell and Thomas 1998, 126).

\section{Activation of the Unemployed}

Among the new government's first actions was the swift launch of the Preventative Strategy in September 1998. The core element of the Preventative Strategy was to "tighten the screws" for young benefit claimants by introducing more stringent job search requirements (interview, UCD2) ${ }^{34}$ Accordingly, all jobseekers under the age of 25 would receive a letter from the Department of Social and Family Affairs (DSFA), inviting them for an interview at the nearest FÁS office after six months of being unemployed. At the interview, the suitability of jobseekers for job vacancies or active labour market measures was assessed, an Individual Action Plan was drawn up, and referrals to Jobs Clubs or the LES were made. This Preventative Strategy was, to a large extent, a direct "response to Guideline 1 of the EES, which committed Ireland to assist the unemployed after a certain period by offering them a job or an employability support" (O'Donnell and Moss 2005). As such, the EES was very influential in determining the direction of this change (interview, DETE2, FÁS3, ICTU2, UCD2), while it also provided a political lever and external legitimacy for civil servants in the Department for Enterprise, Trade and Employment (DETE), who had been eager to introduce such a scheme (interview, CDI). This shift toward activation - which was a "quite new concept in Ireland" (interview, ICTU2) - was subsequently reinforced in the bi-annual meetings of the Heads of PES, where "everybody commits to activation" (interview, FÁS1).

The launch of the Preventative Strategy was, at least partially, also a product of the groundwork prepared by the previous government. In other words, the successful and swift launch of this new activation measure became politically possible because the Rainbow Coalition had already launched the Youth Progression Programme for 18 and 19 year olds, which entailed individualised, intensive support plans, while a governmental White Paper published in May 1997 also foresaw the gradual expansion of this scheme to youth aged 18-21 (Carthaigh 1997). 
When subsequent studies confirmed the effectiveness of Irish activation policy (e.g., OECD 1999a; O'Connell 2002) - despite its "soft" character $^{35}$ - it enjoyed widespread acceptance. Accordingly, the Preventative Strategy was first expanded to other age groups, i.e., to those aged 25 to 54 in 2000 , after nine months of unemployment in 2000 , and the timetables were gradually tightened. Since 2006, all jobseekers aged 18-64 are "activated" after three months of unemployment (FÁS 2006,49 ). That same year, unemployment benefits and unemployment assistance schemes were renamed Jobseekers' Benefits and Jobseekers' Allowance to further reflect the new work orientation in Irish labour market policy.

In summary, the FF-PD government - inspired by the EES - introduced Ireland's first formal and systematic approach to interacting with jobseekers and established a comprehensive "activation" and "PES service model" paradigm based on early intervention, individual case management, and contractualised action plans (cf., Burke 2006, 2). Considering "activation" in the Irish context, it should also be mentioned here that the LES network was placed under the FÁS umbrella in 1999 (Fitzgerald 2005, 128). This decision was made after the publication of disappointing LES results regarding their counselling, guidance and placement services (NESF 20oob). While LES offices retained their separate status and a remit to provide "specialised services" to jobseekers facing additional hurdles, they were from that point on under contract with FÁS, which included the setting of detailed outcome and process targets (interview, FÁS 5 ).

\section{Recalibration of Active Labour Market Policy}

While the introduction of activation measures found widespread support across partisan lines and societal stakeholders, the new FF-PD government's attempts to reform the ALMP toolbox faced significant resistance. Following the OECD's recommendations and drawing on the independently run evaluations published in the Deloitte Touche Report, Mary Harney (PD), Tanaiste (Vice Prime Minister) and Minister for the Department for Enterprise, Trade and Employment (DETE), suggested excluding up to 8,ooo people from the CE on 1 October 1998. Mary Harney had welcomed the report's conclusions on the grounds of both efficiency and ideology. On the one hand, she argued that such a cut would generate "between 44 million (pounds) and 58 million (pounds)", while adequately reflecting changing economic conditions (Yeates 1998). In 1998, the CE had reached a new record, employing 41,0oo unemployed 
people, while the Irish unemployment rate was down to 7.5 percent and still falling (PARTNERSHIP 1997, 16; OECD 2005b, table 14). On the other hand, based on her ideological convictions, she had great antipathy towards the demand-side oriented programme and considered the CE economically of "no value" (Quinn 2006, 225). Mary Harney's proposal to reduce CE numbers was also supported by IBEC as employers had become increasingly disillusioned with a programme that had failed to significantly improve participants' chances to move into the private labour market (interview, IBEC). Accordingly, IBEC began "calling for a reduction of 12,00o in the numbers on community employment schemes, by only targeting the hardest to place and the most at risk of poverty" (Suiter 1998). IBEC also suggested raising the age threshold at which people can enter CE schemes from 21 to 25 , while arguing that some of the money spent on CE could be better spent on courses in Specific Skill Training and other "market-led training" courses for the unemployed (Suiter 1998).

In January 1999, the government announced that the number of places in CE schemes would be cut by 2,500. Even these modest cuts, however, encountered great resistance from the social partners, including the Irish National Organisation for the Unemployed (INOU) whose representatives claimed that the government "failed" to provide assistance for the long-term unemployed, and ICTU, arguing that such cuts were "unacceptable" (Yeates 1999b). Nonetheless, in July 1999, Mary Harney announced that she would overhaul the CE by raising the participation age to 25 , increasing the waiting period for people wishing to repeat a one-year scheme, introducing a three-year "lifetime participation" cap, and cutting 5,00o places. In exchange for these reforms, the young single parents who were hardest hit by the CE overhaul were to be redirected into 800 extra places in "mainstream training courses" (Yeates 1999a). Subsequently, Mary Harney also promised a new programme, the Social Economy Programme (SEP), which would create up to 2,500 full-time jobs in the social economy for the older, long-term unemployed by 2002 (Yeates 2000). ${ }^{36}$

When on 20 August 1999 the DEE announced that the CE was "scheduled to be phased out over the next five years", CE supporters rallied quickly to its defence, including the INOU, ICTU, SIPTU, the Conference of the Religious of Ireland (CORI), the Labour Party, Sinn Fein, as well as activists in many local communities, which increasingly depended on the provision of the CE's services (Dunne 1999). The social partners claimed that the cuts were "totally unacceptable and in breach 
of specific agreements reached under Partnership 2000", the national partnership agreement reached in 1997 (Dunne 1999). Most, if not all, socially concerned actors argued that cutting CE places in response to job growth failed to acknowledge the special needs of the long-term, often older or otherwise disadvantaged workers and overlooked the valuable contributions made to local communities (interviews, ICTU1, CORI, and INOU1). Although the plans to phase out the CE entirely were quickly discarded and the participation rate remained as high as 37,500 in 1999 - when unemployment had fallen below six percent - the government, now in negotiation with the social partners, was able to gradually reduce the CE to 30,000 in 2000 , roughly 28,000 by 2002 , and to 20,000 in 2008.37

While the government gradually reduced the demand-side oriented $\mathrm{CE}$, it also shifted new resources first to supply-side oriented instruments for unemployed jobseekers, and subsequently made "lifelong learning" of workers in employment a real priority. Between 1998 and 2008 , FÁS more than doubled the number of apprenticeships, while also significantly increasing participation in the Foundation Training, which prepares low-skilled jobseekers for Specific Skills Training. With the rapid increase in apprenticeships, FÁS training facilities quickly filled up, which then led to the introduction of (outsourced) Sponsored Training, where jobseekers waitlisted for FÁS training programmes could begin taking training and education courses. In roughly 2003, DETE and FÁS also began to prioritise the improvement of skills for workers already employed. FÁS had realised that there was a "sizeable proportion of people who have below second level education", whose competences needed to be improved (interview, FÁS 3 ). Accordingly, a series of initiatives were introduced under the label of lifelong learning, a focus that had "trickled down" from the Lisbon Agenda (interview, FÁS 4). Among those programmes were the Competencies Development Programme, which provided financial assistance to employers who train their employees (available at various skill levels), the Skills for Work programme, designed to help employees with basic skills demands (such as literacy, numeracy, basic computer skills), and the Excellence Through People Award, which formally recognised companies' training efforts. The following table reveals the FÁS's shift from a demand-side to a supply-side focus regarding unemployment. 
FÁS Throughput, 1998-2006

\begin{tabular}{llllllllll}
\hline & 1998 & 1999 & 2000 & 2001 & 2002 & 2003 & 2004 & 2005 & 2006 \\
\hline $\begin{array}{l}\text { Appren- } \\
\text { ticeship }\end{array}$ & 7,151 & 10,316 & 13,193 & 17,654 & 18,656 & 17,179 & 16,357 & 17,748 & 17,400 \\
\hline $\begin{array}{l}\text { Specific Skills } \\
\text { Training }\end{array}$ & 14,607 & 18,356 & 16,022 & 14,691 & 15,525 & 15,225 & 8,861 & 8,882 & 8,253 \\
\hline $\begin{array}{l}\text { Foundation } \\
\text { skills }\end{array}$ & 8,305 & 11,090 & 10,722 & 12,606 & 12,597 & 12,053 & 11,870 & 14,178 & 13,117 \\
\hline $\begin{array}{l}\text { Sponsored } \\
\text { Training* }\end{array}$ & - & - & - & - & - & - & 2,613 & 2,423 & 1,669 \\
\hline Total Training & 30,063 & 39,762 & 39,937 & 44,951 & 46,778 & 44,457 & 39,701 & 43,231 & 40,439 \\
\hline $\begin{array}{l}\text { Employment } \\
\text { Programs }\end{array}$ & 58,522 & 58,919 & 55,230 & 48,941 & 43,750 & 36,907 & 31,793 & 32,101 & 32,126 \\
\hline Total & 88,585 & 98,681 & 95,167 & 93,892 & 90,528 & 81,364 & 71,494 & 75,332 & 75,565 \\
\hline
\end{tabular}

* This was included in the (mainly) Specific Skills Training program prior to 2004 Source: FÁS 2006

\section{MaKing Work Pay}

While the government reshuffle in 1997 led to some important policy changes with respect to labour market policy, the impact on tax policy was even more pronounced. The new Finance Minister Charlie McCreevy (FF) and Minister for Enterprise, Trade and Employment (DETE) Mary Harney (PD) quickly developed a "coherent and sustaining approach on taxing labour, while making economic growth their key priority" (interview, UCD2). Their initial tax reforms mainly benefitted the middle- and upper-class households rather than low-income families. This occurred despite the agreements reached in Partnership 200o, much to the irritation of the opposition (cf., Hardiman 2005a, 18). Over time, however, the marginal tax rate fell from its peak at 68.5 percent in 1984 for an unmarried industrial worker on average wages (Walsh 2004, 17), to just 20 percent in 2007 (OECD 2007d). ${ }^{38}$

In 1998, the FF-PD coalition government also set up a National Minimum Wage Commission to come up with an appropriate rate for a national minimum wage. In April 2000, a national minimum wage of $€ 5.59$ was introduced under the National Minimum Wage Act. Since then, the minimum wage has been repeatedly increased, most recently (on 1 July 2007 ) to $€ 8.65$, making it one of the most generous in Europe. Moreover, since the early 2000 s, the government has effectively "removed all those on the national minimum wage from the tax net" (Government of Ireland 2005, 39). 
To summarise, when combining the effects of pay gains for low-wage workers in the national partnership agreements, the introduction of a "quite generous" national minimum wage and tax cuts/credits aimed at the low-wage workers, Ireland's "make work pay" strategy has taken "a huge amount of people" out the income tax net at the lower level (interview, DETE2), which "undoubtedly contributed to an improvement in the absolute position of low paid workers" (cf., Dobbins 2004).

\section{WOMEN AND WORK}

In addition to significantly reducing workers' income tax rates, the FFPD also pushed through the "individualisation" of tax bands in 2000. As shown in chapter IV, individualised taxes are typically found in the Nordic countries and challenge the male breadwinner norm as "the returns to a second income earner in a household" are substantially increased (Walsh 2004, 17). Not surprisingly, the government faced loud resistance to this policy from the main opposition party (Fine Gael), the Archbishop of Dublin, the Irish Family Planning Association as well as many socially conservative voters (cf., Brennock 1999). However, the government did not renege on its decision because it believed that the reforms would advance the economic opportunities of women (interview, UCD2).

While pushing through tax reforms was largely in line with the FF and PD market-oriented ideology, an expansion of state-led childcare provision was more difficult to accept politically. As such, the provision of childcare was initially mainly placed in the context of tackling child poverty and assisting low-income families, while the government - fearing an electoral backlash - chose to gradually and significantly increase the provision of universal child benefits, which, so they argued, offered a "real choice to parents" (McCreevy cited in IBEC/ICTU 2005, 27). ${ }^{39}$

Some first attempts to improve childcare provision, however, had previously been obtained as part of the Partnership 2000 agreement and therefore was achieved still under the Rainbow Coalition. The agreement foresaw the establishment of an Expert Working Group on Childcare to develop a national childcare strategy. The Working Group was subsequently established and produced its report in 1999 in which it was argued that there was a "virtual crisis in the childcare supply" and that the lack of childcare places was "one of the most significant barriers to women accessing and participating in the labour force" (Report of the Partnership 2000 Expert Working Group on Childcare 1999, iv). Almost immediately after the publication of this report, the government launched an Equal Opportunities Childcare Programme (EOCP), which advocated 
the improvement of the quality and quantity of childcare places, mainly in disadvantaged areas, and the introduction of a co-ordinated approach to deliver childcare services. Under the EOCP, 33 City/County Childcare Committees (CCCs) were established to govern - with the input of the social partners - local childcare needs. The Department of Justice, Equality and Law Reform (DJELR) also established the National Childcare Co-ordinating Committee (NCCC) in 1999, again with social partner representation, to advise the government on the development of childcare services, develop a co-ordinated national approach, and to co-ordinate the workings of the CCCs (SIPTU 2005, 7).

Shortly thereafter, the EOCP II (2000-2006) was launched as part of the Irish National Development Plan 2000-2006 (NDP) with the objective to (a) improve the quality of childcare; (b) maintain and increase the number of childcare facilities and places; and (c) introduce a co-ordinated approach to the delivery of childcare services (Government of Ireland $2003 \mathrm{~b}, 11)$. The EOCP II received significant funding both from the European Social Fund (ESF) and the European Regional Development Fund (ERDF), totalling $€ 181.8$ million. The Exchequer provided an additional $€ 317.2$ million, adding up to a total budget of just under $€ 500$ million (IBEC/ICTU 2005, 15). Despite these efforts, formal childcare remained very limited in its availability and one of the most expensive in Europe, even after tax allowances and subsidies were taken into account (Immervoll and Barber 2005, 21f; NESC 2005a, 135).

While the pressure to address the issue of childcare provision developed slowly during the late 1990 s, it rapidly gained salience after the turn of the millennium, especially when the ECOP II was about to reach its conclusion (e.g., IBEC/ICTU 2005). As women's labour market participation had dramatically increased during the boom years - from some 40 percent in 1994 to over 58 percent in 2005, growing faster than anywhere else in the OECD world - it became apparent that the participation of women had been a crucial ingredient in Ireland's economic success story, particularly as women had become as well as - if not better - educated and trained as men (Sweeney 2006, 11). Women's rising labour market participation, especially the extremely high participation rate of young women in their 20 s, also meant that there was a great potential for an economic backlash when these women would decide to have children in their 30 s, thus withdrawing from the labour market and causing major skills shortages in Ireland's knowledge economy (interview, FÁS4). Accordingly employers (and some policymakers) became interested in addressing issues related to the reconciliation of work and 
family life, while the labour unions saw this as an area where they could promote developments toward an expansion of working women's rights. In other words, in contrast to Germany (and the UK), the Irish social partners quickly aligned on this issue and jointly began lobbying the government to make childcare available through public funds (cf., IBEC/ ICTU 2005, 1). The EU's Barcelona targets, the EES, ${ }^{40}$ and various OECD reports and recommendations ${ }^{41}$ served as a legitimisation for the social partners' demands and a lever for their lobbying activities (interviews, IBEC, ICTU2, NESC). In addition, "more than 20 childcare and children's rights organisations" joined the social partners' demands in 2005 (Holmquist 2005).

Facing continuous pressure from domestic and international sources to do more than merely rely on improved universal child benefits and tax credits to make childcare accessible to average families, the government committed itself to directly investing in childcare places during the partnership negotiations in 2006 (called Toward 2016). Accordingly, the government launched a new National Childcare Investment Programme (NCIP) 2006-2010 as the successor to EOCP II with a target of an additional 50,000 childcare places by 2010 . While the NCIP will directly create 5,000 after-school, and 10,000 pre-school education places, the bulk of the new childcare places are to be created by private and voluntary sector actors, who can apply for large monetary grants to defray the capital costs of developing a childcare facility. Grants are available also to individual or group childminders who offer childcare services in their homes. As such, the NCIP marks an important departure from the EOCPI and II, because it is an explicit attempt to directly invest in the creation of childcare places and to improve the reconciliation of "work and family life" among average families, in contrast to the previous exclusive focus on families in economically disadvantaged neighbourhoods (interview, NESC).

The National Childcare Strategy (2006-2010) also introduced new entitlements to parents with children under the age of six, including a new direct and tax free Early Childcare Supplement payment to parents, amounting to $€ 1$, ooo annually (paid in four instalments); improved maternity and adoption leave (see table 37 below); an increase in maternity benefits (the maximum rate has been increased by $€ 16.60$ a week); and a new programme to foster educational opportunities for children and adults in economically deprived areas. 


\begin{tabular}{llll}
\hline & Pre-March 2006 & March 2006 & March 2007 \\
\hline Paid Maternity Leave & 18 weeks & 22 weeks & 26 weeks \\
\hline $\begin{array}{l}\text { Unpaid Maternity } \\
\text { Leave }\end{array}$ & 8 weeks & 12 weeks & 16 weeks \\
\hline Parental Leave & 14 weeks & 14 weeks & 14 weeks \\
\hline Total entitlement & 40 weeks & 48 weeks & 56 weeks \\
\hline
\end{tabular}

Source: National Childcare Strategy 2006-2010

In summary, like their German counterparts the FF-PD government tried to find a compromise that would be acceptable to proponents of both the male breadwinner and the dual breadwinner model. By committing to the expansion of the availability, affordability, and quality of childcare places and simultaneously expanding childcare benefits, introducing a new supplement (available irrespective of employment status), and improving both paid and unpaid maternity leave, the government hoped to satisfy the electoral concerns of their socially conservative Catholic constituency and address the concerns/recommendations of employers, unions, childcare organisations, the EU, and the OECD alike.

\section{Older WORKERS}

Ireland has a favourable old age dependency ratio, a relatively high fertility rate (cf., Government of Ireland 2003a, 29), and an employment rate for older workers (55-64) of 54 percent in 2007, which is well above the EU target of 50 percent for 2010 (Government of Ireland 2007, 45). Likewise, the current Eurostat data (2005) shows that the average exit age from the workforce is 64.1 years, the highest in the EU. Because of this favourable situation, "active ageing" did not receive much attention among employers (interview, IBEC), while ICTU members "were not dying to work longer" (interview, ICTU1). Nevertheless, during the early 2ooos, the European Commission and the OECD repeatedly called upon the Irish government and the social partners to "expedite the long-awaited lifelong learning strategy and also to intensify efforts to promote in-company training, in particular for older workers" (NESF 2003, 48; OECD 2006b, 100). These calls from external actors intensified worries that had slowly come to the fore during the late 1990s, when unemployment dropped rapidly and labour shortages became prevalent (most importantly, see NESF 2000a).

However, the government remained initially reluctant to push through legislation that specifically targeted improving the skills of older work- 
ers. Likewise, the social partners did not make the issue of older workers a top priority, and accordingly, no mention of older workers is found in the partnership agreements reached in 2000 and 2003 (cf., Government of Ireland 2000; Government of Ireland 2003c). Rather, the government issued various legislative acts to prevent age discrimination, while relying on flexible work arrangements to generate job opportunities for older workers. ${ }^{42}$ In 2002, however, the government set up a taskforce for lifelong learning, which triggered the introduction of a National Framework of Qualifications (NFQ) formalising accreditation in 2003, while the $\mathrm{Na}$ tional Training Fund (NTF) set up in 2000 provided the financial means for a range of schemes aimed at raising skill levels among Irish workers. ${ }^{43}$ As such, the government embedded its commitment to older workers within the effort to enhance the overall skill levels of the Irish workforce. Older workers were expected, however, to benefit disproportionately from the new formal accreditation system because they were "more likely than younger workers to have acquired skills that have not been formally recognised" (OECD 2006b, 100). In September 2005, the government also included the new "One-Step-Up" initiative - subsuming both the Competencies Development Programme and the Skills for Work programme outlined above - into its budget to promote workplace education, especially literacy and numeracy. ${ }^{44}$ While "One-Step-Up" is not an ALMP, it is designed to provide transferable skills to workers, which - similar to the "Train to Gain" programme in Britain (see chapter VI) - enables workers to progress to the next level on the NFQ.

In the meantime, the social partners also became more sensitive to the issues related to older workers. While IBEC joined the unions' calls, it was ICTU that "really pushed the issue of older workers in the [Toward 2016] partnership agreement" (interview, NESC). In a large-scale political compromise, the Toward 2016 agreement foresaw a three-pronged strategy to address older workers: first, following the recommendations of the EU and the OECD with respect to "early exit" schemes, the Irish government decided to phase out its Pre-retirement Allowance (PRETA) scheme introduced in the early 1990s. ${ }^{45}$ This policy change was supplemented "by the decision to extend the Preventative Process and associated supports to those over 55" (Government of Ireland 2006, 35), which meant that older workers who became unemployed would receive the regular Jobseeker's Allowance and had to fulfil all regular job-search and availability criteria. Second, the government promised to provide additional measures to help upgrade older workers' skills, including access to apprenticeships that are typically reserved for young workers. ${ }^{46}$ And 
third, the government - like in Germany - launched a campaign "to promote a cultural mindset change" with regard to older workers (Government of Ireland 2006, 35).47

\section{VII.3 Conclusions}

Both Ireland and Germany have sequentially introduced similar public policies over the past decade, despite very different welfare state trajectories, actor constellations, and problem situations. Both countries introduced a "fourth" labour market pillar based on activation, i.e., early interventionism, case management, and individual contractualism. In Ireland, this change was launched with the 1998 Preventative Strategy for young jobseekers, which was mainstreamed to include adults in 2000, and expanded to also include older workers in 2006. In Germany, nationwide activation was first introduced with JUMP for young jobseekers in 1998. Subsequently, the concept was expanded through the Job-AQTIV Act in 2001 and later mainstreamed through the Hartz reforms. Both countries also pursued - at times reluctantly - a state-led strategy for the provision of childcare facilities. Facing opposition from socially conservative groups adhering to the male breadwinner norm, both countries have coupled the expansion of childcare with additional cash benefits made available to women who choose not to engage in employment. And, finally, both countries adopted, more recently, strategies that combine the phasing out and/or limiting the use of "exit options" with the introduction of (a) new labour market measures designed to upgrade the skills of older workers (plus prolonged access to public works programmes), and (b) political campaigns to overcome societal misconceptions about older workers. Based on these common institutional developments, the influence of both the OECD and the EU on policymakers' reassessments in key policy fields, including an "activating" labour market policy, the reconciliation of work and family life through the provision of affordable childcare places, and lifelong learning and active ageing, is hard to "argue away".

However, welfare state trajectories and actor constellations have certainly conditioned the shape of these processes of institutional convergence and regime hybridisation. Since 1987 , Ireland has successfully combined a socio-economic path typically associated with the Nordic regime type, including consensus-seeking partnership, women-friendly social welfare and tax policies, and universal access to pre-employment ALMPs, with Anglophone elements such as a flexible labour market, low taxa- 
tion, and economic openness..$^{48}$ Irish success is, at least in part, based on "conscious" policy making on parts of the decision makers, the absence of a strong ideological left-right divide, and the consensus orientation of the centrist Fianna Fáil (Hardiman 2005b, 44), which has been in office since $1997 .{ }^{49}$ Therefore, the absence of major political reshuffles and the institutionalised inclusion of all of the main policy stakeholders through national partnership agreements, allowed for the successful alignment of political forces in favour of "puzzling" rather than a juxtaposition of competing coalitions, pursuing change through "powering". In other words, Irish policies since 1987 have been "based on mutual understanding between the government and the social partners on the fundamental economic and social priorities" (Schweiger and Wickham 2005, 16).

In Germany, in turn, major ideological rifts within and across the social partners and the main political parties have made "inclusive" coalition building impossible. When the Social Democrats returned to power after sixteen years in opposition, they initially sought to reintroduce a partnership-based policymaking style through the creation of a tripartite Alliance for Jobs. However, when the Alliance stalled and the economy stagnated, Chancellor Schröder resorted to a more unilateral approach in 2001, which produced the controversial Hartz proposals and the Agenda 2010. Even though the Chancellor had failed to convince his fellow Social Democrats and the labour movement that his reform plans were adequate, he was able to push legislation through Parliament by building an "informal" Grand Coalition with the Christian Democrats. However, outraged by the alleged attack on the German welfare state, many voters ceased to support the SPD, the labour unions felt betrayed, and a new political party, the Left Party, emerged as a political force, enticing the support from former Communists in Eastern Germany, as well as disillusioned unionists and disgruntled Social Democrats in the West. While the loud "anti-Hartz" and "anti-Agenda-2010" voice of the Left Party effectively de-legitimised the Social Democrats' reform efforts, also the supposed "winners" of the reforms - the employers and business associations - turned their backs on Schröder, when they sided with the Christian Democrats in the run-up to the 2005 election. In short, it was Schröder's failure to successfully align forces in a cross-class coalition in support of his reforms that ultimately led to his downfall.

When in the fall of 2005, a Grand Coalition under the leadership of Angela Merkel (CDU) took office, both parties began to attend to the voters' concerns about recent welfare cuts and the large majority of both Christian Democrats and the Social Democrats fully embraced a "wom- 
en-friendly" welfare state and "active ageing" policies. These policies were promoted by the new Minister for Family Affairs Ursula von der Leyen (CDU), who advanced the creation of childcare facilities, and by the Minister for Employment and Social Affairs Franz Müntefering (SPD), who spearheaded a supportive strategy for the promotion of longer working lives, making the overall trajectory of the German welfare state largely consistent with the EU and OECD agendas. However, while the Grand Coalition internalised much of the open political conflict, the exact "mix" of welfare policies remained controversial, especially as the Left Party and the unions continue to adhere to more traditional ALMPs, and socially conservative parts of the CDU/CSU objected to the promotion of a "progressive" family policy. As a result, policymaking in Germany has continued to be characterised by both "puzzling" and "powering" and a process of "contingent convergence" remains likely for the foreseeable future. 



\section{Conclusion}

In concluding this book, I would like to revisit the three central questions posed in the introduction, including:

(1) Do national labour market policy reform efforts exhibit covariation across Western Europe, and if so, how and why?

(2) What impact, if any, have the recommendations of international organisations such as the OECD and the EU had on national reform agendas?

(3) Have recent reform activities, in the context of the OECD Jobs Study and the EES, fundamentally transformed the historic composition of national labour market policy regimes, and if so, to what effect?

Given the rapid developments associated with the economic and financial crisis that has haunted the global economy since 2008 , a fourth section reflects on government responses to the crisis and closes with an interpretation of the long-term consequences of the crisis on the "activation paradigm".

\section{VIII.1 Do National Labour Market Policy Reform Efforts Exhibit Covariation across Western Europe, and if so, How and Why?}

The principal theme in this book has been my claim that transformative institutional changes follow actors' reassessments about existing institutions' capacity to tackle problem situations. This book has thus offered a new "lens" to better understand the origins and evolution of contemporary labour market policy regimes by focusing on changes in predominant worldviews, i.e., the causal and normative ideas about the causes of, and remedies for, high levels and, often, persistent unemployment and inactivity. Tracing how new ideas evolve and spread - often through the active proliferation of the OECD and the EU - and how these ideas have (not) 
been interpreted, internalised and implemented, has been the focus of this book. I have argued that it is precisely the acceptance or rejection of new ideas that has allowed - or prevented - the emergence of new actor constellations and coalitions, which are critical in stimulating the processes of institutional convergence, divergence and hybridisation.

The manpower paradigm that originated in Sweden during the 1940s and 1950 s triggered a phase of labour market policy convergence during the 1960 s in most parts of Western Europe. Policymakers shared the view that full (male) employment could be reached and sustained through interventionist macro-economic and industrial policy. In this context, the development of "active manpower policy" became a critical element to support economic growth and societal welfare. The associated "manpower revolution" was built on the assumption that labour market policy needed to be organised centrally by the state, who, in turn, would solicit the active support of the social partners. Programmatically, it concentrated on two pillars, including (a) a supply-side pillar with a focus on the provision of qualified labour to avoid bottlenecks in production, to support rapidly growing opportunities in new export markets, and to assist companies in their efforts to modernise and rationalise; and (b) a demand-side pillar that offered sheltered employment for disadvantaged groups and the possibility to bridge short periods of (seasonal) unemployment with more generous benefits. Labour market policy was thus seen as an important supplement to macro-economic and industrial policies, but was - at that time - not intended to fight mass unemployment. Most Western governments, irrespective of their partisan constellations, embraced these new ideas inspired by the Swedish Model, which were circulated and advocated at a variety of OECD conferences, workshops, and field reviews - often under the leadership of Gösta Rehn - and available in print in numerous OECD recommendations and associated publications. Major legislative initiatives were accepted in parliaments, which were more often than not dominated by liberal or conservative political parties at that time. The most important examples include the Austrian Christian Democrats' 1969 labour market promotion act, or $A M F G$, the German Grand Coalition's 1969 work promotion act, or $A F G$, the Danish Liberal-Conservative coalition government's decision to create a national PES, the Labour Market Board, in 1969, the centrist Fianna Fáil's creation of the Irish National Manpower Service (NMS) in 1971, or the British Conservatives' introduction of the Manpower Service Commission (MSC) in 1973.

The oil crises, in turn, produced two reactions: first, a consolidation, but also a reorientation, of manpower policy during the mid-1970s, and 
second, a divergence of instruments and the emergence of competing paradigms. More specifically, during the initial phase of the economic crisis, governments believed that the economic downturn was temporary and that their newly introduced manpower policies could be used as effective instruments to cushion the socio-economic effects of unemployment. Accordingly, manpower policies were strengthened and often recalibrated so that they mainly operated on the demand side. Even though alternative ideas about the causes of and remedies for skyrocketing unemployment began to circulate during the early 1970 , these ideas failed to challenge policymakers' normative and cognitive beliefs in any significant way at that time. This "manpower consensus", however, was subsequently shattered when the second oil crisis led simultaneously to increasing unemployment and inflation rates. By the early 1980s, not only Keynesianism had lost its credibility, but an increasing number of centre-right politicians also embraced the new "monetarist" orientation of economic governance, which was promoted by Milton Friedman and other economists at the University of Chicago. This reorientation included the removal of so-called labour market rigidities, such as stringent employment protection legislation, high minimum wages, co-ordinated wage bargaining, or generous benefits. Labour unions and social democratic parties alike fiercely contested this interpretation, which meant that their transposition into public policy was mixed, and institutional alternatives were actively sought. While there was a shared perception that the welfare state was in crisis (OECD 1981), no consensus could be reached either about the root causes of unemployment or its most appropriate remedies. Accordingly, throughout the early $198 \mathrm{os}$, the OECD issued a variety of recommendations, including labour market deregulation, a reduction in the supply of labour through "innovative" early retirement schemes and working-time reductions, as well as an expansion of active labour market policies. This disagreement with respect to the most appropriate "solution" to stagnating if not rising levels of unemployment then led to diverging institutional strategies.

The Anglophone world, led by two fiscal conservatives, Prime Minister Thatcher and President Reagan, largely followed the monetarist paradigm, which consolidated the institutional configuration of a "liberal" welfare state and production regime. In the UK, this strategy necessitated confronting and eventually breaking the unions' backbone in order for the government to be able to decentralise wage agreements, to gradually dismantle the tripartite Manpower Services Commission that was in charge of co-ordinating labour market policy and vocational training, to significantly reduce employment protection, and - at a later stage - to pursue 
a shift toward a tighter benefits regime and less encompassing ALMPs with very weak training components. During the mid-198os, Ireland also followed a path of wage decentralisation that the Irish government hoped would ease unemployment and inflationary pressures. However, the Irish economy did not recover. On the contrary, the unfavourable situation became worse. In a concerted effort, the tripartite National Economic and Social Council presented an alternative strategy in 1986, which laid the foundation for Ireland's partnership-based reform approach. Based on the successful alignment of employers and labour unions, and supported by the main opposition party, the Irish government was able to conclude a comprehensive, national partnership agreement in 1987, in which moderate wage setting was agreed to in exchange for tax cuts and an expansion of social and welfare policies. Even though some voices among the labour unions and the opposition were initially sceptical, a second partnership package followed in 1990 and, since then, social concertation had been the norm, distinguishing Ireland from its British neighbour.

Continental Europe attempted to reduce labour demand through reductions in working hours, the introduction and rapid expansion of various "early exit" schemes, and a significant growth of public works programmes. ALMP training programmes, in which participants could often stay for several years, also remained an important measure, especially in Germany, but less so in Austria. This strategy of reducing the overall supply of labour was preferred and supported by the social partners, who remained crucial actors in welfare reforms. It was also acceptable to the centre-right Christian Democrats, who were less inclined than their Anglo-American conservative counterparts to fully incorporate a monetarist paradigm. The Nordic exemplars, in turn, sought a strategy that was based on heavy investments in the welfare state, thereby creating new jobs in the service sector. The strong influence of social democracy, strong labour unions, and the rapid emancipation of women and associated pressure groups provided the necessary political will and societal support to expand state interventions, and thus substantially increase tax burdens. ALMPs were massively expanded in Sweden under both the Social Democrats and the centre-right, four-party coalition government. Conservative-Liberal ruled Denmark also increased their use, albeit, on a much smaller scale. Like her continental neighbours, however, the non-socialist coalition in Denmark promoted "early exit" programmes - most importantly the efterløn scheme - which had a major impact on reducing unemployment.

In summary, the 1980 os were characterised by the failure to produce a shared labour market policy paradigm. This resulted in the issuance of a variety of 
OECD recommendations, and a divergence in national reform trajectories which, in turn, led to the emergence of the famous "worlds of welfare capitalism".

Finally, during the late 1990s, a new consensus gradually emerged across Europe, largely irrespective of regime types and across partisan divisions. During the early 1990s, however, ideational dissent was still prevalent as the main prescriptions for reform were based on the results of the extensive OECD Jobs Study, conducted in the period 1992-1994. The OECD's message prioritised the reduction of unemployment through labour market deregulation and welfare retrenchment, which was justified by referring to the US with its seemingly stellar labour market, and embedded in the theoretical concept of NAIRU. Yet, moving to a USstyle labour market was not an option for most of the European political actors, especially the centre-left and allied labour unions. Even though left-leaning actors acknowledged that existing measures had failed to reduce, if not contributed to, large-scale and often persistent unemployment, recalibration rather than retrenchment of European welfare states was envisaged. Moreover, many European policymakers started to believe that unemployment was a European rather than a purely national issue during the 1990 os as the Maastricht Treaty consolidated the European single market and paved the way for the establishment of a common currency. In an attempt to establish an alternative way forward, the European Union members put forward the European Employment Strategy, which was modelled on the OECD, but was more inclusive, deliberative, and ambitious. The message of the EES - in contrast to the OECD JS - was not focused on deregulation and (only) reducing unemployment, but rather, on rebalancing welfare rights and responsibilities by turning overly passive welfare institutions into active ones. At that time, Denmark emerged as the new Nordic model state, while Tony Blair's Third Way philosophy inspired many reform-oriented policy makers across Europe. As such, it was Anglo-Nordic rather than US ideals that became the foundation for a new, decidedly European labour market policy paradigm.

More specifically, while both the UK and Denmark transformed their labour market policy regimes into very distinct models, they shared "activation" as a focal point, which was located somewhere between the Anglo-Saxon confidence in market mechanisms and Puritan ideals of self-reliance, and the Nordic emphasis on state interventions and social investments. Reviving, but also repackaging, old Swedish ideas associated with the "work line", labour market benefits should no longer be seen as a citizen's automatic right. Instead, recipients of benefits had an obligation to seek employment, participate in appropriate measures, and accept 
gainful employment whenever possible. The normative justification of this new "activation paradigm" was based on the abandonment of the social-democratic belief that the unemployed were "victims" of the market, a notion, which previously had "ruled out" any obligations for jobseekers. Social Democrats now accepted obligations, and even the application of sanctions, under the terms that mandatory activation measures were of high quality and welfare recipients were offered a "menu of options" from which they could choose. This rebalancing of welfare "rights" and "responsibilities" thus legitimised the continued existence of European welfare states, promised to make welfare states sustainable to future generations (which was an important aspect for centre-left politicians), and separated "deserving" from "undeserving" welfare recipients (which was dear to centre-right politicians). When both the EU and the OECD adopted the Anglo-Nordic concept of activation, these ideas were quickly diffused, accepted and internalised across Western Europe.

Part and parcel of the successful implementation of activation policies was also the modernisation of PESs, which entailed a focus on new business-like governance systems and improved and streamlined provision of services. In the broad context of New Public Management, PES reforms across Europe were conducted with similar goals, including making public services more effective, efficient and transparent. While the interpretation of NPM ideas was certainly contingent on specific historical trajectories and actor constellations, common trajectories nevertheless included a focus on performance management through the issuance of quantitative targets, quality management through the conducting of customer surveys and programme evaluation, case management codified in the widespread use of individualised action plans, and turning PESs into outward-looking organisations that collaborate more closely with relevant stakeholders, while increasingly relying on competitive bids to select third-party service providers.

Last, and in contrast to the beliefs held throughout the 1980 os and early 1990 s, the new "activation paradigm" brought an end to the belief that reducing unemployment could only occur by accepting lower employment levels. Instead, the new belief was that overall employment rates could and should be raised, thus activating not only the unemployed who received social benefits, but also a variety of other "inactive" people. Raising the overall level of employment in turn would stimulate job growth in the private sector as new services were needed, more money spent as more people had greater disposable incomes, and employers had a larger pool of available workers, which made the market more dynamic. In order to 
reach "inactive" persons, the functions of PESs were extended and labour market policy more systematically linked to family, education, old-age social security, immigration, and tax policy. This latter view is not limited to the EU, but the OECD also performed an ideological "turnaround" in the sense that its most recent series, including Babies and Bosses and Live Longer, Work Longer, propagate active state interventions - in contrast to market solutions - through the launch of comprehensive lifelong learning measures and the expansion of childcare places.

It is important to reiterate that this consolidated "activation paradigm" has led to both the convergence on a variety of ideas, measures, and instruments and the persistence of institutional differences, which is mostly visible with respect to positive and negative financial incentives. In other words, EU members continue to differ with respect to the generosity of their benefits - but increasingly less with respect to the duration of those benefits - as well as their choice of how to "make work pay". Institutional convergence, however, can be seen when considering most of the negative and positive non-financial incentives. Thus, a tighter, more conditional benefits regime has been coupled with efforts to modernise public employment services through a customer orientation and a business-like operation, as well as an expansion of the state's responsibilities by focusing on the prevention of (long-term) unemployment, active ageing, lifelong learning, and the expansion of childcare places. As such, the new paradigm is one that seeks to introduce market mechanisms into the operations of the state, while simultaneously also strengthening central policymakers' influence in new policy areas that were previously under the jurisdiction of municipal authorities or the social partners.

As such, even though European countries have not become identical and ideological differences persist with respect to the exact balance and combination of negative and positive incentives, the overall orientation of European labour market policy has been recalibrated along similar lines, with a shared understanding of the main problems facing European welfare states, and with the common goal to increase the overall level of employment in Europe. The common vision of a "European Social Model" is thus based on a new social contract that is explicitly re-commodifying, but one that also seeks to limit social hardship through enabling social policies and a more gender-neutral welfare state. The result is that neither a purely Nordic nor Anglo-Saxon model serves as the "focal point", but rather a mix of both worlds, adjusted for national specificities and problem situations. The table below summarises all three phases of institutional evolution identified in this book. 
Table 38 Evolution of European Labour Market Policy - Thought and Practice

\begin{tabular}{|c|c|c|}
\hline $\begin{array}{c}\text { Decade } \\
\text { (global economic } \\
\text { environment) }\end{array}$ & $\begin{array}{c}\text { Normative/Cognitive } \\
\text { Developments }\end{array}$ & Labour Market Policy \\
\hline $\begin{array}{l}\text { 1960s } \\
\text { (sustained econo- } \\
\text { mic growth; full } \\
\text { employment; era of } \\
\text { the "Golden Age" of } \\
\text { the welfare state) }\end{array}$ & $\begin{array}{l}\text { Dominant idea: } \\
\text { • Keynesianism } \\
\text { Main objective: } \\
\text { • Full employment } \\
\text { Main method:- } \\
\text { - Counter-cyclical macro-eco- } \\
\text { nomic demand management }\end{array}$ & $\begin{array}{l}\text { Emergence of Active Manpower } \\
\text { Policy (1950s and 1960s) } \\
\text { - Supplementary supply-side } \\
\text { instrument to aid with: } \\
\text { ○ Economic growth } \\
\text { - Industrial restructuring } \\
\text { - } \text { Bottlenecks of unemploy- } \\
\text { ment } \\
\text { - Individual mobility }\end{array}$ \\
\hline $\begin{array}{c}\text { 1970/80s } \\
\text { (oil crises trigger } \\
\text { global economic } \\
\text { downturn; era of } \\
\text { "stagflation") }\end{array}$ & $\begin{array}{l}\text { Dominant idea: } \\
\text { •Keynesianism challenged in } \\
\text { 1970s; emergence of moneta- } \\
\text { rism in 1980s } \\
\text { Main objective: } \\
\text { - Full employment (1970s) } \\
\text { gives way to price stability } \\
\text { (1980s) } \\
\text { Main method: } \\
\text { - Demand-management } \\
\text { (1970s) gives way to } \\
\text { structural reforms; compet- } \\
\text { ing strategies lead to the } \\
\text { divergence/consolidation of } \\
\text { regime clusters (1980s) }\end{array}$ & $\begin{array}{l}\text { Active Manpower Policy (1970s) } \\
\text { turns into Active Labour Market } \\
\text { Policy (1980s) } \\
\text { - New remit for labour market } \\
\text { instruments: } \\
\text { o Fight mass unemployment } \\
\text { ○ Expansion of public work } \\
\text { projects } \\
\text { ○ Expansion of wage/em- } \\
\text { ployment subsidies } \\
\text { o More training, specifically } \\
\text { for the unemployment } \\
\text { - Introduction of demand- } \\
\text { reducing measures (early reti- } \\
\text { rement, disability pensions) }\end{array}$ \\
\hline $\begin{array}{c}\text { 1990/2000s } \\
\text { (end of Cold War; } \\
\text { era of "permanent } \\
\text { austerity") }\end{array}$ & $\begin{array}{l}\text { Dominant idea: } \\
\text { - Pure form of monetarism not } \\
\text { accepted, search for "Euro- } \\
\text { pean Social Model” } \\
\text { Main objective: } \\
\text { - Hard currency plus high } \\
\text { employment rates and social } \\
\text { cohesion } \\
\text { Main method: } \\
\text { - EMU (1990s) plus activation, } \\
\text { PES service model, and state- } \\
\text { led strategy to make labour } \\
\text { markets more inclusive } \\
\text { (2000s) }\end{array}$ & $\begin{array}{l}\text { Activating Labour Market Policy } \\
\text { (since mid to late 1990s) } \\
\text { - Prevention of long-term } \\
\text { unemployment through } \\
\text { early interventions, individu- } \\
\text { alised case management and } \\
\text { more benefit conditionality } \\
\text { - Focus on the provision of } \\
\text { proper incentive structures \& } \\
\text { customer orientation } \\
\text { - Enhanced scope (activation } \\
\text { is placed at the nexus of } \\
\text { welfare and work, including } \\
\text { tax, family, education, and } \\
\text { welfare policy) } \\
\text { - Enhanced reach (unemploy- } \\
\text { ed plus "inactive" persons }\end{array}$ \\
\hline
\end{tabular}




\section{VIII.2 What Impact, if any, have the Recommendations of International Organisations such as the OECD and the EU had on National Reform Agendas?}

Many researchers are sceptical about the impact of "soft" mechanisms for the co-ordination of European public policy. The common argument is based on the assumption that actors do not care about soft mechanisms because they are not legally enforceable or binding and thus, policymakers have no incentives to pay any attention to them (e.g., Schäfer 2004; 2005; Idema and Kelemen 2006; Büchs 2007; Citi and Rhodes 2007; Hartlapp 2009; Kröger 2009). Likewise, many interviewees have argued that the impact of the EU/OECD's peer review processes has been limited, and if a convergence were to occur, these trends would have emerged even in the absence of international deliberations.

In this book, I have presented theoretical and empirical reasons why we should be sceptical about this kind of claim. Theoretically, I have argued that policymakers are often engaged in exercises of "puzzling". In other words, policymakers are often confronted with problems for which no clear-cut solutions are easily identifiable, and likewise, the outcomes and consequences of reform proposals are not predictable. Accordingly, learning from - and with - other policymakers, facing, or having faced, similar challenges becomes a desirable strategy (cf., also Visser and Hemerijck 2003; Hemerijck 2007). With respect to policies located at the work-welfare nexus, the OECD offers a wide variety of reports, including, but not limited to the Economic Outlook, the Employment Outlook, Country Notes and Reports, and specialised series such as Babies and Bosses or Live Longer, Work Longer, which are not only valuable sources for new ideas, but also, and perhaps more importantly, provide "evidence-based" empirical findings, which reform-minded policymakers can utilise to legitimise their legislative proposals. ${ }^{1}$ In turn, the EU peer-review mechanisms associated with the EES, including the multi-annual meetings in EMCO, the bi-annual meetings in HoPES, and the thematic meetings via the Mutual Learning Process, have been fruitful forums for social learning and policy diffusion (e.g., Zohlnhöfer and Ostheim, 2005; Nedergaard 2006; Heidenreich 2009; López-Santana, 2009; Weishaupt 2009; 2010a; Zeitlin 2005a; 2009). In contrast to Schäfer, who argues that scholars such as Jonathan Zeitlin "fail to recognise the limitations of deliberation" in the EU (2005, 16, my translation), I have shown precisely the opposite. More specifically, I have made the case that the "ideas" travelling back and forth from national capitals to Brussels and Paris had a substantial 
impact on national debates, political agendas, and actual policy outputs. In particular, it is the EES that has been singled out as a particularly helpful device for "systematised learning". This is to say, while members were already exchanging ideas and best practices prior to the Luxembourg Process, it is "no longer ad hoc; it is now a formalised process" (interviews, BMAS4, BMAS6), which has helped shift "perspectives on problems and solutions" (interviews, AK, BMAS4, IHS2, DETE2).

Admittedly, because policymakers like to claim "ownership" for new legislation, they often do not admit that they have "learned" from others. This poses somewhat of a challenge for researchers, who - like myself trace the occurrence of policy diffusion and social learning. To illustrate this fact, a common response by policymakers in many of my interviews has been: "We don't need someone in Brussels [or Paris] to tell us what to do. We can think for ourselves". However, the empirical trajectory, i.e., the significant congruence between what the EU/OECD have suggested as "good practices" and what policymakers have articulated as their policy goals or even adopted as policy instruments, tells a different story. The EES - and, I would add, the OECD - have not only "raised the political salience and ambitions of employment and social inclusion politics at the national as well as the EU level", they have also "contributed to broad shifts in national policy orientation and thinking, involving the incorporation of EU [and OECD] concepts and categories into domestic debates" (Zeitlin 2005a, 45of). The most obvious examples for such shifts in policy orientation and thinking include locating the causes of unemployment in structural features of labour markets (which necessitates supply-side responses); accepting mutual obligations (which runs counter to earlier beliefs that unemployment is largely outside of individuals' control); and focusing on raising employment levels (which contradicts earlier preferences for a reduction of demand as a means to reduce unemployment).

In turn, frequently used concepts and categories are activation, "the PES service model”, gender mainstreaming, active ageing, lifelong learning, and most recently, flexicurity. The use of, and reference to, these concepts has substantially shaped national debates and has triggered, inter alia, the introduction of a variety of activating labour market polices, PES reform, the extension of the quality and availability of (public) childcare, and the improvement of employment opportunities for women and older workers. Even if policymakers were not interested in advancing these issues, they could no longer simply ignore the international discourses or OECD/EU recommendations. As one interviewee (Metall NRW) stated and many others confirmed - policymakers cannot "discuss these debates 
away". As such, the room to manoeuvre has become more restricted than before and passing legislation that runs against EU/OECD recommendations has become more difficult, but - of course - not impossible.

In conclusion, it is important to reiterate that the deliberations at the EU/OECD level are not designed as processes in which "Brussels bureaucrats" or "Paris technocrats" lecture Member States on how to run a national economy or welfare state. Instead, the processes of peer-review need to be seen as opportunities for Member States who want to learn from one another (interview, DGEmpl3). In other words, if Member States can be "persuaded" about the appropriateness, necessity, and/or viability of "good practices" found in other Member States, emulation will follow. That the recommendations can serve as inspiration for domestic reformers has been confirmed in a variety of interviews (interviews, AK, BMAS6, and CDI). This works through open deliberations and the unrestricted flow of ideas, both vertically, i.e., as a "two-way interaction" between national policymakers and officials at the respective international organisations (cf., Zeitlin 2007), and horizontally, i.e., as a "level-field interaction" among policymakers and experts gathered at roundtables, such as EMCO or HoPES. In these deliberations the EU [and presumably the OECD] see their members' institutional diversity as representing a "natural laboratory for policy experimentation" (Mario Joao Rodrigues, cited in Zeitlin 2003, 17), from which particular experiences in some states are brought to the attention of others.

\section{VIII.3 Have Recent Reform Activities, in the Context of the OECD Jobs Study and the EES, Fundamentally Transformed the Historic Composition of National Labour Market Policy Regimes, and if so, to What Effect?}

The trajectory outlined throughout this book suggests that, during the 1970/8os, three readily identifiable regime clusters emerged in the European context, centred on Sweden, Germany, and the UK. These clusters were analytically distinguishable because they differed on their ideational underpinnings and their main institutional configurations. More specifically, the Nordic cluster combined the universality principle (generous access to welfare services - including ALMPs - based on citizenship, financed mainly by general taxation), the equity principle (achieving social homogeneity, while not tolerating social exclusion), the dual breadwinner norm (high and voluntary female labour market participation, encour- 
aged by access to public childcare and individual tax bands), and the partnership norm (involving the social partners in labour market policymaking and implementation).

The Continental cluster, in turn, combined the insurance principle (access to welfare services - including ALMPs - based on contributory history), the equivalence principle (the welfare state preserves workers' - and their dependents' - status in case of job loss), the male breadwinner norm (low female labour market participation mainly due to lack of childcare support and unaccommodating school and store hours, supported by generous and long maternity leave schemes), and the partnership norm (involving the social partners in labour market policymaking and implementation).

Finally, the Anglophone cluster combined a weak universality principle (universal access to flat-rate income support at a low level and weakly institutionalised ALMPs, financed mainly by general taxation), the market principle (individuals are responsible for their own fate), the male breadwinner norm (low female labour market participation mainly due to lack of childcare support), and weak social partnership (social partners increasingly excluded from policymaking and "free-for-all" expectations predominate in wage-setting negotiations).

In the 1990s, and even more so in the early 20oos, however, most of these regime-typical principles were challenged through the spread of the "activation paradigm". In the Nordic cluster, the revisiting, consolidation, and spread of such ideas have accelerated a variety of market-type reforms with the aim to improve both the efficiency and effectiveness of labour market programmes. Most notably since the inception of centre-right governments in both Denmark and Sweden, major institutional changes have taken place that are typically associated with the Anglophone cluster: (1) benefits conditionality has been tightened and a tougher "work-first" approach is increasingly acceptable; (2) ALMPs have been recalibrated by reducing the use of demand-side measures and curtailing the availability of extensive training measures, while increasing "make work pay" instruments through the tax system; (3) the influence that the social partners have on labour market policymaking has been severely weakened; and (4) PESs have been exposed to more competition in awarding contracts for the implementation of various services and programmes. Accordingly, the universality principle has seen a shift from "education first" to "work first", the equity principle has been somewhat compromised in favour of the Anglophone market principle, and the social partners - in particular the unions - are increasingly "on the defensive". 
In turn, the Anglophone countries have moved toward the Nordic cluster. Most notably, there has been a move away from "residual universalism" and toward "selective universalism". More specifically, by substantially reforming the tax and benefits systems, and introducing a national minimum wage in both Ireland and the UK, a "life on benefits" has become less attractive than (low-wage) work, which is subsidised through tax credits and other transfer payments. Moreover, access to free in-work training has been introduced through the One Step Up scheme in Ireland and Train to Gain in the UK. In other words, for those who can participate in the workforce, new universal programmes have become available, while the welfare state for the jobless has remained limited. Likewise, both countries - in particular Ireland - have improved relations with the social partners. While Ireland has moved to a system in which the social partners are involved in every major decision with regard to the labour market, the UK has also shown significant improvements, most noticeably in the creation of the Minimum Wage Commission, in which both the TUC and CBI are represented. Finally, both Ireland and the UK have launched national childcare strategies with the dual objective of reducing child poverty (which constitutes a move toward a more equitable society) and improving female employment rates (which is a necessary condition for the establishment of a dual breadwinner norm). Clearly, these developments have become possible because centre-left parties (Fianna Fáil and New Labour) have been in office over the past decade, but they certainly also reflect their respective governments' ambition to approximate a Nordic welfare model.

Finally, the Continental cluster shows an institutional pathway that effectively combines Anglophone and Nordic elements, while retaining other regime-typical features. Both the insurance and the equivalence principles have become increasingly challenged. In a "negative" sense, the increase in benefits conditionality and the substantial reduction in UB duration in Germany forces workers to accept work not only faster, but also to possibly accept significant pay cuts. This change therefore brings Austria and Germany closer to Anglophone market principles because the workers' insurance history and status are less important than before. In a "positive" sense, however, Austria has dramatically increased its ALMP expenditures, while Germany's Hartz reforms permit former SA recipients to access most of the ALMPs, previously only available to insured workers. In this sense, Germany has moved a small step toward universalism, while Austria's labour market interventions help to foster a more equitable society. Moreover, the male breadwinner norm was - more recently - chal- 
lenged by both countries' ambition to substantially improve childcare infrastructures (for Austria, see also Weishaupt 2009). Both countries largely followed a similar strategy in which the national government provided large amounts of "seed money" to local authorities, thus enabling them to create new childcare places, expand pre-school hours, and hire new teachers and childminders. In Germany, this trend was first initiated by the Social Democrats, but subsequently extended by the Christian Democrats. In Austria, in turn, such changes could only be introduced after the government reshuffle in 2006, which brought the Social Democrats back into office.

These findings therefore suggest that constitutive elements in all of the "worlds of welfare capitalism" have been weakened in recent years. While welfare states continue to differ in many respects, they increasingly share common ideas and ideals, institutional differences across clusters are less sharp, and reforms are less regime-specific in character. At least with respect to their labour market policy regimes, it is thus argued that welfare states have undergone a process of hybridisation that was triggered and accelerated by the emergence of the common "activation paradigm". Accordingly, I concur with Colin Crouch, who argues - by referring to Zeitlin (2003) - that regime typologies are unnecessarily static and rigid, which, in turn, "render[s] learning almost impossible" (Crouch 2005, 31). Instead of "labelling" individual country cases as examples of certain theoretical models, while considering all those features which do not fit as noise (Crouch 2005, 69), Crouch suggests an analytical approach that is able to capture empirical diversity by considering "to what extent each of a series of models can be found within [each] case" (Crouch 2005, 68). With this book, I hope I have taken the first step toward that goal. I have corroborated the existence of three "models" that crystallised in the 1970/80s, while admitting, however, that these "models" were not perfectly homogenous. I have also identified each of these models' constitutive pieces, organised along four principles/norms. And finally, I have shown how innovative actors have combined various elements of these models in new ways throughout the 1990 os and early 2000 .

\section{VIII.4 Reactions to the Global Financial and Economic Crisis and the Future of the Activation Paradigm}

The financial and economic crisis that began in 2008 has confronted $\mathrm{Eu}-$ ropean welfare states with the most severe employment challenge since the 1970s. In particular, the most deregulated labour markets in this study, 
including Denmark, Ireland, and the UK, have seen the most drastic and most rapid rise in unemployment. But also Sweden has seen a substantial increase in unemployment numbers, despite its regulated labour market. Austria and Germany, in turn, have been able to minimise job losses, at least at the time of writing. The following table summarises recent trends in unemployment levels in Austria, Denmark, Germany, Ireland, Sweden, and the UK.

Table 39 Harmonised Unemployment Rate as Percentage of Civilian Labour Force, 2008 through 2009, Quarters

\begin{tabular}{|c|c|c|c|c|c|c|c|c|}
\hline & $\begin{array}{c}Q-1 \\
2008\end{array}$ & $\begin{array}{c}Q-2 \\
2008\end{array}$ & $\begin{array}{c}Q-3 \\
2008\end{array}$ & $\begin{array}{c}Q-4 \\
2008\end{array}$ & $\begin{array}{c}Q-1 \\
2009\end{array}$ & $\begin{array}{c}Q-2 \\
2009\end{array}$ & $\begin{array}{c}Q-3 \\
2009\end{array}$ & $\begin{array}{c}Q-4 \\
2009\end{array}$ \\
\hline AT & 4.2 & 3.5 & 3.7 & 4.0 & 4.7 & 4.6 & 5.1 & 5.3 \\
\hline $\mathrm{BE}$ & 7.1 & 6.3 & 7.7 & 6.8 & 7.9 & 7.5 & 8.2 & 7.9 \\
\hline DK & 3.3 & 3.0 & 3.4 & 3.5 & 5.2 & 6.0 & 6.1 & 6.7 \\
\hline $\mathrm{FI}$ & 6.7 & 7.3 & 5.6 & 6.0 & 7.6 & 9.6 & 7.5 & 8.2 \\
\hline FR & 7.8 & 7.4 & 7.6 & 8.3 & 9.3 & 9.2 & 9.4 & 10.0 \\
\hline $\mathrm{DE}$ & 8.0 & 7.5 & 7.0 & 6.8 & 7.8 & 7.5 & 7.5 & 7.1 \\
\hline GR & 8.3 & 7.2 & 7.2 & 8.0 & 9.4 & 8.9 & 9.3 &. \\
\hline $\mathrm{IE}$ & 4.7 & 5.2 & 6.7 & 7.5 & 10.1 & 12.0 & 12.6 & 12.5 \\
\hline IT & 7.0 & 6.7 & 6.1 & 7.0 & 8.0 & 7.3 & 7.3 & 8.8 \\
\hline NL & 3.1 & 2.8 & 2.5 & 2.6 & 3.2 & 3.2 & 3.5 & 3.9 \\
\hline PT & 7.8 & 7.4 & 7.8 & 8.0 & 9.0 & 9.3 & 10.0 & 10.3 \\
\hline ES & 9.6 & 10.4 & 11.3 & 13.9 & 17.4 & 18.0 & 17.9 & 18.9 \\
\hline SE & 6.3 & 6.7 & 5.6 & 6.1 & 7.9 & 9.0 & 8.1 & 8.2 \\
\hline UK & 5.1 & 5.2 & 6.0 & 6.2 & 7.1 & 7.6 & 8.0 & .. \\
\hline
\end{tabular}

Source: OECD.stat accessed on 12 March 2010

The extremely rapid and unexpected increase in unemployment - after many years of employment growth - is a particularly striking consequence of the crisis. In the UK, for instance, the Guardian reported on 17 April 2008 the UK's lowest unemployment claimant count of 794,300 since 1975 (Seager 2008). Yet, almost exactly one year later, on 23 April 2009, Chancellor of the Exchequer Alistair Darling had to signal that the jobless queue would almost quadruple to more than "three million by the end of next year" (Elliott 2009). Likewise, in Ireland, the spring of 2008 seemed promising, and ESRI, the Economic and Social Research Institute, predicted that Ireland would "outperform" its EU neighbours and foresaw a "strong economic rebound in 2010 " with economic growth rates 
above five percent (Tansey 2008). However, already by the fall of 2008 , the economic climate had significantly changed as a collapse of the construction sector and a dramatic fall in exports triggered a decline in employment and consumer spending (NESC 2009). For the first time since 1983, employment contracted at the same time as unemployment increased sharply, tax receipts declined, and the national budget deficit threatened to double in 2010 (Smyth 2008; Irish Times 2008). By spring 2009, the government faced a money market in turmoil, a dried-up financial sector, a burst housing bubble, unemployment in double digits, and collapsing tax revenues.

The two Anglophone countries reacted, however, rather differently to the crisis. The Brown government in the UK issued a massive stimulus package that was designed to "rescue" the financial sector, unfreeze credit markets, and cushion the effects of the housing crisis. With respect to the labour market, Brown announced a moratorium on planned JobCentre Plus closures and promised more money for frontline staff (Economist 2008). A package worth three billion pounds followed, which included more generous contracts to providers of the Flexible New Deal - who had threatened to pull out of the scheme as they are only paid when they place jobseekers into jobs - additional resources for JCP to hire more personnel and open longer hours, recruitment subsidies for firms that employ 18 to 24-year olds who had been out of work for more than 12 months, and direct job-creation measures with the aim to generate 250 , ooo jobs over the following two years (Elliott 2009). As such, the government expanded both supply-side instruments that are designed to assist jobseekers to find available jobs whenever possible, and demand-side ones, which are intended to keep jobseekers attached to the labour market.

The Irish government's primary concern, in turn, was to convince international creditors that the solvency of the state was not at risk. Accordingly, the government issued tough budget consolidation measures through job and expenditure cuts in the public sector, large-scale savings in public programmes, tax increases and new levies on insurance policies (Collins et al. 2009). In contrast to the UK - and many other European governments - Ireland aimed to save billions in public expenditures and remained hesitant - or perhaps unable - to expand labour market programmes, which resulted in hefty criticism from the opposition, business groups and labour unions as the government was perceived to not adequately address the unemployment crisis (Slattery 2009). As unemployment continued to soar, the NESC produced a strategy report in March 2009 which called upon the government to - inter alia - "stimulate the 
creation of '21st century' equivalents to the special labour market programmes that were introduced in the late 1980 os and early 1990s"(NESC 2009, xiii). While a large-scale response by the government did not follow, various (small) steps were taken in the subsequent months. In April, the government unveiled an emergency budget in response to the country's deteriorating finances, which included "an Enterprise Stabilisation Fund to help protect jobs" (Dobbins 2009a). The Enterprise Stabilisation Fund would then support 181 projects throughout 2009, supporting approximately 7,500 jobs (Éireann 2010). During the summer, the government also outlined plans to launch a Temporary Employment Subsidy Scheme - funded through the European Commission - which would provide support to companies in their attempts to retain workers. Further measures included the Employer Jobs Incentive Scheme, through which companies recruiting a person who had been unemployed for at least six months would be exempt from paying payroll taxes (PRSI) for the first year of that employment. The government then also introduced a "short-time work" scheme - supported through the European Social Fund - where workers work for three days and receive unemployment benefits and training for two days each week for up to one year (Dobbins 2009b; OECD 2009b, 8). Additional resources were also made available to enable FÁS to double job-search support, to expand existing skills-enhancing programmes from 66,000 places in 2008 to 130,000 in 2009 , and to immediately rather than after three months - "activate" young jobseekers aged 18 or 19 (Éireann 2010; see also OECD 2009b, 13).

In the Nordic cases, the crisis first and foremost spurred new debates about the Swedish and Danish currencies' volatility and the prospects of joining the Eurozone. In Denmark, the Danish National Bank had to intervene in the foreign-exchange market to counter speculative attacks on the krone, which resulted in higher interests rates. Higher interest rates, in turn, were translated into higher mortgages and credits for the Danish people (Pop 2008). As Denmark had been able to generate budget surpluses for the past 13 years (Copenhagen Post 2009), the government could issue two bailout programmes for banks in January 2009, press on with its plans to cut taxes, while putting forward various, albeit moderate, measures to cope with employment losses. In contrast to most other European countries, Denmark did not make "any arrangements of direct support to firms which are at risk of having to reduce employment" (Stuvøy and Jørgensen 2009). The main instrument to "bridge" months of low productivity due to weak demand was a "work-sharing" scheme, which was limited to a maximum of two periods of 13 weeks. A worker who is 
placed on "work-sharing" is paid by the company during working days and receives unemployment benefits - if a member of an UI fund - or means-tested social assistance otherwise during days without work. The government also pushed the activation threshold for jobseekers under the age of 30 forward from six to three months (OECD 2009b, 12), and "automatically" increased its expenditures on ALMPs. ${ }^{2}$ Last, the government also increased funding for the further training of employed workers, enabling them more and faster access to such measures. This has been welcomed by employers, who are now able to utilise this time by training their workers "after a long period of a high demand in the market" where this type of opportunity had not presented itself (Stuvøy and Jørgensen 2009).

Sweden's conservative government, in turn, reacted in as early as December 2008 with Europe's most extensive - in relative terms - stimulus package (Gamillscheg 2008). The automobile industry, however, did not receive any special state aid - which is in stark contrast to Austria and Germany. Instead, the automobile and other industries only received "rescue loans" to facilitate the economic restructuring or liquidation plans of adversely affected companies. More direct state support was issued in the form of a massive tax reduction for the construction sector, allocating $€ 92$ million for the restoration of roads and railways, and channelling more money to local governments to avoid redundancies in the public sector (Lovén 2009). These efforts to prevent job losses were coupled not only with decreases in payroll taxes and the introduction of other tax cuts to stimulate job creation through the Spring Fiscal Policy Bill of 2009, but also with the expansion of labour market policy programmes. More specifically, the government provided additional resources to the PES, increased the number of places available in work-placement schemes, initiated an expansion of education and training measures, appointed regional "coordinators" to promote regional co-operation when redundancy notices were issued, and introduced new "coaching" measures that involve private placement agencies with the aim of improving job-placement and counselling services (Government of Sweden 2009; see also OECD 2009b, 15).

The reactions to the crisis in the two Continental cases were very similar. Both countries started in fairly good condition. German employment levels were at an all-time high in 2008, while Austria had reached full employment with an unemployment rate below four percent. Both countries had been pursuing balanced budgets, and in both cases, grand coalitions had been formed between Christian Democrats and Social Democrats, internalising major political conflicts. In both cases, the governments 
reacted with extensive economic stimulus packages - roughly the same size, relatively speaking - which combined (payroll) tax cuts with public investments into education, infrastructure and public housing. In both countries, with Germany leading the way and being more generous, the government also provided financial incentives for the purchase of new cars (Der Standard 2009). With respect to labour market policies, both countries increased their budgets for ALMPs, hired new PES staff to cope with the increased demand, and created incentives for companies to recruit/retain apprentices. The main instrument, however, was the "shorttime work" measure (Kurzarbeit), which allowed companies to reduce the working hours of their workers, while the PES (partially) compensated these workers for loss of income. The duration a worker can be employed as a "short-time worker" was temporarely lengthened in both countries from three and six months in Austria and Germany to 18 and 24 months respectively. In both countries, these "short-time workers" could utilise their newfound "spare" time to invest in their vocational skills. This extra training was subsidised via the ministry of employment. The Kurzarbeit measure in both countries was clearly the governments' most important instrument to avoid major job cuts.

This admittedly brief overview shows that neither the "activation paradigm" nor the "PES service model" has become obsolete since the crisis. In fact, no European country has relaxed activation requirements, while some - predominantly Denmark and the UK - have actually increased the activation threshold for young workers (cf., OECD 2009a; 2009b). Both the European Commission and the OECD have repeatedly stressed the reinforcement rather than the easing of activation measures (e.g., Commission of the European Communities 2009; OECD 2009a, 2009c), and the overall focus of national governments has been to "maintain the course" with respect to labour market policy and to minimise the loss in overall levels of employment. There has not been any noticeable trend of rebalancing ALMPs in favour of passive programmes, and demand-reducing ALMPs continue to be rare. Instead - and in stark contrast to the years following the oil crises - most governments have attempted to "bridge" the cyclical downturn through a shortening of working hours, stimulating employment growth through tax cuts, and improving job prospects of (low-skilled) workers through better access to education and training programmes.

Overall, there is reason to be optimistic. European labour markets entered the crisis with significantly higher levels of employment than ever before, healthier levels of debt, and low levels of inflation due to the Sta- 
bility and Growth Pact. Moreover, policymakers have focused on qualifications measures to improve the vocational skills of workers, and "activation blueprints" have been prepared for when the economy rebounds and new jobs become available. When the recession ultimately comes to an end, the economic recovery will probably be more rapid and the longterm financial costs to the welfare state will be less severe than in the 1980 . 


\section{List of Interviews and Personal Conversations}

In Chronological Order, by Country'

\section{Austria}

WIFO Researcher at Institute for the Study of the Economy (WIFO); Section for Labour Market, Income and Social Policy, 4 June 2007.

IHS1 Researcher at the Institute for Graduate Studies (IHS); Centre for Employment, Qualifications, and Innovation (EQUI), Vienna, 4 June 2007.

AMS Public Employment Service (Arbeitsmarktservice); Head of Labour Market Board, 6 June 2007.

BMWA1, 2 Two representatives of the Ministry for Economics and Labour; Labour Market Division (II/5), 6 June 2007.

ÖGB Austrian Labour Union Federation (ÖGB); Division for Labour Market and Education Policy, 8 June 2007.

WKÖ1 Chamber of Commerce (City of Vienna); Division for Social Policy, 8 June 2007.

IHS2 Researcher at the Institute for Graduate Studies (IHS); Department for Economics and Finance, Vienna, 11 June 2007.

WKÖ2 Representative of Chamber of Commerce (National); Division for Social and Health Policy, 13 June 2007.

BMWA3 Representative of the Ministry for Economics and Labour; Labour Market Division (II/10), 14 June 2007.

AK Representative of Austrian Chamber of Labour; Division for Employment Policy, 15 June 2007.

BMWA4 Representative of the Ministry for Economics and Labour; Labour Market Division (II/3), 15 June 2007. 


\section{Germany}

SPD1 Representative of the German Social Democratic Party (SPD); Chair of BAG-IF (sheltered employment for people with disabilities), Cologne, 15 March 2007.

HBS Representative of the Hans-Böckler Foundation; Researcher in Economics and Social Policy Division, Düsseldorf, 28 March 2007.

BMAS1 Representative of the Federal Ministry for Labour and Social Affairs (BMAS); Labour Market Division (IIa1), Berlin, 3 April 2007.

BDA1, 2 Two representatives of the Confederation of German Employers (BDA); Labour Market and Social Policy E Labour Law, Berlin, 3 April 2007.

SPD2, 3 Two representatives of the German Social Democratic Party (SPD), Berlin, 4 April 2007.

WZB1 Senior Researcher at the Social Science Research Centre Berlin; Division for Labour Market Policy, Berlin, 4. April 2007.

Metall NRW Employers' Association for Metal Firms, North-Rhine Westphalia; Division for Labour Market Policy, Düsseldorf, 10 April 2007.

BMAS2 Federal Ministry for Labour and Social Affairs (BMAS); Labour Market Division and rotating EMCO member, Bonn, 11 April 2007.

CDU1 Representative of the German Christian Democratic Party (CDU); former regional government minister, Bonn, 16 April 2007.

INFAS Institute for Applied Social Sciences; Labour Market Policy Evaluations, Bonn, 16 April 2007.

DGB1 German Labour Union Federation; Regional Chair for Köln, Leverkusen, Erft, Berg, Cologne, 24 April20o7.

IQA Researcher at the Institute for the Quality of Work; Division for Labour Market Policy, Gelsenkirchen, 3 May 2007.

DST German Assembly of Cities (Deutscher Städtetag); former Chair, Cologne, 3 May 2007.

DHIK German Chamber for Industry and Trade (DIHK); Division for Labour Market and Immigration, Berlin 23 May 2007. ZDH German Confederation of Skilled Crafts (ZDH); Division for Social Security, Berlin, 23 May 2007. 
BMAS3 $_{3} \quad$ Federal Ministry for Labour and Social Affairs (BMAS); European Employment and Social Policy, Berlin, 24 May 2007 and 17 January 2008.

WZB2 Senior Researcher at the Social Science Research Centre Berlin; Division for Labour Market Policy, Berlin, 24 May 2007.

DGB2 German Labour Union Federation (national representative); Labour Market Division, Berlin, 24 May 2007.

BMAS $_{4} \quad$ Representative of the Federal Ministry for Labour and Social Affairs (BMAS); Labour Market Policy Division, Berlin, 25 May 2007.

Ver.di1 United Service Sector Union; Division for Social Policy, Berlin 25 May 2007.

IZA Researcher at the Institute for the Study of Labour, Division for Labour Market Policy, Bonn, 30 May 2007.

BA1 Federal Employment Agency (BA), International Relations, Nuremberg, 14 January 2008.

BA2 Representative of the Federal Employment Agency (BA), Division Social Code Book II, Nuremberg, 15 January 2008.

SPD4 Representative of the German Social Democratic Party (SPD), Parliamentary Group, Working Group on Labour Market and Social Policy, Berlin, 17 January 2008.

Ver.di2 United Service Sector Union; Division for People Without Incomes, Berlin 17 January 2008.

BMAS5 $_{5}$ Representative of the Federal Ministry for Labour and Social Affairs (BMAS), Labour Market Division, IIa4 (Women's issues), Berlin, 17 January 2008.

\section{Ireland}

DETE1 Department for Enterprise, Trade and Employment (DETE); Labour Market Policy Division (European Employment Strategy), 12 April 2006.

ICTU1 Irish Congress of Trade Unions (ICTU); Research Officer, Labour Market and Social Policy, 17 April 2006.

UCD1 Professor at University College Dublin (UCD); School for Politics and International Relations, 13 April 12006, 27 April 2006, 28 February 2007, and 9 January 2008. 
NESC National Economic and Social Council (NESC); Director, 18 April 2006 and 27 February 2007.

CORI Conference of Religious of Ireland (CORI); Justice Division, 19 April 2006.

INOU1 Irish National Organisation for the Unemployed (INOU), 24. April 2006.

IBEC Irish Business and Employers Confederation (IBEC), Senior Economist, 25 April 2006 and 28 February 2007.

MIN Former Minister (DEE and Finance), currently Member of Parliament, Labour Party, telephone interview, 15 May 2006.

YOUTH Representative of Department of Education, Division Youthreach, 26 February 2007.

FÁS1, 2 Two representatives of FÁS, Employment Services/Social Inclusion Division \& Research Unit (Skills and Labour Market), February 27, 2007; FÁS1 again on 8 January 2008.

TRIN Lecturer at Trinity College, 28 February 2007.

DETE2 Department for Economy, Trade and Employment (DETE); Labour Market Division, 1 March 2007.

FÁS 3,4 Two representatives of FÁS, both Research Unit (Skills and Labour Market), 1 March 2007.

$\mathrm{ICTU}_{2} \quad$ Irish Congress of Trade Unions (ICTU), 1 March 2007.

FÁS $_{5}$ Two representatives of FAS, Local Employment Services

Division, 8 January 2008 (accompanied by FÁS1).

UCD2 Professor at University College Dublin (UCD), Michael

Smurfit School of Business, 8 January 2008.

INOU 2 Irish National Organisation for the Unemployed (INOU), 9 January 2008.

UK

LSE Professor at London School of Economics and Political

Science (LSE), Department of Political Science, 2 May 2006.

TUC1 Trade Union Congress, Division for New Deal, 3 May 2006.

BE $\quad$ Bank of England, Monetary Policy Committee, 3 May 2006.

DWP1 Department for Work and Pensions (DWP), New Deal, Phone Interview, 12 May 2006.

HMT HM Treasury, 8 May 2007.

DWP2 Department for Work and Pensions (DWP), Senior Economist, 8 May 2007. 
DWP, 4 Two representatives of the Department for Work and Pensions (DWP), Skills Unit, 9 May 2007.

DWP5 Representative of DWP, Economics and Labour Market Division, May 9, 2007 and 10 January 2008.

IES1 Researcher at the Institute for Employment Studies, Skills and Training, Brighton, 10 May 2007.

UO1 Professor at University of Oxford, 14 May 2007.

$\mathrm{UO}_{2} \quad$ Professor at University of Oxford, 14 May 2007.

CESI Centre for Economic and Social Inclusion (CESI), Director, 16 May 2007.

DfES Department for Education and Skills (DfES), Skills Division, Phone Interview, 18 May 2007.

IES2 Researcher at Institute for Employment Studies, New Deal, Brighton, telephone interview, 18 May 2007.

JCP1, 2 Two representatives of JobCentre Plus (JCP), one of them via a conference call, 10 January 2008.

\section{Denmark}

CARMA Senior researcher at Centre for Labour Market Research (CARMA) at Aalborg University, telephone conversation, 20 August 2009.

\section{Sweden}

SOFI1 Two researchers at Institute for Social Studies (SOFI), personal conversation, Stockholm, 8 May and 28 May 2008.

PES-SE1 Senior civil servant at the Swedish Public Employment Service (AF), International Relations, Stockholm, 11 August 2009.

DEMPL Two senior civil servants at the Ministry for Employment, Division for Labour Market Policy, Stockholm, 17 August 2009.

IFS Senior researcher at the Institute for Futures Studies, personal conversation, Stockholm, 18 August 2009.

CSE Representative of the Confederation of Swedish Enterprise, Stockholm, 19 August 2009.

PES-SE2 Two civil servants at the Swedish Public Employment Service (AF), Stockholm, 20 August 2009. 
SOFI2 Senior researcher at Institute for Social Studies (SOFI), personal conversation, 21 August 2008.

VÄXJÖ Senior researcher at Växjö University, School of Health Science and Social Work, and senior researcher from Uppsala University, personal conversation, Stockholm, 14 August 2009.

\section{European Union}

CDI Country Desk Officer, Ireland, 21 May 2007.

CDA Country Desk Officer, Austria, 22 May 2007.

DGEmpl1 DG Employment, Social Affairs \& Equal Opportunities, Social Protection Committee, 29 October 2004; personal conversation, Madison, Wisconsin, USA.

DGEmpl2 Representative of DG Employment, Social Affairs \& Equal Opportunities, 22 May 2007.

DGEmpl3 Representative of DG Employment, Social Affairs \& Equal Opportunities, Employment Strategy Unit, 9 July 2008.

EMCO1 Formerly member of EMCO \& Representative for Germany, 29 October and 2 November 2004; personal conversations, Madison, Wisconsin, USA.

$\mathrm{EMCO}_{2} \quad$ EMCO and DG Employment \& Social Affairs \& Equal Opportunities representative, 21 May 2007 


\section{Notes}

\section{Chapter I}

1 Following Esping-Andersen $(1987,6)$, I define a policy regime as "the specific institutional arrangements adopted by societies in the pursuit of work and welfare".

2 The latter term is borrowed from Friedman (2000).

3 The separation of policy changes into cognitive shifts, political (i.e., agenda) shifts, and policy shifts was inspired by a presentation by Jonathan Zeitlin (see also, Zeitlin 2009).

4 In the European context, Sweden is also identified as a NPM frontrunner. When the Social Democrats returned to office in 1982, their self-proclaimed goal was to reform the public administration that was seen as "too slow, too rigid, too centralized, too large, and too bureaucratic" through decentralization, deregulation, and delegation/devolution. (Forssell 2001, 269-274). Likewise, the Swedish PES was restructured by Allan Larsson in the mid-1980s through the introduction of $\mathrm{MBO}$ techniques and and decentralization (cf., http://www.arbetsformedlingen.se/go.aspx?c=57, last accessed on 31 July 2008.)

5 To be precise, this analysis is confined to England and does not include Northern Ireland, Scotland, and Wales.

6 France, which is not discussed in this study, also followed this trajectory by remodelling its labour market administration along Swedish lines in 1967 (Morel 1978). Italy, however, did not, and has in many respects remained an outlier (Mazzoleni 1978). Note also that Greece, Portugal, and Spain were under military dictatorships until 1974, 1975, and 1978 respectively.

\section{Chapter II}

1 More recently, scholars have begun to develop a fourth type, which is identified as discursive institutionalism (Schmidt 2002). 
2 Following Pollitt and Bouckaert (2004, 65f), I define a trajectory as "an intentional pattern - a route that someone is trying to take". A trend, in turn, is "simply some pattern in the data (e.g., if rainfall goes up every year for ten years, that is a trend.)"

3 Since the early 20oos, there has been a rapidly growing body of "rational choice" literature that does not see institutions as equilibrium outcomes. For a good review, see Daniel Diermeier and Keith Krehbiel (2003).

4 Historical institutionalists are also conscious, however, of the context in which these power struggles take place. This is to say, many historical institutionalists operate under the premise that there is never a total tabula rasa and newly emerging institutions always reflect some elements of pre-existing ones (e.g., Skocpol 1979; 1992; see also, Zeitlin 2008a).

5 Pierson also argues that the structure of a political system affects the likelihood of institutional stability. In other words, the more "veto points" there are in a system, the harder it is to rapidly push through radical changes. These veto points include constitutional features such as bicameralism, federalism, or judicial review and "veto players" such as coalition partners, dual executives, etc. (Pierson 2001b).

6 The "effective number" refers to political parties that have an actual chance of winning electoral representation and thus the potential to affect legislative outcomes (cf., Lijphart 1999).

7 I am grateful to Jonathan Zeitlin for suggesting these terms.

8 Other scholars using a two-fold categorization of labour market regime types include Lødemel and Trickey (2001), who differentiate between two worlds, applying either a "work first" or "human-capital development" strategy.

9 Handler may also fit into the partial convergence category, because he perceives continued diversity regarding "typical" jobseekers for whom the European welfare state remains intact.

10 The term "contingent convergence" was first coined by Anton Hemerijck.

11 A sixth category specifically addressing the needs of disabled jobseekers is often included as well. However, in this book, no special attention will be paid to this group because a different operational and normative logic applies to the process of assisting disabled persons to find work.

12 Social wages refer to transfer payments plus other benefits, such as housing subsidies, access to medical care, etc.

13 Childcare support may include instruments such as access to childcare facilities, but also parental, maternal, paternal leave schemes, which enable the parent to care for the child, as well pre-school and school hours that affect the opportunities for a parent to reconcile (part-time) work and family life. 


\section{Chapter III}

1 In 1831, the foundrymen's union created the first unemployment insurance fund for its members in Britain. Within ten years, five more unions followed, and by 1908 , some " 2.4 million workers, largely higher skilled and paid, were in unions with out-of-work benefits" (Heclo 1974, 68).

2 Sweden's late introduction is based on the Conservative government's reluctance to introduce such a scheme on the national level. The establishment of a national UI system, however, followed quickly after the Social Democrats assumed power in 1932 (cf., Wadensjö 2009). For a more detailed historical overview of the Swedish case, see Wadensjö 1991; 2002.

3 However, as public exchanges co-existed alongside union-, employer- and voluntary sector-based exchanges, their numbers remained modest and there were only public labour exchanges for some occupations (cf., Hülber 1965).

4 Like in Austria, the extent to which public offices were created remained limited and they fulfilled only "niche" functions. This was mainly due to the fact that Denmark had already established its nation wide, union-run UI system in 1907, which allowed the unions to "dominate" all aspects of policy that was related to the labour market. Hence, "placement activities of the public employment service had been confined to marginal groups of jobseekers (such as disabled persons and people with no qualifications at all) and marginal demand for labour (e.g. seasonal employment in agriculture, part-time chairwomen in private households etc.)" (Aage Tarp 1966, 15).

5 Rudolf Meidner was actually born in Breslau, then in Germany, but went into exile in Sweden after the Nazis came to power (Meidner 1979, 1).

6 For instance, the scope of vocational training for adults increased more then tenfold, from some 4,ooo participants in 1958 to about 46,ooo in 1965 (OECD 1967a, 22).

7 While this basic structure, first established in 1961, is still present today, it has become more complex with additional layers, including more Directorates and semi-autonomous bodies.

8 The OECD legitimised its focus on full employment and the advance of active manpower policies, in turn, by referring to the ILO resolution of 1961 on a "Full Productive and Freely Chosen Employment Policy" (OECD 1965, 7).

9 Sweden was the first country represented in a series of 17 publications on the labour market policy regimes of OECD Member States, published between 1963 and the late 1970 .

10 About one month later, on 17 June 1964, the ILO also passed Convention 122 Concerning Employment, which compelled Member States to pursue an "ac- 
tive" labour market policy, "designed to promote full, productive and freely chosen employment" (ILO 1964, Article 1).

11 In 1976, the Social Assistance Act came into force, which introduced a single, unified structure for social assistance claims (Madsen 2007, 19).

12 However, in contrast to Sweden, Denmark did not introduce a separate unemployment assistance (UA) pillar.

13 For a study of the origins of German vocational training, see Kathleen Thelen (2004; 2006).

14 Another important development was the launch of a "concerted action" (Konzertierte Aktion) in 1967, which mobilized all of the main societal stakeholders in order to reach full employment and price stability simultaneously. The Konzertierte Aktion resulted iter alia in the passing of the Stability and Growth Act (Stabilitäts- und Wachstumsgesetz). However, the Konzertierte Aktion was subsequently abolished in 1977.

15 The Austrian government did, however, grant the social partners representation on all advisory committees and councils at the national, regional, and local levels after the war.

16 As unemployment hovered at about two percent during the first two postwar decades, most of the unemployed would frequently find work without ever setting foot in an Employment Exchange office (Beale 2005, 68).

17 I thank Graham Wilson for suggesting this term.

18 NIEC was the predecessor of today's National Economic and Social Council, responsible for providing the government with information about ways to achieve economic growth and social justice.

19 Likewise, Portugal created its National Employment Service (SNE) in 1965, while Greece completely overhauled its PES (OAED) in 1969, renamed it Manpower Employment Organization, and created seven regional directorates (OECD 1998, $18 \mathrm{f}$ and 33). In France, the OECD recommendations triggered the Ortoli Report, which subsequently led to the creation of the Agence Nationale Pour l'Emploi (APNE). In contrast to Germany (and, to some extent, Sweden), France, however, maintained separate training (AFPA) and unemployment insurance (UNEDIC) institutions (Phan-Thuy, et al. 2001, 5)

\section{Chapter IV}

1 To be entirely correct, Keynes's General Theory did not consider inflation. However, after Phillips' discovery, Keynesianism was quickly revised so that an acceptable point on the Phillips Curve was reached (Hall 1986, 80). 
2 Moreover, the Labour Ministers re-affirmed their commitment to full employment, while a progressive reduction of inflation was envisioned (OECD $1978 \mathrm{~b}, 58)$. The commitment to full employment further demonstrated policymakers' hesitance to embrace the monetarist paradigm because monetarists believed that a certain level of unemployment is necessary to keep inflation in check.

3 Moreover, the late 1970 os were also years of volatile industrial relations, which further hampered the government's ability to push through unpopular reforms.

4 In 1976, the Commission worked on a proposal to develop the Equal Opportunities Act, which subsequently came into force in 1980.

5 Denmark had joined the European Exchange Rate Mechanism, the so-called "Snake in the Tunnel", in 1973 and would join the European Monetary System (EMS) in 1979.

6 This programme was subsequently recalibrated and renamed, first Individual Job Training and then Job Training.

7 The combination of counter-cyclical deficit spending, competitive wagesetting agreements, and pegging the Austrian schilling to the German mark would become known as Austria's version of Keynesianism, or Austrokeynesianism.

8 To make matters worse, national insurance contributions and taxes had also been rising steadily from 21 percent in 1960 to 47 percent of net earnings in 1980 (Rhodes 20oob, 38).

9 While unemployment remained low, the extremely high levels of inflation resulted in tense industrial relations as the development of "real wages had been negative since the middle 1970s" and ideological clashes between the LO and the SAF became "common" (Thoursie and Wadensjö 1997, 57).

10 The Great Conflict of 1980 was the largest strike in more than 70 years, affecting some 900,0oo workers. The traditional Swedish consensual spirit was at stake and employers increasingly demanded industry-wide, as opposed to nation wide, wage agreements.

11 Nation wide implementation was achieved by 1991.

12 Even though counter-cyclical spending was less pronounced, Scharpf and Schmidt remind us that Sweden was "the only European democracy that [continued to use] macro-economic policy to prevent job loss" (Scharpf and Schmidt 2000a, 321).

13 For instance, in 1985, the government pushed through "a one-hour reduction of the working week without wage reductions, with the effect of a total wage increase of about 2 percent per year" (the social partners' conciliation proposal suggested a reduction by one-and-a-half hours, leading to a wage 
increase of about four percent) (PLS Consult and Jensen 1997, 88). Despite massive political protest and a wave of wildcat strikes, the government remained firm in its decision.

14. While the AMS has administrative power over the AMU, the main influence over the training of the unemployed was through "its role as a purchaser" (OECD 1996c, 48).

15 Over time, the active line grew into an "availability test" intended to sort out the "deserving" from the "undeserving" welfare recipients (Rosdahl and Weise 2001, 176).

16 However, as outline above, the removal of the automatic cost-of-living adjustment led to a gradual decrease in the "value" of benefits.

17 This is a slightly different argument from Trampusch (2005), who sees this development as an example of drift, i.e., the government's non-interference as a cause for institutional change.

18 The government's accreditation of childrearing years to a woman's calculation of old-age social security further promoted conservative family values because access to these benefits was only available when women refrained from participating in the work force (Schmid and Oschmiansky 2005b, 282).

19 Schools typically end at midday, while stores closed at 6 p.m. Moreover, in contrast to American schools, German school children have a series of shorter, one-to-two week long breaks, throughout the school year, roughly every four to six weeks, and a six-and-a-half week summer vacation.

20 The reference to ravens is based on the connotation that raven mothers leave their young before they are able to fly.

21 The discrepancy between the national unemployment figures used in this section and the standardised ILO figures presented in the appendix are due to Austria's stricter criteria of what constitutes employment.

22 In the 1970s, training was equally available for both employed and unemployed workers.

23 The Community Enterprise Programme replaced the Special Temporary Employment Programme.

24 Job Clubs was a US-inspired project that offered its members resources and new techniques for the most efficient job-hunting methods, while the Restart Course was a project designed to improve jobseeker motivation and initiative (Price 2000).

25 The employers, in turn, endorsed the social partnership agreement because decentralised wage bargaining had not been particularly successful. Wage increases had been moderate, but still "outstripped inflation, thereby reducing firms' competitive position” (Sexton and O'Connell 1996, 82). 
26 For a similar assessment compare Siebert 1997, who writes: "Whereas Europe looks like a more or less homogenous train on the track to the welfare state in the 1960 s and the 1970s, marked differences in the institutional approaches of individual countries have developed since the mid-1980s" (Siebert 1997, 41).

27 Even though Sweden, unlike Denmark, does rely on substantial payroll contributions, the money is not used for designated expenses as in the Continental examples, but rather flows into the general state budget.

28 The labour force participation rate is the sum of employed workers plus those seeking work.

29 Early-exit expenditures for labour market reasons only, i.e., "regular" early retirement spending is not captured in this table, which is why spending in Germany, for instance, appears comparatively low. Likewise, disability pensions introduced in Sweden in 1970 and 1972, which allowed older workers to withdraw from the labour market, are also not included (personal conversation, SOFI2).

\section{Chapter V}

1 Please see this chapter's appendix for data on unemployment levels and employment rates.

2 Since the late 1980 s, the OECD analytically juxtaposed "active" labour market policy - comprising job-placement and matching services, and supplyside and demand-side measures - with the receipt of transfer payments and demand-reducing measures, which were relabelled as "passive" labour market policies.

3 At that time, the US "outperformed" Europe with its unemployment rate of six percent compared with the EU-12's 11.2 percent (Riding 1994). Moreover, the (open) unemployment rate in Sweden, the previous "model" for emulation, skyrocketed - despite the massive expansion of ALMPs - from below two percent in 1990 to almost ten percent in 1994 (cf., OECD Labour Force Statistics).

4 Training and education, however, still played a significant role in the JS. But rather than applying massive ALMPs, the OECD recommended reforming education and training systems, improving pre-school education, reducing early school leaving, introducing broader school curricula, and encouraging the co-operation between firms and schools (cf., The Economist 1994).

5 As of 23 January 2007 UNICE is called BUSINESSEUROPE.

6 The EEI was a very active working group within the Party of European Socialists (PES) created in late 1993. The EEI supported Delors' initiatives and was 
an active proponent of a European employment policy (cf., van Riel and van der Meer 2002).

The Westendorp Reflection Group was first established in June 1994.

8 The Commission proposals were unacceptable, mainly because they included a hard target of seven percent unemployment (Raveaud 2007).

9 The countries singled out as the most successful cases, include the Netherlands and Ireland, but also Denmark, New Zealand, and the UK were all mentioned as cases with positive achievements. It was also mentioned that the US "seems to have improved an already good performance", while Sweden and Finland were identified as appearing at "the other end of the spectrum", but showing significant improvement (OECD 1999b, 1of). Meanwhile, the large continental countries, including France, Germany, and Italy were identified as cases in which structural unemployment had actually increased.

10 In fact, the OECD Secretariat could build on the original JS, which had already called for three interrelated modernization steps, including (1) the integration of three PES services, including placement and counselling services, the payment of unemployment benefits and the management of labour market programmes (often referred to as "one-stop service centres"); (2) regular contact between benefit claimants and the PES to maintain job search efforts, and (3) the elimination of placement monopolies (cf., Phan-Thuy, et al. 2001, 6).

11 The World Bank also contributed to the spread of NPM ideas through the publication of the 1997 World Development Report (World Bank 1997).

12 The extent to which NPM encourages the privatisation of public services varies both across time and space. The early writings were much more based on privatisation, while more recent texts focus more on "re-engineering" public governance through competition and benchmarking. Likewise, in the nonEuropean, Anglophone countries, including Australia, New Zealand and to some extent the US, privatisation is much more important than in the European context (cf., Meier and Hill 2005, 53).

13 The Commission adopted a NPM-style programme in early 1995 entitled Sound and Efficient 2000 Programme (SEM2Ooo), which aimed to instil a better culture of resource management in the Commission's system (Mathiasen 2005, 651).

14 The EU Commission was also careful not to recommend the "contestability" of PES services (interview, DGEmpl3).

15 HoPES was set up as a forum in addition to, but separate from, EMCO. The two bodies are headed, however, by the same DG Employment Director, who co-ordinates both of their activities. 
16 HoPES also supports the daily activities of national PESs by collecting and disseminating labour market data and has set up EURES, a pan-European job portal.

17 Likewise, the study argued that the EU requirement to regularly write $\mathrm{Na}$ tional Action Plans had consolidated and reinforced the use of MBO instruments in those countries that had introduced such instruments already before the launch of the EES (Mosley, et al. 2000, iii).

18 Other high profile members included Günther Schmid, former member of the Hartz Commission (see chapter VII) and Maria João Rodrigues, often dubbed the "mother of the OMC".

19 For a good overview of the different meanings of the European Social Model, see Jepsen and Serrano Pascual (2005).

20 Quite tellingly, a Lexis Nexis search for "flexicurity" using the rubric European Information Service revealed eight "hits" for the time period 1 January 2000 to 31 December 2005, compared to 138 hits between 1 January 2006 and 31 July 2008.

21 For the wide range of activities subsumed under flexicurity at the European level, see http://ec.europa.eu/employment_social/employment_strategy/ flex_steps_en.htm, last accessed on 25 April 2008.

22 Interestingly, this report identifies Sweden as having "flexicurity-oriented policies", even though Sweden still has strict EPL, which is typically considered to be the antithesis to flexicurity.

23 However, not all actors share this optimistic vision. Labour unions and other actors on the political left in particular fear that flexicurity is a Trojan Horse that will lead to asymmetrical institutional outcomes, favouring employers to the disadvantage of workers (Keune and Jepsen 2007).

24 European countries studied, include Austria, Belgium (two communities), Czech Republic, Denmark, Finland, France, Germany, Hungary, Ireland, Italy, the Netherlands, Norway, Portugal, Sweden, and the United Kingdom. Reports are available at http://www.oecd.org/document/3/o,3343, en_2649_39263231_27000067_1_1_1_1,oo.html, last accessed 24 July 2008.

25 The OECD text subsequently argues that strict EPL have "indirect" effects by compromising the employment prospects of groups with "entry problems" such as older workers, women, or LTU (OECD 2006a, 86). It is quite striking, however, that the EU Commission begins its treatment of EPL by saying "[a] ccording to analytical evidence, strict EPL ... decreases the entry rate from unemployment into work", and only subsequently clarifies that this relationship actually holds only for particular groups (Commission of the European Communities 2007,6 ). In other words, the EU approaches the same findings in the reverse order, which sends a different message to the reader! 
26 Many interviewees, however, noted that the annual cycle is too tight and that they preferred a two- or even three-year cycle instead.

27 The disappearance of NAPs in favour of NRPs has, however, led to "greater unevenness in national employment policy reporting and a loss of Europeanlevel monitoring capacity" (Zeitlin 2008b, 438).

28 During the 1990s, the Dutch model was heavily debated. However, as Dutch job growth was mainly achieved through a reduction in working hours and the expansion of part-time work, mimicking the Dutch strategy seemed undesirable for many of the other European countries.

29 All three countries relied - at least partially - on labour-shedding strategies, including the extensive use of the "disability option" (NL and the UK) and early retirement for labour market reasons (DK).

\section{Chapter VI}

1 Leading labour economists believed that labour market policies could affect levels of unemployment anywhere from 15 to 50 percent (Calmfors 2004, 6).

2 While it is not entirely clear which kinds of effects can be attributed to active and activating policies in this context, they probably had a positive impact, especially considering the fact that employment rates continued to grow, despite the global economic turbulence caused by the burst of the "dot.com bubble" in 2000 and the terrorist attacks on 11 September 2001.

3 The flipside to the large-scale activation necessarily means that new employment opportunities are not always full-time, secure, and well-paid jobs. The risk is therefore that "any" job may become appropriate in the eyes of the state if certain employment targets are to be reached. In particular, but not exclusively, many labour unions have become concerned with the growth of "atypical" jobs and the potential displacement of regular employment opportunities, especially in the Continental context (interviews, DGB1; DGB2; ÖGB). Similarly, Thelen and Palier (2008) have described this trend as a "dualisation" of labour markets, characterised by a core of traditional "good" jobs, and a rapidly growing segment of peripheral, "atypical" and often precarious employment contracts. The political challenge must therefore be to ensure that "atypical" work becomes a "steppingstone" rather then a "deadend street" for activated workers.

4 The Manpower Services Commission had already used some performance targets in the 1970s. However, the scale and importance was rather modest at the time (interview, $\mathrm{DWP}_{5}$ ). 
In 2008, about 100,000 JCP clients were categorised as so-called "revolving door" clients, i.e., clients that rotate in and out of work and benefits (interview, CESI). This pattern suggested that the system was "failing" for this subgroup of clients and a different approach was necessary.

6 While Ireland used some elements of $\mathrm{MBO}$, a Commission funded research project, published in 2000 found that $\mathrm{MBO}$ techniques in Ireland had little substantive influence (Mosley, et al. 2000, iv). Since the publication of this report, new FÁS Chairman Brian Geogheghan (2001-2005) significantly expanded the use of performance targets as part of the newly initiated FÁS Strategy Vision statements (interview, FAS 1 ).

7 A survey conducted by researchers at the Social Science Centre in Berlin (WZB) in 2000, found that Belgium (Flanders), Finland and Norway also introduced full MBO systems throughout the 1990s, while Belgium (Walloon), Portugal and Spain adopted some MBO elements (Mosley, et al. 200o, iv).

8 The German PES had already considered the introduction of MBO structures in the late 1990s, and subtle steps towards performance-oriented management were developed in the Arbeitsamt 2000 reform project (interview, DGB1).

9 It must be noted, however, that the German PES has been using MBO techniques only for a short period of time, and an interviewee noted that the actors involved still needed to learn how to use the system (interview, BA1).

10 In December 2007, the German Federal Constitutional Court declared the ARGEn unconstitutional and mandated their reform by 2010. At this point in time, it is not clear what the new institutional design will look like, but continued close collaboration between welfare and employment offices is expected.

11 The administration of UB payments has been retained with the Unemployment Insurance (UI) funds, i.e., job centres need to solicit the approval of benefit payments/sanctions from UI funds.

12 In 2007, the centre-right government replaced these programmes with the (rather similar) Job Guarantee for Young Workers (jobbgaranti för ungdomar) and Job and Development Guarantee (Jobb-och utvecklingsgaranti) for the long-term unemployed.

13 The LES provided an array of services to disadvantaged jobseekers and were linked to Area-Based Partnerships (ABP), i.e., limited multi-partnership companies to promote local economic development and job growth. While the LESs were originally only responsible to the ABPs, the government decided to integrate them into FÁS in the late 1990s.

14 The "objectivity" of standardised procedures is by no means guaranteed. For instance, in Germany, case managers informed me that they can "manipu- 
late" the system, if needed, by entering certain data in the system to obtain the desired profiling category for the client.

15 While similar trajectories are also identifiable in Belgium, the Netherlands, France, Finland and most of the other European countries, the PESs in Southern Europe remain laggards. The reason for the lack of convergence is most likely one of underdeveloped institutional capacity and the strong devolution to regional jurisdictions.

16 Another important trend not discussed in this book includes the increased commitment to improve the services for, and collaboration with, local employers. As such, the PES "service model" targets both employers and jobseekers alike.

17 As far as governments are able to, they try to convince the social partners to settle on internationally competitive wage increases. For an overview of this trend of "competitive corporatism" see, for instance, Rhodes (2003). This feature, however, is often criticised by union leaders in neighbouring countries. Putting pressure on low-wage settlements forces other unions to engage in a "race to the bottom" and one country's (employment) gains become another country's losses (interview, DGB2).

18 If applicable, starting rate only.

19 Note that this is a rather "rough" insight as the expenditures refer to national spending levels. In many instances, however, ALMP programmes are delivered and managed by local or regional authorities, which means that the numbers in this table may not be complete. Moreover, while the use of taxcredits is functionally equivalent to in-work wage subsidies, wage subsidies are considered ALMP expenditures, but tax credits are not. These features might skew the interpretation of the data.

20 The Liberal countries, including Ireland and the UK, in turn, use a combination of statutory minimum wages and negative income taxes to reward lowwage employment. As both of these instruments are not considered ALMPs, they are not included in the table below (but see section 4 on work incentives below).

21 In his study, Gangl also shows that while unemployment benefits paid over a long duration prolongs unemployment spells, they are also associated with higher post-unemployment wages (particularly in the German context). Therefore, he argues that UB should "subsidise" workers' job search activities and thus reduce the "scar effects" of unemployment.

22 Interestingly, the EU has not set any targets for the provision of childcare to older school children even though in the Continental countries, where full school days are rare, childminding in the afternoon is still a barrier for (mostly) women to take up full employment. 
23 The receipt of child benefits was conditional on families not exceeding a certain wage threshold for the second wage earner, effectively promoting singleincome families for those women with limited wage prospects (interview, WIFO).

24 Increasingly, governments also seek to reverse the trend of low birth rates through the expansion of childcare.

25 There was also a Kombilohn or wage subsidy paid directly to jobseekers, which started in 2006. It was seen as a failure, however, because only a total of some 300 unemployed workers made use of this instrument.

\section{Chapter VII}

1 As a consequence, HzA measures steadily increased from its inception in the late 1980s, when some 14,000 SA recipients participated (Voges, et al. 2001, 88) to 200,00o in 1996 (Schmuhl, et al. 2003, 581).

2 Decentralisation was particularly pronounced in former East Germany, where employers withdrew their memberships from employers associations to avoid collectively agreed-upon wage settlements. Similarly, East German workers' councils voluntarily accepted below-settlement wages in order to prevent job cuts. I thank Wade Jacoby for bringing this to my attention.

3 It was the larger firms that also disproportionately benefited from training and retraining ALMPs and took advantage of the early exit options to shed their access labour (interviews, CDU, ZDH).

4 In the mid-1970s, the government came up with the goal to write one single Social Code, legally codifying all of German social policy. The Social Code includes a series of "books", each regulating a specific dimension of the welfare state. There are currently 12 such books.

5 The divisions between the political left and right in turn led to open political alignments, unprecedented in Germany's post-war history. The labour movement not only supported but actively campaigned for the Social Democrats, while the BDA President Dieter Hundt called upon the CDU/CSU and FDP to continue their path and make further welfare state expenditure cuts.

6 By empowering local authorities, the government tried to strengthen the $s u b$ sidiarity principle.

7 The Greens emerged as a political party in 1980 and gained seats in the Bundestag for the first time in 1983.

8 JUMP built on the experiences from a pilot programme launched by the Social Democrats in Kalk (North-Rhine Westphalia) in 1997 (interview, SPD1). 
Integration agreements (Eingliederungsvereinbarung) had already existed in the past, albeit in a different form for a number of the long-term unemployed and those considered difficult to place. Rather than presenting a "contract" between the jobseeker and the employment centre, these integration agreements were intended to build a bridge between potential employers and the jobseeker, offering up to six months wage subsidies to firms willing to "try out" one of these clients. These agreements were phased out in 2001.

10 While the spring 1999 wage round concluded with an above-average settlement, the subsequent agreements have seen a modest increase in wage levels, leading to a de facto drop in incomes.

11 The Chancellor advocated a "calm" approach to politics, i.e., the Politik der ruhigen Hand.

12 Florian Gerster, subsequent Director of the restructured PES, would frequently participate in the Commission meetings as well.

13 It is also noteworthy that the social partner representatives were not leading figures such as Dieter Hundt (BDA) or Wilhelm Adamy (DGB). This was a deliberate attempt to depoliticise the meetings and make room for compromise (interview, SPD1).

14 It is important to note, however, that the DGB was willing to support the Hartz concept under the condition that the Chancellor promised not to ease employment protection standards (Kündigungsschutz) or interfere in wage settlements (Tarifautonomie) (interview, DGB1). Moreover, the original Hartz report did not make any specific recommendations on the generosity of benefits, while suggesting paying UB between six and 32 months, depending on a jobseeker's age and contributions history (Hartz Commission 2002). As such, the popularly used name "Hartz IV" for the controversial piece of legislation that was issued subsequently - as part of the Agenda 2010 - is in principle a misnomer.

15 While Hartz I did not need the approval of the Bundesrat, Germany's upper chamber representing all 16 federal states (Bundesländer), Hartz II passed the Bundesrat on 20 December 2002 after some minor adjustments requested by the CDU/CSU.

16 The labour unions agreed to the expansion of temporary jobs since the Social Democrats had promised that wages would be based on collective agreements. However, when a clause was included in the final legislative text that allowed temporary job agencies to refer to "any" collective agreement, employers quickly adopted the (low) wage settlements reached by the Christian Trade Union Federation (CGB), which is not a member of the DGB. The DGB was then pressured to downgrade their own wage settlements, which effec- 
tively undermined the introduction of "fair wages" to temporarily employed workers (interview, DGB2).

17 Hartz II also envisioned so-called Job Floaters, which, however, failed to deliver many new jobs (Handelsblatt 2004). The idea was that firms that agreed to hire a long-term unemployed worker would receive attractive loans, issued by the government, of up to $€ 100,000$.

18 Keeping an eye on her constituency, Angela Merkel, the CDU Party Leader indicated, however, that some reforms may go too far and she opposed curbs on unemployment benefits for older workers.

19 A study conducted by the Institute for the Study of Labour (IAB) has shown that about 11 percent of previous UA recipients have lost their assistance payments entirely, while some four percent progressed into work or retirement. Therefore, about 85 percent of previous UA recipients now receive ALG-2. The ALG-2 payments are below previous UA payments for about 56 percent (on average some $€ 150$ ), while about 44 percent receive more (on average $€ 220$ ). Long-term, prime-aged men in former East Germany are often considered the main "losers" of the new benefits system (Bruckmeier and Schnitzlein 2007).

20 In reaction to these critiques, the BA attempted to reduce the alleged "parking" of clients by earmarking certain budget items to be spent on disadvantaged jobseekers (interview, BDA, BA1).

21 In June 2003, IG Metall had to call off its four-week strike for a 35-hour workweek in eastern Germany after no agreement could be reached. IG Metall had demanded a three-hour reduction to bring eastern firms in line with western firms. However, employers insisted this difference was a competitive advantage that secured investments in jobs for the eastern German plants. The media, some western German works council members, and members of the government were very critical of the strikes and feared that they would adversely affect the entire German economy, which further diminished the popularity of the unions. The IG Metall strike was the first one they had lost since the mid-1950s and Klaus Zwickel had to resign as the union chair.

22 The two far-left parties officially merged in 2007 to create the Left Party (Die Linke).

23 Even though the left-leaning parties, including the SPD, the Greens, and the Left Party, won more than 50 percent of the votes, the Social Democrats' refusal to form a coalition with the former Communists prevented a left-led government from taking office.

24 The positive impact of the Barcelona targets was confirmed in many interviews, including $\mathrm{HBS}, \mathrm{SPD}_{3}, \mathrm{SPD}_{4}$ and BMAS6, while the OECD report was mentioned in many newspapers at that time. 
25 The parts related to the child and youth assistance laws (Kinder-und Jugendhilfegesetz), which were the ones requiring the approval of the Bundesrat, Germany's upper chamber, were separated out.

26 On 1 January 2006, the TAG was further supplemented by more generous deductions for parents who utilise childcare facilities.

27 A discourse on the "quality" of child minding has been largely absent, however, and it is not clear what exactly these childcare places entail.

28 These cash payments might, however, prove counter-productive as low-income families may opt not to go to work, preferring instead to receive the transfer payments (interview, INQA).

29 Franz Müntefering's official reason for resigning was, however, his wife's ill health.

30 The decline in industrial strife was also fostered by the 1990 Industrial Relations Act that mirrored the UK Employment Acts of 1980 and 1982. The Act was a deliberate attempt by the FF government to "provide a stable industrial relations environment" to foreign, mainly US, investors by limiting union power in regards to strike initiation and picketing (Schweiger and Wickham 2005, 15).

31 While the conclusion of the PNR represents a major political breakthrough, many observers quickly forget that the success of the PNR was partially secured by an "international economic upturn and a drop in the inflation rate, which turned a modest pay-and-tax-cuts deal into an increase in real disposable income" (Hardiman 2002, 9).

32 To provide a reference, in the 1993-94 period there were roughly 220,000 unemployed people in Ireland (Indecon 2002, 6).

33 The Democratic Left was founded in 1992 and merged with the Labour Party in 1998.

34 The government saw the need to "tighten the screws" because a study conducted by Ireland's Central Statistics Office had shown that about 50 percent of all Live Register claimants did not appear to be actively seeking employment, which was "the largest [percentage] in any OECD country" (Walsh 2004, 15).

35 While the letter indicates possible benefits sanctions upon refusal to attend an interview, the actual application of sanctions is extremely rare (interview, DETE2).

36 The SEP was designed as a social rather than as a labour market programme. Accordingly, it did not make labour market progression a real target and was located in the Department for Community, Rural and Gaeltacht Affairs.

37 The CORI interviewee explained that 20,00o participants is a "realistic" current figure because more places would be difficult to fill in times of almost 
full employment. However, he and the INOU interviewee were very concerned about the gradual phasing out of the Jobs Initiative as its participants are particularly vulnerable and need special assistance.

38 The most recent tax reforms effectively reduced the tax burden to 20 percent for individuals with an income of less than $€ 34,000$, and 41 percent for incomes exceeding $€ 34$,ooo.

39 However, the increase in childcare benefits was often criticised because it is (a) not sufficient to truly help low-income families (the additional $€ 150$ covered only about one-quarter of the monthly childcare fees for one child); (b) an inappropriate instrument to fight child poverty; and (c) stimulates, if anything, the demand - rather than the supply - for childcare places, which was already high (Timmins 1999).

40 Throughout the early 200os, the European Commission repeatedly stressed that while childcare provision was growing, "it is nowhere near the commitment to provide childcare for ' $90 \%$ of children between 3 years and school going age and $33 \%$ of children under 3 years"' (Government of Ireland 2004, 84).

41 In November 2002, an OECD team visited Ireland and subsequently published a 100-page country note, in which it stated that "significant energies and funding" will be needed to create a care system that can sustain Ireland's full employment economy (OECD 2004a, 8). Similarly, in 2005, a report published by the OECD suggested that female employment rates could be raised to about 60 percent by reliance on relatives, friends, and neighbours, who could fulfil these care needs. However, for increases above 60 percent, public interventions were needed (OECD 2005a). Moreover, an OECD working paper predicted a drastic increase in the need for childcare places in Ireland as young, skilled women increasingly decided to start a family. In other words, the extremely high employment rate of young women could become a liability if formal childcare remained limited in its availability and one of the most expensive in Europe (Immervoll and Barber 2005, 21f).

42 The FF-PD government issued two important pieces of legislation, including the Employment Equality Act of 1998, which "prohibits discrimination on the grounds of age and provides for positive action for those aged over 50 years of age [while the] Equality Authority [has been] engaging in proactive initiatives in this area" (Government of Ireland 2001, 55). In July 2004, the Equality Act 2004 was introduced to comply with three EU equality directives. This act extended the Employment Equality Act, 1998 (and the Equal Status Act, 2000 which further prohibits discrimination on various grounds).

43 The Fund is resourced by a 0.7 percent levy on employers, covering some 75 percent of all insured employees (OECD 2006b). 
44 Because free secondary education was not available until the 1960s, basic skills shortages are particularly pronounced among older workers.

45 In April 2002, prior to Toward 2016, the government had removed hurdles for PRETA recipients to (temporarily) engage in paid work by allowing them to return to PRETA in case of a new spell of unemployment.

46 Other measures available to older workers include the Return to Education programme aimed at increasing basic skill levels of adults including and the Core Skills Programme, which is available to Community Employment participants and is being implemented nationwide by FÁS. Moreover, the government allows people aged 55-64 to participate on CE for a maximum of six years, instead of three. At the end of the program, participants can receive their Jobseekers Allowance again. The Community Employment scheme remains the most popular programme among older jobseekers. Three-quarters of all men aged 50-64 in FÁS ALMP programmes are in CE, and more than 60 percent in the case of women (OECD 2006b, 105). Last, FÁS and ICTU have put in place a Workplace Basic Education Scheme for older workers, addressing literacy, numeracy and basic computer skill issues.

47 Moreover, the government removed the compulsory retirement age of 65 to enable people to remain at work as long as they wished (Government of Ireland 2004, 39).

48 It must be noted here that the Irish welfare state has failed to serve all of the vulnerable groups equally. Instead, as expected in the Anglophone cluster that prioritises work as the best form of welfare, Ireland has seen a "dramatic" increase in the (relative) rates of poverty "for groups outside the labour force (particularly for retired people and people who are ill or disabled" (NESC 2005b, 38).

49 Likewise, Bertie Ahern was Taoiseach from 1997 to 2008, while Charlie McCreevy served as Finance Minister and Mary Harney as Minister for Enterprise, Trade and Employment uninterrupted from 1997 to 2004.

\section{Chapter VIII}

1 While governments in some countries chose not to refer to the OECD as an ideational inspiration for political reasons, they may, however, use OECD statistics to prove that there is a "need" for new legislation (cf., Armingeon and Beyeler 2004).

2 Because funding for ALMPs in Denmark is indexed to the unemployment rate, automatic increases are triggered whenever the labour market situation deteriorates (OECD 2009b, 10). 


\section{List of Interviews and Personal Conversations}

1 Many of these interviews have been conducted to acquire "background information" and most of the interviewees were ensured their anonymity. Thus all of their names have been withheld. All of the interviews were conducted on a face-to-face basis, unless noted otherwise. 



\section{Bibliography}

Aage, Tarp (1966). "Denmark”, in: OECD (ed.), The Public Employment Services and Management. International Management Seminar, Madrid, 23-26 March 1965; Final Report. Paris: Organisation for Economic Co-operation and Development, Manpower and Social Affairs Directorate, 15-27.

Abrahamson, Peter (2006). "Welfare Reform. Renewal or Deviation?" in: John L. Campbell, John A. Hall, and Ove Kaj Pedersen (eds.), National Identity and the Varieties of Capitalism: The Danish Experience. Montreal and Ithaca: McGill-Queen's University Press, 356374.

Ahlqvist, Eva-Lena (1979). "Helping the Job-seeker: On Local Employment Offices", in: Swedish Institute, Labour Market Reforms in Sweden: Facts and Employee Views. Stockholm, Sweden: Swedish Institute, 44-49.

Ahrens, Regina, and Blum, Sonja (2009). "Veto Players - Restraining or Facilitating Family Policy Change?” PoliThesis, Research Paper 09/o1. Aichholzer, Georg (1982). "Arbeitsmarktpolitik in Österreich. Zum Verhältnis von Eingliederungs- und Ausgliederungsstrategien”, Österreichische Zeitschrift für Soziologie 7(3/4), 69-80.

Ainley, Patrick, and Corney, Mark (1990). Training for the Future: The Rise and Fall of the Manpower Services Commission. London: Cassell.

Alber, Jens (1982). Vom Armenhaus zum Wohlfahrtsstaat: Analysen zur Entwicklung der Sozialversicherung in Westeuropa. Frankfurt and New York: Campus.

Allan, James and Scruggs, Lyle (2004). "Political Partisanship and Welfare State Reform in Advanced Industrial Democracies." American Journal of Political Science 48(3), 496-512.

Amenta, Edwin (2003). "Development of Social Policy", in: James Mahoney, and Dietrich Rueschemeyer (eds.), Comparative Historical Analysis in the Social Sciences. Cambridge and New York: Cambridge University Press, 91-130. 
Andersen, Jørgen Goul, and Pedersen, Jacob J. (2007). "Continuity and Change in Danish Active Labour Market Policy: 1990-2007; The Battlefield Between Activation and Workfare". CCWS Working Paper 54. Anxo, Dominique, and Niklasson, Harald (2004). "The Swedish Model in Turbulent Times: Decline or Renaissance?" DYNAMO National Report - Sweden.

Armingeon, Klaus, and Beyeler, Michelle (eds.) (2004). The OECD and European Welfare States. Cheltenham, UK and Northampton, MA: Edward Elgar.

Atzmüller, Roland (2009). "Aktivierung statt Vollbeschäftigung. Die Entwicklung der Arbeitsmarktpolitik in Österreich”, In: Christoph Hermann, and Roland Atzmüller (eds.), Die Dynamik des "österreichischen Modells". Brüche und Kontinuitäten im Beschäftigungs- und Sozialsystem. Berlin: Edition Sigma, 135-186.

Auer, Peter (200o). Employment Revival in Europe: Labour Market Success in Austria, Denmark, Ireland and the Netherlands. Geneva: International Labour Organisation.

Baccaro, Lucia (2003). "What is Alive and What is Dead in the Theory of Corporatism", British Journal of Industrial Relations 41(4), 683-706.

Bakke, E. Wight (1964). "Economic and Social Implications of an Active Manpower Policy", in: OECD, International Trade Union Seminar on Active Manpower Policy. Final Report. Paris: Organisation for Economic Co-operation and Development. Manpower and Social Affairs Directorate, Social Affairs Division, 53-66.

Barbezat, Daniel (1997). "The Marshall Plan and the Origin of the OEEC", in: Richard T. Griffiths (ed.), Explorations in OEEC History. Paris: Organisation for Economic Co-operation and Development, 33-48.

Barbier, Jean-Claude (2001). "Welfare to Work Policies in Europe: The Current Challenges of Activation Policies". Working Paper: Centre d'etudes de l'emploi 11, 1-24.

Barbier, Jean-Claude (2007). "The French Activation Strategy in a Comparative Perspective", in: Amparo Serrano Pascual, and Lars Magnusson (eds.), Reshaping Welfare States and Activation Regimes in Europe. Brussels and Oxford: P.I.E.-Peter Lang, 145-171.

Barbier, Jean-Claude, and Ludwig-Mayerhofer, Wolfgang (2004). "The Many Worlds of Activation". European Societies 6(4), 423-436.

Beale, Edward (2005). "Employment and Training Programmes for the Unemployed. Volume II: Other Programmes and Pilots". House of Commons Library Research Paper 05(62). 
Beckert, Jens (1999). "Agency, Entrepreneurs, and Institutional Change: The Role of Strategic Choice and Institutionalized Practices in Organizations". Organization Studies 20, 777-799.

Beermann, Hermann (1964). "The Trade Union Attitude towards an Active Manpower Policy", in: OECD, International Trade Union Seminar on Active Manpower Policy. Final Report. Paris: Organisation for Economic Co-operation and Development. Manpower and Social Affairs Directorate, Social Affairs Division, 143-16o.

Behrens, Martin, and Niechoj, Torsten (2003). "Future of National Alliance for Jobs under Debate". EIROnline. 7 January, DE0212205F.

Berkel, Rik van (2007). "Activation in the Netherlands: The Gradual Introduction of a Paradigm Shift", in: Amparo Serrano Pascual (ed.), Reshaping Welfare States and Activation Regimes in Europe. Brussels: P.I.E. Peter Lang, 71-98.

Béland, Daniel (2005). "Ideas and Social Policy: An Institutional Perspective". Social Policy \& Administration 39 (1), 1-18.

Béland, Daniel, and Hacker, Jacob S. (2004). "Ideas, Private Institutions and American Welfare State 'Exceptionalism': The Case of Health and Old-age Insurance, 1915-1965". International Journal of Social Welfare $13,42-54$.

Benner, Matts, and Vad, Troben Bundgaard (2000). "Sweden and Denmark. Defending the Welfare State", in: Fritz Wilhelm Scharpf, and Vivien Ann Schmidt (eds.), Welfare and Work in the Open Economy. Oxford and New York: Oxford University Press, 399-466.

Bennett, Colin J. (1997). "Understanding Ripple Effects: The Cross-National Adoption of Policy Instruments for Bureaucratic Accountability". Governance. An International Journal of Policy and Administration 10(3), 213-233.

Berman, Sheri (1998). The Social Democratic Moment: Ideas and Politics in the Making of Interwar Europe. Cambridge: Harvard University Press

Berman, Sheri (2001). "Review: Ideas, Norms, and Culture in Political Analysis”. Comparative Politics 33(2), 231-250.

Bertelsmann Stiftung (1999). International Reform Monitor: Social Policy, Labour Market Policy, Industrial Relations. Berlin: Bertelsmann Stiftung.

Biffl, Gudrun (1989). "Schwerpunkte der Arbeitsmarktentwicklung in den achtziger Jahren”. WIFO Monatsberichte 3, 137-142.

Biffl, Gudrun (1996). "Entwicklung der Langzeitarbeitslosigkeit in Österreich und Maßnahmen zu ihrer Bekämpfung”. WIFO Monatsberichte 1, 69-82. 
Bispinck, Reinhard (1997). "The Chequered History of the Alliance for Jobs", in: Philippe Pochet and Giuseppe Fajertag (eds.), Social Pact in Europe. Brussels: European Trade Union Institute, 63-78.

Bivand, Paul (2004). "Aim: The Best Employment Rate in the Industrialised World". CESI Working Brief 159 (Nov.), 20-22.

Blanchard, Olivier (2006). "European Unemployment: the Evolution of Facts and Ideas”. Economic Policy (21) 45, 6-59.

Bleses, Peter and Seeleib-Kaiser, Martin (2004). The Dual Transformation of the German Welfare State. Basingstoke, Hampshire and New York: Palgrave Macmillan.

Blom-Hansen, Jens (2000). Review Article. Still Corporatism in Scandinavia? A Survey of Recent Empirical Findings. Scandinavian Political Studies 23(2), 157-181.

Blyth, Mark (2002). Great Transformations: Economic Ideas and Institutional Change in the Twentieth Century. Cambridge and New York: Cambridge University Press.

Boeri, Tito, Layard, Richard, and Nickell, Stephen (2000). "Welfare-toWork and the Fight Against Long-Term Unemployment". Department for Education and Employment Research Report 206.

Boix, Carles (1998). Political Parties, Growth and Equality: Conservative and Social Democratic Economic Strategies in the World Economy. Cambridge and New York: Cambridge University Press.

Boje, Thomas P., and Madsen, Per Kongshoj (1994). "Wages Formation and Incomes Policy in Denmark in the 1980s", in: Ronald Philip Dore, Robert Boyer, and Zoe Mars (eds.), The Return to Incomes Policy. London and New York: Pinter Publishers; St. Martin's Press, 94-117.

Brandt, Nicola, Burniaux, Jean-Marc, and Duval, Romain (2005). "Assessing the OECD Jobs Strategy: Past Developments and Reforms. Annexes". OECD Economics Department Working Papers 429.

Bredgaard, Thomas, and Larsen, Flemming (2007). "Quasi-Markets in Employment Policy in Australia, the Netherlands and Denmark: Do They Deliver on Promises?" Paper presented at ESPAnet, Vienna, 2022 September.

Brehmer, Ekhard and Bradford, Maxwell R. (1974). Incomes Policy and Labor Market Policies in Sweden, 1945-1970. Staff Papers - International Monetary Fund 21(1), March.

Brennock, Mark (1999). "Bruton Promises to Reverse FF's Controversial Tax Plan". Irish Times 4 December, p. 1.

Bruckmeier, Kerstin, and Schnitzlein, Daniel (2007). "Was wurde aus den Arbeitslosenhilfeempfängern? Eine empirische Analyse des Über- 
gangs und Verbleibs von Arbeitslosenhilfeempfängern nach der Hartz-IV-Reform". IAB Discussion Paper 24.

Büchs, Milena, and Friedrich, Dawid (2003). "Surface Integration: The National Action Plans for Employment and Social Inclusion in Germany", in: Jonathan Zeitlin, and Philippe Pochet (eds.), The Open Method of Co-ordination in Action. The European Employment and Social Inclusion Strategies. Brussels: P.I.E.-Peter Lang, 249-285.

Büchs, Milena (2007). New Governance in European Social Policy: The Open Method of Co-ordination. Basingstoke: Palgrave Macmillan.

Buntenbach, Annelie (2007). "Fünf Jahre Hartz - Bilanz aus der Sicht des DGB". Pressekonferenz, Berlin, 15 August, available for download at: http://www.dgb.de/themen/++co++7d64ac62-2c40-11df-4a4c - ooo93d114afd, last retrieved on 6 May, 2010.

Burke, Leonard (2006). "Discussion Paper - Ireland". International Experts Workshop of the ISSA Technical Commission on Unemployment Insurance and Employment Maintenance. Brussels, Belgium, 10-11 April.

Butschek, Felix (1981). Vollbeschäftigung in der Krise. Die österreichischen Erfahrungen 1974-1979. Vienna: Wirtschaftsverlag Dr. Anton Orac.

Calmfors, Lars (2004). "Keynote Speech at the International Reform Monitor Conference on 'Activation without Perspective?'- Increasing Employment Opportunities for the Low-Skilled". Arranged by the Bertelsmann Foundation in Berlin, 31 March.

Campbell, John L., and Pedersen, Ove K. (2007). "The Varieties of Capitalism and Hybrid Success: Denmark in the Global Economy". Comparative Political Studies 40(3), 307-333.

Camps, Maarten (2006). "Employment Conference: Toward Higher Productivity and Better Employment. 16-17 October, Epsoo, Finland, Speaking Points for EMCO Chair". Available for download at: http:// mol.fi/mol/en/99_pdf/en/o1_ministry/eu_camps.pdf, last retrieved on 5 May 2008.

Carone, Giuseppe, Koopman, Gert Jan, and Pichelmann, Karl (2009). "Labour Market Prospects and Policies to Soften the Impact of the Financial Crisis”. ECFIN Economic Brief 1 (May).

Carthaigh, Sean Ma (1997). "White Paper Outlines Policy to Nurture Human Resources”. Irish Times 8 May, p. 17.

Casey, Bernard H. (2004). "The OECD Jobs Strategy and the European Employment Strategy: Two Views on the Labour Market and the Welfare State". European Journal of Industrial Relations 10(3), 329-352. 
Casey, Bernard H (2009). "Policy Learning and Social Protection: What Have We Learnt?” International Social Security Review 62(4), 103-106. Cerny, Josef (1997). “Die Sozialpolitik der 'Ära Kreisky' 1970-1983”, in: Werner Gatty, Gerhard Schmid, Maria Steiner, and Doris Wiesinger, Die Ära Kreisky: Österreich im Wandel 1970-1983. Innsbruck: StudienVerlag, 107-116.

Christensen, Tom, and Lægreid, Per (2001). "New Public Management Undermining Political Control?” in: Tom Christensen, and Per Lægreid (eds.), New Public Management: The Transformation of Ideas and Practice. Aldershot, UK and Burlington, VT: Ashgate, 93-119.

Citi, Manuele, and Rhodes, Martin (2007). "New Modes of Governance in the EU: Common Objectives versus National Preferences". European Governance Papers $07(1)$.

Clasen, Jochen (2005). Reforming European Welfare States: Germany and the United Kingdom Compared. Oxford and New York: Oxford University Press.

Collier, Irwin (2004). "Can Gerhard Schröder Do It? Prospects for Fundamental Reform of the German Economy and a Return to High Employment". IZA Discussion Paper Series 1059 (March).

Collins, Stephen, O'Brien, Tim, and Carswell, Simon (2009). "EUR 3.5bn Tax and Savings Measures Expected in Budget”. Irish Times 4 April, p. 1.

Commission of the European Communities (1993a). Community-wide Framework for Employment. COM (93) 238 final, 26 May 1993.

Commission of the European Communities (1993b). Growth, Competitiveness, Employment. The Challenges and Ways Forward into the 21st Century. White Paper. COM (93) 700 final, 5 December.

Commission of the European Communities (1998). Commission Communication: Modernising Public Employment Services to Support the European Employment Strategy. COM (98) 641 final, 13 November.

Commission of the European Communities (1999a). The Modernisation of Public Employment Services in Europe: Three Key Documents. Luxembourg and Lanham, MD: Office for Official Publications of the European Communities.

Commission of the European Communities (1999b). Quality Work in the Public Employment Services of the EU/EEA. Lahiti, Finland, available for download at: http://ec.europa.eu/employment_social/employment_ strategy/pub_empl_services_en.htm, last retrieved 28 April 2008.

Commission of the European Communities (2000). "The Service Model of Public Employment Services (PES) to Support the Fight Against 
Long-term Unemployment". Working Paper of the Commission Services. 22 June.

Commission of the European Communities (2002). Communication from the Commission to the Council, the European Parliament, the Economic and Social Committee and the Committee of the Regions - Taking Stock of Five Years of the European Employment Strategy. COM (2002) 416 final.

Commission of the European Communities (2004). Development of EES. http://europa.eu.int/comm/employment_social/employment_strategy/develop_en.htm, last accessed 26 April 2005.

Commission of the European Communities (2006). Employment in Europe. Brussels: Director-General for Employment, Social Affairs and Equal Opportunities.

Commission of the European Communities (2007). Commission Communication: Towards Common Principles of Flexicurity: More and Better Jobs through Flexibility and Security. COM (2007) 359 final.

Commission of the European Communities (2009). Communication for the Spring European Council. Driving European Recovery, vol. 1. COM (2009) 114 final, 2009.

Copenhagen Post (2009). "Next Year's Economic Forecast: Lousy”, 27 May, online edition.

Council of the European Union (1993). Presidency Conclusions. Copenhagen European Council, 21-22 June.

Council of the European Union (1994). Presidency Conclusions. Essen European Council, 9 and 10 December.

Council of the European Union (1996). Presidency Conclusions. Madrid European Council, 16 December.

Council of the European Union (1997). "The 1998 Employment Guidelines. Council Resolution of 15 December 1997", available for download at: http://ec.europa.eu/employment_social/employment_strategy/98_guidelines_en.htm, last retrieved on 15 July, 2008.

Council of the European Union (200o). Presidency Conclusions. Lisbon European Council, 23-24 March.

Council of the European Union (2002). Presidency Conclusions. Barcelona European Council, 15-16 March.

Cousins, Mel (1995). The Irish Social Welfare System: Law and Social Policy. Blackrock, CO and Dublin: Round Hall Press.

Cox, Robert Henry (1998). "From Safety Net to Trampoline: Labor Market Activation in the Netherlands and Denmark". Governance. An International Journal of Policy and Administration 11(4), 397-414. 
Crouch, Colin (2005). Capitalist Diversity and Change: Recombinant Governance and Institutional Entrepreneurs. Oxford and New York: Oxford University Press.

Culpepper, Pepper (2002). 'Puzzling, Powering, and 'Pacting': The Informational Logic of Negotiated Reforms". Journal of European Public Policy 9(5), 774-790.

Daguerre, Anne (2007). Active Labour Market Policies and Welfare Reform. Europe and the US in Comparative Perspective. Houndsmills, Basingstoke, Hampshire: Palgrave Macmillan.

Dar, Amit, and Tzannatos, Zafiris (1999). "Active Labor Market Programs: A Review of the Evidence from Evaluations". Social Protection Discussion Paper Series 9901.

Davern, Eamonn (2008). "The Jobcentre Plus Business and Customer Strategy Team in the United Kingdom". in: Silvia Spattini, and Germana di Domenico (eds.). New European Approaches to Long-term Unemployment What Role for Public Employment Services and What Market for Private Stakeholders. Alphen aan den Rijn: Kluwer Law and Business, 115-25.

Delander, Lennart (1991). "Placement, Counselling, and Occupational Rehabilitation in Sweden". WZB Discussion Paper 91(6).

DETE (1998). Review of CE Programme. September 1998. Final Report. Dublin: Department of Enterprise, Trade and Employment.

Diermeier, Daniel, and Krehbiel, Keith (2003). "Institutionalism as a Methodology". Journal of Theoretical Politics 15(2), 123-144.

Dingeldey, Irene (2001). "European Tax Systems and their Impact on Family Employment Patterns". Journal of Social Policy 3o(4), 653-672.

Dingeldey, Irene (2005). "Zehn Jahre aktivierende Arbeitsmarktpolitik in Dänemark”. WSI Mitteilungen (1), 18-24.

Ditch, John, and Roberts, Ellen (2002). Integrated Approaches to Active Welfare and Employment Policies. Luxembourg: Office for Official Publications of the European Communities.

Djelic Marie-Laure and Quack, Sigrid (2007). "Overcoming Path Dependency: Path Generation in Open Systems". Theory and Society (36), 161-186.

Dobbins, Tony (2004). Questionnaire for EIRO Comparative Study on Occupational Pensions, available for download at: $h t t p: / / w w w . e i r o . e u r o-$ found.eu.int/2004/o4/study/index.html, last retrieved on 6 May 2010.

Dobbins, Tony (2009a). "Emergency Budget Includes Public Service Pay Review and Early Retirement”. EIROnline, 11 May, IEo904019I. 
Dobbins, Tony (2009b). “Tackling the Recession: Ireland". EIROnline, 13 July, IE0907029Q.

Dostal, Jörg M. (2004). "Campaining on Expertise: How the OECD Framed EU Welfare and Labour Market Policies - and Why Success Could Trigger Failure". Journal of European Public Policy 11(3), 440-60.

Downs, Anthony (1965). An Economic Theory of Democracy. New York: Harper \& Row.

Duggan, Carmel (1999). Work Experience Programmes: Impact and Potential, Work Research Co-Operative. Dublin: Combat Poverty Agency.

Dunne, Jim (1999). "Minister Defends Cutback of 4,500 Places in Schemes". Irish Times, 21 August, p. 6.

DW-world.online (2003). "The Road Ahead for Labour Market Reforms", available for download at: http://www.dw-world.de/dw/article/o,,1000610,oo. $\mathrm{html}$, last retrieved on 15 July, 2008.

Ebbinghaus, Bernhard (2001). "Reforming the Welfare State through 'Old' or 'New' Social Partnership?" in: Carsten Kjaergaard and Sven-Åge Westphalen (eds.). From Collective Bargaining to Social Partnerships: New Roles of the Social Partners in Europe. Copenhagen: The Copenhagen Centre, 103-120.

Ebbinghaus, Bernhard (2005). Can Path Dependence Explain Institutional Change? Two Approaches Applied to Welfare State Reform. MPIfG Working Paper 5 (2).

Ebbinghaus, Bernhard (2006). Reforming Early Retirement in Europe, Japan and the USA. Oxford and New York: Oxford University Press.

The Economist (1994). "The OECD and Jobs: Adapt and Survive". 11 June, p. 64.

Edling, Nils (2006). "Limited Universalism: Unemployment Insurance", in: Niels F. Christiansen, Klaus Petersen, Nils Edling and Per Haave (eds.), The Nordic Model of Welfare: A Historical Reappraisal. Copenhagen: Museum Tusculanum Press, 99-139.

Eichhorst, Werner and Hemerijck, Anton (2008). "Welfare and Employment: A European Dilemma?" IZA Discussion Paper 3870 (Dec.).

Eichhorst, Werner, Grienberger-Zingerle, Maria, and Konle-Seidl, Regina (2006). "Activation Policies in Germany: From Status Protection to Basic Income Support". IZA Discussion Paper 2514 (Dec.).

Éireann, Kelleher Seanad (2010). "Government Measures to Create Employment". Speech delivered on 3 March; available for download at: http://www.entemp.ie/press/2010/20100303a-htm, last retrieved on 11 March 2010. 
Elliott, Francis (2009). " $\exists_{3} b n$ to Save Future Generations from Unemployment Scrapheap”. The Times, 23 April, p.10.

Elster, Jon (1989). The Cement of Society: A Study of Social Order. Cambridge and New York: Cambridge University Press.

EMCO (2006). "Flexicurity". Employment Committee, Working Group on Flexicurity. May.

Esping-Andersen, Gøsta (1987). "The Comparison of Policy Regimes: An Introduction”, in: Martin Rein, Gøsta Esping-Andersen, and Lee Rainwater (eds.), Stagnation and Renewal in Social Policy: The Rise and Fall of Policy Regimes. Armonk, NY: M.E. Sharpe, 3-12.

Esping-Andersen, Gøsta (1985). Politics Against Markets: The Social Democratic Road to Power. Princeton, NJ: Princeton University Press.

Esping-Andersen, Gøsta (1990). The Three Worlds of Welfare Capitalism. Cambridge, UK: Polity Press.

Esping-Andersen, Gøsta (1996). "After the Golden Age? Welfare State Dilemmas in a Global Economy", in: Gøsta Esping-Andersen (ed.), Welfare States in Transition: National Adaptations in Global Economies. London and Thousand Oaks, CA.: Sage Publications, published in association with the United Nations Research Institute for Social Development, 1-31.

Esping-Andersen, Gøsta (200oa). Social Foundations of Postindustrial Economies. Oxford and New York: Oxford University Press.

Esping-Andersen, Gøsta (20oob). "Who is Harmed by Labour Market Regulations? Quantitative Evidence", in: Gøsta Esping-Andersen, and Marino Regini (eds.), Why Deregulate Labour Markets? Oxford and New York: Oxford University Press, 66-97.

Esping-Andersen, Gøsta (2002). Why We Need a New Welfare State. Oxford and New York: Oxford University Press.

Esping-Andersen, Gøsta, and Korpi, Walter (1987). "From Poor Relief to Institutional Welfare States: The Development of Scandinavian Social Policy", in: Robert Erikson (ed.), The Scandinavian Model: Welfare States and Welfare Research. Armonk, N.Y.: M.E. Sharpe, 39-74.

European Foundation for the Improvement of Living and Working Conditions (2004). "Equal Opportunities for Women and Men in Services of General Interest”. Foundation Paper 6.

European Parliament (2007). Fact Sheets. 4.8.3. Employment Policy. Available for download at: http://www.europarl.europa.eu/facts/4_8_3_ en.htm, last retrieved on 23 April 2008.

European Report (2004a). "Social Policy Council: Ministers Look Towards Spring European Council”. 3 March (no. 2848). 
European Report (2004b). "Social Summit: Commission Proposes Setting up High-level Group to Save Lisbon Strategy”. 27 March (no. 2855).

Faust, Anselm (1987). "Von der Fürsorge zur Arbeitsmarktpolitik: Die Errichtung der Arbeitslosenversicherung", in: Werner Abelshauser (ed.), Die Weimarer Republik als Wohlfahrtsstaat zum Verhältnis von Wirtschafts- und Sozialpolitik in der Industriegesellschaft. Stuttgart: Steiner-Verlag-Wiesbaden-GmbH, 260-279.

FÁS (2006). The Irish Labour Market Review 2006. A FÁS Review of Irish Labour Market Trends and Policies. Dublin: Irish National Training and Employment Authority.

FAZ (2001). "Im Streit um die Arbeitsmarktpolitik verhärten sich die Fronten". 7 August, p. 15.

Ferrara, Federico, and Weishaupt, J. Timo (2004). "Get Your Act Together: Party Performance in European Parliament Elections". European Union Politics 5(3), 283-306.

Ferrera, Maurizio, and Hemerijck, Anton (2003). "Recalibrating Europe's Welfare Regimes", in: Jonathan Zeitlin, and David M. Trubek (eds.), Governing Work and Welfare in a New Economy: European and American Experiments. Oxford and New York: Oxford University Press, 88-128.

Financial Times (1993). "The Labour Party Conference: European Action Urged on Jobless”. 3o September.

Finegold, David and Soskice, David W. (1988). "The Failure of Training in Britain: Analysis and Prescription." Oxford Review of Economic Policy 4(3), 21-53.

Finn, Dan (1987). Training Without Jobs: New Deals and Broken Promises. From Raising the School Leaving Age to the Youth Training Scheme. London: Macmillan.

Finn, Dan, and Blackmore, Martin (2001). "Activation: The Point of View of Clients and 'Front Line' Staff”, in: OECD, Labour Market Policies and the Public Employment Service: Prague conference, July 20oo. Paris: Organisation for Economic Co-operation and Development, 293-307.

Finn, Dan, Knuth, Matthias, Schweer, Oliver, and Sommerville, Will (2005).

"Reinventing the Public Employment Service: The Changing Role of Employment Assistance in Britain and Germany". Paper published by the Anglo-German Foundation for the Study of Industrial Society.

Fiscal Policy Council (2009). "Swedish Fiscal Policy. Report of the Fiscal Policy Council 2009”. Report published online at http:// www.finanspolitiskaradet.se, last accessed on March 24, 2010. 
Fischer, Georg, and Potmesil, Stefan (1984). "Arbeiterbewegung und Arbeitsmarktpolitik in Österreich". Österreichische Zeitschrift für Politikwissenschaft 13(3), 263-278.

Fitzgerald, Eithne (2005). "Employment Policy", in: Suzanne Quin (ed.), Contemporary Irish Social Policy. Dublin: University College Dublin Press, 115-137.

Fligstein, Neil (1991). "The Structural Transformation of American Industry", in: Walter W. Powell, and Paul DiMaggio (eds.), The New institutionalism in Organizational Analysis. Chicago: University of Chicago Press, 311-36.

Forslund, Anders, and Krueger, Alan B. (1994). An Evaluation of the Swedish Active Labor Market Policy: New and Received Wisdom. Cambridge, MA.: National Bureau of Economic Research.

Forssell, Anders (2001). "Reform Theory Meets New Public Management", in: Tom Christensen, and Per Lægreid (eds.), New Public Management: The Transformation of Ideas and Practice. Aldershot, UK and Burlington, VT: Ashgate, 261-287.

Fowler, Norman (1991). Ministers Decide: A Personal Memoir of the Thatcher Years. London: Chapmans.

Fraser, Derek 2009). The Evolution of the British Welfare State: A History of Social Policy Since the Industrial Revolution. London: Palgrave Macmillan.

Friedman, Thomas L. (200o). The Lexus and the Olive Tree. New York: Anchor Books.

Funk, Lothar (2003a). "Chancellor Proposes Agenda 2010 to Revive Economy”. EIROnline, 31 March, DEo303105F.

Funk, Lothar (2003b). "Public Want Less Influence for Unions". EIROnline, 13 March, DEo303101N.

Funk, Lothar (2003c). "Revival of Alliance for Jobs Unlikely at Present". EIROnline, 12 February, DE0302104N.

Funk, Lothar (2004). "Business and Employers' Associations Adopt Joint Declaration on Government's Reforms”. EIROnline, 7 April, DE0404104N.

Gamillscheg, Hannes (2009). "Schweden mit größtem Paket". Die Presse. 6 December, online edition.

Gangl, Markus (2002). "Unemployment Benefits as a Search Subsidy: New Evidence on Duration and Wage Effects of Unemployment Insurance". WZB Discussion Paper 02 (208).

Garrett, Geoffrey (1998). Partisan Politics in the Global Economy. Cambridge and New York: Cambridge University Press. 
George, Alexander L., and Bennett, Andrew (2005). Case Studies and Theory Development in the Social Sciences. Cambridge: MIT Press.

Gerven, Minna van, and Beckers, Mieke (2009). "Unemployment Protection Reform in Belgium, Finland, the Netherlands, and the UK. Policy Learning through OMC?" in: Martin Heidenreich, and Jonathan Zeitlin (eds.), Changing European Employment and Welfare Regimes: The Influence of the Open Method of Co-ordination on National Reforms. London: Routledge, 61-83.

Geyer, Robert (200o). Exploring European Social Policy. Cambridge, UK and Malden, MA: Polity Press.

Gilbert, Neil (2002). Transformation of the Welfare State: The Silent Surrender of Public Responsibility. Oxford and New York: Oxford University Press.

Glyn, Andrew, and Wood, Stewart (2001). "New Labour's Economic Policy", in: Andrew Glyn (ed.), Social Democracy in Neo-liberal Times: The Left and Economic Policy Since 1980. Oxford and New York: Oxford University Press, 200-222.

Goldberg, Gertrude S., and Rosenthal, Marguerite G. (2002). Diminishing Welfare: A Cross-national Study of Social Provision. Westport, CT: Auburn House.

Goldstein, Judith, and Keohane, Robert O. (ed.). (1993). Ideas and Foreign Policy: Beliefs, Institutions, and Political Change. Ithaca: Cornell University Press.

Goldstein, Judith and Keohane, Robert O. (1993). "Ideas and the Social Sciences”. In: Judith Goldstein and Robert O. Keohane (eds.), Ideas, Interests, and Institutions: Constructing the European Community's Internal Market. Ithaca: Cornell University Press, 3-30.

Government of Austria (1968). Bundesgesetzblatt, no. 31/1969.

Government of Ireland (200o). Programme for Prosperity and Fairness: Social Partnership Agreement 2001-2003. Dublin: Stationary Office.

Government of Ireland (2001). Ireland's Employment Action Plan. Dublin: Stationary Office.

Government of Ireland (2003a). National Employment Action Plan. 20032005. Dublin: Stationary Office.

Government of Ireland (2003b). A Review of Progress to End 2003 on the Implementation of the Equal Opportunities Childcare Programme 200o-2006. Dublin: Department of Justice, Equality and Law Reform.

Government of Ireland (2003c). Sustaining Progress. Social Partnership Agreement 2003-2005. Dublin: Stationary Office. 
Government of Ireland (2004). National Employment Action Plan. Dublin: Stationary Office.

Government of Ireland (2005). National Reform Programme. Dublin: Stationary Office.

Government of Ireland (2006). Lisbon Agenda. Integrated Guidelines for Growth and Jobs. Dublin: Stationary Office.

Government of Ireland (2007). National Reform Programme. Dublin: Stationary Office.

Government of Sweden (2007). The Swedish Reform Programme for Growth and Jobs: Progress Report 2007. Stockholm: Prime Minister's Office.

Government of Sweden (2008). The Swedish Reform Programme for Growth and Jobs 2008 to 2010. Stockholm: Prime Minister's Office.

Government of Sweden (2009). "Labour Market Policy Measures", available for download at: http://www.sweden.gov.se/sb/d/11786/a/122697, last retrieved on 21 September 2009.

Greve, Bent (200o). "Aktive Arbeitsmarktpolitik in Dänemark - Realität oder Rhetorik?" WSI Mitteilungen 5(oo), 322-328.

Hagemann, Karen (2006). "Between Ideology and Economy: The 'Time Politics' of Child Care and Public Education in the two Germanys". Social Politics 13(2), 217-260.

Hall, Peter A. (1986). Governing the Economy: The Politics of State Intervention in Britain and France. Oxford and New York: Oxford University Press.

Hall, Peter A. (ed.). (1989). The Political Power of Economic Ideas: Keynesianism Across Nations. Princeton, NJ: Princeton University Press.

Hall, Peter A. (1993). "Policy Paradigms, Social Learning and the State: The Case of Economic Policy-Making in Britain". Comparative Politics 25(3), 275-296.

Hall, Peter A. (1997). "The Role of Interests, Institutions, and Ideas in the Comparative Political Economy of the Industrialized Nations", in: Mark Irving Lichbach, and Alan S. Zuckerman (eds.), Comparative Politics: Rationality, Culture, and Structure. Cambridge and New York: Cambridge University Press, 174-207.

Hall, Peter A. (2003a). "Aligning Ontology and Methodology", in: James Mahoney, and Dietrich Rueschemeyer (eds.), Comparative Historical Analysis in the Social Sciences. Cambridge and New York: Cambridge University Press, 373-404.

Hall, Peter A. (2003b). "The Comparative Political Economy of the 'Third Way", in: Oliver Schmidtke (ed.), The Third Way Transformation of Social Democracy. Hampshire: Ashgate. 
Hall, Peter A., and Gingrich, Daniel (2004). "Varieties of Capitalism and Institutional Complementarities in the Macro-economy: An Empirical Analysis". Max Planck Institute for the Study of Societies Discussion Paper (04/5).

Hall, Peter A., and Soskice, David W. (eds.) (2001). Varieties of Capitalism: The Institutional Foundations of Comparative Advantage. Oxford and New York: Oxford University Press.

Hall, Peter A., and Thelen, Kathleen (2009). "Institutional Change in Varieties of Capitalism". Socio-Economic Review 7(1), 7-34.

Handelsblatt (2003). "Union bei Hartz-Reform auf Kompromiss Kurs". 9 October, p. 4.

Handelsblatt (2004). "Job-Floater bringt keine Job-Flut". 6 January.

Handler, Joel (2003). "Social Citizenship and Workfare in the US and Western Europe: From Status to Contract". Journal of European Social Policy 13(3), 229-243.

Handler, Joel F. (2004). Social Citizenship and Workfare in the United States and Western Europe: The Paradox of Inclusion. Cambridge and New York: Cambridge University Press.

Hansen, Leif Christian (2007). "The Welfare Agreement and Other Activation Measures - Or Where are the Options for More People at Work". Presentation available for download at www.bm.dk. March.

Hardiman, Niamh (2002). "From Conflict to Co-ordination: Economic Governance and Political Innovation in Ireland". West European Politics 25(4), 1-24.

Hardiman, Niamh (2005a). "Partnership and Politics: How Embedded is Social Partnership?" Geary Discussion Paper Series. 08, 1-37.

Hardiman, Niamh (2005b). "Politics and Markets in the Irish 'Celtic Tiger". Political Quarterly, 37-47.

Harris, José (1996). "From Sunspots to Social Welfare: The Unemployment Problem 1870-1914", in: Bernard Corry (ed.), Unemployment and the Economists. Cheltenham, UK and Brookfield, VT: Edward Elgar, 52-68.

Harris, José (1997). William Beveridge: A Biography. Oxford and New York: Clarendon Press.

Hartlapp, Miriam (2009). "Learning about Policy Learning. Reflections on the European Employment Strategy", in: Sandra Kröger (ed.): What we have Learnt: Advances, Pitfalls and Remaining Questions of OMC Research. European Integration online Papers, Special Issue 1, 13.

Hartz Commission (2002). Moderne Dienstleistungen am Arbeitsmarkt. Berlin: Brandenburgische Universitätsdruckerei und Verlagsgesellschaft Potsdam mbH. 
Hartz, Peter, and Kloepfer, Inge (2007). Macht und Ohnmacht: Ein Gespräch mit Inge Kloepfer. Hamburg: Hoffmann und Campe.

Hasselpflug, Soren (2005). "Availability Criteria in 25 Countries". Danish Ministry of Finance. Working Paper, 12.

Hauschild, Helmut, and Noe, Martin (2002). "Wasser im Zaubertrank". Handelsblatt. 19 August.

Hay, Colin (2004). "Common Trajectories, Variable Paces, Divergent Outcomes? Models of European Capitalism under Conditions of Complex Economic Interdependence". Review of International Political Economy 11(2), 231-262.

Heclo, Hugh (1974). Modern Social Politics in Britain and Sweden: From Relief to Income Maintenance. New Haven: Yale University Press.

Heffernan, Richard (2002). "The Possible as the Art of Politics: Understanding Consensus Politics". Political Studies 5o(4), 742-760.

Heidemann, Winfried, and Rademacker, Hermann (2004). "Activation in Youth Unemployment Policy in Germany and Austria", in: Amparo Serrano Pascual (ed.), Are Activation Policies Converging in Europe? The European Employment Strategy for Young People. Brussels: European Trade Union Institute, 349-371.

Heidenreich, Martin (2009). "The Open Method of Co-ordination. A Pathway to the Gradual Transformation of National Employment and Welfare Regimes?" in: Martin Heidenreich and Jonathan Zeitlin (eds.) Changing European Employment and Welfare Regimes. The Influence of the Open Method of Co-ordination on National Reforms. London: Routledge, 10-36.

Hemerijck, Anton (2002). "Self-Transformation of European Social Model(s)", in: Gøsta Esping-Andersen (ed.), Why We Need a New Welfare State. Oxford and New York: Oxford University Press, 173-213.

Hemerijck, Anton (2007). "From Retrenchment to Recalibration: How Welfare States Learn". Unpublished Working Paper.

Hemerijck, Anton (2008). Welfare Recalibration as Social Learning. Unpublished Working Paper.

Hempel, Carl Gustav, and Oppenheim, Paul (1948). "Studies in the Logic of Explanation". Philosophy of Science. XV, 135-175.

Hendeliowitz, Jan (2005). "Regional Labour Market Councils to Ensure that Labour Market Policy meets Business Needs. A Danish Case". Seminar on Employment, Economic Development and Local Governance in North West Russia, Skt. Petersburg, 21 September.

Hendeliowitz, Jan, and Hertz, Marie (2008). Danish Employment Policy. National Target Setting, Regional Performance Management and Lo- 
cal Delivery. Employment Region Copenhagen and Zealand: Danish National Labour Market Authority.

Hendeliowitz, Jan, and Woollhead, Carina Bastlund (2007). "Employment Policy in Denmark - High Levels of Employment, Flexibility and Welfare Security", in: Sylvain Giguere, and Yoshio Higuchi (eds.), Local Governance for Promoting Employment. The Japan Institute for Labour Policy and Training, 121-138.

Henninger, Annette, Wimbauer, Christine, and Dombrowski, Rosine (2008). "Demography as a Push towards Gender Equality? Current Reforms of German Family Policy", Social Politics: International Studies in Gender, State E Society 17(1), 287-314.

Hennock, Peter (1982). "Die Ursprünge der staatlichen Sozialversicherung in Großbritannien und das deutsche Beispiel 1880 - 1914", in: Mommsen, Wolfgang J. and Mock, Wolfgang (eds.) Die Entstehung des Wohlfahrtsstaates in Großbritannien und Deutschland 1850-1950. Stuttgart: Klett-Cotta, 92-114.

Hetzel, Robert L. (2003). "German Monetary History in the Second Half of the Twentieth Century: From the Deutsche Mark to the Euro". Economic Quarterly 88(2), 29-64.

Heyes, Jason (2000). "Labour administration in the United Kingdom". Report produced for ILO Department for Government and Labour Law and Administration (GLLAD).

Holmquist, Kate (2005). "Groups Demand Direct Investment in Childcare". Irish Times, 7 November, p. 3.

House, J.D., and McGrath, Kyla (2004). "Innovative Governance and Development in the New Ireland: Social Partnership and the Integrated Approach". Governance. An International Journal of Policy and Administration 17(1), 29-58.

Huber, Evelyne, and Stephens, John D. (2001). Development and Crisis of the Welfare State: Parties and Policies in Global Markets. Chicago: University of Chicago Press.

Hudson, John, and Lowe, Stuart (2004). Understanding the Policy Process: Analysing Welfare Policy and Practice. Bristol: Policy.

Hülber, Hans (1965). Weg und Ziel der Arbeitsvermittlung: Studie über das Arbeitsmarktgeschehen in Österreich von 1848 bis 1934. Vienna: Österreichischer Gewerkschaftsbund.

IBEC/ICTU (2005). Report by and IBEC/ICTU Sub-Committee Prepared in the Context of Sustaining Progress. Dublin: Irish Business and Employers Confederation/Irish Congress of Trade Unions. 
Idema, Timo, and Kelemen, Daniel (2006). "New Modes of Governance, the Open Method of Co-ordination and Other Fashionable Red Herring". Perspectives on European Politics and Society 7(1), 108-123.

ILO (1919), "C2 Unemployment Convention", available for download at http://www.ilo.org/ilolex/english/convdisp1.htm, last retrieved on 28 April 2010.

ILO (1948) “C88 Employment Service Convention"available for download at http://www.ilo.org/ilolex/english/convdisp1.htm, last retrieved on 28 April 2010.

ILO (1949) "C96 Fee-Charging Employment Agencies Convention (Revised)" available for download at http://www.ilo.org/ilolex/english/ convdisp1.htm, last retrieved on 28 April 2010.

ILO (1964) "C122 Employment Policy Convention" available for download at http://www.ilo.org/ilolex/english/convdisp1.htm, last retrieved on 28 April 2010.

ILO (1997) "C181 Private Employment Agencies Convention" available for download at http://www.ilo.org/ilolex/english/convdisp1.htm, last retrieved on 28 April 2010.

Immergut, Ellen (1990). "Institutions, Veto Points, and Policy Results: A Comparative Analysis of Health Care". Journal of Public Policy 10(4), 391-416. Immervoll, Herwig (2007). "Minimum Wages, Minimum Labour Costs and the Tax Treatment of Low-wage Employment". OECD Social Employment and Migration Working Papers, 46.

Immervoll, Herwig, and Barber, David (2005). Can Parents Afford to Work? Childcare Costs, Tax-Benefit Policies and Work Incentives, OECD Social, Employment and Migration Working Papers vol. 31. Paris: Organisation for Economic Co-operation and Development.

Indecon, International Economic Consultants (2002). "Review of Active Labour Market Programmes". Dublin: Report Commissioned by the Department for Enterprise, Trade and Employment.

Irish Times (1994). "Jobs Scheme 'Excluding' Youth". 11 April, p. 2.

Irish Times (1996). "Dole Measures for Teenagers". 5 March, p. 2, supplement.

Irish Times (2008). "Number of Employed Falls for First Time in 17 Years". 22 November, p. 19.

Iversen, Torben (2005). Capitalism, Democracy, and Welfare. Cambridge and New York: Cambridge University Press.

Iversen, Torben, and Wren, Ann (1998). "Equality, Employment, and Budgetary Restraint: The Trilemma of the Service Economy". World Politics 50(4), 507-546. 
Jepsen, Maria, and Pascual, Amparo Serrano (2005). "The European Social Model: An Exercise in Deconstruction". Journal of European Social Policy 15(3), 231-245.

Johansson, K. M. (1999). "Tracing the Employment Title in the Amsterdam Treaty: Uncovering Transnational Coalitions". Journal of European Public Policy 6(1), 85-101.

Johnson, Christopher (1991). The Economy under Mrs Thatcher, 1979-199o. London: Penguin Books.

Jørgensen, Henning (2002). Consensus, Co-operation and Conflict: The Policy Making Process in Denmark. Cheltenham, UK and Northampton, MA: Edward Elgar.

Jørgensen, Henning (2009). From a Beautiful Swan to an Ugly Duckling: Changes in Danish Activation Policies Since 2003. Paper delivered at the ASPEN/ETUI Activation Conference Brno, 20-21 March.

Kahl, Sigrun (2007). The Religious Foundations of the Welfare State: Poverty Regimes, Unemployment and Welfare-to-Work in Europe and the United States. Humboldt University: Unpublished Doctoral Thesis.

Katznelson, Ira (2005). When Affirmative Action Was White: An Untold History of Racial Inequality in Twentieth-Century America. New York: W.W. Norton.

Kavanagh, Ray (2001). Spring, Summer \& Fall: The Rise and Fall of the Labour Party 1986-99. Dublin, Ireland: Blackwater Press.

Kennedy, Kieran Anthony (1993). Facing the Unemployment Crisis in Ireland. Cork: Cork University Press.

Kersbergen, Kees van (1995). Social Capitalism: A Study of Christian Democracy and the Welfare State. London and New York: Routledge.

Keune, Maarten, and Jepsen, Maria (2007). "Not Balanced and Hardly New: The European Commission's Quest for Flexicurity”. ETUI-REHS Working Paper (01).

King, Desmond (1997). "Employers, Training Policy, and the Tenacity of Voluntarism in Britain". Twentieth Century British History 8(3), 383-411. King, Desmond S. (1999). In the Name of Liberalism: Illiberal Social Policy in the USA and Britain. Oxford and New York: Oxford University Press.

King, Desmond S., and Rothstein, Bo (1993). "Institutional Choices and Labor Market Policy. A British-Swedish Comparison". Comparative Political Studies 26(2), 147-177.

Kitschelt, Herbert (2001). "Partisan Competition and Retrenchment", in: Paul Pierson (ed.) The New Politics of the Welfare State. Oxford and New York: Oxford University Press, 265-303. 
Knuth, Matthias, Schweer, Oliver, and Siemes, Sabine (2004). "Drei Menüs und kein Rezept?” Discussion Paper, Institut Arbeit und Technik, Gelsenkirchen.

Knuth, Matthias (2006). "Activation as a Change of the Unemployment Regime". Paper prepared for the ASPEN/ETUI Conference, Brussels, 20-21 October 2006.

Köditz, Volker (1990). A Summary Report on the Services Available for the Unemployed and Especially the Long-Term Unemployed in Denmark, the Federal Republic of Germany, France, Italy, the Netherlands, Portugal, Spain and the United Kingdom. Berlin and Lanham, MD: CEDEFOP and UNIPUB.

Kohl, Helmut (1983). Der Weg zur Wende: Von der Wohlfahrtsgesellschaft zur Leistungsgemeinschaft. Druck- und Verlagsgesellschaft: Husum.

Köhler-Rama, Tim (2003). Invaliditätssicherung in der gesetzlichen Sozialversicherung in Deutschland: Strukturprinzipien, Defizite und Reformansätze aus sozialrechtlicher und versicherungsökonomischer Sicht. Darmstadt: Technische Universität Darmstadt. Book.

Kok, Wim (2003). Jobs, Jobs, Jobs: Creating More Employment in Europe. Report of the Employment Taskforce Chaired by Wim Kok. Brussels: European Commission.

Kok, Wim (2004). Facing the Challenge: The Lisbon Strategy for Growth and Employment. Report from the High Level Group Chaired by Wim Kok. Brussels: European Commission.

Korpi, Walter (1983). The Democratic Class Struggle. London and Boston: Routledge \& Kegan Paul.

Korpi, Walter and Palme, Joakim ( 2003). "New Politics and Class Politics in the Context of Austerity and Globalization: Welfare State Regress in 18 Countries, 1975-95". American Political Science Review 97(3), 425-446.

Korthouwer, Gerben (2008). How German Christian Democrats have said Farewell to Famialism. ASSR Working Paper Series, o1(June).

Krasner, Stephen D. (1991). "Global Communication and National Power: Life at the Pareto Frontier". World Politics 43(3), 336-366.

Krautkrämer, Uta (1978). Labour Market Administration in the Federal Republic of Germany. Berlin: International Institute of Management.

Kristensen, Peer Hull, and Petersen, James Hopner (1996). The Role of the Company in Generating Skills. The Learning Effects of Work Organisation. Denmark. Brussels: CEDEFOP, European Centre for the Development of Vocational Training. 
Kröger, Sandra (2009). "The Open Method of Co-ordination: Underconceptualisation, overdetermination, de-politicisation and beyond". in: Sandra Kröger Kröger (ed.) "What Have We Learnt: Advances, Pitfalls and Remaining Questions of OMC Research" European Integration online Papers, Special Issue 1(13).

Kvist, Jon, Pedersen, Liesbet, and Köhler, Peter (2008). "Making All Persons Work: Modern Danish Labour Market Policies". In Werner Eichhorst, Otto Kaufmann, and Regina Konle-Seidl (eds.), Bringing the Jobless into Work? Experiences with Activation Schemes in Europe and the US. Berlin and Heidelberg: Springer, 221-256.

Landsorganisationen i Sverige (1953). Trade Unions and Full Employment. Stockholm.

Larsen, Flemming (2005). "Active Labour Market Policy in Denmark", in: Thomas Bredgaard, and Flemming Larsen, Employment Policy from Different Angles. Copenhagen: DJØF Publishing, 115-133.

Larsen, Flemming, and Mailand, Mikkel (2007). "Danish Activation Policy: The Role of the Normative Foundation, the Institutional Set-up and Other Drivers", in: Amparo Serrano Pascual, Lars Magnusson (eds.), Reshaping Welfare States and Activation Regimes in Europe. Brussels and Oxford: P.I.E.-Peter Lang, 99-125.

Larsson, Allan (1979). "Working Life and the Labour Market - About 'the Swedish Model”, in: Swedish Institute, Labour Market Reforms in Sweden: Facts and Employee views. Stockholm: Swedish Institute, 9-19.

Larsson, Allan (1998). "The European Employment Strategy and the EMU: You Must Invest to Save". Economic and Industrial Democracy 19, 391415.

Larsson, Allan (1999a). "European Employment Strategy: Progress and Perspectives". Speech given to the Foundation for Economic and Industrial Research, Athens, Greece, 21 May.

Larsson, Allan (1999b). "TUC Conference: Partners for Progress". Speech Given to the Trade Union Conference, London, 24 May.

Larsson, Allan (2001). "A Turning Point for Employment Policy". Europa: Novas Fronteiras 9/10 (June/December), 49-54.

Layard, Richard, Nickell, Stephen, and Jackman, Richard (2005). Unemployment: Macroeconomic Performance and the Labour Market. Oxford and New York: Oxford University Press.

Lechner, Ferdinand, Reiter, Walter, and Wilk, Marius (1993). "Sozialpartnerschaft Kontinuität und Wandel eines Modells", in: Emmerich 
Tálos (ed.), Österreichische Texte zur Gesellschaftskritik vol. 58. Wien: Verlag für Gesellschaftskritik, 207-226.

Lehto, Juhani, Moss, Nina, and Rostgaard, Tine (1999). "Universal Public Social Care and Health Services? ", in: Mikko Kautto, Matti Heikkilä, Bjørn Hvinden, Staffan Marklund, and Nils Ploug (eds.), Nordic Social Policy: Changing Welfare States. London and New York: Routledge, 104-132.

Leibfried, Stephan, and Pierson, Paul (1995). European Social Policy: Between Fragmentation and Integration. Washington, DC: Brookings Institution.

Leitch, Lord Sandy (2006). Leitch Review of Skills: Prosperity for all in the Global Economy. London: HM Treasury.

Lenert, Franz (1964). "Comparison of National Manpower Policies", in: OECD, International Trade Union Seminar on Active Manpower Policy: Final Report. Paris: Organisation for Economic Co-operation and Development. Manpower and Social Affairs Directorate, Social Affairs Division, 63-66.

Lessenich, Stephan (2003). Dynamischer Immobilismus: Kontinuität und Wandel im deutschen Sozialmodell. Frankfurt am Main and New York: Campus Verlag.

Levine, Louis (1969). The Public Employment Service in Social and Economic Policy. Paris: Organisation for Economic Co-operation and Development.

Levy, Jonah D. (1999). "Vice into Virtue? Progressive Politics and Welfare Reform in Continental Europe". Politics and Society 27(2), 239-273.

Lewis, Janet (1978). Labour Market Administration in the United Kingdom. Berlin: International Institute of Management.

Lichbach, Mark Irving, and Zuckerman, Alan S. (1997). Comparative Politics: Rationality, Culture, and Structure. Cambridge and New York: Cambridge University Press.

Lieberman, Robert C. (2002). "Ideas, Institutions, and Political Order: Explaining Political Change”. American Political Science Review 96(4), 697-712.

Lijphart, Arend (1999). Patterns of Democracy: Government Forms and Performance in Thirty-Six Countries. New Haven: Yale University Press.

Lin, Ann Chih (1998). "Bridging Positivist and Interpretivist Approaches to Qualitative Methods". Policy Studies Journal 26(1), 162-180.

Lind, Jens (1988). Labour Market Policy and Industrial Relations in Denmark. Aalborg: ATA-projektet. 
Lindsay, Colin (2007). "Activation, Inter-Agency Co-operation and the EES: Comparing Experiences in two Vanguard Active Welfare States". Unpublished Manuscript.

Lindsay, Colin, and Mailand, Mikkel (2004). "Different Routes, Common Directions? Activation Policies for Young People in Denmark and the UK”. International Journal of Social Welfare 13(3), 195-207.

Lindsay, Colin, and McQuaid, Ronald W. (2008). "Inter-agency Co-operation in Activation: Comparing Experiences in Three Vanguard 'Active' Welfare States". Social Policy \& Society 7(3), 353-365.

Lindvall, Johannes, and Sebring, Joakim (2005). "Policy Reform and the Decline of Corporatism in Sweden". West European Politics 28(5), 1057-1074.

Lødemel, Ivar, and Trickey, Heather (2001). 'An Offer You Can't Refuse': Workfare in International Perspective. Bristol, UK: Policy Press.

López-Santana, Mariely (2009). "Having a Say and Acting: Assessing the Effectiveness of the European Employment Strategy as an Intra-Governmental Co-ordinative Instrument", in: Sandra Kröger (ed.) What Have We Learnt: Advances, Pitfalls and Remaining Questions of OMC Research, European Integration online Papers, Special Issue 1(13).

López-Santana, Mariely (2009). "Soft Europeanization? The Differential Influence of the European Employment Strategy in Belgium, Spain and Sweden", in: Martin Heidenreich, and Jonathan Zeitlin (eds.). Changing European Employment and Welfare Regimes. The Influence of the Open Method of Co-ordination on National Reforms. London: Routledge, 134-53.

Lord Young (1990). The Enterprise Years. A Businessman in the Cabinet. London: Headline Book Publishing PLC.

Lovén, Karoline (2009). “Tackling the Recession: Sweden”, EIROnline, July 14, SE0907029Q.

Lundberg, Jenny (2007). "New Tax Incentive for Employers to Create More Jobs". EIROnline, 14 May, SEo703019I.

Lutz, Hedwig, and Mahringer, Helmut (2007). "Wirkt die Arbeitsmarktförderung in Österreich? Überblick über die Ergebnisse einer Evaluierung der Instrumente der Arbeitsmarktförderung in Österreich". WIFO Monatsberichte 3, 199-218.

MacCashin, Anthony (2004). Social Security in Ireland. Dublin: Gill \& Macmillan.

Madsen, Per K. (2005). "The Danish Road to 'Flexicurity', in: Thomas Bredgaard, and Flemming Larsen (eds.), Employment Policy from Different Angles. Copenhagen: DJØF Publishing, 269-289. 
Madsen, Per K. (2007). "Distribution of Responsibility for Social Security and Labour Market Policy. Country Report: Denmark”, AIAS Working Paper 07.

Magnusson, Lars (2007). The Swedish Labour Market Model in a Globalised World. Report by the Friedrich Ebert Stiftung, Referat für westliche Industrieländer o7(01).

Magnusson, Lars, Jørgensen, Henning, and Dølvik, Jon Erik (2008). The Nordic Approach to Growth and Welfare: European Lessons to be Learned? Brussels: European Trade Union Institute.

Manning, Alan (1993). "Pre-Strike Ballots and Wage-Employment Bargaining". Oxford Economic Papers 45, 422-439.

Manow, Philip, and Seils, Eric (200o). "The Employment Crisis of the German Welfare State", in: Maurizio Ferrera, and Martin Rhodes (eds.), Recasting European Welfare States. London and Portland, OR: Frank Cass, 137-16o.

Marcussen, Martin (200o). Ideas and Elites: The Social Construction of Economic and Monetary Union. Aalborg: Aalborg University Press.

Marcussen, Martin (2001). "The OECD in Search of a Role: Playing the Idea Game”. Paper prepared for presentation at the European Consortium for Political Research (ECPR), 29th Joint Sessions of Workshops, Grenoble, France, 6-11 April.

Marcussen, Martin (2004). "Multilateral Surveillance and the OECD: Playing the Idea Game", in: Klaus Armingeon, and Michelle Beyeler (eds.), The OECD and European Welfare States. Cheltenham, UK and Northampton, MA: Edward Elgar, 13-31.

Mares, Isabela (2003). The Politics of Social Risk: Business and Welfare State Development. Cambridge and New York: Cambridge University Press.

Marston, Greg, Larson, Jorgen Elm, and McDonald, Catherine (2005). "The Active Subjects of Welfare Reform: A Street-Level Comparison of Employment Services in Australia and Denmark". Social Work and Society 3(2), 141-157.

Martin, Andrew (1975). "Labor Movement Parties and Inflation: Contrasting Responses in Britain \& Sweden". Polity 7(4), 427-451.

Martin, John P. (2006). "Creating Jobs in the 21st Century". OECD Forum 2006. Balancing Globalisation, 22-23 May, Paris.

Mathiasen, David (2005). "International Public Management”, in: Ewan Ferlie, Laurence E. Lynn, and Christopher Pollitt (eds.), The Oxford Handbook of Public Management. Oxford and New York: Oxford University Press, 643-670. 
Mazzoleni, Gianpietro (1978). Labour Market Administration in Italy. Berlin: International Institute of Management.

McLaughlin, Kate, and Osborne, Stephen P. (2002). "Current Trends and Future Prospects of Public Management. A guide", in: Kate McLaughlin, Stephen P. Osborne, and Ewan Ferlie (eds.), New Public Management: Current Trends and Future Prospects. London: Routledge, 1-3.

McNamara, Kathleen R. (1998). The Currency of Ideas: Monetary Politics in the European Union. Ithaca, NY: Cornell University Press.

McNeil, Claire (2009). Now It's Personal. Personal Advisers and the New Public Service Workforce. London: Institute for Public Policy Research.

Mead, Lawrence M. (1986). Beyond Entitlement the Social Obligations of Citizenship. New York: Free Press.

Meidner, Rudolf (1979). Full Employment: Problems and Policies. PetitLancy, Switzerland: International Union of Food and Allied Workers' Associations.

Meier, Kenneth J., and Hill, Gregory C. (2005). "Bureaucracy in the Twenty-First Century", in: Ewan Ferlie, Laurence E. Lynn, and Christopher Pollitt (eds.), The Oxford Handbook of Public Management. Oxford and New York: Oxford University Press, 51-71.

Milner, Henry (1989). Sweden: Social Democracy in Practice. Oxford and New York: Oxford University Press.

Minas, Renate (2005). Administrating Poverty. Studies of Intake Organisation and Social Assistance in Sweden. Stockholm: Stockholms Universitet.

Mjøset, Lars (1987). "Nordic Economic Policies in the 1970 and 1980s". International Organization. 41(3), 403-456.

MLP (2005). "Newsletter 1". Mutual Learning Programme.

Morel, Martine (1978). Labour Market Administration in France. Berlin: International Institute of Management.

Mosher, James S., and Trubek, David M. (2003). "Alternative Approaches to Governance in the EU: EU Social Policy and the European Employment Strategy". Journal of Common Market Studies 41(1), 63-88.

Mosley, Hugh, Schütz, Holger, and Breyer, Nicole (200o). Operational Objectives and Performance Indicators in European Public Employment Services. (Final Report). Berlin: Wissenschaftszentrum Berlin.

Murray, Charles A. (1984). Losing Ground American Social Policy, 19501980. New York: Basic Books. 
Nachtwey, Oliver, and Heise, Arne (2006). "Großbritannien: Vom kranken Mann Europas zum Wirtschaftswunderland?” WSI Mitteilungen, 3.

Nedergaard, Peter (2006). "Policy Learning in the European Union: The Case of the European Employment Strategy". Policy Studies 27(4), 311-23.

NESC (1985). Manpower Policy in Ireland. Dublin: National Economic and Social Council.

NESC (2005a). The Developmental Welfare State. Dublin: National Economic and Social Council.

NESC (2005b). NESC Strategy 2006: People, Productivity and Purpose. Dublin: National Economic and Social Council.

NESC (2009). Ireland's Five-Part Crisis: An Integrated National Response. Dublin: National Economic and Social Council.

NESF (200oa). Alleviating Labour Shortages. Forum Report no. 19. Dublin: National Economic and Social Forum.

NESF (20oob). Enhancing the Effectiveness of the Local Employment Service. Forum Report, no. 17. Dublin: National Economic and Social Forum.

NESF (2003). Labour Market Issues for Older Workers. Forum Report no. 26. Dublin: National Economic and Social Forum.

Niess, Frank (1982). Geschichte der Arbeitslosigkeit ökonomische Ursachen und politische Kämpfe: ein Kapitel deutscher Sozialgeschichte. Cologne: Pahl-Rugenstein.

Noaksson, Niklas, and Jacobsson, Kerstin (2003). "The Production of Ideas and Expert Knowledge in OECD. The OECD Jobs Strategy in Contrast with the EU Employment Strategy". Score Rapportserie 7.

Nørgaard, Asbjørn Sonne (1997). The Politics of Institutional Control: Corporatism in Danish Occupational Safety and Health Regulation and Unemployment Insurance, 1870-1995. Århus: Forlaget Politica.

North, Douglass Cecil (1990). Institutions, Institutional Change, and Economic Performance. Cambridge and New York: Cambridge University Press.

O'Connell, Philip J. (2002). "Are They Working? Market Orientation and the Effectiveness of Active Labour-Market Programmes in Ireland". European Sociological Review 18(1), 65-83.

O'Connell, Philip J., and McGinnity, Frances (1997). Working Schemes?: Active Labour Market Policy in Ireland. Aldershot, and Brookfield, VT: Ashgate.

O'Donnell, Rory (2004). "Ireland: Social Partnership and the 'Celtic Tiger' Economy", in: Jonathan Perraton, and Ben Clift (eds.), Where are National Capitalisms Now? New York: Palgrave, 50-69. 
O'Donnell, Rory, and Moss, Brian (2005). "Ireland: The Very Idea of an Open Method of Co-ordination", in: Jonathan Zeitlin, and Philippe Pochet (eds.) The Open Method of Co-ordination in Action: The European Employment and Social Inclusion Strategies. Brussels and New York: P.I.E.-Peter Lang, 311-352.

O'Donnell, Rory, and O'Reardon, Colm (1997). "Ireland's Experiment in Social Partnership 1987-1996", in: Giuseppe Fajertag, and Philippe Pochet, Social Pacts in Europe. Brussels: European Trade Union Institute, 79-95.

O'Donnell, Rory, and Thomas, Damian (1998). "Partnership and PolicyMaking", in: Seán Healy, and Brigid Reynolds (eds.), Social Policy in Ireland: Principles, Practice and Problems. Dublin, Ireland: Oak Tree Press, 117-146.

OECD (1963). Labour Market Policy in Sweden. Paris: Organisation for Economic Co-operation and Development.

OECD (1964a). International Management Seminar on Active Manpower Policy. Brussels, 14th-17th April. Supplement to the Final Report. Paris: Organisation for Economic Co-operation and Development. Manpower and Social Affairs Directorate, Social Affairs Division.

OECD (1964b). International Trade Union Seminar on Active Manpower Policy: Final Report. Paris: Organisation for Economic Co-operation and Development. Manpower and Social Affairs Directorate, Social Affairs Division.

OECD (1964c). Recommendations of the Council on Manpower Policy as a Means for the Promotion of Economic Growth: C(64)48/Final, 21 May.

OECD (1965). Active Manpower Policy, International Management Seminar, Brussels, 14th-17th April 1964; Final Report. Paris: Organisation for Economic Co-operation and Development. Manpower and Social Affairs Directorate, Social Affairs Division.

OECD (1966). The Public Employment Services and Management. International Management Seminar. Supplement to the Final Report. Paris: Organisation for Economic Co-operation and Development. Manpower and Social Affairs Directorate, Social Affairs Division.

OECD (1967a). Active Manpower Policy. Scandinavian Regional Seminar. Oslo, 23rd-24th November. Final Report. Paris: Organisation for Economic Co-operation and Development. Manpower and Social Affairs Directorate, Social Affairs Division.

OECD (1967b). Manpower Policy in Austria. Paris: Organisation for Cooperation and Development. 
OECD (1970). Manpower Policy in the United Kingdom. Paris, London: Organisation for Economic Co-operation and Development.

OECD (1974). Manpower Policy in Denmark. Paris: Organisation for Economic Co-operation and Development.

OECD (1976). Ministers of Labour and the Problems of Employment vol. 1. Paris and Washington, D.C.: Organisation for Economic Co-operation and Development.

OECD (1978a). Economic Survey: Austria. Paris: Organisation for Economic Co-operation and Development.

OECD (1978b). A Medium Term Strategy for Employment and Manpower Policies. Paris and Washington, DC: Organisation for Economic Cooperation and Development.

OECD (1981). The Welfare State in Crisis. Paris: Organisation for Economic Co-operation and Development.

OECD (1983). Employment Outlook. Paris: Organisation for Economic Co-operation and Development.

OECD (1984). Employment Outlook. Paris: Organisation for Economic Co-operation and Development.

OECD (1985). Employment Outlook. Paris: Organisation for Economic Co-operation and Development.

OECD (1986). Employment Outlook. Paris: Organisation for Economic Co-operation and Development.

OECD (1988). Employment Outlook. Paris: Organisation for Economic Co-operation and Development.

OECD (1989). Employment Outlook. Paris: Organisation for Economic Co-operation and Development.

OECD (1990a). Employment Outlook. Paris: Organisation for Economic Co-operation and Development.

OECD (199ob). Labour Market Policies for the 199os. Paris: Organisation for Economic Co-operation and Development.

OECD (1992). Employment Outlook. Paris: Organisation for Economic Co-operation and Development.

OECD (1993a). The Labour Market in the Netherlands. Paris: Organisation for Economic Co-operation and Development.

OECD (1993b). Managing with Market-type Mechanisms. Paris: Organisation for Economic Co-operation and Development.

OECD (1993c). The Public Employment Service in Japan, Norway, Spain and the United Kingdom. Paris: Organisation for Economic Co-operation and Development.

OECD (1993ff). Public Management Developments. Survey 1993. Updates 
1994, 1995, 1996. Paris.

OECD (1994). The OECD Jobs Study: Facts, Analysis, Strategy. Paris: Organisation for Economic Co-operation and Development.

OECD (1995a). Employment Outlook. Paris: Organisation for Economic Co-operation and Development.

OECD (1995b). The OECD Jobs Strategy. Implementing the Strategy. Paris: Organisation for Economic Co-operation and Development.

OECD (1996a). Employment Outlook. Paris: Organisation for Economic Co-operation and Development.

OECD (1996b). The OECD Jobs Strategy. Enhancing the Effectiveness of Active Labour Market Policies. Paris: Organisation for Economic Cooperation and Development.

OECD (1996c). The Public Employment Service in Denmark, Finland and Italy. Paris: Organisation for Economic Co-operation and Development.

OECD (1996d). The Public Employment Service: Austria, Germany, Sweden. Paris: Organisation for Economic Co-operation and Development.

OECD (1996e). Pushing Ahead with the Strategy. Paris: Organisation for Economic Co-operation and Development.

OECD (1997a). "Enhancing the Effectiveness of Active Labour Market Policies: A Streamlined Public Employment Service”. OECD Occasional Papers.

OECD (1997b). In Search of Results: Performance Management Practices. Paris: Organisation for Economic Co-operation and Development.

OECD (1997c). The Public Employment Service: Belgium. Paris: Organisation for Economic Co-operation and Development.

OECD (1997d). Benefits and Wages. Paris: Organisation for Economic Cooperation and Development.

OECD (1998). The Public Employment Service. Greece, Ireland, Portugal. Paris: Organisation for Economic Co-operation and Development.

OECD (1999a). Economic Surveys: Ireland. Paris: Organisation for Economic Co-operation and Development.

OECD (1999b). Implementing the OECD Jobs Strategy: Assessing Performance and Policy. Paris: Organisation for Economic Co-operation and Development.

OECD (200o). Regulatory Reform in Denmark. Paris: Organisation for Economic Co-operation and Development.

OECD (2001). Labour Market Policies and the Public Employment Service: Prague Conference, July 20oo. Paris: Organisation for Economic Co-operation and Development. 
OECD (2002). Economic Outlook. Paris: Organisation for Economic Cooperation and Development.

OECD (2003). Employment Outlook. Paris: Organisation for Economic Co-operation and Development.

OECD (2004a). Country Note for Ireland: Early Childhood Education and Care Policy. Paris: Organisation for Economic Co-operation and Development.

OECD (2004b). OECD Country Note. Early Childhood Education and Care Policy in The Federal Republic of Germany. Paris: Organisation for Economic Co-operation and Development.

OECD (2005a). Babies and Bosses: Reconciling Work and Family Life Volume 4. Canada, Finland, Sweden and the UK. Paris: Organisation for Economic Co-operation and Development.

OECD (2005b). Economic Outlook. Paris: Organisation for Economic Cooperation and Development.

OECD (2005c). Factbook. Paris: Organisation for Economic Co-operation and Development.

OECD (2006a). Employment Outlook. Paris: Organisation for Economic Co-operation and Development.

OECD (2006b). Ireland. Ageing and Employment Policies. Paris: Organisation for Economic Co-operation and Development.

OECD (2006c). Live Longer, Work longer: A Synthesis Report. Paris: Organisation for Economic Co-operation and Development.

OECD (2007a). Benefits and Wages. Paris: Organisation for Economic Cooperation and Development.

OECD (2007b). Economic Surveys. Sweden. Paris: Organisation for Economic Co-operation and Development.

OECD (2007c). Employment Outlook. Further Materials. Paris: Organisation for Economic Co-operation and Development.

OECD (2007d). Taxing Wages. Paris: Organisation for Economic Co-operation and Development.

OECD (2008a). Economic Surveys. Austria. Paris: Organisation for Economic Co-operation and Development.

OECD (20o8b). OECD Economic Surveys: Denmark. Paris: Organisation for Economic Co-operation and Development.

OECD (2009a). Employment Outlook. Paris: Organisation for Economic Co-operation and Development.

OECD (2009b). Adressing the Labour Market Challenges of the Economic Downturn: A Summary of Country Responses to the OECDEC Questionnaire. Background Document to OECD Employment 
Outlook. Paris: Organisation for Economic Co-operation and Development.

OECD (2009c). Tackling the Jobs Crisis. The Labour Market and Social Policy Response. Background Document to the OECD Labour and Employment Ministerial Meeting, 29 September 2009. Paris: Organisation for Economic Co-operation and Development, 2009.

OPTEM (2007). Qualitative Study on the European Employment Strategy: Analysis of the Attitudes of the main Actors in Employment Policy in 28 European countries. Versailles: OPTEM.

Orde, Sabina am, and Schmitt, Cosima (2008). "Jetzt wird regiert". Die Tageszeitung, 28 February, p. 2.

Osborne, David, and Gaebler, Ted (1993). Reinventing Government: How the Entrepreneurial Spirit is Transforming the Public Sector. New York: Plume.

Ostheim, Tobias, and Zohlnhöfer, Reimut (2004). "Europäisierung der Arbeitsmarkt- und Beschäftigungspolitik?" in: Susanne Lütz, and Roland Czada (eds.), Wohlfahrtsstaat - Transformation und Perspektiven. Wiesbaden: VS Verlag für Sozialwissenschaften, 373-401.

Ostleitner, Herbert (1997). "Die wirtschaftspolitischen Erfolge des Austro-Keynesianismus unter der Regierung Bruno Kreiskys", in: Werner Gatty, Gerhard Schmid, Maria Steiner, and Doris Wiesinger, Die Ära Kreisky: Österreich im Wandel 1970-1983. Innsbruck: Studien Verlag, 97-106.

Oxely, H., Maher, M., Martin, John P., Nicoletti, Giuseppe, and AlonsoGamo, P. (1991). "The Public Sector: Issues for the 199os". OECD Economics Department Working Papers 90.

Page, Rosie, and Hillage, Jim (2006). "Vocational Education and Training in the UK”. WZB Discussion Papers, SP I 2006-102.

Palier, Bruno (2004). "Social Protection Reforms in Europe: Strategies for a New Social Model”. Canadian Policy Research Networks. Jan., 1-20.

Palier, Bruno and Claude Martin (2007). "Editorial Introduction: From 'a Frozen Landscape' to Structural Reforms: The Sequential Transformation of Bismarkian Welfare States", Social Policy E Administration 41(6), 535-554.

Palier, Bruno (ed.) (2010). A Long Goodbye to Bismarck? The Politics of Welfare Reforms in Continental Europe. Amsterdam: Amsterdam University Press.

Parsons, Craig (2003). A Certain Idea of Europe. Ithaca and London: Cornell University Press. 
PARTNERSHIP (1997). Partnership 2000 for Inclusion, Employment and Competitiveness. Dublin: Stationary Office.

PESP (1991). Programme for Economic and Social Progress. Dublin: Stationary Office.

Phan-Thuy, N., Hansen, Ellen, Price, David, and International Labour Office. (2001). The Public Employment Service in a Changing Labour Market. Geneva: International Labour Office.

Pierson, Paul (1994). Dismantling the Welfare State? Reagan, Thatcher, and the Politics of Retrenchment. Cambridge and New York: Cambridge University Press.

Pierson, Paul (1996a). "The New Politics of the Welfare State”. World Politics. 48(2), 143-179.

Pierson, Paul (1996b). "The Path to European Integration: A Historical Institutionalist Analysis". Comparative Political Studies 29(2), 123-163.

Pierson, Paul (1998). "Irresistible Forces, Immovable Objects: Post-Industrial Welfare States Confront Permanent Austerity”. Journal of European Public Policy 5(4), 539-56o.

Pierson, Paul (2000). "Increasing Returns, Path Dependence, and the Study of Politics". American Political Science Review 92(2), 251-267.

Pierson, Paul (2001a). "Coping with Permant Austerity: Welfare State Restructuring in Affluent Democracies”, in: Paul Pierson (ed.), The New Politics of the Welfare State. Oxford and New York: Oxford University Press, 410-514.

Pierson, Paul (2001b). "Post-industrial Pressures on the Mature Welfare States", in: Paul Pierson (ed.), The New Politics of the Welfare State. Oxford and New York: Oxford University Press, 80-106.

Pierson, Paul (2004). Politics in Time: History, Institutions, and Social Analysis. Princeton: Princeton University Press.

Pierson, Paul, and Skocpol, Theda (2002). "Historical Institutionalism in Contemporary Political Science", in: Ira Katznelson, and Helen V. Milner (eds.), Political Science: The State of the Discipline. New York, Washington, DC: Norton and American Political Science Association, 693-721.

Pilz, Frank (2004). Der Sozialstaat. Ausbau - Kontroversen - Umbau. Bonn: Bundeszentrale für politische Bildung.

PLS Consult, and Jensen, Peter (1997). Labour Market Studies. Denmark. Luxembourg and Lanham, MD: Office for the Official Publications of the European Communities and Bernan Associates.

Pochet, Philippe (2005). "The Open Method of Co-ordination and the Construction of Social Europe. A Historical Perspective”, in: Jonathan 
Zeitlin, Philippe Pochet, Lars Magnusson (eds.), The Open Method of Co-ordination in Action: The European Employment and Social Inclusion Strategies. Brussels and New York: P.I.E.-Peter Lang, 37-82.

Pochet, Philippe, and Jenson, Jane (2006). "Employment and Social Policy since Maastricht: Standing up to the European Monetary Union", in: Robert M. Fishman, and Anthony M. Messina (eds.), The Year of the Euro: The Cultural, Social, and Political Import of Europe's Common Currency. Notre Dame: University of Notre Dame Press, 161-185.

Pollack, Mark (1999). "A Blairite Treaty: Neo-liberalism and Regulated Capitalism in the Treaty of Amsterdam", in: Karl-Heinz Neunreither, and Antje Weiner (eds.), European Integration after Amsterdam: Institutional Dynamics and Prospects for Democracy. Oxford and New York: Oxford University Press, 266-289.

Pollitt, Christopher, and Bouckaert, Geert (1995). Quality Improvement in European Public Services: Concepts, Cases and Commentary. London and Thousand Oaks, CA: Sage.

Pollitt, Christopher, and Bouckaert, Geert (200o). Public Management Reform: A Comparative Analysis. Oxford and New York: Oxford University Press.

Pollitt, Christopher, and Bouckaert, Geert (2004). Public Management Reform: A Comparative Analysis. Oxford and New York: Oxford University Press.

Pop, Valentia (2008). "Denmark Re-thinks Euro Adoption Amid Financial Crisis". EUobserver.com. 31 October.

Powell, G. Bingham (200o). Elections as Instruments of Democracy: Majoritarian and Proportional Visions. New Haven: Yale University Press.

Price, David (200o). Office of Hope: A History of the Public Employment Service in Great Britain. London: Policy Studies Institute.

Przeworski, Adam, and Teune, Henry (1970). The Logic of Comparative Social Inquiry. New York: Wiley-Interscience.

Quinn, Ruairi (2006). Straight Left: A Journey in Politics. Dublin: Hodder Headline Ireland.

Rabe, Birgitta, and Schmid, Günther (1999). "Eine Frage der Balance: Reform der Arbeitsmarktpolitik" Aus Politik und Zeitgeschichte (37), 21-30.

Raveaud, Gilles (2007). “The European Employment Strategy: Towards More and Better Jobs?" Journal of Common Market Studies 45(2), 411-434. 
Rehn, Gösta, and Svenska institutet för kulturellt utbyte med utlandet. (1984). Co-operation Between the Government and Workers' and Employers' Organisations on Labour Market Policy in Sweden. Stockholm: Swedish Institute.

Report Commissioned by Eurociett (2007). More Work Opportunities for more People. Unlocking the Private Employment Agency Industry's Contribution to a better Functioning Labour Market. Brussels: Eurociett.

Rhodes, Martin (20ooa). "The Political Economy of Social Pacts: 'Competitive Corporatism' and European Welfare Reform”, in: Gøsta Esping-Andersen, and Marino Regini (eds.), Why Deregulate Labour Markets? Oxford and New York: Oxford University Press, 165-194.

Rhodes, Martin (200ob). "Restructuring the British Welfare State: Between Domestic Constraints and Global Imperatives", in: Fritz Wilhelm Scharpf, and Vivien Ann Schmidt (eds.), Welfare and Work in the Open Economy. Oxford and New York: Oxford University Press, 19-68.

Rhodes, Martin (2003). "National 'Pacts' and EU Governance in Social Policy and the Labour Market", in: Jonathan Zeitlin, and David M. Trubek (eds.), Governing Work and Welfare in the New Economy: European and American Experiments. Oxford and New York: Oxford University Press, 129-157.

Riding, Alan (1994). "O.E.C.D. Being Pressed to Change its Mission". New York Times, 7 June, p. 2.

Riel, Bart van, and van der Meer, Marc (2002). "The Advocacy Coalition for European Employment policy - The European Integration Process after EMU", in: Horst Hegmann, and Bernhard Neumärker (eds.), Die Europäische Union aus politökonomischer Perspektive: Metropolis Verlag, 309-328.

Robinson, Peter (1997). Labour Market Studies. United Kingdom. Luxembourg and Lanham, MD: Office for the Official Publications of the European Communities and Bernan Associates.

Rodrigues, Maria João (2003). European Policies for a Knowledge Econo$m y$. Cheltenham, UK and Northhampton, MA: Edward Elgar.

Rosdahl, Anders, and Weise, Hanne (2001). "When All Must Be Active Workfare in Denmark", in: Ivar Lødemel, and Heather Trickey (eds.), 'An Offer You Can't Refuse': Workfare in International Perspective. Bristol, UK: Policy Press, 159-180.

Rothstein, Bo (1985). "The Success of the Swedish Labour Market Policy: the Organisational Connection to Policy". European Journal of Political Research 13(2), 153-165. 
Rothstein, Bo, and Steinmo, Sven (2002a). "Restructuring Politics: Institutional Analysis and the Challenges of Modern Welfare States", in: Bo Rothstein, and Sven Steinmo (eds.), Restructuring the Welfare State: Political Institutions and Policy Change. New York: Palgrave Macmillan, 1-20.

Rothstein, Bo, and Steinmo, Sven (eds.) (2002b). Restructuring the Welfare State: Political Institutions and Policy Change. New York: Palgrave Macmillan.

Rottenecker, Heribert, and Schneider, J. (1996). Geschichte der Arbeitsverwaltung in Deutschland. Stuttgart: W. Kohlhammer.

Royal Swedish Academy of Sciences (2006). Edmund Phelp's Contributions to Macroeconomics. Advanced Information on Sveriges Riksbank Price in Economic Sciences in Memory of Alfred Nobel. 9 October.

Rueda, David (2006). "Social Democracy and Active Labour Market Policies: Insiders, Outsiders, and the Politics of Employment Promotion." British Journal of Political Science 36(3), 385-406.

Rueda, David (2007). Social Democracy Inside Out. Partisanship and Labor Market Policy in Advanced Industrialized Democracies. Oxford and New York: Oxford University Press.

Rueschemeyer, Dietrich, Huber, Evelyne, and Stephens, John D. (1992). Capitalist Development and Democracy. Chicago: University of Chicago Press.

Ruggles, Patrica, and O'Higgins, Michael (1987). "Retrenchment and the New Right: A Comparative Analysis of the Impacts of the Thatcher and Reagan Administrations", in: Martin Rein, Gösta Esping-Andersen, and Lee Rainwater (eds.), Stagnation and Renewal in Social Policy: The Rise and Fall of Policy Regimes. Armonk, NY: M.E. Sharpe, 16o190.

Salais, Robert, Baverez, Nicolas, and Reynaud, Bénédicte (1986). L'invention $d u$ chômage: histoire et transformations d'une catégorie en France des années 1890 aux années 1980. Paris: Presses universitaires de France.

Sapir, Andre (2006). "Globalisation and the Reform of European Social Models". Journal of Common Market Studies 44(2), 369-390.

Schäfer, Armin (2004). "Beyond the Community Method: Why the Open Method of Co-ordination was Introduced to EU Policy-making". European Integration online Papers, 13.

Schäfer, Armin (2005). Die neue Unverbindlichkeit: Wirtschaftspolitische Koordinierung in Europa. Frankfurt: Campus. 
Schäfer, Armin (2006). "A New Form of Governance? Comparing the Open Method of Co-ordination to Multilateral Surveillance by the IMF and the OECD". Journal of European Public Policy 13(1), 70-88.

Scharpf, Fritz (20ooa). "Economic Changes, Vulnerabilities, and Institutional Capabilities", in: Fritz Scharpf, and Vivien Schmidt (eds.), Welfare and Work in the Open Economy. From Vulnerability to Competitiveness. Oxford and New York: Oxford University Press, 21-124.

Scharpf, Fritz (20oob). "Notes Toward a Theory of Multilevel Governing in Europe." MPIfG Working Paper oo(5).

Scharpf, Fritz, and Schmidt, Vivien (2oooa). "Conclusions", in: Fritz Scharpf, and Vivien Schmidt (eds.), Welfare and Work in the Open Economy. Oxford and New York: Oxford University Press.

Scharpf, Fritz Wilhelm (1987). Sozialdemokratische Krisenpolitik in Europa. Frankfurt and New York: Campus.

Scharpf, Fritz Wilhelm (1997). Games Real Actors Play: Actor-Centered Institutionalism in Policy Research. Boulder, CO.: Westview Press.

Scharpf, Fritz Wilhelm, and Schmidt, Vivien Ann (eds.) (2ooob). Welfare and Work in the Open Economy. Oxford and New York: Oxford University Press.

Schedler, Andreas (2000). "The Democratic Revelation". Journal of Democracy 11(4), 5-19.

Schmid, Günther (1975). Steuerungssysteme des Arbeitsmarktes: Vergleich von Frankreich, Grossbritannien, Schweden, DDR und Sowjetunion mit der Bundesrepublik Deutschland. Göttingen: Schwartz.

Schmid, Günther, and Oschmiansky, Frank (2005a). "Arbeitsmarktpolitik und Arbeitslosenversicherung", in: Manfred Schmidt (ed.), Geschichte der Sozialpolitik in Deutschland seit 1945 vol. 7. Baden-Baden: Nomos (Sonderdruck).

Schmid, Günther, and Oschmiansky, Frank (2005b). "Arbeitsmarktpolitik und Arbeitslosenversicherung", in: Hans Günter Hockerts (ed.), Geschichte der Sozialpolitik in Deutschland seit 1945 vol. 5 (Sonderdruck). Baden-Baden: Nomos, 331-380.

Schmid, Günther, Wiebe, Nicola, and Hoffmann, Dierk (2005). "Arbeitsmarktpolitik (Westzonen), Arbeitskräftegewinnung (SBZ)”, in: Udo Wengst (ed.), Geschichte der Sozialpolitik in Deutschland seit 1945 vol. 2 (Sonderdruck). Baden-Baden: Nomos, 266-315.

Schmidt, Karl (1990). Geschichte der Arbeitsmarktverwaltung Österreichs von ihren Anfängen an. Salzburg: Kammer für Arbeiter und Angestellte für Salzburg. 
Schmidt, Vivien (2002). The Future of European Capitalism. Oxford and New York: Oxford University Press.

Schmidt, Vivien (2008). "Discursive Institutionalism: The Explanatory Power of Ideas and Discourse". Annual Review of Political Science 11 (June), 303-326.

Schmitt, Cosima (2004). "Krippenaufbau West". Die Tageszeitung, 29 October, p. 7 .

Schmuhl, Hans-Walter, Peters, Gerd, Dorsch, Martina, and Institut für Arbeitsmarkt- und Berufsforschung. (2003). Arbeitsmarktpolitik und Arbeitsverwaltung in Deutschland, 1871-2002: zwischen Fürsorge, Hoheit und Markt. Nürnberg: Institut für Arbeitsmarkt- und Berufsforschung der Bundesanstalt für Arbeit.

Schweiger, Christian, and Wickham, James (2005). "Is the Irish Tiger Eating Its Children? The Two Sides Of The Irish Employment Model". DYNAMO National Report - The Republic of Ireland.

Seager, Ashley (2008). "Unemployment falls to a 30-year low". The Guardian, 17 April, p. 27.

Serrano Pascual, Amparo (2007). "Reshaping Welfare States: Activation Regimes in Europe", in: Amparo Serrano Pascual, Lars Magnusson (eds.), Reshaping Welfare States and Activation Regimes in Europe. Brussels and Oxford: P.I.E.-Peter Lang, 11-34.

Sexton, J. J., and O'Connell, Phillip J. (1996). Labour Market Studies. Ireland. Luxembourg: Office for Official Publications of the European Communities and Bernan Associates.

Sheehan, Brian (2009). "Recovery Plan Includes Job and Pension Protection Measures". EIROnline, 21 July, IEo907019I.

Shepsle, Kenneth A., and Bonchek, Mark S. (1997). Analyzing Politics: Rationality, Behavior, and Institutions. New York: W.W. Norton.

Shugart, Matthew Soberg, and Carey, John M. (1992). Presidents and Assemblies: Constitutional Design and Electoral Dynamics. Cambridge and New York: Cambridge University Press.

Siebert, Horst (1997). "Labour Market Rigidities: At the Root of Unemployment in Europe". Journal of Economic Perspectives 11(3), 37-54.

Siems, Dorothea (2004a). "2300oo zusätzliche Kita-Plätze: Familienministerin will Kinderbetreuung ausbauen - Elterngeld soll Geburtenrate erhöhen". Die Welt, 9 September, online edition.

Siems, Dorothea (2004b). "Negative Botschaft für Familien: Union lehnt Kita-Gesetz ab - Grüne verlangen Rechtsanspruch”. Die Welt, 10 September, online edition.

SIPTU (2005). Childcare in Ireland. A Trade Union View. Dublin: Services, Industrial, Professional and Technical Union. 
Skatteministeriet (2004). "The Danish Tax Cut in 2004". Available for download at: http://www.skm.dk/foreign/english/2177.html, last retrieved on 15 September 2009.

Skocpol, Theda (1979). States and Social Revolutions: A Comparative Analysis of France, Russia, and China. Cambridge and New York: Cambridge University Press.

Skocpol, Theda (1992). Protecting Soldiers and Mothers: The Political Origins of Social Policy in the United States. Cambridge: Belknap Press of Harvard University Press.

Slattery, Laura (2009). "Percentage of Jobless in Workforce Rises to 11.4\%". Irish Times 30 April, p. 20.

Smyth, Jamie (2008). "Commission Acts over Irish Budget Deficit". Irish Times 4 November, p. 18.

Sol, Els, and Westerveld, Mies (2005). Contractualism in Employment Services: A New Form of Welfare State Governance. The Hague and Frederick, MD: Kluwer Law International and Aspen Publishers.

Soldt, Rüdiger (2004). "Mehr Kinder, weniger Transfers: Familienministerin Schmidt bereitet einen Paradigmenwechsel in der Familienpolitik vor". Frankfurter Allgemeine Zeitung 6 September, p. 12.

Sproß, Cornelia, and Kristina Lang (2008). "Länderspezifische Ausgestaltung von Aktivierungspolitiken. Chronologie und gesetzliche Grundlagen". IAB Forschungsbericht 08(09).

Der Standard 2009. "Stützen aus Berlin und Wien". 13 January, p. 2.

Steinmo, Sven (2009). "Historical Institutionalism", in: Donatella Della Porta, and Michael Keating (eds.), Approaches in the Social Sciences. Cambridge and New York: Cambridge University Press, 118-138.

Steinmo, Sven, and Thelen, Kathleen Ann (1992). "Historical Institutionalism in Comparative Politics", in: Sven Steinmo, Kathleen Ann Thelen, and Frank Longstreth (eds.), Structuring Politics: Historical Institutionalism in Comparative Analysis. Cambridge and New York: Cambridge University Press, 1-32.

Stephens, John D. (1980). The Transition from Capitalism to Socialism. Atlantic Highlands, NJ: Humanities Press.

Streeck, Wolfgang (2001). High Equality, Low Activity: The Contribution of the Social Welfare System to the Stability of the German Collective Bargaining Regime. San Domenico di Fiesole, Italy: European University Institute, Robert Schuman Centre.

Streeck, Wolfgang (2003). "No Longer the Century of Corporatism. Das Ende des 'Bündnisses für Arbeit”. MPIfG Working Paper o3(4). 
Streeck, Wolfgang, and Hassel, Anke (2003). "The Crumbling Pillars of Social Partnership". West European Politics 26(4), 101-124.

Streeck, Wolfgang, and Thelen, Kathleen Ann (eds.). (2005a). Beyond Continuity: Institutional Change in Advanced Political Economies. Oxford and New York: Oxford University Press.

Streeck, Wolfgang, and Thelen, Kathleen Ann (2005b). "Introduction: Institutional Change in Advanced Political Economies", in: Wolfgang Streeck, and Kathleen Ann Thelen (eds.), Beyond Continuity: Institutional Change in Advanced Political Economies. Oxford and New York: Oxford University Press, 1-39.

Streeck, Wolfgang, and Trampusch, Christine (2005). "Economic Reform and the Political Economy of the German Welfare State". German Politics 14(2), 174-195.

Stuttgarter Zeitung (2003). "Grüne geben Weg zu Reformen frei: Sehr große Mehrheit für Agenda 2010 beim Parteitag - Kritik an Düsseldorfer Koalitionskrise". 16 June, p. 1.

Suiter, Jane (1998). "IBEC sets out action plan to boost jobs". Irish Times, 17 November, p. 18.

Swank, Duane (2002). Global Capital, Political Institutions, and Policy Change in Developed Welfare States. Cambridge and New York: Cambridge University Press.

Sweeney, John (2006). Social Partnership in Ireland and Job Creation for Women. Dublin: National Economic and Social Council.

Tálos, Emmerich (1981). Staatliche Sozialpolitik in Österreich. Rekonstruktion und Analyse. Wien: Verlag für Gesellschaftskritik.

Tálos, Emmerich (1987). "Arbeitslosigkeit und beschäftigungspolitische Steuerung: Problemwahrnemung/Problemartikulation, Zielsetzungen, Strategien und Maßnahmen in Österreich seit Mitte der siebzieger Jahre", in: Emmerich Tálos, and Margit Wiederschwinger (eds.), Arbeitslosigkeit: Österreichs Vollbeschäftigungspolitik am Ende? Wien: Verlag für Gesellschaftskritik, 91-166.

Tamkin, Penny, Hillage, Jim, and Gerova, Viona (2006). “The Regional Implementation of the Employer Training Pilots in the United Kingdom", in: OECD, Skills Upgrading: New Policy Perspectives. Paris: Organisation for Economic Co-operation and Development.

Tansey, Paul (1998). Ireland at Work: Economic Growth and the Labour Market, 1987-1997. Dublin: Oak Tree Press.

Tansey, Paul (2008). "3.75\% Yearly Growth Predicted in Positive View of 
Economy: Ireland will Continue to Outdo EU Neighbours, says ESRI". Irish Times 14 May, p. 1.

Taylor, George (2005). Negotiated Governance and Public Policy in Ireland. Manchester and New York: Manchester University Press.

Taylor, Stan (1990). "The Politics of Unemployment", in: Derek W. Urwin, and William E. Paterson, Politics in Western Europe Today: Perspectives, Policies, and Issues Since 1980. London and New York: Longman, 33-58.

Thelen, Kathleen (2003). "How Institutions Evolve: Insights from Comparative-Historical Analysis", in: James Mahoney, and Dietrich Rueschemeyer (eds.), Comparative Historical Analysis in the Social Sciences. Cambridge and New York: Cambridge University Press, 208-240.

Thelen, Kathleen (2004). How Institutions Evolve: The Political Economy of Skills in Germany, Britain, the United States, and Japan. Cambridge and New York: Cambridge University Press.

Thelen, Kathleen (2006). "Institutionen und sozialer Wandel: Die Entwicklung der beruflichen Bildung in Deutschland”, in: Jens Beckert, Bernhard Ebbinghaus, Anke Hassel, and Philip Manow (eds.), Transformationen des Kapitalismus: Festschrift für Wolfgang Streeck zum sechzigsten Geburtstag. Frankfurt and New York: Campus Verlag, 399-423.

Thelen, Kathleen, and Palier, Bruno (2008). "The Dualization of Continental European CMEs". Paper presented at Sixteenth International Conference of the Council for European Studies, Chicago, 6-8 March.

Thorén, Katarina (2008). Activation Policy in Action: A Street-Level Study of Social Assistance in the Swedish Welfare State. Göteborg: Växjö University Press.

Thoursie, Anna and Wadensjö, Eskil. (1997). Labour Market Studies. Sweden. Luxembourg and Lanham, MD: Office for Official Publications of the European Communities and Bernan Associates.

Timmins, Eamon (1999). “IBEC Seeks More Childcare Places”, Irish Times 9 September, p. 4.

Timmins, Nicholas (2008). "The Jobless Multinationals. How Welfare-toWork Schemes are Becoming a Globalised Business", Financial Times 28 February, p. 9.

Timonen, Virpi (2003). Restructuring the Welfare State: Globalization and Social Policy Reform in Finland and Sweden. Cheltenham, UK and Northampton, MA: Edward Elgar.

Toft, Christian (2001). "The Making of the Danish Public Employment Service, 1960-72", in: Henry Milner, and Eskil Wadensjö (eds.), Gösta 
Rehn, the Swedish Model and Labour Market Policies. International and National Perspectives. Aldershot: Ashgate, 189-217.

Torfing, Jacob (1999). "Workfare with Welfare: Recent Reforms of the Danish Welfare State". Journal of European Social Policy 9(1), 5-28.

Trampusch, Christine (200oa). Arbeitsmarktpolitik, Gewerkschaften und Arbeitgeber. Ein Vergleich der Entstehung und Transformation der öffentlichen Arbeitsverwaltungen in Deutschland, Großbitannien und den Niederlanden zwischen 1909 und 1999. Unpublished Doctoral Thesis.

Trampusch, Christine (20oob). "Ein Bündnis für die nachhaltige Finanzierung der Sozialversicherungssysteme: Interessenvermittlung in der bundesdeutschen Arbeitsmarkt- und Rentenpolitik". MPIfG Working Paper 01.

Trampusch, Christine (2005). "Institutional Resettlement: The Case of Early Retirement in Germany", in: Wolfgang Streeck, and Kathleen Ann Thelen (eds.), Beyond Continuity: Institutional Change in Advanced Political Economies. Oxford and New York: Oxford University Press, 201-228.

Trubek, David M., and Trubek, Louise G. (2005). "The Open Method of Co-ordination and the Debate over 'Hard' and 'Soft' Law', in: Jonathan Zeitlin, Philippe Pochet, Lars Magnusson (eds.), The Open Method of Co-ordination in Action: The European Employment and Social Inclusion Strategies. Brussels and New York: P.I.E.-Peter Lang, 83-103.

Tsebelis, George (2002). Veto Players: How Political Institutions Work. New York, Princeton, NJ: Russell Sage Foundation and Princeton University Press.

Tynan, Maol Muire (1994). "PD Programme Would Offer Part-time Work to all Jobless". Irish Times, 21 January, p. 4.

Vandaele, Kurt (2006). "A Report From the Homeland of the Ghent System: Unemployment and Union Membership in Belgium". Transfer 13(4), 647-657.

Visser, Jelle (2005). "The OMC as Selective Amplifier for National Strategies of Reform", in: Jonathan Zeitlin, Philippe Pochet, Lars Magnusson (eds.). The Open Method of Co-ordination in Action: The European Employment and Social Inclusion Strategies. Brussels and New York: P.I.E.-Peter Lang, 173-215.

Visser, Jelle, and Hemerijck, Anton (1997). A Dutch Miracle: Job Growth, Welfare Reform and Corporatism in the Netherlands. Amsterdam: Amsterdam University Press. 
Visser, Jelle, and Anton Hemerijck (2003). "Policy Learning in European Welfare States". Unpublished Working Paper.

Visser, Jelle, and Kouw, Marcia (2006). "Ensuring Effective Implementation Through Better Governance". Synthesis Report: Mutual Learning Programme (July).

Voges, Wolfgang, Jacobs, Herbert, and Trickey, Heather (2001). "Uneven Development - Local Authorities and Workfare in Germany", in: Ivar Lødemel, and Heather Trickey (eds.), "An Offer you can't Refuse": Workfare in International Perspective. Bristol, UK: Policy Press, 71103.

Wadensjö, Eskil (1991). "Sweden: Partial Exit”, in: Martin Kohli, Martin Rein, Anne-Marie Guillemard, and Herman van Gunsteren (eds.), Time for Retirement. Comparative Studies of Early Exit from the Labour Force. Cambridge and New York: Cambridge University Press, 284-323.

Wadensjö, Eskil (1991). "The Committee on Unemployment and the Stockholm School", in: Lars Jonung (ed.), The Stockholm School of Economics Revisited. Cambridge and New York: Cambridge University Press, 103-123.

Wadensjö, Eskil (2001). "The Labour Market Policy - Rehn or Rubbestad”, in: Henry Milner, and Eskil Wadensjö (eds.), Gösta Rehn, the Swedish Model and Labour Market Policies. International and National Perspectives. Aldershot: Ashgate, 3-11.

Wadensjö, Eskil (2002). "Bertil Ohlin and the Committee on Unemployment, 1927 to 1935". In Ronald Findlay (ed.), Bertil Ohlin a Centennial Velebration (1899-1999). Cambridge, MA: MIT Press, 325-340.

Wadensjö, Eskil (2007). "Activation Policy in Sweden”, in: Amparo Serrano Pascual and Lars Magnusson (eds.), Reshaping Welfare States and Activation Regimes in Europe. Brussels: P.I.E. Peter Lang, 127144 .

Wadensjö, Eskil (2009). "Sweden", in: Paul de Beer and Trudie Schils (eds.). The Labour Market Triangle. Employment Protection, Unemployment Compensation and Activation in Europe. Cheltenham and Northampton: Edward Elgar Publishing, 26-43.

Walsh, Brendan (2004). “The Transformation of the Irish Labour Market: 1980-2003". Centre For Economic Research Working Paper Series (WPo4/12).

Walterskirchen, Ewald (1991). Unemployment and Labour Market Flexibility: Austria. Geneva: International Labour Office. 
Watt, Andrew (2004). "Reform of the European Employment Strategy After Five Years: A Change of Course or Merely of Presentation?" European Journal of Industrial Relations 10(2), 117-137.

Watt, Andrew (2006). "Assessing the Reassessment of the OECD Jobs Strategy: eppur si muove?" European Economic and Employment Policy Brief 2, 1-13.

Watts, A.G., and Sultana, R.G. (2005). Career Guidance in Europe's Public Employment Services. Brussels: European Commission. DG for Employment, Social Affairs and Equal Opportunities.

Weir, Margaret (1992). Politics and Jobs: The Boundaries of Employment Policy in the United States. Princeton, NJ: Princeton University Press.

Weishaupt, J. Timo (2009) "Money, Votes or Good Ideas? How Partisan Politics Shape the Impact of the European Employment Strategy", in: Sandra Kröger (ed.): What we have Learnt: Advances, Pitfalls and Remaining Questions of OMC Research. European Integration online Papers, Special Issue 1, 13.

Weishaupt, J. Timo (2010a). "A Silent Revolution? Management Ideas and the Reinvention of European Public Employment Services". Socio-Economic Review 8(3), 461-486.

Weishaupt, J. Timo (2010b). "Germany After a Decade of Social Democrats in Government: The End of the Continental Model?" German Politics 19(2), 105-122.

Wells, William (2001). "From Restart to the New Deal in the United Kingdom", in: OECD, Labour Market Policies and the Public Employment Service. Paris: Organisation for Economic Co-operation and Development, 241-262.

Whiteside, Noel (2003). "Employment Policy", in: Christopher Pierson, and Nicholas Ellison (eds.), Developments in British Social Policy 2. Basingstoke: Palgrave Macmillan, 97-129.

Whiteside, Noel, and Salais, Robert (1998). Governance, Industry and Labour Markets in Britain and France: The Modernising State in the Mid-Twentieth Century. London and New York: Routledge.

Whitford, Josh (2002). "Pragmatism and the Untenable Dualism of Means and Ends: Why Rational Choice Theory Does not Deserve Paradigmatic Privilege". Theory and Society 31(3), 325-363.

Wikeley, Nick (1990). "Legislation. Training and Employment in the 199os". Modern Law Review 53(3), 354-368.

Willemer, Thees (2003). Verwaltungskulturen. Inwieweit prägt das kulturelle Umfeld politisch-administrative Konzepte? Dargestellt anhand 
eines Vergleiches der politisch-administrativen Kultur in Dänemark und Deutschland. Münster, Hamburg and London: LIT Verlag.

Wilk, Marius (1991). "Die Entwicklung der Arbeitsmarktpolitik in Österreich unter besonderer Berücksichtigung der aktiven Arbeitsmarktpolitik in Österreich von 1980-1984", in: Christine Stelzer-Orthofer (ed.), Arbeitsmarktpolitik in Österreich. Linz: Sozialwissenschaftliche Vereinigung, 129-217.

Wilthagen, Ton (2005). "Striking a Balance? Flexicurity and Security in European Labour Markets". In Thomas Bredgaard, and Flemming Larsen (eds.), Employment Policy from Different Angles. Copenhagen: DJØF Publishing, 253-268.

Wood, Steward (2001). "Labour Market Regimes Under Threat? Sources of Continuity in Germany, Britain, and Sweden”, in: Paul Pierson (ed.), The New Politics of the Welfare State. Oxford and New York: Oxford University Press, 368-410.

World Bank (1997). The State in a Changing World. Washington, DC: World Bank.

Wroblewski, Angela (2004). "More Activation - More Chances for the Unemployed?" European Journal of Social Security 6(1), 60-82.

Yeates, Padraig (1998). "8,ooo Face Exclusion from CE Schemes". Irish Times, 30 September, p. 1.

Yeates, Padraig (1999a). "Harney Cuts 5,0oo Places on Jobs Scheme". Irish Times, 24 July, p. 4.

Yeates, Padraig (1999b). "Jobs Scheme Cut by 2,500 Places". Irish Times, 12 January, p. 4.

Yeates, Padraig (200o). "Harney sets aside (Pounds) 41m to Develop Social Economy”. Irish Times, 19 September, p. 17.

Zeitlin, Jonathan (2003). "Introduction: Governing Work and Welfare in a New Economy", in: Jonathan Zeitlin, and David M. Trubek (eds.), Governing Work and Welfare in the New Economy: European and American Experiments. Oxford and New York: Oxford University Press, 1-30.

Zeitlin, Jonathan (2005a). "Conclusion: The Open Method of Co-ordination in Action. Theoretical Promise, Empirical Realities, Reform Strategy", in: Jonathan Zeitlin, Philippe Pochet, Lars Magnusson (eds.), The Open Method of Co-ordination in Action: The European Employment and Social Inclusion Strategies. Brussels and New York: P.I.E.-Peter Lang, 447-203. 
Zeitlin, Jonathan (2005b). "Social Europe and Experimentalist Governance: Towards a New Constitutional Compromise?" in: Gráinne De Búrca (ed.), EU Law and the Welfare State: In Search of Solidarity. Oxford and New York: Oxford University Press, 213-241.

Zeitlin, Jonathan (2007). "The Open Method of Co-ordination and the Governance of the Lisbon Strategy". Paper presented at EUSA conference, 16-19 May.

Zeitlin, Jonathan (2008a). "Institutions, Actors and the Changing Boundaries of European Welfare". Socio-Economic Review 6(1), 20-24.

Zeitlin, Jonathan (2008b). "The Open Method of Co-ordination and the Governance of the Lisbon Strategy". Journal of Common Market Studies 46(2), 436-450.

Zeitlin, Jonathan (2009). "The Open Method of Co-ordination and Reform of National Social and Employment Policies: Influences, Mechanisms, Effects", in: Martin Heidenreich, and Jonathan Zeitlin (eds.), Changing European Employment and Welfare Regimes: The Influence of the Open Method of Co-ordination on National Reforms. London: Routledge, 214-245.

Zeitlin, Jonathan, Pochet, Philippe, Magnusson, Lars (eds.) (2005). The Open Method of Co-ordination in Action: The European Employment and Social Inclusion Strategies. Brussels and New York: P.I.E.-Peter Lang.

Zeitlin, Jonathan, and Trubek, David M. (ed.). (2003). Governing Work and Welfare in a New Economy: European and American Experiments. Oxford and New York: Oxford University Press.

Zimmermann, Benedicte (2006). Arbeitslosigkeit in Deutschland. Zur Entstehung einer sozialen Kategorie. Frankfurt: Campus Verlag.

Zippel, Kathrin (2004). "Transnational Advocacy Networks and Policy Cycles in the European Union: The Case of Sexual Harassment". Social Politics: International Studies in Gender, State, Society 11(1), 57-85.

Zohlnhöfer, Reimut (2003). "Partisan Politics, Party Competition and Veto Players: German Economic Policy in the Kohl Era". Journal of Public Policy 23(2), 123-156.

Zohlnhöfer, Reimut, and Tobias Ostheim (2005). "Paving the Way for Employment? The Impact of the Luxembourg Process on German Labour Market Policies". Journal of European Integration. 27(2), 147-67.

Zöllner, Detlev (1959). "Öffentliche Sozialleistungen und wirtschaftliche Entwicklung", in: Kurt Jantz, Horst Neumann-Duesberg, and Dieter Schewe (eds.), Sozialreform und Sozialrecht. Festschrift für Walter Borgs. Berlin: Duncker \& Humblot, 397-423. 



\section{Index}

ABM (Arbeitsbeschaffungsmaßnahmen) 114, 129, 24.2, 254-255

activation

activating (labour market/so-

cial) policies $33-34,164,174$,

225, 251, 258, 262-263, 277,

291, 300, 302, 304, 330 (n. 2)

Activation Guarantee 213

activation paradigm 27, 32-34,

123, 136, 149, 193-194, 201,

247, 250, 251, 295, 300-301,

306, 308, 313

active line $126,133,170,326(\mathrm{n}$.

15)

Active manpower/labour market measures (supply-side measures, occupational (re-)training) $35,66-69,87,94,101-103$, $107,154-155$, 166, 171, 186, 233235, 238, 244, 246, 248

Austria 95-96, 115, 234, 244, 250

Denmark 89-91, 111, 124-126, 170, 234, 24.4, 249

Germany 93-94, 114, 212, 234, 244, 250, 266

Great Britain 97-99, 116, 165, 234-235, 245, 249 see also Employment Training, New Deal, Train to Gain

Ireland 100-101, 117-118, 137, 216, 234, 244-245, 249, 284-
285 see also Back to Work

Allowance, Foundation

Training, One-Step-Up Initiative, Specific Skills Training

Sweden 108, 122, 234, 244, 249 AF (Arbejdsformidlingen) 92 AFG see Work Promotion Act Agenda 2010 266, 269-270, 292 Ahern, Bertie 279, 338 (n. 49) Aktion 8ooo 131

Alliance for Jobs, Training and

Competitiveness 260-265, 292 $A L U$ (working-life development)

241

AMFG see Employment Promotion Act AMS (Public Employment Service) Austria (Arbeitsmarktservice) 95-96, 131, 231

Denmark (Arbejdsmarkedsstyrelsens) 111, 124, 126, 170, 204, 326 (n. 14)

Sweden (Arbetsmarknadsstyrelsen) 88, 121, 206-207, 215, 321 (n. 4)

AMU Centres (Arbeidsmarkedsuddannelse) 90, 124-125, 326 (n. 14) AnCO 100-101, 117, 138 Arbetslinjen see work line ARGEn, 203, 212, 268, 275, 331 (n. 10) 
$B A$ (German Public Employment Service, Bundesanstalt für Arbeit/Bundesagentur für Arbeit) 79, 81, 88, 93-94, 114, 128, 203204, 207, 254, 267-268, 275, 331 (n. 8-9), 335 (n. 20)

Back to Work Allowance (BTWA) 243, 279-280

Barcelona targets (Council, Summit) 236, 271-272, 274, 288, 335 (n. 24)

Barroso, José Manuel Durão 176, 183

Beveridge, William (Report) 76, 78, 97, 133

Bildt, Carl 155

Bismarck, Otto von (Bismarckian)

$33,74-75,77,258,267$

Blair, Tony 161, 164-165, 200, 299

Blüm, Norbert 127-128

Brandt, Willy 113-114, 261

breadwinner (dual, male) 34, 116,

120, 127, 129, 131-132, 140-143,

236, 247, 249-250, 260, 270-272,

274, 277, 286, 289, 291, 305-307

Brown, Gordon $165,235,310$

case management $26,33,171-173$, 186, 205, 216-217, 251, 282, 291, 300, 302

childcare $27,34,50,68,109,112$,

$115,129,140,153,175,180-181$, 235-238, 243, 245, 247, 249-251, 260, 271-274, 276-277, 281, 286289, 291, 293, 301, 304, 306-308, 322 (n. 13; n. 22), 333 (n. 24), 336 (n. 26-27), 337 (n. 39-41)

Churchill, Winston 76 Clement, Wolfgang 266 collective bargaining see wage setting
Community Employment (Development Programme) 223, 243, 276, 278, 283, 338 (n. 46)

Community Enterprise Programme (Community Programme) 132, 134-135, 326 (n. 23)

contracting out (contestability) 168-169, 205, 215, 246, 328 (n. 14) co-ordinated market economy (CME) 33, 40-41, 61, 253 culture of dependency see welfare dependency

Darling, Alistair 309 de-commodification 26,50 Delors, Jacques 156-158, 164, 170, $183,197,327$ (n. 6) demand-side measure see public works projects/programmes demand-reducing measure see early retirement direct job-creation scheme see public works projects/programmes disability (benefits, pension) 66, 69, 108, 128, 131, 198, 232, 302, 327 (n. 29), 330 (n. 29)

Dukes, Alan 138-139

early retirement (early exit, demandreducing measure) $34,38,66,68$ 69, 108, 111-112, 116, 120, 127-129, $131,136,141,166,180,230-233,247$, 248, 254-255, 262, 274-276, 290, 297-298, 302, 313, 327 (n. 2; n. 29), 330 (n. 29), 333 (n. 3)

Economic and Monetary Union (EMU) 23, 156, 158, 160, 183, 196, 302 
efterløn (early exit scheme) 112, 116, 298

Eichel, Hans 261

Employment Act 133, 336 (n. 30)

Employment Committee (EMCO) $162,177-178,182,184-185,194-$ 195, 199, 207, 303, 305

employment exchanges see labour exchanges

Employment Protection Legislation (EPL) 24, 141, 154, 159, 177178, 181-182, 186, 219, 249, 257, 259, 263, 266, 297, 329 (n. 22; n. 25), 334 (n. 14)

Employment Training (ET) 135, 242

Employment Zone (EZ) 211

Essen Process 159, 199

European Commission 157, 172, 179, 205, 289, 311, 313, 337 (n. 4o)

European Employment Strategy (EES) 21, 32, 156, 160-165, 171, 173-176, 181-186, 194-195, 207208, 236, 259, 262-263, 274-277, 281-282, 288, 299, 303-305, 329 (n. 17)

European Exchange Rate Mechanism (ERM) 156, 325 (n. 5)

European Social Fund (ESF) 184, 276-278, 287, 311

European Social Model 174, 177, 180, 183, 186, 246, 301-302, 329 (n. 19)

European Union (EU) 25-27, 32$34,126,151,156-157,159-162,164$, 171-177, 181-186, 194-195, 197, 199, 201, 207-208, 216, 218-220, 226, 230, 233, 237-238, 243, 245-247, 250, 253, 271-272,274, 277, 279280, 288-291, 293, 295, 299-301,
303-305, 309, 327 (n. 3), 329 (n. 17), 332 (n. 22), 337 (n. 42)

\section{FÁS (Foras Áiseanna Saothair)} $138,142,202,204,214,243,281$ $282,284-285,311$

flexicurity $32,177-178,187,272$, 304, 329 (n. 20-23)

Foundation Training 284

Fowler, Norman 135

Friedman, Milton 31, 106-107, 120, 132, 141, 297

gender $35,110,118,123,167,175$, 178, 181, 183, 259-260, 262-263, 270, 272-273, 277, 301, 304

Ghent system $\quad 75-76$

Golden Triangle 177

Great Conflict 121, 325 (n. 19)

guest workers 93, 95, 109, 115

Harney, Mary 282-283, 285, 338 (n. 49)

Hartz reforms (acts I, II, III, IV) 234, 265, 267-270, 273, 334 (n. 14-15), 335 (n. 17)

Hartz Commission 264-265, 267268, 329 (n. 18)

Hartz, Peter 264

Haughey, Charles 138

Heath, Edward 98, 116

Henkel, Hans-Olaf 257

Hundt, Dieter 265-266, 333 (n. 5), 334 (n. 13)

hybridisation $24,27,31,33,58,61$, 193, 250, 253-254, 291, 296, 308

ideas (cognitive, normative beliefs) 22, 25, 30, 32, 44-47, 49, 53-57, $62-63,105,107,110,125-126$, 
$151,153,157,164-165,178,186$,

$193-201,218,225,232,234,246$,

$274-275,295,297,300,302,322$

(n. 11)

individual action plan (IAP) 166,

171-172, 205, 216, 246, 259

individual taxation see tax code

Initiative 50-plus 274-276

institution, definition of 36-37

institutional change $22,24,29-31$,

$33,36,41-43,45-47,49-51,53-54$,

$56,58,81,91,94,98,100,102$,

126-127, 184, 193-194, 221, 253,

$295,306,326$ (n. 17)

institutional complementarities

40, 44, 56

International Labour Organisation

(ILO, Convention) 81, 83, 214, 323 (n. 8; n. 10)

International Monetary Fund

(IMF) 116, 137

Job Centre, Jobcentre Plus (JCP)

99, 134-135, 201-202, 211-212,

235, 310, 331 (n. 5)

Job Creation Programme 116

Job Offer Scheme 111, 124

Job Release Scheme (early exit

scheme) 116, 136

Job Rotation Scheme 124

Job Security Law 108

Job-AQTIV 262-263, 291

Jobs Initiative Programme (JIP)

279

job-search requirements 68-69,

108, 225, 232, 234

Jospin, Lionel 161

JUMP 259, 291, 333 (n. 8)

Juncker, Jean-Claude 162
Keynesian (Keynesiansim) 26, 31, 105, 107, 109, 111, 113-118, 120121, 130, 137, 193, 261, 297, 302, 324 (n. 1), 325 (n. 7)

Kinnock, Neil 135

Kohl, Helmut 127-129, 155, 161162, 254-255, 257, 259, 261

Kok, Wim 175-176, 183

Kreisky, Bruno 114-115, 130

labour exchanges (employment exchange) $31,76-81,89,91-92$, 99, 101-102, 323 (n. 3)

Labour Exchanges Act 78

Labour Market Board (Denmark) 92, 296

Labour Market Board (Sweden) $88,99,160$

Labour Market Council 89, 92

Labour Market Promotion Act (AMFG) 95-96, 130, 296

Lafontaine, Oskar 259-261, 270

Larsson, Alan 160, 164, 173, 205, 207, 321 (n. 4)

Learning and Skills Council (LSC) 211

Leitch Review 211, 235

Lemass, Sean 100

liberal market economy (LME)

40-41, 6o-61, 136

lifelong learning $27,32,34,152$, $163,175,178,180-181,230,272-$

273, 281, 284, 289-291, 301,

304

Lisbon Agenda (Strategy, Summit, targets) 173-174, 176-179, 183, 186, 199, 250, 260, 284

Local Employment Service (LES) 213-214, 280-282, 331 (n. 13) 
Luxembourg Process 162, 182-183, 304

Lynch, Jack 100

Maastricht Treaty see Treaty on the European Union

Macmillan, Harold 98

Major, John 206

make work pay $68,165-166,175,179$ 18o, 183, 239, 241, 245, 247, 249, $521,273,280,285-286,301,306$ management-by-objectives 26 , 125, 168, 172-173, 205-209, 251, 321 (n. 4), 329 (n. 17), 331 (n. 6-9) manpower policy see active manpower/labour market measure manpower revolution $25,31,83$, 88, 102, 193, 296

Manpower Services Commission (MSC) 98-99, 116, 132-135, 138, 203, 297, 330 (n. 4)

McCreevy, Charlie 285-286

Meidner, Rudolf 83-84, 323 (n. 5)

Merkel, Angela 270, 273-275, 292, 335 (n. 18)

minimum wage see statutory minimum wage $59,154,165$, 219, 238-241, 245, 247, 280, 285286, 297, 307, 332 (n. 20)

monetarism (monetarist) 25, 31, 107, 109, 111, 113-114, 120, 132, $136,141,193,297-298,302,325$ (n. 2)

Müntefering, Franz 274-276, 293, 336 (n. 29)

mutual learning 22, 25, 171, 174, 184-185

mutual obligations $157,170,180$, 183, 197-198, 200-201, 218, 232, 246, 304
National Economic and Social

Council (NESC) 137-138, 277$278,298,310,324$ (n. 18)

National Economic and Social Forum (NESF) 278, 280

National Manpower Service (NMS) 100-101, 138, 202, 296

Network of the Heads of Public Employment Services (HoPES) 171, 281

New Deal (Flexible New Deal) 82, 133, 164-165, 197, 211, 242, 259, 310

New Public Management (NPM) 26, 32, 170-173, 186, 205, 207, 214, 216, 218, 246, 250, 300, 321 (n. 4), 328 (n. 11-13)

Next Step Agency 206

Non-Accelerating Inflation Rate of Unemployment (NAIRU) 27, 106, 164, 183, 198, 299

Nordic Model 109

occupational (re-)training measure see active manpower/labour market measure

OECD

Employment Outlook 119-120, 153, 167, 179, 303

Employment, Labour and Social Affairs Committee 153 Jobs Study (Strategy) 153-155, 158, 165-167, 181-184, 195, 197, 299, 327 (n. 4), 328 (n. 10)

Manpower and Social Affairs (Director, Directorate, Committee, Commission) 31, 86, 102, 107, 153, 193

Public Management Service (PUMA) 170 
recommendations $32,86-88$, 92-93, 95-96, 98-102, 138, 151155, 158-159, 179-181

Olesen, Aase 125

One-Euro Job 242 one-shop office (one-stop shop) $138,167,169,172,211-213,218$, $246,265,268,328$ (n. 10)

One-Step-Up Initiative 290 Open Method of Co-ordination (OMC) 174, 329 (n. 18)

Optionskommune 203, 212, 275

Partnership 2000 284-286 path dependent (dependency) 2324, 33, 39-40, 44, 58, 225, 253

Pay Related Social Insurance

(PRSI) 204, 279, 311

Perspektive 5o-plus 274-276

Pool Jobs 171, 241

Phelps, Edmund 31, 105

poor laws $74,78,82$

powering (puzzling) 25, 47-49, 52,

$53,185,194,254,276,292-293,303$

Pre-Retirement Allowance (PRE-

TA) 290

Preventative Strategy 281-282, 291 private employment agencies

(PREAs) 26, 64-65, 168, 214215,218

profiling $166-167,217,233,332$ (n. 14)

Programme for Competitiveness and Work (PCW) 278

Programme for Economic and Social Progress (PESP) 277

Programme for National Recovery (PNR) 138, 277, 336 (n. 31)

Public Employment Service (PES) $25,63-65,67,81,87-88,102,139$ -
140, 147, 152-153, 165-173, 179, 183, 201-218, 233, 251, 300-302, 304, 306, 324 (n. 19), 328 (n. 10), 332 (n. 15)

Austria 78, 80, 95-96, 131, 202218, 231, 243, 313 see also $A M S$

Denmark $79,81,89,92,111$, 124-126, 170, 202-218, 296 see also $A M S, A F$, Labour Market Board, Labour Market Council

Germany 79-80, 93, 114, 124, 202-218, 254, 268, 275, 313, 331 (n. 8-9), 334 (n. 12) see also $A R G E, B A$, Optionskommune

Great Britain 78, 81, 97-99, 201-218, 234, 296 see Jobcentre Plus, Manpower Services Commission, Next Step Agency, UBO

Ireland 78, 100-101, 202-218, 296 see also AnCO, FÁS, Local Employment Service

Service Model 26, 126, 172-173, 178, 182-183, 186, 194, 201, 247, 249-251, 272, 282, 302, $304,313,332$ (n. 16)

Sweden $78,81,88-89,121,124$ $125,202-218,312,321$ (n. 4) see also $A M S$, Labour Market Board

public works projects/programmes (demand-side measures, direct job-creation scheme) 67,82 , 147, 154-155, 166, 223-224, 241, 246, 248-249

Austria 130-131, 243, 250 see also Aktion 80oo, social economy firms 
Denmark 111, 170, 241, 249 see also Job Offer Scheme, Pool Jobs

Germany $82,114,124,127,129$, 242,250 see also $A B M$, OneEuro Job

Great Britain 116, 132-135, 165, 242, 249-250, 310 see also Community Enterprise Programme, Community Programme, Job Creation Programme, Employment Training, New Deal, Work Experience Programme, Youth Opportunity Programme

Ireland 117-118, 137-138, 243, 249-250 see also Community Employment, Community Employment Development Programme, Jobs Initiative Programme, Social Employment Scheme

Sweden 82, 84, 108, 122, 241, 249 see also ALU workhouses 78,82 puzzling see powering

Quinn, Ruairi 137, 278

Rainbow Coalition 279, 281, 286 re-commodification 301 reflexive agents (action, agency) 22, 25, 28-29, 55

Rehn, Gösta (Rehn-Meidner model) 31, 83-84, 86, 95, 99, 193, 296 Restart (Course, Interview, menu) 133-136, 326 (n. 24) Reynolds, Albert 278-279 Riester, Walter 261, 264 rights and duties (obligations, responsibilities) $26,58,62,126$, 170-171, 197-198, 216, 233, 246, 249, 299-300

Schlüter, Poul 123, 155

Schmidt, Helmut 113, 127

Schmidt, Renate 271

Schmoldt, Hubertus 265

Schröder, Gerhard 197, 258-261, 263-267, 270, 273, 292

short-time work 254, 311, 313 single gateway see one-stop shop social economy firms 223, 243 Social Economy Programme (SEP) 283, 336 (n. 36)

Social Employment Scheme (SES) 137-138, 278

Social Security Act 135

Social Service Act 198, 213

Sommer, Michael 266

Specific Skills Training (SST) 216, 234, 284

Stability and Growth Pact (SGP) 161, 256

stagflation 113

statutory minimum wage see minimum wage

Stoiber, Edmund 265, 268, 274

Stricter Benefits Regime 136 suitable job offer (suitability) 68-69, 114, 135, 168, 226, 232, 247-248

supply-side measure see active manpower/labour market measure

tax code (regarding female employment) 110, 115, 129, 140, 271, 286, 306 
tax credit 68-69, 238-239, 245,

247-248, 313, 332 (n. 19)

Denmark 240

Great Britain 165, 239, 307

Ireland 239, 286, 288, 298, 307, 336 (n. 31)

Sweden 240, 312

Thatcher, Margaret (Thatcherism, Thatcherite) 121, 132-133, 139, 141, 297

Toward $2016 \quad 288,290$

Train to Gain 235, 290, 307

Training and Enterprise Council

(TEC) 136

Training Opportunities Scheme (TOPS) 99

Treaty on the European Union

(Maastricht Treaty) 156, 161, 299

unemployment

benefits (duration) 69, 101, 229-230, 232, 247-248, 267, 275-276, 301, 307, 332 (n. 21) benefits (generosity, level) 59$61,83,92,100,124,159,170$, 220, 226-228, 229-230, 232, 240, 247-249, 258, 269, 301, 306, 334 (n. 14)

Unemployment Benefits Office (UBO) 97, 99

insurance (origins, schemes, systems) 31, 64, 75-76, 79, 83, 90-92, 96, 204-205, 229, 255, 324 (n. 19) insurance funds 90-92, 112, 205, 215, 312, 323 (n. 1), 331 (n. 11)

von der Leyen, Ursula 273, 293 Vranitzky, Franz 130

wage setting (collective bargaining) $138,142,154,159,180,219$, 240, 249, 256, 279, 298, 306

Welfare Agreement 230 welfare dependency (culture of dependency) 136, 142, 163, 167, 246

Wilson, Harold 98, 116

Work Experience Programme (WEP) 116

work line (arbetslinjen) 26, 81, 125, 198, 299

Work Promotion Act (AFG) 9495, 113-114, 258, 262, 296 workfare (workfarism) 60, 134135, 197, 242, 255. 258, 262, 268

Young, David 125, 133-134

Youth Allowance Scheme 125, 134, 170

Youth Guarantee 213

Youth Opportunity Programme (YOP) 116

Youth Progression Programme (YPP) 279-281

Zwickel, Klaus 257, 335 (n. 21) 


\section{CHANGING WELFARE STATES}

\section{PREVIOUSLY PUBLISHED}

Jelle Visser and Anton Hemerijck, A Dutch Miracle. Job Growth, Welfare Reform and Corporatism in the Netherlands, 1997 ISBN 978905356271 o

Christoffer Green-Pedersen, The Politics of Justification. Party Competition and Welfare-State Retrenchment in Denmark and the Netherlands from 1982 to 1998, 2002 ISBN 9789053565902

Jan Høgelund, In Search of Effective Disability Policy. Comparing the Developments and Outcomes of the Dutch and Danish Disability Policies, 2003 ISBN 9789053566442

Maurizio Ferrera and Elisabetta Gualmini, Rescued by Europe? Social and Labour Market Reforms from Maastricht to Berlusconi, 2004 ISBN 978905356651 o

Martin Schludi, The Reform of Bismarckian Pension Systems. A Comparison of Pension Politics in Austria, France, Germany, Italy and Sweden, 2005 ISBN 9789053567401

Uwe Becker and Herman Schwartz (eds.), Employment 'Miracles'. A Critical Comparison of the Dutch, Scandinavian, Swiss, Australian and Irish Cases Versus Germany and the US, 2005 ISBN 9789053567555

Sanneke Kuipers, The Crisis Imperative. Crisis Rhetoric and Welfare State Reform in Belgium and the Netherlands in the Early 1990s, 2006 ISBN 9789053568088

Anke Hassel, Wage Setting, Social Pacts and the Euro. A New Role for the State, 2006 ISBN 9789053569191

Ive Marx, A New Social Question? On Minimum Income Protection in the Postindustrial Era, 2007 ISBN 9789053569252

Monique Kremer, How Welfare States Care. Culture, Gender and Parenting in Europe, 2007 ISBN 9789053569757

Sabina Stiller, Ideational Leadership in German Welfare State Reform. How Politicians and Policy Ideas Transform Resilient Institutions, 2010 ISBN 9789089641861 
Barbara Vis, Politics of Risk-taking. Welfare State Reform in Advanced Democracies, 2010 ISBN 9789089642271

Bruno Palier (ed.), A Long Goodbye to Bismarck? The Politics of Welfare Reform in Continental Europe, 2010

ISBN 9789089642349 
From the Manpower Revolution to the Activation Paradigm: Explaining Institutional Continuity and Change in an Integrating Europe examines the evolution of labor market policy in Western Europe, while paying close attention to the OECD and the European Union as proliferators of new ideas. Three evolutionary phases are identified: (a) a "manpower revolution" phase during the 1960s/1970s, when governments emulated Swedish manpower policies and introduced/modernized their public employment services; (b) a phase of international disagreement about the root causes of and remedies for unemployment, triggering a diversity of responses during the late 1970s and 1980s; and (c) the emergence of an "activation paradigm" in the late 1990s, causing a process of institutional hybridization. The book's main contention is that the evolution of labor market policy is not only determined by historical trajectories or coalitional struggles, but also by policy makers' changing normative and cognitive beliefs. The case studies include Austria, Britain, Denmark, Germany, Ireland, and Sweden.

J. Timo Weishaupt received a Ph.D. at the University of Wisconsin, Madison. Currently, he is a Junior Professor for the Sociology of the Welfare State at the University of Mannheim.

"A major contribution to the crowded but inconclusive literature on the activation of European labour market policies."

Jonathan Zeitlin, Professor of Public Policy and Governance, University of Amsterdam

"This volume provides an impressive in-depth analysis stretching over five decades of policy development."

Dr. Werner Eichhorst, Deputy Director of Labor Policy, IZA, Bonn

ISBN 9789089642523

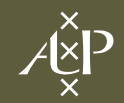

WWW.AUP.NL

Amsterdam University Press

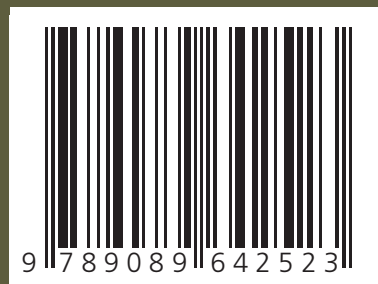

